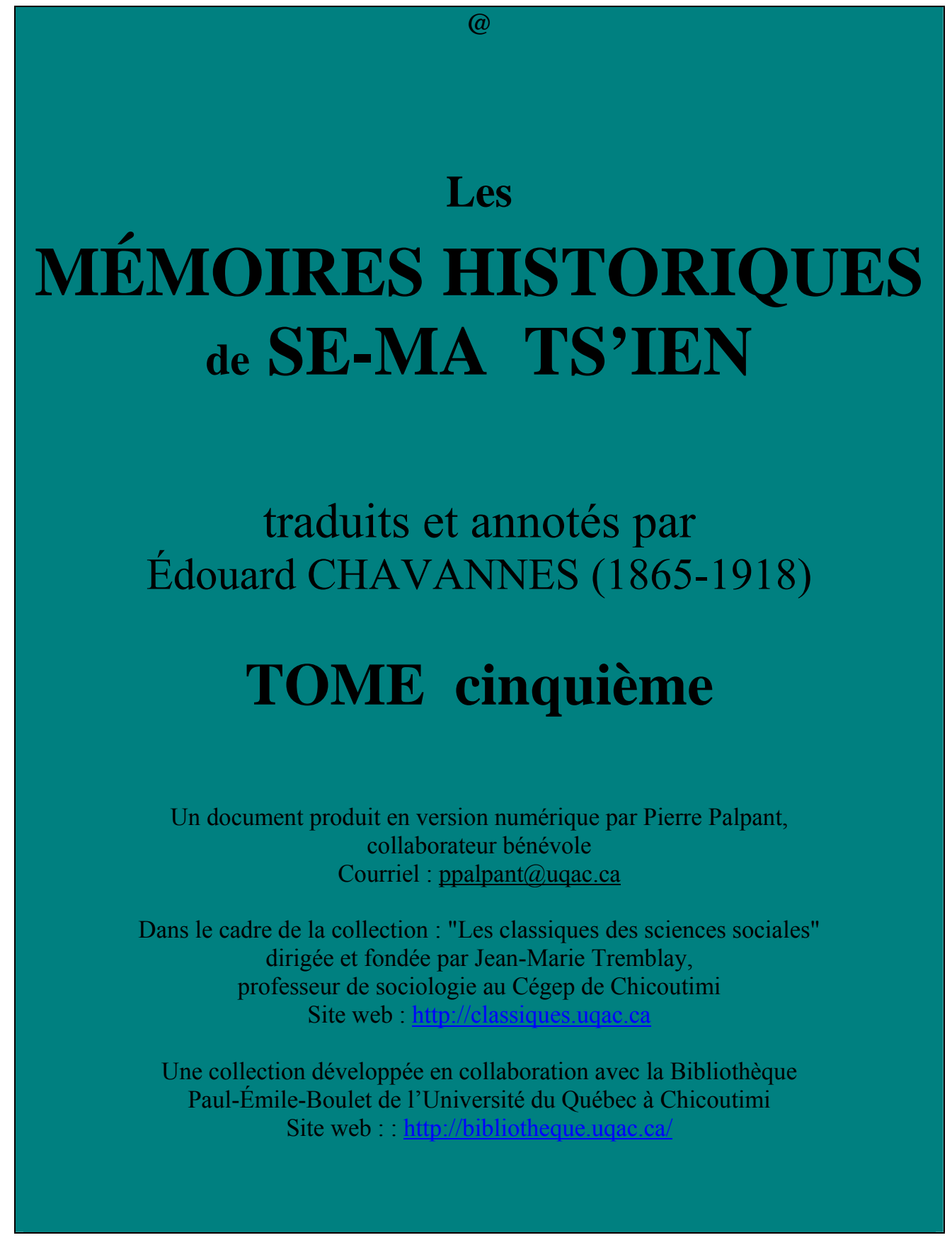


Un document produit en version numérique par Pierre Palpant, collaborateur bénévole, Courriel : ppalpant@uqac.ca

à partir de :

\section{Les Mémoires historiques de Se-ma Ts ’ien, Tome cinquième,}

\section{traduits et annotés par Edouard CHAVANNES (1865-1918)}

Librairie d'Amérique et d'Orient Adrien Maisonneuve, Paris, 1967.

Polices de caractères utilisée : Times, 10 et 12 points.

Mise en page sur papier format Lettre (US letter), 8.5 x 11'’.

Édition complétée le 15 décembre 2006 à Chicoutimi, Québec. 


\section{T A B LE D E S M A T I È R E S}

\section{Quatrième section : Les maisons héréditaires.}

\section{Chapitres :}

XLIII. $\underline{\text { Tchao. }}$.

XLIV. $\underline{W e i}$.

XLV. Han.

XLVI. T'ien King-tchong Wan.

XLVII. $\quad \underline{\text { Kong-tse }}$

\section{Appendices :}

I. De l'authenticité des « Annales écrites sur bambou ».

II. Le voyage au pays de Si-wang-mou.

$\underline{\text { Notes }}$

Chapitres : $\underline{\mathrm{XLIII}}-\underline{\mathrm{XLIV}}-\underline{\mathrm{XLV}}-\underline{\mathrm{XLVI}}-\underline{\mathrm{XLVII}}$

Appendices : $\underline{\mathrm{I}}-\underline{\mathrm{II}}$ 


\section{NOTE PRÉLIMINAIRE}

p.1 La série des maisons héréditaires peut se diviser en quatre sections. La première, qui compte douze chapitres, forme le tome IV de notre traduction; elle embrasse toute l'histoire des royaumes féodaux qui figurent dans la période tch'oen ts'ieou (722-481 av. J.-C.). La seconde section comprend les monographies des royaumes qui n'ont commencé d'exister à l'état indépendant qu'après cette période : ce sont, d'une part, les trois familles de Tchao, Wei et Han qui se substituent, à la fin du Ve siècle avant notre ère, aux princes de $T$ sin, et, d'autre part, la lignée des $T$ 'ien qui, vers le même temps, remplace les Kiang sur le trône de $T s^{\prime} i$. La troisième section est constituée par la biographie de Confucius. La quatrième section traite des maisons héréditaires à l'époque de la Chine impériale.

La seconde section dont nous allons maintenant commencer l'étude caractérise l'époque dite « des royaumes combattants ». En l'année 403, les trois familles de Tchao, Wei et Han reçurent du Fils du Ciel le titre de seigneur et par là fut consacrée officiellement la division en trois de l'État de $T \sin$; d'autre part, en l'an 391, le dernier duc de $T s^{\prime} i$ appartenant à la famille Kiang fut déposé et dut céder la place à la famille T'ien. Ainsi, à deux dates très voisines l'une de l'autre, le royaume de $T \sin$ se trouva démembré et le royaume de $T s$ ' $i$ fut affaibli par un changement de dynastie. Ce double événement marque un tournant dans l'histoire de Chine : Tsin et $T s$ ' $i$ avaient été en effet, à l'époque $t c h$ 'oen-ts'ieou, les deux plus puissants États de race purement chinoise ; c'étaient eux qui, à défaut des Fils du Ciel devenus quantité négligeable, maintenaient l'intégrité de la fédération des royaumes du Milieu; ils tenaient en échec, à l'ouest, le belliqueux État de $T s$ 'in embusqué à l'intérieur des passes montagneuses du Chàn-si; au sud, le vaste État de Tch'ou qui occupait le Hou-pei, le sud du Ho-nan et la majeure partie du Ngan-hoei. Ts'in et Tch'ou n'étaient pas, à proprement parler, au nombre des royaumes du Milieu; leurs p.2 populations, bien que civilisées par la Chine, étaient de races différentes. A partir du moment où $T$ sin et $T s^{\prime} i$ se perdirent par leurs dissensions intestines, $T s^{\prime}$ in et $T c h$ 'ou devinrent les protagonistes du drame qui devait aboutir au triomphe de $T s^{\prime}$ in et à la constitution de l'empire par $T s$ 'in Che-hoang-ti en 221 av. J.-C. On peut donc dire que les origines de l'évolution qui aboutit à la constitution de la Chine impériale remontent à l'année 403 av. J.-C., et c'est pourquoi Se-ma Koang fait débuter à cette date sa grande histoire intitulée Tse tche t'ong kien.

Pendant les deux siècles qui s'écoulent de 403 à 221 av. J.-C., la lutte que soutinrent $T s^{\prime}$ 'in et $T c h$ 'ou pour s'assurer la suprématie comporta des phases diverses. Chacun des deux rivaux s'efforçait de faire rentrer dans sa sphère d'influence les royaumes du Milieu; Ts'in, plus brutal, pratiquait le système de l'extension continue de l'ouest à l'est (lien heng) par lequel il tentait de s'avancer graduellement vers l'Orient, dévorant peu à peu les territoires « comme un ver à soie qui ronge une feuille de mûrier »; Tch'ou, moins hardi, se contentait de solliciter l'alliance des États chinois pour former avec eux une ligue du nord au sud (ho tsong) qui pût tenir $T s$ 'in en échec. Quant aux royaumes du Milieu, dont les cinq principaux étaient les trois Tsin (Tchao, Wei, Han), Ts'i et Yen, préoccupés de leurs intérêts particuliers, ils ne suivaient pas une ligne de conduite invariable et tantôt s'unissaient à $T c h$ 'ou, tantôt se rapprochaient de $T s^{\prime}$ 'in; ils étaient 
incessamment visités par des gens habiles, commis-voyageurs de la politique, qui venaient leur exposer suivant les circonstances du moment, les avantages de l'une ou de l'autre combinaison; les discours subtils de ces Machiavels errants nous ont été conservés dans un livre intitulé "Conseils des royaumes combattants » (tchan kouo ts'e) dont Se-ma Ts'ien a fait un ample usage.

Se-ma Ts'ien s'est souvent servi de cet ouvrage parce que, à vrai dire, c'était la principale source d'informations qu'il pût avoir sur la période des royaumes combattants. Quand on observe de près sa méthode de composition dans cette partie de son œuvre, on s'aperçoit qu'elle consiste à encadrer les discours du Tchan kouo ts'e dans une sèche énumération de faits tels que prises de villes, batailles, morts ou intronisations de princes, en y mêlant quelques fragments d'un tour assez littéraire qui se retrouvent chez des écrivains tels que p.3 Lu Pou-wei, Hoai-nan tse, Han Yng et Lieou Hiang (ce dernier étant postérieur à Se-ma Ts 'ien, mais pouvant avoir puisé aux mêmes sources que lui). Tandis que, pour la période tch'oen ts'ieou, il avait à sa disposition, grâce au Tso tchoan, un tableau détaillé et vivant des événements, il en est réduit, pour les deux siècles qui précédèrent la fondation de l'empire des Ts'in, aux dissertations plus ou moins authentiques ${ }^{1}$ des professeurs de diplomatie et aux anecdotes des littérateurs ; c'est à grand peine s'il parvient à les relier entre elles par quelques brèves indications chronologiques, qui sont d'ailleurs fort sujettes à caution, comme nous le montrerons en examinant, dans l'appendice placé à la fin de ce volume, les Annales écrites sur bambou (Tchou chou ki nien). Nous sommes ainsi amenés à cette conclusion que c'est surtout pour la période des royaumes combattants que se firent sentir les effets de la proscription des livres ordonnée en 213 av. J.-C. par Ts'in Che-hoang-ti. Tandis que la période tch'oen ts 'ieou nous est restée assez bien connue grâce à l'ouvrage de Confucius autour duquel est venue se cristalliser toute la masse de documents qui forme le Tso tchoan, les chroniques relatives à l'époque des royaumes combattants ont été bien réellement détruites et c'est cette disparition que déplorait Se-ma Ts 'ien quand il regrettait que les Mémoires historiques des maisons seigneuriales eussent été anéantis ${ }^{2}$.

Vu l'importance du rôle joué par le Tchan kouo ts'e dans les pages qui vont suivre, il peut être utile de donner ici quelques indications sur les principales éditions de cet ouvrage.

- C'est Lieou Hiang (76-5 av. J.-C.) qui le premier réunit les «Conseils des royaumes combattants» et les classa en 33 chapitres.

- Sous les Han postérieurs, Kao Yeou écrivit un commentaire pour expliquer les passages obscurs de ce livre.

- Nous avons ensuite à mentionner l'édition revisée du Tchan kouo ts'e qui fut publiée par Ts'eng Kong; Ts'eng Kong (cf. Song che, chap. 319, p. $7 \mathrm{r}^{\circ}$ ) fut reçu docteur en l'an 1057; il était contemporain de Wang Ngan-che (1021-1086) et de Ngeou-yang Sieou (1007-1072).

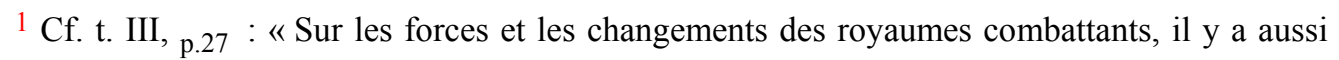
(quelques textes) qu'on peut recueillir; mais comment serait-on sûr qu'ils remontent à une haute antiquité ?»

${ }^{2}$ Cf. t. III, pp.26-27. 
- $\quad$ En 1067, édition de ${ }_{\text {p. }}$ Wang Kio.

- $\quad$ En 1093, édition de Suen Yuen-tchong.

- $\quad$ En 1134, édition publiée par Keng Yen-hi pendant qu'il se trouvait à Kouo-ts'ang (ville près de la ville préfectorale de Tch'ou-tcheou, prov. de Tche-kiang), et connue pour cette raison sous le nom d'édition de Kouo-ts'ang.

- En 1146, Yao Hong, et, en 1147, Pao Piao publient chacun une édition nouvelle; celle de Pao Piao était accompagnée d'un commentaire ; en outre, elle comportait une division du texte en 10 chapitres (et non en 33, comme dans l'édition primitive de Lieou Hiang).

- A l'époque mongole, Ou Che-tao revisa le texte et écrivit, en 1325, un commentaire qui complète ou corrige ceux de Kao Yeou et de Pao Piao ; l'ouvrage d'Ou Che-tao ne vit le jour qu'en 1355, après la mort de l'auteur, par les soins de Yen Po-hi et avec une préface de Tch'en Tsou-jen.

- $\quad$ En 1522, édition de Wang T'ing-siang.

- $\quad$ En 1577, le conseiller d'État Tchang et le t'ai-che Lou Wen font paraître 4 chapitres de notes critiques sur le Tchan kouo $t s$ ' $e$; leur livre était précédé d'une préface par Wang Tchoan.

- En 1581, édition de Tchang I-koen; cette édition adopte la division en 10 chapitres de Pao Piao, mais en conservant, pour la table des matières, la répartition en 33 chapitres de Lieou Hiang; elle ajoute aux anciens commentaires de Kao Yeou et de Pao Piao les indications souvent fort utiles d'Ou Che-tao; enfin elle reporte dans la marge au haut des pages les notes critiques du conseiller d'État Tchang et de Lou Wen-yu. Tchang I-koen mentionne dans sa préface les noms de ses trois collaborateurs qui furent Kouo Siang-k'oei, Lin Tchao-kie et Wang Yuen-fou.

- En 1803, Hoang P'ei-lie publia une édition fondée sur le texte de Yao Hong (1146) qui était le plus ancien texte conservé à son époque; il $\mathrm{y}$ ajouta 3 chapitres d'annotations critiques (littéralement «annotations sous forme de fiches»); il p.5 demanda une préface à Kou Koang-hin et une autre à Ts'ien Ta-hin. Cette édition de 1803 a été reproduite lithographiquement à Chang-hai en 1896 par la librairie Hong pao tchai.

Je me suis servi de l'édition de Tchang I-koen (1581) et de celle de Hoang P'ei-lie (1803) dans la reproduction lithographique de Chang-hai. 


\title{
CHAPITRE XLIII
}

\author{
TREIZIÈME MAISON HÉRÉDITAIRE \\ TCHAO (101)
}

p.7 Les aïeux de la famille Tchao se rattachent au même ${ }_{\text {p. } 8}$ ancêtre que les Ts 'in (102). Lorsqu' apparut Tchong-yen (103), il fut le cocher de l'empereur T'aimeou (104). Son descendant, Fei-lien, eut deux fils: l'un s'appelait Ngo-lai (105); il servit Tcheou (106) et fut tué par (le roi Ou, de la dynastie) Tcheou; ses descendants furent (les princes de) $T s$ 'in. Le frère cadet de Ngo-lai s'appelait Ki-cheng; ses descendants furent (les princes de) Tchao. Ki-cheng engendra Mong-tseng; Mong-tseng fut en faveur auprès du roi Tch'eng, de (la dynastie) Tcheou; il fut « celui qui demeure à Kao-lang (107) ». Kao-lang engendra Heng-fou. Heng-fou engendra Tsao-fou; Tsao-fou fut en faveur auprès du roi Mou, de (la dynastie) Tcheou; Tsao-fou assortit le

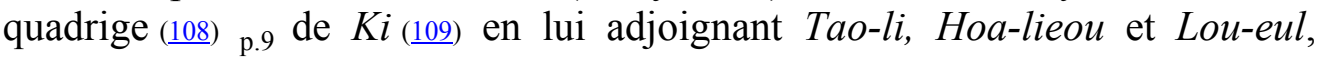
originaires de T'ao-lin (110), puis il l'offrit au roi Mou; le roi Mou chargea Tsao-fou de lui servir de cocher et alla dans l'ouest inspecter les fiefs; il vit

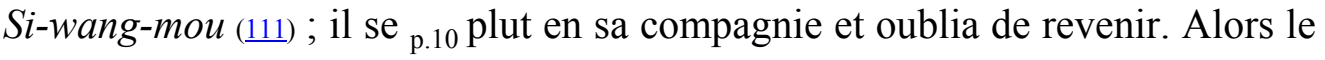
roi Yen, de Siu (112), se révolta. Le roi $M o u$, grâce à ses chevaux qui franchissaient mille $l i$ en un jour, attaqua le roi Yen de Siu, et lui fit subir une grande défaite. Puis il donna en présent la ville de Tchao (113) à Tsao-fou; à partir de ce moment, (cette famille) devint la famille Tchao.

Six générations après Tsao-fou, on arrive à Yen-fou, qui est appelé Kong-tchong. Le roi Siuen, de (la dynastie) Tcheou, en ce temps attaqua les Jong, et fit de lui son cocher; à la bataille de Ts'ien-meou (114), Yen-fou sauva le roi Siuen. - Yen-fou engendra Chou-tai; à l'époque de Chou-tai, le roi Yeou (781-771) de (la dynastie) Tcheou, p.11 se conduisit d'une manière déraisonnable; (Chou-tai) quitta (donc la cour des) Tcheou et se rendit dans (le pays de) $T \sin$; il servit le marquis Wen (780-746), de Tsin; c'est alors qu'il établit pour la première fois la famille Tchao dans le royaume de $T$ sin.

A partir de Chou-tai, les aïeux des Tchao devinrent de plus en plus florissants ; à la cinquième génération, ils engendrèrent Tchao Sou (115). (A l'époque de) Tchao Sou, le duc Hien, de Tsin, en la seizième année de son règne (661), attaqua (les pays de) Houo, Wei et Keng (116); alors Tchao Sou, en qualité de général, attaqua Houo ; le duc de Houo chercha son refuge dans (le pays de) Ts'i. Tsin souffrit d'une grande sécheresse ; on consulta les sorts qui dirent que le Houo-t'ai-chan (117) était le principe (du mal) (118); Tchao Sou fut chargé d'aller chercher dans (le p.12 $_{\text {pays de) } T s} i$ le prince de Houo et de le réinstaller pour qu'il s'acquittât des sacrifices au Houo-t'ai-chan; (à la 
suite de cela), Tsin eut de nouveau la fertilité. Le duc Hien, de Tsin, donna en présent à Tchao Sou (la principauté de) Keng. (Tchao) Sou engendra Kong-mong. C'était alors la première année (661) du duc Min de Lou (119).

Kong-mong engendra Tchao Tch'oei (120), dont l'appellation fut Tse-yu. Tchao Tch'oei consulta les sorts afin de savoir qui il devait servir, du duc Hien, de $T \sin$, et des divers princes ; pour aucun la réponse ne fut favorable ; il consulta les sorts afin de savoir s'il devait servir le prince Tch'ong-eul; la réponse fut favorable; il se mit donc au service de Tch'ong-eul. A cause des troubles suscités par $L i K i$ (121), Tch'ong-eul s'enfuit chez les Ti (655) (122). p.13 Les Ti, accompagnés par Tchao Tch'oei, attaquèrent (la tribu) Tsiang-kaojou (123) et lui prirent deux filles; les Ti donnèrent la cadette pour femme à Tch'ong-eul; l'aînée épousa Tchao Tch'oei et enfanta Toen. Auparavant lorsque Tch'ong-eul était dans le pays de Tsin, la femme (124) de Tchao Tch'oei avait déjà enfanté Tchao T'ong, Tchao Kouo et Tchao Yng-ts'i. Tchao Tch'oei accompagna Tch'ong-eul dans son exil qui dura en tout dix-neuf années ; ayant pu revenir dans son pays (636), Tch'ong-eul devint le duc Wen, de Tsin. Tchao Tch'oei fut nommé seigneur (ta fou) de Yuen (633) (125); il résida à Yuen et fut chargé du gouvernement de l'État. Si le duc Wen put rentrer dans son pays et atteindre à l'hégémonie, ce fut en grande partie aux conseils de Tchao Tch'oei qu'il le dut. Cela est raconté dans le récit des événements du pays de $T \sin (126)$. Lorsque Tchao Tch'oei fut revenu dans le pays de $T \sin$, sa femme originaire de $T \sin$ voulut absolument aller à la rencontre de son autre femme, originaire du pays des $T i$; le fils de cette dernière, (Tchao) Toen, fut considéré comme l'héritier légitime; les trois fils de la femme originaire de $T \sin$ lui furent soumis et le servirent. La sixième année (622) du duc Siang, de Tsin, Tchao Tch'oei mourut. Son nom posthume fut Tch'eng-ki.

p.14 Tchao Toen remplaça Tch'eng-ki dans le gouvernement du royaume. Deux ans plus tard (621), le duc Siang, de Tsin, mourut. L'héritier présomptif, I-kao, était un enfant. (Tchao) Toen, considérant que la situation du royaume était fort difficile, désira mettre sur le trône Yong, frère cadet du duc Siang, et, comme, en ce temps, Yong se trouvait dans le pays de $T_{s}$ 'in, il envoya des émissaires le chercher. La mère de l'héritier présomptif jour et nuit gémissait et pleurait ; frappant de son front la terre, elle dit à Tchao Toen :

- Quel crime a commis le prince défunt pour que vous rejetiez son héritier légitime et que vous cherchiez un autre prince?

Tchao Toen s'inquiéta de cela ; il eut peur d'être attaqué soudain et mis à mort par la famille (de la princesse-mère) et par les grands officiers : il plaça donc sur le trône l'héritier présomptif; ce fut le duc Ling; il fit partir des troupes pour arrêter le frère cadet du duc Siang qu'on était allé chercher dans le pays de $T s^{\prime}$ 'in (127).

Quand le duc Ling fut monté sur le trône, Tchao Toen accapara de plus en plus le gouvernement du royaume. Au bout de quatorze ans de règne, le duc 
Ling se montra d'une arrogance toujours plus grande ; Tchao Toen lui fit de vives remontrances, le duc Ling ne les écouta pas; puis, un jour qu'il mangeait des pattes d'ours, comme la cuisson n'était pas à point, il tua le cuisinier et fit emporter au dehors son cadavre ; Tchao Toen vit (ce corps); à partir de ce moment, le duc Ling eut peur et désira tuer (Tchao) Toen. Tchao Toen était habituellement bon et charitable; l'homme affamé auquel il avait donné à manger sous un mûrier revint s'opposer (aux assassins) et secourut (Tchao) Toen. (Tchao) Toen put ${ }_{\text {p.15 }}$ ainsi s'échapper (128). Avant qu'il fût sorti du territoire du pays de Tsin, Tchao Tch'oan fit périr le duc Ling (607) et mit sur le trône Hei-t'oen, frère cadet du duc Siang; ce fut le duc Tch'eng. Tchao Toen revint de nouveau et se chargea du gouvernement de l'État. Les sages blâmèrent (Tchao) Toen de ce que, étant haut dignitaire du premier rang, il s'était enfui sans sortir du territoire (129), et, à son retour, n'avait pas mis à mort les coupables. C'est pourquoi le grand historien écrivit cette phrase :

$$
\text { « Tchao Toen a assassiné son prince ». }
$$

Au temps du duc King (599-581), de Tsin, Tchao Toen mourut; son nom posthume fut Siuen-mong.

Son fils, (Tchao) Cho lui succéda. Tchao Cho (130), la troisième année (597) du duc King, de Tsin, (Tchao) Cho, en qualité de commandant de la troisième armée (131) de Tsin, vint au secours (du pays) de Tcheng; il livra bataille au roi Tchoang, de Tch'ou, sur les bords du Ho (132).

(Tchao) Cho avait pris pour épouse la sœur aînée du duc Tch'eng, de Tsin. La troisième année (597) du duc King, le grand officier T'ou-ngan Kou voulut exterminer la famille Tchao (133). Auparavant, lorsque Tchao Toen ${ }_{\text {p.16 }}$ était encore en vie, il vit en songe Chou-tai qui se tenait la taille (134) avec ses mains et se lamentait; il était fort affligé, puis il se mit à rire, il battit des mains et même chanta. (Tchao) Toen consulta les sorts à ce sujet au moyen de l'écaille de tortue ; les fissures (135) S'interrompaient et ensuite étaient bonnes; le clerc attaché à la famille Tchao, Yuen, interpréta l'augure en disant :

- Ce songe est fort mauvais : ce n'est pas votre propre personne (qu'il menace), mais c'est assurément votre fils; p.17 ce sera cependant aussi une calamité pour vous-même; lorsque viendra votre petit-fils, les générations futures de la famille Tchao déclineront de plus en plus.

T'ou-ngan Kou avait commencé par être en grande faveur auprès du duc Ling, puis, sous le règne du duc King, il devint ministre de la justice. Voulant susciter des difficultés, il fit le procès des assassins du duc Ling, afin d'atteindre Tchao Toen. Il allait partout dire aux généraux :

- Quoique (Tchao) Toen ne fût pas informé (du complot), c'est lui qui était le chef des assassins; quand un sujet a fait périr son prince et que ses descendants sont en charge à la cour, comment 
réprimerait-on les criminels ? Je propose qu'on extermine (les descendants de Tchao Toen).

Han Kiue (136) répliqua :

- Quand le duc Ling tomba sous les coups des assassins, Tchao Toen était sorti (de la ville). Nos pères estimaient qu'il n'était pas coupable et c'est pourquoi ils ne l'exterminèrent pas lui et sa parenté ; maintenant, vous autres, vous vous proposez d'exterminer ses descendants ; cela n'est point conforme aux intentions de nos pères. D'ailleurs, si maintenant vous les exterminez à tort, (sachez que) ceux qui exterminent à tort sont appelés des sujets rebelles. (Enfin), quand il y a une affaire d'importance et qu'on n'en informe pas le prince, c'est se conduire comme si on ne reconnaissait pas de prince.

T'ou-ngan Kou ne l'écouta pas. Han Kiue avertit Tchao Cho pour qu'il s'enfuît au plus vite. (Tchao) Cho s'y refusa en disant :

- Si vous vous engagez à faire en sorte que les sacrifices de la famille Tchao ne soient pas interrompus, moi, Cho, je ne craindrai pas de mourir.

Han Kiue fit cette promesse; il prétexta une ${ }_{\text {p.18 }}$ maladie et ne sortit plus. (T'ou-ngan) Kou, sans en demander l'autorisation (au duc King), se permit d'attaquer avec les généraux la famille Tchao dans le palais inférieur; il tua Tchao Cho, Tchao T'ong, Tchao Kouo, Tchao Yng-ts' $i$, et anéantit entièrement toute leur parenté.

La femme de Tchao Cho, sœur aînée du duc Tch'eng, se trouvait être enceinte à la mort de son mari ; elle alla se cacher dans le palais ducal. Un client de Tchao Cho en informa Kong-suen Tch'ou-kieou; celui-ci dit à un ami de (Tchao) Cho nommé Tch'eng Yng :

— Pourquoi ne mourez-vous pas?

Tch'eng Yng répondit :

- La femme de (Tchao) Cho est enceinte après la mort de son mari ; si par bonne fortune elle a un fils, je le servirai ; si c'est une fille, je mourrai tranquillement.

Peu après, la femme de (Tchao) Cho accoucha; elle enfanta un fils. T'ou-ngan Kou l'ayant appris, fit faire une perquisition dans le palais; la femme plaça son enfant dans son caleçon et adressa aux dieux ce souhait :

- Si la lignée des Tchao doit être anéantie, qu'il crie ; si elle ne doit pas être anéantie, qu'il ne fasse aucun bruit.

Quand on procéda à la perquisition, aussi longtemps qu'elle dura, l'enfant ne fit aucun bruit. Quand il eut ainsi échappé (à ses ennemis), Tch'eng Yng dit à Kong-suen Tch'ou-kieou : 
- Maintenant on a fait une perquisition et on ne l'a pas trouvé ; mais plus tard on ne manquera pas de le rechercher de nouveau; que faut-il faire?

Kong-suen Tch'ou-kieou lui demanda :

— Faire rendre ses droits à un orphelin ou mourir, lequel est le plus difficile?

- Mourir est plus facile, répondit Tch'eng Yng, faire rendre ses droits à un orphelin est plus difficile.

Kong-suen Tch'ou-kieou dit :

— Le chef défunt de la famille Tchao vous a fort bien traité ; c'est

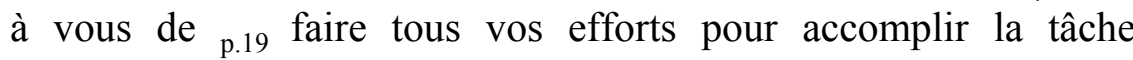
difficile ; pour moi, j'accomplirai la tâche facile. Je demande à mourir le premier.

Alors ces deux hommes combinèrent un plan; prenant le nourrisson d'une autre personne, ils l'emportèrent sur leurs épaules, ils le vêtirent de langes ornés et le cachèrent dans la montagne. Puis Tch'eng Yng sortit de là et vint dire par ruse aux généraux :

- Moi, (Tch'eng) Yng, je suis un homme indigne ; je ne suis pas capable de faire rendre ses droits à l'orphelin de la famille Tchao; celui qui me donnera mille livres d'or, je lui dirai où se trouve l'orphelin de la famille Tchao.

Les généraux furent tous joyeux et consentirent à ce qu'il demandait; ils envoyèrent des soldats, guidés par Tch'eng Yng, attaquer Kong-suen Tch'oukieou ; celui-ci, feignant (l'indignation), dit :

- C'est en vérité un homme méprisable, ce Tch'eng Yng; autrefois, lors du malheur qui est survenu dans le palais inférieur, il n'a pas su mourir et il a projeté avec moi de cacher l'orphelin de la famille Tchao; maintenant, voilà qu'il me vend; même s'il était incapable de faire rendre ses droits (à cet enfant), devait-il consentir à le vendre ?

Tenant l'enfant embrassé, il s'écria :

- O Ciel ! O Ciel ! Quel crime a commis l'orphelin de la famille Tchao ? Je vous demande de le laisser vivre et de ne tuer que moi, Tch'ou-kieou.

Les généraux n'y consentirent pas et tuèrent aussitôt (Kong-suen) Tch'oukieou et l'enfant. Les généraux, pensant que l'orphelin de la famille Tchao était bien réellement mort, furent tous joyeux.

Cependant le véritable orphelin de la famille Tchao était au contraire en vie ; Tch'eng Yng en définitive se cacha avec lui dans la montagne. Quinze 
ans plus tard (583), le duc King, de Tsin, tomba malade ; on consulta les sorts (qui dirent que) ceux qui, après avoir accompli p.20 une grande œuvre n'étaient pas satisfaits, étaient la cause du mal (137). Le duc King interrogea Han Kiue; celui-ci, qui savait que l'orphelin de Tchao était vivant, répondit alors :

- Ceux qui, après avoir accompli une grande œuvre ont vu leurs sacrifices interrompus dans le pays de Tsin, ce sont (les membres de) la famille Tchao. Depuis (leur ancêtre) Tchong-yen, tous ont eu le nom de clan Yng; Tchong-yen avait un visage d'homme et un bec d'oiseau (138); il descendit (dans le monde) pour aider T'aimeou, empereur de la dynastie $Y n$; sous les Fils du Ciel de la dynastie Tcheou, tous (les membres de la famille Tchao) eurent une éclatante vertu; si nous descendons jusqu'aux rois Yeou et $L i$, (nous constatons que,) comme ils agissaient sans raison, Chou-tai quitta les Tcheou et vint dans le pays de $T \sin$; il servit notre ancien prince, le marquis Wen; jusqu'au duc Tch'eng, de génération en génération (la famille Tchao) fit œuvre glorieuse et ne vit jamais ses sacrifices interrompus. Notre prince d'aujourd'hui est le seul qui ait exterminé le clan des Tchao ; les gens du pays le déplorent, et c'est pourquoi on le voit par la tortue et par le millefeuille. Que Votre Altesse y avise.

Le duc King demanda s'il y avait encore des descendants des Tchao: Han Kiue lui dévoila toute la vérité. Alors le duc King et Han Kiue projetèrent de faire rendre ses droits à l'orphelin de la famille Tchao; ils le firent venir et le cachèrent dans le palais. Les généraux étant venus pour s'informer de la maladie du duc King, celui-ci se servit de la foule des partisans de Han Kiue pour entourer d'une manière menaçante ${ }_{\mathrm{p} .21}$ les généraux, puis il fit apparaître l'orphelin de Tchao; le nom personnel de l'orphelin était $O u$. Les généraux, ne sachant plus que faire, dirent alors :

- Autrefois, le malheur qui est survenu dans le palais inférieur, c'est T'ou-ngan Kou qui en a été cause. Il a faussement allégué un ordre du prince pour tout commander à nous, vos sujets. S'il n'en eût pas été ainsi, qui aurait osé susciter ces troubles? Même sans le déplaisir que Votre Altesse en éprouve, nous, vos sujets, nous étions résolus à demander spontanément qu'on rendit ses droits à l'héritier des Tchao ; maintenant, que Votre Altesse nous donne ses ordres. Elle répond aux désirs de nous, vos sujets.

Alors (le duc King) appela Tchao Ou et Tch'eng Yng pour qu'ils saluassent à la ronde tous les généraux; ensuite, ceux-ci avec Tch'eng Yng et Tchao Ou se retournèrent contre T'ou-ngan Kou et exterminèrent toute sa parenté. On rendit à Tchao $\mathrm{Ou}$ les champs et les villes qui avaient appartenu auparavant à sa famille (583) (139).

Quand Tchao Ou eut pris le bonnet viril et fut devenu un homme fait, Tch'eng Yng prit congé des grands officiers et dit à Tchao Ou : 
- Autrefois, lors du malheur qui survint dans le palais inférieur, tous (vos partisans) ont su mourir. Quant à moi, (si je ne suis pas mort) ce n'est pas que je fusse incapable de sacrifier ma vie, mais c'est parce que je voulais faire rendre ses droits au descendant de la famille Tchao. Maintenant que Tchao Ou est rentré dans ses droits, qu'il est devenu un homme fait et qu'il a retrouvé ses anciennes dignités, je vais p.22 aller en bas (140) en avertir Tchao Siuen-mong (141) et Kong-suen Tch'ou-kieou (142).

Tchao $\mathrm{Ou}$, fondant en larmes, frappa de son front le sol et le supplia avec instances, disant :

- Moi, (Tchao) Ou, je voudrais fatiguer jusqu'à en mourir mes nerfs et mes os pour reconnaître vos bienfaits; consentiriez-vous à me quitter et à mourir ?

Tch'eng Yng répondit :

- Je ne puis faire autrement. Si l'autre est mort avant moi, c'est parce qu'il estimait que je pouvais mener à bien l'entreprise. Si je ne vais pas l'informer, il pensera que c'est parce que mon entreprise n'a pas réussi.

Il se tua donc. Tchao $O u$ revêtit pendant trois ans le vêtement de toile ourlé (143); il consacra une ville aux sacrifices en l'honneur de (Tch'eng Yng); on lui fit au printemps et en automne des sacrifices qui de génération en génération ne s'interrompirent pas.

p.23 Onze ans après que la famille Tchao eut retrouvé ses dignités, le duc $L i$, de $T \sin$, fit périr les trois $K^{\prime} i$ (144) qui étaient ses grands officiers (573). Loan Chou craignit d'être atteint et assassina aussitôt son prince, le duc $\mathrm{Li}$. Il mit à sa place sur le trône Tcheou, arrière-petit-fils (145) du duc Siang; ce fut le duc Tao. A partir de ce moment, les grands officiers devinrent de plus en puissants dans le pays de Tsin.

Vingt-sept ans après que Tchao $O u$ eut renoué la lignée des Tchao, le duc $P$ 'ing, de Tsin, prit le pouvoir (557). La douzième année du duc $P$ 'ing (546), Tchao $\mathrm{Ou}$ devint haut dignitaire du premier rang.

La treizième année (146) (545), Ki-tse (prince) de Yen-ling, (du pays) de Ou, fut envoyé en mission dans le pays de Tsin. Il dit :

- Le gouvernement du royaume de $T \sin$ finira par revenir aux descendants de Tchao Ou-tse (147), de Han Siuen-tse et de Wei Hien-tse.

Tchao Ou mourut; son nom posthume fut Wen-tse. Wen-tse engendra King-chou. Au temps de King-chou, le duc King de Ts'i, envoya Yen Yng en mission dans le pays de Tsin (539). Yen Yng eut une conversation avec Chou-hiang, du pays de $T$ sin; il lui dit : 
— Le gouvernement de $T s^{\prime} i$ finira plus tard par revenir à la famille T'ien (148).

Chou-hiang lui dit à son tour :

- Le ${ }_{\text {p.24 }}$ gouvernement du royaume de $T$ sin devra revenir aux six hauts dignitaires (149). Les six hauts dignitaires ont une ambition démesurée et notre prince ne sait pas s'en inquiéter.

Tchao King-chou mourut; il engendra Tchao Yang, qui n'est autre que (Tchao) Kien-tse. Quand Tchao Kien-tse était en charge, la neuvième année (517) du duc K'ing, de Tsin, (Tchao) Kien-tse prit l'initiative de réunir les seigneurs pour tenir garnison dans le pays de Tcheou; l'année suivante (516), il fit rentrer dans son royaume le roi King, de (la dynastie) Tcheou; c'était pour éviter son cadet Tchao (que le roi King avait dû sortir de sa capitale) (150). - La douzième année (514) du duc $K^{\prime}$ 'ing, de $T \sin$, les six hauts dignitaires exterminèrent au nom des lois les familles $K$ ' $i$ et Yang-cho qui faisaient partie du clan ducal et se partagèrent leurs terres dont ils firent dix préfectures à la tête desquelles chacun des six hauts dignitaires plaça quelqu'un de ses parents comme gouverneur (151). A la suite de cela, la maison ducale de Tsin s'affaiblit de plus en plus.

p.25 Treize ans plus tard (501), Yang Hou, sujet rebelle du pays de Lou, vint se réfugier (dans le pays de $T \sin )$; Tchao Kien-tse accepta ses présents et le traita fort bien.

Tchao Kien-tse tomba malade, et cinq jours durant ne reconnut personne. Les grands officiers étaient tous saisis de crainte. Le médecin Pien Ts 'io (152) vint le voir ; quand il sortit, Tong Ngan-yu l'interrogea ; Pien Ts 'io répondit :

- Le pouls est bon; pourquoi s'étonner? autrefois, le duc Mou (659-621), de $T s^{\prime}$ 'in, se trouva dans le même état; au bout de sept jours il se réveilla (153); le jour où il se réveilla, il dit à Kong-suen Tche et à Tse-yu (154) :

— Je suis allé à la résidence de l'Empereur (155) et m'y suis fort plu. Si j'y suis resté longtemps, c'est parce qu'il s'est trouvé que j'avais à m'instruire. L'Empereur m'a dit que le royaume de Tsin allait être fort troublé et que, pendant cinq générations, il ne jouirait pas du calme ; que celui qui viendrait ensuite devrait avoir l'hégémonie, mais qu'il mourrait avant d'être devenu vieux ; que le fils de celui qui aurait eu l'hégémonie commanderait à mon royaume, mais que (par sa faute) les hommes et les femmes ne seraient pas séparés (156).

Kong-suen Tche ${ }_{\text {p.26 }}$ écrivit tout cela et le conserva en lieu sûr (157) ; telle est l'origine des livres de divination dans le pays de $T s$ 'in. Les troubles qui (survinrent à l'époque) du duc Hien (676-651) (158), l'hégémonie (que sut prendre) le duc Wen (636-628), la victoire que remporta le duc Siang sur les soldats de $T$ s'in à Hiao 
(627) (159), puis la débauche à laquelle (ce prince) se livra quand il fut revenu (dans ses États), ce sont là des faits qui m'ont été racontés (160). Maintenant, la maladie de votre maître est la même que celle (du duc Mou, de $T s^{\prime}$ in). Avant que trois jours se soient écoulés, sa maladie ne manquera pas de se dissiper; quand elle se sera dissipée, (Tchao Kien-tse) aura certainement quelque chose à vous dire $»$.

Deux jours et demi plus tard (Tchao) Kien-tse reprit ses sens; il dit à ses grands officiers :

— Je suis allé à la résidence de l'Empereur et m'y suis fort plu. Avec les cent génies, je me suis promené dans le ciel formateur $(161)$; la musique Vaste ${ }_{\text {p.27 }}$ comportait neuf airs et dix mille attitudes de danse (162); elle ne ressemblait pas aux musiques des trois dynasties (163); ses mélodies émouvaient le cœur humain. Il y eut un ours qui voulut venir se saisir de moi ; l'Empereur m'ordonna de tirer une flèche sur lui ; j'atteignis l'ours ; l'ours ${ }_{\text {p.28 }}$ mourut (164). Puis il y eut un ours rayé qui vint; sur lui aussi je tirai une flèche; j'atteignis l'ours rayé; l'ours rayé mourut. L'Empereur fut très joyeux ; il me donna deux boîtes carrées qui étaient assorties l'une à l'autre (165). Je vis un garçon (166) à côté de l'Empereur; l'Empereur me remit un chien (de l'espèce qui se trouve chez les barbares) $T i$ (167), en me disant :

- Quand votre fils aura atteint l'âge mûr, vous ferez présent (de ce chien) à ce garçon.

L'Empereur m'avertit que la maison princière de $T$ sin allait s'affaiblir de génération en génération, et qu'à la septième génération elle disparaîtrait (168); que ceux dont le nom de clan est Yng deviendraient grands et qu'ils battraient les hommes (du clan des) Tcheou (169) à l'ouest de p.29 Fan-k'oei (170), mais qu'ils ne pourraient pas cependant s'approprier (leur territoire) (171). Maintenant (ajouta l'Empereur), je pense à la gloire de Yu-choen, et c'est précisément pourquoi je ferai que sa descendante, Mong-Yao, soit unie à votre descendant à la septième génération (172).

Tong Ngan-yu recueillit ce récit et le conserva par écrit. Il raconta à (Tchao) Kien-tse ce qu'avait dit Pien Ts 'io, et (Tchao) Kien-tse fit présent à Pien Ts'io de quarante mille arpents (meou) de champs.

Un autre jour, (Tchao) Kien-tse étant sorti, un homme se trouva qui barrait le chemin ; on voulut l'écarter, mais il ne s'en alla pas; les gens de l'escorte, irrités, allaient le frapper à coups de sabre lorsque l'homme qui barrait le chemin leur dit :

— Je désire avoir une audience de votre maître. 
Les gens de l'escorte rapportèrent ce propos à (Tchao) Kien-tse qui fit venir p.30l'homme et lui dit :

— Eh ! j'ai déjà eu l'occasion de vous voir ; cela est clair (173) !

Celui qui barrait le chemin répondit :

— Éloignez votre entourage; je désire avoir un entretien avec vous.

Quand (Tchao) Kien-tse eut éloigné ses gens, celui qui barrait le chemin lui dit :

— Lors de la maladie de Votre Seigneurie, je me trouvais à côté de l'Empereur.

— En effet, répliqua (Tchao) Kien-tse ; il en était ainsi ; puisque vous m'avez vu, qu'ai-je fait?

- L'Empereur, dit celui qui barrait le chemin, a ordonné à Votre Seigneurie de tirer des flèches sur un ours et sur un ours rayé qui tous deux en moururent.

— Oui, dit (Tchao) Kien-tse ; mais qu'est-ce que cela signifiait ?

Celui qui barrait le chemin répondit :

- Le royaume de $T$ sin sera bientôt en proie à de grandes difficultés; Votre Seigneurie en sera le principe. L'Empereur a ordonné que Votre Seigneurie fasse périr deux hauts dignitaires (174), car l'ours et l'ours rayé sont, pour l'un et pour l'autre, leurs ancêtres.

(Tchao) Kien-tse dit :

- L'Empereur me fit présent de deux boîtes carrées qui étaient assorties l'une à l'autre. Qu'est-ce que cela signifiait ?

Celui qui barrait la route répondit :

- Le fils de Votre Seigneurie vaincra parmi (les barbares) Ti deux principautés qui appartiennent toutes deux au clan Tse (175).

(Tchao) Kien-tse ajouta :

— J'ai vu un garçon à côté de l'Empereur; l'Empereur me remit un chien ${ }_{\text {p.31 }}$ (de l'espèce qui se trouve chez les barbares) $\mathrm{Ti}$ en me disant que lorsque mon fils serait devenu grand je devrais faire présent (de ce chien à ce garçon). Eh bien, ce garçon, que signifie le présent qu'il faut lui faire du chien (de l'espèce qui se trouve chez les barbares) $T i$ ?

Celui qui barrait le chemin répondit : 
- Le garçon c'est le propre fils de Votre Seigneurie. Le chien (de l'espère qui se trouve chez les barbares) $T i$, c'est l'ancêtre (des princes) de Tai. Le fils de Votre Seigneurie doit certainement posséder (la principauté de) Tai. Puis un successeur de Votre Seigneurie devra modifier les principes du gouvernement et adopter les vêtements des barbares) Hou (176); il s'annexera deux principautés dans (le pays des) $T i(177)$.

(Tchao) Kien-tse demanda (à son interlocuteur) quel était son nom de famille et lui proposa de lui donner une charge officielle, mais celui qui barrait la route répondit :

- Je suis un homme des champs ; je n'ai fait que vous apporter les ordres de l'Empereur.

Aussitôt il disparut. (Tchao) Kien-tse écrivit tout cela et la conserva dans son palais.

Un autre jour, Kou-pou Tse-k'ing vint voir (Tchao) Kien-tse qui fit venir tous ses fils pour qu'il tirât leur horoscope. Tse-k'ing dit :

- Aucun d'eux ne sera général.

— La famille Tchao, demanda (Tchao) Kien-tse, doit-elle donc être anéantie?

Tse-k'ing dit :

— J'ai vu auparavant un enfant sur la route; il est sans doute votre fils.

p.32 (Tchao) Kien-tse fit donc venir son fils Ou-siu (178); dès qu'Ou-siu fut arrivé, Tse-k'ing se leva et s'écria :

— Voilà le véritable général!

- La mère de cet enfant, dit (Tchao) Kien-tse, est de basse extraction ; c'est une servante (du pays des barbares) Ti. Comment expliquez-vous qu'il soit appelé à une haute destinée ?

- C'est le Ciel qui la lui donnera, répondit Tse-k’ing; quoique de basse extraction, il ne manquera pas de parvenir aux honneurs.

Après cet événement (Tchao) Kien-tse manda auprès de lui tous ses fils et conversa avec eux; Ou-siu fut le plus sage. Puis (Tchao) Kien-tse dit à ses fils :

- J'ai caché un sceau précieux sur le sommet de la montagne Tch'ang (179) ; je le donnerai à celui de vous qui le trouvera le premier.

Les fils se rendirent à toute hâte sur la montagne Tch'ang, firent des recherches, mais ne trouvèrent rien. Ou-siu revint et dit : 
— J'ai trouvé le sceau.

— Présentez-le moi, dit (Tchao) Kien-tse.

- Du sommet de la montagne Tch'ang, répondit Ou-siu, j’ai observé le pays de Tai; on peut s'emparer du pays de Tai.

(Tchao) Kien-tse reconnut alors que Ou-siu était bien réellement un sage (180). Il retira donc son rang à ${ }_{\text {p. } 33}$ l'héritier présomptif Po-lou et nomma Ou-siu héritier présomptif.

Deux ans plus tard, la quatorzième année (498) du duc Ting, de Tsin, (les chefs des familles) Fan et Tchong-hang (181) suscitèrent des troubles.

L'année suivante (497), au printemps, (Tchao) Kien-tse dit à Ou, gouverneur de Han-tan :

- Rendez-moi les cinq cents familles de gens de Wei; je veux les établir à Tsin-yang (182).

$O u$ y consentit ; mais, quand il fut de ${ }_{\text {p. } 34}$ retour, son père et son frère aîné s'y refusèrent et il viola sa promesse. Tchao Yang se saisit de $O u$ et l'emprisonna à Tsin-yang, puis il dit aux gens de Han-tan :

- J'ai eu des raisons personnelles pour faire périr $\mathrm{Ou}$; qui voulez-vous nommer à sa place (183) ?

Il tua alors $O u$. - Tchao Tsi (184) et Cho Pin mirent Han-tan en état de rébellion ; le prince de $T$ sin chargea $T s i T$ s'in d'assiéger Han-tan. - Siun Yn et $F a n K i-i(\underline{185})$ avaient été des amis de $O u$; ils se refusèrent à aider $(T s i) T_{s}$ 'in et projetèrent de faire des troubles. Tong Ngan-yu en eut connaissance. - Le dixième mois, (les chefs des familles) Fan et Tchong-hang (186) attaquèrent Tchao Yang; celui-ci s'enfuit à Tsin-yang; les gens de Tsin 1'y assiégèrent. - Wei Siang et d'autres, qui étaient les ennemis de Fan Ki-i et de Siun Yn, projetèrent de chasser Siun Yn en le remplaçant par Leang Yng-fou, et de chasser (Fan) Ki-i en le remplaçant ${ }_{\text {p.35 }}$ par Fan Kao-i. - Siun Li (187) dit au marquis de $T \sin$ :

- Votre Altesse a décrété envers ses principaux sujets que le premier d'entre eux qui se révolterait périrait (188); maintenant trois de vos sujets (189) ont été les premiers à se révolter; cependant vous ne poursuivez que le seul (Tchao) Yang; c'est appliquer les châtiments d'une manière inégale. Je vous demande de les poursuivre tous.

Le onzième mois, Siun Li, Han Pou-sin et Wei Tch'e, reçurent du duc des ordres pour attaquer (les chefs des familles) Fan et Tchong-hang, mais ils n'eurent pas l'avantage. (Les chefs des familles) Fan et Tchong-hang prirent à leur tour l'offensive contre le duc ; le duc leur livra bataille ; ils furent battus et se retirèrent; le jour ting-wei, ils se réfugièrent à Tchao-ko. - (Les chefs des familles) Han et Wei intercédèrent en faveur (du chef de la famille) Tchao. 
Le douzième mois, le jour sin-wei, Tchao Yang vint faire sa soumission; il accepta une convention faite avec serment dans le palais ducal.

L'année suivante (496), Tche-po Wei-tse dit à Tchao Yang :

- Quoique (les chefs des familles) Fan et Tchong-hang se soient bien réellement révoltés, c'est (Tong) Ngan-yu qui les y a incités ; ainsi il a pris part à leur complot. Or une loi a été rendue dans le royaume de $T \sin$ pour dire que ceux qui seraient les premiers à se révolter seraient mis à mort. Les deux autres ont subi p.36 leur châtiment et (Tong) Ngan-yu seul survit.

Tchao Yang se montrant anxieux à ce sujet, (Tong) Ngan-yu lui dit :

- Si, par ma mort, la famille Tchao est en sécurité et le royaume de $T \sin$ en paix, je n'ai que trop vécu.

Il se tua aussitôt. Tchao (Yang) en informa Tche po, et, à la suite de cela, la famille Tchao jouit du calme (190).

K'ong tse apprit que Tchao Kien-tse n'avait pas demandé l'autorisation du prince de Tsin pour s'emparer de $\mathrm{Ou}$ (gouverneur de) Han-tan et pour se tenir sur la défensive à Tsin-yang; c'est pourquoi, quand il écrivit le Tch'oen-ts'ieou, il dit :

«Tchao Yang mit Tsin-yang en état de révolte (191) ».

Tchao Kien-tse avait un de ses sujets, nommé Tcheou Cho, qui excellait à lui adresser de franches réprimandes. Quand Tcheou Cho fut mort, (Tchao) Kien-tse, chaque fois qu'il tenait sa cour se montrait mécontent; ses grands officiers lui demandèrent à être punis (de la faute qu'ils avaient pu commettre). (Tchao) Kien-tse leur dit :

- O grands officiers, vous ne m'avez fait aucune offense. Mais j'ai entendu dire que mille peaux de mouton ne valent pas la peau des aisselles d'un seul renard; or, quand vous êtes réunis à ma cour, je n'entends que vos murmures d'assentiment et je n'entends plus les gronderies ${ }_{\text {p.37 }}$ de Tcheou Cho; voilà pourquoi je suis triste (192).

A partir de ce moment (Tchao) Kien-tse sut s'attacher les villes qui appartenaient au clan Tchao et chérir les gens (du pays) de Tsin.

p.38 La dix-huitième année (494) du duc Ting, de Tsin, Tchao Kien-tse assiégea (les chefs des familles) Fan et Tchong-hang à Tchao-ko. Tchong-hang Wen-tse s'enfuit à Han-tan.

L'année suivante (493), le duc Ling, de Wei, mourut. Tchao Kien-tse et Yang Hou ramenèrent dans son pays K'oai-wai, héritier présomptif de $W e i(\underline{193})$, mais les gens de Wei ne l'admirent pas; il fixa sa résidence à $T s^{\prime} i$ (194). 
La vingt et unième année (491) du duc Ting, de Tsin, (Tchao) Kien-tse prit Han-tan. Tchong-hang Wen-tse s'enfuit à Po-jen (195) et (Tchao) Kien-tse assiégea derechef cette ville. Tchong-hang Wen-tse et Fan Tchao-tse s'enfuirent alors (dans le pays de) Ts'i. En définitive, Tchao (Kien-tse) eut la possession de Han-tan et de Po-jen tandis que les autres villes (des familles) Fan et Tchong-hang furent incorporées au (domaine des princes de) Tsin. Tchao (Kien-tse) était de nom un haut dignitaire de Tsin, mais, en fait, il exerçait toute l'autorité dans le pays de $T \sin$ et ses apanages étaient aussi considérables qu'une principauté féodale.

La trentième année (482) du duc Ting, de Tsin, le duc Ting et le roi de $O u$, Fou-tch'ai, se disputèrent la prééminence à Hoang-tch'e (196). Tchao Kien-tse était à la suite (du duc, et c'est pourquoi) le duc Ting, de Tsin, eut en définitive la prééminence sur (le roi de) $O u(197)$.

p.39 La trente-septième année (475), le duc Ting mourut. Alors (Tchao) Kien-tse quitta le deuil de trois ans et se contenta du deuil d'un an (198). Cette même année, Keou-tsien, roi de Yue, anéantit (l'État de) Ou (199).

La onzième année (464), du duc Tch'ou, de Tsin, Tche po attaqua Tcheng. Tchao Kien-tse étant malade, chargea son héritier présomptif Ou-siu de se mettre à la tête de ses troupes pour assiéger Tcheng (200). Tche po s'étant enivré avec du vin, aspergea de liquide et frappa Ou-siu; les officiers de $\mathrm{Ou}$ siu lui demandèrent de faire périr Tche po, mais Ou-siu leur dit :

- Si mon prince m'a nommé (héritier présomptif), c'est parce que j'étais capable de supporter les outrages.

Il en conçut cependant de la haine contre Tche po. Quand Tche po fut de retour, il raconta l'incident à (Tchao) Kien-tse pour qu'il dégradât Ou-siu ; mais (Tchao) Kien-tse s'y refusa, et, à partir de ce moment, Ou-siu détesta Tche po.

La dix-septième (458) du duc Tch'ou, de Tsin, (Tchao) ${ }_{\text {p.40 Kien-tse }}$ mourut (201). Son héritier présomptif, Ou-siu, lui succéda; ce fut (Tchao) Siang-tse.

La première année (457) de Tchao Siang-tse, comme Yue assiégeait Ou, (Tchao) Siang-tse retrancha sur la nourriture permise en temps de deuil et envoya Tch'ou Long demander des nouvelles du roi de $\mathrm{Ou}$ (202).

La sœur aînée de (Tchao) Siang-tse était devenue auparavant la femme du roi de Tai (203). Quand (Tchao) Kien-tse fut mort, avant même qu'on eût quitté les vêtements de deuil, (Tchao Siang-tse) alla au nord monter sur la montagne Hia-ou (204) et invita le roi de Tai; il chargea ses cuisiniers de se munir de cuillers en cuivre pour donner à manger au roi de Tai et à ceux qui l'accompagnaient; quand on versa à boire, il ordonna secrètement aux p.41 aides de cuisine de frapper tous (205) avec leurs cuillers et de tuer le roi de Tai et les officiers de son escorte ; puis il mit en campagne ses soldats, et conquit 
le territoire de Tai. Quand sa sœur aînée l'apprit, elle invoqua le ciel en pleurant ; elle aiguisa l'épingle de sa coiffure et se tua. Les gens de Tai eurent compassion d'elle et donnèrent le nom de montagne Mo-ki (206) à l'endroit où elle était morte (207). Alors (Tchao Siang-tse) conféra à Tcheou, p.42 fils de Po-lou, (le territoire de Tai) pour qu'il fût le prince Tch'eng, de Tai. Po-lou était le frère aîné de (Tchao) Siang-tse et avait été autrefois héritier présomptif ; cet héritier présomptif était mort prématurément ; c'est pourquoi on donna un fief à son fils.

Quatre ans (454) après que (Tchao) Siang-tse eut pris le pouvoir, Tche po ainsi que Tchao, Han et Wei se partagèrent entièrement les territoires qui avaient autrefois appartenu (aux familles) Fan et Tchong-hang. Le duc $T c h$ 'ou, de $T \sin$, en fut irrité (208); il se plaignit (aux princes de) $T s^{\prime} i$ et de $L o u$, désirant se servir d'eux pour attaquer les quatre hauts dignitaires. Les quatre hauts dignitaires eurent peur et s'unirent aussitôt pour attaquer le duc Tch'ou. Le duc Tch'ou s'enfuit (dans le pays de) $T s$ ' $i$, mais il mourut en chemin. Tche Po mit alors sur p.43 le trône Kiao, arrière petit-fils du duc Tchao ; ce fut le duc $I$, de $T \sin (\underline{209})$.

Tche po redoubla d'arrogance. Il demanda des terres à Han et à Wei qui les lui livrèrent; il en demanda à Tchao qui les refusa à cause de l'affront qui lui avait été fait lors du siège de Tcheng (210). Tche po, irrité, entraîna avec lui Han et Wei et attaqua Tchao. Tchao Siang-tse, saisi de crainte, courut se mettre sur la défensive à Tsin-yang (211). Yuen Kouo 1'y suivit; comme il se trouvait en arrière, lorsqu'il arriva à Wang-tse (212), trois hommes p.44 lui apparurent qui étaient visibles dans toute la partie du corps au dessus de la ceinture, tandis que la partie au-dessous de la ceinture était invisible. Ils donnèrent à Yuen Kouo une section de bambou comprise entre deux nœuds dont aucun n'était percé (213) et lui dirent :

— Remettez ceci de notre part à Tchao Ou-siu.

Quand Yuen Kouo fut arrivé (à Tsin-yang), il raconta la chose à (Tchao) Siang-tse ; celui-ci, après avoir jeûné pendant trois jours, rompit en personne le bambou ; il s'y trouvait un écrit en caractères rouges qui était ainsi conçu :

«Ô Tchao Ou-siu, nous sommes le Houo t'ai chan, le marquis de Chan-yang et l'envoyé céleste (214). Le troisième mois, le jour ping-siu, nous ferons que ce sera vous qui, contrairement (aux apparences actuelles), détruirez la famille Tche (215). Vous, de votre côté, consacrez-nous cent villes. Nous vous donnerons le territoire des Lin-hou (216). Puis, p.46 parmi vos descendants, il y aura un roi puissant (217); il aura d'un dragon noir la face (218); d'un oiseau le bec recourbé (219) et les poils sur les tempes, d'un cerf la barbe au menton et sur les joues; il aura un grand thorax et une vaste poitrine; il sera long du bas du corps et grand; il croisera ses vêtements à gauche (220) et montera à cheval revêtu d'une 
cuirasse (221). Il possédera entièrement le territoire p.47 de Ho-tsong (222) et s'étendra jusqu'aux diverses peuplades $M e$ (223) de Hieou-hoen; au sud, il attaquera les (territoires) réparés de $T \sin (\underline{24})$; au nord, il détruira les Hei-kou (225).

(Tchao) Siang-tse se prosterna par deux fois et reçut ce ${ }_{\text {p.48 }}$ décret des trois dieux (226).

Les trois royaumes assiégèrent Tsin-yang; au bout de plus d'un an, ils amenèrent l'eau de la rivière Fen (227) pour p.49 inonder les remparts; il n'y avait que trois pan (228) des remparts qui n'étaient pas immergés. A l'intérieur de la ville, on suspendait en l'air les marmites pour faire la cuisine (229); on échangeait les enfants pour les manger. Les officiers étaient tous démoralisés et négligeaient de plus en plus les rites; seul Kao Kong (230) ne se permit pas de manquer aux rites. (Tchao) Siang tse eut peur ; alors, de nuit, il envoya son conseiller Tchang mong T'ong s'entendre secrètement avec Han et Wei; Han et $\mathrm{Wei}$ firent un complot de connivence avec lui ; le troisième mois (453), le jour ping-siu, les trois royaumes (231), contrairement à ce qu'on attendait, détruisirent le clan Tche et se partagèrent entre eux ses terres (232).

p.50 Alors (Tchao) Siang-tse procéda à la distribution des ${ }_{\text {p.51 }}$ récompenses. Kao Kong fut le premier. Tchang mong T'ong dit :

— Lors des difficultés où nous fûmes à Tsin-yang, c'est précisément (Kao) Kong qui n'a eu aucun mérite.

(Tchao) Siang-tse répondit :

- Lorsque la situation était critique à Tsin-yang, tous mes officiers ont été négligents; seul (Kao) Kong ne s'est pas permis de manquer aux rites qui incombent à un sujet; c'est pourquoi je le mets avant les autres.

A la suite de ces événements, Tchao, qui, au nord, possédait Tai, et qui, au sud, s'était annexé (les territoires du) clan Tche, devint plus puissant que Han et que Wei. Il institua alors des sacrifices aux trois dieux (233), dans cent villes et chargea Yuen Kouo de présider aux sacrifices offerts au Houo-t'ai chan.

Dans la suite, (Tchao Siang-tse) épousa une fille de la famille K'ong-t'ong (234); elle enfanta cinq fils. (Tchao) Siang-tse, considérant que Po-lou n'avait pas exercé le pouvoir, ne voulut pas mettre sur le trône un de ses propres fils, mais désirait fermement transmettre sa dignité au ${ }_{\text {p. } 52}$ fils de Po-lou, le prince Tch'eng, de Tai; le prince Tch'eng étant mort avant lui, il prit Hoan, fils du prince Tch'eng, de Tai, et le nomma héritier présomptif. (Tchao) Siang-tse mourut (425), après avoir eu le pouvoir pendant trente-trois années.

Hoan prit le pouvoir ; ce fut le marquis Hien. Le marquis Hien était jeune quand il monta sur le trône; il eut le siège de son gouvernement à 
Tchong-meou (235). Hoan-tse, frère cadet de Siang-tse, chassa le marquis Hien et s'arrogea le pouvoir à Tai. Il mourut au bout d'un an. Les gens du pays dirent :

— L'avènement de Hoan-tse n'était pas conforme aux intentions de Siang-tse.

Ils s'unirent alors pour tuer son fils, puis ils allèrent de nouveau chercher le marquis Hien et le remirent sur le trône. - La dixième année (414), le duc Ou, de Tchong-chan (236), prit pour la première fois le pouvoir. - La p.53 treizième année (411), (le marquis Hien) construisit les remparts de P'ing-i (237). - La quinzième année (409), le marquis Hien mourut. Son fils, $T s i$, qui fut le marquis Lie, prit le pouvoir.

La première année (408) du marquis Lie, le marquis Wen, de Wei, attaqua Tchong-chan et envoya son héritier présomptif, $K i$, y tenir garnison. - La sixième année (403), Wei, Han et Tchao se conférèrent les uns aux autres le titre de seigneur. Par un hommage rétrospectif, on honora Hien-tse du nom de marquis Hien (238).

Le marquis Lie aimait la musique. Il dit au conseiller d'État Kong-tchong Lien :

— Si j'ai des favoris, puis-je les anoblir?

Kong-tchong répondit :

— Les enrichir, vous le pouvez ; mais les anoblir, non.

Le marquis Lie répliqua :

- C'est bien. Or il y a deux chanteurs du pays de Tcheng, nommés Ts'iang et Che; je veux les gratifier de terres cultivables en attribuant une superficie de dix mille meou à chacun d'eux.

Kong-tchong approuva, mais il ne donna pas (les champs). Un mois plus tard, le marquis Lie revint de Tai et s'informa des terres des chanteurs. Kong-tchong lui dit qu'il avait cherché (des terres), mais n'avait pu encore en trouver qui fussent convenables. Quelque temps après, le marquis Lie ayant posé de nouveau la même question, Kong-tchong, qui, en définitive, ne (voulait) pas donner (les champs), se prétendit malade et ne vint plus à la cour. Le prince de ${ }_{\text {p.54 }} P^{\prime}$ 'an-ou (239), étant venu du pays de Tai, dit à Kong-tchong :

- Notre prince en réalité aime le bien, mais il ne sait pas encore à quoi s'attacher fermement. Maintenant, ô Kong-tchong, vous êtes conseiller de Tchao depuis déjà quatre années; avez-vous cependant recommandé des gens de valeur?

— Je ne l'ai pas encore fait, dit Kong-tchong.

Le prince de $P$ 'an-ou reprit : 
- Nieou Hiu, Siun Hin et Siu Yue sont tous trois dignes (d'être recommandés).

Kong-tchong alors (se décida à) recommander ces trois hommes. Quand il fut venu à la cour, le marquis Lie l'interrogea encore au sujet des terres des chanteurs en lui demandant ce qu'il avait fait. Kong-tchong dit :

- Justement j'ai envoyé (ici des gens) pour que vous choisissiez ce qui est le plus avantageux (240).

Nieou Hiu entretint le marquis Lie de la bonté et de la justice et lui résuma les devoirs royaux. Le marquis Lie se sentit à l'aise. Le lendemain, Siun Hin l'entretint (de la nécessité) de promouvoir les sages lorsqu'on fait des choix, de confier les fonctions à des hommes capables lorsqu'on nomme à des charges publiques. Le jour suivant, Siu Yue l'entretint (de la nécessité) d'user avec tempérance des richesses et de dépenser avec ${ }_{\text {p.55 }}$ modération, de tenir compte des mérites et de ne faire de don à aucun de ceux qui ne rempliraient pas toutes les conditions requises. Le prince fut satisfait. Le marquis Lie envoya un émissaire dire au conseiller d'État :

— Les terres des chanteurs, maintenant j'y renonce.

Il conféra à Nieou Hiu le titre de précepteur, à Siun Hin celui de tchong-wei, et à Siu Yue celui de nei-che (241); il donna au conseiller d'État deux vêtements (242).

La neuvième année (400), le marquis Lie mourut. Son frère cadet, qui fut le duc $O u$, prit le pouvoir. - Le duc $O u$ mourut en la treizième année (387) de son règne. Les gens de Tchao mirent alors sur le trône Tchang, fils aîné du marquis Lie; ce fut le marquis King. Cette même année (387), le marquis Wen, de Wei mourut.

La première année (386) du marquis King, Tchao, fils du duc Ou, suscita une rébellion; il ne fut pas vainqueur; il sortit (du pays de Tchao) et se réfugia dans (le pays de) Wei. - Tchao fixa pour la première fois sa capitale à Han-tan (243). - La deuxième année (385), (le marquis King) battit Ts'i à Ling-k'ieou (244). - La troisième ${ }_{\text {p.56 }}$ année (384), il secourut Wei à Lin- $k$ 'ieou (245) et fit essuyer une grande défaite aux gens de Ts'i. - La quatrième année (383), Wei nous vainquit à T'ou-t'ai. (Le marquis King) construisit un rempart à Kang-p'ing (246) afin de faire des incursions dans le pays de $W e i[\mathrm{~b}](247)$. - La cinquième année (382), Ts' $i$ et $W e i$, intervenant en faveur de Wei [b], attaquèrent Tchao et prirent notre ville de Kang-p'ing. La sixième année (381), (le marquis King) emprunta des soldats à Tch'ou, battit Wei et s'empara de (la ville de) Ki-p'ou (248). — La huitième année (379) (249), il prit à Wei (la ville de) Hoang-tch'eng (250). - La neuvième p.57 année (378), il attaqua $T s$ ' $i$. Ts' $i$, ayant attaqué Yen, Tchao vint au secours de Yen. - La dixième année (377), (Tchao) combattit contre Tchong-chan à Fang-tse (251). - La onzième année (376), Wei, Han et Tchao s'entendirent pour supprimer $T$ sin et se partager son territoire. (Tchao) attaqua Tchong-chan 
et combattit encore (contre lui) à Tchong-jen (252). - La douzième année (375), le marquis King mourut. Son fils, Tchong, qui fut le marquis Tch'eng, prit le pouvoir.

La première année (374) du marquis Tch'eng, le kong-tse Cheng contesta le pouvoir au marquis Tch'eng et se révolta. — La deuxième année (373), le sixième mois (253), il neigea. — La troisième année (372), Ta-meou-ou (254) devint conseiller. (Tchao) attaqua Wei et lui prit soixante-treize places. Wei nous vainquit à $\operatorname{Lin}(\underline{255})$. - La quatrième année (371), (Tchao) combattit contre $T$ s'in à Kao-ngan (256) et le vainquit. - La cinquième année (370), p.58 il attaqua $T s$ ' $i$ à Kiuen (257). Wei nous vainquit à Hoai (258). (Tchao) attaqua Tcheng (259), le vainquit et le donna à Han; Han nous donna Tchang-tse (260). - La sixième année (369), (le prince de) Tchong-chan construisit un long mur (261). (Tchao) attaqua Wei et le vainquit à Tchouo-tse (262); il assiégea le roi Hoei, de Wei (263). - La septième année (368), p.59 (Tchao) fit une incursion dans le pays de $T s$ ' $i$ et arriva jusqu'au long mur (264). S'alliant à Han, il attaqua Tcheou (265). La huitième année (367), allié à Han, il divisa (le royaume des) Tcheou et en fit deux (royaumes) (266). - La neuvième année (366), il combattit contre $T s^{\prime} i$ sous les murs de $N g o$ (267). - La dixième année (365), il attaqua Wei [b] et lui prit Kiuen (268). — La onzième année (364), $T s^{\prime}$ in attaqua Wei; Tchao le secourut à Che-ngo (269). - La douzième année (363), Ts'in attaqua Chao-Leang (270), (ville) de Wei; Tchao vint à son secours. - La treizième année (362), le duc Hien, de Ts'in, chargea le chou-tchang Kouo d'attaquer Chao-leang, (ville) de Wei ; (ce général) fit prisonnier $T s^{\prime} O$, héritier présomptif (de Wei). Wei nous ${ }_{\text {p.60 }}$ battit à Koai (271) et nous prit (la ville de) P'i-lao. Le marquis Tch'eng rencontra (272) le marquis Tchao, de Han, à Chang-tang (273). - La quatorzième année (361), (Tchao), allié à Han, attaqua $T s$ 'in. — La quinzième année (360), il aida Wei à attaquer $T s$ 'i. - La seizième année (359), (Tchao), ainsi que Han et Wei se partagèrent (les terres de) Tsin; ils conférèrent au prince de $T$ sin (la principauté de) Toan-che (274). - La dix-septième année (358), le marquis Tch'eng et le roi Hoei, de Wei, se rencontrèrent à Ko-ye (275). - La dix-neuvième année (356) (276), (Tchao) rencontra (les princes de) Ts'i et Song à P'ing-lou (277). Il eut ${ }_{\text {p.61 }}$ une entrevue avec (le prince de) Yen à $N g o$ (278). - La vingtième année (355), Wei offrit (à Tchao des pièces de bois propres à faire) des acrotères et des chevrons; (le marquis Tch'eng) s'en servit pour construire la terrasse T'an (279). - La vingt et unième année (354), Wei assiégea notre ville de Hantan (280). - La vingt-deuxième année (353), le roi Hoei, de Wei, nous prit Han-tan. De son côté, Ts'i vainquit Wei à Koei-ling (281). — La vingt-quatrième année (351), Wei nous rendit Han-tan. (Tchao) conclut un traité avec Wei sur les bords de la rivière ${ }_{\text {p.62 }}$ Tchang (282). Ts 'in nous attaqua à Lin (283). La vingt-cinquième année (350), le marquis Tch'eng mourut. — Le kong-tse Sie contesta le trône à l'héritier présomptif qui fut le marquis Sou (284); Sie, battu, s'enfuit dans le pays de Han. 
La première année (349) de son règne, le marquis Sou enleva Toan-che (285) au prince de $T \sin$ et en transporta la population à T'oen-lieou (286). - La deuxième année (348), il rencontra le roi Hoei, de Wei, à Yn-tsin (287). - La troisième année (347), le kong-tse Fan attaqua par surprise Han-tan; il ne fut pas victorieux et il périt. — La quatrième année (346), (le marquis Sou) rendit hommage au Fils du Ciel. — La sixième année (344), il attaqua $T s$ ' $i$ et s'empara de Kao-t'ang (288). - La septième année (343), le p.63 kong-tse $K^{\prime}$ o attaqua Wei à Cheou-yuen (289). - La onzième année (339), le duc Hiao, de Ts'in, envoya le prince de Chang (290) attaquer Wei; (le prince de Chang fit prisonnier le kong-tse Ang, qui était le général (de Wei). Tchao attaqua Wei. — La douzième année (338), le duc Hiao, de Ts 'in, mourut. Le prince de Chang mourut. - La quinzième année (335), (le marquis Sou) éleva la sépulture Cheou (291). Le roi Hoei, de Wei, mourut. La seizième année (334), le marquis Sou étant allé se promener à Ta-ling (292), sortit par la Porte du Cerf (293). Ta-meou-ou (294), tirant son cheval par la bride, dit (au marquis) :

- L'occupation du labourage est une affaire urgente. Si pendant un seul jour on la néglige, pendant cent jours on ne mangera pas.

Le marquis Sou descendit de son char et le remercia. - La dix-septième année (333), (Tchao) assiégea (la ville de) Hoang (295) (qui appartenait à) Wei, mais ne réussit ${ }_{\text {p.64 }}$ pas. Il construisit un long mur (296). - La dix-huitième année (332), Ts 'i et Wei nous attaquèrent ; nous ouvrîmes une brèche aux eaux du Ho pour les submerger, et les soldats se retirèrent. — La vingt-deuxième année (328), Tchang I devint conseiller de $T$ s'in. Tchao $T$ s'e combattit contre Ts'in et fut vaincu; Ts'in tua (Tchao) Ts'e dans le Ho-si et prit Lin et Liche (297) (dans la région) de Tai. — La vingt-troisième année (327), Han Kiu (298) combattit contre $T_{S}$ ' $i$ et $W e i$; il périt à Sang-k'ieou (299). - La p.65 vingt-quatrième année (326), le marquis Sou mourut. (Les princes de) Ts'in, Tch'ou, Yen, Ts'i et Wei mirent chacun sur pied dix mille soldats d'élite et vinrent assister ensemble aux funérailles. Le fils (du marquis Sou), qui fut le roi Ou-ling (300), prit le pouvoir.

La première année (325) du roi Ou-ling, Tchao pao, prince de Yang-wen, fut son conseiller. Le roi Siang, de Leang (301), avec son héritier présomptif $S e$, et le roi Siuen, de Han, avec son héritier présomptif $T s$ 'ang, vinrent rendre visite (au roi Ou-ling) dans le palais Sin (302). - Comme le roi Ou-ling était jeune, il ne pouvait encore gouverner par lui-même et consultait souvent trois hommes qui étaient ses précepteurs et trois hommes qui, se tenant à ses côtés, étaient chargés de veiller à ses fautes. Quand il exerça le gouvernement, il commença par s'informer de Fei I, haut fonctionnaire sous le règne du roi précédent, et augmenta ses dignités. Dans son royaume, aux vieillards honorables (303) qui p.66 avaient atteint l'âge de quatre-vingt ans, il témoignait chaque mois les honneurs qui leur étaient dus. - La troisième année (304) (323), il éleva un rempart à Hao (305). - La quatrième année (322), il eut une 
entrevue avec (le prince de) Han à $K^{\prime} i u$-chou (06). - La cinquième année (321), il prit pour femme la fille (du prince) de Han et en fit son épouse principale. - La huitième année (318), Han attaqua $T s$ 'in, mais, n'ayant pas été vainqueur, il se retira. Les cinq royaumes (307) se décernèrent les uns aux autres le titre de « roi » (wang); Tchao seul se refusa à le prendre, disant :

- Là où il n’y a pas de réalité, oserait-on placer le nom qui convient (seulement à cette réalité) ?

Il ordonna aux gens de son pays de parler de lui en l'appelant «prince » (kiun). - La neuvième année (317), il s'allia à Han et à Wei pour attaquer avec eux $T s^{\prime}$ in (308); $T s^{\prime}$ in nous battit et coupa quatre-vingt mille têtes. - Ts' $i$ nous battit à Koan-tse (309). - La dixième année (316), Ts 'in nous prit ${ }_{\text {p.67 }} \mathrm{Si}$ tou et Tchong-yang ( $(10)$. - Ts'i écrasa Yen; le conseiller de Yen, Tse-tche, devint prince, tandis que le prince (de Yen) devenait sujet (311). - La onzième année (315), le roi (de Tchao) fit venir (du pays) de Han le kong-tse Tche et le nomma roi de Yen; il chargea Lo Tch'e de le ramener (dans le pays de Yen) (312). - La treizième année (313), Ts'in nous prit (la ville de) Lin et fit prisonnier le général Tchao Tchoang (313). Les rois de Tch'ou et de Wei vinrent et passèrent par Han-tan. — La quatorzième année (312), Tchao Ho attaqua Wei.

p.68 La seizième année (310), le roi Hoei, de $T$ s'in, mourut (314). — Le roi (Ou-ling) alla se promener à Ta-ling ( $\underline{315}$; le lendemain, le roi vit en songe une vierge qui jouait du luth et chantait une poésie ainsi conçue :

- Je suis une belle femme fort gracieuse ; mon visage a l'élégance (de la fleur) de t'iao (316). C'est la destinée, c'est la destinée (317) que personne ne m'égale, moi (dont le nom de famille est) Yng.

Un autre jour, le roi, au milieu de la joie d'un banquet, parla du songe qu'il avait eu et de la figure qu'il avait cru voir. Ou Koang (318) l'entendit; par l'intermédiaire de l'épouse principale (du roi), il fit entrer (dans le palais) sa fille qui était la belle Mong-Yao (dont le nom de famille était) Yng (319). MongYao jouit d'une grande faveur auprès du roi ; elle devint la reine Hoei.

p.69 La dix-septième année (309), le roi sortit par Kieou-men (320). Il fit la terrasse $Y e$ (321) pour observer de loin les territoires de $T s$ ' $i$ et de Tchong-chan. — La dix-huitième année (308), le roi Ou, de Ts'in, ayant soulevé avec Mongyue le trépied rouge orné de dragons, se brisa les rotules et mourut (322). Le roi de Tchao chargea Tchao Kou, conseiller de Tai, d'aller chercher dans (le pays de) Yen le kong-tse Tsi et de le ramener (dans le pays de $T s$ 'in). Il le nomma roi de $T s$ 'in; ce fut le roi Tchao.

La dix-neuvième année (307), au printemps, le premier mois, (le roi $\mathrm{Ou}$ Ling) tint cour plénière dans le palais $\operatorname{Sin}(323)$; il manda auprès de lui Fei $I$ (324) et s'entretint avec lui de la politique générale ; ce ne fut qu'au bout de cinq jours que (ces conversations) prirent fin. Le roi alla dans le nord

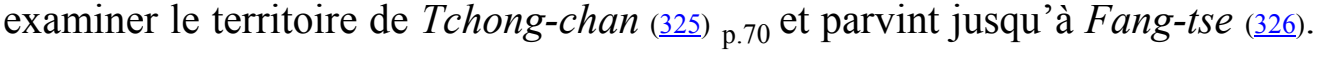


Puis il alla (dans la région de) Tai, et au nord, arriva jusqu'à Ou- $k$ 'iong (227). A l'ouest il parvint jusqu'au Ho. Il monta sur (la montagne) Hoang-hoa (228). Il manda auprès de lui Leou Hoan pour délibérer avec lui ; il lui dit :

- Le roi mon prédécesseur profita des changements qui s'étaient introduits de son temps pour agrandir son territoire sur sa frontière méridionale ; barrant d'une manière continue les parages difficiles (des rivières) Tchang (2329) et Fou (330), il éleva un long mur (31); en

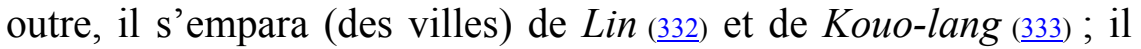
battit les gens de Lin (334) dans (la localité appelée) Yen (335); cependant son œuvre glorieuse ne put être terminée. Maintenant Tchong-chan est sur notre ventre et notre cœur (336); au nord, se trouve Yen; à l'est p.71 sont les Hou (337); à l'ouest, les Lin-hou (338), les Leou-fan (339) et notre frontière avec Ts'in et avec Han. Si nous n'avons pas de vaillants soldats pour nous sauver, ce sera la ruine de nos dieux du sol et des moissons. Que faut-il donc faire ? Or celui dont la renommée s'élève au-dessus d'une époque est accablé sous les difficultés qu'on lui fait au nom des coutumes traditionnelles. Je désire adopter l'habillement des Hou.

Leou Hoan l'approuva. Ses ministres assemblés s'y montrèrent tous contraires. Alors, [(40) Fei I se trouvant à ses côtés (341), le roi dit : p.72

— La gloire des souverains Kien et Siang (242) a consisté en ceci qu'ils ont fait des plans pour s'assurer l'avantage (de conquérir) les Hou et les $T i$ (343). Celui qui est sujet, quand il jouit de la faveur (344) (de son prince), observe les devoirs de la piété filiale et de l'amour fraternel, (les devoirs) des égards envers ceux qui sont âgés et ceux qui sont jeunes, (les devoirs de) se montrer obéissant et de comprendre (les ordres qui lui sont donnés); quand il réussit, il s'applique à aider le peuple et à être utile à son souverain. Telles sont les deux séries d'attributions qui conviennent à un sujet (345). Maintenant, je désire marcher sur les traces des rois Kien et Siang et m'ouvrir le territoire des $\mathrm{Hou}$ et des $\mathrm{Ti}$; mais, dans tout le monde, je ne vois personne (346). Si, en faisant cela, mes ennemis sont affaiblis, p.73 avec peu d'efforts (347) mon triomphe sera grand ; je pourrai, sans épuiser mon peuple de fatigue, renouveler la gloire de l'antiquité passée. Or celui dont les mérites s'élèvent au-dessus de son époque est accablé sous les difficultés qu'on lui suscite au nom des coutumes traditionnelles; celui dont les pensées sont pleines d'une sagesse extraordinaire est en butte aux haines du peuple insolent (348). Maintenant, je me propose d'adopter les vêtements des $\mathrm{Hou}$ et le tir à l'arc à cheval afin d'enseigner (ces usages) à mon peuple; mais le monde ne manquera pas de me critiquer ; comment faut-il faire ?

Fei I répondit : 
- J'ai entendu dire que celui qui hésite dans ses entreprises n'atteint pas la gloire, que celui qui hésite dans ses actions n'obtient aucune renommée. Puisque, ô roi, vous avez résolu de vous exposer aux soucis que vous feront les coutumes traditionnelles, sans doute il faut que vous ne teniez aucun compte des critiques du monde. En effet, ceux qui visent à la vertu parfaite ne sont pas d'accord avec le vulgaire ; ceux qui accomplissent de grandes actions ne délibèrent pas avec la foule. Autrefois, Choen, en exécutant des danses, gagna les Miao $(\underline{349}) ; Y u$, en se dénudant le torse, (pénétra dans) le royaume des hommes nus (350); (s'ils agissaient de la sorte), p.74 ce n'était pas pour satisfaire leurs désirs et réjouir leur volonté ; ils travaillaient ainsi à se régler sur la vertu et à s'assurer de la gloire. Le sot ne voit pas les choses même quand elles sont réalisées; le sage les discerne avant même qu'elles aient pris forme. Ainsi, ô roi, pourquoi hésitez-vous (ㅎ1) ?

- Le roi dit :

- Je n'ai aucun doute sur (la nécessité qu'il y a d'adopter) les vêtements $\mathrm{Hou}$, mais je crains que le monde ne se moque de moi. La joie de l'insensé afflige celui qui est plein de sens; le rire du sot attriste (352) le sage. Si, à notre époque, il y a des gens qui me suivent, la gloire que nous vaudra l'adoption des vêtements $\mathrm{Hou}$ sera incalculable, et, même si on excite le monde à se moquer de moi, le territoire des Hou et le Tchong-chan certainement je les posséderai.

Alors donc il adopta les vêtements Hou.]

[(Le roi Ou-ling) envoya Wan-Sie (353) dire (en son nom) ${ }_{\text {p.75 }}$ au kong-tse Tch'eng :

- J'ai adopté les vêtements Hou et même je me propose de les porter aux audiences de la cour. Je désire aussi que vous, mon oncle, vous les revêtiez. Que, dans la famille, on obéisse aux parents, et que, dans l'État, on obéisse au prince, c'est la conduite qui a été généralement tenue depuis l'antiquité jusqu'à nos jours. Que le fils ne se révolte pas contre ses parents et que le sujet ne s'oppose pas à son prince, c'est le principe général (qui règle les relations) entre ceux qui sont à la tête et ceux qui sont soumis (354). Maintenant, j'ai donné des instructions pour qu'on change les vêtements et si vous, mon oncle, ne revêtez pas (le nouveau costume), je crains que le monde ne critique (la décision que j'ai prise). Pour diriger un État il y a une règle constante, à savoir que l'intérêt du peuple est l'essentiel ; pour obéir au gouvernement il y a une loi immuable, à savoir que l'exécution des ordres est la chose la plus importante. (Le prince) qui veut mettre en lumière sa vertu commence donc par s'occuper des gens du peuple; (le sujet) qui 
veut agir en obéissant au gouvernement commence par avoir confiance dans son supérieur. Maintenant, si j'ai résolu d'adopter les vêtements $\mathrm{Hou}$, ce n'est pas pour satisfaire mes désirs et pour réjouir ma volonté. Mon entreprise a un but et mon action glorieuse a le moyen de se réaliser. Quand mon entreprise ${ }_{\text {p.76 }}$ sera accomplie et que mon action glorieuse sera faite, alors tout ira bien. Maintenant, je crains, mon oncle, que vous ne violiez la loi immuable qui préside à l'obéissance au gouvernement, et c'est pourquoi j'aide à votre délibération (par les explications que je vous donne). En outre, d'après ce que j'ai appris, celui qui travaille au bien de son royaume, sa conduite n'est point mauvaise; celui qui s'appuie sur ceux de ses parents qui sont élevés en dignité, sa renommée ne sera point compromise. C'est pourquoi je désire faire appel à votre justice, mon oncle, afin de pouvoir réaliser la gloire que j'attends de l'adoption des vêtements Hou. J'ai envoyé Sie vous exposer cela, mon oncle, pour vous prier de revêtir (ce nouveau costume).

[Le kong-tse Tch'eng se prosterna par deux fois, frappa du front le sol et dit :

- Votre sujet avait bien entendu parler de l'adoption des vêtements Hou décidée par Votre Majesté. Moi, homme sans talent, j'étais couché et malade et c'est pourquoi je n'ai pas pu me mettre en route au plus vite pour venir auprès de vous et vous entourer de soins (355). Votre Majesté m'ayant donné un ordre, moi, votre sujet, je me permets de vous répondre : allant donc jusqu'au bout de mon humble fidélité, je vous dis : J'ai appris que les royaumes du Milieu étaient l'endroit où résidaient ceux qui sont intelligents et ${ }_{\text {p.77 }}$ savants, où sont rassemblées toutes les choses de quelque valeur ou de quelque utilité, où les hommes les plus sages et les plus vertueux ont répandu leurs enseignements, où la bonté et la justice se sont déployées, où (les leçons du) Che (King) et du Chou (King), des rites et de la musique sont mises en pratique, où les intelligences extraordinaires et les capacités magistrales s'exercent; c'est le pays qu'admirent et vers lequel vont avec empressement les contrées éloignées ; c'est celui que les (barbares) Man et $I$ considèrent comme un modèle de justice et de bonne conduite. Maintenant, ô roi, vous renoncez à tout cela pour adopter les vêtements des contrées éloignées; vous changez ce que l'antiquité nous a enseigné, vous modifiez la sagesse des anciens. Vous allez à l'encontre des désirs des hommes; vous excitez la colère de ceux qui ont étudié ; vous vous séparez des royaumes du Milieu. C'est pourquoi je désire, ô roi, que vous y réfléchissiez.

[L'envoyé ayant rapporté (ces paroles), le roi dit : 
— En effet, j'avais entendu dire que mon oncle était malade ; je vais me rendre en personne auprès de lui pour lui adresser ma prière.

Le roi alors se rendit dans la demeure du kong-tse Tch'eng et en profita pour lui exprimer ses désirs en ces termes :

- Il est de fait que l'habillement doit être approprié à l'usage (qu'on en veut faire) ; les rites doivent être appropriés aux circonstances. L'homme saint observe le lieu où il se trouve et se conforme à ce qui est nécessaire ; il tient compte des circonstances pour façonner les rites; par ce moyen, il est avantageux à son peuple et rend de grands services ${ }_{\text {p.78 }}$ à son royaume. Couper sa chevelure, peindre son corps, tatouer ses épaules (566), boutonner son vêtement à gauche, c'est ce que fait le peuple de Ngeou-yue (357). Se noircir les dents (358), se tatouer le front, refuser de porter le bonnet (359), p.79 se servir d'aiguilles grossières (360), c'est ce que fait le grand royaume de $O u(\underline{361})$. Ainsi, pour ce qui est des rites et des vêtements, personne n'est d'accord; c'est la commodité qui est la règle universelle. Quand les régions sont différentes, les usages changent; quand les circonstances sont autres, les rites se modifient. C'est pourquoi l'homme saint, si effectivement il peut par là être utile à son royaume, ne maintiendra pas l'uniformité des usages ; si effectivement il peut par là s'accommoder aux circonstances, il ne maintiendra pas l'immutabilité des rites. Les lettrés quoique reconnaissant un seul maître (362), ont des mœurs diverses; les royaumes du Milieu, quoique observant des rites identiques, ont des enseignements divergents; à combien plus forte raison (les différences seront-elles marquées) lorsqu'il s'agira ${ }_{\text {p. } 80}$ de ce qui est profitable à (un pays de) montagnes et de vallées (363)! Ainsi, en ce qui concerne les variations dans le rejet ou l'adoption (de telle ou telle coutume), les hommes intelligents ne peuvent pas être d'un seul avis; en ce qui concerne les vêtements suivant qu'(un pays) est loin ou près (du centre de l'empire), les sages ne peuvent pas être unanimes. Dans les régions les plus reculées, il y a beaucoup de singularités; ceux qui étudient à l'écart ont beaucoup de particularités distinctives. Ne pas suspecter ce qu'on ignore et ne pas condamner ce qui est différent de soi-même, c'est agir d'une manière équitable et rechercher dans tous les cas le maximum de bien. Maintenant, ô mon oncle ce dont vous parlez, c'est de la coutume établie ; ce dont moi je parle, c'est des moyens d'établir la coutume. A l'Est de mon royaume il y a les fleuves Ho (364) et Po-Lo (365) qui nous sont communs avec Ts'i et Tchong-chan (366); or nous n'avons à notre service ni barques ni rames; depuis la montagne Tch'ang (267) jusqu'à Tai et à Chang-tang (368) nous 
avons, du côté de l'Est, les territoires de Yen et des p.81 Tong-hou (369), tandis qu'à l'Ouest nous sommes limitrophes des Leou-fan (370), de Ts'in et de Han ; or maintenant nous ne sommes pas prémunis par des archers à cheval. Si donc je n'ai à mon service ni barques, ni rames, la population riveraine des rivières comment s'y prendra-t-elle pour défendre les fleuves $\mathrm{Ho}$ et Po-lo (371)? Je changerai les vêtements et (j'organiserai des escadrons d')archers à cheval pour prémunir ma frontière contre (les attaques de) Yen, des trois Hou (372), de Ts'in et de Han. En outre, autrefois le souverain Kien (373) ne se mura pas dans Tsinyang (374), et ainsi atteignit jusqu'au Chang-tang; puis, le souverain Siang (375) s'annexa les Jong, s'empara de Tai, et ainsi repoussa les divers peuples $\mathrm{Hou}$; c'est là ce que tous savent, les ignorants aussi bien que les sages. Il y a quelque temps, Tchong-chan, se fiant sur les vaillants soldats de $T s$ ' $i$, envahit et ravagea notre territoire, chargea de liens notre peuple et amena l'eau de la rivière pour assiéger Hao $(\underline{376})$; n'eût été l'influence surnaturelle des ${ }_{\text {p.82 }}$ dieux du sol et des moissons, Hao était bien près d'être perdue ; le roi mon prédécesseur subit cet affront, mais son ressentiment n'a pas encore pu être assouvi. Si maintenant nous faisons des préparatifs (en organisant des escadrons) d'archers à cheval, pour parler de ce qui est proche nous pourrons ainsi nous conformer à la configuration physique du Chang-tang, et pour parler de ce qui est lointain, nous pourrons ainsi venger l'affront que nous a infligé Tchong-chan. Vous cependant, mon oncle, vous observez les coutumes des royaumes du Milieu et par là vous vous mettez en opposition avec les intentions de Kien et Siang $(377)$; vous redoutez la réputation d'avoir modifié les vêtements et par là vous oubliez l'affront de l'affaire de Hao. Ce n'est point là ce que j'espérais.]

[Le kong-tse Tch'eng se prosterna à deux reprises, en frappant du front la terre et dit :

- Dans mon ignorance, moi votre sujet, je n'ai pas bien pénétré les intentions de Votre Majesté et je me suis permis de discourir d'après ce que m'ont appris les mœurs qui ont cours dans le monde. Telle est ma faute. Maintenant, puisque Votre Majesté veut continuer les projets de Kien et de Siang pour se conformer aux intentions des anciens rois, comment oserais-je ne pas obéir à vos ordres?

Après qu'il se fut prosterné à deux reprises en frappant du front le sol, on lui donna les vêtements $\mathrm{Hou}$; le lendemain il les revêtit pour venir à la cour. Alors pour la première fois fut promulguée l'ordonnance relative aux vêtements Hou. 
Tchao Wen, Tchao Tsao, Tcheou Chao et Tchao Kiun firent tous des remontrances pour s'y opposer (en disant que) le roi ne devait pas adopter les vêtements $\mathrm{Hou}_{\text {p.83 }}$ et qu'il valait mieux suivre les anciennes règles (378). [Le roi leur dit :

- Les anciens rois n'eurent pas des mœurs identiques; comment observerait-on les règles de l'antiquité ? Les empereurs et les rois (379) ne se sont pas imités les uns les autres; comment suivrait-on les rites? Fou-hi et Chen-nong enseignaient, mais ne punissaient pas ; Hoang-ti, Yao et Choen (380) punissaient, mais ne s'irritaient pas ; puis, quand vinrent les trois dynasties, elles firent des lois adaptées aux époques, elles instituèrent des rites appropriés aux circonstances; dans la réglementation des lois et l'établissement des ordonnances, chacune d'elles se conforma à ce qui lui était avantageux; pour les vêtements et les armes, chacune rechercha ce qui était le plus favorable à l'usage qu'elle devait en faire. Ainsi, pour ce qui est des rites, il n'y a pas nécessairement une seule explication; pour ce qui est de l'avantage de l'État, il ne faut pas nécessairement (prendre pour modèle) l'antiquité. Ce qui a fait le succès des hommes saints, c'est parce qu'ils ont régné sans s'imiter les uns les autres; ce qui a fait la décadence des (dynasties) Hia et $Y n$, c'est qu'elles se sont éteintes pour n'avoir pas modifié les rites. Ainsi donc, agir en opposition avec l'antiquité n'est pas aussitôt blâmable ; se conformer aux rites n'est pas aussitôt louable. D'ailleurs, si il était vrai que, quand les vêtements sont extraordinaires les caractères sont pervers, il faudrait dire que ${ }_{\text {p. } 84}$ à Tseou et à Lou personne n'eut une conduite éminente (381); s'il était vrai que, lorsque les mœurs sont éloignées (de ce qu'elles sont dans les royaumes du Milieu), le peuple s'altère, il faudrait dire que $O u$ et Yue n'eurent pas d'hommes supérieurs (382). En outre, l'homme saint appelle vêtements ce qui est utile à son corps; il appelle rites ce qui est approprié aux circonstances. Ainsi les principes de l'action et de l'abstention, et les statuts concernant les vêtements servent à régulariser le commun peuple, mais ils ne s'imposent point au sage ; c'est pourquoi le peuple ordinaire suit le cours des coutumes; le sage va de compagnie avec les changements. Un proverbe dit: Celui qui conduit (un char) au moyen de connaissances livresques ne connaît pas à fond le tempérament des chevaux. (De même,) celui qui prétend régler les temps présents au moyen de l'antiquité, ne comprend pas les changements produits par les circonstances. Le mérite qu'on a à se conformer aux lois établies ne suffit pas à élever un homme au-dessus de son époque ; l'étude qui consiste à prendre pour modèle l'antiquité ne suffit pas à réglementer les temps modernes. Voilà ce que vous n'avez point saisi.] 
(Le roi Ou-ling) adopta les vêtements Hou et enrôla des archers à cheval.

La vingtième année (306), le roi parcourut le territoire de Tchong-chan et parvint jusqu'à Ning-kia (383); à l'ouest, ${ }_{\text {p.85 }}$ il parcourut le territoire des Hou et arriva jusqu'à Yu-tchong (384). Le roi des Lin-Hou (385) lui offrit des chevaux. A son retour, (le roi Ou-Ling) envoya Leou Hoan dans le pays de Ts 'in, K'ieou I dans le pays de Han, Wang Pen dans le pays de Tch'ou, Fou Ting dans le pays de Wei, Tchao Tsio dans le pays de Ts'i. Tchao Kou, conseiller de Tai, eut la direction des Hou et fit venir leurs soldats (sous ses ordres).

La vingt et unième année (305), (le roi Ou-ling) attaqua (le royaume de) Tchong-chan. Tchao Chao était le général de droite, Hiu Kiun le général de gauche, et le kong-tse Tchang le général du centre; le roi exerçait le commandement sur eux tous. Nieou Tsien commandait aux chars et aux cavaliers; Tchao Hi avait le commandement général des (contingents) des Hou, de Tai et de Tchao (386); avec eux il se rendit à Hing (387) et opéra sa jonction avec l'armée (de Nieou Tsien) à K'iu-yang (388). (Tchao Hi et Nieou Tsien) attaquèrent et prirent Tan-k'ieou (389), p.86 Hoa-yang (390) et la barrière de Tch'e (391). L'armée du roi prit Hao (392), Che-i, Fong-long, Tong-yuen (393). (Le prince de) Tchong-chan offrit quatre villes en demandant la paix. Le roi l'accorda et cessa les hostilités.

La vingt-troisième année (303), (le roi Ou-ling) ${ }_{\text {p.87 }}$ attaqua Tchong-chan. - La vingt-cinquième année (301), la reine Hoei mourut (394). (Le roi Ouling) chargea Tcheou Chao, qui devait être vêtu de vêtements Hou, d'être le précepteur du fils de roi, Ho (395). - La vingt-sixième année (300), il attaqua de nouveau Tchong-chan et lui enleva son territoire ; au nord, il arriva jusqu'à Yen et à Tai (396); à l'ouest, jusqu'à Yun-tchong (397) et Kieou-yuen (398).

La vingt-septième année (299), le cinquième mois, le jour ou-chen, (le roi Ou-ling) tint une cour plénière dans le palais oriental et abdiqua le gouvernement; il mit sur le trône le prince $H o$ (399) qui devint roi. Le (nouveau) roi, après avoir terminé la cérémonie de la présentation au temple ancestral, sortit et tint sa cour; les grands officiers vinrent tous lui rendre hommage. Fei I fut conseiller d'État; il était en même temps précepteur du roi. (Le nouveau roi) fut le roi Hoei-wen; il était le fils ${ }_{\text {p.88 }}$ de $O u$ (400) la Belle, reine $\mathrm{Hoei}$. — Le roi Ou-ling prit pour lui le titre de « père du souverain ».

Le «père du souverain » voulut que son fils dirigeât en personne le royaume. Lui-même, vêtu de vêtements Hou, se mit à la tête de quelques officiers et alla au nord-ouest inspecter le territoire des Hou. Puis il projeta de partir de Yun-tchong et de Kieou-yuen pour aller droit au sud attaquer à l'improviste le pays de $T s$ 'in; alors il se déguisa lui-même en ambassadeur et entra dans le pays de $T s$ 'in : le roi $T$ chao, de $T s$ 'in, qui ne le connaissait pas, s'étonna cependant de son maintien fort majestueux et de ses allures qui n'étaient point celles d'un sujet. Il envoya des gens à sa poursuite; mais le « père du souverain » avait marché à bride abattue et s'était déjà échappé des 
passes. Quand on eut fait une enquête, on sut que c'était le «père du souverain » et les gens de Ts'in furent fort effrayés. Si le «père du souverain » était entré dans le pays de $T s$ 'in, c'est parce qu'il voulait examiner en personne la configuration des lieux et en profiter pour voir quelle sorte d'homme était le roi de $T s$ 'in.

La deuxième année (297) (ㅁ1) du roi Hoei-wen, le «père p.89 du souverain » parcourut les nouveaux territoires et s'avança en dehors du pays de Tai; à l'ouest il rencontra dans le Si-ho (ㅁ2) le roi des Leou-fan (403) et fit venir ses soldats.

La troisième année (296), (le " père du souverain ») anéantit Tchong-chan et transporta son roi à Fou-che. A partir de Ling-cheou (404), le territoire septentrional devint obéissant (405); le chemin pour aller dans (la région de) Tai fut largement ouvert. A son retour, (le « père du souverain ») distribua les récompenses et proclama une amnistie générale; il offrit des banquets et fit des festins pendant cinq jours. Il conféra à son fils aîné Tchang, le titre de prince de Ngan-yang (406), dans le pays de Tai. p.90 Tchang avait un caractère ambitieux, et, dans son for intérieur, il n'acceptait pas que son frère cadet eût été nommé roi. En outre, le "père du souverain » avait chargé Tien Pou-li d'être le conseiller de Tchang. Li Toei dit à Fei I :

- Le kong-tse Tchang est vigoureux et dans la force de l'âge et son caractère est arrogant; ses partisans sont nombreux et ses désirs sont vastes; il a sans doute des visées secrètes. Quant à T'ien Pou-li, c'est un homme qui ne recule pas devant le meurtre et qui est orgueilleux. Ces deux hommes s'étant rencontrés, ils ne manqueront pas de comploter ensemble et des séditions secrètes se fomenteront. Dès que (ces deux hommes) se seront produits en public, ils chercheront à faire une fortune inespérée; en effet, quand des esprits médiocres ont un désir, ils réfléchissent peu et combinent faiblement, ne voient que ce qui leur est avantageux et ne tiennent pas compte de ce qui peut leur être funeste. Étant de même sorte, (ces deux hommes) s'exciteront l'un l'autre et entreront ensemble dans une voie fatale. A mon point de vue, certainement cela ne tardera pas longtemps. Vous avez une charge importante et votre autorité est grande ; là où commenceront les troubles, là où s'accumuleront les calamités, c'est vous qui sûrement serez le premier à souffrir. L'homme bon aime les dix mille sortes d'êtres, et l'homme sage se prémunit contre le malheur avant qu'il ait pris forme ; celui qui n'est ni bon ni sage, n'est pas qualifié pour diriger un royaume. Pourquoi ne vous dites-vous pas malade et ne vous refusez-vous pas à sortir de chez vous? Remettez le gouvernement au kong-tse Tch'eng. Ne faites pas de vous le réceptacle de toutes les haines, l'escalier de toutes les calamités. 
Fei I répondit :

- C'est impossible. Autrefois, le «père ${ }_{\text {p.91 }}$ du souverain » m'a confié le roi, en me disant :

- Ne modifiez pas votre manière de voir; ne changez pas vos projets. Conservez fermement un cœur invariable jusqu'à la fin de votre vie.

Moi, $I$, j'ai reçu ce mandat en me prosternant à deux reprises et je l'ai enregistré. Maintenant, si, par crainte des difficultés que pourrait me susciter (T'ien) Pou-li, j'oubliais ce que j'ai enregistré, quel changement plus grand pourrait-il y avoir? Si, après m'être avancé pour recevoir un ordre strict, je me retire et je ne l'exécute pas intégralement, quelle injure peut être plus grave? Un sujet qui change et qui fait injure encourt une culpabilité à laquelle aucun châtiment ne saurait équivaloir. Un dicton est ainsi conçu : Si les morts revenaient à la vie, que les vivants n'aient point à rougir (407). Ma parole a été engagée antérieurement; je désire la tenir entièrement; comment pourrais-je songer à sauver ma vie ? Un sujet intègre, c'est lorsque les difficultés surviennent que sa vertu apparaît; un sujet loyal, c'est lorsque les embarras se produisent que sa conduite se rend illustre. Quant à vous, vous m'avez témoigné votre fidélité envers moi; cependant ma parole est engagée antérieurement; en définitive je ne saurais y manquer.

Li Toei lui répondit :

- Vous avez raison. Faites donc tous vos efforts. Cette année est la dernière où je vous vois.

Il sortit alors en versant des larmes. Li Toei eut plusieurs entrevues avec le p.92 kong-tse Tch'eng pour le mettre en garde contre toutes les entreprises de T'ien Pou-li.

Un autre jour, Fei I dit à Chen $K^{\prime} i(\underline{408)}$ :

- Le prince et T'ien Pou-li (409) sont de graves sujets d'inquiétude. Pour ce qui est de leur justice, ils ont la réputation d'être bons, mais en réalité ils sont méchants. Ce sont des gens dont l'un ne se conduit pas comme un fils et dont l'autre ne se conduit pas comme un sujet. J'ai appris que lorsqu'un sujet pervers se trouvait à la cour, c'était la ruine du royaume, que lorsqu'un sujet calomniateur se trouvait dans le palais, c'était un insecte rongeur pour le souverain. Ces deux hommes sont ambitieux et leurs désirs sont immenses. A l'intérieur, s'assurer du souverain, et, à l'extérieur, agir avec violence (410), se targuer faussement d'ordres reçus pour manquer à tous leurs devoirs de manière à s'arroger un pouvoir (411) éphémère, cela ne leur sera point difficile à faire (412); cette calamité menace d'atteindre l'État. Maintenant, j'en suis fort préoccupé ; la nuit, j'en perds le sommeil ; aux repas, j'en oublie 
de manger. Quand des malfaiteurs vont et viennent, on ne saurait s'abstenir de se tenir sur ses gardes. A partir de maintenant, si on vient à ${ }_{\text {p.93 }}$ mander le roi (413), ne manquez pas de paraître en ma présence ; j'irai d'abord de ma personne faire face (au péril) ; et, s'il n'y a pas de danger, alors seulement, le roi pourra venir.

- Chen $K$ 'i répondit :

— Fort bien. J'ai entendu ce que vous avez dit.

La quatrième année (295), on donna audience à tous les fonctionnaires; le prince de Ngan-yang (414) vint aussi à la cour. Le «père du souverain » invita le roi à présider l'audience; lui-même se tenant sur le côté, regardait, observant la manière dont les divers fonctionnaires et les membres de la famille royale s'acquittaient des rites ; il vit son fils aîné, Tchang, qui d'un air accablé, se tournait vers le nord dans la posture d'un sujet et s'inclinait devant son frère cadet; il en conçut de la compassion dans son cœur; il souhaita alors de diviser le royaume de Tchao et nommer Tchang roi de Tai. Avant que ce projet eût été arrêté, la situation prit fin (de la manière suivante).

Le « père du souverain » et le roi s'étant rendus en excursion dans le palais I à Cha-k'ieou (415), le kong-tse Tchang alors se servant de ses partisans, se souleva d'accord avec T'ien Pou-li. Au moyen d'un ordre supposé du «père du souverain " (416), il manda le roi ; Fei I se présenta le premier et fut mis à mort. Kao Chen (417) et le roi livrèrent aussitôt bataille (aux rebelles), Le kong-

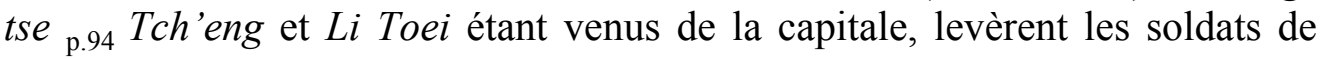
quatre villes et entrèrent (dans Cha-k'ieou) pour réprimer les troubles; ils tuèrent le kong-tse Tchang ainsi que T'ien Pou-Li, exterminèrent les rebelles de leur faction et raffermirent la maison royale. Le kong-tse Tch'eng fut nommé conseiller et reçut le titre de prince de Ngan-p'ing; Li Toei devint ministre de la justice. Quand le kong-tse Tchang avait été battu, il s'était enfui auprès du «père du souverain » qui lui avait ouvert (sa porte pour le mettre à l'abri) ; c'est pourquoi (le kong-tse) Tch'eng et ( $\mathrm{Li}$ ) Toei assiégèrent le palais où se trouvait le " père du souverain ». Quand le kong-tse Tchang eut péri, le kong-tse Tch'eng et Li Toei délibérèrent entre eux, disant :

- A cause de Tchang, nous avons assiégé le «père du souverain »; dès que nous aurons éloigné nos soldats, nous et les nôtres serons exterminés.

Ils continuèrent donc à tenir assiégé le «père du souverain »; ils déclarèrent que ceux des gens du palais qui sortiraient après les autres seraient massacrés ; tous les gens qui étaient dans le palais sortirent. Le "père du souverain » voulut sortir, mais on l'en empêcha; en outre il ne put trouver des aliments ; il dénicha des jeunes moineaux et s'en nourrit. Au bout de plus de trois mois, il mourut de faim dans le palais de Cha-k'ieou (418). Quand il fut avéré que « le père du souverain » était mort (419), on annonça le deuil et on en ${ }_{p .95}$ informa les seigneurs. En ce temps, comme le roi était jeune, (le kong-tse) Tch'eng et ( $\mathrm{Li}$ ) 
Toei assumèrent le gouvernement. C'est parce qu'ils avaient craint d'être mis à mort qu'ils avaient assiégé le « père du souverain ».

Auparavant, le «père du souverain » avait donné à son fils aîné Tchang le titre d'héritier présomptif; dans la suite, quand il eut pris pour concubine $O u$ la Belle, il l'aima et, à cause d'elle, ne sortit pas (du palais) pendant plusieurs années. Quand elle eut enfanté un fils nommé Ho, il dégrada l'héritier présomptif Tchang et nomma roi $H o$. Après la mort de $\mathrm{Ou}$ la Belle, son amour pour elle se relâcha et il eut compassion de l'ex-héritier présomptif; il voulut que ses deux fils eussent le titre de roi ; mais il hésitait et ne se décidait pas; c'est pourquoi les troubles éclatèrent et en arrivèrent à ce point que le père et le fils moururent tous deux et furent la risée de l'empire. Comment ne serait-ce pas un sujet d'affliction?

Quand le «père du souverain » fut mort, le roi Hoei-wen monta sur le trône (420). - Cinq ans (294) après avoir pris le pouvoir, il donna à Yen (les places de) $M o$ et $I$ (421). - La huitième année (291) (422), il fit un rempart au Hing-t'ang méridional (423). - La neuvième année (290), les ${ }_{\text {p.96 }}$ généraux de Tchao et de Leang (424) réunirent leurs armées à celle de $T s$ ' $i$ et attaquèrent Han ; ils arrivèrent jusque sous les murs de Lou-koan (425). - Puis, la dixième année (289), (le roi de) Ts'in se proclama Empereur d'occident (426). - La onzième année (288), Tong-chou allié au prince de Wei attaqua Song ; (Tchao) obtint Ho-yang de Wei(427). Ts'in s'empara de Keng-yang(428). - La douzième année (287), les généraux de Tchao et de Leang (429) attaquèrent Ts'i. - La treizième année (286), Han Siu fut mis à la tête de l'armée et attaqua $T s^{\prime} i$. La princesse (430) mourut. - La quatorzième année (285), le conseiller d'État Yo I, à la tête des armées de Tchao, Ts'in, Han, Wei et Yen, p.97 attaqua $T s^{\prime} i$ et prit Ling-k'ieou (431). (Le roi de Tchao) eut une entrevue avec (le roi de) Ts' in à Tchong-yang (432). - La quinzième année (284), le roi Tchao, de Yen, vint voir (le roi Hoei-wen). Tchao ainsi que Han, Wei et Ts'in attaquèrent ensemble $T s^{\prime} i(\underline{433})$; le roi de $T s^{\prime} i$ fut battu et s'enfuit. Yen seul s'avança profondément (dans le pays de $T s$ 'i) et s'empara de Lin-tse (434).

La seizième année (283), $T_{s}^{\prime}$ 'in, allié à Tchao, attaqua derechef $T_{s}{ }^{\prime} i$ à plusieurs reprises. Les gens de $T s^{\prime} i$ en étaient désolés. Sou $L i$ (435) envoya au nom de $T s$ ' $i$ une lettre au roi de Tchao; elle était ainsi conçue :

[(436) « D'après ce que j'ai appris au sujet des princes sages de l'antiquité, leur conduite vertueuse ne se répandait pas sur toute l'étendue comprise à l'intérieur des mers, leurs enseignements n'étendaient pas leurs bienfaits sur tout le peuple, leurs sacrifices et leurs offrandes p.98 aux époques prescrites n'étaient pas présentés constamment aux mânes et aux esprits ; cependant la rosée douce descendait (sur la terre), les pluies de saison survenaient, les moissons annuelles étaient abondantes, la foule du peuple ne souffrait pas d'épidémies, la multitude des hommes trouvait cet état de choses excellent; néanmoins, les sages souverains 
cherchaient le moyen de mieux faire (437). Maintenant la conduite sage et l'énergie glorieuse de Votre Majesté ne se sont pas souvent employées en ce qui concerne $T s^{\prime}$ 'in; le poison de votre haine et vos ressentiments accumulés ne sont pas profondément invétérés en ce qui concerne $T s^{\prime} i\left({ }^{438}\right)$. $T s$ 'in et ${ }_{\text {p.99 }} T$ Thao s'étant alliés en ont profité pour réquisitionner de force des soldats dans le pays de Han; est-ce parce que Ts'in aime sincèrement Tchao ? Est-ce parce qu'en réalité il déteste $T s^{\prime} i$ ? Quand une chose est arrivée à être exagérée, un souverain sage l'observe avec attention. Or ce n'est pas que $T s^{\prime}$ 'in aime $T$ chao ou déteste $T s^{\prime} i$; mais c'est qu'il veut causer la perte de Han et absorber les deux Tcheou. C'est pourquoi il allèche l'empire en lui présentant $T s$ ' $i$ comme appât ; de peur qu'il n'y ait quelque désaccord dans l'affaire, il a fait sortir ses soldats pour forcer à agir Wei et Tchao; de peur que l'empire ne le redoute lui-même, il a livré des otages pour qu'on ait confiance en lui; de peur que l'empire ne se révolte brusquement contre lui, il a réquisitionné des soldats dans le pays de Han pour le terroriser. Il dit qu'il veut faire du bien à un royaume ami, mais en réalité il se propose d'attaquer Han après l'avoir vidé (de soldats) (439). Pour moi, j'estime que telle est la vraie origine des projets de $T s$ 'in. Dans les événements, il y en a certainement où, les circonstances étant différentes, le malheur qui survient est identique : ainsi, quand Tch'ou eut été attaqué pendant longtemps, c'est Tchong-chan qui périt (440) ; maintenant (de même), quand $T s$ ' $i$ aura p.100 été attaqué pendant longtemps, c'est Han qui certainement périra. Si on détruit $T s$ 'i, Votre Majesté en partagera le bénéfice avec les six royaumes (441); (au contraire), Han étant ruiné, c'est $T s$ 'in qui seul l'accaparera; s'emparer des deux Tcheou (442) et, à l'ouest, prendre les ustensiles de sacrifice (443), c'est $T s$ 'in qui seul s'en assurera l'avantage. Quand on taxera les champs et qu'on évaluera les mérites, le profit que Votre Majesté en retira comment pourra-t-il être considérable au prix de celui que s'assurera $T s$ 'in ? Voici les combinaisons qu'exposait un donneur de conseils : Quand Han aura perdu la région de San-tch'oan (444) et que $W e i$ aura perdu le pays de $T \sin (445)$, avant que le marché et l'audience de la cour aient fait place à un autre marché et à une autre audience (446), p.101 l'infortune sera déjà arrivée (447). Quand Yen aura pris entièrement la partie septentrionale du territoire de $T s^{\prime} i$, il aura diminué de trois cents $l i$ la distance qui le sépare de Cha-k'ieou (448) et de Kiu-lou (449); (d'autre part,) le Chang-tang (450), territoire de Han, n'est qu'à cent li de Han-tan. Lors donc que Yen et $T s$ 'in comploteront contre le Fleuve et les montagnes (451) de Votre Majesté, ils n'auront qu'à franchir un espace de trois cents $l i$ pour être en communication l'un avec l'autre. (Actuellement,) la commanderie de Chang (452), territoire 
de $T s^{\prime}$ in, est voisine de la passe $T^{\prime}$ ing, et, pour aller jusqu'à $Y u$-tchong (453), il y a quinze cents $l i$; (mais), quand $T s$ 'in aura

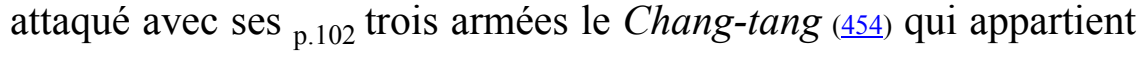
à Votre Majesté, alors vous ne posséderez plus rien de ce qui est à l'ouest du Yang-tch'ang (455) et au sud du Keou-tchou; quand (Ts'in) aura franchi le Keou-tchou (456), il interceptera (la région du) Tch'ang-chan (457) et l'occupera; il n'aura à franchir qu'un espace de trois cents $l i$ pour être en communication avec Yen; alors les chevaux (du pays) de Tai et les chiens des Hou ne descendront plus vers l'est; le jade des montagnes Koen (458) ne sortira plus; ces trois ${ }_{\text {p.103 }}$ choses précieuses elles aussi votre Majesté ne les possédera plus. Si, ô roi, vous persistez longtemps à combattre $T s^{\prime} i$ et à vous mettre à la suite du puissant $T s^{\prime}$ in pour attaquer Han, voilà jusqu'où atteindra certainement la calamité qui en résultera. Je désire que Votre Majesté y réfléchisse mûrement. D'ailleurs, la raison pour laquelle $T_{s}$ ' $i$ est attaqué, c'est parce qu'il peut vous servir; dans l'empire, on se concerte pour comploter contre Votre Majesté, et, dès que Yen et Ts 'in auront formé leur alliance, les soldats entreront en campagne sous peu de jours; les cinq royaumes s se diviseront (alors) le territoire de Votre Majesté. Mais $T s$ ' $i$ s'opposera à l'alliance des cinq royaumes (459) et vous suivra dans les dangers jusqu'à la mort, ô roi ; il enverra dans l'ouest ses soldats pour arrêter le puissant $T s^{\prime}$ 'in, et le pseudo-empereur $T s^{\prime}$ in (460) demandera à se soumettre; (Ts'in) rendra à Wei (les places de) Kao-p'ing (461) et p.104 Ken-jeou (462); il rendra à Tchao (les localités de) Hing-fen (463) et Sien-yu (464). Ainsi donc les services que $T s$ ' $i$ rendra à Votre Majesté devront être de premier ordre. Si cependant maintenant vous lui infligez un châtiment, je crains que, plus tard, ceux qui dans l'empire auront à servir Votre Majesté, n'osent pas s'y décider. Je désire, ô roi, que vous y songiez mûrement. (Au contraire,) si maintenant, ô roi, vous refusez de vous unir à l'empire pour attaquer $T s$ ' $i, l^{\prime}$ 'empire ne manquera pas d'apprécier votre justice, et, quant à $T s$ ' $i$, il prendra avec lui ses dieux du sol et des moissons (465) pour vous servir avec sincérité. Tout l'empire ne manquera pas de faire grand cas de la justice de Votre Majesté, (disant que), avec tout l'empire vous avez bien traité $T s^{\prime}$ in, mais que $T s^{\prime}$ in ayant été cruel, Votre Majesté avec tout l'empire l'a arrêté. p.105 Ainsi la volonté de tout le monde aura été heureusement exécutée par vous, ô roi.]

A la suite de cela, Tchao prit brusquement congé de $T s$ 'in et n'attaqua plus $T s^{\prime} i$.

Le roi se rencontra avec le roi de Yen. - Lien $P^{\prime} O(\underline{466})$, à la tête de l'armée, attaqua (la ville de) Si-yang (467) du pays de $T s$ ' $i$, et la prit. — La dix-septième année (282), Yo $I$, à la tête des soldats de Tchao, attaqua 
Po-yang (468), (ville) de Wei. D'autre part, Ts'in, irrité de ce que Tchao n'avait pas fait cause commune avec lui pour combattre $T s$ ' $i$, fit une expédition contre Tchao et nous prit deux villes. - ${ }_{\text {p.106 }}$ La dix-huitième année (281), Ts 'in nous enleva Che-tch'eng (469). Wang Tsai se rendit à Tong-yang (470), (du pays) de Wei [b], et ouvrit une brèche aux eaux du Ho pour combattre le prince de $W e i[\mathrm{a}]$; il y eut une grande inondation et la rivière Tchang déborda. Wei Jan (471) vint comme conseiller dans (le pays de) Tchao. — La dix-neuvième année (280), Ts'in triompha de deux de nos villes. Tchao donna à Wei (la ville de) Po-yang (472). Tchao Cho, à la tête de l'armée, attaqua Me-k'ieou (473) (ville) de $T s^{\prime} i,{ }_{\text {p.107 }}$ et s'en empara. - La vingtième année (279), Lien P'o, à la tête de l'armée, attaqua $T s^{\prime} i$. Le roi (de $T$ chao) et le roi $T$ chao, de $T s$ 'in, se rencontrèrent en dehors du Si-ho (474). - La vingt et unième année (278), Tchao détourna la rivière Tchang et la fit passer à l'Ouest de Ou-p'ing (475). La vingt-deuxième année (277), il y eut une grande épidémie. On nomma héritier présomptif le kong-tse Tan. - La vingt-troisième année (276), Leou Tch'ang, à la tête de l'armée, attaqua $K i($ (476), (ville) de $W e i$, mais il ne put la prendre. Le douzième mois, Lien $P^{\prime}$, ayant assumé le commandement, attaqua $K i$ et s'en empara. - ${ }_{\text {p.108 }}$ La vingt-quatrième année (275), Lien P'o, à la tête de l'armée attaqua Fang-tse (477), (ville) de Wei et la prit; il en profita pour y construire un rempart, puis revint. Il attaqua encore Ngan-yang (478) et s'en empara. - La vingt-cinquième année (274), Yen Tcheou, à la tête de l'armée, attaqua Tch'ang-tch'eng (479) et Kao-t'ang (480) et s'en empara. Lui et Wei combattirent ensemble contre $T s^{\prime}$ in ; le général de $T s^{\prime}$ in, $P o K^{\prime}$ 'i, nous vainquit à Hoa-yang (481) et fit prisonnier un général. — La vingt-sixième année (273), (Tchao) prit le territoire de Tai qui avait été envahi par les Tong-hou (482). - La vingt-septième année (272), on ${ }_{\text {p.109 }}$ reporta le cours de la rivière Tchang au sud de Ou p'ing (483). Tchao Pao (484) reçut le titre nobiliaire de prince de P'ing-yang. Les eaux du Ho débordèrent et il y eut une grande inondation. - La vingt-huitième année (271), Lin Siang-jou dirigea une expédition contre $T s$ ' $i$ et arriva jusqu'à $P$ 'ing-i $(\underline{485})$; quand il eut cessé les hostilités, il construisit le rempart de la grande ville du Kieou-men (486) septentrional. Un général de Yen, Kong-suen Ts'ao, prince de Tch'eng-ngan, assassina son roi (487). - La vingt-neuvième année (270), Ts'in et Han se combattirent et (Ts'in) assiégea (notre ville de) Yen-yu (488). Tchao chargea Tchao ${ }_{\text {p.110 }}$ Cho de prendre le commandement de l'armée et d'attaquer $T$ s'in ; (Tchao Cho) fit subir une grande défaite à l'armée de $T s$ 'in sous les murs de Yen-yu; il reçut le titre de prince de $M a-f o u ~(489)$. — La trente-troisième année (266), le roi Hoei-wen mourut. L'héritier présomptif Tan monta sur le trône ; ce fut le roi Hiao-tch'eng.

La première année (265) du roi Hiao-tch'eng, Ts'in dirigea une expédition contre nous et prit trois villes. - Comme le roi de Tchao venait de monter sur le trône, la reine douairière prit en mains le gouvernement. [(490) $T$ s' in poussant ses attaques avec vigueur, la famille princière de Tchao demanda le secours de $T s$ ' $i$; Ts' $i$ répondit : 
- A la condition expresse que vous me donnerez le prince de Tch'ang-ngan (491) en otage, mes soldats sortiront.

La reine douairière ne voulut pas y consentir; ses principaux ministres lui ayant adressé des reproches énergiques, la reine douairière déclara nettement à ceux qui l'entouraient :

- Si quelqu'un me parle encore une fois de livrer en otage le prince de Tch'ang-ngan, moi, vieille femme, je lui cracherai au visage.

Le tso che Tch'ou Long exprima (492) le désir de voir la ${ }_{\text {p.111 }}$ reine douairière ; la reine douairière pleine de colère le fit entrer au bout d'un moment. S'avançant lentement, il vint s'asseoir et s'excusa en disant :

- Votre vieux sujet souffre des pieds et est incapable de marcher vite ; je n'ai pas pu venir vous voir depuis longtemps ; maintenant, me pardonnant à moi-même (493) et craignant que vous-même, ô reine, ne souffriez de quelque incommodité (semblable), j'ai désiré vous voir.

La reine douairière dit :

- Moi, vieille femme, je me sers d'une voiture à bras pour aller et venir.

Il demanda :

— Votre appétit est-il toujours bon ?

— Je me soutiens avec de la bouillie de riz, répondit-elle.

Il dit :

- Moi, votre vieux sujet, dans les derniers temps je n'avais plus aucun désir de manger; je me suis alors forcé à faire à pied chaque jour trois ou quatre $l i$; j'ai ainsi un peu augmenté mon goût pour la nourriture et cela profite à mon corps.

La reine douairière répliqua :

- Pour moi, vieille femme, j'en serais incapable.

La mauvaise humeur de la reine douairière s'étant quelque peu dissipée, le vénérable tso-che lui dit :

- Votre vieux sujet a un humble fils nommé Chou- $k$ 'i qui est très jeune et dénué de talents tandis que moi je suis décrépit; j'ai pitié de lui et je l'aime; je voudrais qu'il pût avoir une place de (soldat à) vêtement noir (494) pour monter la garde dans le palais royal ; voilà ce dont je vous informe en bravant la mort.

La reine douairière dit : 
— Je m'empresse de vous accorder (ce que vous demandez); quel p.112 âge a-t-il ?

- Quinze ans, répondit-il ; quoiqu'il soit jeune, je désire vous le confier avant que je sois tombé dans le fossé (495).

— Les hommes aussi aiment-ils donc leurs jeunes fils et en ont-ils compassion?

— Plus que les femmes, répondit-il.

La reine douairière dit en riant :

— Ce sont les femmes qui l'emportent de beaucoup.

Il répliqua :

- Votre vieux sujet pense que votre amour de mère pour la reine de Yen surpasse celui que vous avez pour le prince de Tch'ang-ngan (496).

- Vous vous trompez, dit la reine douairière; je l'aime moins que le prince de Tch'ang-ngan.

Le vénérable $t$ so-che dit :

- Quand un père et une mère aiment leur enfant, ils combinent pour lui des plans à longue portée. Lorsque vous avez accompagné la reine de Yen, vous preniez dans vos mains ses talons et les arrosiez de larmes en songeant à l'éloignement où elle allait être et vous étiez ainsi pleine de compassion pour elle (497); quand elle fut partie vous n'avez pas cessé de penser à elle ; (cependant), lorsque vous faisiez des sacrifices, vous priiez pour elle en disant :

- Qu'à aucun prix on ne la renvoie (498).

N'est-ce pas parce que vous aviez des projets pour un avenir lointain afin que ses fils et ses petits-fils fussent ${ }_{\text {p.113 }}$ rois les uns après les autres $(\underline{499})$ ?

— Il en est bien ainsi, dit la reine douairière.

Le vénérable $t s o$-che reprit :

- Si maintenant nous remontons à trois générations en arrière pour atteindre tous ceux des fils et petits-fils des souverains de Tchao qui ont reçu des fiefs nobiliaires, en trouverons-nous (dont la lignée) ait subsisté (jusqu'à nos jours) ?

— Il n'y en a pas, répondit-elle.

Il ajouta :

- Si nous ne nous bornons pas au royaume de Tchao, parmi les seigneurs en trouverons-nous? 
— Moi, vieille femme, dit-elle, je ne l'ai point entendu dire.

- Ainsi, dit-il, les uns ont été immédiatement atteints par le malheur dans leurs propres personnes; les autres ont été atteints plus tard dans leurs fils et leurs petits-fils. Est-ce à dire que les fils de souverains, par le fait qu'ils ont reçu un fief nobiliaire, sont devenus pervers ? (Non, mais c'est parce que) leur dignité était fort haute sans qu'ils eussent eu de mérites; leurs revenus étaient considérables sans qu'ils eussent fait d'actions d'éclat; ils avaient les mains pleines d'honneurs et de richesses $(\underline{500})$. Maintenant, ô reine, vous avez élevé le prince de Tch'ang-ngan en dignité ; vous lui avez donné des terres fertiles ; vous l'avez comblé d'honneurs et de richesses; cependant vous n'êtes pas parvenue jusqu'à maintenant à lui faire accomplir quelque action méritoire pour son pays. Le jour où la montagne ${ }_{\text {p.114 }}$ s'effondrera (501), comment le prince de Tch'ang-ngan pourra-t-il se fier sur le royaume de Tchao ? Au jugement de votre vieux sujet, les plans que vous faites pour le prince de Tch'ang-ngan témoignent de courtes vues. C'est pourquoi j'estime que vous ne l'aimez pas autant que la reine de Yen.

La reine douairière dit :

- Je vous approuve et je consens à ce que vous voulez faire de lui.

Alors elle fit équiper cent chars pour le prince de Tch'ang-ngan et l'envoya en otage dans le pays de $T s^{\prime} i$; les troupes de $T s^{\prime} i$ entrèrent aussitôt en campagne. $T s e-i$ (502), ayant appris ce qui s'était passé, dit :

- Un fils de souverain est apparenté (au prince) par ses os et par sa chair ; cependant il ne peut garder ses dignités s'il n'a pas de mérite, ni ses revenus s'il n'accomplit pas d'action d'éclat, ni conserver ses richesses en or et en jade. A combien plus forte raison en est-il de même pour nous autres !

T'ien Tan, prince de Ngan-p'ing (503), (du pays) de $T$ s'i, à la tête des troupes de Tchao, attaqua Tchong-yang (504), p.115 (ville) de Yen et la prit. Il attaqua encore Tchou-jen (505), (ville) de Han, et la prit. — La deuxième année (264), la reine Hoei-wen mourut. T'ien Tan devint conseiller.

La quatrième année (262), le roi rêva qu'il était revêtu d'un vêtement mipartie d'une couleur, mi-partie d'une autre et se boutonnant par derrière, que, monté sur un dragon volant, il s'élevait vers le ciel, mais qu'il n'y parvenait pas et tombait, qu'il voyait des amas d'or et de jade hauts comme des montagnes. Le lendemain, le roi manda le devin officiel Kan pour interpréter ce songe ; (le devin) lui dit :

- Si vous avez rêvé que vous étiez vêtu d'un vêtement mi-partie d'une couleur, mi-partie d'une autre, et se boutonnant par derrière, 
c'est (signe de) ruine. Que, monté sur un dragon volant, vous vous éleviez au ciel, mais que vous n'y parveniez pas et tombiez, c'est (signe que) vous avez de l'ardeur, mais sans réel pouvoir. Que vous ayez vu des monceaux d'or et d'argent hauts comme des montagnes, c'est (signe d')affliction.

Trois jours plus tard, Fong T'ing, qui gouvernait le p.116 Chang-tang (506) pour le compte de la famille princière de Han, envoya un émissaire qui vint dire :

- Han ne peut plus garder le Chang-tang et va le livrer à $T s^{\prime}$ in ; or les officiers et le peuple de cette région seraient heureux d'appartenir à Tchao et ne désirent pas appartenir à $T s$ 'in. J'ai dix-sept villes, bourgs et places que je souhaite, en me prosternant par deux fois, livrer à Tchao; j'accepterai le bienfait que Votre Majesté accordera aux officiers et au peuple (507).

Le roi, tout joyeux, manda (Tchao) Pao, prince de P'ing-yang, et l'informa de ce qui venait de se passer en lui disant :

- Fong T'ing nous livre dix-sept villes, bourgs et places; convient-il de les recevoir?

(Tchao Pao) répondit :

— Le sage considère comme très funeste un avantage sans motif.

Le roi répliqua :

- Ces gens chérissent ma vertu ; comment pouvez-vous dire qu'il n'y a pas de motif?

- Ts'in, dit (Tchao Pao), a rongé comme une feuille de mûrier la famille princière de Han dont le territoire se trouve coupé par le milieu, de façon que les deux parties ne peuvent communiquer entre elles; certainement ( $T s^{\prime}$ 'in) estime donc que, en restant assis (508), il recevra le territoire de Chang-tang. Si le prince de Han ne veut pas le livrer à $T s$ 'in, c'est parce qu'il désire faire retomber sur Tchao les malheurs qui en résulteront. Que $T$ s 'in, se soit chargé de toute la peine pour que Tchao recueille tout l'avantage, cela ne pourrait pas se produire, même dans le cas d'un puissant agissant contre un ${ }_{\text {p.117 }}$ faible : à plus forte raison, un faible pourrait-il agir ainsi à l'égard d'un puissant? Comment ne dira-t-on pas que (l'avantage qu'on vous propose) est un avantage sans motif? En outre $T s$ 'in a labouré et ensemencé $(509)$; il a fait parvenir par eau des transports de grain (510); il a dévoré, comme le ver ronge la feuille de mûrier, un pays (511) dont les chars de guerre étaient de première force et dont les combattants valaient double; il a séparé ce territoire pour le rattacher à sa domination supérieure (512); son 
autorité y est reconnue. Vous ne sauriez vous susciter de difficultés avec lui ; gardez-vous d'accepter (ce présent).

Le roi dit :

- Maintenant, quand j'envoie des armées d'un million d'hommes, il faut des années et des années avant qu'on s'empare d'une seule ville; en ce moment, on fait cadeau à mon royaume de dix-sept villes, bourgs et places ; c'est là un grand avantage.

Tchao Pao sortit. Le roi manda le prince de P'ing-yuen (513) ainsi que Tchao $Y u$ et leur exposa l'affaire ; ils répondirent :

- Quand vous envoyez à l'attaque des armées d'un million d'hommes, il se passe des années avant que vous vous empariez d'une seule ville ; maintenant, ${ }_{\text {p.118 }}$ en restant assis, vous recevez dix-sept villes, bourgs et places; c'est là un grand avantage qu'il ne faut pas laisser échapper.

Le roi dit :

- C'est fort bien.

Il ordonna donc à Tchao Cheng (514) de recevoir ce territoire.

(Tchao Cheng) dit à Fong T'ing :

- Je suis l'ambassadeur de mon humble pays, le sujet Cheng. Le prince de mon humble pays m'a chargé de vous apporter ses ordres ; il confère au gouverneur général (515) trois districts de dix mille foyers ; il confère aux préfets trois districts de mille foyers ; tous seront marquis de génération en génération. Les officiers et les hommes du peuple recevront tous trois degrés dans la hiérarchie; les officiers et les hommes du peuple qui sauront maintenir la paix entre eux seront tous gratifiés de six livres d'or.

Fong T'ing, versant des larmes, refusa de voir l'ambassadeur et dit :

- Je ne saurais accepter, car je manquerais par trois fois à la justice. Étant gouverneur d'un territoire pour le compte de mon souverain, je n'aurais pas su le défendre jusqu'à la mort ; tel serait mon premier manquement à la justice. Je l'aurais livré à $T s$ 'in sans écouter les ordres de mon souverain; tel serait mon second manquement à la justice. J'aurais vendu le territoire de mon souverain et $\mathrm{j}$ 'en profiterais ; tel serait mon troisième manquement à la justice (516).

p.119 Tchao envoya alors des soldats pour s'emparer du Chang-tang ; Lien P'o ayant le commandement de l'armée, campa à Tch'ang-p'ing (517).

La septième année (259) (518), on retira ses fonctions à Lien P'o, et Tchao Kouo (519) le remplaça à la tête de l'armée ; les gens de $T$ s'in cernèrent Tchao 
Kouo ; Tchao Kouo se rendit avec son armée ; il y avait là plus de quatre cent mille hommes; on les extermina tous $(\underline{520})$. Le roi regretta de ne pas avoir écouté les avis de Tchao Pao et d'avoir ainsi causé le désastre de Tch'ang p'ing. Le roi, de retour (dans sa capitale), n'obéit pas à $T s^{\prime}$ 'in. $T s^{\prime}$ 'in assiégea p.120 Han-tan (521). Fou Pao, préfet de Ou-yuen (522), Wang fong et Sou Che, à la tête d'une foule de gens de Yen, se révoltèrent sur le territoire de Yen. Tchao conféra la seigneurie de Ling-k'ieou (23) au prince de Tch'oen-chen, conseiller de Tch'ou.

La huitième année (258), le prince de P'ing-yuen se rendit dans le pays de Tch 'ou pour demander du secours. Lorsqu'il fut de retour, Tch'ou vint nous secourir; puis le kong-tse Ou-ki (524), (du pays) de Wei, vint aussi à notre secours. Le siège que $T s$ 'in maintenait devant Han-tan fut alors abandonné ( $\underline{525}$ ). - La dixième année (256), Yen attaqua (la ville de) Tch'angtchoang (526), et, le p.121 cinquième mois, la prit. Les généraux de Tchao, Yo Tch'eng (527) et K'ing Cho attaquèrent l'armée (du général) Sin-Leang (528), de $T s^{\prime}$ 'in, et la vainquirent. L'héritier présomptif mourut. $T s$ 'in attaqua (la ville des) Tcheou occidentaux et s'en empara (2529). T'ou-fou $K^{\prime} i(\underline{530})$ sortit (du royaume de $T$ chao). - La onzième année (255), on construisit un rempart à Yuen-che (531); on érigea Cheng-yuen en préfecture. Tcheng Ngan-p’ing (532), prince de Ou-yang, mourut; (le roi de Tchao) confisqua ses terres. - La douzième année (254), les bâtiments servant à garder le fourrage à Han-tan furent incendiés. - La quatorzième année (252), Tchao Cheng, prince de $P$ 'ing-yuen, mourut (233).

p.122 La quinzième année (251), (le roi de Tchao) conféra la terre de Weiwen (534) au conseiller d'État Lien P'o, avec le titre de prince de Sin ping. [(535) Le roi de Yen (536) chargea son conseiller Li Fou de conclure amitié (avec Tchao) et d'offrir en cadeau gracieux (537) cinq cents livres d'or au roi de Tchao. A son retour, $(\mathrm{Li} \mathrm{Fou})$ revint présenter son rapport au roi de Yen et lui dit :

- Parmi (les sujets du) prince de Tchao, ceux qui étaient dans la force de l'âge sont tous morts à Tch'ang p'ing (538); leurs orphelins ne sont pas encore adultes. Il faut les attaquer.

Le roi manda Yo Kien (539), prince de Tch'ang-kouo, et l'interrogea à ce sujet ; il répondit :

- Tchao est un royaume qui a eu à batailler sur ses quatre fronts $(\underline{540)}$; son peuple est habitué à la guerre; l'attaquer est impossible.

Le roi dit :

- C'est avec une multitude que j'attaque un petit nombre d'hommes. Si nous combattons deux contre un, ne pouvons-nous pas (risquer la lutte) ? 
Il répondit :

- Vous ne le pouvez pas.

- Je combattrai donc cinq contre un (541), dit le roi ; pouvons-nous (risquer la lutte ?)

p.123 Il répondit :

- Vous ne le pouvez pas.

Le roi de Yen fut fort irrité, et, comme tous ses officiers lui disaient qu'on pouvait (combattre),] il se décida à mettre en campagne deux armées et deux mille chars de guerre ; Li Fou avait un des commandements et devait attaquer Hao (542); King Ts'in avait l'autre commandement et devait attaquer Tai. Lien $P^{\prime} o$ était général de Tchao ; il écrasa et tua $\mathrm{Li}$ Fou; il fit prisonniers $K^{\prime}$ ing $T s^{\prime}$ in et Yo Kien.

La seizième année (250), Lien P'o assiégea (la capitale de) Yen. Yo Tch'eng fut nommé prince de Ou-siang (543). - La dix-septième année (249), le vice-conseiller et général en chef, prince de Ou-siang, attaqua Yen et assiégea sa capitale. - La dix-huitième année (248), Kiun, (originaire) de Yen-ling (544), se mit à la tête des troupes, et, à la suite du conseiller d'État, prince de Sin-p'ing (545), il aida Wei à attaquer Yen. Ts 'in nous prit trente-sept villes, parmi lesquelles $Y u$-ts'e (546). — La dix-neuvième année (247), Tchao fit avec Yen un échange de territoires ; il donna à Yen (les localités de) Longtoei (547), p.124 Fen-men (548) et Lin-lo (549); Yen donna à Tchao (les villes de) Ko (550), Ou-yang (551) et P'ing-chou (552). - La vingtième année (246), p.125 Tcheng (553), roi de $T s$ 'in, monta sur le trône. $T s$ 'in nous prit Tsin-yang. - La vingt-et-unième année (245), le roi Hiao-tch'eng mourut. Lien P'o, étant à la tête de l'armée, attaqua (la ville de) Fan-yang (ㄷ5) et la prit; Yo Tch'eng fut envoyé pour le remplacer (dans son commandement); Lien P'o combattit Yo Tch'eng qui se retira; Lien P'o s'enfuit dans le pays de Wei. Le fils (du roi Hiao-tch'eng), Yen, prit le pouvoir; ce fut le roi Tao-siang.

La première année (244) du roi Tao-siang, (on célébra) la grande perfection (555). - Wei voulut s'ouvrir un chemin pour communiquer avec P'ing-i et Tchong-meou (556), mais il n'y parvint pas. - La deuxième année (243), $\mathrm{Li} \mathrm{Mou}$, à la tête de l'armée, attaqua Yen et prit (les villes de) ${ }_{\text {p.126 }} \mathrm{Ou}$ soei et Fang-tch'eng (557). - (Le roi de) Ts'in manda auprès de lui le prince de Tch'oen-p'ing (558), puis en profita pour le retenir. Sie Kiun intervint à ce propos en disant au marquis de Wen-sin (559) :

- Le prince de Tch'oen-p'ing est fort aimé du roi de Tchao, mais les lang-tchong (560) sont jaloux de lui et c'est pourquoi ils ont délibéré entre eux disant: Si le prince de Tch'oen-p'ing entre dans le pays de $T s^{\prime}$ in, $T s^{\prime}$ in le retiendra certainement. Ils ont donc combiné ensemble des plans et ont ainsi fait entrer (le prince de Tch'oen-p'ing) dans le pays de $T s^{\prime}$ 'in. Si maintenant vous le 
retenez, ce sera la rupture avec Tchao et la réussite des machinations des lang-tchong. Il vaudrait mieux, pour vous, renvoyer le prince de Tch'oen-p'ing et garder (le marquis de) $P$ 'ing-tou (561). Le prince de Tch'oen-p'ing jouit d'un grand crédit par ses paroles et par ses actions auprès du roi (de Tchao); le roi (de Tchao) détachera certainement de son pays une grande partie de territoire pour racheter (le marquis de) ${ }_{\text {p.127 }} P^{\prime}$ 'ing-tou.

Le marquis de Wen-sin approuva ce discours et renvoya donc (le prince de Tch'oen p'ing). — On éleva un rempart à Han-kao.

La troisième année (242) (562), P'ang Noan, étant à la tête de l'armée, attaqua Yen et fit prisonnier son général Ki Sin. - La quatrième année (241), P'ang Noan, à la tête de troupes d'élite de Tchao, Tch'ou, Wei et Yen, attaqua Tsoei (563), (ville) de $T s^{\prime}$ in, mais ne put la prendre; changeant alors de direction, il attaqua $T_{s}$ ' $i$ et lui prit Jao-ngan (564). - La cinquième année (240), Fou Ti, à la tête d'une armée, s'établit à $P^{\prime}$ 'ing-i $(\underline{565})$; K'ing Cho, à la tête (d'une autre armée, s'établit) à T'ong-yang (566). Les soldats placés en dehors du Fleuve (567) gardèrent le pont sur le Fleuve. - La sixième année (239), on conféra au prince de Tch'ang-ngan (la ville de) Jao (568). Wei donna à Tchao ${ }_{\text {p.128 }}$ (la ville de) Ye (569). - La neuvième année (236), Tchao attaqua Yen et lui prit la ville de $L i$-yang (570). Avant que les soldats eussent terminé (cette expédition), $T s$ 'in attaqua $Y e$ et s'en empara (571). Le roi Tao-siang mourut. Son fils, Ts 'ien, qui fut le roi Yeou-mou (572), prit le pouvoir.

La première année (235) de $T s^{\prime}$ 'ien, roi Yeou-mou, on éleva un rempart à Po-jen (573). - La deuxième année (234), Ts'in attaqua (la ville de) $O u$ tch'eng (574); Hou Tcho, à la tête de ses troupes, vint au secours (de cette ville), mais son armée fut battue et il périt. — La troisième année (233), Ts 'in attaqua (les villes de) Tch'e-li et I-ngan (575). Li Mou, à la tête des troupes, combattit contre lui sous les murs de Fei (576) et le repoussa. - On conféra à (Li) Mou le titre de prince de Ou-ngan. - La quatrième année ${ }_{\text {p.129 }}$ (232), Ts 'in attaqua $P$ 'an-ou (577); $\mathrm{Li} \mathrm{Mou}$ combattit contre lui et le repoussa. - La cinquième année (231), il y eut un grand tremblement de terre dans le territoire de Tai; dans toute la région à l'ouest de Lo-siu (578) et au sud de P'ing-yn (579), les tours, les maisons, les murailles et les murs furent détruits pour la plus grande partie ; le sol se fendit de l'est à l'ouest sur une longueur de cent trente pas. - La sixième année (230), il y eut une grande famine. Le peuple prononçait des paroles étranges, disant :

Dans (le pays de) Tchao ce sont des lamentations ;

Dans (le pays de) $T s$ 'in ce sont des rires (580);

Si vous ne le croyez pas,

Regardez la terre produire des poils (ㅎ1). 
La septième année (229), les gens de $T s$ 'in attaquèrent Tchao. Le général en chef de Tchao, Li Mou, et le général Se-ma Chang, à la tête de l'armée, les attaquèrent. Li Mou fut mis à mort et Se-ma Chang fut dégradé. Tchao Hou et le général de $T s$ 'i, Yen Tsiu, les remplacèrent. L'armée de Tchao Hou fut vaincue ; Yen Tsiu s'enfuit; il fit sa soumission avec le roi Ts 'ien. - La p.130 huitième année (228), le dixième mois, Han-tan fut annexée à $T s$ 'in (582).

Le duc, grand astrologue, dit : J'ai entendu dire à Fong Wang-suen (583) : La mère de Ts'ien, roi de Tchao, était une chanteuse qui fut la favorite du roi Tao-siang. Le roi Tao-siang dégrada le fils de la première épouse, Kia, et nomma $T s$ 'ien (héritier présomptif). Ts'ien était sans expérience et ajoutait foi aux calomnies; c'est pourquoi il fit périr son excellent général $\mathrm{Li} M o u$ et donna une ${ }_{\text {p.131 }}$ charge à Kouo $K^{\prime}$ 'ai (284). N'était-ce pas là une grave erreur ? Quand $T s^{\prime}$ 'in eut fait $T s^{\prime}$ 'ien prisonnier, les grands officiers de Tchao, qui étaient fugitifs, nommèrent roi Kia (585); il régna dans (le pays de) Tai. Six ans plus tard (222), Ts 'in fit avancer ses soldats et écrasa Kia (586); il anéantit alors (le royaume de) Tchao dont il fit des commanderies. 


\section{CHAPITRE XLIV}

\section{QUATORZIÈME MAISON HÉRÉDITAIRE \\ WEI (101)}

p.132 L'ancêtre de (la maison des) Wei fut un descendant de Kao, duc de $P i$ (102). Kao, duc de $P i$, appartenait à la famille ${ }_{\text {p.133 }}$ des Tcheou. Quand le roi $\mathrm{Ou}$ eut triomphé de Tcheou (103), Kao reçut en fief (la principauté de) Pi. Pi devint alors son nom de famille. Ses descendants perdirent leur fief et furent des hommes du commun; les uns résidèrent dans les Royaumes du Milieu; les autres, chez les (barbares) I et Ti.

Un de ces descendants se nommait Pi Wan; il servit le duc Hien, de Tsin. La seizième année (661) du duc Hien, Tchao Sou (104) conduisait (le char du duc) et $\mathrm{Pi}$ Wan était l'homme de droite, lorsqu'on fit une expédition contre Houo, Keng et Wei (105) et qu'on les anéantit. (Le duc) donna à Tchao Sou (le territoire de) Keng, et, à $\mathrm{Pi}$ Wan (le territoire de) $W e i(\underline{106})$, en leur conférant le titre de grand officier (ta-fou). [(107) Le devin Yen dit :

- Les descendants de Pi Wan seront certainement grands. Wan (= dix mille) est le nombre complet; Wei ( = haut) est un grand nom. Que ce (pays de $\mathrm{Wei}$ ) ait été sa première récompense, c'est la preuve que le Ciel lui ouvre (le chemin du bonheur). Quand on parle du Fils du Ciel, on dit « les millions de son peuple»; quand on parle d'un seigneur, on dit «les myriades (wan) de son « peuple ». Maintenant, on a décerné (à Pi Wan) le nom de grand p.134 $(=$ Wei $)$ qui est suivi du nombre complet $(=$ Wan $)(108) ;$ il ne peut donc manquer d'avoir une multitude (à qui il commandera) (109).

Auparavant, $P i$ Wan avait consulté les sorts au sujet des fonctions qu'il remplirait dans le pays de Tsin; il avait obtenu (l'hexagramme) tchoen combiné à (l'hexagramme) pi (110). Sin Leao interpréta (ces hexagrammes) en disant :

— C'est de bon augure : tchoen, c'est «fermeté »; pi, c'est « entrer»; quel augure peut être plus grandement favorable? ses (descendants) (111) seront certainement nombreux et prospères. »]

Onze ans après que Pi Wan eut reçu le fief, le duc Hien, de Tsin, mourut (651). Ses quatre fils se disputèrent tour à tour le trône (112); le pays de $T \sin$ fut bouleversé, et (la famille de) $P i$ Wan devint de génération en génération plus puissante; du nom de son royaume, elle s'appela la famille Wei. 
(Pi Wan) engendra Ou-tse (113). Wei Ou-tse, avec tous les jeunes gens de Wei, se mit au service du kong-tse de p.135 Tsin, Tch'ong-eul. La vingt-et-unième année (656) du duc Hien, de Tsin, Ou-tse sortit en fugitif (du royaume de $T \sin$ ), à la suite de Tch'ong-eul (114). Dix-neuf ans plus tard (637), il revint; Tch'ong-eul monta sur le trône; ce fut le duc Wen, de Tsin; il ordonna alors que Wei Ou-tse continuerait la descendance de la famille Wei, qu'on lui conférerait le rang de ta-fou et qu'il gouvernerait $W e i$.

(Ou-tse) engendra Tao-tse. Wei Tao-tse transféra sa capitale à Houo (115). Il engendra Wei Kiang.

Wei Kiang servit le duc Tao, de Tsin. La troisième année (570) de son règne, le duc Tao tint une réunion des seigneurs. Le frère cadet du duc Tao, Yang-kan, mit le désordre dans les rangs ; Wei Kiang fit un affront à Yangkan (116); le duc Tao, irrité, dit :

— J'ai réuni les seigneurs pour être couvert de gloire ; maintenant on a fait affront à mon frère cadet.

Il voulait mettre à mort Wei Kiang, mais, quelqu'un l'en ayant dissuadé, il y renonça; en définitive, il confia à Wei Kiang une charge dans le gouvernement et l'envoya maintenir l'harmonie avec les Jong-Ti (117) : les Jong-Ti furent amis et soumis. — ${ }_{\text {p.136 }}$ La onzième année (562), le duc Tao dit :

- Depuis que je me sers de Wei-Kiang, dans un espace de huit années, j'ai réuni neuf fois les seigneurs; les Jong-Ti ont été en bonne harmonie avec moi ; c'est grâce à cet homme ; je lui confère une musique.

(Wei Kiang) déclina par trois fois (cet honneur), mais enfin l'accepta (118). - Il transporta sa capitale à Ngan-i (119). - Wei Kiang mourut. Son nom posthume fut Tchao-tse. Il engendra Wei Yng. Celui-ci engendra Wei Hien-tse.

(Wei) Hien-tse servit le duc Tchao, de Tsin. A la mort du duc Tchao (526), les six hauts dignitaires devinrent puissants et la maison ducale s'affaiblit. La douzième année (514) du duc K'ing de Tsin, Han Siuen-tse étant vieux (120), Wei Hien-tse dirigea le gouvernement du royaume. Les (chefs des) familles $K$ ' $i$ et Yang-cho, qui appartenaient à la maison princière de $T$ sin, s'entr'aidèrent pour se mal conduire (121) ; les six hauts dignitaires les firent périr et s'emparèrent de toutes leurs villes dont ils firent dix préfectures ; les six hauts dignitaires nommèrent chacun leurs fils gouverneurs (de ces villes) (122). (Wei) Hien-tse, avec Tchao Kien-tse, Tchong-hang Wen-tse et Fan Hien-tse (123), étaient tous ensemble ${ }_{\text {p.137 }}$ hauts dignitaires de Tsin. - Quatorze ans plus tard (500), K'ong-tse devint conseiller de Lou. - Quatre ans plus tard (497), Tchao Kien-tse, à la suite des troubles de Tsin-yang (124), s'unit à Han et à Wei, et ensemble ils attaquèrent les familles Fan et Tchong-hang. Wei Hien-tse avait engendré Wei Tch'e (125); c'est Wei Tch'e qui s'unit à Tchao Yang pour attaquer avec lui les familles Fan et Tchong-hang. 
Le petit-fils de Wei Tch'e se nomma Wei Hoan-tse (126); il s'unit à Han K'ang-tse (127) et à Tchao Siang-tse pour attaquer avec eux et anéantir Tche po (128) (453) ; ils se partagèrent ${ }_{\text {p.138 }}$ son territoire. - Le petit-fils de Hoan-tse se nomma Tou (129), marquis Wen. La première année (424) du marquis Wen, de Wei, fut (aussi) la première année du duc Ling, de $T$ ' 'in ; à cette même époque vivaient Han Ou-tse, Tchao Hoan-tse et le roi Wei, de la dynastie Tcheou. - La sixième année (419), on éleva un rempart à Chao-leang (130). La treizième année (412), (le marquis Wen) envoya son fils $K i$ (131) assiéger (les villes de) Fan et $P^{\prime}$ 'ang (132) et en fit sortir la population. - La seizième année (409), (le marquis Wen) combattit contre $T s$ 'in ; il construisit des murs à Lin-tsin (133) et à Yuen-li (134).

La dix-septième année (408), il attaqua Tchong-chan (135) et chargea son fils $K i$ d'y tenir garnison ; Tchao Ts'ang-t'ang (accompagna $K i$ ) en qualité de maître chargé de l'enseigner. Le prince $K i$ rencontra à Tchao-ko T'ien Tse-fang, précepteur du marquis Wen; il tira son char de côté pour lui laisser le passage libre, mit pied à terre et se présenta à lui. T'ien Tse-fang lui manqua d'égards. Le prince $K i$ lui demanda alors :

- Les gens riches et puissants ont-ils le droit de se montrer arrogants envers autrui ? à plus forte raison un homme pauvre et vil ${ }_{\text {p.139 }}$ peut-il se montrer arrogant envers autrui ?

(T'ien) Tse-fang répondit :

- En ce qui le concerne, un homme pauvre et vil peut se montrer arrogant envers autrui. En effet, si un seigneur se conduit avec arrogance, il perd son royaume; si un grand officier se conduit avec arrogance, il perd sa maison. Mais si un homme pauvre et humble agit d'une manière déplacée ou parle d'une façon inconvenante, il n'a qu'à s'en aller dans les pays de Tch'ou et de Yue, ce qui est aussi aisé que d'enlever un soulier de paille (136). Comment donc pouvez-vous dire que le cas est le même ?

Le prince $K i$ s'en alla mécontent (137). - (Le marquis Wen) attaqua à l'ouest $T s$ 'in. $\mathrm{Il}_{\mathrm{p} .140}$ arriva jusqu'à Tcheng puis s'en revint. Il construisit des remparts à Lo-yn et à Ho-yang (138). - La vingt-deuxième année (403), Wei, Tchao et Han furent mis au rang des seigneurs. - La vingt-quatrième année (401), $T s$ 'in nous attaqua et arriva jusqu'à Yang-hou (139). - ${ }_{\mathrm{p} .141}$ La vingt-cinquième année (400), le prince $K i$ engendra le prince $Y n g$.

Le marquis Wen reçut de Tse-hia (140), (l'enseignement) des livres classiques et des arts libéraux. Il traita comme un hôte Toan-kan Mou (141), et, chaque fois qu'il ${ }_{\text {p.142 }}$ passait devant sa maison (142), il ne manquait jamais de p.143 s'incliner sur la barre d'appui de son char (143). Ts'in ayant eu le désir d'attaquer Wei, quelqu'un lui dit : 
- Le prince de Wei envers les hommes sages se montre plein d'égards ; les gens de son pays exaltent sa bonté ; (ainsi) le prince et ses sujets sont d'accord et unis; vous ne pouvez point encore faire des projets contre lui.

A partir de ce moment, le marquis Wen obtint un grand renom parmi les seigneurs. - Il confia à Si-men Pao la charge de préfet de Ye, et le Ho-nei célébra son bon gouvernement (144). - Le marquis Wen, de Wei, dit à $\mathrm{Li}$ $K^{\prime} O(\underline{145})$ :

- Maître, vous m'avez enseigné que, lorsqu'une famille est pauvre, on souhaite une bonne épouse, que, lorsqu'un royaume est troublé, on souhaite un bon ${ }_{\text {p.144 }}$ conseiller; maintenant, celui que je nommerai (conseiller), si ce n'est pas Tch'eng, ce sera Hoang (146). Ces deux hommes, que pensez-vous d'eux ?

Li K'o répondit :

- Votre sujet a entendu dire que, lorsqu'on est dans une situation humble, on ne doit pas se permettre de discuter sur ceux qui sont élevés en dignité, que, lorsqu'on est étranger à la famille, on ne doit pas se permettre de discuter sur ceux qui lui sont apparentés. Je suis en dehors du palais, je ne saurais satisfaire à l'ordre que vous me donnez.

Le marquis Wen lui dit :

— Maître, abordez cette affaire en toute indépendance.

Li K'o dit (alors) :

- O prince, (si vous êtes indécis), c'est parce que vous n'avez pas fait un examen attentif. Quand un homme est dans sa demeure, regardez qui il chérit; quand il est riche, regardez ce qu'il donne ; quand il est parvenu (aux honneurs), regardez qui il recommande ; quand il est sans ressources, regardez ce dont il s'abstient; quand il est pauvre, regardez ce qu'il ne prend pas. Ces cinq considérations suffiront à fixer votre choix. Qu'est-il besoin de moi, $(\mathrm{Li}) \mathrm{K}^{\prime} O$ ?

Le marquis Wen lui dit :

- Maître, retournez chez vous. Le choix de mon conseiller est fixé.

Li K'o se retira promptement et sortit. Il passa devant la maison de Ti Hoang. Ti Hoang lui dit :

- Je viens d'apprendre que le prince vous avait mandé pour vous consulter sur le choix d'un conseiller. Qui le sera effectivement?

Li K'o répondit :

— C'est Wei Tch'eng-tse qui sera conseiller. 
Ti Hoang, irrité, changea de couleur et dit :

- Si j'en crois ce que mes yeux ont vu et ce que mes oreilles se rappellent, en quoi suis-je inférieur à ${ }_{\text {p. } 145}$ Wei Tch'eng-tse ? Le gouverneur du Si-ho, c'est moi qui l'ai fait nommer. A l'intérieur du royaume, (la région de) Ye était un sujet d'anxiété pour le prince ; c'est moi qui ai fait nommer Si-men Pao. Quand le prince a projeté d'attaquer (le pays de) Tchong-chan, c'est moi qui ait fait nommer Yo Yang. Quand le Tchong-chan eut été conquis, on n'avait personne à y envoyer pour le garder; c'est moi qui vous ai fait nommer. Le fils du prince n'avait pas de précepteur ; c'est moi qui ai fait nommer K'iu-heou Fou (147). En quoi donc suis-je inférieur à $W e i_{\text {p.146 }}$ Tch'eng-tse?

Li K'o lui répondit :

- Quand vous avez parlé en faveur de moi, $(\mathrm{Li}) K^{\prime} O$ à mon souverain, comment aurait-ce été dans l'intention de lier partie avec moi pour que je demande (pour vous) de hautes fonctions ? Le prince m'a interrogé au sujet de la nomination d'un conseiller en disant qu'il prendrait soit Tch'eng, soit Hoang, et en me demandant ce que je pensais de ces deux hommes. Moi, ( $\mathrm{Li}$ ) $\mathrm{K}^{\prime} \mathrm{o}$, je lui ai répondu :

- Ô prince (si vous êtes indécis), c'est parce que vous n'avez pas fait un examen attentif. Quand un homme est dans sa demeure, regardez qui il chérit ; quand il est riche, regardez ce qu'il donne ; quand il est parvenu (aux honneurs), regardez qui il recommande ; quand il est sans ressources, regardez ce dont il s'abstient; quand il est pauvre, regardez ce qu'il ne prend pas. Ces cinq considérations suffiront à fixer votre choix. Qu'est-il besoin de moi, ( $\mathrm{Li})$ K'o ?

Voilà pourquoi je sais que Wei Tch'eng-tse sera conseiller. Comment en effet pourriez-vous supporter la comparaison avec Wei Tch'eng-tse ? Wei Tch'eng-tse, ayant des appointements de mille tchong (de grain), en donnait les neuf dixièmes au-dehors et n'en employait qu'un dixième à son propre usage. C'est pourquoi, à l'orient il a trouvé Pou Tse-hia, T'ien Tse-fang et Toan-kan Mou. Ces trois hommes, le ${ }_{\text {p.147 }}$ prince les considère tous comme ses maîtres. Quant aux cinq hommes que vous avez fait nommer, le prince les considère tous comme ses sujets. Comment donc supporteriez-vous la comparaison avec Wei Tch'eng-tse?

Ti Hoang recula, se prosterna à deux reprises et dit :

- Je suis un homme méprisable, ma réponse a été fautive; je désire en définitive être votre disciple. 
La vingt-sixième année (399), la montagne Kouo (148) S'éboula et obstrua le Ho. - La trente-deuxième année (393), (Wei) attaqua Tcheng. Il éleva un rempart à Soan-tsao (149). Il battit Ts'in à Tchou (150). - La trente-cinquième année (390), Ts'i attaqua et prit notre ville de Siang-ling (151). - La trente-sixième année (389), Ts'in envahit notre (territoire de) Yn-tsin (152). La trente-huitième année (387), (Wei) attaqua $T s^{\prime}$ 'in qui nous battit sous les murs de $O u$ (153), mais on prit son général Che. - Cette année-là, le marquis $W e n$ mourut. Son fils $K i$ monta sur le trône ; ce fut le marquis $\mathrm{Ou}$.

p.148 La première année (386) du marquis $\mathrm{Ou}$, de Wei, le marquis $\mathrm{King}$, de Tchao, monta sur le trône ; le kong-tse Cho (154) fit une rébellion ; n'ayant pas été vainqueur, il s'enfuit dans (le pays de) Wei; avec l'aide de Wei, il attaqua à l'improviste Han-tan; Wei fut battu et se retira. - La deuxième année (385), on éleva des remparts à $\operatorname{Ngan-i}(\underline{155})$ et à Wang-yuen (156). — La septième année (380), (Wei) attaqua $T s$ ' $i$ et parvint jusqu'à Sang-k'ieou (157). - La neuvième année (378), les Ti nous battirent sur (les bords de la rivière) Koai (158). (Wei) envoya $O u K^{\prime} i$ attaquer ${ }_{\text {p. } 149} T s^{\prime} i$; (ce général) arriva jusqu'à Ling-k'ieou (159). Le roi $W e i$, de $T s^{\prime} i$, monta sur le trône. — La onzième année (376), (Wei), ainsi que Han et Tchao, partagèrent entre eux trois le territoire (des princes) de $T \sin$ et mirent fin à leur descendance. - La treizième année (374), le duc Hien, de Ts'in, érigea Yo-yang en préfecture (160). - La quinzième année (372) Wei) prit à Tchao (la ville de) Lin septentrional (161). La seizième année (371), (Wei) attaqua Tch'ou et prit Lou-yang (162). - Le marquis $\mathrm{Ou}$ mourut. Son fils Yng monta sur le trône ; ce fut le roi Hoei.

La première année (370) du roi Hoei (se passèrent les événements suivants) : auparavant, au moment de la mort du marquis $O u$, le prince $Y n g$ et Kong-tchong Hoan se disputaient le titre d'héritier présomptif. Kong-suen $K^{\prime} i$ se rendit du pays de Song dans celui de Tchao, puis du pays de Tchao dans celui de $\operatorname{Han}(\underline{163})$; il dit au marquis $I$ (164), de Han :

- Wei Yng (165) et Kong-tchong Hoan (166) se ${ }_{\text {p.150 }}$ disputent le titre d'héritier présomptif. Ô prince, ne l'avez-vous pas vous-même entendu dire ? Maintenant, Wei Yng s'est assuré les services de Wang Ts'o(167), enserre le Chang-tang (168), et certainement divisera votre royaume. Si vous profitez (des circonstances présentes) pour le supprimer, la ruine de Wei est assurée. Il ne faut pas manquer (cette occasion).

Le marquis $I$ fut content; il réunit donc son armée et joignit ses troupes à celles du marquis Tch'eng, de Tchao, pour attaquer Wei; on combattit à Tchouo-tse (169); les gens de Wei essuyèrent une grande défaite et le prince de Wei fut assiégé (170). (Le marquis Tch'eng, de) Tchao dit (au marquis I, de) Han :

- Supprimons le prince de Wei; mettons sur le trône Kong-tchong Hoan; enlevons-lui quelques territoires puis retirons-nous ; nous y aurons trouvé profit. 
(Le marquis $I$, de) Han lui répondit :

- Il ne faut pas agir ainsi. Si nous tuons le prince de $W e i$, les hommes certainement nous taxeront de cruauté; si nous nous retirons après ${ }_{\text {p.151 }}$ avoir enlevé quelques territoires, les gens diront certainement que nous sommes avides. Il vaut mieux diviser en deux le pays; quand Wei aura été divisé en deux, il sera moins puissant encore que Song ou Wei [b] (171). Alors nous n'aurons plus jamais à souffrir de Wei.

(Le marquis Tch'eng, de) Tchao refusa d'écouter (ce conseil) ; (le marquis $I$, de) Han fut mécontent et se retira nuitamment avec ses jeunes soldats. Si le roi Hoei ne périt pas lui-même et si son royaume ne fut pas divisé, c'est parce que les avis de ces deux chefs ne furent pas concordants; si on avait suivi l'avis d'un seul chef, la division de Wei était assurée. On dit donc : Lorsqu'un prince meurt sans avoir de fils légitimement aîné, son royaume risque d'être brisé.

La deuxième année (369), Wei battit Han à Ma-ling (172); il battit Tchao à Hoai (173). - La troisième année (368), Ts' $i$ nous vainquit à Koan (174). — La cinquième année (366), (le roi de Wei) eut une entrevue avec (le roi de) Han à Tchai-yang (175). p.152 Il éleva un rempart à Ou-tou. Il fut battu par Ts 'in. - La sixième année (365), (le roi de $\mathrm{Wei}$ ) attaqua et prit la terrasse $I$ qui appartenait à Song. - La neuvième année (362), il attaqua et battit Han sur (les bords de la rivière) Koai (176). Il combattit contre $T s^{\prime}$ in à Chao-leang (177); (Ts'in) fit prisonnier notre général Kong-suen Ts'o (178). (Le roi de Wei) prit (la ville de) P'ang (179). - Le duc Hien, de Ts'in, mourut ; son fils, qui fut le duc Hiao, monta sur le trône. - La dixième année (361), (le roi de $\mathrm{Wei}$ ) attaqua et prit (la ville de) $P^{\prime}$ i-lao (180) qui appartenait à Tchao. Une comète apparut. — La douzième année (359), une étoile en plein jour tomba avec fracas. - La quatorzième année (357), (le roi de $\mathrm{Wei}$ ) eut une entrevue avec (le roi de) Tchao à Hao (181). - La quinzième année (356), les princes de Lou, Wei [b],

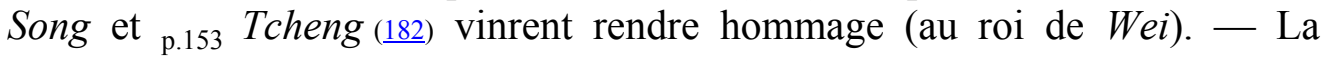
seizième année (355) (le roi de Wei) eut une entrevue avec le duc Hiao, de Ts'in, à Cho-p'ing (183). Il envahit (le territoire de) Hoang-tch'e (184) qui appartenait à Song, mais Song le reprit. - La dix-septième année (354), il combattit contre Ts'in à Yuen-li. Ts'in nous prit Chao-leang (185). (Wei) assiégea Han-tan, (capitale) de Tchao. — La dix-huitième année (353), il prit Han-tan; Tchao implora l'aide de Ts'i; Ts'i envoya T'ien Ki et Suen Pin (186) au secours de Tchao; ils vainquirent Wei à Koei-ling (187). — La dix-neuvième année (352), les seigneurs assiégèrent notre ville de Siang-ling (188). (Le roi de $W e i)$ construisit un long mur et boucha ainsi Kou-yang (189). La vingtième année (351), (Wei) rendit Han-tan ${ }_{\text {p.154 }}$ à Tchao et conclut avec lui un traité sur les bords de la rivière Tchang (190). - La vingt-et-unième année (350), (le roi de $W e i)$ eut une entrevue avec (le roi de $T s^{\prime}$ in) à T'ong (191). Le marquis 
Tch'eng, de Tchao, mourut. — La ${ }_{\text {p.155 }}$ vingt-huitième année (343), le roi Wei, de $T s$ ' $i$, mourut. Le prince de Tchong-chan devint conseiller de Wei.

La trentième année (341), Wei attaqua Tchao (192); Tchao déclara à Ts'i le danger où il se trouvait. Le roi Siuen, de Ts' $i$, suivant les conseils de Suen-tse (193), secourut Tchao et attaqua Wei. Wei alors leva une armée considérable dont il confia le commandement à Pang Kiuen, tandis qu'il donnait le titre de général en chef à l'héritier présomptif Chen. (L'armée) passa par Waihoang (194). [(195) Un homme de Wai-hoang, nommé Siu-tse, dit à l'héritier présomptif :

— Je possède une recette pour, sur cent combats, gagner cent fois la victoire.

L'héritier présomptif demanda :

— Puis-je l'apprendre?

L'étranger lui répondit :

— Je désire assurément vous la communiquer. La voici : ô héritier présomptif, étant en personne à la tête de l'armée, vous allez attaquer $T s^{\prime} i$; à supposer que vous remportiez de grandes victoires et que vous vous annexiez Kiu (196), cependant votre richesse ne sera pas plus considérable que lorsque vous possédez Wei, votre dignité ne s'élèvera pas au-dessus du titre de roi. Mais si, après avoir combattu, vous n'êtes pas vainqueur de $T s$ ' $i$, alors pendant dix mille ${ }_{\text {p.156 }}$ générations vous ne posséderez plus (le royaume) de Wei (197). Telle est ma recette pour, sur cent combats, gagner cent fois la victoire.

L'héritier présomptif dit :

- Je vous approuve; je vous demande donc la permission de suivre votre avis et de m'en retourner.

L'étranger dit :

- Quand bien même, ô héritier présomptif, vous voudriez vous en retourner, vous ne le pourriez pas. Ceux qui vous exhortent à combattre et qui désirent goûter au jus (198), sont très nombreux. Même si vous vouliez revenir, je crains que vous ne le puissiez pas.

L'héritier présomptif voulut donc s'en retourner ; mais son cocher lui dit :

- Quand un général est entré en campagne, s’il revient sur ses pas, c'est comme s'il était battu.]

L'héritier présomptif livra effectivement bataille aux gens de $T s^{\prime} i$ et fut battu à Ma-ling (199). Ts 'i fit ${ }_{\text {p.157 }}$ prisonnier Chen, héritier présomptif de $W e i$, et tua le général (Pang) Kiuen; l'armée (de $\mathrm{Wei}$ ) subit alors une grande défaite. 
La trente et unième année (340), Ts 'in, Tchao et $T s^{\prime} i$ s'unirent pour nous attaquer. Le prince de Chang, général de $T s$ 'in, attira dans une embûche notre général, le kong-tse Ang, puis il assaillit à l'improviste et par ruse son armée et l'écrasa. Grâce au prince de Chang, Ts'in avait étendu à l'est son territoire jusqu'au Ho; en outre, $T s^{\prime} i$ et Tchao nous avaient vaincus à plusieurs reprises ; comme Ngan-i était proche de $T s$ 'in, (le roi de Wei) transféra donc sa capitale à Ta-leang (200). Il nomma le kong-tse Ho héritier présomptif. — La trente-troisième année (338), le duc Hiao, de Ts'in, mourut. Le prince de Chang s'enfuit du pays de $T$ s'in et vint se réfugier dans le pays de Wei; mais (le roi de) Wei, qui était irrité contre lui, ne l'accueillit pas. — La trente-cinquième année (336), (le roi de Wei) eut une entrevue avec le roi Siuen, de $T s$ ' $i$, au sud de $P$ 'ing-ngo (201).

Le roi Hoei, ayant subi de nombreux échecs militaires, se montra humble et fit des présents considérables ${ }_{\text {p. } 158}$ pour attirer auprès de lui des sages. Tseou Yen, Choen-yu K'oen et Mong K'o (202) vinrent tous à Leang. Le roi Hoei, de Leang, dit :

- Je suis dépourvu de talents; mes soldats ont été trois fois vaincus au dehors ; mon héritier présomptif a été fait prisonnier; mon général en chef a péri. Mon royaume se trouve ainsi vide et épuisé ; j'ai ainsi couvert de honte le temple ancestral et les dieux du sol et des moissons des princes mes prédécesseurs. J'en suis fort confus, [(203) ô vieillard, vous n'avez pas jugé trop longue une distance de mille li] et vous avez daigné favoriser de votre venue la cour de mon humble ville. [Quel profit allez-vous apporter à mon royaume?]

[Mong K'o lui dit :

- Votre Majesté ne doit pas parler de profit. En effet, si le prince désire son profit, les grands officiers désirent leur profit; quand les grands officiers désirent leur profit, alors les hommes du commun désirent leur profit. Du haut en bas (de l'échelle sociale) on se dispute pour le profit et le royaume est alors en péril]. Pour celui qui règne sur des hommes [la bonté et la justice sont tout; à quoi bon le profit ?] (204)

La trente-sixième année (335), (le roi Hoei) eut de nouveau une entrevue avec le roi de $T s$ 'i à Kiuen. Cette année-là, le roi Hoei mourut (205). Son fils, qui fut le roi Siang, prit le pouvoir.

La première année (334) de son règne, le roi Siang se ${ }_{\text {p.159 }}$ réunit avec les seigneurs à Siu-tcheou (206). Ils se reconnurent mutuellement le titre de roi ; (le roi Siang) honora rétrospectivement son père, le roi Hoei, en lui conférant le titre de roi (207). - La cinquième année (330) (208), Ts 'in battit l'armée de notre (général) Long Kou, qui comptait quarante-cinq mille hommes, à Tiao-yn (209); il assiégea nos (villes de) Tsiao et de K'iu-ou (210); (Wei) ${ }_{\text {p.160 }}$ 
donna à $T s^{\prime}$ 'in le territoire de Ho-si (211). - La sixième année (329), (le roi Siang) eut une entrevue avec (le roi de) $T$ s'in à $Y n g$ (212). Ts'in prit nos (villes de) Fen-yn (213), P'i-che (214) et Tsiao (215). - Wei attaqua Tch'ou et le battit à Hing-chan (216). - La septième année (328), Wei livra tout le territoire de la commanderie de Chang (217) à Ts'in. Ts'in soumit notre (ville de) P'ou-yang (218). - La huitième année (327), Ts'in nous rendit Tsiao et K'iu-ou (219). - La douzième année (323), Tch'ou nous battit à Siangling (220). Ceux qui exerçaient le gouvernement (221) chez les seigneurs eurent

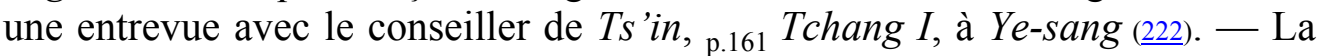
treizième année (322), Tchang I devint conseiller de Wei. - Dans le pays de $W e i$, il y eut une femme qui se changea en homme. - Ts'in prit nos (villes de) K'iu-ou (223) et P'ing-tcheou (224). — La seizième année (319), le roi Siang mourut. Son fils, qui fut le roi Ngai, monta sur le trône. Tchang I retourna dans le pays de $T s$ 'in.

La première année (318) du roi Ngai, les cinq royaumes (225) attaquèrent ensemble $T s^{\prime}$ in ; ils ne furent pas vainqueurs et se retirèrent. - La deuxième année (317), Ts'i nous battit à Koan-tsin (226). - La cinquième année (314), $T s^{\prime}$ 'in envoya Tch'ou-li tse attaquer et prendre notre (ville de) K'iu-ou (227); (ce général) mit en fuite Si-cheou (228) à Ngan-men (229). - La sixième année (313), Ts 'in demanda que le kong-tse Tcheng fût nommé héritier présomptif. (Le roi de $W e i$ ) eut une entrevue avec (le roi de) $T s$ 'in à Lin-tsin (230). — La septième année (312), il attaqua $T s^{\prime} i(231)$. Allié à $T s^{\prime}$ 'in, il attaqua Yen. - La p.162 huitième année (311), il attaqua $W e i[\mathrm{~b}]$, et lui prit deux villes importantes (232). Le prince de Wei [b] en fut accablé d'anxiété. Jou Eul (233) vint voir le prince de $W e i[b]$ et lui dit :

- Je vous propose de faire battre en retraite les soldats de Wei et de faire dégrader le prince de Tch'eng-ling. Qu'en dites-vous?

Le prince de $W e i[b]$ lui répondit :

- Maître, si vous êtes réellement capable de faire cela, je vous demanderai la permission de mettre éternellement toutes les forces de $W e i[\mathrm{~b}]$ à votre service.

Jou Eul se rendit (alors) auprès du prince de Tch'eng-ling et lui dit :

- Autrefois, Wei (234) ayant attaqué Tchao, intercepta le (chemin de la montagne) Yang-tch'ang (235) et prit Yen-yu (236) ; il fit une convention qui ${ }_{\text {p.163 }}$ coupait Tchao et Tchao se trouva divisé en deux parties; s'il échappa à la destruction, c'est parce que Wei était le chef de la ligne tsong (237). Maintenant, si Wei [b] est menacé de destruction, il va se tourner vers l'Ouest pour demander un service à $T s$ 'in. Plutôt que $T s^{\prime}$ 'in délivre $W e i[\mathrm{~b}]$, mieux vaut que $W e i$ délivre $W e i[\mathrm{~b}]$, car alors la reconnaissance de Wei $[\mathrm{b}]$ pour $W e i$ sera en définitive sans limites.

Le prince de Tch'eng-ling dit : 
— Vous avez raison.

Jou Eul se rendit (ensuite) auprès du roi de Wei et lui dit :

- Votre sujet a été reçu en audience par (le prince de) Wei [b]. $W e i[\mathrm{~b}]$ est un ancien rameau détaché de la maison des Tcheou; quoiqu'on le dise un petit royaume il possède beaucoup d'objets précieux. Maintenant que ce royaume est dans un danger pressant, s'il ne livre pas ses objets précieux, c'est parce que dans son for intérieur il pense que ce n'est pas vous, ô roi, qui êtes maître d'attaquer $W e i[\mathrm{~b}]$ ou de délivrer $W e i[\mathrm{~b}]$ (238) ; ainsi, même quand il p.164 livrera ses objets précieux, ce ne sera pas pour les donner à Votre Majesté. A mon avis, celui qui le premier parlera de délivrer $W e i[\mathrm{~b}]$, c'est celui-là qui aura reçu (les cadeaux de) Wei [b].

Quand Jou Eul fut sorti, le prince de Tch'eng-ling entra et, dans l'audience que lui accorda le roi de $W e i$, tint le langage (que lui avait suggéré $J o u E u l$ ) ; dès que le roi l'eut entendu parler, il fit battre en retraite ses soldats et dégrada le prince de Tch'eng-ling qui ne fut plus reçu en sa présence jusqu'à sa mort.

La neuvième année (310), (le roi de $W e i$ ) eut une entrevue avec (le roi de) $T$ s'in à Lin-tsin (239). Tchang I et Wei Tchang revinrent tous deux dans le pays de Wei. - Le conseiller de Wei, T'ien Siu, étant mort, (le roi de) Tch'ou redoutait Tchang I, Si-cheou (240) et le gouverneur de Sie (241). Le conseiller de Tch'ou, [(242) Tchao Yu, dit à Sou Tai :

- T'ien Siu est mort; je crains que l'un de ces trois hommes, Tchang I, Si cheou ou le gouverneur de Sie, ne devienne conseiller de Wei.

(Sou) Tai (243) lui répondit :

- En effet, mais, comme conseiller, qui désireriez-vous qui fût nommé comme pouvant vous être avantageux?

Tchao $_{\text {p.165 }}$ Yu dit :

— Je désirerais que l'héritier présomptif (244) lui-même fût conseiller.

(Sou) Tai dit :

- Je vous demande la permission d'aller pour vous servir dans le Nord (245), et je ferai certainement nommer conseiller (l'héritier présomptif).

- Comment ferez-vous? demanda Tchao Yu.

- Supposez, répliqua (Sou Tai), que vous soyez le roi de Leang (246); moi, (Sou) Tai, je vous demande la permission de vous conseiller.

— Eh bien? demanda Tchao Yu. 
(Sou Tai) dit :

- Moi, (Sou Tai), je viens du pays de Tch'ou; Tchao Yu, fort inquiet, m'a dit :

- T'ien Siu est mort; je crains que l'un de ces trois hommes, Tchang I, Si-cheou ou le gouverneur de Sie, ne devienne conseiller de $W e i$.

Moi, (Sou) Tai, je lui ai répondu :

- Le roi de Leang est un grand souverain ; il ne prendra certainement pas Tchang I pour conseiller; si en effet Tchang I était conseiller, il ne manquerait pas de donner la première place à $T S$ ' $i n$ et la seconde à Wei. (De même), si Si-cheou était conseiller, il ne manquerait pas de donner la première place à Han et la seconde à $W e i$; si le gouverneur de Sie était conseiller, il ne manquerait pas de donner la première place à $T s$ ' $i$ et la seconde à $W e i$. Le roi de Leang est un grand souverain; certainement il ne trouvera pas opportun (de nommer conseiller un de ces trois hommes).

(Quand j'aurai ainsi parlé), le roi me dira :

— Qui donc dois-je prendre pour conseiller?

Moi, Tai, je lui répondrai :

— Le mieux serait que l'héritier présomptif lui-même fût conseiller. Ces trois hommes, considérant tous que l'héritier présomptif ne peut pas être toujours ${ }_{\text {p.166 }}$ conseiller, s'appliqueront à mettre au service de Wei leurs royaumes respectifs, dans le désir d'obtenir (pour eux-mêmes) le sceau de conseiller. Vu la puissance de $W e i$, quand il sera appuyé par trois royaumes possédant chacun dix mille chars de guerre, Wei assurément jouira du calme. C'est pourquoi je dis: Le mieux serait que l'héritier présomptif luimême fût conseiller.

(Sou Tai) se rendit donc dans le nord pour voir le roi de Leang et lui tint ce langage ; l'héritier présomptif devint en effet conseiller de Wei].

La dixième année (309), Tchang I mourut. — La onzième année (308), (le roi de $W e i)$ eut une entrevue avec le roi $O u$, de $T$ s'in, à $Y n g$ (247). - La douzième année (307), l'héritier présomptif alla rendre hommage à $T s$ 'in. $T s^{\prime}$ in vint attaquer notre ville de $P^{\prime} i$-che (248), mais leva le siège avant de l'avoir prise. - La quatorzième année (305), la reine, (femme du roi) $O u$, de Ts'in, revint (249). - La seizième année (303), Ts'in prit nos (villes de) P'ou-fan (250), Yang-tsin (251) p.167 et Fong-ling (252). - La dix-septième année (302), (le roi de Wei) eut une entrevue avec (le roi de) Ts'in à Lin-tsin (253). $T s$ 'in nous donna (la ville de) P'ou-fan (254). La dix-huitième année (301), (le roi de $W e i)$, allié à $T s^{\prime}$ in, attaqua $T c h$ 'ou. — La vingt et unième année (298) (Wei), ainsi que $T s$ ' $i$ et Han battirent ensemble l'armée de $T s$ 'in à Hankou (255). - La vingt-troisième année (296), ${ }_{\text {p. } 168} T$ s'in nous rendit le territoire de Ho-wai (256), ainsi que Fong-Ling (257), pour avoir la paix. — Le roi Ngai mourut (258); son fils, qui fut le roi Tchao, monta sur le trône. 
La première année (295) du roi Tchao, Ts'in prit notre (ville de) Siang-tch'eng (259). - La deuxième année (294), nous combattîmes contre $T s$ 'in, mais nous n'eûmes pas l'avantage. — La troisième année (293), (Wei) aida $H a n$ à attaquer $T s^{\prime} i n$. Le général de $T s^{\prime} i n, P o K^{\prime} i$, battit à $I-k$ 'iue (260) notre armée qui comptait deux cent quarante ${ }_{\text {p.169 }}$ mille hommes. - La sixième année (290), (Wei) donna à $T s$ 'in le territoire de Ho-tong qui avait une superficie de quatre cents $l i$ de côté (261). Mang Mao, par ses ruses (de guerre) fut tenu en grande estime (262). - La septième année (289), Ts 'in nous prit soixante et une villes grandes ou petites. - La huitième année (288), le roi $T c h a o$, de $T s^{\prime} i n$, se proclama empereur d'Occident; le roi Min, de $T s^{\prime} i$, se proclama empereur d'Orient; au bout de plus d'un mois, tous deux reprirent le titre de roi et renoncèrent à celui d'empereur. - La neuvième année (287), Ts'in prit nos villes de Sin-yuen et de K'iu-yang (263). — La dixième année (286), Ts'i anéantit Song; le roi de Song mourut dans notre (ville de) Wen (264). - La douzième année (284), (Wei) ainsi que Ts'in, Tchao, Han et $Y e n$, attaquèrent ensemble $T s^{\prime} i$ et le battirent à l'ouest de la rivière $T s i$; le roi Min s'enfuit (hors de son royaume); (le ${ }_{\text {p. } 170}$ général de) Yen entra seul à Lintse (265). - (Le roi de) Wei et le roi de $T s$ 'in eurent une entrevue dans (la ville des) Tcheou occidentaux (266). - La treizième année (283) Ts'in prit notre (ville de) Ngan-tch'eng (267); ses soldats arrivèrent jusqu'à Ta-leang (268) puis se retirèrent. - La dix-huitième année (278), Ts'in prit $Y n g(\underline{269})$; le roi de Tch'ou se transporta à Tch'en. - La dix-neuvième année (277), le roi Tchao mourut. Son fils, qui fut le roi Ngan-hi, monta sur le trône.

La première année (276) du roi Ngan-hi, Ts'in nous prit deux villes (270). - La deuxième année (275), il nous prit encore trois villes et vint camper sous les murs de Ta-leang; Han vint à notre secours; nous donnâmes à $T$ s'in (la ville de) Wen (271) pour avoir la paix. - La troisième année (274), Tsin nous prit quatre villes et coupa quarante mille têtes. - La quatrième année (273), Ts 'in nous écrasa, ainsi que Han et Tchao, et tua cent ${ }_{\text {p.171 }}$ cinquante mille hommes; il mit en fuite notre général Mang Mao.

[(272) Toan-kan tse (273), général de Wei, proposa de donner à Ts 'in (la ville de) Nan-yang (274) pour avoir la paix. Sou Tai (275) dit au roi de Wei (276) :

- Celui qui désire un sceau c'est Toan-kan tse ; celui qui désire un territoire, c'est Ts 'in (277). Si maintenant Votre Majesté fait en sorte que celui qui désire le territoire, dispose du sceau, et que celui qui désire le sceau dispose du territoire, aussi longtemps que le territoire de Wei ne sera pas entièrement épuisé, je ne sais pas quand cela finira (278). En effet, p.172 rendre service à $T s^{\prime}$ 'in en lui offrant des terres, c'est comme prendre une brassée de bois mort pour secourir au moment d'un incendie (279); aussi longtemps que le bois mort ne sera pas entièrement épuisé, le feu ne s'éteindra pas (280).

Le roi dit : 
— Il en est bien ainsi. Cependant l'affaire a déjà commencé d'être exécutée : je ne puis rien y changer.

L'autre lui répondit :

- Ô roi, ne voyez-vous pas comment les joueurs mettent en valeur la pièce hiao (281) ? quand c'est avantageux, ils mangent; quand ce n'est pas avantageux, ils restent immobiles. Maintenant, ${ }_{\text {p.173 }}$ ô roi, vous dites : L'affaire a déjà commencé d'être exécutée; je ne puis rien y changer. Pourquoi, ô roi, la manière dont vous vous servez de votre sagesse ne vaut-elle pas la manière dont on se sert de la pièce hiao (282)?

La neuvième année (268), Ts'in prit notre (ville de) Hoai (283). — La dixième année (267), l'héritier présomptif de $T s$ 'in qui avait été envoyé hors de son pays comme otage dans le pays de $W e i$, mourut. — La onzième année (266), Ts'in prit notre (ville de) Ts'i-k'ieou (284).

[(285) Le roi Tchao, de Ts 'in, dit à ceux qui l'entouraient (286) :

- Maintenant Han et Wei sont-ils plus ou moins puissants qu'ils ne l'étaient autrefois?

On lui répondit :

- Ils ne sont pas aussi puissants qu'ils l'étaient au début.

Le roi reprit :

- Aujourd'hui Jou Eul (287) et Wei Ts'i (288) sont-ils plus ou moins sages que ne l'étaient (le prince de) Mong-tch'ang (289) et Mang Mao (290)?

On lui répondit :

— Ils ne les valent pas.

Le roi dit :

- Lorsque Han et Wei étaient dans toute leur puissance et avaient pour les guider la sagesse du (prince de) Mong-tch'ang et de ${ }_{\text {p.174 }}$ Mang Mao, quand ils ont attaqué Ts'in, ils n'ont pu cependant venir à bout de moi. Maintenant que Han et Wei sont affaiblis et qu'ils ont pour les guider les incapables Jou Eul et Wei Ts'i, quand ils attaqueront $T s$ 'in, ils ne pourront venir à bout de moi ; cela aussi est évident.

Les assistants dirent tous :

— Vous avez parfaitement raison.

Tchong $K^{\prime} i$ s'appuya sur son luth et répliqua : 
- O roi, vos appréciations sur le monde sont erronées. A l'époque des six hauts dignitaires de $T \sin$, le chef de la famille Tche était le plus puissant; il anéantit (les familles) Fan et Tchong-hang; en outre, à la tête des soldats (des familles) Han et Wei, il assiégea Tchao Siang-tse à Tsin-yang (291); il ouvrit une brèche à la rivière $T \sin (292)$ pour inonder les remparts de Tsin-yang; il n'y avait que trois pan (293) des remparts qui n'étaient pas immergés. (Au moment où) Tche po faisait avancer les eaux, Wei Hoan-tse était son cocher et Han $K$ 'ang-tse était l'homme qui était à côté de lui sur le char. Tche po dit :

- Je ne savais pas auparavant que l'on pût détruire le royaume d'un homme ; maintenant je le sais; la rivière Fen peut servir à inonder Ngan-i (294) et la rivière Kiang (295) p.175 peut servir à inonder P'ing-yang (296).

Wei Hoan-tse poussa du coude Han K'ang-tse et Han K'ang-tse mit son pied sur celui de Wei Hoan-tse (297); les coudes et les pieds s'étant ainsi touchés sur le char, c'est à la suite de cela que le territoire du chef de la famille Tche fut divisé, que lui-même périt, que son royaume fut anéanti et qu'il devint la risée de l'empire. Maintenant, quoique les forces militaires de $T s^{\prime}$ in soient grandes, elles ne peuvent surpasser celle du chef de la famille Tche; quoique Han et Wei soient affaiblis, ils sont encore plus sages qu'ils ne l'étaient sous les murs de Tsin-yang. Or voici précisément le moment où ils font usage du pied et du coude (298); je désire que Votre Majesté se garde de les traiter à la légère.]

Alors le roi de $T s$ 'in eut peur.

p.176 [(299) Ts' $i$ et $T$ ch'ou se concertèrent pour attaquer Wei; Wei envoya des émissaires demander du secours à $T s$ 'in; (ces envoyés) voyaient de loin les

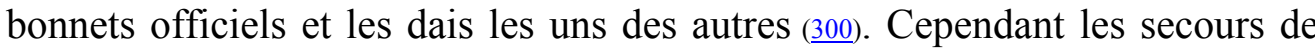
$T s^{\prime}$ in n'arrivaient pas. Parmi les gens de Wei, il y avait un certain T'ang Soei qui était âgé de plus de quatre-vingt-dix ans. Il dit au roi de $\mathrm{Wei}$ :

- Votre vieux sujet vous demande la permission d'aller à l'ouest donner des conseils à $T s$ 'in et obtenir que ses soldats sortent avant votre sujet (301).

Le roi de Wei s'inclina à deux reprises devant lui ; il fit atteler aussitôt des chars et l'envoya. Quand T'ang Soei fut arrivé et vint rendre visite au roi de $T s^{\prime}$ 'in, le roi de $T s^{\prime}$ 'in lui dit:

- Vieillard, vous avez l'air accablé de fatigue (302) et vous êtes venu de loin, ce qui a dû être fort pénible. Or nombreux sont les envoyés de Wei qui sont déjà venus demander des secours; le danger où se trouve Wei m'est chose connue (․3).

T'ang Soei répondit : 
- $\mathrm{Si}$, ô grand roi, vous connaissiez le danger où se trouve Wei et que vous n'ayez pas envoyé de secours, j'estime que les ministres qui préparent les plans à votre usage ne sont pas capables de remplir leur charge. En effet $\mathrm{Wei}$ est un royaume qui possède dix mille chars de ${ }_{\text {p.177 }}$ guerre; si cependant il se tourne vers l'ouest pour servir $T s^{\prime}$ in, s'il se dit sa barrière orientale (304), s'il revoit de lui les bonnets et les ceintures (officiels) (305), et s'il sacrifie pour lui au printemps et en automne, c'est parce qu'il estime que la puissance de $T s$ 'in est telle qu'il vaut la peine de l'avoir pour allié. Or maintenant les soldats de $T s^{\prime} i$ et de $T c h o u$ sont déjà réunis dans la banlieue de $W e i$ et néanmoins les secours de $T s$ 'in ne sont pas partis ; de son côté ( $\mathrm{Wei}$ ), peut compter qu'il n'est pas encore en danger pressant (306). A supposer en effet que le danger fût pressant pour lui, il livrerait aussitôt une partie de son territoire (307) et se rattacherait à la ligue tsong (308). Quel besoin y aurait-il que vous, ô roi, le secouriez? Si donc vous attendez qu'il soit en danger pressant pour le secourir, vous perdrez Wei qui est votre unique barrière orientale et vous fortifierez $T s$ ' $i$ et $T c h$ 'ou qui sont vos deux ennemis. Quel avantage en retirerez-vous, ô roi ?

Alors le roi Tchao, de $T s$ 'in, se hâta d'envoyer des soldats au secours de $W e i$ et la famille princière de Wei fut de nouveau raffermie].

[(이) (Le roi de) Tchao envoya un homme dire au roi de ${ }_{\mathrm{p} .178} \mathrm{Wei}$ :

- Faites-moi le plaisir de tuer Fan Ts'o et je vous demanderai la permission de vous offrir un territoire de soixante-dix $l i$.

Le roi de $W e i$ dit :

- C'est bien.

et envoya des officiers arrêter (Fan Ts'o) ; ils l'avaient cerné mais ne l'avaient pas encore tué, lorsque (Fan Ts'o) monta sur sa maison, et, à cheval sur le faîte (310), dit, aux envoyés :

- Plutôt que de faire un marché avec $T s^{\prime}$ 'o mort, il vaudrait mieux faire un marché avec $T s^{\prime} O$ vivant, car une fois que $T s^{\prime} O$ sera mort, Tchao ne donnera pas au roi le territoire (qu'il lui a promis); que pourra faire alors le roi ? Le mieux serait donc de décider au préalable la cession du territoire et de tuer ensuite $T s^{\prime} o$.

Le roi de Wei approuva ces paroles. (Fan Ts'o) adressa alors au prince de Sinling (311) une lettre où il lui disait :

- Moi, (Fan) Ts'o, je suis un ancien conseiller de Wei, qui ai donné ma démission (312). Quand Tchao, par l'offre d'un p.179 territoire, m'aura fait mettre à mort et que le roi de Wei y aura consenti, s'il arrive que le puissant $T$ s'in à son tour veuille imiter Tchao dans ses désirs, que pourrez-vous faire, ô prince ? 
Le prince de Sin-ling rapporta cela au roi et on relâcha (Fan $\left.\left.T s^{\prime} o\right)\right]$.

[(313) Le roi de $W e i$, à cause du secours que lui avait donné $T S$ 'in, désirait entretenir des rapports d'amitié avec $T s^{\prime}$ 'in et attaquer Han pour lui redemander le territoire qui lui avait autrefois appartenu. Ou-ki (314) dit au roi de $W e i$ :

- (Le roi de) $T s^{\prime}$ in (315) a les mêmes mœurs que (les barbares) Jong et $T i$; il a un cœur de tigre et de loup. Il est avide et cruel ; il aime son intérêt et est déloyal; il ne connaît ni les rites, ni la justice, ni la conduite vertueuse. Si vraiment il y trouve son avantage, il ne tient plus aucun compte de ses parents et de ses frères; il est semblable à une bête sauvage ; c'est là ce que sait le monde entier; jamais il n'a répandu de grands bienfaits ni accumulé des actes vertueux. C'est ainsi que la reine douairière (316), quoiqu'elle fût sa mère, est morte de chagrin ; le marquis de Jang (317), quoiqu'il fût son oncle maternel et que personne n'eût rendu plus de services signalés que lui, a été en définitive banni ; ses deux frères cadets $(\underline{318})$ p.180 $\mathrm{n}$ 'avaient commis aucun crime et furent tous deux dépouillés de leur fiefs. Si telle est sa conduite envers ses parents, quelle ne sera pas celle qu'il tiendra à l'égard d'un royaume ennemi ? Si maintenant, ô roi, vous vous alliez à $T s$ 'in pour attaquer avec lui Han, vous rapprochez davantage de vous les malheurs dont vous menace Ts'in. Je considère cela comme une grave erreur, et si, ô roi, vous ne le comprenez pas, c'est que vous n'y voyez pas clair. Parmi tous vos sujets, il n'en est aucun qui vous ait informé à ce sujet, mais c'est là manque de loyalisme. Maintenant la maison princière de Han est représentée par un souverain enfant qui est confié à une femme (319); à l'intérieur (ce royaume) est fort troublé ; si au dehors, il se trouve aux prises avec les soldats des puissants (États de) T's'in et de $W e i$, pensez-vous, ô roi, qu'il puisse éviter d'être détruit? Lorsque Han aura été détruit, $T s$ 'in prendra le territoire de Tcheng et sera voisin de Ta-Leang (320); pensez-vous, ô roi, que vous serez tranquille? Vous désirez recouvrer votre ancien territoire et maintenant vous vous confiez (321) dans l'amitié du puissant p.181 Ts'in; mais pensez-vous, ô roi, que ce soit avantageux pour vous? $T s$ 'in n'est pas un royaume qui reste inactif; quand Han aura été détruit, il se disposera certainement à tenter une autre entreprise ; quand il tentera une autre entreprise, il ne manquera pas de se porter vers ce qui est à la fois facile et profitable; pour se porter vers ce qui est à la fois facile et profitable, ce n'est ni Tch'ou ni Tchao qu'il attaquera. Pourquoi cela? S'il faut passer des montagnes, franchir des fleuves et traverser le Chang-tang, territoire de Han, pour aller attaquer le puissant Tchao, ce serait une réédition de l'affaire de Yen-yu (322), 
et $T s$ 'in certainement ne le tentera pas. S'il faut aller par le Ho-nei, tourner le dos (aux villes de) Ye et Tchao-ko (323) et couper les (digues des) rivières Tchang et Fou (324), pour livrer une bataille décisive aux soldats de Tchao dans la banlieue de Han-tan (325), c'est (s'exposer à) l'infortune de Tche po (326) ; cela non plus, $T s$ 'in ne l'osera pas. Pour ce qui est d'attaquer Tch'ou, s'il faut passer par les gorges montagneuses qu'on traverse (327) et parcourir trois mille $_{\text {p.182 }} l i$ pour attaquer la barrière de Meng-ngo (328), la marche est $_{\text {p.183 }}$ fort longue et l'attaque très difficile ; cela encore, $T S^{\prime}{ }^{\prime}{ }_{\text {p. }}{ }_{\text {p.184 }}$ ne le fera pas (329). S'il faut passer par le Ho-wai, tourner le dos à Ta-leang (330), laisser $T s^{\prime}$ 'ai à sa droite et Chao-ling à sa gauche (331), pour aller livrer une bataille décisive aux soldats de Tch'ou dans la banlieue de Tch'en (332), cela aussi, Ts'in ne s'y risquera pas. C'est pourquoi je dis : $T s$ 'in certainement n'attaquera ni Tch'ou ni Tchao. En outre, il n'attaquera ni Wei [b] ni Ts'i. Ainsi, après que Han aura été détruit, le jour où les soldats de $T s$ 'in entreront ${ }_{\text {p. } 185}$ en campagne ils n'attaqueront personne d'autre que Wei. Ts 'in possédant déjà (333) les places de Hoai (334), Mao (335) et Hing-k'ieou (336) et ayant élevé un rempart à Koei-tsin (337) pour surveiller le Ho-nei, (vos villes de) Kong et $K i$ (338) dans le Ho-nei p.186 seront certainement en péril. (D'autre part, $T s$ 'in), étant en possession du territoire de Tcheng( Yuen-yong (340) et ouvrira une brèche à la rivière Yong-tse (341) pour inonder Ta-leang; la ruine de Ta-leang sera alors certaine. $\mathrm{O}$ roi, votre envoyé est parti, ce qui est une (première) faute (342); mais (en outre), il a mal parlé (du prince) de Ngan-ling (343) à Ts 'in, alors que $T s^{\prime}$ 'in désirait depuis ${ }_{\text {p. } 187}$ longtemps le faire périr ; Che-yang et Koen-yang (344), (villes) de Ts'in, sont voisines de Ou-yang; en permettant que votre envoyé parle mal (du prince de Ngan-ling), vous abandonnez ce dernier à sa perte; (quand cette perte sera consommée), Ts'in contournera Ou-yang (345) par le nord pour s'approcher de Hiu (346) vers l'est (347), et le Nan-kouo (348) sera certainement en danger; ne sera-ce pas fort mauvais pour votre royaume ( $\underline{349}$ ) ? Sans doute, il vous est ${ }_{\text {p. } 188}$ permis de haïr Han et de ne pas aimer (350) (le prince de) Ngan-ling, mais non de ne pas vous inquiéter de ce que $T s$ 'in n'aime pas le Nan-kouo (351). Autrefois, $T s$ 'in se trouvait dans le Ho-si (352), et (la capitale du) royaume de $T \sin (\underline{353})$ était à mille $l i$ de Leang (254); il y avait (entre $T s^{\prime}$ in et $T \sin )$ le Fleuve et les montagnes pour faire une barrière, Tcheou et Han pour les séparer; (cependant), à partir du moment où les armées vinrent à Lin-Hiang (355), et jusqu'à maintenant $T s$ 'in attaqua sept fois $\mathrm{Wei}$; cinq fois il entra dans vos jardins (356); vos villes de la frontière furent ${ }_{\text {p.189 }}$ toutes prises; la terrasse Wen (357) fut renversée; (le temple) Tou à Tch'oei (358) fut incendié ; les 
arbres de vos forêts furent coupés; vos grands cerfs furent tous détruits et votre capitale eut à subir une succession de sièges. Puis $T s$ 'in est venu à grandes chevauchées au nord de Leang, et, vers l'est, il s'est avancé jusqu'aux banlieues de Tao et de Wei [b] (359), tandis qu'au nord il allait jusqu'à $P$ 'ing (360) ${ }^{\text {p.190 }}$ et à Kien (361). Ce qui fut perdu par le fait de $T$ s'in (qui se l'annexa), ce fut le territoire au sud de la montagne et le territoire au nord de la montagne (362), le Ho-wai (363) et le Ho-nei (364), plusieurs dizaines de grandes préfectures, plusieurs centaines de places renommées. Tel a donc été le désastre, alors que $T s$ 'in se trouvait (encore) dans le Ho-si, et que (la capitale de) $T s$ 'in était à mille $l i$ de Ta-leang. A combien plus forte raison, lorsque vous aurez laissé $T s$ 'in supprimer Han et posséder le territoire de Tcheng (365), lorsque vous n'aurez plus le Fleuve et les montagnes pour faire une barrière, ni Tcheou et Han pour vous séparer de lui, et lorsqu'il ne sera plus qu'à cent $l i$ de Ta-leang, le malheur viendra-t-il sûrement de là. Autrefois, si la ligue tsong ne réussit pas, c'est parce que Tch'ou et Wei se soupçonnaient et que Han ne put pas être gagné ; or maintenant Han souffre de la guerre depuis trois années ; Ts'in le

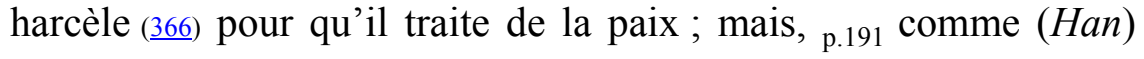
sait que ce serait sa perte, il s'y refuse ; après avoir livré des otages à Tchao, il le prie de former l'empire comme un vol d'oies sauvages (367) et d'émousser le tranchant (de ses épées) (368); Tch'ou et Tchao ne manqueront pas de rassembler leurs soldats, car ils savent bien tous que les appétits de $T s^{\prime}$ in n'ont pas de limites, et qu'il n'aura pas de cesse aussi longtemps qu'il n'aura pas entièrement supprimé les royaumes de l'empire et qu'il ne se sera pas asservi tout ce qui est à l'intérieur des mers; c'est pourquoi je désire mettre la ligue tsong au service de Votre Majesté ; ô roi, hâtez-vous d'accepter le pacte que vous proposent Tch'ou et Tchao; puisque Tchao tient entre ses mains les otages de Han, si vous réclamez (à Han) votre ancien territoire en offrant à Han de le sauver, Han ne manquera pas de vous le remettre : de cette façon, sans que vos soldats ni votre peuple aient eu à endurer des fatigues, vous aurez recouvré votre ancien territoire ; ce sera un acte bien plus méritoire que de vous allier à $T s$ 'in pour combattre Han avec lui, et surtout que d'avoir causé la calamité de faire du puissant $T s$ 'in votre voisin. Pour sauver Han, assurer la tranquillité à Wei et être profitable à tout l'empire, il y a là d'ailleurs pour Votre Majesté une occasion qui lui est fournie par le Ciel. Mettez en communication le Chang-tang (369), qui appartient à Han, avec Kong (370) p.192 et Ning (371) et faites que le chemin aille à Ngan-tch'eng (372); à l'entrée et à la sortie (de cette route) imposez des taxes; par ce moyen, Wei aura pris sur Han un gage important qui ne sera autre que son territoire de Chang-tang; (en outre), dès 
maintenant les taxes suffiront à enrichir vos royaumes (곡); Han ne manquera pas d'être reconnaissant envers Wei, d'aimer Wei, d'apprécier hautement $W e i$, de craindre Wei; Han certainement n'osera pas se tourner contre Wei, et, de la sorte, Han sera comme une préfecture de Wei. Quand Wei aura réussi à faire de Han une de ses préfectures, Wei [b], Ta-leang et le Ho-wai jouiront assurément du calme. Si maintenant (au contraire) vous ne sauvez pas Han, les deux Tcheou et Ngan-ling seront nécessairement en péril ; Tch'ou et Tchao subiront de grandes défaites ; Wei [b] et $T S$ ' $i$ auront tout à craindre ; l'empire (alors) se tournera du côté de l'ouest et accourra vers $T s^{\prime}$ 'in; il ira lui rendre hommage et deviendra son sujet avant qu'il soit longtemps .]

p.193 La vingtième année (257), Ts 'in assiégea Han-tan (374). Ou-ki, prince de Sin-ling, usant de fraude, enleva au général Tsin $P i$ ses soldats pour secourir Tchao (375). Tchao put ainsi être sauvé, et $O u-k i$, à la suite de cela, resta dans le pays de Tchao. - La vingt-sixième année (251) (376), le roi Tchao, de $T$ s'in, mourut. — La trentième année (247), Ou-ki revint dans le pays de $W e i$. A la tête des soldats des cinq royaumes, il attaqua $T s$ 'in, le battit dans le Ho-nei (377) et mit en fuite (son général) Mong Ngao. Tseng, héritier présomptif de $W e i$, se trouvait en otage dans le pays de $T s^{\prime}$ 'in; (le roi de) $T s$ 'in, dans sa colère, p.194 voulut jeter en prison Tseng, héritier présomptif de $W e i$. Quelqu'un intercéda en faveur de Tseng auprès du roi de $T$ s'in en ces termes (378) :

- Kong-suen $\mathrm{Hi}$ a insisté auprès du conseiller de Wei en lui disant :

- Je vous demande de vous servir (des troupes) de Wei pour attaquer promptement $T s^{\prime}$ 'in; le roi de $T s$ 'in sera irrité et ne manquera pas de jeter Tseng en prison; le roi de Wei à son tour se fâchera ; il attaquera $T s$ 'in et $T s^{\prime}$ 'in certainement en souffrira.

Si donc maintenant, ô roi, vous emprisonnez Tseng, ce sera la réussite du plan de (Kong-suen) $\mathrm{Hi}$; par conséquent il vaut mieux traiter avec honneur Tseng et vous unir à Wei pour rendre ce dernier suspect à $T S^{\prime} i$ et à Han.

(Le roi de) $T s$ 'in renonça alors à (son projet d'emprisonner) Tseng. - La trente et unième année (246), le roi de Ts'in, Tcheng (379), monta sur le trône. - La trente-quatrième année (243), le roi Ngan-hi mourut. L'héritier présomptif Tseng prit le pouvoir ; ce fut le roi King-min. Ou-ki, prince de Sinling, mourut.

La première année (242) du roi King-min, Ts 'in nous prit vingt villes qu'il annexa au royaume de $T s^{\prime}$ in sous le nom de commanderie Tong (380). La deuxième année (241), Ts'in nous prit Tchao-ko (381); (le prince de) Wei [b] p.195 se transporta à Ye-wang (282). - La troisième année (240), Ts 'in prit notre (ville de) $K i(\underline{383})$. - La cinquième année (238), Ts'in prit nos (villes de) 
Yuen (여), P'ou-yang (385) et Yen (386). - La quinzième année (228), le roi King-min mourut. Son fils, Kia, roi, prit le pouvoir.

La première année (227) de Kia, roi, l'héritier présomptif de Yen, Tan, chargea King K'o d'assassiner le roi de $T$ s'in (387); le roi de $T s^{\prime}$ 'in s'aperçut (des intentions) de King $K^{\prime} O$. La troisième année (225), Ts'in inonda Ta-Leang et fit prisonnier Kia, roi ; il anéantit alors (le royaume de) Wei dont il fit des commanderies et des préfectures.

Le duc grand astrologue dit: Je suis allé sur p.196 l'emplacement de l'antique Ta-leang. Les gens qui demeuraient sur cet emplacement me dirent : Lorsque $T s$ 'in détruisit Leang, il amena une dérivation du Ho (388) et inonda Ta-leang ; au bout de trois mois les remparts s'effondrèrent; le roi demanda à se soumettre et alors on anéantit (le royaume de) Wei. — Les discoureurs disent tous : C'est parce que Wei ne sut pas se servir du prince de Sin-ling (389) que son royaume fut amoindri et affaibli et finit par disparaître. Pour moi, je ne partage pas cette opinion; le Ciel avait justement alors ordonné à $T s$ 'in de conquérir (tout le pays compris à) l'intérieur des mers; tant que sa tâche n'avait pas encore été entièrement exécutée, même l'appui d'un Ngo-heng (390), de quelle utilité aurait-il pu être à Wei ? 


\title{
CHAPITRE XLV
}

\author{
QUINZIÈME MAISON HÉRÉDITAIRE \\ $H A N_{(101)}$
}

p.197 L'ancêtre des Han appartenait au clan des ${ }_{\text {p.198 }}$ Tcheou (102); son nom de clan était $K i$. Plus tard, un de ses descendants fut au service de $T \sin$ et obtint en fief Han-yuen (103); il s'appelait Han Ou-tse. Trois générations après (Han) Ou-tse, il y eut Han Kiue (104); il tira de son fief son nom de famille et

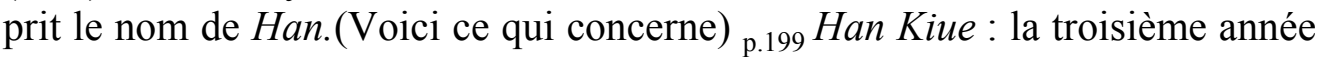
(597), du duc King, de Tsin, le ministre de la justice de Tsin, T'ou-ngan Kou, voulut susciter des troubles en mettant à mort Tchao Toen, assassin du duc Ling (105) ; Tchao Toen étant déjà mort, il désira faire périr son fils, Tchao Cho ; Han Kiue (chercha à) détourner (T'ou-ngan) Kou de ce projet, mais ne fut pas écouté par lui. (Han) Kiue dit à Tchao Cho:

— On a décidé votre perte.

(Tchao) Cho répliqua :

- Si vous pouvez certainement faire en sorte que les sacrifices de (la famille) Tchao ne soient pas interrompus, je ne regretterai pas de mourir (106).

Han Kiue prit cet engagement. Puis, quand (T'ou-ngan) Kou extermina la famille Tchao, (Han) Kiue prétexta une maladie et ne sortit plus. Lorsque Tch'eng Yng et Kong-suen Tch'ou-kieou cachèrent Tchao Ou, l'orphelin de (la famille) Tchao, (Han) Kiue le sut (107). - La onzième année (589) du duc King, (Han) Kiue, étant avec Ki K'o à la tête de huit cents chars de guerre, attaqua $T s$ ' $i$ et battit le duc King, de $T s$ ' $i$, à $\operatorname{Ngan~(108)}$; il fit prisonnier Fong Tch'eou-fou (109). Alors (le prince de) Tsin institua six hauts dignitaires et Han Kiue occupa une de ces positions de haut dignitaire. Son appellation était Hien-tse. - La dix-septième année (583) de son règne, le duc King, de Tsin, tomba malade ; les sorts consultés dirent que la cause du mal (110) provenait de ceux qui, ayant accompli une grande œuvre, n'étaient pas satisfaits. p.200 Han Kiue parla des actions d'éclat de Tchao Tch'eng-ki (111) qui maintenant n'avait pas de descendant pour lui offrir des sacrifices, et, ainsi, émut le duc King; le duc King lui demanda :

- Existe-t-il encore des représentants de cette famille?

(Han) Kiue parla alors de Tchao Ou (112) et on restitua à la famille Tchao les terres et les villes qui lui avaient appartenu autrefois, pour qu'elle continuât les sacrifices de la famille Tchao. - La dixième année (563) du duc Tao, de Tsin, Han Hien-tse mourut de vieillesse. Son fils, Siuen-tse, lui succéda. 
(Han) Siuen-tse transféra sa résidence à Tcheou (113). - La quatorzième année (543) du duc P'ing, de Tsin, Ki-tcha, du pays de $O u$, vint en mission dans le pays de $T \sin$ et dit :

- Le gouvernement du royaume de $T \sin$ reviendra en définitive à Han, à Wei et à Tchao (114).

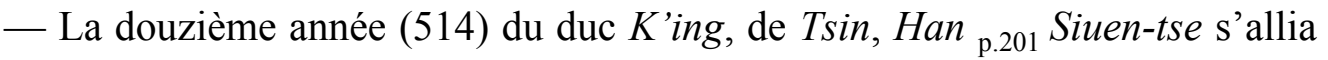
avec Tchao et $W e i$ et ils se partagèrent entre eux les dix préfectures qui appartenaient aux familles $K^{\prime} i$ et Yang-cho. - La quinzième année (497) du duc Ting, de Tsin, (Han) Siuen-tse s'allia avec Tchao Kien-tse pour dépouiller et punir les familles Fan et Tchong-hang. — (Han) Siuen-tse mourut (115) ; son fils (Han) Tcheng-tse lui succéda.

(Han) Tcheng-tse transféra sa résidence à P'ing-yang(116). Tcheng-tse mourut; son fils, (Han) Kien-tse lui succéda. - Kien-tse mourut; son fils (Han) Tchoang-tse lui succéda. - Tchoang-tse mourut; son fils (Han) $K^{\prime}$ 'ang-tse lui succéda. (Han) K'ang-tse s'allia à Tchao Siang-tse et à Wei Hoan-tse, et ensemble ils vainquirent Tche po (453) et se partagèrent ses territoires; leurs propres territoires en furent augmentés et devinrent aussi grands que ceux des seigneurs. - K'ang-tse mourut; son fils (Han) Ou-tse lui succéda. - La deuxième année (423) de son règne, (Han) Ou-tse attaqua Tcheng et tua son prince, le duc Yeou (117). - La seizième année (409), (Han) Ou-tse mourut. Son fils, qui fut le marquis King, prit le pouvoir.

p.202 La première année (408) de son règne, K'ien, marquis King, attaqua Tcheng et lui prit (la ville de) Yong-k'ieou (118). — La deuxième année (407), Tcheng nous battit à Fou-chou (119). - La sixième année (403), (Han), en même temps que Tchao et Wei obtinrent ensemble d'être mis au rang des seigneurs. - La neuvième année (400), Tcheng assiégea notre (ville de) Yang-ti (120). - Le marquis King mourut. Son fils, $T s$ 'iu, qui fut le marquis Lie, prit le pouvoir.

La troisième année (397) du marquis Lie, Nie Tcheng tua Hie-lei, conseiller de Han (121). - La neuvième année (391), Ts'in attaqua notre (ville de) I-yang (122) et s'empara de six places. — La treizième année (387), le marquis ${ }_{\text {p.203 }}$ Lie mourut; son fils, qui fut le marquis Wen, monta sur le trône. Cette même année, le marquis $W e n$, de $W e i$, mourut.

La deuxième année (385) de son règne, le marquis Wen attaqua Tcheng et prit Yang-tch'eng (123). Il attaqua Song, arriva jusqu'à $P$ 'ong-tch'eng (124) et se saisit du prince de Song. — La septième année (380), il attaqua Ts' $i$ et arriva jusqu'à Sang-k'ieou (125). - Tcheng se révolta contre Ts'in. - La neuvième année (378), (Han) attaqua $T s^{\prime} i$ et arriva jusqu'à Ling-k'ieou (126). - La dixième année (377), le marquis Wen mourut. Son fils, qui fut le marquis Ngai, monta sur le trône.

La première année (376) du marquis Ngai, (Han) ainsi que Tchao et Wei se partagèrent le royaume de $T \sin ($ (127). - La deuxième année (375), (Han) 
anéantit Tcheng (128), et, à la suite de cela, il transporta sa capitale à Tcheng (129). - La sixième année (371), Han Yen (130) assassina son prince, le marquis Ngai ; le fils de ce dernier, qui fut le marquis $I(131)$, monta sur le trône.

p.204 La deuxième année (369) du marquis $I$, Wei nous battit à Ma-ling (132). - La cinquième année (366), le marquis $I$, eut une entrevue avec le roi Hoei, de Wei, à Tchai-yang (133). — La neuvième année (362), Wei nous battit (sur les bords de la rivière) Koai. — La douzième année (359), le marquis $I$ mourut. Son fils, qui fut le marquis Tchao, monta sur le trône.

La première année (358) du marquis Tchao, Ts 'in nous battit à Si-chan. La deuxième année (357), Song prit notre (ville de) Hoang-tch'e (134). Wei nous prit Tchou. — La sixième année (353), Han attaqua les Tcheou orientaux et leur prit Ling-koan (135) et Hing-k'ieou (136). - La huitième année (351), Chen Pou-hai devint conseiller de Han (137); il mit en honneur les bonnes méthodes et ${ }_{\text {p.205 }}$ marcha dans la voie vertueuse (138); le royaume à l'intérieur se trouva ainsi bien gouverné ; les seigneurs ne vinrent plus l'envahir ou le combattre. - La dixième année (349), Han I (139) assassina son prince le duc Tao. - La onzième année (348), le marquis Tchao se rendit dans le pays de Ts'in. - La vingt-deuxième année (337), Chen Pou-hai mourut. - La vingt-quatrième année (355), Ts'in vint s'emparer de notre (ville de) Iyang (140). - La vingt-cinquième année (334), il y eut une sécheresse. (Le marquis Tchao) fit construire la Porte Haute. K'iu I-kieou (141) dit :

- Le marquis Tchao ne sortira pas par cette porte. Pourquoi cela ? Parce que ce n'était pas le moment (de la construire.) Quand je parle du moment, il ne s'agit pas de l'époque et du jour; mais pour les hommes, il y a certainement les moments avantageux et les moments désavantageux. Le marquis Tchao a eu auparavant des moments avantageux, mais il n'a point fait construire la Porte Haute. L'année dernière, $T$ s'in lui a pris $I$-yang; cette année, il y a une sécheresse ; or le marquis Tchao, en un tel moment, n'a pas compassion de la détresse de son peuple et ne songe qu'à p.206 augmenter ses prodigalités ; de cela on peut dire que c'est en temps défavorable entreprendre des choses excessives.

La vingt-sixième année (333), la Porte Haute fut achevée ; le marquis Tchao mourut, et, en effet, il ne sortit point par cette porte. Son fils, qui fut le roi Siuen-hoei, monta sur trône.

La cinquième année (328) du roi Siuen-hoei, Tchang I devint conseiller de Ts 'in. - La huitième année (325), Wei battit notre général Han Kiu (142). La onzième année (322), le prince prit le titre de roi (143). Il eut une entrevue avec Tchao à Kiu-chou (144). - La quatorzième année (319), Ts'in attaqua et soumit notre (ville de) Yen (145). - La seizième année (317), Ts'in nous battit à Sieou-yu; il fit prisonnier le général de Han, Cheou Chen-tch'a, à Tchouo- 
tse (146). [(147) La maison de Han se trouva en péril ; Kong-tchong (148) p.207 dit au roi de Han :

- Les royaumes alliés (149), nous ne pouvons mettre en eux notre confiance. Maintenant, il y a longtemps que $T s$ 'in désire attaquer Tch'ou. Le mieux serait, ô roi, que vous vous serviez de Tchang I pour vous mettre en bonne intelligence avec $T s$ 'in, que vous gagniez l'amitié (de $T s^{\prime}$ in) par le don d'une ville importante, et que de concert avec lui vous attaquiez au Sud Tch'ou; c'est là un procédé qui vous permettra d'échanger un contre deux.

Le roi de Han approuva ce discours et avertit Kong-tchong d'avoir à se tenir prêt à partir pour aller dans l'ouest négocier avec $T s$ 'in. Le roi de $T c h$ 'ou (150) l'apprit et en fut fort irrité; il appela auprès de lui Tch'en Tchen pour l'informer (de ce qui se passait); Tch'en Tchen lui dit :

- Il y a déjà longtemps que $T s^{\prime}$ in désire attaquer Tch'ou. Maintenant si, en outre, il obtient de Han une ville importante et des soldats tout équipés (151) et si $T s$ 'in et Han réunissent leurs forces militaires pour attaquer Tch'ou, c'est là ce que $T s^{\prime}$ 'in souhaitait dans ses prières et ses sacrifices (aux dieux). Quand il aura obtenu cela, Tch'ou sera certainement attaqué. Ô roi, si vous suivez mes conseils pour arranger cette affaire, vous avertirez (la population) sur toute l'étendue ${ }_{\text {p.208 }}$ de votre territoire que vous levez des troupes, en disant que c'est pour secourir Han ; vous ordonnerez que les chars de combat couvrent les routes; vous enverrez un ambassadeur (152) en multipliant les chars mis à sa disposition et en augmentant les présents dont il sera chargé, pour faire que (le roi de Han) croie que les secours de Votre Majesté sont déjà partis. Même si Han ne peut pas vous obéir (153), il ne manquera pas cependant d'être reconnaissant envers Votre Majesté ; certainement il ne viendra plus ici en se mettant à la suite (de $T s$ 'in) comme les oies sauvages dans leur vol (154); ainsi $T s^{\prime}$ 'in et Han ne seront plus d'accord. Même quand les hostilités nous atteindront, Tch'ou n'en souffrira pas beaucoup. Si (Han) peut vous obéir (155) et rompt ses bons rapports avec $T s$ 'in, $T s$ 'in en sera certainement fort irrité et en concevra un grand ressentiment contre Han. Han étant au sud en relations avec Tch'ou, fera peu de cas de $T S$ 'in; faisant peu de cas de $T s^{\prime}$ 'in, lorsqu'il répondra à ses demandes, il lui manquera d'égard. Ainsi vous profiterez des hostilités entre $T s$ 'in et Han pour sauver du ${ }_{\text {p.209 }}$ péril le royaume de Tch'ou.

Le roi de Tch'ou approuva (ce conseil) ; alors il répandit des avertissements sur toute l'étendue de son territoire pour lever des troupes en disant que c'était pour secourir Han; il ordonna aux chars de combat de couvrir les routes ; il envoya un ambassadeur en multipliant les chars mis à sa disposition et en 
augmentant les présents dont il était chargé, et dit (par son entremise) au roi de Han :

- Quoique le royaume de moi, pauvre prince (156), soit petit, je l'ai mis tout entier sur le pied de guerre; je désire que votre grand royaume fasse tout ce qu'il veut à l'égard de $T s^{\prime}$ in ; moi, pauvre prince, je me propose avec (mon royaume de) Tch'ou, de suivre Han jusque dans la mort.

En entendant ces paroles, le roi de Han fut très content et contremanda le départ de Kong-tchong. Kong-tchong lui dit:

- Vous avez tort. En effet, celui qui réellement nous attaque, c'est $T s$ 'in ; celui qui prétend faussement nous secourir, c'est Tch'ou. Si, ô roi, vous vous fiez aux vaines promesses de Tch'ou et si vous rompez à la légère avec le puissant $T s$ 'in qui est votre ennemi, vous deviendrez un sujet de grande risée pour l'empire. D'ailleurs Tch'ou et Han ne sont point des royaumes fraternels ; bien plus il n'y a pas entre eux de conventions anciennes par lesquelles ils aient projeté de combattre p.210 Ts'in. C'est parce qu'il y a apparence pour lui-même d'une attaque prochaine que (Tch'ou) lève des troupes en disant qu'il veut secourir Han. C'est là certainement un stratagème de Tch'en Tchen. En outre, ô roi, vous avez déjà envoyé des gens pour annoncer à $T s$ 'in vos intentions; si maintenant je ne pars pas, ce sera tromper $T$ s 'in. Si vous trompez à la légère le puissant $T s^{\prime}$ in et si vous ajoutez foi aux machinations de Tch'ou, je crains que Votre Majesté n'ait certainement à s'en repentir.

Le roi de Han ne l'écouta pas et rompit aussitôt avec $T$ s'in. Ts 'in en fut fort irrité ; il augmenta le nombre de ses soldats pour attaquer Han et lui livra une grande bataille; aucun secours de Tch'ou ne vint à Han]. La dix-neuvième année (314), (Ts'in) nous fit essuyer une grande défaite (157) à Ngan-men. Pour obtenir la paix, l'héritier présomptif $T$ s'ang fut envoyé en otage dans le pays de $T$ s'in.

La vingt et unième année (312), (Han) allié à $T s^{\prime}$ in, attaqua Tch'ou; il vainquit le général de Tch'ou, $K^{\prime}$ iu Kai, et coupa quatre-vingt mille têtes au nord de (la rivière) Tan (158). - Cette année-là, le roi Siuen-hoei mourut. L'héritier $_{\text {p.211 }}$ présomptif $T s$ 'ang monta sur le trône ; ce fut le roi Siang (159).

La quatrième année (308) de son règne, le roi Siang eut une entrevue avec le roi $O u$, de $T s$ 'in, à $\operatorname{Lin}$-tsin (160). En l'automne de cette année, $T s$ 'in envoya Kan Meou attaquer notre (ville de) I-yang (161). — La cinquième année (307), $T s$ 'in prit notre (ville de) I-yang et coupa soixante mille têtes. Le roi $O u$, de $T s$ 'in mourut. - La sixième année (306), $T s$ 'in nous rendit (la ville de) $\mathrm{Ou}$ soei (162). - La neuvième année (303), Ts'in nous reprit (la ville de) Ou-soei. - La dixième année (302), l'héritier présomptif Yng alla rendre hommage à 
$T s^{\prime}$ in, puis revint (163). - La onzième année (301), Ts'in nous attaqua et prit (la ville de) Jang (164). (Han), allié à $T s$ 'in, attaqua Tch'ou et vainquit le général de Tch'ou, T'ang Mei (165).

La douzième année (300), l'héritier présomptif Yng mourut (166). Le kongtse Kieou et le kong-tse Ki-che (167) se p.212 disputèrent le titre d'héritier présomptif. En ce temps, Ki-che se trouvait en otage dans le pays de Tch'ou. [(168) Sou Tai (169) dit à Han Kieou (170) :

- Ki-che s'est enfui dans le pays de Tch'ou et le roi de Tch'ou a un vif désir de le faire rentrer (ici). Maintenant, les soldats de Tch'ou au nombre de plus de cent mille sont au delà de Fang-tch'eng (171). Ô prince, pourquoi n'invitez-vous pas le roi de Tch'ou à construire une ville de dix mille habitations à côté de Yong-che (172) ? (Le roi de) Han ne manquera pas de lever des p.213 soldats afin de secourir (173) (Yong-che); vous serez certainement mis à leur tête; alors vous vous servirez des soldats de Han et de ceux de Tch'ou pour les mettre au service de $\mathrm{Ki}$-che et pour faire rentrer ici ce dernier. (Ki-che) vous obéira certainement et ne manquera pas de vous donner des fiefs dans les pays de Tch'ou et de $\operatorname{Han}$ (174).]

Han Kieou suivit cet avis ; Tchou assiégea Yong-che.

[(175) Han demanda des secours à $T s^{\prime}$ 'in. Ts 'in ne les avait pas encore fait partir, lorsqu'il envoya Kong-suen Mei (176) dans le pays de Han. Kong-tchong lui dit :

- Pensez-vous que $T s^{\prime}$ in se dispose à secourir Han ?

(Kong-suen Mei) répondit :

- Le roi de $T S$ ' in a tenu ce langage :

« Je me propose de passer par Nan-tcheng (177) et Lan-tien (178) pour p.214 faire sortir mes troupes dans le pays de Tch'ou en vous attendant. "

Mais il semble qu'il y ait là une contradiction (179).

Kong-tchong lui demanda :

- Pensez-vous qu'il en soit réellement ainsi ?

(Kong-suen Mei) répondit :

- Le roi de $T S$ 'in met assurément en honneur l'ancienne sagesse de Tchang $I(\underline{180})$. (Autrefois en effet), quand le roi Wei, de Tch'ou, attaqua Leang (181), Tchang I dit au roi de $T s$ 'in :

- Si vous vous alliez à Tch'ou pour combattre Wei, Wei se tournera brusquement et se rendra à Tch'ou; comme d'ailleurs Han est depuis longtemps l'allié (de Wei), Ts'in se trouvera ainsi isolé. Mieux vaut faire sortir vos soldats pour tromper (182) $(\mathrm{Wei})$. 
Wei et $T c h$ 'ou se livrèrent une grande bataille et $T s^{\prime}$ in se retira après s'être emparé du territoire extérieur au Si-ho (183). Or p.215 maintenant voici quelle est la situation : ( $\left.T s^{\prime}{ }^{\prime} i n\right)$ en apparence se dit l'allié de Han, mais en réalité il est secrètement en excellents rapports avec Tch'ou. Comme vous croirez à tort que vous pouvez vous attendre à $T s^{\prime}$ in, vous ne manquerez pas d'engager à la légère les hostilités contre Tch'ou; Tch'ou, (de son côté), ayant obtenu secrètement que $T s^{\prime}$ in ne vous rendrait aucun service, vous tiendra tête volontiers. Si, lorsque la bataille se livrera, vous êtes vainqueur de Tch'ou, alors (Ts'in) profitera avec vous de (la victoire remportée sur) Tch'ou, se glorifiera (184) dans le San-tch'oan et s'en retournera. Si, lorsque la bataille se livrera, vous n'êtes pas vainqueur de Tch'ou, Tch'ou vous fermera le San-tch'oan et y tiendra garnison sans que vous puissiez y porter remède. A mon avis, cela sera funeste pour vous. Se-ma Keng (185) est p.216 allé par trois fois à Yng (186); Kan Meou (187) s'est rencontré à Chang-yu (188) avec Tchao $Y u(189)$; il a prétendu que c'était pour recevoir un sceau (190); en réalité (tout s'est passé), comme si il y avait eu un traité conclu (191).

Kong-tchong effrayé dit :

— Mais alors que faut-il faire?

(Kong-suen $\mathrm{Mei}$ ) répondit :

- Mettez au premier rang Han, et au second Ts'in; préoccupez-vous d'abord de vous-même et ensuite de Tchang $I$ (192). Le mieux est pour vous de faire au plus vite la paix entre votre royaume et $T s^{\prime} i$ et $T c h$ 'ou ; Ts' $i$ et $T c h$ 'ou ne manqueront pas de vous confier la direction de votre royaume. Ce que vous n'aurez pas aimé, c'est Tchang I, et en réalité vous n'aurez pas manqué (de l'appui) de $T s$ 'in (193).]

Alors Tch'ou leva le siège de Yong-che.

p.217 Sou Tai dit encore à Mi Jong (194), frère cadet de la reine-mère (195) de Ts'in :

- [(196) Kong-chou Po-yng (197) craint que Ts'in et Tch'ou ne fassent rentrer $K i$-che (dans le pays de Han). Pourquoi ne réclamez-vous pas au nom de Han l'otage (198) qu'il a donné à Tch'ou ? Si le roi de Tch'ou consent à livrer cet otage à Han (199), alors Kong-chou Po-yng reconnaîtra que Ts'in et Tch'ou ne veulent pas lui faire des embarras en se servant de $K i$-che et il fera de Han p.218 l'ami de Ts'in et de Tch'ou; Ts'in et Tch'ou profiteront de Han pour réduire Wei à l'extrémité ; le prince de Wei n'osera plus s'allier à $T s$ ' $i$ et $T s$ ' $i$ se trouvera isolé. Vous pourriez encore réclamer au nom de $T$ s'in l'otage (que Han a donné) à Tch'ou (200); 
si Tch'ou ne vous écoute pas, il s'attirera la haine de Han ; Han profitera de $T s$ ' $i$ et de Wei pour assiéger Tch'ou, (et alors) Tch'ou vous tiendra certainement en haute estime (201). Jouissant ainsi de l'estime de $T s$ 'in et de Tch'ou, vous pourrez en profiter pour rendre de nombreux services à Han; Kong-chou Po-yng ne manquera pas de mettre tout son royaume à votre service.

Alors $\mathrm{Ki}$-che en définitive ne put pas revenir dans le pays de Han et Kieou fut nommé héritier présomptif de Han.- Les rois de $T s$ ' $i$ et de $W e i$ vinrent (dans le pays de Han).

La quatorzième année (298), (le roi de Han), avec les rois de $T s$ ' $i$ et de Wei, attaquèrent $T s^{\prime}$ 'in ; ils arrivèrent à (la passe) Han-kou et y campèrent. La seizième année (296), Ts'in nous donna le Ho-wai (202), ainsi que (la ville de) Ou-soei (203). - Le roi Siang mourut. L'héritier ${ }_{\text {p.219 }}$ présomptif Kieou monta sur le trône ; ce fut le roi $H i$ (204).

La troisième année (293), le roi Hi chargea Kong-suen Hi de marcher à la tête (des troupes) de Tcheou et de Wei pour attaquer $T s$ ' $i$. Ts'in vainquit notre armée de deux cent quarante mille hommes (205) et fit prisonnier (Kong-suen) $H i$ à $I-k$ 'iue (206). - La cinquième année (291), Ts'in prit notre (ville de) Yuan (207). - La sixième année (290), (Han) donna à Ts'in (la ville de) Ousoei (208) avec deux cents $l i$ de territoire. - La dixième année (286), Ts'in battit nos soldats à Hia-chan. - La douzième année (284), (le roi de Han) eut une entrevue avec le roi Tchao, de Ts'in, dans (la ville des) Tcheou occidentaux (209), puis il aida $T s^{\prime}$ 'in à attaquer $T s^{\prime} i$; $T s^{\prime} i$ fut battu ; le roi Min sortit (de son royaume) et s'enfuit. - La quatorzième année (282), (le roi de Han) eut une entrevue avec (le roi de) $T s$ 'in dans l'intervalle compris entre les deux Tcheou (210). - La vingt et unième année (275), (le roi de ${ }_{\text {p.220 Han) }}$ envoya Pao Yuen au secours de Wei, mais, battu par Ts'in, (Pao) Yuen s'enfuit à $K^{\prime}$ ai-fong (211).

La vingt-troisième année (273), Tchao et Wei nous attaquèrent à Hoa-yang (212). Han informa $T s$ 'in du péril où il se trouvait, mais [(213) $T s$ 'in ne venait point à son secours. Le conseiller de Han dit à Tch'en Che (214) :

- La situation est périlleuse ; je désire que, quoique vous soyez malade, vous fassiez un voyage d'une étape (215).

Tch'en Che alla voir le marquis de Jang (216); celui-ci lui dit :

- La situation est donc bien périlleuse pour qu'on vous ait chargé de venir ici?

Tch'en Che répliqua :

- Elle n'est pas encore périlleuse.

- S'il en est ainsi, repartit le marquis de Jang, comment puis-je vous considérer comme un ambassadeur officiel (217) ? En effet (les ambassadeurs de Han) qui viennent dire que leur pauvre pays est 
fort menacé (se succèdent en si grand nombre) qu'ils aperçoivent de loin (sur la route) les dais et les bonnets officiels les uns des autres. Comment peut-il se faire ${ }_{p .221}$ que vous veniez dire qu'il n'y a pas encore de péril ?

Tch'en Che répondit :

- Si Han était en péril, il se disposerait à changer de politique et à suivre un autre (maître) (218); c'est parce qu'il n'est pas encore en péril qu'il vient encore s'adresser à vous.

Le marquis de Jang dit :

- N'allez pas voir le roi (219). Je me permettrai de donner l'ordre d'envoyer des soldats au secours de Han.

Dans un délai de huit jours, (ces renforts) arrivèrent et firent essuyer une défaite à Tchao et à Wei sous les murs de Hoa-yang.]

Cette année-là (273), le roi Hi mourut. Son fils, qui fut le roi Hoan-hoei, monta sur le trône. - La première année de son règne (272), le roi Hoan-hoei attaqua Yen. - La neuvième année (264), Ts'in prit notre (ville de) Hingtch'eng (220) qui était sur le bord de (la rivière) Fen. - La dixième année (263), Ts'in nous attaqua sur (les monts) T'ai-hang (221). Le gouverneur de notre commanderie de Chang-tang fit sa soumission à Tchao en lui livrant la commanderie de Chang-tang (222). - La quatorzième année (259), Ts'in conquit le Chang-tang qui appartenait à Tchao et tua plus de quatre cent mille

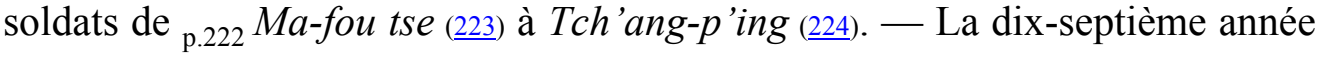
(256), Ts'in nous prit (la ville de) Fou-chou (225), (près de) Yang-tch'eng. La vingt-deuxième année (251), le roi Tchao de $T s^{\prime}$ 'in mourut. - La vingt-quatrième année (249), Ts'in nous prit (les villes de) Tch'eng-kao (226) et Yong-yang (227). - La vingt-sixième année (247), Ts'in nous enleva entièrement le Chang-tang (228). - La vingt-neuvième année (244), Ts'in nous prit treize villes. - La trente-quatrième année (239), le roi Hoan-hoei mourut. Son fils, Ngan, roi, monta sur le trône.

La cinquième année (234) de Ngan, roi, Ts'in attaqua Han. Han, se trouvant en péril, envoya $\mathrm{Han} F e i$ en mission dans le pays de $T s^{\prime}$ 'in ; $T$ s'in retint (Han) Fei (229), puis le mit à mort. — La neuvième année (230), Ts 'in fit prisonnier Ngan, roi, et s'annexa entièrement son territoire dont il fit la commanderie de Yng-tch'oan. Ainsi finit (le royaume de) Han.

Le duc grand astrologue dit : Lorsque Han Kine émut ${ }_{\text {p.223 }}$ le duc King, de $T \sin$, lorsqu'il fit succéder à ses ancêtres $O u$, l'orphelin de la famille Tchao, et lorsqu'il fit triompher ainsi la conduite intègre de Tch'eng Yng et de Kongsuen Tch'ou-kieou, il accomplit là une action qui devait avoir une vertu secrète dans le monde ; on ne voit point que la gloire de la famille Han dans le 
pays de $T \sin$ ait été grande; en définitive cependant les Han devinrent seigneurs aussi bien que les Tchao et les Wei ; cela leur était bien dû (230) ! 


\title{
CHAPITRE XLVI $(101)$
}

\author{
SEIZIÈME MAISON HÉRÉDITAIRE \\ T'IEN KING-TCHONG WAN (102)
}

p.224 Tch'en Wan (103) était le fils de T'o, duc $L i$, de Tch'en. A la naissance de Wan (705) le grand astrologue des Tcheou ayant passé par (le pays de) Tch'en, le duc $L i$, de Tch'en, p.225 le chargea de consulter les sorts au sujet de Wan; dans les hexagrammes il obtint koan combiné à $p$ ' $i$ :

- Cela donne : Contempler l'éclat d'un royaume. Il est avantageux d'être un hôte auprès d'un roi. Cela signifie que cet (enfant), au lieu de Tch'en, aura un royaume ; ce ne sera pas ici, mais dans un royaume étranger ; ce ne sera pas à cet (enfant) en personne, mais c'est à ses descendants (qu'écherra ce royaume). Quant au fait que ce sera dans un royaume étranger, ce sera certainement (dans un royaume dont) le nom de clan est Kiang; le clan Kiang est celui des descendants (du chef) des quatre montagnes. Il n'est rien qui puisse être grand en deux endroits à la fois ; quand Tch'en tombera en décadence, c'est alors que celui-ci deviendra florissant (104).

Le duc $L i$ était le fils cadet du duc Wen, de Tch'en; sa mère était une fille (du prince) de $T s^{\prime} a i$ (105). A la mort du duc Wen (745), Pao, frère aîné du duc $L i$, prit le pouvoir ; ce fut le duc Hoan. Le duc Hoan était né d'une autre mère que $T$ 'o ; aussi, lorsque le duc Hoan tomba malade, les gens de $T s$ 'ai, agissant en faveur de T'o, tuèrent Pao, duc Hoan (707), ainsi que l'héritier présomptif Mien, et mirent ainsi sur le trône T'o qui fut le duc $L i$ (106). Quand le duc $L i$ fut monté sur le trône, il épousa une fille (du prince) de $T s^{\prime} a i$; cette fille de $T s$ ' $a i$ se livrait à la débauche avec des gens de $T s$ 'ai et retourna plusieurs fois (dans son pays); le duc $L i$, lui aussi, se rendit à plusieurs reprises dans le pays de Ts'ai. Lin, fils cadet du ${ }_{\text {p.226 }}$ duc Hoan, était irrité de ce que le duc $L i$ avait fait périr son père et son frère aîné : il invita donc des gens de $T$ s'ai à attirer le duc Li dans une embûche et à le tuer (700). Lin s'empara alors du pouvoir ; ce fut le duc Tchoang. C'est ainsi que Tch'en Wan ne put pas monter sur le trône ; il devint un grand officier (ta-fou) du pays de Tch'en. Quand le duc Li fut mis à mort, il était sorti de son royaume pour se livrer à la débauche ; c'est pourquoi le Tch'oen-ts'ieou dit :

— Les gens de $T$ s'ai tuèrent Tch'en T'o.

Ainsi il l'incrimine (107). 
A la mort du duc Tchoang (693), on mit sur le trône son frère cadet Tch'ou-kieou qui fut le duc Siuen. La onzième année (682) (108) de son règne, le duc Siuen tua son héritier présomptif Yu-k'eou; Yu-k'eou était l'ami de Wan ; craignant donc que le malheur l'atteignît lui-même, Wan s'enfuit dans le pays de $T s^{\prime} i(109)$. Le duc Hoan, p.227 de $T s^{\prime} i$, voulut le nommer haut dignitaire ; il refusa en disant :

- Moi, qui suis un hôte étranger retenu (en ce lieu), si, par bonheur, j'ai pu éviter d'être accablé (par mes ennemis), c'est grâce à la bienveillance de Votre Altesse; mais je ne saurais remplir un poste élevé.

Le duc Hoan le nomma directeur des artisans. I-tchong, (du pays) de $T s^{\prime} i$ voulut donner (sa fille) en mariage à Wan; il consulta les sorts à ce sujet; l'oracle fut :

« Cela signifie :

Le phénix mâle et le phénix femelle volent ensemble ;

Ils chantent harmonieusement avec un son semblable à celui du jade (110).

«Le descendant de la famille Koei sera nourri dans la famille Kiang (111). A la cinquième génération il sera florissant et il aura le rang d'un haut dignitaire de première catégorie. Après la huitième génération, personne ne sera aussi grand que lui (112).

En définitive (I-tchong) donna en mariage sa fille à Wan. - Quand Wan s'enfuit à $T s$ ' $i$, c'était la quatorzième année (672) du duc Hoan, de $T s$ ' $i$. Wan mourut; son nom posthume fut King-tchong. Il engendra Tche Mong-i (113). Quand King-tchong fut entré ${ }_{\text {p.228 }}$ dans le pays de $T s^{\prime} i$, il changea le caractère de son nom de famille Tch'en en T'ien (114).

T'ien Tche Mong-i engendra (T'ien) Min Mong-tchoang. - T'ien Min Mong-tchoang engendra (T'ien) Wen-tse Siu-ou; T'ien Wen-tse servit le duc Tchoang, de $T s^{\prime} i$. - Un grand officier (du pays) de $T s^{\prime}$ 'in, nommé Loan Yng (115), ayant suscité des troubles dans (le royaume de) Tsin, vint se réfugier (551) dans (le pays) de $T s^{\prime} i$; le duc Tchoang, de $T s$ ' $i$, le traita en hôte de distinction; Yen Yng (116), et T'ien Wen-tse l'en blâmèrent, mais le duc Tchoang ne les écouta pas. - (T'ien) Wen-tse mourut; il avait engendré (T'ien) Hoan-tse Ou-yu.

T'ien Hoan-tse Ou-yu fut un homme fort; il servit le duc Tchoang, de $T s^{\prime} i$, et fut en grande faveur auprès de lui. $O u-y u$ mourut; il avait engendré (T'ien) Ou-tse Kai et T'ien Hi-tse K'i.

\# T'ien Hi-tse $K^{\prime} i$ servit le duc King, de $T$ s' $i$, et fut nommé grand officier ; quand il percevait des redevances et des taxes sur le peuple, il les recevait en se servant d'un ${ }_{\text {p.229 }}$ petit boisseau ; mais quand il donnait du grain au peuple il employait un grand boisseau ; (ainsi) il répandait secrètement des bienfaits sur 
le peuple et le duc King ne l'en empêchait pas; à partir de ce moment, les $T$ 'ien gagnèrent le cœur de la foule dans le pays de $T s$ ' $i$; les membres de cette famille devinrent de plus en plus puissants et le peuple pensait avec affection à la famille T'ien. Yen-tse (117) adressa plusieurs fois des remontrances à ce sujet au duc King, mais le duc King ne les écouta pas ; plus tard (539), (Yen Yng) ayant été envoyé en mission dans le pays de Tsin, eut avec Chou-Hiang un entretien particulier dans lequel il lui dit :

— Le gouvernement du royaume de $T s^{\prime} i$ finira par revenir à la famille T'ien (118).

Après la mort de Yen Yng, les (chefs des familles) Fan et Tchong-hang se révoltèrent contre (le duc de) $T \sin (\underline{119})$. (Le duc de) $T \sin$ les ayant attaqués avec vigueur, ils demandèrent du grain à $T s^{\prime} i$ (493). T'ien $K i$, qui désirait fomenter une rébellion et se créer un parti parmi les seigneurs (120), conseilla donc le duc King en ces termes :

- Fan et Tchong-hang ont à plusieurs reprises bien mérité de $T s^{\prime} i ; T s^{\prime} i$ ne peut pas se dispenser de les secourir.

(Le duc de) ${ }_{\text {p.230 }} T s^{\prime} i$ chargea $T$ 'ien $K$ ' $i$ de les secourir et de leur faire parvenir du grain.

L'héritier présomptif du duc King mourut (490) (121). Après (avoir engendré ce fils), le duc King avait eu une concubine favorite nommée Joeitse, qui avait enfanté le prince T'ou ; le duc King étant tombé malade, ordonna à ses conseillers Kouo Hoei-tse et Kao Tchao-tse de nommer le prince T'ou héritier présomptif; quand le duc King fut mort (490), les deux conseillers Kao et Kouo mirent sur le trône T'ou ; ce fut Yen Jou-tse. Cependant T'ien K'i ne fut pas satisfait et voulut mettre sur le trône Yang-cheng, fils de $T$ 'o, duc King, car Yang-cheng entretenait depuis longtemps des relations d'amitié avec (T'ien) $K^{\prime} i$. Quand Yen Jou-tse était monté sur le trône, Yang-cheng s'était enfui dans le pays de Lou. T'ien $K^{\prime} i$ feignit d'être un homme dévoué à Kao Tchao-tse et à Kouo Hoei-tse ; chaque fois que l'un d'eux allait à la cour, il prenait la place de celui qui se tenait à côté de lui sur le char et lui disait :

- Au début, les grands officiers ne voulaient pas mettre sur le trône Jou-tse ; après que Jou-tse fut monté sur le trône, vous êtes devenu son conseiller; les grands officiers se sentent tous en péril et projettent une rébellion.

D'autre part, il trompait les grands officiers en leur disant :

- Kao Tchao-tse est redoutable ; avant qu'il se soit manifesté, prévenez-le.

Les grands officiers suivirent ses conseils. T'ien K'i, Pao Mou et les grands officiers entrèrent en armes dans la demeure ducale pour attaquer Kao Tchao-tse. (Kao) Tchao-tse informé de ce qui se passait, vint avec Kouo Hoeitse au secours du duc. Les soldats du duc furent battus. Les partisans de T'ien 
K'i poursuivirent Kouo Hoei-tse qui s'enfuit dans p.231 (la ville de) Kiu (122) ; revenant aussitôt, ils tuèrent Kao Tchao-tse ; Yen Jou-tse (123) s'enfuit dans (le pays de) Lou. T'ien K'i chargea des gens de se rendre dans le pays de Lou pour aller chercher Yang-cheng; quand Yang-cheng fut arrivé dans (le pays de $\left.T s^{\prime} i\right)$, il se cacha dans la maison de $T^{\prime}$ ien $K^{\prime} i$. T'ien $K^{\prime} i$ invita les grands officiers en leur disant :

— La mère de (T'ien) Tch'ang (124) va offrir un sacrifice de poisson et de haricots; faites-moi la faveur de venir vous réunir pour un banquet.

On se réunit pour le banquet chez la famille T'ien; T'ien $K^{\prime} i$ avait mis Yang-cheng dans un sac et le plaça au milieu des assistants; il ouvrit le sac, fit sortir Yang-cheng et dit :

- Celui-ci est le prince de $T s^{\prime} i$.

Les grands officiers le reçurent tous prosternés. Au moment de faire avec eux une convention jurée pour le mettre sur le trône, T'ien $K^{\prime} i$ dit faussement :

- Moi et Pao Mou avons projeté ensemble de mettre sur le trône Yang-cheng.

Pao Mou, irrité, dit :

— Ô grands officiers, avez-vous oublié l'ordre donné par le duc King?

Les grands officiers eurent envie de regretter (ce qu'ils avaient fait). Yang-cheng alors, frappant de son front le sol, leur dit :

— Si c'est possible, faites la nomination, sinon, restons-en là.

Pao-Mou, craignant d'attirer sur lui le malheur, reprit alors :

— Vous êtes tous fils du duc King. Pourquoi serait-ce impossible?

On donna alors le titre de prince à Yang-cheng dans la ${ }_{\text {p.232 }}$ maison de T'ien $K^{\prime} i$; ce fut le duc Tao. (Le duc Tao) chargea des gens de transporter Yen Joutse à T'ai, puis de tuer Jou-tse T'ou (125). Quand le duc Tao fut monté sur le trône, T'ien $K^{\prime} i$ fut son conseiller et concentra entre ses mains tout le gouvernement de $T s^{\prime} i$.

La quatrième année (485), T'ien K'i mourut. Son fils, (T'ien) Tch'ang, lui succéda ; ce fut T'ien Tch'eng-tse (126). - Pao Mou, étant en mésintelligence avec le duc Tao, de $T s$ ' $i$, assassina le duc Tao. Les gens de $T s^{\prime} i$ s'entendirent pour mettre sur le trône son fils, Jen; ce fut le duc Kien. T'ien Tch'ang Tch'eng-tse et $K$ 'an Tche (127) furent ensemble conseillers, l'un de gauche, l'autre de droite, et conseillèrent le duc Kien. T'ien Tch'ang haïssait de tout son cœur $K^{\prime}$ an Tche; mais $K$ 'an Tche jouissait de la faveur du duc Kien; il était puissant et on ne pouvait l'écarter. Alors T'ien Tch'ang pratiqua de nouveau les moyens de gouvernement de $\mathrm{Hi}$-tse (128) ; il se servait d'un grand 
boisseau pour donner, d'un petit boisseau pour recevoir. Les gens de $T s^{\prime} i$ firent à ce sujet la chanson suivante :

«Quand une vieille femme cueille du millet, elle ${ }_{\text {p.233 }}$ l'apporte à T'ien Tch'eng-tse (129).

Les grands officiers de $T s^{\prime} i$ étant venus à la cour, le cocher Yang (130) adressa des remontrances au duc Kien en lui disant :

- T'ien (Tch'ang) et $K^{\prime}$ 'an (Tche) ne peuvent rester ensemble : que Votre Altesse choisisse entre eux.

Le prince ne l'écouta pas. - Tse-ouo était un membre de la famille de $K$ 'an Tche (131) ; il était sans cesse en inimitié avec T'ien (Tch'ang). Un parent éloigné de T'ien (Tch'ang) nommé T'ien Pao, était au service de Tse-ouo et jouissait de sa faveur; Tse-ouo lui dit :

- Je veux détruire entièrement l'hostilité des T'ien et remplacer par vous, (T'ien) Pao, le chef de la famille T'ien.

(T'ien) Pao répondit :

— Mes relations de parenté avec T’ien (Tch'ang) sont éloignées.

Il n'accepta pas (cette proposition); ensuite, Pao dit à T'ien Tch'ang :

- Tse-ouo se propose d'exterminer la famille T'ien; si les T'ien ne prennent pas les devants, le malheur fondra sur eux.

Tse-ouo était logé dans le palais ducal; T'ien Tch'ang et ses trois frères, montés sur des chars, entrèrent dans le palais ducal avec l'intention de tuer Tse-ouo ; Tse-ouo ferma la porte (132). Le duc Kien et sa femme étaient en train de boire sur le belvédère en bois de $t$ 'an; il se disposait à combattre contre T'ien Tch'ang, mais le t'ai-che Tse-yu lui dit :

- T'ien Tch'ang ne se permet point de se révolter; il se propose de supprimer une chose nuisible (133).

Alors le duc Kien renonça (à la lutte). p.234 T'ien Tch'ang, étant sorti (du palais, apprit que le duc Kien était irrité : il craignit d'être mis à mort et se disposa à s'enfuir au loin. T'ien Tse-hang lui dit :

— L'hésitation est la ruine des entreprises.

Alors T'ien Tch'ang attaqua Tse-ouo ; Tse-ouo, à la tête de ses partisans, combattit contre les T'ien, mais il ne fut pas vainqueur et s'enfuit au loin; les partisans des T'ien poursuivirent et tuèrent Tse-ouo ainsi que $K^{\prime}$ an Tche (134). Le duc Kien sortit (de la capitale) et prit la fuite; les partisans des T'ien poursuivirent le duc Kien et l'arrêtèrent à Siu-tcheou (135). Le duc Kien dit :

— Si j'avais dès le début suivi les conseils de mon cocher Yang, je n'aurais pas été réduit à cette extrémité. 
Les partisans des T'ien, craignant que le duc Kien ne montât de nouveau sur le trône et ne les fît périr, tuèrent donc le duc Kien. Le duc Kien était au pouvoir depuis quatre ans quand il fut tué (481).

T'ien Tch'ang mit alors sur le trône Ngao, frère cadet du duc Kien ; ce fut le duc P'ing. Quand le duc P'ing fut monté sur le trône, T'ien Tch'ang devint son conseiller. Après avoir tué le duc Kien, T'ien Tch'ang craignit que les seigneurs ne s'unissent pour le faire périr lui-même ; il rendit donc à Lou et à Wei [b] tous les territoires qui leur avaient été enlevés; du côté de l'ouest, il conclut des conventions avec les familles Han, I, Yei et Tchao du pays de $T \sin$; du côté du sud, il entra en rapport par des ambassades avec Ou et Yue; il mit en honneur le mérite et distribua des récompenses; il se montra bon pour le peuple ; par ces moyens, le calme se rétablit dans le pays de $T s$ ' $i$.

p.235 T'ien Tch'ang dit au duc P'ing, de $T s^{\prime} i$ :

- Les bienfaits sont ce que les hommes désirent; ô prince, occupez-vous en. Les châtiments sont ce que les hommes redoutent ; permettez que ce soit moi qui les applique.

Quand ils eurent fait ainsi pendant cinq ans, le gouvernement du royaume de $T s^{\prime} i$ se trouva pour toutes les affaires entre les mains de T'ien Tch'ang. Alors T'ien Tch'ang extermina Pao, Yen (136), K'an Tche ainsi que ceux qui étaient puissants parmi les membres de la famille ducale. Puis il coupa le territoire de $T s$ ' $i$, et, à partir de Ngan-p'ing (137), tout ce qui s'étendait vers l'est jusqu'à Lang-ya, il en fit son propre fief; son fief était plus considérable que les terres dont jouissait le duc $P$ 'ing.

\# T'ien Tch'ang choisit dans le royaume de $T s$ 'i les femmes qui avaient sept pieds de haut ou davantage et en peupla son harem ; son harem comptait une centaine de femmes; il laissait ses hôtes et ses clients entrer dans son harem ou en sortir, sans y mettre opposition. Quand T'ien Tch'ang mourut, il avait plus de soixante-dix fils.

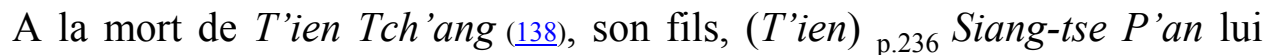
succéda et fut conseiller de $T s^{\prime} i$. (T'ien) Tch'ang reçut le nom posthume de Tch'eng-tse. Quand T'ien Siang-tse fut devenu conseiller du duc Siuen, de $T s^{\prime} i$, les trois $T \sin (139)$ tuèrent $T c h e-p o$ (453) et se partagèrent ses terres. (T'ien) Siang-tse nomma ses frères et ses parents gouverneurs de toutes les villes et places de $T_{s}{ }^{\prime} i$; il entretint des rapports par ambassadeurs avec les trois $T \sin \left(\underline{140)}\right.$; il s'apprêtait ainsi à entrer en possession du royaume de $T s^{\prime} i$.

A la mort de T'ien Siang-tse, son fils, (T'ien) Tchoang-tse Po prit le pouvoir. T'ien Tchoang-tse fut le conseiller du duc Siuen, de Ts'i. — La quarante-troisième année (413) du duc Siuen, ( $\left.T_{s}{ }^{\prime} i\right)$ attaqua $T$ sin, détruisit

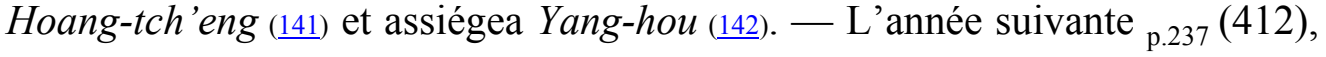
il attaqua les villes de $\operatorname{Lou}(\underline{143})$, Ko (144) et Ngan-ling (145). - L'année suivante (411), il prit une ville (du royaume) de Lou. 
A la mort de (T'ien) Tchoang-tse, son fils, (T'ien) T'ai-kong Ho, prit le pouvoir (146). T'ien T'ai-kong fut le conseiller du duc Siuen, de Ts'i. — La quarante-huitième année (408) du duc Siuen, (Ts'i) prit à Lou (la ville de) Tch'eng (147). - L'année suivante (407), le duc Siuen eut une entrevue avec les gens de Tcheng à Si-tch'eng. Il attaqua $W e i[\mathrm{~b}]_{\text {p.238 }}$ et prit la ville de Che-k'ieou (148). - La cinquante et unième année du duc Siuen (405), T'ien Hoei se révolta à (149) Ling-k'ieou (150). — Le duc Siuen mourut (405); son fils, Tai, qui fut le duc $K$ 'ang monta sur le trône (151). Quand Tai eut été sur le trône pendant quatorze ans (391), comme il se livrait à des excès avec le vin et les femmes, et comme il ne s'occupait pas du gouvernement, ${ }_{\text {p.239 }}$ (T'ien) T'aikong alors déporta le duc Kang sur le bord de la mer en lui donnant pour apanage une seule ville afin qu'il pût s'acquitter des sacrifices à ses ancêtres.

L'année suivante (390), Lou attaqua P'ing-Lou (152), (ville) de Ts'i. Trois ans plus tard (387) (153), T'ai-kong eut une entrevue avec le marquis $W e n$, de Wei, à Tchouo-tse (154) et lui demanda à être seigneur; le marquis $W e n$, de $W e i$, envoya alors des ambassadeurs exposer l'affaire au Fils du Ciel de (la dynastie) Tcheou ainsi qu'aux seigneurs, et leur demander de mettre sur le trône T'ien $\mathrm{Ho}$, conseiller de $T s^{\prime}$ ' $i$, en en faisant un seigneur. Le Fils du Ciel de (la dynastie) Tcheou y consentit. — La dix-neuvième année (386) du duc $K$ 'ang, T'ien $H o$ prit le pouvoir comme marquis de $T s^{\prime} i$; il eut son rang marqué auprès de la maison des Tcheou; on compta les années d'après son règne dont ce fut la première année. - Quand T'ai-kong Ho, marquis de $T s^{\prime} i$, eut été sur le trône pendant deux ans, il mourut (385). Son fils, $O u$, qui fut le duc Hoan, prit le pouvoir.

La cinquième année (380) de $\mathrm{Ou}$, duc Hoan, Ts'in et Wei attaquèrent Han ; [(155) Han demanda le secours de Ts'i. Le duc Hoan, de Ts' $i$, convoqua ses principaux officiers et leur proposa ce sujet de délibération :

- Vaut-il p.240 mieux le secourir tôt ou tard ?]

Tseou Ki (156) dit :

- Le mieux est de ne pas le secourir du tout.

Toan-kan P'ong (157) [dit :

- Si on ne le secourt pas, Han cédera et sera annexé à Wei. Il vaut mieux le secourir.]

T'ien Tch'en-se (158) dit :

- Ils sont fautifs, vos avis, messieurs. Si $T$ s'in et Wei attaquent Han, (alors) Tch'ou et Tchao ne manqueront pas de le secourir. Ainsi le Ciel livrera Yen à $T s^{\prime} i(\underline{159)}$.

Le duc Hoan approuva ces paroles. Il avertit p.241 donc secrètement (160) l'ambassadeur de Han et le renvoya. Han, pensant qu'il était assuré du secours de $T s$ ' $i$, engagea les hostilités contre $T s$ 'in et Wei; Tch'ou et Tchao, l'ayant 
appris, mirent en effet des soldats en campagne pour venir à son secours. $T s^{\prime} i$ en profita pour partir en guerre, attaquer à l'improviste le royaume de Yen et lui prendre (la ville de) Sang-k'ieou (161). — La sixième année (379), (Ts'i) secourut $W e i[\mathrm{~b}]$. — Le duc Hoan mourut. Son fils, Yn-ts' $i$, qui fut le roi $W e i$, monta sur le trône. - Cette année-là, l'ex-duc Kang, de Ts'i, mourut; sa lignée s'interrompit et il n'eut pas de descendants. Les places qui lui appartenaient tombèrent toutes entre les mains de la famille T'ien.

La première année (378) du roi Wei, les trois Tsin, profitant du deuil de $T s^{\prime} i$, vinrent attaquer notre (ville de) Ling-k'ieou (162). — La troisième année (376), les trois $T \sin$ anéantirent la descendance de $T \sin$ et se partagèrent ses territoires. - La sixième année (373), Lou ${ }_{\text {p.242 }}$ nous attaqua et pénétra dans (la ville de) Yang-koan (163). Ts'in nous attaqua et arriva à Po-ling (164). — La septième année (372), Wei [b] nous attaqua et prit (la ville de) Sie-ling (165). La neuvième année (370), Tchao nous attaqua et prit (la ville de) Kiuen (166).

Depuis le moment où le roi Wei était monté sur le trône jusqu'à ce jour, il ne s'était pas occupé du gouvernement et avait remis l'administration de l'État aux ${ }_{\text {p.243 }}$ hauts dignitaires et aux grands officiers. Pendant ces neuf années, les seigneurs attaquèrent tous son royaume; son peuple n'avait plus de direction. En ce temps, le roi Wei appela auprès de lui le gouverneur de Tsi-mo (167), et lui dit :

- Depuis que vous résidez à $T s i-m o$, des malédictions contre vous me parvenaient journellement; cependant j'ai envoyé des gens faire une inspection : les champs et la campagne de Tsi-mo étaient productifs; les habitants vivaient dans l'abondance; les fonctionnaires n'étaient pas négligents; la région orientale jouissait ainsi du calme. (Si on a mal parlé de vous), c'est parce que vous n'avez pas gagné par des bons offices ceux qui m'entourent afin de leur demander de faire votre éloge.

Il lui donna une terre de dix mille foyers. Il appela auprès de lui le gouverneur de $N g o$ (168) et lui dit :

- Depuis que vous administrez Ngo, j'ai entendu chaque jour votre louange; cependant j'ai envoyé des émissaires faire une inspection: les champs et la campagne de Ngo n'étaient pas productifs ; le peuple était accablé de souffrances. Autrefois, quand Tchao attaqua Kiuen (169), vous avez été incapable de secourir (cette ville); quand Wei prit (la ville de) Sie-ling (170), vous n'en avez rien su. (Si on vous a loué), c'est parce que vous avez gagné par de riches présents ceux qui m'entourent afin de leur demander de faire votre éloge.

Ce jour-là même, il jeta dans la chaudière bouillante le gouverneur de Ngo, et bouillit en même temps avec lui tous ceux de son entourage qui avaient coutume de faire ${ }_{\text {p.244 }}$ l'éloge (de cet homme). Puis il leva des soldats et 
attaqua dans l'ouest Tchao et Wei [b]; il battit Wei à Tchouo-tse (171) et assiégea le roi Hoei. Le roi Hoei demanda à lui faire présent de Koan (172) pour obtenir la paix et être délivré. Les gens de Tchao nous rendirent le long mur (173). Alors tout le royaume de $T s$ ' $i$ fut frappé de crainte ; personne n'osa plus dissimuler les fautes; on s'efforça d'être absolument sincère. Le royaume de $T s^{\prime} i$ fut très bien gouverné ; les seigneurs l'ayant appris, aucun d'eux n'osa ouvrir les hostilités contre $T s$ 'i pendant plus de vingt années (174).

Tseou Ki-tse (175), à cause de son habileté à jouer du luth, ${ }_{\text {p.245 }}$ fut admis en présence du roi Wei. Il plut au roi Wei qui le logea dans la chambre de droite (176). Quelque temps après, comme le roi jouait du luth, Tseou Ki-tse poussa la porte et entra en disant :

- C'est bien joué du luth.

Le roi, changeant de visage, fut mécontent ; il repoussa le luth, mit la main sur son épée et dit :

- Vous n'avez vu que l'apparence extérieure et vous n'avez point eu le temps de faire un examen (attentif) ; comment pouvez-vous savoir que c'est bien ?

Tseou Ki-tse dit :

- Les grandes cordes donnaient un son vague et en même temps doux comme le printemps: (elles symbolisaient) le prince ; les petites cordes rendaient des sons distincts et nets et en même temps purs : (elles symbolisaient) le conseiller. Quand vous pinciez les cordes, vous les tiriez profondément; quand vous les relâchiez, vous le faisiez sans brusquerie: (cela symbolisait) les ordres du gouvernement. Toutes étant d'accord dans leur résonance, les grandes et les petites s'entr'aidaient ; en revenant et en obliquant, elles ne se nuisaient pas les unes aux autres : (cela symbolisait) les quatre saisons. Voilà comment j'ai su que c'était bien (joué du luth).

Le roi lui dit :

- Vous discourez habilement sur la musique.

Tseou Ki-tse répliqua :

- Comment serait-ce là ne parler que de musique ? En effet le gouvernement du royaume et l'art d'assurer le calme de la population sont entièrement contenus dans (cette explication).

Le roi changea de nouveau de visage et, irrité, dit :

- Lorsque vous discourez sur les règles des cinq notes musicales, en vérité il n'est personne qui vous vaille; mais, pour ce qui est du gouvernement du royaume et de l'art ${ }_{\text {p.246 }}$ d'assurer le calme de la 
population, comment cela serait-il compris dans les cordes musicales et le bois d'éléococca (177)?

Tseou Ki-tse dit :

- Les grandes cordes donnant un son vague et en même temps doux comme le printemps (symbolisent) le prince; les petites cordes rendant des sons distincts et nets et en même temps purs (symbolisent) le conseiller, (les cordes) étant pincées en les tirant profondément et relâchées sans brusquerie (symbolisent) les ordres du gouvernement; toutes étant d'accord dans leur résonance de manière à ce que grandes et petites s'entraident, revenant et obliquant sans se nuire les unes aux autres, (cela symbolise les quatre saisons. Or, quand (les sons) se répètent sans se confondre, c'est par là que le gouvernement est prospère ; quand (les sons) se trouvent liés entre eux et vont droit à leur but, c'est par là qu'on conserve ce qui pourrait être ruiné ; c'est pourquoi on dit : quand les sons du luth sont harmonieux, l'empire est bien gouverné. Ainsi, pour gouverner l'État et pour assurer le calme du peuple, rien ne vaut les cinq notes musicales.

Le roi dit :

- C'est fort bien.

Quand Tseou Ki-tse eut vu le roi pendant trois mois, il reçut le sceau de conseiller.

Choen-yu K'oen (178) eut une entrevue avec (Tseou Ki-tse) et lui dit :

- Vous excellez à discourir. Moi, K'oen, j’ai des pensées sans valeur que je désire exposer en votre présence.

Tseou Ki-tse dit :

- Je reçois avec respect ${ }_{\text {p.247 }}$ vos instructions (179).

Choen-yu K'oen dit :

- Celui qui garde l'intégralité, intégralement réussit; celui qui perd l'intégralité, intégralement se ruine (180).

Tseou Ki-tse dit :

- Avec respect je reçois cet ordre ; permettez-moi de veiller à ne pas m'écarter de la présence (du prince) (181).

Choen-yu K'oen dit :

- La graisse de porc et l'essieu en bois de jujubier sont ce qui fait glisser (la roue autour de son axe); ils ne pourraient cependant la faire tourner autour d'un trou carré (182).

Tseou Ki-tse dit : 
- Avec respect je reçois cet ordre ; permettez-moi de veiller à servir ceux qui entourent (le prince).

Choen-yu K'oen dit :

- De la colle à arc et des matériaux anciens sont ce qui sert à faire la réunion ; cependant cela ne peut pas réunir ce qui est fendu (183).

Tseou Ki-tse dit :

- Avec respect je reçois cet ordre ; permettez-moi de veiller à me tenir attaché à la foule du peuple.

Choen-yu K'oen ${ }_{\text {p.248 }}$ dit :

- Même quand un vêtement en peau de renard est usé, on ne peut le réparer avec une peau de chien jaune (184).

Tseou Ki-tse dit :

- Avec respect je reçois cet ordre; permettez-moi de veiller à choisir des sages et à ne pas mêler avec eux des hommes méprisables.

Choen-yu K'oen dit :

- Si un grand char n'a pas été contrôlé, il est incapable de porter sa charge normale ; si un luth n'a pas été contrôlé, il ne peut rendre les cinq notes musicales pour lesquelles il est fait (185).

Tseou Ki-tse dit :

- Avec respect je reçois cet ordre; permettez-moi de veiller à mettre en vigueur les lois et les règles et à réprimer les mauvais fonctionnaires.

Choen-yu K'oen ayant fini de parler sortit rapidement ; parvenu à la porte, il rencontra son cocher à qui il dit :

- Cet homme, je lui ai dit cinq paroles subtiles et il m'a répondu comme l'écho répond au son; cet homme recevra certainement un titre nobiliaire avant qu'il soit longtemps (186).

Au bout d'un an, (le roi) donna en apanage ${ }_{\text {p.249 }}$ (le territoire de) Hia-p'ei (187) (à Tseou Ki-tse), qui eut le titre de marquis Tch'eng.

La vingt-troisième année (356) de son règne, le roi Wei eut une entrevue

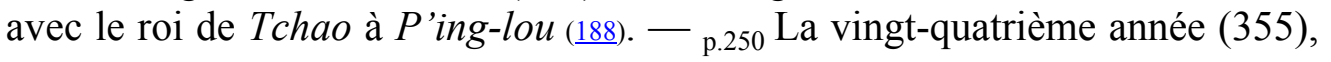
[ (189) il chassa en compagnie du roi de Wei dans les environs (de sa capitale). Le roi de Wei lui demanda :

- O roi, vous aussi avez-vous des joyaux?

Le roi Wei répondit : 
— Je n'en ai pas.

Le roi de Leang (190), reprit :

- Pour moi, quoique mon royaume soit petit, j'ai cependant des perles d'un pouce de diamètre; il y en a dix dont l'éclat est tel qu'ils éclairent douze chars en avant et douze chars en arrière ; comment se fait-il que, possédant un royaume avec dix mille chars de guerre, vous n'ayez point de joyaux ?

Le roi $W e i$ répliqua :

- Ce que je considère comme des joyaux, ce n'est pas la même chose que Votre Majesté (191). Parmi mes sujets se trouve T'an-tse (192) ; je l'ai chargé de garder (la ville de) Nan-tch'eng (193); depuis lors, les gens de Tch'ou n'ont plus osé faire de brigandages et aller du côté de l'Est pour piller; les douze seigneurs des bords de la rivière $S e$ (194) sont tous venus me rendre ${ }_{\mathrm{p} .251}$ hommage. Parmi mes sujets se trouve aussi $P$ 'an-tse (195) ; je l'ai chargé de garder (la ville de) Kao-t'ang (196) ; depuis lors, les gens de Tchao n'ont plus osé aller à l'orient pêcher dans le Ho. Parmi mes officiers, il y a encore K'ien Fou; je l'ai chargé de garder (la ville de) Siutcheou (197) ; depuis lors, les gens de Yen (198) sacrifient à notre porte du nord, et les gens de Tchao sacrifient à notre porte de l'ouest; ceux qui ont émigré pour suivre (Kien-Fou) sont au nombre de plus de sept mille familles. Parmi mes sujets, se trouve Tchong-Cheou; je l'ai chargé de prévenir les vols ; depuis lors, sur les grandes routes on n'a pas ramassé ce qui avait été perdu (199). Je prends (ces hommes éminents) pour éclairer à mille $l i$ de distance ; comment ne s'agirait-il que de douze chars?

Le roi Hoei, de Leang, fut couvert de confusion et se retira mécontent.]

La vingt-sixième année (353), le roi Hoei, de Wei, assiégea Han-tan (200). [(201) Tchao implora le secours de ${ }_{\mathrm{p} .252} T s^{\prime} i$. Le roi $W e i$, de $T s$ ' $i$, manda auprès de lui ses principaux ministres et délibéra avec eux, disant :

- Vaut-il mieux secourir Tchao ou ne pas le secourir (202) ?

Tseou Ki-tse dit :

- Le mieux est de ne pas le secourir.

Toan-kan P'ong dit :

- Ne pas le secourir n'est pas juste et d'ailleurs ce n'est pas avantageux.

— Comment cela ? demanda le roi.

Il répondit : 
- Si le prince de Wei s'annexe Han-tan, quel profit en retirera $T s$ ' $i$ ? Si d'autre part nous secourons Tchao et que nous campions dans la banlieue (de Han-tan), il en résultera que Tchao ne sera pas vaincu, tandis que Wei restera intact. C'est pourquoi, le mieux est d'aller au sud attaquer Siang-ling (203) pour épuiser Wei. Quand Han-tan aura été pris, vous profiterez de l'épuisement de Wei.

Le roi Wei suivit ce conseil (204).]

p.253 Quelque temps plus tard, comme [(205) Tseou Ki, marquis Tch'eng, était en mauvais rapports avec T'ien Ki, Kong-suen Yue dit à (Tseou) Ki, marquis Tch'eng :

- Pourquoi ne conseillez-vous pas (au roi) d'attaquer Wei ? (Si on attaque $\mathrm{Wei}$,) T'ien $\mathrm{Ki}$ sera certainement mis à la tête de l'armée ; si, lorsque la bataille sera livrée, il est vainqueur et se couvre de gloire, ce sera la réussite de vos plans; si, lorsque la bataille sera livrée, il n'est pas vainqueur, au cas où il ne serait pas mort au premier rang de l'armée, il aura reculé et se sera enfui, et alors sa destinée sera entre vos mains.

Alors le marquis Tch'eng conseilla au roi Wei d'envoyer T'ien $K i$ dans le sud attaquer (la ville de) Siang-ling (206).] Le dixième mois, Han-tan fut pris. Ts' $i$ p.254 profita de l'occasion pour entrer en campagne et combattre $\mathrm{Wei}$; il lui fit essuyer une grande défaite à Koei-ling (207). Alors Ts'i se trouva le plus puissant parmi les seigneurs; il prit le titre de roi afin de commander à tout l'empire.

La trente-troisième année (346), (le roi $\mathrm{Wei}$ ) tua son grand officier Meou $\operatorname{Sin}(\underline{208)}$.

La trente-cinquième année (344). Kong-suen Yue dit encore à (Tseou) Ki, marquis Tch'eng :

- [(209) Pourquoi n'ordonnez-vous pas à un homme de prendre en main dix livres d'or et d'aller consulter les sorts sur la place publique en disant : " Je suis au nombre des gens de T'ien Ki; ( $T$ 'ien $K i$ m'a chargé de dire en son nom :) J'ai livré trois combats et j'ai remporté trois fois la victoire; ma renommée en impose à tout l'univers ; je désire faire une grande entreprise ; (les sorts), de leur côté, sont-ils favorables ou défavorables ? "Quand 1'homme qui aura ${ }_{\text {p. } 255}$ consulté les sorts sera sorti, vous ordonnerez à des gens de se saisir du devin qui lui aura donné cette consultation et vous attesterez en présence du roi la véracité de ses accusations.]

T'ien $K i$, apprenant ce qui se passait se mit aussitôt à la tête de ses partisans et attaqua à l'improviste (la ville de) Lin-tse (210) dans le but de prendre le marquis Tch'eng; mais il ne fut pas vainqueur et s'enfuit. 
La trente-sixième année (343), le roi Wei mourut; son fils, Pi-k’iang, qui fut le roi Siuen, prit le pouvoir.

La première année (342) du roi Siuen, (le roi de) $T$ s'in prit à son service Yang, (prince) de Chang (211). (Le Fils du Ciel, de la dynastie) Tcheou conféra le titre d'hégémon au duc Hiao, de Ts 'in (212).

La deuxième année (341), Wei attaqua Tchao; Tchao s'allia à Han, et ensemble ils combattirent contre Wei. Tchao fut vaincu dans une bataille qui se livra à Nan-leang (213). Le roi Siuen appela auprès de lui T'ien Ki et lui rendit ses anciennes dignités. [(214)Le prince de Han ayant ${ }_{\mathrm{p} .256}$ demandé à $T s$ ' $i$ de lui prêter secours, le roi Siuen (215) convoqua ses principaux ministres et délibéra avec eux disant :

— Vaut-il mieux le secourir tôt ou le secourir tard ?]

Tseou Ki-tse dit :

- Le mieux est de ne pas le secourir (216).

[T'ien $K i$ (217) dit :

- Si on ne le secourt pas, Han va faire volte-face et entrer dans le parti de $\mathrm{Wei}$; il vaut mieux le secourir promptement.

Suen-tse (218) dit :

- $\mathrm{Si}$, avant que les soldats de Han et de Wei se soient épuisés, nous secourons (Han), c'est nous qui, au lieu de Han, subirons le choc des armées de Wei, et c'est alors nous au contraire qui devrons obéir aux ordres de ${ }_{\text {p. } 257}$ Han (219). D'ailleurs Wei a résolu de détruire ce royaume (220). Quand Han se verra perdu, il ne manquera pas de se tourner vers l'Est pour se plaindre à $T s$ ' $i$. Nous alors, nous nouerons avec Han une étroite amitié, et, grâce à ce que nous aurons tardé, nous trouverons Wei épuisé ; ainsi vous pourrez en retirer un bénéfice important et acquérir un glorieux renom.

Le roi Siuen dit :

- C'est bien.

Il fit donc secrètement des promesses aux émissaires de Han, puis les renvoya ; c'est pourquoi Han, comptant sur l'appui de $T s$ ' $i$, livra cinq fois bataille sans être vainqueur; alors il remit à l'Est son royaume à (la garde de) $T s^{\prime} i$. Ts' $i$ entra donc en campagne ;] il nomma T'ien $K i$ et T'ien Yng généraux et Suen-tse fut leur directeur, il secourut Han et Tchao en attaquant Wei auquel il fit subir une grande défaite à Ma-ling (221); il tua le général (de Wei) $P$ 'ang Kiuen, et fit prisonnier Chen, héritier présomptif de Wei. A la suite de cela, les rois des trois $T \sin (222)$, à cause de (l'habileté de) T'ien Yng, p.258 vinrent rendre hommage au roi de $T_{S}$ ' $i$ à Po-wang (223); après avoir conclu un traité, ils se retirèrent. 
La septième année (336), (le roi Siuen) eut une entrevue avec (le roi de) Wei au sud de P'ing-ngo (224). - L'année suivante (335), il eut une nouvelle entrevue avec lui à Kiuen (225). - Le roi Hoei, de Wei, mourut (226). L'année suivante (334), le roi Siuen eut une entrevue avec le roi Siang, de $W e i$, à Siu-tcheou (227). Les seigneurs se décernèrent les uns aux autres le titre de roi. - La dixième année (333), Tch'ou assiégea notre (ville de) Siutcheou (228). - La onzième année (332), (Ts'i) s'allia à Wei pour attaquer Tchao ; Tchao ouvrit une brèche aux eaux du Fleuve de manière à inonder les soldats de $T s$ 'i et de Wei qui se retirèrent (229). - La dix-huitième année (325), le roi Hoei, de $T s$ 'in, prit le titre de roi.

Le roi Siuen aimait les hommes instruits qui voyageaient (de pays en pays) pour donner des conseils. Soixante-seize hommes, parmi lesquels Tseou Yen (230), p.259 Choen-yu K'oen (231), T'ien P'ien (232), Tsie Yu (233), Chen Tao (234), Hoan Yuen (235) reçurent tous de lui des palais particuliers et p.260 furent nommés grands officiers de premier rang. Ils ne participaient pas au gouvernement, mais ils discutaient (sur les affaires d'État). Ainsi, dans le pays de $T s^{\prime} i$, les savants au pied de (la porte) $T s i$ (236) redevinrent abondants ; ils se comptèrent par centaines et furent près de mille.

La dix-neuvième année (324), le roi Siuen mourut. Son fils, Ti, qui fut le roi Min, monta sur le trône. - La première année (323) du roi Min, Ts'in chargea Tchang d'avoir une entrevue à Ye-sang (237) avec ceux qui exerçaient p.261 le gouvernement chez les seigneurs (238). - La troisième année (321), (le roi Min) conféra en apanage nobiliaire (la ville de) Sie à T'ien Yng (239). — La quatrième année (321), il alla chercher une épouse dans (le pays de) Ts'in. La septième année (317), il attaqua Wei et le battit à Koan-tse (240). - La douzième année (312), il attaqua Wei. Tch'ou assiégea (la ville de) Yong-che (241). Ts 'in vainquit K'iu Kai (242).

\section{Sou Tai dit à T'ien Tchen (243) :}

- Je désire avoir une audience de vous. Ce que (j'ai à vous proposer) est une affaire très sûre pour engager Tch'ou à vous être profitable; si elle réussit, ce sera heureux (pour vous); si elle ne réussit pas, ce sera aussi heureux (pour vous). En ce moment, comme j'étais debout devant la porte (244), un étranger dit : «Le roi de Wei a dit à Han P'ing et à Tchang I (245) : « (La ville de) Tchoutsao (246) va être prise, et p.262 les soldats de $T s$ ' $i$ s'avanceront davantage encore ; si vous venez me secourir (247), je pourrai m'en tirer; si vous ne me secourez pas, je ne pourrai pas empêcher (que Tchou-tsao) soit pris. " Ce n'est là qu'un discours sujet à être modifié ; si en effet il s'écoule plus de dix jours sans que les soldats de $T s$ 'in et de Han aillent dans l'Est, alors le prince de Wei se détournera de Han pour suivre Ts 'in (248). Ts 'in chassera Tchang $I$ (249), et, bras-dessus bras-dessous avec $T s^{\prime} i$ et $T c h$ 'ou, il se mettra à leur service. Dans ce cas, votre affaire aura réussi (250). 
T'ien Tchen dit :

- Mais s'il n'y a pas moyen de faire que (Han et $T s^{\prime}$ 'in) n'aillent pas dans l'Est (251)?

(Sou Tai) répondit :

- Quand Han P'ing parlera de secourir Wei, il ne dira certainement pas au roi de Han :

- Moi, (Han) P'ing, j'agis dans l'intérêt de Wei.

Il dira certainement :

- Moi, (Han) P'ing, je me propose de me servir des soldats de $T s^{\prime}$ 'in et de Han pour aller dans l'Est repousser ${ }_{\text {p.263 }} T s^{\prime} i$ et Song (252); comme j'aurai réuni ensemble les soldats de trois royaumes (253), je profiterai de l'affaiblissement de $K^{\prime} i u$ Kai (254) pour enlever dans le Sud (des terres) à Tch'ou et notre ancien territoire sera entièrement récupéré.

Quand Tchang I parlera de secourir Wei il ne dira certainement pas au roi de $T s$ 'in:

- Moi, (Tchang) I, j'agis dans l'intérêt de Wei.

Il dira certainement :

- Moi, (Tchang) I, je vais me servir des soldats de Ts 'in et de Han pour aller dans l'Est repousser Ts' $i$ et Song ; moi, (Tchang) I, je me propose de réunir les soldats de trois royaumes (255), et, profitant de l'affaiblissement de $K^{\prime} i u$ Kai, d'enlever au Sud (des terres) à Tch'ou. Vous vous serez donné l'air de sauver un royaume qui allait à sa perte (256), et en réalité vous reviendrez en vous étant substitué (257) au San-tch 'oan. C'est là une œuvre digne d'un roi souverain.

Vous cependant (258), invitez le roi de Tch'ou à donner un territoire au prince de Han et faites que (le roi de) Ts'in organise la concorde ; (pour cela), dites au roi de $T S$ 'in :

- Je vous demande la permission de donner à Han un territoire, et

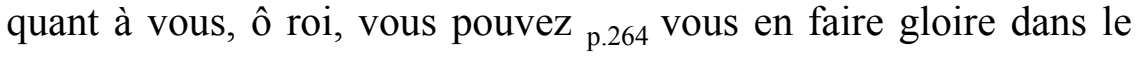
San-tch'oan (259).

Lorsque le prince de Han, sans se servir de ses soldats, aura obtenu de Tch'ou un territoire, quel langage Han P'ing tiendra-t-il à $T S$ 'in (260) pour expliquer qu'il convient d'envoyer des soldats dans l'Est? Il dira :

- Sans que les soldats de $T s^{\prime}$ in aient été employés, (Ts'in) a obtenu le San-tch'oan; attaquez Tch'ou; Han vous servira à réduire Wei à l'extrémité ; le prince de Wei n'osera pas se tourner vers l'Est, et ainsi $T s$ ' $i$ se trouvera isolé.

D'autre part, quel langage tiendra Tchang I pour expliquer qu'il convient d'envoyer des soldats dans l'Est? Il dira : 
- Ts'in et Han désirent des territoires et leurs soldats sont prêts ; le prestige de leur renommée s'est étendu jusque dans le pays de $W e i$; telle est la raison pour laquelle $W e i$ désire ne pas perdre (l'amitié de) Ts'i et Tch'ou.

Le prince de Wei se détournera donc de Ts'in et de Han et s'empressera de servir $T s^{\prime} i$ et $T c h$ 'ou. Le roi de Tch'ou (ayant obtenu) ce qu'il désirait (261), ne donnera plus (à Han) le territoire (qu'il lui avait promis). Vous (262), (cependant), en faisant que $T s$ 'in et Han obtiennent des territoires sans avoir recours à leurs soldats, vous leur aurez rendu un grand service. Si les rois de $T s^{\prime}$ 'in et de Han, forcés par Han P'ing et Tchang $I$, font une expédition militaire dans l'Est pour soumettre à leurs ordres le pays ${ }_{\text {p. } 265}$ de $W e i$, vous aurez toujours en main votre créance (263) pour réclamer votre paiement à $T s$ 'in et à Han. Ainsi il y aura là ample matière à ce que (ces deux rois) vous aiment et haïssent Tchang-tse (264).

La treizième année (311), le roi Hoei, de $T s^{\prime}$ in, mourut. - La vingt-deuxième année (303), (Ts'i), allié à $T s^{\prime} i n$, attaqua et vainquit $T c h$ 'ou à Tch'ong-k'ieou (265). - La vingt-quatrième année (300), Ts'in envoya le prince de King-yang (266) en otage dans le pays de $T s$ ' $i$. — La vingt-cinquième année (299), on renvoya le prince de King-yang dans le pays de Ts'in ; Wen, (seigneur de) Sie et prince de Mong-tch'ang (267), se rendit dans le pays de $T s^{\prime}$ in ${ }_{\text {p.266 }}$ et devint conseiller (du roi) de Ts'in; Wen s'enfuit (du pays de $T s^{\prime}$ in) (268). - La vingt-sixième année (298), $T s^{\prime} i$ s'allia à Han et à Wei, et ensemble ils attaquèrent $T s^{\prime}$ in ; ils arrivèrent à (la passe) Han-kou et y campèrent (269). - La vingt-huitième année (296), Ts'in donna à Han (le territoire de) Ho-wai (270) pour faire la paix ; les hostilités cessèrent. — La vingt-neuvième année (295), Tchao tua son "père du souverain » (271). Ts' $i$ aida Tchao à anéantir le Tchong-chan (272).

La trente-sixième année (288), le roi (de $T s^{\prime} i$ ) prit le titre d'Empereur d'Orient, tandis que le roi Tchao, de Ts'in, prenait le titre d'Empereur d'Occident. [(273) Sou Tai (274), venant de Yen, entra dans le pays de Ts' $i$; il se rencontra (avec le roi de $T s^{\prime} i$ ) à la porte orientale Tchan-hoa (275). p.267 Le roi de $T s^{\prime} i$ lui dit :

- Hé ! vous venez bien à point. Ts'in a envoyé Wei Jan me conférer le titre d'empereur. Qu'en pensez-vous ?

(Sou Tai) répondit :

- La question que me pose Votre Majesté est inopinée et ce qui peut être l'origine de tourments est encore invisible. Je désire que Votre Majesté reçoive (ce titre), mais que vous n'en fassiez pas étalage; si $T s$ 'in en fait étalage et que l'empire ne s'en émeuve pas, vous pourrez alors vous en parer; il ne sera point trop tard pour le faire; d'ailleurs, soit que vous cédiez le pas à $T s$ 'in, soit 
que vous rivalisiez avec lui, cela ne portera aucune atteinte au titre d'empereur (276). Si $T s$ 'in se pare de ce titre et que l'empire en soit mécontent, vous en profiterez pour ne pas vous en parer vous-même afin de vous gagner (les sympathies de) l'empire ; ce sera là pour vous une grande ressource. D'ailleurs, si dans l'empire se lèvent deux empereurs, pensez-vous, ô roi, que l'empire honorera davantage $T s$ ' $i$ ou honorera davantage $T s$ 'in ?

- Il honorera davantage $T s^{\prime}$ in, dit le roi.

- Si vous renoncez au titre d'empereur, reprit (Sou Tai), l'empire aimera-t-il mieux $T s^{\prime} i$ ou aimera-t-il mieux $T s^{\prime}$ in ?

- Il aimera $T s^{\prime} i$ et détestera $T s^{\prime}$ 'in, dit le roi.

(Sou Tai) dit :

- Si les deux empereurs font une convention pour attaquer Tchao, cela sera-t-il plus profitable que de combattre (le prince de) Song (semblable à) Kie (277) ?

Le roi dit :

- Il serait plus avantageux de combattre (le prince de) Song (semblable à) Kie.

(Sou Tai) répliqua :

- Ainsi donc, si vous faites p.268 une convention pour que également vous et $T s$ 'in deveniez empereurs, l'empire honorera seulement $T s^{\prime} i n$ et méprisera $T s^{\prime} i$; si vous renoncez au titre d'empereur, l'empire aimera $T s^{\prime} i$ et détestera $T s^{\prime}$ 'in; attaquer Tchao n'est pas aussi profitable que d'attaquer (le prince de) Song (semblable à) Kie. Pour ces raisons, je désire que Votre Majesté rejette nettement le titre d'empereur pour se gagner (les sympathies de) l'empire. Renoncez à la convention et rejetez $T s^{\prime}$ in; ne rivalisez pas d'importance avec lui ; mais profitez de l'occasion pour enlever Song. En effet, quand vous posséderez Song (278), le territoire de (P'ou-)yang (279) qui appartient à Wei [b] sera en danger ; quand vous aurez (le territoire à) l'ouest de (la rivière) Tsi, Ngo (280), qui appartient à Tchao et qui est la partie orientale de ce royaume sera en péril; quand vous posséderez (le territoire au) nord de (la rivière) ${ }_{\text {p.269 }}$ Hoai, la partie orientale du royaume de Tch 'ou sera en péril ; quand vous posséderez T'ao et P'ing-lou, les portes de Leang ne s'ouvriront plus (281). Si vous renoncez au titre d'empereur et que vous vous en indemnisiez par l'attaque du (prince de) Song (semblable à) Kie, votre royaume croîtra en importance et votre nom sera glorieux. Yen et Tch'ou, à cause de cela s'inclineront devant votre prestige : dans l'empire il n'y aura personne qui ose ne pas vous obéir. C'est là une entreprise (digne) 
de $T^{\prime}$ 'ang et de $O u$. Respecter $T s^{\prime}$ 'in de manière à ce que vous ayez la réputation (de l'avoir respecté), mais faire ensuite que l'empire le haïsse ; c'est là le moyen de transformer l'humiliation en honneur. Je désire que Votre Majesté y réfléchisse mûrement.

Alors (le roi de) $T s^{\prime} i$ abandonna (le titre d')empereur et reprit celui de roi. $T s^{\prime}$ in à son tour renonça à la dignité royale.

La trente-huitième année (286), (le roi de $T s^{\prime}$ i) attaqua Song ; le roi Tchao, de $T s$ 'in, en fut irrité et dit :

- Je tiens à Song autant qu'(aux villes de) Sin-tch'eng (282) et p.270 Yang-tsin (283). Han Nie (284) est mon ami ; comment se fait-il qu'il attaque ce à quoi je tiens?

Sou Tai, étant l'agent de $T s$ ' $i$, tint au roi de $T s$ 'in ce langage :

- Si Han Nie attaque Song, c'est pour vous être utile, ô roi. Ts'i est puissant ; s'il est renforcé de Song (285), Tch'ou et Wei ne manqueront pas de le craindre; le craignant, ils se tourneront certainement vers l'Ouest pour servir $T s$ 'in ; ainsi, ô roi, sans avoir la peine de vous servir d'une seule arme de guerre, sans blesser un seul de vos soldats, sans que vous agissiez, vous détacherez (à votre profit le territoire de) Ngan- $i(\underline{286})$. Tel est le résultat que Han Nie demande dans ses prières aux dieux pour Votre Majesté.

Le roi de $T s$ 'in répliqua :

— Je m'afflige de ce que (les dispositions de) $T s$ ' $i$ sont difficiles à connaître ; tantôt (il se rattache à la ligue) tsong ; tantôt (il est pour le système) heng (287). Qu'est-ce à dire ?

(Sou Tai) répondit :

- Est-ce que les royaumes de l'empire permettent que (les dispositions de) $T s$ ' $i$ puissent vous être connues (288) ? Quand $T s$ ' $i$ attaque Song, il sait qu'il sert $T$ ' 'in; quand en effet il se sera renforcé d'un royaume comprenant dix mille chars de guerre, s'il ne se tourne ${ }_{\text {p.271 }}$ pas vers l'Ouest pour servir $T s^{\prime}$ in, il ne pourra pas administrer Song (289) tranquillement. Dans les royaumes du milieu, les sophistes voyageurs à têtes blanches (290) ont tous une sagesse acquise par l'expérience et désirent désunir $T s^{\prime} i$ et $T s^{\prime} i n$; parmi ceux qui, appuyés sur la barre d'appui de leur char et entrecroisant leurs ornières (291), vont en toute hâte vers l'Ouest, il ne s'en est pas encore trouvé un seul qui ait bien parlé de $T s$ ' $i$; parmi ceux qui, appuyés sur la barre d'appui de leur char et entrecroisant leurs ornières, vont en toute hâte vers l'Est, il ne s'en est pas encore trouvé un seul qui ait bien parlé de $T s$ 'in. Quelle en est la raison? c'est que tous redoutent que $T s$ ' $i$ et $T s$ 'in soient unis. Pourquoi $T s i n$ et Tch'ou sont-ils perspicaces tandis que $T s^{\prime} i$ et $T s^{\prime}$ in sont 
aveuglés? Tsin et Tch'ou sont unis et ne manqueront pas de comploter contre $T s^{\prime} i$ et $T s^{\prime} i n$; si $T s^{\prime} i$ et $T s^{\prime} i n$ étaient unis, ils feraient certainement des plans contre $T$ sin et Tch'ou. Je vous prie de prendre une décision en tenant compte de cela.

Le roi de $T s^{\prime}$ 'in dit :

- Je vous approuve.

Alors donc $T s$ ' $i$ attaqua Song; le roi de Song sortit (de sa capitale) et s'enfuit ; il mourut à $W e n$ (292). Du côté du Sud, Ts'i détacha à son profit le territoire du nord de la rivière Hoai qui appartenait à Tch'ou; du côté de ${ }_{\text {p.272 }}$ l'Ouest, il envahit (le pays des) trois $T \sin$ dans l'intention de s'annexer la maison des Tcheou et de devenir Fils du Ciel ; les seigneurs des bords de la rivière $\mathrm{Se}(\underline{293})$ tels que les princes de Tseou et de Lou, se dirent tous ses sujets ; les seigneurs furent saisis de crainte.

La trente-neuvième année (285), $T s$ 'in vint nous attaquer et nous prit neuf villes d'importance. - La quarantième année (284), Yen, Ts'in, Tch'ou et les trois Tsin, après s'être concertés ensemble (294), firent sortir chacun de leur côté des troupes d'élite pour nous attaquer; ils nous battirent à l'ouest de (la rivière) $T s i$. (Les troupes $\mathrm{du}$ ) roi (de $\left.T s^{\prime} i\right)$ (295) se dispersèrent et quittèrent la place. Le général de Yen, Yo I, entra alors dans Lin-tse (296) et s'empara de tous les trésors de $T s$ ' $i$. Le roi Min sortit (de son pays) et s'enfuit dans (le pays de) Wei [b]; le prince de Wei [b] quitta son propre palais pour l'y loger ; il se disait son sujet et fournissait à tous ses besoins; mais, le roi Min s'étant conduit sans condescendance, les gens de $\mathrm{Wei}$ [b] l'assaillirent. Le roi Min partit et se rendit dans (les principautés de) Tseou et de Lou (297); il eut une attitude arrogante; aussi les p.273 princes de Tseou et de Lou ne l'accueillirent-ils pas. Il s'enfuit alors à Kiu (298). (Le roi de) Tch'ou envoya Nao Tch'e à la tête de soldats secourir (le roi de) Ts'i; (Nao Tch'e) devint ainsi conseiller du roi Min, de Ts'i. Nao Tch'e alors tua le roi Min et partagea avec Yen le territoire enlevé à $T s$ ' $i$ ainsi que les objets précieux qu'on lui avait pris (299).

p.274 [(300) Quand le roi Min eut été mis à mort (284), son fils Fa-tchang changea de nom personnel et de nom de famille et se fit domestique dans la famille de Kiao qui était $t$ 'ai-che dans (la ville de) Kiu. La fille du t'ai-che Kiao trouva que l'attitude et la physionomie de Fa-tchang étaient fort remarquables et jugea qu'il n'était pas un homme ordinaire. Elle eut compassion de lui et constamment elle lui donnait des vêtements et de la p.275 nourriture ; puis elle eut avec lui des rapports secrets.] Quand Nao Tch'e fut parti de Kiu, [les gens de Kiu et les officiers fugitifs de $T s$ ' $i$ se rassemblèrent pour rechercher le fils du roi Min avec l'intention de le mettre sur le trône. Fa-tchang] craignit (d'abord) qu'ils ne voulussent le faire périr et ce ne fut qu'après quelque temps qu'il osa [déclarer qu'il était le fils du roi Min. Alors les gens de Kiu d'un commun accord mirent sur le trône Fa-tchang, qui fut le 
roi Siang,] afin qu'il défendît la ville de Kiu; puis ils annoncèrent dans tout le royaume de $T s$ ' $i$ que le roi était monté sur le trône à Kiu. Quand le roi Siang eut pris le pouvoir, il nomma reine la fille du t'ai-che; ce fut la reine Heou (301); elle $_{\text {p.276 }}$ enfanta un fils nommé Kien. Le t'ai-che Kiao dit :

- Une fille qui ne se sert pas d'un entremetteur et qui se marie d'elle-même n'est pas de ma race et déshonore ma famille.

Jusqu'à sa mort il refusa de voir la reine Heou. La reine Heou était une femme sage ; elle ne prit point prétexte de ce que (son père) refusait de la voir pour cesser d'avoir envers lui les égards qu'un enfant doit à ses parents (302).]

Le roi Siang était à Kiu depuis cinq années (279), lorsque T'ien Tan, en se servant (des gens) de Tsi-mo, attaqua et battit l'armée de Yen; il alla chercher le roi Siang à Kiu et le fit rentrer à Lin-tse ; l'ancien territoire de $T$ s' $i$ fut de nouveau entièrement soumis à $T s^{\prime} i$; (le roi de) $T s^{\prime} i$ conféra à $T$ 'ien Tan le titre de prince de ${ }_{\text {p.277 }}$ Ngan-p'ing (303). - La quatorzième année (270), Ts 'in attaqua nos (villes de) Kang et Cheou (304). - La dix-neuvième année (265), le roi Siang mourut. Son fils Kien prit le pouvoir.

Kien, roi, était au pouvoir depuis six ans (259) lorsque $T s^{\prime}$ in attaqua Tchao ; Ts ' $i$ et Tch'ou secoururent ce dernier. (Le roi de) $T s$ 'in fit ce calcul :

- Ts'i et Tch'ou viennent au secours de Tchao; s'ils sont unis avec lui, je retirerai mes soldats; s'ils ne sont pas unis avec lui, je l'attaquerai.

Tchao était à bout de vivres; il demanda du grain au (roi de) $T s^{\prime} i$; celui-ci refusa; Tcheou tse (305) lui dit :

- Il vaudrait mieux le lui accorder afin d'obliger les soldats de $T s^{\prime}$ 'in à se retirer; si vous ne le lui accordez pas, les soldats de $T s^{\prime}$ in ne s'en iront pas. Ainsi les calculs de $T s$ 'in auront réussi et ceux de $T s$ ' $i$ et de Tch'ou auront été déjoués. En outre, Tchao est pour $T s^{\prime} i$ et $T c h$ 'ou une barrière protectrice; il est pour eux ce que les lèvres sont aux dents; si les lèvres disparaissent, les dents auront froid; si aujourd'hui on cause la perte de Tchao, demain le malheur atteindra $T s^{\prime} i$ et $T c h$ 'ou. En outre l'affaire de secourir Tchao est aussi urgente que si on vous présentait une jarre dont l'eau ${ }_{\text {p.278 }}$ fuit pour arroser une marmite que le feu fait déjà rougir. Enfin, secourir Tchao est une œuvre de haute justice ; obliger à se retirer les soldats de $T s$ 'in rendra illustre votre nom ; il est juste de secourir un royaume qui va périr; il est glorieux d'obliger à la retraite les soldats du puissant $T s^{\prime}$ in. Si vous n'attachez pas d'importance à faire cela et que vous attachiez de l'importance à tenir à votre grain, ceux qui dirigent votre politique auront un échec. 
Le roi de $T s$ 'i ne l'écouta pas. $T s$ 'in écrasa plus de quatre cent mille soldats de Tchao à Tch'ang-p'ing, et, aussitôt après, assiégea Han-tan.

La seizième année (249), Ts'in anéantit les Tcheou (306). La reine Heou mourut (307). - La vingt-troisième année (242), Ts 'in institua la commanderie de Tong (308). - La vingt-huitième année (237), le roi vint rendre hommage à $T s^{\prime}$ in ; Tcheng (309), roi de Ts'in, donna (en son honneur) un banquet à Hien-yang. - La trente-cinquième année (230), Ts'in anéantit Han.- La trente-septième année (228), Ts'in anéantit Tchao. — La trente-huitième année (227) (1'héritier présomptif de) Yen chargea King K'o d'assassiner le roi de $T$ s'in ; le roi de $T$ s'in s'aperçut (des intentions ${ }_{\text {p.279 }}$ de King K'o) et le tua. - L'année suivante (226), Ts'in, écrasa Yen ; le roi de Yen s'enfuit dans le Leao-tong. - L'année suivante (225), Ts'in anéantit Wei. Les soldats de $T s$ 'in firent halte sous (les murs de) $L i(\underline{310})$. - La quarante-deuxième année (223), Ts 'in anéantit Tch'ou. - L'année suivante (222), il fit prisonnier Kia, roi de $T a i$, et anéantit $H i$, roi de Yen. - La quarante-quatrième année (221), les soldats de $T s^{\prime}$ in attaquèrent $T s^{\prime} i$. Le roi de $T s$ ' $i$, écoutant les avis de son conseiller Heou Cheng, ne combattit pas et se rendit avec son armée à $T s$ 'in. $T s^{\prime}$ in fit prisonnier Kien, roi, et le déporta à Kong (311) ; il anéantit alors (le royaume de) $T s$ ' $i$ et en fit des commanderies ; l'empire se trouva réuni sous la domination de Ts'in. Tcheng, roi de Ts'in, prit alors le titre de Souverain-empereur.

Auparavant, la reine $\mathrm{Heou}$, qui était sage, servit $T s^{\prime}$ in avec attention et fut de bonne foi avec les seigneurs ; $T s$ ' $i$, d'ailleurs, était bordé à l'Est par le rivage de la mer; $T$ s'in jour et nuit combattait contre les cinq royaumes qui étaient les trois $T$ sin, Yen et Tch'ou, et ${ }_{\text {p.280 }}$ chacun de ces royaumes aidait les autres contre $T s$ 'in ; c'est grâce à ces circonstances que Kien, roi, put être sur le trône pendant plus de quarante années sans souffrir de la guerre (312). Après la mort de la reine Heou (249), Heou Cheng devint conseiller de Ts'i; il accepta l'or que $T$ s'in lui offrit secrètement en quantité considérable; il envoya dans le pays de $T s^{\prime}$ in des hôtes nombreux auxquels $T s$ 'in aussi donna beaucoup d'or; ces hôtes devinrent tous des agents de désunion; ils exhortèrent le roi à abandonner la ligue tsong, à rendre hommage à $T s$ 'in, à ne plus faire de préparatifs de guerre, à ne plus aider les cinq royaumes dans leur lutte contre $T s$ 'in ; c'est ainsi que $T s$ 'in parvint à anéantir les cinq royaumes. Quand les cinq royaumes eurent péri, les troupes de $T s$ 'in en définitive pénétrèrent dans Lin-tse et il n'y eut personne parmi le peuple qui pût leur faire obstacle. Kien, roi, se soumit alors et fut déporté à Kong (313). C'est pourquoi, les gens de $T s$ ' $i$, irrités de ce que Kien, roi, ne s'était pas hâté de former avec les seigneurs la ligue tsong pour lutter contre $T s^{\prime} i n$, et de ce qu'il avait causé la perte de son royaume en écoutant des ministres pervers et des hôtes étrangers, firent cette chanson :

- Parmi les pins, parmi les cyprès, celui qui a établi Kien à Kong, c'est l'étranger (314). 
Ils p.281 regrettaient en effet que Kien eût suivi sans défiance les avis d'un étranger.

Le duc grand astrologue dit : $K^{\prime}$ ong-tse, sur le tard, se plut au $I$ (king); le $I$ (king) renferme une doctrine profonde, lumineuse et s'étendant au loin; qui pourra y appliquer sa réflexion sinon les hommes intelligents ${ }_{\text {p.282 }}$ doués d'une grande perspicacité ? Ainsi, quand le grand astrologue des Tcheou consulta les diagrammes au sujet de T'ien King-tchong Wan (315), la prédiction qu'il fit s'étendit jusqu'au delà de la dixième génération. Puis, après que Wan se fut enfui dans le pays de $T s$ ' $i$, quand $I$-tchong consulta à son sujet les sorts (316), ils dirent aussi comment T'ien $K^{\prime} i$ et (T'ien) Tch'an, devraient se révolter l'un après l'autre contre deux princes $(\underline{317})$ et accapareraient le gouvernement du royaume de $T s^{\prime} i$. 


\section{CHAPITRE XLVII}

\section{Dix-septième maison héréditaire K'ONG-TSE ${ }_{(101) .}$}

p.283 K'ong-tse naquit dans la ville de Tseou (102), qui faisait ${ }_{\text {p.284 }}$ partie du district de Tch'ang-p'ing (103) dans (l'État de) Lou. Son ancêtre était originaire (du pays) de Song et s'appelait K'ong Fang-chou (104). (K'ong) Fang-chou engendra p.285 Po-hia; p.287 Po-hia engendra Chou-leang Ho (105). (Chou-leang) Ho contracta une union disproportionnée (106) avec une fille de p.288 la famille Yen (107) et engendra $K^{\prime}$ 'ong-tse. (Sa mère) pria sur ${ }_{\text {p.289 }}$ la colline $N i(\underline{108)}$ et conçut $K$ 'ong-tse. C'est la vingt-deuxième année du duc Siang (551) que $K^{\prime}$ 'ong-tse naquit (109). A sa ${ }_{\text {p.290 }}$ naissance, le sommet de son crâne se relevait sur les bords ; c'est pourquoi on tira de là son nom personnel qui fut K'ieou ; son appellation fut Tchong-ni (110); son nom de famille était Kong.

p.291 Après la naissance de Kieou, Chou-leang Ho mourut (111). p.292 On l'enterra sur la montagne Fang; la montagne Fang se trouvait à l'Est (de la capitale) de Lou (112); à la suite de cela, K'ong-tse fut dans l'incertitude au sujet de l'emplacement de la tombe de son père, car sa mère avait évité de lui en parler (113).

Lorsque $K$ 'ong-tse était enfant, dans ses jeux, il avait coutume de disposer des étals et des vases pour les sacrifices et de préparer les formes extérieures des rites.

La mère de $K$ 'ong-tse étant morte, il l'enterra provisoirement près de la route des Cinq pères (114); telle fut sans doute sa circonspection (115). La mère d'un certain Wan-fou p.293 qui était (de la ville) de Tseou, révéla à K'ong-tse (l'emplacement de) la tombe de son père ; à la suite de cela donc, il réunit la sépulture (de sa mère à celle de son père) à Fang.

Lorsque $K$ 'ong-tse portait encore la ceinture de deuil, le chef de la famille $K i(116)$ offrit un banquet aux hommes ${ }_{\text {p.294 }}$ de valeur; K'ong-tse s'y rendit en leur compagnie. Yang Hou (117) lui fit un affront en lui disant :

- Le chef de la famille $K i$ offre un banquet aux hommes de valeur; il ne se permettrait pas de vous offrir un banquet.

A la suite de cela, $K^{\prime}$ ong-tse se retira (118).

Lorsque $K^{\prime}$ ong-tse était âgé de dix-sept ans (119), un grand officier de Lou, Mong Hi-tse (120), tomba malade et, se trouvant sur le point de mourir, donna cet avertissement au fils qui devait lui succéder, (Mong) I-tse (121) : 
- [ (122) Kong K'ieou est le descendant d'un homme saint (123); son aïeul p.295 Fou-fou Ho avait d'abord (le trône de) Song, mais, quoique étant l'héritier légitime, il céda la place au duc $L i$ (124). Puis Tcheng K'ao-lou (125) aida les ducs Tai (799-766), Ou (765-748) et Siuen (747-729) ; (élevé à des dignités de plus en plus hautes par) trois décrets (successifs), il ne fit que redoubler d'humilité ; c'est pourquoi l'inscription de son trépied était ainsi conçue :

« A la première nomination, j'ai courbé la tête ; — à la seconde nomination, j'ai baissé les épaules ; - à la troisième nomination, je me suis tenu profondément incliné (126). - Je marche en p.296 rasant les murs; — d'ailleurs personne ne se permet de me mépriser ; - je prépare ma bouillie épaisse de millet dans cet (ustensile); - je prépare ma bouillie claire de millet dans cet (ustensile) — pour donner la bouillie à ma bouche (127).

Telle fut son humilité. Pour moi, j'ai entendu dire que, même si le descendant d'un p.297 homme saint n'occupe pas dans le monde la place qui lui revient (128), (dans sa postérité) cependant il ne manquera pas d'y avoir un homme doué de pénétration.] Maintenant, Kong K'ieou, quoique jeune, s'entend bien aux rites; ne serait-ce pas lui qui est l'homme doué de pénétration? Quand je ne serai plus, ayez soin de le prendre pour maître. »

Puis (Mong) Hi-tse mourut (129); (Mong) Hi-se et Nan-kong King-chou (130), du pays de Lou, allèrent (auprès de $K$ 'ong-tse), pour étudier les rites.

En cette année (535), Ki Ou-tse mourut (131); (Ki) P'ing-tse lui succéda.

$K$ 'ong-tse était pauvre et de condition humble (132). Devenu homme fait, il fut scribe au service (du chef) de la famille $K i$ (133) et le compte et la mesure des grains furent ${ }_{\text {p.298 }}$ exacts ; il fut officier chargé de s'occuper des pieux (134) (auxquels on attache les bœufs et les moutons) et les bestiaux devinrent nombreux et se multiplièrent. De ces (fonctions), il s'éleva à la charge de $s e-k$ 'ong ; puis il quitta (le pays de) Lou ; il fut chassé (du pays) de $T s^{\prime} i$; il fut rejeté (des pays) de Song et de $W e i$; il se trouva en péril entre (les pays) de Tch'en et de Ts'ai; puis il revint dans (le pays de) Lou (135).

K'ong-tse était haut de neuf pieds six pouces. Les hommes l'appelaient tous un géant et s'émerveillaient (de sa taille) (136). (Le prince de) Lou le traita de nouveau bien, et c'est pourquoi il revint dans (le pays de) Lou (137).

p.299 Nan-kong King-chou, (du pays) de Lou, dit au prince de Lou :

- Je vous demande la permission d'aller avec K'ong-tse dans (le pays des) Tcheou. 
Le prince de Lou lui donna un char, deux chevaux et un serviteur (138), et ensemble (139) (Nan-kong King-chou et K'ong-tse) se rendirent dans (le pays des) Tcheou (140). (K'ong-tse) s'informa des rites. Ce fut sans doute alors qu'il vit Lao-tse (141). Quand ${ }_{\text {p.300 }}$ il prit congé pour s'en aller, Lao-tse le reconduisit en lui disant :

- J'ai entendu dire que l'homme riche et puissant reconduit les gens en leur donnant des richesses, que l'homme bon reconduit les gens en leur donnant des paroles. Je ne saurais être riche et p.301 puissant, mais je prends furtivement (142) le titre d'homme bon; je vous reconduirai donc en vous donnant des paroles, et voici ce que je vous dirai : Celui qui est intelligent et qui est profond observateur est près de mourir, car il critique les hommes avec justesse ; celui dont l'esprit est très savant, ouvert et vaste (143), met en péril sa personne, car il dévoile les défauts des hommes. Celui qui est fils ne peut plus se posséder ; celui qui est sujet ne peut plus se posséder (144).

Quand K'ong-tse fut revenu du (pays des) Tcheou (145) p.302 dans (la principauté de) Lou, ses disciples affluèrent graduellement en nombre de plus en plus grand (146).

En ce temps, le duc P'ing (557-532)(147), de $T$ sin, se livrait à des excès (148); les six hauts dignitaires empiétèrent sur son autorité ; du côté de l'Est, ils attaquèrent les seigneurs. Le roi Ling (540-529), de Tch'ou, avait une forte puissance militaire; il opprimait (149) les Royaumes du Milieu (150). Ts' $i$ était grand et était voisin de Lou. Lou était petit et faible; s'il voulait se rattacher à $T c h$ 'ou, $T \sin$ s'en irriterait; s'il prétendait se rattacher à $T \sin$, c'est alors Tch'ou qui viendrait l'attaquer; s'il ne se mettait pas en garde contre $T s^{\prime} i$, les soldats de $T s^{\prime} i$ envahiraient (le territoire de) Lou.

La vingtième année (522) du duc Tchao, de Lou, K'ong-tse étant donc (151) âgé de trente ans, le duc King, de Ts'i, vint avec Yen Yng dans le pays de Lou (152). Le duc King demanda à K'ong-tse :

- Autrefois le duc Mou (659-621), de Ts'in, avait un royaume petit et demeurait dans une ${ }_{\text {p.303 }}$ région écartée. Comment se fait-il qu'il ait obtenu l'hégémonie?

(K’ong-tse lui) répondit :

- Quoique (le duc de) Ts 'in eût un royaume petit, sa résolution était grande; quoiqu'il demeurât dans une région écartée, sa conduite était juste et correcte (153). Lui-même il éleva en dignité « (le grand officier des) cinq béliers » (154) et lui donna le titre de grand officier; il le retira des liens qui le garrottaient ${ }_{(155)}$ et s'entretint avec lui pendant trois jours; il lui confia le gouvernement. Si on prend cela en considération, (on reconnaîtra 
que,) même obtenir la royauté (156) (le duc de $T s^{\prime}$ 'in) l'eût pu ; c'est peu qu'il ait obtenu l'hégémonie. »

Le duc King fut satisfait (157).

Lorsque $K$ 'ong-tse avait trente-cinq ans (517), Ki P'ing-tse, à cause d'un combat de coqs qu'il avait fait avec Heou Tchao-po (158), se rendit coupable aux yeux du duc Tchao, de Lou; le duc Tchao, à la tête de ses soldats, attaqua (Ki) P'ing-tse ; mais celui-ci, unissant les forces de sa famille ${ }_{\mathrm{p} .304}$ à celles des deux familles Mong et Chou-suen (159), attaqua le duc Tchao ; les soldats du duc Tchao furent battus, et lui-même s'enfuit dans (le pays de) $T s^{\prime} i$; le duc de) $T s$ ' $i$ logea le duc Tchao à Kan-heou (160). Peu de temps après cela, (le pays de) Lou fut en révolution ; $K$ 'ong-tse se rendit dans (le pays de) $T s^{\prime} i$ et se mit au service personnel de Kao Tchao-tse (161), dans l'espérance de parvenir ainsi jusqu'au duc King. Il conversa sur la musique avec le grand maître de la musique (du pays) de $T s^{\prime} i$; il entendit les airs de (la musique) chao; il les étudia, et, pendant trois mois, il ne connut pas le goût de la viande (162). Les gens de $T s$ ' $i$ le louèrent.

p.305 [ (163) Le duc King interrogea K'ong-tse sur le gouvernement. K'ongtse lui dit :

- (Pour que le gouvernement soit bon, il faut) que le prince agisse en prince, que le sujet agisse en sujet, que le père agisse en père, que le fils agisse en fils (164).

Le duc King dit :

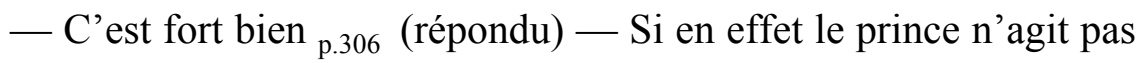
en prince, si le sujet n'agit pas en sujet, si le père n'agit pas en père, si le fils n'agit pas en fils, même si j'avais mes revenus, comment pourrai-je en jouir ? » (165)].

Un autre jour, (le duc King) interrogea encore K'ong-tse sur le gouvernement. K'ong-tse dit :

- Le bon gouvernement consiste à user avec modération des richesses (166) ».

[ (167) Le duc King fut satisfait (168); il se proposait de ${ }_{\text {p.307 }}$ donner en apanage $\grave{a}$ K'ong-tse les champs de $\mathrm{Ni}$ - $k^{\prime} i$, (mais) Yen Yng s'avança et dit :

- Les lettrés (169) sont des sophistes (170) qu'on ne peut prendre pour modèle et pour norme (171). Arrogants, et ne suivant que leurs propres opinions, on ${ }_{\text {p.308 }}$ ne saurait leur faire diriger le peuple (172). Attachant une grande importance aux deuils, ils se livrent à l'affliction ; ils ruinent les fortunes dans des funérailles somptueuses (173); on ne saurait leur faire diriger les mœurs. Discoureurs qui vont de lieu en lieu pour demander à emprunter (174), on ne saurait leur faire diriger l'État. Après l'apparition des grands sages (175), quand la 
maison des Tcheou tomba en décadence, les rites et la musique furent défectueux et eurent des lacunes. (C'est pourquoi) maintenant $K$ 'ong-tse multiplie les formes extérieures et les belles apparences (176) ; il complique les rites pour ${ }_{\text {p.309 }}$ monter et pour descendre, les règles pour marcher rapidement et pour marcher les bras étendus (177). Plusieurs vies ne suffiraient pas à épuiser les études (qu'il prescrit); en y employant des années (178) on ne parviendrait pas à examiner à fond les rites (qu'il impose). $\mathrm{O}$ prince, si vous voulez lui confier un emploi afin d'amener un changement dans les mœurs (du pays) de $T s^{\prime} i$, ce ne sera point là le moyen de mettre le (bien du) menu peuple au premier rang (de vos préoccupations) (179).

Après cela, le duc King traita $K^{\prime}$ 'ong-tse avec respect quand il l'admettait en sa présence, mais il ne l'interrogea plus sur (ses opinions concernant les) rites (180).]

[Un autre jour, le duc King retint $K^{\prime}$ 'ong-tse et lui dit :

- Vous honorer comme (le duc de Lou honore) le chef de la famille $K i$, je ne le puis.

Il le traita d'une manière ${ }_{\text {p.310 }}$ intermédiaire entre celle qui convenait au chef de la famille $K i$ et celle qui convenait au chef de la famille Mong (181) ].

Les grands officiers de $T s^{\prime} i$ voulaient du mal à K'ong-tse ; K'ong-tse en informa (le duc King); le duc King lui [dit: "Je suis vieux; je ne puis me servir de vous (182) " K'ong-tse alors s'en alla] et revint dans (le pays de) Lou (183).

Lorsque K'ong-tse eut quarante-deux ans (510), le duc Tchao, de Lou, mourut à Kan-heou (184). Le duc Ting monta sur le trône. La cinquième année (505) du duc Ting, en été, Ki P'ing-tse mourut. (Ki) Hoan-tse lui succéda (comme chef de la famille $K i$ ).

\# [Ki Hoan-tse, en creusant,un puits, trouva une jarre de terre dans laquelle était un être qui ressemblait à un mouton. Il interrogea $K^{\prime}$ 'ong-tse à ce sujet en lui disant :

— J'ai trouvé un chien.

Tchong-ni dit :

- D'après ce que moi, K'ieou, j'ai appris, c'est un mouton. Voici ce que ${ }_{\text {p.311 }}$ moi, K'ieou, j'ai appris : les prodiges du bois et de la pierre sont le $k$ 'oei et le wang-leang; les prodiges de l'eau sont le dragon et le wang-siang; le prodige de la terre est le mouton fen (185).]

p.312 [(Le prince de) $O u(186)$, ayant attaqué (le prince de) Yue (494), bouleversa le Koei-ki (187) et trouva un ossement, qui faisait la charge entière 
d'un char. (Le prince de) $O u$ envoya un émissaire demander à Tchong-ni comment il se faisait que cet ossement fût si grand. Tchong-ni dit :

- Yu fit venir la foule des divins sur la montagne Koei-ki (188). p.313 Fang-fong (189) arriva en retard, Yu le tua et exposa son corps ; chacun de ses ossements faisait la charge entière d'un char. Voilà pourquoi cet (ossement) est grand.

L'étranger de $O u$ dit :

- Qui étaient les divins ?

Tchong-ni répondit :

- Les dieux (190) des montagnes et des cours d'eau sont capables de régler le monde (191); ceux qui président (aux sacrifices qu'on leur rend) sont les divins. (Ceux qui président aux sacrifices qu'on rend aux) dieux du sol et des moissons sont les ducs et les p.314 marquis (192). Tous dépendaient du roi (193).

L'étranger dit :

- (A quels sacrifices) présidait Fang-fong?

Tchong-ni répondit :

- Il était prince de Wang-wang (194); il présidait aux montagnes Fong et $Y u$ (195). Il était du clan $H i$. A l'époque de $Y u$ (Choen), des Hia et des Chang, (cette principauté) était celle de Wang-wang; à l'époque des Tcheou, ce fut celle des Ti géants (196); aujourd'hui on appelle (les gens de ce pays) les hommes grands.

L'étranger demanda :

— Quelle est la grandeur de la taille humaine (197) ?

Tchong-ni répondit :

- (Le peuple des) Tsiao-yao a trois pieds $\left(\frac{198}{)}\right)$; c'est la dernière petitesse ; les hommes les plus ${ }_{\text {p. } 315}$ grands ne dépassent pas dix fois cette taille (199) ; c'est là le chiffre extrême. »]

Alors l'étranger de $\mathrm{Ou}$ dit :

— Très bien (répondu) ! Voilà un homme saint.

Un courtisan de (Ki) Hoan-tse, nommé Tchong-leang Hoai, avait des raisons d'inimitié contre Yang Hou ; p.316 Yang Hou voulut chasser (Tchong leang) Hoai ; Kong-chan Pou-nieou l'en empêcha (200). L'automne de cette même année (505), (Tchong-leang) Hoai ayant redoublé d'arrogance, Yang Hou l'arrêta. (Ki) Hoan-tse en fut irrité et c'est pourquoi Yang Hou emprisonna $(K i)$ Hoan-tse ; il fit une convention avec lui, puis le relâcha ; à la suite de cela, Yang Hou redoubla de mépris pour la famille $\mathrm{Ki}$. La famille $\mathrm{Ki}$, de son côté, empiétait sur les prérogatives de la famille ducale. Ceux qui 
étaient doublement sujets (201) exerçaient le gouvernement de 1'État; ainsi, dans le pays de Lou, depuis les grands officiers jusqu'aux fonctionnaires subalternes, tous s'arrogeaient des droits usurpés et s'éloignaient de la droite voie. Aussi, K'ong-tse n'exerça-t-il aucune fonction publique ; il se retira et arrangea (202) les Poésies, le Chou (king), les rites et la musique ; ses disciples furent plus nombreux que jamais; ils venaient même des contrées éloignées p.317 et il n'était personne qui ne reçût son enseignement (203).

La huitième année du duc Ting (502 av. J.-C.), Kong-chan Pou-nieou, n'obtenant pas ce qu'il désirait de la famille $K i$, s'unit à Yang Hou pour faire des troubles; (lui et Yang Hou) désiraient dégrader les chefs par droit de naissance des trois familles issues du duc Hoan, et leur substituer ceux des fils de naissance inférieure qui étaient de longue date affectionnés à Yang Hou ; ils (tentèrent) donc de s'emparer de Ki Hoan-tse ; mais (Ki) Hoan-tse, grâce à un stratagème, put s'échapper (204).

La neuvième année du duc Ting (501 av. J.-C.), Yang Hou, n'ayant pas eu le dessus, s'enfuit dans le pays de $T$ s' $i$. A cette époque, $K$ 'ong-tse était âgé de cinquante ans (205).

Kong-chan Pou-nieou, s'étant rendu maître de la ville de $P i$ (206), se révolta contre la famille $K i$. Il envoya un messager inviter $K$ 'ong-tse à venir auprès de lui. K'ong-tse se conformait à la raison depuis fort longtemps; il était très expérimenté (207) et ne trouvait cependant point à être mis dans des fonctions publiques (208); il n'était personne qui ${ }_{\text {p.318 }}$ pût se servir de lui ; il dit :

- Puisque (les rois) Wen et $\mathrm{Ou}(\underline{209})$ de (la dynastie) Tcheou sont partis de Fong et de Hao pour devenir rois (210), maintenant $P i$, quoique étant une petite localité, ne pourrait-il peut-être pas (avoir la même destinée) ?

Il désirait se rendre (auprès de Kong-chan Pou-nieou). Tse-Lou ne fut pas content et retint $K^{\prime}$ ong-tse. $K^{\prime}$ 'ong-tse lui dit :

[ (211) - Celui qui m'appelle à lui, comment le ferait-il sans raison? S'il se sert de moi, ne ferai-je pas de lui un Tcheou oriental ? (212)]

En définitive cependant, il ne partit pas (213).

Quelque temps plus tard, le duc Ting nomma $K^{\prime}$ 'ong-tse gouverneur de Tchong-tou (214); au bout d'un an, aux p.319 quatre points cardinaux tous prenaient (K'ong-tse) pour modèle $(\underline{215})$; du poste de gouverneur de Tchongtou il fut promu à celui d'intendant des travaux publics (216), et, de ce poste, à celui de chef de la justice (217).

La dixième année du duc Ting (500 av. J.-C.), au printemps, (Lou) fit la paix avec $T s^{\prime} i$. En été, un grand officier de $T s^{\prime} i$, Li Tch'ou, dit au duc King : 
- (Le duc de) Lou se sert de Kong K'ieou et cette circonstance est dangereuse pour $T s^{\prime} i$.

Alors (le duc de $T s^{\prime} i$ ) envoya un ambassadeur pour inviter (le duc de) Lou à une réunion p.320 amicale ; on se réunit à Kia-kou (218). Le duc Ting, de Lou, se disposait à y aller amicalement (219) avec ses chars ordinaires (220) ; K'ongtse, qui exerçait les fonctions de conseiller (221), lui dit :

- Votre sujet a entendu dire que, lorsqu'il y a une affaire pacifique, on doit avoir fait des préparatifs de guerre, et que, lorsqu'il y a une affaire guerrière, on doit avoir fait des préparatifs de paix. Dans p.321 l'antiquité, lorsqu'un seigneur sortait de son territoire, il ne manquait pas de prendre ses officiers avec lui pour l'accompagner. Je vous demande de prendre avec vous vos maréchaux de gauche et de droite.

Le duc Ting dit :

- Je vous approuve.

Il prit avec lui ses maréchaux de gauche et de droite. Il se rencontra avec le prince de $T_{s}$ ' $i$ à Kia-kou. On disposa une esplanade avec trois marches en terre et (les deux princes) se virent suivant les rites des entrevues (222). Après s'être salués et s'être cédé le pas, ils montèrent (sur l'esplanade). Quand ils eurent terminé le rite de s'offrir le vin de part et d'autre, un fonctionnaire de $T s$ ' $i$ s'avança rapidement et vint dire :

- Je propose qu'on fasse la musique des quatre points cardinaux (223).

Le duc King y consentit. Aussitôt, guidons en plumes et en poils, plumes et genouillères (224), piques et hallebardes, épées et boucliers de s'avancer au bruit des tambours et des cris (225). K'ong-tse s'avança ${ }_{\text {p.322 }}$ promptement et gravit les marches (de l'esplanade), mais sans monter sur la dernière; il leva ses manches et dit :

- Nos deux princes tiennent une réunion amicale. Que vient faire ici la musique des barbares $I$ et $T i$ ? Je demande que des ordres soient donnés aux officiers pour que les officiers repoussent (ces danseurs).

Comme (les danseurs) ne s'en allaient pas, les assistants regardèrent alors Yen-tse et le duc King ; le duc King éprouvait de la honte dans son cœur; il fit donner un signal avec le drapeau et renvoya (les danseurs). Au bout d'un moment, un fonctionnaire de $T s$ ' $i$ s'avança rapidement et dit :

- Je propose qu'on fasse la musique de l'intérieur du palais.

Le duc King y consentit. Des chanteurs grotesques et des nains (226) se présentèrent en faisant des tours. $K$ 'ong-tse s'avança promptement ; il gravit les marches (de l'esplanade), mais sans monter sur la dernière, et dit : 
- Quand des hommes de basse condition jettent le trouble (227) parmi des seigneurs, leur crime mérite la mort. Je demande que des ordres ${ }_{\text {p.323 }}$ soient donnés aux officiers pour que les officiers appliquent la loi.

(Alors on mit à mort les nains (228)) ; leurs mains et leurs pieds (229) furent dispersés (230). Le duc King, saisi de crainte, fut ébranlé ; il comprit qu'il ne s'était pas conformé à la justice. A son retour, il eut fort peur et dit à ses officiers assemblés :

- (Les gens de) Lou soutiennent leur prince par la doctrine des sages ; mais vous, vous ne m'avez instruit que dans les doctrines des barbares $I$ et $T i$ et vous avez fait que je me suis rendu coupable envers le prince de Lou. Quel remède y apporter?

Un fonctionnaire s'avança et lui répondit :

«Quand le sage a commis une faute, il s'en excuse par des actes réels; quand un homme inférieur a commis une faute, il s'en excuse par des paroles (vides) ; ô prince, si vous êtes affligé de ce que vous avez fait, excusez-vous en d'une manière réelle.

Alors le marquis de $T s$ ' $i$ (231), pour s'excuser de sa faute, rendit les champs de Yun, Wen-yang et Koei-yn (232) qu'il avait pris à Lou.

p.324 La treizième année du duc Ting (497) (233), en été, K'ong-tse dit au duc Ting :

- Un sujet ne doit pas avoir des armes cachées ; un grand officier ne doit pas avoir des murailles de cent $t c h e$ de tour (234).

Il chargea ${ }_{\text {p.325 }}$ [Tchong-yeou (235) d'être le conseiller du chef de la famille $K i$ dans l'intention de démanteler les trois places fortes (236) : Alors le chef de la famille Chou-suen commença par démanteler Heou. Le chef de la famille $K i$ s'apprêtait à démanteler Pi, mais Kong-chan Pou-nieou (237) et Chou-suen Tche se mettant à la tête des gens de $P i$, attaquèrent à l'improviste (la capitale) de Lou; le duc et les chefs des trois (familles issues du duc Hoan) entrèrent dans le palais du chef de la famille $K i$ et montèrent sur le belvédère $O u$-tse. Les gens de $P i$ les attaquèrent mais n'eurent pas l'avantage; il y en eut cependant qui pénétrèrent jusqu'auprès du duc (238). K'ong-tse ordonna à Chen Kiu-siu et à Yo K'i (239) de descendre (du belvédère) pour les combattre. Les gens de $P i$ furent vaincus ; ceux du royaume (de Lou) les ${ }_{\text {p.326 }}$ poursuivirent et les battirent à Kou-mie (240). (Kong-chan Pou-nieou et Chou-suen Tche) s'enfuirent tous deux dans (le pays de) $T s$ ' $i$. Alors on démantela $P i]$.

[Comme on s'apprêtait à démanteler Tch'eng, Kong-lien Tch'ou-fou dit au chef de la famille Mong-suen :

« Si on démantèle Tch'eng, les gens de $T s$ 'i arriveront certainement (aussitôt) à la porte du nord; d'ailleurs, Tch'eng est le rempart 
protecteur de la famille Mong ; supprimer Tch'eng, c'est supprimer la famille Mong. Pour moi, je ne démantèlerai pas (cette ville) $(\underline{241})$. Le douzième mois, le duc assiégea Tch'eng, mais ne put en triompher.]

La quatorzième année (496) du duc Ting, K'ong-tse, alors âgé de cinquante-six ans, quitta la charge de ministre de la justice pour exercer les fonctions de conseiller (242). Comme il avait l'air content, un de ses disciples lui dit :

- J'ai entendu dire que le sage, lorsque le malheur arrive n'est pas saisi de crainte, et, lorsque le bonheur arrive n'éprouve pas de joie.

K'ong-tse dit :

« Ce dicton existe en effet. Mais ne dit-on pas aussi : Il se réjouit de ce que, étant élevé en dignité, il s'humilie devant les autres $(\underline{243})$ ?

Puis (244) il mit à mort le chao tcheng Mao, grand officier de Lou qui jetait le désordre dans le gouvernement (245).

p.327 Quand on eut associé (K'ong-tse) au gouvernement de l'État, au bout de trois mois ceux qui vendaient des agneaux et de jeunes porcs ne faussaient plus leurs prix ; les hommes et les femmes qui passaient se tenaient séparés les uns des autres sur la route ; sur le chemin on ne ramassait pas ce qui avait été laissé par mégarde (246); les étrangers venus des quatre points cardinaux, quand ils étaient arrivés dans la ville, n'avaient pas à recourir aux magistrats, car on les traitait tous comme s'ils avaient été dans leur propre pays (247).

Les gens de $T s$ ' $i$ apprirent cela et en furent effrayés ; p.328 ils dirent :

«Puisque K'ong-tse exerce le gouvernement, certainement (Lou) obtiendra l'hégémonie. Quand il aura atteint l'hégémonie, comme c'est nous dont le territoire est le plus proche, c'est nous qui serons les premiers annexés. Pourquoi ne pas lui offrir un territoire (248) ?

Li Tch'ou (249) dit :

- Je propose d'essayer d'abord de mettre obstacle (à K'ong-tse) ; si nous lui mettons obstacle, mais que cela ne réussisse pas, comment serait-il alors trop tard pour offrir (à Lou) un territoire ?

Alors (250) a on choisit dans le pays de $T s^{\prime} i$ quatre-vingts belles femmes (251), qui, revêtues toutes d'habits élégants, jouaient en dansant la musique $k$ 'ang (252), et trente quadriges de chevaux superbes pour les envoyer au prince de Lou. Ces danseuses et ces beaux chevaux furent exposés en dehors de la Porte Haute, au sud de la capitale de Lou. Ki Hoan-tse alla les voir ${ }_{\text {p.329 }}$ sous un déguisement et y retourna à deux et à trois reprises ; désireux d'accepter (les présents), il dit au prince de Lou d'aller faire un tour sur la route; (le prince de Lou) alla et contempla (ces femmes et ces chevaux) 
jusqu'à la fin du jour ; il négligea les affaires du gouvernement. Tse-lou dit (à K'ong-tse) :

- Maître, il vous faut partir.

K'ong-tse répondit :

- (Le prince de) Lou va bientôt faire le sacrifice kiao ; s'il envoie de la viande du sacrifice aux grands officiers (253), je pourrai encore rester.

[ (254) (Ki) Hoan-tse en définitive reçut les danseuses (du pays) de $T s$ ' $i$, et trois jours durant, on ne s'occupa pas du gouvernement.] En outre lors du sacrifice kiao, on n'envoya pas de la viande du sacrifice découpée sur l'étal aux grands officiers. $K^{\prime}$ 'ong-tse alors partit (255).

Il passa la nuit à T'oen (256). Or, le maître de musique $I$, p.330 qui l'avait accompagné, lui dit :

- Maître, vous n'avez commis aucune faute.

K'ong-tse lui dit :

— Puis-je vous chanter quelque chose?

Il chanta ceci :

Les bouches de ces femmes (257) - ont réussi à me chasser:

La visite de ces femmes - est cause de mort et de ruine:

J'errerai donc de ci et de là, - et cela jusqu'à l'année de ma fin (258).

Lorsque le maître de musique $I$ fut revenu (dans la capitale de Lou), (Ki) Hoan-tse lui demanda :

- Que vous a dit de son côté K'ong-tse?

Le maître de ${ }_{\text {p.331 }}$ musique $I$ lui raconta ce qui s'était passé. (Ki) Hoan-tse dit en poussant un profond soupir :

- Si le maître me juge coupable, c'est à cause de cette troupe de femmes viles (259).

K'ong-tse se rendit alors dans le pays de Wei (260). Il habita dans la maison de Yen Tchouo-tseou (261), frère aîné de la femme de Tse-lou.

Le duc Ling, de Wei, demanda à K'ong-tse quels étaient ses appointements quand il résidait dans (le pays de) Lou. Il répondit qu'il recevait soixante mille mesures (262) de grain. Les gens de Wei lui attribuèrent aussi soixante mille mesures de grain. Au bout d'un certain temps, quelqu'un ayant calomnié K'ong-tse auprès du duc Ling de Wei, le duc Ling chargea Kongsuen Yu-kia de l'accompagner dans toutes ses allées et venues. K'ong-tse craignit d'être accusé d'un crime, et, au bout de dix mois, il quitta le pays de Wei. 
p.332 Se proposant d'aller dans (le pays de) Tch'en (263), il passa par $K^{\prime}$ oang (264). Yen $K^{\prime} O(\underline{265})$ lui servait de cocher; il lui montra de son fouet (la ville) en lui disant :

- Autrefois je suis entré ici par cette brèche (266).

Des gens de $K^{\prime}$ oang entendirent ce propos et prirent ( $K^{\prime}$ ong-tse) pour Yang Hou, du pays de Lou. Yang Hou avait autrefois violenté les gens de K'oang. Les gens de $K^{\prime}$ oang arrêtèrent donc $K^{\prime}$ 'ong-tse. K'ong-tse avait un extérieur qui ressemblait à celui de Yang Hou; on se saisit de lui. Au bout de cinq jours, [ (267) Yen Yuen arriva en retard ; le maître lui dit :

— Je pensais que vous étiez mort.

Yen Yuen répondit :

- O maître, tant que vous vivez, comment pourrais-je mourir (268) ?]

Les gens de $K^{\prime}$ oang gardant $K^{\prime}$ 'ong-tse avec ${ }_{\text {p. } 333}$ un redoublement de rigueur, les disciples eurent peur ; [ (269) K'ong-tse leur dit :

- Après que le roi Wen eut disparu, sa perfection ne fut-elle pas placée en cet homme-ci (270) ? Si le Ciel avait voulu faire périr cette perfection, moi, le successeur du mort (271), je n'aurais pu obtenir de participer à cette perfection. Puisque le Ciel ne veut point encore faire périr cette perfection, que peuvent les gens de $K^{\prime}$ 'oang contre moi ?

K'ong-tse chargea un de ceux qui le suivaient de se mettre au service de Ning Ou-tse (272) dans (le pays de) Wei et c'est ainsi qu'il put s'en aller.

Il partit et passa alors à $P$ 'ou (273).

p.334 Au bout de plus d'un mois il revint dans le pays de Wei. Il demeura dans la maison de K'iu Po-yu (274).

Parmi les femmes du duc Ling, il y avait Nan-tse (275). Elle envoya un messager dire à $K^{\prime}$ ong-tse :

- Les sages, venus des quatre points cardinaux, qui n'ont pas eu honte de désirer entretenir des relations fraternelles avec notre prince, n'ont pas manqué de me rendre visite, à moi humble princesse (276); moi humble princesse, je désire vous voir.

K'ong-tse (commença par) s'excuser, mais, ne pouvant faire autrement, il alla lui rendre visite. L'épouse (du prince) était cachée derrière des tentures ; quand $K$ 'ong-tse eut franchi la porte, il se prosterna en se tournant vers le nord. L'épouse (du prince) salua par deux fois de derrière les tentures ; ses bracelets et ses pendeloques rendirent un son de jade comme lorsqu'on frappe la pierre sonore (277). $K^{\prime}$ ong-tse ${ }_{\text {p.335 }}$ dit : 
— Je pensais d'abord ne pas lui rendre visite ; mais, quand j'ai été en sa présence elle m'a répondu suivant les rites.

[ (278) Tse-Lou étant mécontent, K'ong-tse s'expliqua franchement (279) avec lui, disant :

« Si j'ai mal fait, c'est le Ciel qui m'y a contraint, c'est le Ciel qui m'y a contraint $(\underline{280})$.]

Après qu'il eut résidé plus d'un mois dans le pays de Wei, le duc Ling fit une sortie dans un char où il était avec sa femme et où l'eunuque Yong K'iu était monté à côté d'eux (281); il ordonna à $K^{\prime}$ 'ong-tse de monter ${ }_{\text {p.336 }}$ sur un char derrière eux (282); ils se promenèrent ainsi à travers toute la place du marché. [ (283) K'ong-tse dit :

- Je n'ai point encore vu quelqu'un qui aime la vertu comme on aime une belle femme (284). ]

Alors, trouvant cela honteux, il quitta (le pays de) Wei.

Il passa par Ts'ao (285). Cette année-là, le duc Ting, de Lou, mourut (495) (286).

K'ong-tse partit de $T s^{\prime}$ 'ao et alla (dans le pays de) Song (287). Tandis qu'il s'exerçait aux rites avec ses disciples au ${ }_{\text {p.337 }}$ pied d'un grand arbre, Hoan T'oei, se-ma de Song, voulant tuer $K^{\prime}$ 'ong-tse, abattit cet arbre. K'ong-tse se retira, mais comme ses disciples lui disaient qu'il fallait se hâter, il leur répondit :

[ (288) - Le Ciel a produit en moi la vertu. Que peut Hoan T'oei contre moi (289) ?]

K'ong-tse se rendit (dans le pays de) Tcheng (290). S'étant séparé par mégarde de ses disciples (291), K'ong-tse se trouvait seul debout à la porte orientale du faubourg (292). Un homme de Tcheng dit à Tse-kong :

- A la porte orientale est un homme (293) qui par le front (294) ressemble à Yao, par la nuque ressemble à Kao-yao (295), par les épaules ${ }_{\text {p.338 }}$ ressemble à Tse-tch'an (296). Cependant, il s'en faut de trois pouces que la partie de son corps qui est au-dessous de la ceinture n'atteigne (la taille de) $Y u$ (297). Il est tout embarrassé, comme le chien dans une famille où il y a un mort (298).

Tse-kong rapporta fidèlement ce propos à K'ong-tse ; K'ong tse tout joyeux dit en riant :

- La forme extérieure (du corps) est sans importance (299) ; mais que je ressemble au chien dans une famille où il y a un mort, cela est bien vrai, cela est bien vrai (300).

p. 340 K'ong-tse alla alors (dans le pays) de) Tch'en (301). Il demeura dans la maison du surveillant des remparts Tcheng-tse (302). Au bout de plus d'un an, 
le roi de $O u$, Fou-tch'ai, attaqua Tch'en; il lui prit trois villes, puis se retira (303). Tchao Yang attaqua (la ville de) Tchao-ko. (Le roi de) Tch'ou assiégea (la capitale de) $T s$ 'ai ; (le prince (de) $T s$ 'ai se transporta dans (le pays de) $O u$. (Le roi de $O u$ battit le roi de Yue, Keou-tsien, à Koei-ki (304).

[ ( $\underline{305}$ ) Il y eut un épervier ( $\underline{306}$ ) qui s'abattit dans le palais (du p.341 prince) de Tch'en et mourut; une flèche en bois hou (307) le traversait; elle avait une pointe en pierre $(\underline{308})$; la flèche était longue d'un pied et huit pouces. Le duc Min (무), de Tch'en, envoya un messager interroger Tchong-ni (à ce sujet). Tchong-ni dit :

- Cet épervier vient de loin (110), c'est là une flèche des Sou-chen (311). Autrefois, quand le roi $O u$ eut triomphé (de la dynastie) des Chang, il fit pénétrer entièrement son influence) chez les neuf (peuples) ${ }_{\text {p. } 342} I$ et chez les cent (tribus) Man; il les obligea tous à venir apporter en tribut des présents consistant en produits de leurs pays respectifs et les empêcha ainsi d'oublier les obligations de leurs fonctions. Alors les Sou-chen apportèrent en tribut des flèches en bois hou, qui avaient une pointe en pierre et qui étaient longues de un pied et huit pouces. L'ancien roi (11), voulant manifester son excellente vertu (313), donna en partage les flèches des Sou-chen à Ta-ki (314); il maria celle-ci au duc Hou, (descendant) de $Y u(\underline{315})$, en donnant Tch'en en fief (à ce dernier). (Dans l'antiquité), on attribuait à ceux qui appartenaient à la famille royale des joyaux, (afin de) renforcer leur amitié ; on attribuait à ceux qui appartenaient à des familles étrangères les redevances des pays lointains, afin qu'ils n'oubliassent pas d'être soumis. C'est ainsi qu'on attribua à Tch'en les flèches des Sou-chen.

On vérifia le fait en opérant des recherches dans les ${ }_{\text {p.343 }}$ anciens magasins (du palais) et en effet on y trouva (ces flèches) (316).]

K'ong-tse demeura trois années dans (le pays de) Tch'en. A cette époque Tsin et Tch'ou se contestaient la prédominance et tour à tour ils attaquaient Tch'en; Ou aussi envahissait Tch'en; Tch'en subissait constamment des ravages. [ (317) K'ong-tse dit :

— Je m'en retourne ! je m'en retourne! mes jeunes disciples sont ardents mais négligents ; ils vont de l'avant pour saisir (la sagesse), mais ils n'oublient pas leur ancienne nature (318).]

Alors K'ong-tse partit (du pays de) Tch'en.

p.344 Il passa par $P^{\prime}$ ou (319). En ce moment, le chef de la famille Kong-chou s'était révolté dans cette ville (320). Les gens de $P^{\prime}$ 'ou arrêtèrent $K$ 'ong-tse. Parmi ses disciples se trouvait un certain Kong Leang Jou ; il suivait K'ongtse avec cinq chars qui étaient sa propriété particulière; c'était un homme d'âge mûr, et il était sage ; il était brave et fort. Il dit : 
- Auparavant déjà, en vous accompagnant, ô ${ }_{\text {p.345 }}$ maître, je me suis trouvé en péril à Koang (321). Si maintenant je me trouve de nouveau en péril ici, c'est la destinée qui le veut. Puisque pour la seconde fois, ô maître, je suis pris dans des difficultés avec vous, il vaut mieux que je meure en combattant.

Il combattit avec une extrême vigueur (322). Les gens de $P^{\prime}$ ou eurent peur et dirent à $K^{\prime}$ ong-tse :

- Si réellement vous n'allez pas dans le pays de $W e i$, nous vous laisserons sortir.

Ils conclurent avec lui une convention jurée et firent sortir $K^{\prime}$ ong-tse par la porte orientale (323). K'ong-tse se rendit immédiatement dans le pays de Wei (324). Tse-kong lui demanda :

- A-t-on le droit de violer un serment?

K'ong-tse répondit :

- C'était un serment extorqué par la violence; les dieux ne l'ont pas entendu (325).

p.346 Le duc Ling, de Wei, apprenant la venue de $K$ 'ong-tse, fut content et alla à sa rencontre hors de la ville. Il lui demanda :

- Devons-nous attaquer $P^{\prime}$ ou ?

- Vous le devez, répondit ( $K^{\prime}$ ong-tse).

Le duc Ling reprit :

- Mes grands officiers estiment que nous ne le devons pas. Maintenant en effet, $P^{\prime}$ ou est ce par quoi $W e i$ se prémunit contre $T$ sin et Tch'ou. L'attaquer avec (les forces mêmes de) Wei, n'est-ce pas une chose qu'on ne doit pas faire (326) ?

K'ong-tse dit :

- Dans cette ville, les hommes sont résolus à mourir (pour leur patrie) (327); les femmes désirent protéger le $S i$-ho (328); ceux que nous combattrons ne seront que quatre ou cinq hommes.

p.347 Le duc Ling approuva fort ces paroles, mais il n'attaqua pas $P$ 'ou.

Le duc Ling était vieux ; il négligeait le gouvernement ; il ne se servit pas de K'ong-tse. K'ong-tse dit en soupirant profondément :

[ (로) - S'il il y avait (un prince) qui fût capable de se servir de moi, au bout d'un cycle de douze mois il y aurait déjà un résultat obtenu ; au bout de trois ans, la perfection serait réalisée. ]

K'ong-tse partit (3ㅜ). 
Pi Hi était gouverneur de Tchong-meou (31); lorsque Tchao Kien-tse fit la guerre aux familles Fan et Tchong-hang et attaqua Tchong-meou, Pi Hi se révolta. Il envoya des gens inviter $K^{\prime}$ 'ong-tse à venir ; [ (332) $K^{\prime}$ ong-tse était disposé à se rendre auprès de lui ; Tse-lou (33) lui dit :

- O maître, moi Yeou, je vous ai entendu dire : Lorsqu'un homme agit personnellement d'une manière mauvaise, le sage n'entre pas (dans son pays). Maintenant $\mathrm{Pi} H i$ s'est révolté en personne à Tchong-meou et vous désirez vous rendre auprès de lui. Qu'est-ce que cela signifie?

K'ong-tse répondit :

- Il y a en effet ce dicton. Mais ne dit-on pas (aussi) : Ce qui est dur, on peut le frotter sans l'user? ne dit-on pas : Ce qui est blanc, on peut le plonger dans la teinture sans le rendre ${ }_{\text {p.348 }}$ noir $(\underline{334})$ ? Suis-je une calebasse qui peut rester pendue sans manger (335) ?]

[ (336) Comme $K$ 'ong-tse jouait de la pierre sonore, un homme portant un panier pour les herbes vint à passer devant sa porte et dit :

- Il a du cœur, celui qui joue (ainsi) de ${ }_{\text {p.349 }}$ la pierre sonore ! mais il est trop opiniâtre! puisque personne ne l'apprécie, qu'il se résigne (337).]

[ (338) K'ong-tse apprit à jouer du luth (3ㅜ) auprès du maître de musique Siang-tse (340). Au bout de dix jours, comme il ne p.350 progressait pas, le maître de musique Siang-tse lui dit :

— Vous pouvez aller plus loin.

K'ong-tse lui répondit :

- Moi K'ieou, je me suis exercé aux mélodies (de cette musique), mais je n'ai pas encore saisi les proportions numériques.

Quelque temps après, (Siang-tse) lui dit :

- Vous vous êtes exercé aux proportions numériques; vous pouvez aller plus loin.

$K$ 'ong-tse répondit :

- Moi K'ieou, je n'ai pas encore saisi les intentions (de cette musique).

Quelque temps après, (Siang-tse) lui dit :

- Vous vous êtes exercé aux intentions (de cette musique); vous pouvez aller plus loin.

K'ong-tse répondit : 
- Moi K'ieou, je n'ai pas encore compris quel homme était (celui qui a fait cette musique).

Quelque temps après, (Siang-tse) lui dit :

- Vous avez avec votre air majestueux quelque pensée profonde : vous avez avec votre air joyeux quelque haute espérance et

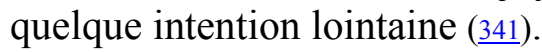

( $K^{\prime}$ ong-tse) répondit :

- Moi K'ieou, j'ai saisi qui était cet homme. Sous une apparence ténébreuse il est noir (342); p.351 de haute taille, il est grand. Son regard est celui du mouton qui regarde au loin ( $\underline{343}$ ); son cœur est comme celui de quelqu'un qui règne sur les royaumes des quatre points cardinaux. Si ce n'est le roi Wen, qui peut être un tel homme (344) ?

Le maître de musique Siang-tse quitta sa natte (345) et se prosterna par deux fois en disant :

- Les maîtres de musique disent en effet que c'est un air de musique du roi $W e n$.

K'ong-tse n'étant pas parvenu à obtenir un emploi public dans (le pays de) Wei (346), se disposa à aller dans l'Ouest rendre visite à Tchao Kien-tse (347). Mais, arrivé au Fleuve (348) il apprit la mort de Teou Ming-tou (349) et de Choen-hoa.

p.352 Il s'approcha du bord du Fleuve et dit en soupirant :

«Qu'elle est belle, cette onde dont l'étendue est immense ! Si moi K'ieou je ne traverse pas ce (Fleuve), c'est la Destinée qui l'a voulu.

Tse-kong, s'avançant promptement vers lui, lui dit :

— Permettez-moi de vous demander pourquoi vous dites cela.

K'ong-tse répondit :

- Teou Ming-tou et Choen hoa étaient de sages grands officiers du royaume de $T \sin$. Tant que Tchao Kien-tse ne fut point parvenu à ses fins, il eut besoin de ces deux hommes pour pouvoir plus tard exercer le gouvernement; mais ensuite, quand il fut parvenu à ses fins, il tua (ces deux hommes) et alors exerça le gouvernement. Moi K'ieou, j'ai entendu dire ceci : Quand on fend les matrices pleines pour tuer les êtres prématurément, le $k$ ' $i$ et le lin (350) ne viennent pas dans la banlieue ; lorsqu'on dessèche les étangs pour prendre les poissons en les mettant à sec, le dragon kiao (351) ne maintient pas l'harmonie entre les principes yn et yang; lorsqu'on renverse les nids pour briser les neufs, le fong et le hoang (352) 
n'arrivent pas en voltigeant. Qu'est-ce à dire ? C'est que le sage s'éloignera de celui qui fait du mal à ceux qui lui sont semblables ; en effet, si les oiseaux et ${ }_{\text {p. } 353}$ les quadrupèdes eux-mêmes, en ce qui concerne ceux qui se conduisent contrairement à la justice, savent les éviter, à combien plus forte raison, moi Kieou (devrai-je agir de même) (ㅎ3) !

Alors il revint sur ses pas, et, s'étant reposé dans le bourg de Tseou (354), il y composa le chant Tseou ( $\underline{355}$ ) afin d'exprimer son affliction à ce sujet. Puis il revint dans le pays de $\mathrm{Wei}$ et alla demeurer dans la maison de K'iu Po-yu (356).

Un autre jour, [ (357) le duc Ling l'interrogea sur la manière de disposer les rangs des soldats. $K$ 'ong-tse lui dit :

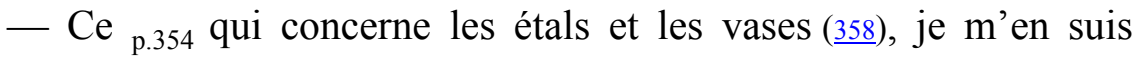
enquis depuis longtemps. Mais ce qui concerne les armées et les bataillons, je ne l'ai jamais étudié (ㅁ5).]

Le lendemain, (le duc Ling) s'entretenait avec K'ong-tse (ㅎ6) lorsqu'il vit une oie sauvage qui volait; il leva la tête pour la regarder et parut ne plus s'occuper de $K^{\prime}$ 'ong-tse (361). K'ong-tse aussitôt partit. Il se rendit de nouveau dans (le pays de) Tch'en (362).

En été (493), le duc Ling, de Wei, mourut. On mit sur le trône son petit-fils Tchao; ce fut le duc Tch'ou, de Wei. [ (363) Le sixième mois, Tchao Yang réinstalla l'héritier présomptif $K^{\prime}$ 'oai-wai dans (la ville de) Ts'i (364). Yang Hou fit prendre le bonnet de deuil à l'héritier présomptif et chargea huit hommes, portant le pectoral et la ceinture de deuil, de se prétendre faussement venus de Wei pour l'accueillir. (K'oai-wai) fit son entrée en pleurant (dans la ville de $\left.T s^{\prime} i\right)$ et s'y installa ( $\left.\underline{365}\right)$.

p.355 En hiver, (le prince de) Ts'ai transféra (sa capitale) à Tcheou-lai (366). Cette année était la troisième année (492) du duc Ngai; K'ong-tse était alors âgé de soixante ans (367). Ts'i aida Wei (368) à assiéger (la ville de) $T s^{\prime} i$ parce que l'héritier présomptif $K^{\prime}$ oai-wai s'y trouvait.

En été (492), les temples funéraires (des ducs) Hoan (711-694) et $\mathrm{Hi}$ (659-627), de Lou, furent incendiés. Nan-kong King-chou prit les mesures de secours en cette ${ }_{\text {p.356 }}$ occasion ( $\underline{369)}$. K'ong-tse, qui se trouvait dans (le pays de)

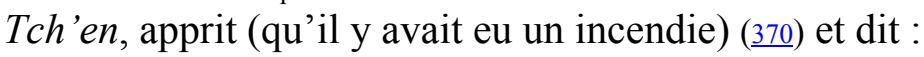

- Cette calamité a dû atteindre les temples funéraires (des ducs) Hoan et Hi.

Plus tard, on sut qu'il en avait été réellement ainsi.

p.357 En automne (492), Ki Hoan-tse tomba malade ; porté dans une voiture tirée par des hommes, il vint visiter la ville (capitale du pays) de Lou et dit en soupirant profondément : 
- Ce royaume a failli devenir prospère ; ${ }_{\text {. } 358}$ mais, parce que j'ai commis une faute à l'égard de $K^{\prime}$ ong tse (371), il n'a point été prospère.

Il fit ses dernières recommandations à son héritier $(\mathrm{Ki}) \mathrm{Kang}$-tse en lui disant :

- Quand je serai mort, vous deviendrez certainement conseiller (du prince) de Lou. Quand vous serez conseiller du prince de Lou, ne manquez pas d'appeler auprès de vous Tchong-ni.

Quelques jours après, $(\mathrm{Ki})$ Hoan-tse mourut ; $(\mathrm{Ki}) K^{\prime}$ 'ang-tse lui succéda dans ses dignités. Quand il eut fait les funérailles (de son père), il voulut appeler auprès de lui Tchong-ni ; (mais) Kong Tche-yu lui dit :

- Autrefois, votre père défunt donna un emploi à $K$ 'ong-tse, mais ne le garda pas jusqu'au bout, et, en définitive, fut la risée des seigneurs. Si maintenant vous le reprenez à votre service et que vous ne puissiez pas le garder jusqu'au bout, vous serez de rechef la risée des seigneurs.

(Ki) K'ang-tse demanda :

— Qui dois-je alors appeler auprès de moi ?

(Kong Tche-yu) lui répondit :

- Il vous faut appeler Jan K'ieou (372).

Alors (Ki K'ang-tse) envoya un messager mander Jan K'ieou. Jan K'ieou se disposant à partir, $K^{\prime}$ ong-tse dit :

- Si les gens de Lou mandent (Jan) K'ieou, ce n'est pas pour l'employer à de petites choses, c'est pour l'employer à de grandes choses.

Ce même jour, $K$ 'ong-tse dit :

p.359 [ $(\underline{373})$ - Je m'en retourne ! je m'en retourne ! Mes jeunes disciples sont ardents, mais négligents; ils réalisent (parfois) avec élégance la perfection, mais ils (374) ne savent comment régler (leur conduite).]

Tse-kong, sachant que K'ong-tse songeait à revenir (dans le pays de Lou), accompagna Jan K'ieou et en profita pour lui donner cet avertissement :

- Quand vous serez entré en charge, faites en sorte que $K^{\prime}$ ong-tse soit appelé.

Jan Kieou partit alors.

L'année suivante (491), K'ong-tse se transporta (du pays) de Tch'en dans celui de $T s$ 'ai (375). Le duc Tchao, de $T s^{\prime}$ 'ai, se disposait (alors) à se rendre auprès (du roi) de $O u$, car (le roi de) Ou l'avait mandé ; comme le duc Tchao avait précédemment (493), en trompant ses ministres, p.360 transféré (sa 
capitale) à Tcheou-lai, lorsque, plus tard (491) il se disposa à aller (auprès du roi de $O u$ ), ses grands officiers craignirent qu'il ne fît un nouveau transfert (de capitale); (aussi) Kong-suen P'ien tua-t-il à coups de flèches le duc Tchao (491) (376). (Le roi de) Tch'ou envahit (alors le territoire de) Ts'ai. En automne, le duc King, de Ts' $i$, mourut (377).

L'année suivante (489) (378), K'ong-tse partit de Ts'ai pour aller dans (la ville de) Che (379). [ ( $\underline{380}$ ) Le gouverneur de Che interrogea sur le gouvernement $K$ 'ong-tse qui lui p.361 répondit :

- Le bon gouvernement consiste à attirer à soi ceux qui sont éloignés, et à attacher à soi ceux qui sont proches (381).]

Un autre jour, [ (382) le gouverneur de Che interrogea Tse-Lou au sujet de K'ong-tse et Tse-Lou ne lui répondit pas (383). K'ong-tse, l'ayant appris, dit :

- Vous, Yeou (384), pourquoi ne lui avez-vous pas répondu : C'est un homme] qui étudie la sagesse sans se lasser, qui enseigne les hommes sans en éprouver de satiété (호), [qui a une telle ardeur (pour atteindre la vertu) qu'il en oublie de manger, qui a une telle joie (quand il l'a obtenue) qu'il en oublie ses tristesses, et qui ne s'aperçoit pas que la vieillesse arrive (386)?

(K'ong-tse) partit de Che et revint à Ts'ai (387). p.362 [ (388) Tch'ang-tsiu et Kie-ni (389) étaient ensemble à labourer. K'ong-tse, jugeant que c'étaient des (sages) qui se cachaient (390), envoya Tse-lou leur demander où était le gué. Tch'ang-tsiu dit :

- Celui qui tient les rênes dans le char, qui est-ce?

Tse-lou répondit :

- C'est K'ong- K'ieou.

L'autre dit :

— Est-ce donc K'ong K'ieou, (du pays) de Lou (391) ?

Sur la réponse affirmative (de Tse-lou), il dit :

- Cet homme connaît le gué (392).

Kie-ni demanda à Tse-lou :

- Qui ${ }_{\text {p.363 }}$ êtes-vous?

— Je suis Tchong Yeou, répondit-il.

— Êtes-vous, ajouta (Kie-ni), disciple de Kong K'ieou?

Sur sa réponse affirmative, Kie-ni dit :

- Comme cette immensité désordonnée (393), ainsi est tout l'empire. Qui pourrait le changer? Plutôt donc que de suivre un 
sage qui évite (tel ou tel) homme, ne vaudrait-il pas mieux suivre les sages qui évitent le monde (entier) (394)?

Il se mit à recouvrir les semences (ㅁ5) sans s'arrêter. - Tse-lou rapporta (ces paroles) à $K^{\prime}$ ong-tse. $K^{\prime}$ ong-tse dit avec abattement :

- Les oiseaux et les bêtes sauvages, nous ne pouvons nous associer avec eux et vivre en leur compagnie (부). Si l'empire était bien ordonné, qu'aurais-je besoin de le changer ?]

Un autre jour, [ (397) (Tse-lou rencontra sur sa route un vieillard qui portait sur l'épaule un panier, et lui demanda :

- Avez-vous vu le Maître ?

Le vieillard répondit :

- Vos quatre membres ne se donnent pas de ${ }_{\text {p.364 }}$ peine ; les cinq espèces de céréales ne sont pas distinguées (par vous). Qui est le Maître (398) !

Il enfonça son bâton dans le sol et se mit à sarcler. Tse-Lou raconta ce qui s'était passé à $K$ 'ong-tse qui dit :

— C'est un sage) qui se cache.

(Tse-lou) retourna (là où il avait vu le vieillard), mais celui-ci avait disparu.]

K'ong-tse s'était transporté dans (le pays de) $T s^{\prime}$ 'ai depuis trois ans (491-489), lorsque (le roi de) $O u$ attaqua (le pays de) Tch'en. (Le roi de) Tch'ou vint au secours de Tch'en et campa à Tch'eng-fou (399) (489); il apprit que $K^{\prime}$ 'ong-tse se trouvait dans la région comprise entre Tch'en et $T s^{\prime}$ 'ai (400); (le roi de) Tch'ou envoya des gens apporter des présents à $K$ 'ong-tse pour l'inviter à venir. $K$ 'ong-tse se disposait à aller (l'en remercier en) le saluant suivant les rites; mais les grands officiers de $T c h$ 'eu et de $T s$ 'ai firent un complot entre eux, en disant :

- K'ong-tse est un sage ; tous les blâmes qu'il formule atteignent les défauts des seigneurs. Maintenant, il a longtemps séjourné dans la région comprise entre ${ }_{\mathrm{p} .365} T \mathrm{Th}$ 'en et $T \mathrm{~s}^{\prime} a i$; la conduite que nous tenons, nous les grands officiers, n'est en rien conforme aux intentions de Tchong-ni. Maintenant, (le roi de) Tch'ou (règne sur) un grand royaume; il a apporté des présents à $K^{\prime}$ 'ong-tse pour l'inviter à venir; si K'ong-tse trouve un emploi auprès (du roi) de Tch'ou, les grands officiers qui exercent le gouvernement à Tch'en et à $T s$ 'ai seront en péril.

Ils s'entendirent donc pour envoyer des satellites qui cernèrent $K$ 'ong-tse dans la campagne et l'empêchèrent d'avancer (401).

p.366 [ (402) Les vivres firent défaut (403); ceux qui l'accompagnaient tombèrent malades et devinrent incapables de se lever;] K'ong-tse 
(cependant) discourait et récitait, jouait d'un instrument à cordes et chantait sans se laisser abattre. [Tse-lou, manifestant un vif déplaisir, vint à lui et dit :

— Le sage lui aussi doit-il être en détresse?

K'ong-tse répondit :

— Le sage supporte avec fermeté d'être en détresse (404); mais quand l'homme vulgaire est ${ }_{\text {p.367 }}$ en détresse, il ne connaît plus aucun frein.]

Tse-lou rougit (405).

[ (

- Vous, $S e$ (407), vous pensez sans doute que je suis un homme qui a appris beaucoup de choses et qui les sait.

(Toan-mou $\mathrm{Se}$ ) répondit :

— Oui. Ne serait-ce pas exact?

K'ong-tse répondit :

- Ce n'est pas exact. Je n'ai que le seul principe qui fait tout comprendre.]

K'ong-tse, sachant que ses disciples avaient de l'irritation dans leur cour, appela Tse-lou (408) et lui demanda :

- Il est dit dans le Che (king) :

"Nous ne sommes ni des rhinocéros ni des tigres pour nous tenir dans ces régions désertes (409).

Ma sagesse serait-elle en faute ? Pourquoi me trouvé-je dans une telle situation?

Tse-lou répondit :

- A mon avis, c'est parce que nous ne sommes point encore bons que les hommes ne nous croient pas; à mon avis, c'est parce que nous ne sommes point encore sages que les hommes ne mettent pas en pratique nos préceptes (410).

Kong-tse répliqua :

- En ${ }_{\text {p.368 }}$ serait-il ainsi ? O Yeou, pour prendre des exemples, si l'homme bon était nécessairement cru, comment y aurait-il eu Po-i et Ch'ou-ts'i (411)? si l'homme sage voyait nécessairement ses préceptes mis en pratique, comment y aurait-il eu le fils de roi Pi$\operatorname{kan}(\underline{412})$ ?

Tse-lou étant parti, Tse-kong se présenta. K'ong-tse lui dit :

- O Se (413), il est dit dans le Che (king) : 


\section{"Nous ne sommes ${ }_{\mathrm{p} .369}$ ni des rhinocéros ni des tigres pour nous tenir dans ces régions désertes.}

Ma sagesse serait-elle en faute ? Pourquoi me trouvé-je dans une telle situation?

Tse-kong répondit :

- Votre sagesse, ô Maître, est d'une grandeur extrême. C'est pourquoi il n'est personne dans l'empire qui puisse vous admettre. O maître, vous devriez vous abaisser un peu.

$K$ 'ong-tse répliqua :

«O Se, un bon laboureur peut semer, mais il n'est pas sûr qu'il puisse récolter; un bon artisan peut être habile, mais il n'est pas sûr qu'il puisse plaire (au goût des clients); l'homme supérieur peut mettre en pratique sa sagesse; les règles essentielles, les maintenir ; les principes généraux, les observer ; mais il n'est pas sûr qu'il puisse se faire admettre. Maintenant, quand vous dites qu'il ne faut pas mettre en pratique la sagesse qu'on possède, mais chercher à se faire admettre, ô $S e$, vos visées ne sont pas à longue portée.

Tse-kong étant parti, Yen Hoei se présenta. K'ong-tse lui dit :

— O Hoei, il est dit dans le Che (king) :

"Nous ne sommes ni des rhinocéros ni des tigres pour nous tenir dans ces régions désertes.

Ma sagesse serait-elle en faute ? Pourquoi me trouvé-je dans une telle situation?

Yen Hoei répondit :

- Votre sagesse, ô Maître est d'une grandeur extrême; c'est pourquoi il n'est personne dans l'empire qui. puisse vous admettre ; cependant, ô Maître, continuez sans relâche à la mettre en pratique : si on ne vous admet pas, quel mal y a-t-il à cela ? si on ne vous admet pas, plus tard pourtant on reconnaîtra en vous l'homme supérieur (414). Quand la sagesse n'est pas mise en pratique (par nous), c'est une honte pour nous ; mais ${ }_{\text {p.370 }}$ quand la sagesse s'est trouvée pleinement réalisée par nous et qu'on ne nous emploie pas, c'est une honte pour ceux qui possèdent des royaumes. Si on ne vous admet pas, quel mal y a-t-il à cela ? Si on ne vous admet pas, plus tard pourtant on reconnaîtra en vous l'homme supérieur.

K'ong-tse se montra content et dit en riant : 
- Vous avez raison. O enfant de la famille Yen, si vous aviez beaucoup de richesses, je serais votre intendant (415).

p.371 Ensuite, (K'ong-tse) envoya Tse-kong à Tch'ou (416). Le roi Tchao, de Tch'ou, mit en campagne des soldats qui vinrent au devant de $K^{\prime}$ 'ong-tse, et c'est ainsi qu'il put échapper.

Le roi Tchao se proposait de donner en fief à K'ong-tse (417) un territoire comprenant sept cents groupes de familles (1ㅛ) p.372 enregistrées ; le ling-yn de Tch'ou, Tse-si (419), lui dit :

- Parmi les ambassadeurs que Votre Majesté envoie auprès des seigneurs, en est-il qui vaillent Tse-kong?

La réponse étant négative, il reprit :

- Parmi les conseillers d'État de Votre Majesté, en est-il qui vaillent Yen Hoei?

La réponse étant négative, il ajouta :

- Parmi les généraux de Votre Majesté, en est-il qui vaillent Tselou?

La réponse étant négative, il ajouta :

- Parmi les fonctionnaires de Votre Majesté, en est-il qui vaillent Tsai $Y u$ $(\underline{420})$ ?

La réponse ayant encore été négative, ${ }_{\mathrm{p} .373}$ il reprit :

- En outre, l'ancêtre (des rois) de Tch'ou reçut l'investiture des Tcheou qui lui conférèrent le titre de vicomte ou de baron et un territoire de cinquante $l i$. Maintenant $K^{\prime}$ 'ong-tse se conforme aux règlements des trois premières dynasties et remet en honneur la politique (des ducs) de Tcheou et de Chao (ㄴ1). Si Votre Majesté le prend à son service, comment (le royaume de) Tch'ou pourra-t-il devenir de génération en génération de plus en plus magnifique et occuper une étendue de plusieurs milliers de $l i$ ? (D'autre part), lorsque le roi Wen était à Fong et lorsque le roi $\mathrm{Ou}$ était à $\mathrm{Hao}$, ils n'étaient princes que d'un pays de cent $l i$ (422) ; en définitive cependant ils régnèrent sur l'empire entier. Maintenant si K'ong K'ieou devient maître d'un territoire et s'il a pour l'aider ses disciples sages, cela ne peut porter bonheur à Tch'ou (423).

Alors le roi Tchao renonça (à son projet). Dans l'automne de cette année-là (489), le roi Tchao mourut à Tch'eng-fou (424).

[ Le fou (du pays) de Tch'ou, Tsie-yu (425), passa en ${ }_{\text {p.374 }}$ chantant devant K'ong-tse ; il disait : 
- O phénix ! O phénix ! ${ }_{\text {p.375 }}$ combien ta vertu est dégénérée (426); pour ce qui est passé, les reproches sont inutiles, mais, pour l'avenir, on peut encore aller à ta poursuite (pour t'empêcher d'aller plus loin) (427). Cesse ! Cesse ! Dans le temps présent, les hommes qui prennent part au gouvernement sont en péril (428).

$K$ 'ong-tse descendit (de son char) (229) dans l'intention de causer avec lui, mais il se retira en toute hâte, et (K'ong-tse) ne put lui parler.]

Alors $K^{\prime}$ 'ong-tse revint (du pays) de Tch'ou (430) dans celui ${ }_{\text {p.376 }}$ de Wei. En cette année-là, $K^{\prime}$ 'ong-tse avait soixante-trois ans et c'était la sixième année (489) du duc Ngai, de Lou.

L'année suivante (488), (le roi de) Ou et (le duc de) Lou eurent une entrevue à Tseng (431). (Le roi de $O u$ ) exigea cent groupes de victimes. Le premier ministre (de $\mathrm{Ou})$, (Po) P'i manda Ki Kang-tse ; (Ki) K'ang-tse chargea Tse-kong (432) de se rendre auprès de lui et c'est ainsi qu'il put mettre fin (à cette affaire) (ㄴ3).

[ (434) $\mathrm{K}^{\prime}$ ong-tse dit :

— Les gouvernements de Lou et de Wei sont frères (노).]

p.377 En ce temps, le père de Tcho, prince de Wei, n'avait pu monter sur le trône et se trouvait à l'étranger (436); les seigneurs avaient souvent fait des remontrances à ce sujet (au prince de $\mathrm{Wei}$ ). (D'autre part), un grand nombre de disciples de $K^{\prime}$ 'ong-tse étaient investis de charges publiques dans le pays de $W e i$. Le prince de Wei désira s'attacher K'ong-tse afin de lui confier le gouvernement (437).

p.378 [ (438) Tse-Lou dit (à K'ong-tse) :

- Le duc de Wei vous retient pour vous confier le gouvernement. Que considérerez-vous comme la première (tâche à entreprendre) ?

$K$ 'ong-tse répondit :

— L'essentiel, c'est de rendre les dénominations correctes (439).

Tse-Lou dit :

— En est-il vraiment ${ }_{\text {p.381 }}$ ainsi ? Maître, vous vous égarez (440). A quoi bon cette correction?

$K$ 'ong-tse répliqua :

- Que vous êtes simple, ô Yeou (441). Si les dénominations ne sont pas correctes, p.384 les paroles ne sont pas conformes (à la réalité des choses); si les paroles ne sont pas conformes (à la réalité des choses), les entreprises ne réussissent pas; si les entreprises ne réussissent pas, les rites et la musique ne sont pas florissants; si les rites et la musique ne sont pas florissants, les supplices et les punitions ne sont pas équitables; si les supplices et les 
punitions ne sont pas équitables, le peuple ne sait où mettre la main ni le pied (442). Ainsi le sage peut certainement dénommer ${ }_{\text {p.385 }}$ ce qu'il fait (443) et peut certainement mettre, à exécution ce qu'il dit. L'homme supérieur, dans ses paroles, ne (prononce) rien à la légère (ㄴ4) $)$.

L'année suivante (484), Jan Yeou (445), étant à la tête de l'armée pour le compte de $K i$ ( $K^{\prime}$ ang-tse), combattit contre $T s^{\prime} i$ à Leang (446) et le vainquit. $K i$ $K$ 'ang-tse lui demanda :

- Vos talents militaires sont-ils acquis par l'étude, ou vous sont-ils innés?

Jan Yeou répondit :

- $\mathrm{Je}_{\mathrm{p} .386}$ les ai acquis en étudiant auprès de $K^{\prime}$ ong-tse.

Ki K'ang-tse reprit :

— Quelle sorte d'homme est K'ong-tse?

(Jan Yeou) répondit :

- Si on lui donne une fonction publique, il aura de la gloire (447); quand il annoncera (녕) au peuple (ce qu'il aura fait) et quand il interrogera à ce sujet les divinités (449), nul ne sera mécontent (ㄴ5); ce qu'il recherche, p.387 c'est d'atteindre à cette conduite vertueuse (451). Même si vous accumulez autour de lui mille groupes de familles (452) (pour les lui donner en apanage), $K^{\prime}$ ongtse n'en tirera pas d'avantage personnel (ㄴ5).

(Ki) K'ang-tse dit :

— Je désire le mander auprès de moi. Est-ce possible ?

(Jan Yeou) répondit :

- Si vous désirez le mander auprès de vous, ne le traitez pas avec étroitesse (454) comme vous feriez pour un homme de peu; dans ces conditions ce sera possible.

Cependant, dans le pays de Wei, [(455) K'ong Wen-tse (456), se p.388 disposant à attaquer T'ai-chou (457), demanda à Tchong-ni de lui proposer un plan (d'attaque) ; Tchong-ni s'excusa en disant qu'il n'y connaissait rien (458); puis, s'étant retiré, il donna des ordres pour qu'on attelât son char et pour partir ; il dit (alors) :

- L'oiseau peut choisir l'arbre (sur lequel il se pose); mais comment l'arbre pourrait-il choisir l'oiseau (ㄴ5) ?

(K'ong) Wen-tse s'efforçait de le retenir lorsque $K i$ K'ang-tse envoya (460) l'honorable Hoa, l'honorable Pin et l'honorable Lin, avec des présents, p.389 au-devant de $K^{\prime}$ ong-tse. K'ong-tse revint (donc) dans (le pays de) Lou.] 
K'ong-tse était parti de Lou depuis quatorze années en tout (461) lorsqu'il revint dans (le pays de) Lou.

Le duc Ngai ayant interrogé (K’ong-tse) sur le gouvernement, il répondit :

- Le gouvernement consiste à (savoir) choisir les ministres (462).

Ki K'ang-tse ayant interrogé ( $K^{\prime}$ ong-tse) sur le gouvernement, il répondit :

[ (463) - (Le bon gouvernement consiste à) élever les bons et à placer les méchants (dans des places inférieures) (464); alors les méchants deviendront bons.]

[ (ㄴ5) $(K i) K^{\prime}$ 'ang-tse se plaignant des voleurs, $K^{\prime}$ ong-tse lui dit :

- Si vous ${ }_{\text {p. } 390}$ n'aviez pas de convoitises, même si vous offriez des récompenses on ne déroberait pas (466).]

En définitive cependant, Lou (467) ne put pas confier de fonctions à $K$ 'ong-tse, et $K$ 'ong-tse de son côté ne demanda aucune charge officielle.

A l'époque de $K$ 'ong-tse, la maison des Tcheou s'était amoindrie et les rites et la musique avaient été négligés : le Che et le Chou (468) étaient devenus défectueux. (K'ong-tse) rechercha et suivit à la piste les (textes relatifs aux) rites des trois dynasties.

Il fit des préfaces aux récits du Chou (469); en haut, il mit p.391 en ordre les temps de T'ang (Yao) et de $Y u$ (Choen) ; en bas, il arriva jusqu'au (duc) Mou,

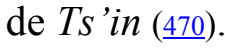

Il groupa et classa les sujets dont ils traitaient (471). Il disait :

[ (472) - Les rites des Hia, je puis en parler, mais $K^{\prime} i$ ne fournit pas une vérification suffisante; les rites des Yin, je puis en parler, mais Song ne fournit pas une vérification suffisante (473). Si (ces deux royaumes) suffisaient (à p.392 la vérification), moi je pourrais (à mon tour) fournir la vérification (de mes dires (474)).]

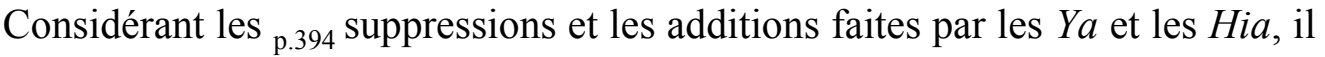
disait :

[ (475) - Même dans cent générations on pourra les connaître (476)].

Tant pour la forme que pour le fond, [les p.395 Tcheou ont observé les deux dynasties (477). Très achevée est la perfection (de leurs rites). Je me conformerai aux (rites des) Tcheou (478).

p.396 Ainsi les récits du Chou et les mémoires sur les rites (479) nous viennent de $K$ 'ong (tse).

[ (480) K'ong-tse tint ce discours au grand maître de la musique (481) (du pays) de Lou : 
- La musique, on peut la connaître (482). Lorsque le début se produit (483), il y a accord. Quand on donne carrière (aux autres instruments) (484), il p.397 $\mathrm{y}$ a harmonie, il y a distinction, il y a continuité (485), et ainsi se réalise (la musique parfaite.)] [(ㅃ6) Depuis que je suis revenu (du pays) de Wei dans celui de Lou, la musique a été rendue correcte : le ya et le song ont été chacun mis à leur place (487).

p.398 Autrefois, le Che (488) comprenait plus de trois mille pièces. Lorsque vint $K^{\prime}$ ong-tse, il supprima celles qui faisaient double emploi et ne conserva que celles qui pouvaient être utiles pour les rites et la justice. En haut, il recueillit (celles qui concernaient) Sie et Heou-tsi (489); au milieu, il transmit (celles qui se rapportaient aux) temps prospères des $Y n$ et des Tcheou; il arriva jusqu'à (celles qui traitaient des) époques défectueuses, des (rois) Yeou et $L i(\underline{490)}$. Commençant aux nattes sur lesquelles on se couche, ce qui est la raison de l'expression « les désordres de (l'ode) Koan ts'iu (491) », il en fit le p.399 commencement du fong; de (l'ode) lou ming, il fit le commencement du siao ya; de (l'ode) Wen wang, il fit le commencement du ta ya; de (l'ode) ts'ing miao, il fit le ${ }_{\text {p.400 }}$ commencement du song (492). Il y eut trois cent cinq pièces (493) que $K$ 'ong-tse jouait sur la cithare et chantait, afin de chercher à les accorder avec les harmonies (des musiques) chao, ou, ya et song (494).

A partir de ce moment, les rites et la musique purent être connus et transmis afin de montrer au complet la conduite qui convient au souverain et afin de rendre parfaites les six disciplines (495).

K'ong-tse sur le tard, se plut au I (496), au siu, au t'oan, au hi, au siang, au chouo koa et au wen yen (497). Quand il p.402 lisait le $I$, les lanières de cuir se rompirent trois fois (보). Il dit :

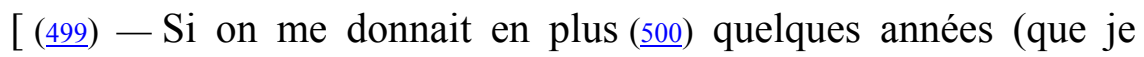
pusse employer) ainsi, je parviendrais à une connaissance parfaite du $I(\underline{501})$.]

p.403 K'ong-tse prenait pour matière de son enseignement le Che (les Poésies), le Chou (les Documents historiques), les Rites et la Musique. Ses disciples doivent avoir été au nombre de trois mille. Ceux qui personnellement comprirent entièrement les six disciplines (502) furent au nombre de soixante-douze (503). Quant à ceux qui, p.404 comme Yen, Tchouo et Tsiu (504), reçurent quelques parties de sa doctrine, ils furent extrêmement nombreux.

[ ( $\underline{505})$ K'ong-tse enseignait quatre choses : les sujets d'instruction (506), les devoirs sociaux (507), le loyalisme et la bonne foi.] [ (0ㅛ) Il s'était affranchi de quatre choses: il s'abstenait de présumer; il s'abstenait des résolutions arbitraires ; il n'avait pas d'obstination ; il n'avait pas d'égoïsme,]

[ (무) Ce à quoi il était attentif, c'étaient les cas de jeûne, de combat (510), de maladie] 
p.405 [ (511) Le Maître parlait rarement de l'avantage, de la destinée et de la bonté absolue (512).]

[ (1ㅡ) Devant celui qui ne manifestait pas un vif désir (d'apprendre), il ne s'expliquait pas (514); quand il avait montré un coin (d'une question) (515), si on ne lui répondait p.406 pas (en témoignant qu'on avait vu) les trois autres coins, il ne recommençait pas (sa leçon).]

[ (516) Lorsqu'il était dans son village, il paraissait saisi de respect et semblait quelqu'un qui n'osait pas parler (517). Lorsqu'il était dans le temple ancestral (518) ou aux p.407 audiences de la cour, il discourait avec beaucoup de netteté, mais en restant attentif.]

[ (519) Lorsqu'il était à la cour (avant l'audience), il s'entretenait avec les grands officiers supérieurs d'une manière correcte et cérémonieuse; il s'entretenait avec les grands officiers inférieurs d'une manière aimable et enjouée ( $\underline{520})$. ]

p.408 [ (521) Quand il entrait par la porte du duc (22), c'était en pliant p.409 son corps $(\underline{523})$;) [il s'avançait rapidement en étendant (ses bras comme) des ailes. ( $\underline{524})]$

p.410 [(525) Quand le prince l'appelait pour le charger de recevoir un

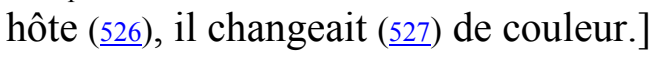

[ (528) Quand il était appelé par un ordre du prince, il n'attendait pas que sa voiture fût prête (529).]

[ (530) Quand le poisson était trop avancé ou quand la viande était gâtée,] [ou quand (la nourriture) n'était pas coupée régulièrement, il ne mangeait pas.]

p.411 [ (531) Quand sa natte n'était pas disposée régulièrement, il ne S'asseyait pas (ㅌ52).]

[ (533) Quand il mangeait à côté d'une personne en deuil, il ne mangeait jamais de manière à se rassasier. — Le jour où il avait fait des lamentations (sur un mort), il ne chantait pas,]

[ (534) Quand il voyait un homme en deuil ou un aveugle, même si c'était un jeune garçon, il ne manquait pas de changer de contenance.]

[ (535) (Le Maître disait) : «Quand nous sommes trois hommes allant

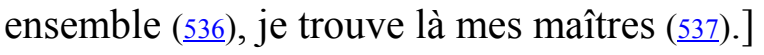

p.412 [ (효) (Le Maître disait) :

- Que, lorsqu'il s'agit de la vertu, on ne la pratique pas constamment, que, lorsqu'il s'agit de l'étude, on ne s'y exerce pas par la discussion, que, lorsqu'on apprend ce qui est juste, on ne s'y porte pas (539), que, lorsqu'on fait ce qui n'est pas bien, on ne se corrige pas, voilà ce qui me tourmente (540). ] 
[ (41) Quand il faisait chanter un homme, si c'était bien il le faisait recommencer et alors il l'accompagnait.]

[ (42) Le Maître ne discourait pas sur les prodiges, les tours de force (543), les actes de rébellion et les êtres surnaturels (544).

[ (ㄴ5) Tse-kong dit :

- Les enseignements du Maître sur les arts libéraux, on peut les apprendre ; mais les paroles du Maître sur la voie céleste ainsi que sur la nature humaine et la destinée, on ne peut les apprendre (546).]

p.413 [ (547)Yen-Yuen dit en poussant un profond soupir :

- Lorsque je levais la tête pour regarder (les enseignements du Maître), ils me semblaient de plus en plus élevés ; quand je les creusais, ils me semblaient de plus en plus résistants ; quand je les considérais devant moi, soudain ils se trouvaient derrière moi. Le Maître, d'une manière très méthodique, excelle à guider les hommes. Il m'a développé par l'instruction et m'a contenu par les rites. Quand je voulais renoncer (à l'étude de ces enseignements), je ne le pouvais pas ; après avoir épuisé toutes mes capacités, il y avait encore comme quelque chose de très élevé qui se dressait (devant moi); quand bien même je voulais y atteindre, je ne trouvais pas le moyen de le faire. ]

p.414 [ (548) Un jeune garçon du canton de Ta-Hiang (49) dit :

- Vraiment grand est $K^{\prime}$ ong-tse ; il a des connaissances vastes sans avoir acquis de réputation en quelque spécialité.

Le Maître ayant appris ce propos, dit :

- A quoi m'attacherai-je ? m'attacherai-je à l'art de conduire un char ou m'attacherai-je au tir à l'arc ? Je m'attacherai à l'art de conduire un char!]

[ (550) Lao (ㅎ51) dit :

- Le Maître disait : C'est parce que je n'avais pas de fonction publique que je me suis adonné aux arts libéraux.]

p.415 [ (552) La quatorzième année (481) du duc Ngai, de Lou, au printemps, on chassa à Ta-ye (553). Tch'ou-chang, conducteur d'un des chars de Chou-suen, captura un animal (étrange) (554); il pensait que c'était un mauvais p.416 présage ( $\underline{555})$ - Tchong- $n i$ vit (cet animal) et dit :

- C'est un lin.

(Alors) on l'emporta (ㅎ56).]

[ (557) (Le Maître) dit : 
— Le $H o$ ne produit plus le Tableau] ; le Lo ne produit plus l'Écrit. [C'en est fini de moi ( $\underline{58})$.]

p.417 [ (559)Yen Yuen (560) étant mort, K'ong-tse dit :

- Le Ciel veut ma mort (ㅎ1). ]

Puis, lors de la chasse du côté de l'Ouest (ㅌ2), il vit le lin et dit :

- Ma carrière est terminée (563).

[ (6ㄴ) Il dit en poussant un profond soupir :

- Personne ne me connait.

Tse-kong lui demanda :

- Que signifie ceci que personne ne vous connaît ?

Le Maître ${ }_{\text {p.418 }}$ répondit :

- Je ne suis pas irrité contre le Ciel et je ne blâme pas les hommes. Puisque j'étudie ce qui est en bas et que je pénètre ce qui est en haut, celui qui me connaîtra, ce sera sans doute le Ciel (565). $][$ ( $\underline{566})$ Ceux (567) qui ne soumirent pas leur volonté et qui ne laissèrent subir aucun affront à leur personne, est-ce que ce ne furent pas po I et chou Ts'i (568) ? On peut dire de Hoei (originaire) de Lieou-hia (569), et de Chao-Lien (570) qu'ils soumirent leur volonté et qu'ils ${ }_{\text {p.419 }}$ exposèrent aux affronts leur personne (571); on peut dire de Yu-tchong (572) et de $I-i$ (573) qu'ils restèrent dans la retraite et qu'ils gardèrent le silence (574); lorsqu'ils agirent, ils se conformèrent à la pureté ; lorsqu'ils se retirèrent, ils se conformèrent aux circonstances. Pour moi, je suis différent de ces hommes. Il n'est pas (de règle fixe) pour que j'aille de l'avant et il n'est pas (de règle fixe) pour que je m'abstienne (575).]

Le Maître dit :

— Non ! non ( $\underline{576})$ ! [ (ㅎ7) L'homme supérieur s'affligerait que sa bonne renommée ne fût pas célébrée p.420 après sa mort (7ㅛ).] Puisque ma doctrine n'a pas été mise en pratique, par quoi me ferai-je connaître à la postérité ?

Alors, en se servant des mémoires des historiens (579), il composa (580) le Tch'oen-ts'ieou (581). En remontant, il alla jusqu'au duc Yn (722-712); en

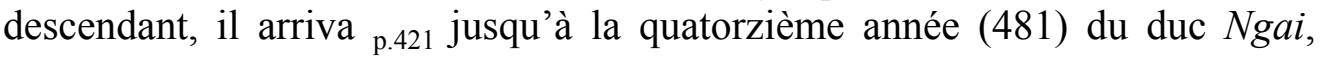
(embrassant ainsi les règnes de) douze ducs. Se fondant sur le fait que (les princes de) Lou étaient apparentés aux (rois de la dynastie) Tcheou, il transporta donc dans (leur histoire des récits concernant) les trois dynasties (582). Il condensa son style, mais en lui faisant indiquer beaucoup de choses (583) : c'est ainsi que les princes de $\mathrm{Ou}$ et de ${ }_{\text {p.422 }} T c h$ 'ou se donnaient le titre de roi ; or le Tch'oen-ts'ieou les rabaisse en les appelant des vicomtes; 
lors de la réunion de Tsien-t'ou (632), le Fils du Ciel (la dynastie) Tcheou, fut en réalité sommé d'y venir ; or le Tch'oen-ts'ieou dissimule ce fait en disant : Le roi par la grâce du Ciel (passa l'inspection des) fiefs à Ho-yang (584). C'est en remontant à des exemples de ce genre qu'on trouve une règle pour le temps présent (585); la signification des abaissements et des suppressions (586) (que fait le Tch'oen-ts'ieou) sera mise au jour et expliquée quand il y aura des souverains (dignes de ce nom) ; si la signification du Tch'oen-ts'ieou prévaut, alors dans tout le monde les sujets rebelles et les malfaiteurs seront saisis de crainte ( $\underline{587}$ ). Lorsque $K^{\prime}$ ong-tse exerçait une fonction publique, les phrases par lesquelles il s'exprimait quand il jugeait des procès étaient à peu près semblables à celles qu'employaient les autres hommes et ne présentaient rien qui lui fût particulier; mais, lorsqu'il fit le Tch'oen-ts 'ieou, il écrivit ce qu'il fallait écrire, il supprima ce qui était à ${ }_{\text {p.423 }}$ supprimer, (de telle sorte que) les gens tels que Tse-hia (588) ne purent critiquer une seule expression. Quand ses disciples reçurent le Tch'oen-ts 'ieou, K'ong-tse (leur) dit :

- Dans les générations à venir, [ (ㅎ9) ceux qui me rendront justice, ce sera à cause du Tch'oen-ts'ieou; et ceux qui me condamneront, ce sera aussi à cause du Tch'oen-ts'ieou (590). ]

L'année suivante (480), Tse-lou mourut dans le pays de Wen (591).

K'ong-tse étant tombé malade, Tse-kong demanda à le voir. [ (592) En ce moment, K'ong-tse s'appuyant sur son bâton (593), p.424 allait et venait devant sa porte ; il lui dit :

- O Se, pourquoi venez-vous si tard (פㅕ) ?

K'ong-tse chanta alors ceci en soupirant :

Le T'ai-chan va s'écrouler ;

La maîtresse poutre va s'affaisser ;

L'homme sage va se flétrir ( $\underline{595})$.

En même temps (qu'il chantait cela), ses larmes coulaient. Il dit à Tse-kong :

- Voici longtemps que le monde n'a plus de sagesse ; personne n'a été capable de me prendre pour maître (596). [Les gens de l'époque des Hia déposaient le cercueil (en haut de l'escalier de l'Est; les gens de l'époque des Tcheou, (en haut de l'escalier de l'Ouest; les gens de l'époque des $Y n$ le plaçaient entre les deux

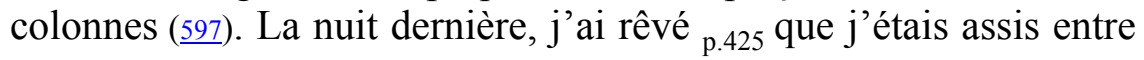
les deux colonnes, devant les offrandes qu'on fait à un mort. C'est sans doute parce que je suis un homme (qui descend) des $Y n$ (598).

Sept jours plus tard, il mourut.]. 
K'ong-tse était âgé de soixante-treize ans et c'était le jour ki-tch'eou du quatrième mois de la seizième année (479) du duc Ngai, de Lou, quand il mourut (599).

[ (600) Le duc Ngai prononça son éloge funèbre en disant (ㅁ1) :

« Le Ciel miséricordieux n'a pas compassion (de moi); il n'a pas pu prendre sur lui de me laisser un seul vieillard expérimenté (므) qui fût capable de me protéger, moi l'homme unique (603), pendant que je règne. Plein de tristesse, je suis plongé dans l'affliction. Hélas! Vénérable ${ }_{\text {p.426 }} \mathrm{Ni}(\underline{604})$ ! je n'ai plus personne qui me serve de règle.

Tse-kong dit :

- Le prince, ne mourra certainement pas dans le pays de Lou (605)! Le Maître en effet a dit: Pécher dans la pratique des rites, c'est preuve d'aveuglement d'esprit; pécher dans l'emploi des mots, c'est preuve de tendance aux abus. Pécher en ce qui concerne les intentions, c'est aveuglement d'esprit; pécher en ce qui concerne les places appropriées, c'est tendance aux abus. (Or, ce que vient de faire le duc Ngai, à savoir :) celui dont il n'a pas su se servir pendant qu'il vivait, faire son éloge après sa mort, c'est pécher dans la pratique des rites; dire en parlant de lui-même " moi l'homme unique (606) », c'est pécher dans l'emploi des mots.]

K'ong-tse fut enterré au nord de la capitale (du pays) de Lou, sur les bords (de la rivière) $S e$ (607).

p.427 Ses disciples portèrent tous les vêtements de deuil pendant trois années (608) ; au bout de trois ans, leur deuil de cœur étant terminé, quand ils se séparèrent les uns des autres pour s'en aller (609), ils éclatèrent en lamentations p.428 et chacun d'eux donna de nouveau libre cours à son affliction. Quelques-uns d'entre eux restèrent encore (610). Seul Tse-kong habita dans une butte sur le tertre de la tombe (611) et y passa en tout six années (612), après lesquelles il partit.

Parmi les disciples et les gens (du pays) de Lou, ceux qui vinrent s'établir à demeure aux environs de la tombe formèrent plus de cent habitations qu'on appela pour cette raison « le hameau de $K^{\prime}$ ong (613) ».

p.429 (Les princes de) Lou se transmirent de génération en génération la coutume d'offrir des sacrifices à K'ong-tse à des époques fixes de l'année. D'autre part, les lettrés aussi s'exercèrent à pratiquer les rites tels que le banquet de district et le grand tir à l'arc auprès de la tombe de K'ong-tse. La sépulture de $K^{\prime}$ 'ong-tse est grande de un k'ing (614). La salle dans laquelle demeurèrent autrefois les disciples (615) a été transformée en un temple funéraire par les générations suivantes qui y ont déposé les vêtements de 
K'ong-tse, son chapeau de cérémonie, son luth, son char et ses écrits. Tout cela se conserva sans interruption pendant plus de deux cents années jusqu'à l'avènement des Han. Lorsque l'empereur Kao passa dans le pays de Lou (195), il offrit un sacrifice de trois grandes victimes (à la tombe de K'ongtse) (616). Quand les seigneurs, les hauts dignitaires et les conseillers arrivent (dans le pays de Lou), ils commencent toujours par aller rendre visite (à cette tombe) et ce n'est qu'ensuite qu'ils s'occupent du gouvernement (617).

p.430 K'ong-tse engendra $L i$, dont l'appellation fut Po-yu.

Po-yu mourut à l'âge de cinquante ans, avant $K^{\prime}$ 'ong-tse (618).

Po-yu engendra $\mathrm{Ki}$, dont l'appellation fut Tse-se (619). (Il p.431 vécut) soixante-deux ans. Il fut en danger dans (le pays de) Song (620). Tse-se composa le Tchong-yong (21).

Tse-se engendra Po, dont l'appellation fut Tse-chang. (Il vécut) quarante-sept ans.

Tse-chang engendra K'ieou, dont l'appellation fut Tse-kia. (Il vécut) quarante-cinq ans.

Tse-kia engendra $K i$, dont l'appellation fut Tse-king (622). (Il vécut) quarante-six ans.

Tse-king engendra Tch'oan, dont l'appellation fut Tse-kao. (Il vécut) cinquante et un ans.

Tse-kao engendra Tse-chen (2ㅡ) qui (vécut) cinquante-sept ans et qui fut conseiller de $\mathrm{Wei}$.

p.432 Tse-chen engendra Fou (624) qui (vécut) cinquante-sept ans et qui fut po-che au service de Tch'en Che, le roi (2625); il mourut à la suite de Tch'en (Che) (26).

p.433 Le frère cadet de Fou, Tse-siang (627), (vécut) cinquante-sept années ; il fut po-che au service de l'empereur Hiao-hoei (194-188), puis il fut promu au titre de gouverneur de Tch'ang-cha (628); il était grand de neuf pieds et six pouces (629).

Tse-siang engendra Tchong, qui (vécut) cinquante-sept ans.

Tchong engendra $\mathrm{Ou}(\underline{630})$.

Ou engendra Yen-nien (631) et Ngan-kouo. K'ong p.434 Ngan-kouo fut po-che au service de l'empereur actuel; il parvint au grade de gouverneur de Lin-hoai (632). Il mourut prématurément (633).

Ngan-kouo engendra Ang.

Ang engendra Hoan.

Le duc grand astrologue dit : le Livre des Vers renferme cette parole : 
La haute montagne, il la contempla:

La voie large, il y marcha (634).

Même sans pouvoir y atteindre, son cœur cependant p.435 tendait à $\mathrm{y}$ aller (635). - Pour moi, quand je lisais les écrits de K'ong-tse, j'ai cru voir quel homme il fut; (puis,) lorsque je suis allé dans (le pays) de Lou, que j'ai regardé la salle du temple funéraire de Tchong-ni, son char, ses vêtements, ses ustensiles rituels, (lorsque j'ai vu) tous les maîtres qui, aux époques prescrites, s'exerçaient aux rites dans sa demeure (636), je revenais pénétré de respect m'attarder là et je ne pouvais m'éloigner. Dans le monde, ils sont légion ceux qui, depuis les souverains jusqu'aux hommes sages, eurent de leur vivant une gloire qui prit fin après leur mort. Mais $K^{\prime}$ 'ong-tse, quoique vêtu de toile (637), a transmis (sa renommée) pendant plus de dix générations (638); ceux qui se livrent à l'étude le considèrent comme leur chef. Depuis le Fils du Ciel, les rois et les seigneurs, tous ceux qui dans le Royaume du Milieu dissertent sur les six arts libéraux se décident et se règlent d'après le Maître. C'est là ce qu'on peut appeler la parfaite sainteté ! 


\section{NOTE ADDITIONNELLE}

p.436 La biographie de Confucius est un des chapitres les plus importants des Mémoires historiques. Se-ma Ts'ien lui-même a bien compris l'influence considérable que Confucius a exercée dans le monde et c'est pourquoi il a réservé à ce sage qui fut investi d'une véritable royauté intellectuelle et morale un des chapitres qui sont affectés aux maisons seigneuriales. On a donc tort de représenter Se-ma Ts 'ien comme ayant préféré les enseignements de Lao tse à la doctrine de Confucius ; telle avait pu être l'opinion de son père Se-ma T'an, mais, pour lui, il sut reconnaître en Confucius le prince de la pensée chinoise, et l'éloge qu'il fait de lui à la fin des pages qu'il lui a consacrées témoigne de la profonde vénération qu'il lui avait vouée (639).

Pour écrire la biographie de Confucius, Se-ma Ts'ien dut soumettre à un examen critique les documents nombreux et divers dont il disposait et les arranger suivant un plan qui lui est entièrement personnel; cette biographie en effet n'existait pas avant lui; il est le premier à l'avoir constituée ; quels que soient les défauts de son essai de systématisation, on devra toujours en tenir compte, car c'est à travers le texte de Se-ma Ts'ien que nous voyons encore aujourd'hui la vie de Confucius. Les matériaux que Se-ma Ts 'ien trouvait sous sa main étaient de deux sortes. d'une part, les Commentaires du Tch'oen ts 'ieou, et plus particulièrement le Tso tchoan, lui fournissaient, avec certaines indications se rapportant à Confucius lui-même, le récit chronologique des événements qui se passèrent de son temps ; d'autre part, une grande quantité de propos attribués à Confucius étaient, soit groupés en recueil, soit épars dans la littérature et quelques-uns d'entre eux étaient ${ }_{\text {p.437 }}$ susceptibles d'être replacés dans leur cadre historique et de figurer dans une biographie. Une étude attentive de ce chapitre nous révèle comment Se-ma Ts 'ien s'est inspiré de cette double série de témoignages.

Pour ce qui est des Commentaires du Tch'oen ts 'ieou, Se-ma Ts'ien paraît en avoir extrait tous les renseignements qu'ils étaient susceptibles de fournir. Cependant, il commet parfois des inadvertances : c'est ainsi qu'il rapporte à l'année 535 la mort de Mong Hi-tse parce qu'il n'a pas remarqué que le Tso tchoan relate par anticipation à cette date une anecdote qui doit être placée en 518 ; 1'historien est donc amené à dire faussement que Confucius était âgé de 17 ans quand il fut désigné par Mong Hi-tse pour être le conseiller de son fils ; en réalité, Confucius était alors un homme de 34 ans (640). En outre, Se-ma Ts'ien ne s'est pas servi exclusivement du Tso tchoan; il a également mis à contribution les Commentaires de Kong-yang et de Kou-leang quoiqu'ils aient moins d'autorité ; c'est dans ces deux derniers ouvrages que, lorsqu'il raconte l'entrevue des princes de Lou et de Ts'i à Kia-kou en 500 av. J.-C., il recueille 
certains détails peut-être suspects que le Tso tchoan avait cru devoir omettre (641).

C'est surtout dans l'interprétation et l'agencement des propos ou logia attribués à Confucius que l'intervention de Se-ma Ts'ien est sensible. Ces propos peuvent être répartis en deux groupes suivant qu'ils ont été recueillis par l'école de Confucius ou qu'ils émanent d'ouvrages étrangers à cette école. Le premier groupe se distingue nettement du second par une certaine homogénéité de langage et de doctrine, et la différence entre les deux séries de témoignages est fort visible dans l'assemblage qu'en fait Se-ma Ts 'ien.

Si nous considérons d'abord le second groupe, nous voyons l'historien tirer du Kоио yu trois textes dans lesquels Confucius nous apparaît comme donnant des explications au sujet d'êtres ou d'objet merveilleux (642), p.438 ce qui est en contradiction formelle avec l'affirmation du Luen yu que le Maître ne discourait pas sur les prodiges (643) ; un de ces textes est d'ailleurs assigné à une date manifestement erronée (644). A Yen-tse (ou Yen Yng), mort en 493 av. J.-C.), Se-ma Ts 'ien emprunte une des critiques les plus pénétrantes qui aient jamais été faites de la doctrine des lettrés (645), à telle enseigne que Mo-tse (ou Mo Ti) a eu soin de la recueillir dans le chapitre où il combat les lettrés. A quelque auteur taoïste aujourd'hui perdu, il demande un récit de cette fameuse entrevue de Lao-tse et de Confucius (646) qui est la scène probablement fictive que l'école taoïste a souvent choisie pour opposer triomphalement ses théories à celles de ses rivaux (647). Enfin dans l'ouvrage de Han Yng, qui était contemporain de Se-ma T'an, Se-ma Ts'ien prend une anecdote peu vraisemblable qui représente Confucius comme doué d'une sorte de faculté surnaturelle de divination en matière de musique (648). Se-ma Ts'ien aurait pu aisément multiplier ces textes qui sentent l'hérésie, car ils abondent dans la littérature non-confucéenne (649) ; c'est du moins chose remarquable qu'il ait cru devoir accueillir dans son œuvre quelques-uns d'entre eux. Sa bonne foi d'historien ne lui permettait pas en effet de négliger entièrement des traditions qui étaient fort répandues; mais il ne leur a fait que de discrets emprunts parce qu'il devait sentir que la légende ou l'esprit de polémique y jouaient ${ }_{\text {p.439 }}$ un trop grand rôle. Nous voyons ici de près comment fonctionne sa méthode critique qui, s'abstenant de jamais modifier un témoignage pour dégager par une discussion raisonnée l'âme de vérité qu'il renferme, se borne à opérer dans les livres des prélèvements plus ou moins considérables suivant le degré de crédit qu'elle leur accorde.

Entre les textes non-confucéens et les textes confucéens, il faut faire une place à part à deux ouvrages dont certains passages se retrouvent dans le chapitre XLVII de Se-ma Ts'ien; ce sont le Kia yu (650) et le Li ki. Il serait difficile de considérer le Kia yu actuel comme une des sources auxquelles puisa Se-ma Ts'ien; déjà Yen Che-kou (579-645) déclarait que le Kia yu qu'il connaissait n'avait rien de commun avec l'ouvrage malheureusement perdu qui est catalogué sous ce nom dans le Ts'ien Han chou (chapitre XXX, p. 7 $\mathrm{r}^{\circ}$ ), et la critique chinoise moderne s'accorde à reconnaître dans le Kia $y u$ 
actuel l'œuvre de Wang Sou, mort en 256 de notre ère. Mais, si le Kia yu n'a reçu sa forme définitive que trois siècles environ après la publication des Mémoires historiques. et si par conséquent on ne peut le regarder comme une des sources de Se-ma Ts'ien, il serait également faux de soutenir la proposition inverse et de dire que c'est Wang Sou qui a fait des emprunts directs à Se-ma Ts'ien. Il semble plutôt que Wang Sou ait recueilli un certain nombre de documents plus anciens qui avaient déjà été utilisés par son illustre prédécesseur; les variantes que présentent les deux rédactions des Mémoires historiques d'une part et du Kia yu d'autre part prouvent qu'elles sont indépendantes l'une de l'autre; peut-être leur source commune est-elle précisément ce Kia yu aujourd'hui perdu qui apparaît dans le catalogue littéraire du ${ }_{\text {p.440 }} T s$ 'ien Han chou. Une conclusion analogue s'impose lorsqu'il s'agit du $\mathrm{Li} k i$ dont les recensions successives se poursuivirent jusqu'au premier et au second siècle de notre ère ; les points de contact entre le texte du $\mathrm{Li} \mathrm{ki}$ et celui des Mémoires historiques sont d'ailleurs peu nombreux et n'atteignent à l'identité verbale que dans le récit de la mort de Confucius, Ainsi donc bien que le Kia yu et le $L i$ ki actuels ne soient pas au nombre des sources immédiates des Mémoires historiques, ils reproduisent cependant quelques documents anciens qui peuvent être tenus à juste titre pour être ceux-là mêmes dont s'inspira Se-ma Ts'ien.

Si les textes du Kia yu aussi bien que ceux du Li ki ne sont pas à proprement parler hétérodoxes, on ne saurait cependant les ranger dans la catégorie des textes purement confucéens que nous allons maintenant étudier. En dehors de deux courts passages qui proviennent de Mencius (651), tous les textes confucéens dont se sert Se-ma Ts'ien sont tirés du Luen yu. Les paroles de Confucius qui nous ont été conservées dans le Luen yu sont souvent fort énigmatiques parce que nous ne savons pas exactement dans quelles circonstances elles ont été prononcées; or, quand Se-ma Ts'ien les cite, il les rapporte à des épisodes déterminés de la vie de Confucius, et, par là même, il en fixe le sens ; aussi peut-on dire qu'il a puissamment contribué à établir l'explication devenue traditionnelle du Luen yu. Cependant, la critique moderne chinoise a dénoncé ce qu'il y avait de factice dans bon nombre des interprétations de Se-ma Ts'ien; elle a dégagé les textes du Luen yu de la gangue des Mémoires historiques, et, en les considérant dans leur pureté, elle a été amenée à leur attribuer des sens nouveaux. Pour ne citer qu'un des exemples les plus topiques, tandis que Se-ma $T$ s'ien voyait dans la formule [] l'énoncé de la théorie philosophique d'après laquelle les dénominations doivent être conformes à la réalité des choses, l'exégèse actuelle (652) y reconnaît le ${ }_{\text {p.441 }}$ précepte que les caractères de l'écriture doivent être corrects (ㄷ3). Dans d'autres cas, Se-ma Ts'ien ajoute aux textes du Luen yu des indications qui, bien qu'ayant fini par acquérir droit de cité dans la glose communément admise du livre classique, n'en sont pas moins adventices; ainsi, le Luen yu nous apprend que Confucius et ses disciples se trouvèrent en danger lorsqu'ils étaient dans la région comprise entre $T c h$ 'en et $T s$ 'ai ; mais 
l'histoire dramatique dans laquelle Confucius encadre ce fait est fort sujette à caution (654).

Il nous reste à dire quelques mots de l'importance philologique du chapitre XLVII de Se-ma Ts'ien pour l'établissement du texte du Luen yu. De même que pour le Chou king, quoiqu'à un moindre degré, les Mémoires historiques peuvent fournir pour le Luen yu des leçons qui méritent d'être prises en considération. Se-ma Ts'ien s'est servi du Luen yu, non seulement dans la biographie de Confucius, mais encore dans son étude sur les disciples du Maître. A la fin de ce dernier chapitre (chap. LXVII, p. $11 \mathrm{r}^{\circ}$ ), Se-ma Ts'ien dit :

«Le signalement des disciples est tiré du texte ancien de $K$ 'ong ; il est suffisamment exact. Pour moi, me servant (comme d'un principe de groupement) des noms personnels, des noms de famille et des appellations des disciples, j'ai recueilli dans le Luen yu toutes les questions des disciples et je les ai ordonnées de manière à en former un chapitre. Ce qui était douteux, je l'ai omis.

Le texte ${ }_{\text {p.442 }}$ ancien de K'ong, c'est le texte en caractères antiques qui fut trouvé dans un mur de la maison de Confucius (655) et qui fut publié par $K$ 'ong Ngan-kouo († 91 av. J.-C.). Nous ne devons point être surpris que Se-ma Ts'ien s'en soit servi, car nous savons par Pan Kou qu'il avait recu les enseignements de K'ong Ngan-kouo (656). Faut-il admettre que toutes les différences qu'on relève entre le texte actuel du Luen yu et les citations que les Mémoires historiques font de cet ouvrage proviennent de ce que Se-ma Ts 'ien a toujours recours au texte antique, tandis que le texte actuel est fondé essentiellement sur la recension dite de Lou ? c'est l'opinion qu'ont soutenue certains critiques chinois (657), mais nous ne ${ }_{\text {p.443 }}$ saurions la partager. Se-ma Ts 'ien lui-même nous dit qu'il s'est servi du texte antique lorsqu'il a dressé la liste des disciples en indiquant leurs signalements, c'est-à-dire leurs noms de famille, leurs noms personnels, leurs appellations et aussi quelquefois leur âge (658); ces indications en effet paraissent ne s'être trouvées que dans le texte antique et c'est pourquoi Se-ma Ts'ien a dû les en tirer; il a pris ensuite cette liste comme un principe de groupement pour disposer les documents que lui fournissait le Luen yu relativement à chacun des disciples; mais, dans cette seconde partie de sa tâche, il s'est servi, dit-il, du Luen yu qu'il distingue ainsi nettement du texte antique auquel il avait eu recours pour la première partie de son travail. Ainsi, de l'aveu de Se-ma Ts'ien lui-même, il n'a emprunté au texte antique que des renseignements qui manquaient au Luen yu; mais p.444 quand il eut à faire des citations de passages existant dans le Luen yu, ce n'est plus le texte antique qui les lui a procurées. En conclusion donc, les variantes de Se-ma Ts'ien ne sont pas nécessairement tirées du texte antique ; elles nous indiquent plutôt quel était l'état du manuscrit du Luen yu avant que les travaux des érudits qui se succédèrent du premier siècle av. J.-C. au deuxième siècle ap. J.-C., en eussent définitivement arrêté le texte (659); ce manuscrit devait 
être sans doute celui de la recension de Lou, qui a servi de base à toutes les éditions ultérieures, quelles que soient les modifications de détail qu'on ait pu y apporter par la collation tant de la recension de $T s^{\prime} i$ que du texte antique ( $\underline{600})$. 


\section{APPENDICE I}

\section{De l'authenticité des Annales écrites sur bambou.}

Le présent volume de la traduction de Se-ma Ts 'ien contient l'histoire de la maison princière de $\mathrm{Wei}$; en étudiant ce chapitre des Mémoires historiques, nous avons eu souvent l'occasion dans nos notes de faire allusion aux Annales écrites sur bambou qui sont, dans leurs dernières pages, une chronique du pays de Wei. Le moment paraît donc venu de dire notre opinion sur l'authenticité de cet ouvrage (101). La question est d'importance. En effet, les Annales écrites sur bambou ont été déposées dans une tombe en l'an 299 av. J.-C., quatre-vingt-six ans par conséquent avant la proscription de la littérature édictée en 213 av. J.-C. par Ts'in Che-hoang-ti; elles échappent donc entièrement à la cause de suspicion qui atteint les livres anciens publiés par les érudits de l'époque des Han.D'autre part, comme les Annales écrites sur bambou sont restées enfouies dans la terre pendant près de six siècles, de 299 av. J.-C. à 281 ap. J.-C., elles n'ont pas été connues de Se-ma Ts'ien qui écrivait vers l'an 100 avant notre ère ; elles se trouvent ainsi être un témoin dont la parole est indépendante de celle de Se-ma Ts'ien et elles peuvent servir à contrôler, à compléter et parfois à rectifier les Mémoires historiques. Enfin elles ont été utilisées par les quatre principaux commentateurs des Mémoires historiques, Sin Koang, P'ei Yn, Se-ma Tcheng et Tchang ${ }_{\text {p.447 }}$ Cheou-tsie, et se trouvent ainsi étroitement rattachées à l'œuvre de Se-ma Ts'ien.

Considérons d'abord les conditions dans lesquelles ont été découvertes ces Annales. Quoique les renseignements que nous possédons à ce sujet soient étendus, il ne sera pas inutile d'en traduire ici la majeure partie afin de bien montrer que peu de trouvailles archéologiques anciennes se présentent à l'examen de la critique moderne avec des garanties aussi sérieuses.

Le célèbre commentateur du Tso tchoan, Tou Yu (app. Yuen-k'ai), qui vécut de 222 à 284, put, dans les dernières années de sa vie, prendre connaissance des Annales qui venaient de reparaître au jour; il dit dans sa Postface au Tso tchoan (102) :

«La première année (280) t'ai-kang, le troisième mois, les rebelles de $O u$ étant enfin pacifiés (103), je revins de Kiang-ling (104) à Siang-yang (105) ; je me débarrassai de la cuirasse et je déposai les armes ; alors je donnai suite à mes anciens projets et je rédigeai entièrement (les ouvrages intitulés) Tch'oen ts'ieou che li (Interprétation et arrangement du Tch'oen ts'ieou). ${ }_{\text {p.448 }}$ et King tchoan tsi kie (Explications réunies du livre classique et de son commentaire). A peine avais-je fini cela que, dans la sous-préfecture de $K i(\underline{106})$ de la commanderie de $K i$, il y eut des 
gens qui, en ouvrant une ancienne tombe de cette région, trouvèrent en grande quantité d'anciens livres qui étaient tous écrits en caractères $k$ 'o-teou (107) sur des liasses de fiches en bois ; les hommes qui avaient ouvert la tombe, n'attachant pas d'importance (à ces fiches) les dispersèrent au hasard au fur et à mesure (de la découverte) ; l'écriture k'o-teou est depuis longtemps tombée en désuétude et quand on cherche à remonter au sens, on ne peut tout expliquer (108); on commença par serrer (ces fiches) dans les archives secrètes; je ne pus les voir qu'assez tard (109). Ce qu'elles relatent formerait en tout approximativement soixante-quinze rouleaux (110); beaucoup d'entre elles sont brisées en fragments pêle-mêle ou contiennent des choses bizarres et ne peuvent être expliquées et comprises. Le I (king) des Tcheou et les Annales sont ce qu'il y a de plus distinct. Le I (king) des Tcheou, tant pour la première que pour la seconde partie, est exactement identique au (I king) actuel; il s'y trouve annexée à part une dissertation sur le $y n$ et le yang, mais il y manque (les appendices appelés) t'oan, siang, wen yen et hi-ts'e (111); peut-être est-ce parce qu'à cette époque Tchong-ni p.449 (Confucius) avait implanté (ces appendices) dans le pays de Lou mais qu'on ne les avait pas encore répandus dans les royaumes éloignés. Quant au volume des Annales, il commence par les Hia, les $Y n$ et les Tcheou et traite des règnes des souverains de ces trois dynasties; il ne fait pas de distinction entre les divers royaumes, si ce n'est cependant qu'il traite plus spécialement du royaume de $T \sin$; (en ce qui concerne ce dernier royaume), il commence à Chang-chou (784-781) et passe en revue (les règnes) du marquis Wen (780-746) et du marquis Tchao (745-730) pour arriver jusqu'au comte Tchoang, de K'iu-ou (112). Le onzième mois de la onzième année du comte Tchoang correspond au premier mois de la première année (722) du duc Yn de Lou (113) ; constamment c'est en se servant du calendrier des Hia qui fait du mois yn le début de l'année que (ce livre) range les années à la suite les unes des autres. Après l'extinction du p.450 royaume de $T \sin (403)$, il ne rappelle plus que les événements du royaume de $W e i$ et descend jusqu'à la vingtième année (299) du roi Ngai, de Wei (114); (ce livre) doit donc être les Mémoires historiques 13 du royaume de Wei (115). Si on vérifie par le calcul ce qu'est la vingtième année du roi Ngai, (on constate que) le $t^{\prime} a i$ soei était dans les signes jen-siu (299), que c'était la $16^{\mathrm{e}}$ année du roi Nan de la dynastie Tcheou, la $8^{\mathrm{e}}$ année du roi Tchao de $T$ s'in, la $13^{\mathrm{e}}$ année du roi Siang de Han, la $27^{\mathrm{e}}$ année du roi Ou-ling de Tchao, la $30^{\mathrm{e}}$ année du roi Hoai de Tch'ou, la $13^{\mathrm{e}}$ année du roi Tchao de Yen, la $25^{\mathrm{e}}$ année du roi Min de $T s^{\prime} i$; de cette date, en remontant jusqu'à la mort de Kong K'ieou (Confucius $† 479$ av. J.-C.), il y a 181 années, et en descendant jusqu'à la présente $3^{\mathrm{e}}$ 
année $t^{\prime}$ ai-k'ang (282 ap. J.-C.) (116), il y a 581 années. Le roi Ngai serait, d'après les Mémoires historiques (de Se-ma Ts'ien), le fils du roi Siang et le petit-fils du roi Hoei ; le roi Hoei serait mort dans la $36^{\mathrm{e}}$ année de son règne; le roi Siang serait alors monté sur le trône et serait mort après un règne de 16 années; alors le roi Ngai serait monté sur le trône. D'après les Annales écrites en caractères antiques, le roi $H o e i$, dans la $36^{\mathrm{e}}$ année de son règne, aurait changé le principe (du calcul des années), et, partant de la $1^{\mathrm{e}}$ année serait arrivé jusqu'à la $16^{\mathrm{e}}$ année ; (les Annales) disent alors que le roi Hoei-tch'eng mourut ; (ce roi) n'est autre que le roi Hoei. Peut-être les Mémoires historiques (de Se-ma Ts'ien) ont-ils fait par erreur de Hoei et de Tch'eng deux rois successifs de manière à constituer les années d'un second règne. Le roi $N g a i$ mourut en la $23^{\mathrm{e}}$ année de son règne; c'est pourquoi précisément (les Annales) ne mentionnent pas son nom posthume et l'appellent «le roi actuel » (117).

p.451 Un autre témoignage, contemporain de celui de Tou Yu, est celui de Siun Hiu (app. Kong-ts'eng) (118), qui mourut en l'an 289 ap. J.-C. et qui prit part au travail de l'édition du Tchou chou ki nien ; ce lettré écrivit une préface au Mou t'ien tse tchoan ou récit du voyage légendaire du roi Mou en Occident, ouvrage qui faisait partie, en même temps que les Annales, de la masse de livres que renfermait la tombe de $K i$; dans cette préface, il nous dit :

«Le Mou t'ien tse tchoan en caractères antiques est un livre qui fut trouvé lorsque, en la deuxième année t'ai-k'ang (281), un homme de la sous-préfecture de Ki, nommé Piao (119) Tchoen, ouvrit une ancienne tombe pour la piller. Tout cet ouvrage était p.452 constitué par des fiches en bambou que reliaient des cordons en soie; si on les mesure avec l'ancien pied dont j'ai précédemment déterminé la valeur, ces fiches étaient longues de deux pieds et quatre pouces; chaque fiche contenait quarante mots écrits à l'encre noire. La région de $K i$ était, à l'époque des royaumes combattants, un territoire du pays de Wei.Les Annales qu'on y trouva prouvent que cette tombe devait être celle du roi Ling (120), fils du roi Hoei-tch'eng, de Wei ; d'après le Che pen, ce roi serait le roi Siang. D'après le tableau chronologique des six royaumes qui se trouve dans les Mémoires historiques (de Se-ma Ts'ien), depuis la vingt et unième année du roi Ling jusqu'à la trente-quattrième année de $T$ s'in Che-hoang, qui est celle où on brûla les livres, il s'écoula quatre-vingt six années; jusqu'à la deuxième année t'ai-k'ang (281), qui est celle où on découvrit cet ouvrage, il s'est écoulé cinq cent soixantg dix-neuf années. »

Un troisième texte, contemporain lui aussi des témoignages de Tou Yu et de Siun Hiu, nous est fourni par une stèle gravée en l'année 289 ap. J-C. En effet, dans le Koang tch'oan chou pa, de Tong Yeou (ouvrage qui parut après 
la mort de l'auteur avec une préface écrite par son fils et datée de l'année 1157 ; ce traité épigraphique a été réimprimé dans la quatrième section du Hoai lou ts'ong chou), on voit citée (chap. VI, p. $3 \mathrm{v}^{\circ}-4 \mathrm{v}^{\circ}$ ) la stèle du temple funéraire de T'ai-kong ; cette inscription, qui fut gravée sous la dynastie $T$ sin, en la dixième année t'ai-k'ang (289 ap. J.-C.), se trouvait, à l'époque où écrivait Tong Yeou, dans la sous-préfecture de Kong, qui est aujourd'hui la

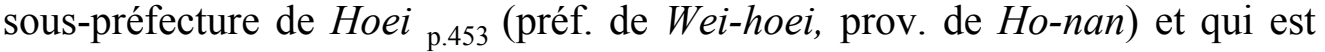
assez voisine de la sous-préfecture de $K i$ où furent découvertes, en l'an 281 de notre ère, les fiches de bois du Tchou chou ki nien; la stèle de 289 fut gravée pour commémorer le souvenir d'un fragment historique écrit sur quelques-unes des fiches qui furent exhumées en même temps que celles du Tchou chou ki nien; elle nous atteste donc la réalité de la trouvaille qu'on avait faite huit années seulement auparavant et elle nous montre l'importance qu'on attribua à ces textes anciens dès qu'ils eurent reparu à la lumière. Voici la partie de cette inscription que cite Tong Yeou:

«L'Illustre duc Wang était originaire de cette sous-préfecture ; la deuxième année $t^{\prime} a i$ - $k$ 'ang (281), du côté occidental (121) de la sous-préfecture, des voleurs, en violant une sépulture, trouvèrent des textes écrits sur des fiches de bambou. L'année où furent enterrés ces textes (299 av. J.-C.) doit être de quatre-vingt six ans antérieure à celle où $T s$ 'in fit périr les lettrés (122). Le mémoire sur les Tcheou, qui fait partie de ces textes, dit :

«Le roi Wen rêva que l'Empereur céleste, revêtu d'un vêtement (123) noir, se tenait debout auprès du gué de Ling-hou; l'Empereur lui dit :

- O Tch'ang (124), ${ }_{p .454}$ je vous donne en présent Wang (125).

Le roi Wen se prosterna par deux fois et toucha du front la terre. L'Illustre duc derrière lui se prosterna par deux fois et toucha du front la terre. Dans la nuit où le roi Wen eut ce songe. l'Illustre duc fit le même songe. Plus tard, quand le roi Wen vit l'illustre duc, il l'interrogea en disant :

— Votre nom personnel n'est-il pas Wang?

L'autre répondit. qu'il en était effectivernent ainsi. Le roi Wen lui dit :

- Il me semble que je vous ai déjà vu.

L'Illustre duc lui raconta en quel jour c'était, puis lui rapporta les paroles qui avaient été dites (en ajoutant) :

- C'est en cette occasion que moi, votre sujet, j'ai pu vous voir.

Le roi $W e n$ dit : 

passé.

- C'est bien là ce qui s'est passé, c'est bien là ce qui s'est

Alors il revint en l'emmenant avec lui et le nomma haut dignitaire.

A Côté des Annales, de la relation du roi Mou et des nombreux textes historiques dont un fragment fut reproduit sur la stèle de 289 ap. J.-C., la tombe de $\mathrm{Mou}$ recélait encore une masse d'ouvrages plus ou moins endommagés. L'inventaire le plus complet que nous en ayons nous est fourni dans la biographie de Chou Si, qui mourut à quarante ans vers l'an 300 de notre ère. Cette biographie fait partie d'un des chapitres du Tsin chou dont la composition est attribuée à l'empereur T'ai-tsong (qui régna de 627 à 649), de la dynastie $T$ 'ang ; mais elle paraît bien reproduire, dans le passage que nous allons traduire, un document rédigé dès l'époque de la dynastie $T \sin$ : ( $T \sin$ chou, chap. LI, p. $10 \mathrm{v}^{\circ}-11 \mathrm{r}^{\circ}$ )

« Auparavant, la deuxième année t'ai-kang (281 ap. J.-C.), un homme de la commanderie de Ki, (nommé) Piao Tchoen, avait violé pour la piller la tombe du roi Siang, (du pays) de Wei; d'autres disent que c'était la tombe du roi Ngan-hi; il y trouva plusieurs dizaines de charretées de livres écrits sur bambou. C'étaient les ouvrages suivants :

1. Les Annales en 13 liasses; elles rappellent, en mettant bout à bout les événements, ce qui s'est passé depuis (la p.455 dynastie) Hia jusqu'à (l'époque où) le roi Yeou fut mis à mort par les Kiuen-Jong ; après que les trois familles (Han, Tchao et Wei) se furent partagé (le royaume de $T$ sin), (ces Annales) continuent à raconter les événements du pays de Wei et vont jusqu'à la vingtième année du roi Ngan-hi; c'est sans doute l'ouvrage des historiens du royaume de Wei; en gros, ces Annales sont sur tous les points en accord fréquent avec le Tch'oen-ts'ieou; ce qu'on y trouve qui diffère fort des livres classiques et de leurs commentaires, ce sont les faits que voici : la durée de la dynastie Hia fut plus grande que celle de la dynastie $Y n$ (126) ; I s'opposa à ce que $K^{\prime} i$ montât sur le trône et $K$ ' $i$ le tua (127); T'ai-kia tua $I-y n$ (128); Wen-ting tua Ki-li (129); depuis l'époque où les Tcheou reçurent le mandat (céleste leur conférant la royauté) il y eut cent années, mais ce n'est pas à dire que le roi Mou vécut cent ans (130); quand le roi Yeou fut allé à sa perte, le comte de Kong, Ho, assuma par intérim la charge du Fils du Ciel, mais ce ne furent pas les deux conseillers qui furent ensemble en bonne harmonie (131). 
2. Le $I$ king, en deux liasses; il est identique aux deux parties du livre classique appelé le $I$ des Tcheou.

3. Le I yao et le Yn yang koa, en deux liasses ; (ces ouvrages) sont assez semblables au $I$ des Tcheou, mais le style du (I) yao est différent.

4. Le Koa hia $i$ king, en une liasse, ressemble à (l'appendice) chouo koa, mais présente ${ }_{\mathrm{p} .456}$ des différences.

5. Le Kong-suen Toan (132), en deux liasses, contient les discussions de Kong-suen Toan avec Chao Tche au sujet de $I$.

6. Le Kоио yu, en trois liasses, parle des événements (des pays) de Tch'ou et de Tsin.

7. Le Ming, en trois liasses, ressemble au $L i K i$ et offre aussi des ressemblances avec le Eul ya et le Luen yu.

8. Le Che Tch'oen, en une liasse, relate les cas de divination par la tortue et par l'achillée qui se trouvent dans le Tso tchoan; (le titre) Che Tch'oen semble être le nom de famille et le nom personnel de l'auteur du livre.

9. Le So yu (textes fragmentaires), en onze liasses, est un livre de divination traitant des augures, des songes et des prodiges.

10. Le Leang k'ieou ts'ang, en une liasse, commence par dresser la liste généalogique (des princes) de Wei avec les nombres (d'années de leurs règnes); ensuite il parle de ce qui concerne les objets en or et en jade du trésor K'ieou.

11. Le Kiao chou, en deux liasses, traite de la méthode du tir à l'arc.

12. Le Cheng fong, en une liasse, (parle) des fiefs qui furent conférés par les empereurs et les rois.

13. Le $\mathrm{Ta} l i$, en deux liasses, est du genre des dissertations de Tseou-tse sur le ciel.

14. Le Mou t'ien tse tchoan, en cinq liasses, parle du voyage que fit le Fils du Ciel Mou chez les barbares, et de sa visite à la Mère Reine d'Occident sur le belvédère impérial.

15. Le T'ou chou, en une liasse, est de la catégorie des notices qu'on met sur les peintures. En outre, dix-neuf liasses d'écrits divers, traitant des règles des apanages sous les Tcheou, de la diseussion des affaires de p.457 Tch'ou écrite au temps des Tcheou, de la mort de Cheng-ki, mei-jen (concubine de rang élevé) du roi Mou de la dynastie Tcheou. — En tout, il y avait soixante-quinze liasses, mais, pour sept liasses, les fiches 
écrites étaient rompues et endommagées et on ne peut en connaître le titre (133). - On trouva, en outre, une épée en bronze qui était longue de deux pieds et cinq pouces. L'écriture faite au vernis était tout entière en caractères k'o-teou. Au premier moment, ceux qui violèrent la tombe allumèrent les fiches de bois pour s'éclairer afin de prendre les objets précieux ; lorsqu'ensuite les fonctionnaires recueillirent (ces fiches), il y avait un grand nombre de fiches brûlées et de morceaux de bois brisés; le texte était endommagé et on ne pouvait le discerner et en rétablir l'enchaînement. L'empereur $O u$ plaça ces écrits dans les archives secrètes pour qu'on les examinât, qu'on les rassemblât. qu'on les mît en ordre, qu'on en déterminât le sens et qu'on les écrivît en caractères modernes. (Chou) Si lut au nombre de ceux qui firent ce travail de rédaction; il put étudier ces écrits sur bambou; à chaque point ${ }_{\text {p.458 }}$ douteux il assigna une explication et tout (ce qu'il dit à ce sujet) était juste et bien démontré.

Chou Si ne fut pas le seul érudit qui fut chargé d'étudier et de publier le texte des Annales ; il n'avait été en réalité que le continuateur de son supérieur hiérarchique, Wei Heng, qui avait été mis à mort en 291 avant d'avoir pu terminer son œuvre :

«En ce temps, lisons-nous dans la biographie de Wang Tsie ( $T$ sin chou,chap. LI, p. $12 \mathrm{r}^{\circ}$ ) le préposé en second aux archives secrètes, Wei Heng, faisait une recension critique des livres trouvés dans la tombe de $K i$; mais, avant qu'il eût terminé, il lui arriva malheur (291). Le tchou-tso-lang qui l'aidait, Chou Si, continua sa tâche et l'acheva; en beaucoup de cas, il déterminait des sens très particuliers. Le gouverneur de Tong-lai, Wang T'ing-kien, originaire de Tch'en lieou, lui fit des objections et lui aussi apportait la démonstration (de ses dires). (Chou) $\mathrm{Si}$ à son tour fournit des explications et fit des objections. Cependant, (Wang) T'ing-kien étant mort, le san-ki-che-lang P'an T'ao dit à (Wang) Tsie:

- Vos talents, votre science, votre jugement et votre sens critique vous qualifient pour trancher le débat entre ces deux hommes ; vous devriez essayer de traiter ce sujet.

Alors (Wang) Tsie exposa minutieusement les points où (Chou si et Wang T'ing-kien) avaient raison et ceux où ils s'étaient trompés ; Tche Yu et Sie Heng qui étaient tous deux fort instruits en toutes sortes de matières, furent d'accord pour juger que (ses dires) étaient parfaitement exacts.

Wei Heng lui-même a fait allusion aux livres de la tombe de $K i$ dans sa dissertation sur l'écriture (Tsin chou, chap. XXXVI, p. $3 \mathrm{v}^{\circ}$ ) : 
«La première année t'ai-k'ang (280), dit-il, un homme de la sous-préfecture de $K i$ viola pour la piller la tombe du roi Siang, du royaume de $W e i$; il y trouva des textes écrits sur fiches contenant plus de cent mille caractères; ils offraient quelque ressemblance avec les caractères tracés par (Wei) King-heou; des caractères antiques de plusieurs sortes s'y trouvaient aussi. Parmi ces écrits, un chapitre qui traitait ${ }_{\text {p.459 }}$ des événements (du pays) de Tch'ou était particulièrement parfait (au point de vue de l'écriture); moi, (Wei) Heng, j'ai pris plaisir à ce livre et c'est pourquoi j'épuise mes faibles pensées pour en louer la beauté.

Un autre lettré qui paraît avoir joué un rôle considérable dans la publication des fiches du Tchou chou ki nien, est Ho Kiao (app. Tch'ang yu), qui mourut en 292. A vrai dire, la biographie de ce personnage, telle qu'elle se trouve dans le $T \sin$ chou (chap. XLV, p. $6 \mathrm{r}^{\circ}-\mathrm{v}^{\circ}$ ), ne nous fournit aucun renseignement à ce sujet; mais nous pouvons glaner ailleurs quelques informations. Dans les chapitres du Soei chou consacrés à la littérature, chapitres qui furent composés par Wei Tcheng entre 629 et 636 (134), il est dit (chap. XXXIII, p. 3 ro) :

«Sous les Tsin, la première année t'ai-k'ang (280), des gens de la commanderie de $K i$ violèrent la tombe du roi Siang, de $W e i$, et y trouvèrent d'anciens écrits sur fiches en bambou; les caractères étaient tous de l'espèce k'o-teou. Ceux qui violèrent la tombe, n'attachant pas d'importance (à cette découverte), dispersèrent en désordre (ces fiches). L'empereur ordonna au tchong-chou-kien Siun Hiu et au (tchong-chou-) ling Ho Kiao de rédiger et de mettre en ordre (ces écrits) qui formèrent quinze ouvrages en quatre-vingt sept rouleaux... (135) »" D'autre part, Lieou Tche-ki, qui date de l'année 710 la préface de son grand ${ }_{\text {p.460 }}$ ouvrage de critique historique intitulé Che t'ong, parle (136) des Annales de la tombe de $K i$ par Ho Kiao. Enfin Tchang Cheou-tsie, dans son commentaire des Mémoires historiques de Se-ma Ts'ien qu'il publia en 736, rappelle ceci (137) : "Siun Hiu dit : Au témoignage de Ho Kiao, les Annales commencent à Hoang-ti et finissent au roi actuel de Wei, ce roi actuel étant le fils du roi Hoei-tch'eng de Wei».

A côté de tous les lettrés que nous venons de nommer comme s'étant occupés du Tchou chou ki nien, citons encore Siu Hien (app. Hiao-tsong), qui mourut âgé de quatre-vingt-dix-sept ans sous le règne de Che Ki-long (335-349) et qui avait composé une «Explication des textes écrits en caractères antiques de la tombe de $K i »\left(T \sin\right.$ chou, chap. XCI, p. $\left.5 \mathrm{v}^{\circ}\right)$.

Comme on le voit par tous ces témoignages, les Annales écrites sur bambou furent, dès leur apparition, l'objet de travaux nombreux et considérables; elles faisaient partie de tout un ensemble de livres exhumés dans des circonstances qui nous sont décrites minutieusement et à diverses 
reprises. Les affirmations précises des contemporains ne nous laissent donc aucun doute sur la réalité de la trouvaille faite dans la tombe de $K i$ et sur l'importance qu'on attribua aussitôt aux ouvrages qu'un heureux hasard remettait ainsi au jour.

Sur trois points cependant les textes que nous avons traduits présentent quelque incertitude, car ils ne s'accordent ni sur la date exacte à laquelle la tombe de $K i$ fut violée, ni sur le nom du roi de Wei dont cette sépulture renfermait les restes, ni sur le point de départ chronologique des Annales.

En ce qui concerne la date où Piao Tchoen commit son bienheureux ${ }_{p .461}$ sacrilège, Siun Hiu, dans sa Préface au Mou t'ien tse tchoan (138), l'inscription de 289 (139) et la biographie de Chou Si dans le Tsin chou (140), la fixent à l'année 281 ; Wei Heng, dans sa dissertation sur l'écriture (141), et Wei Tcheng, dans le traité sur la littérature qui fait partie du Soei-chou (142), opinent pour l'année 280. Tou Yu, écrivant en 282 sa Postface au Tso tchoan, se plaint de n'avoir pu voir qu'assez tard les fiches du Tchou chou ki nien qui étaient restées quelque temps cachées aux profanes dans les archives du palais (143); d'autre part, il dit que ces fiches avaient été découvertes au moment où il venait de terminer deux ouvrages qu'il avait commencé d'écrire le troisième mois de l'année $280(\underline{144)}$; cette double indication tendrait à reporter la violation de la tombe de $K i$ à la fin de l'année 280 ou, plus vraisemblablement, au commencement de l'année 281. En tous cas, il me semble qu'il faut rejeter comme fautif le témoignage suivant des Annales principales du Soei chou (chap. III, p. 8 r $^{\circ}$ ) :

« La cinquième année hien-ning (279 ap. J.-C.), le dixième mois, un homme de la commanderie de Ki, (nommé) Piao Tchoen, fit un trou dans la tombe du roi Siang, (du pays) de Wei, et trouva des fiches de bambou couvertes de plus de cent mille mots en caractères antiques de la petite écriture tchoan; on les serra dans les archives secrètes.

Cette date de 279, qui nous est donnée par un livre écrit au VIIe siècle et qui ne concorde pas avec la date de 280 ou 281 relatée par ceux qui furent contemporains de la découverte, ne saurait être tenue pour exacte (145).

Considérons maintenant le problème soulevé par le nom du roi de $\mathrm{Wei}$ enterré dans la tombe de $K i$ : remarquons d'abord que c'est par une simple hypothèse qu'on regarde généralement la sépulture de $K i$ comme étant celle d'un roi de $W e i$; les faits sur lesquels s'appuie cette conjecture sont les suivants: les Annales, qui sont, dans leur dernière partie, une chronique du

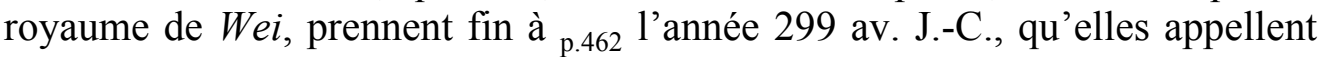
«la vingtième année du roi actuel»; d'autre part, la localité de $K i$ faisait partie du royaume de $W e i$; enfin la sépulture témoignait par l'abondance même des trésors renfermés dans son sein qu'elle devait abriter les restes d'un très haut personnage; de ces considérations on conclut que cette tombe si magnifique qui se trouvait dans l'État de Wei devait être celle d'un roi de ce 
pays, lequel roi dut mourir en l'année 299 puisque c'est à cette date que les Annales furent interrompues pour être placées dans la sépulture. Encore que cette théorie soit plausible, elle ne s'impose pas cependant d'une manière irrésistible, et Tou $Y u$ a peut-être été bien inspiré en se bornant à dire simplement que les Annales furent trouvées dans une ancienne tombe de la région de $K i(146)$. Mais, que cette sépulture soit celle du roi lui-même, ou simplement celle d'un grand dignitaire du pays de $W e i$, encore importe-t-il de déterminer quel était le roi de Wei qui était en la vingtième année de son règne quand les Annales furent déposées dans cette tombe. Ho Kiao se contente de rappeler que le roi actuel dont parlent les Annales est le fils du roi Hoeitch'eng (147); Tou Yu dit que les Annales s'arrêtent à la vingtième année du roi Ngai (148) ; Siun Hiu et Wei Heng, suivis par Wei Tcheng, voient dans la tombe de $K i$ celle du roi Siang (149); la biographie de Chou Si met aussi en avant le nom du roi Siang, mais paraît ensuite admettre que le roi Ngan-hi doit être substitué au roi Siang (150). Cette dernière opinion est insoutenable, car le roi Ngan-hi, qui régna de 276 à 243 est bien postérieur à l'époque du « roi actuel » dont la vingtième année est l'année 299 ; nous pouvons donc mettre sans discussion le roi Ngan-hi hors de cause. Si maintenant on se reporte aux Tableaux chronologiques de Se-ma Ts'ien, le roi qui régnait en 299 était le roi Ngai (318-196) et il semble ainsi au premier abord que Tou Yu ait raison. Mais un examen plus attentif nous révèle qu'il est peut-être imprudent d'accepter les indications de Se-ma Ts'ien. D'après cet historien, en effet, la succession des rois de Wei comporte : le roi Hoei (370-335), le roi Siang (334-319), le roi Ngai (318-296); au contraire, d'après les Annales écrites p.463 sur bambou, il faudrait admettre que le roi dont le nom posthume est Hoei-tch'eng régna d'abord de 370 à 335, puis de 334 à 319, en faisant de l'année 334 le point de départ d'une nouvelle supputation des années; le roi Hoei-tch'eng eut pour successeur «le roi actuel» dont la vingtième année correspond à l'année 299 av. J.-C. Qui a tort, des Annales ou de Se-ma Ts'ien?

Les avis ont été longtemps partagés, car, encore au VIIIe siècle de notre ère, si Tchang Cheou-tsie opinait en faveur des Annales, Se-ma Tcheng donnait raison à Se-ma Ts'ien (151). Il semble bien cependant qu'en définitive le système des Annales doive être considéré comme exact; seul en effet, il permet d'établir l'ordre chronologique dans la biographie de Mencius où se trouvent mentionnés les entretiens de ce philosophe avec le roi Hoei, puis avec le roi Siang (152); seul aussi il s'accorde avec le Che pen qui, comme les Annales, ne reconnaissent que deux souverains (le roi Hoei, le roi Siang) là où Se-ma Ts'ien en admet trois (le roi Hoei, le roi Siang et le roi Ngai). Ainsi le roi Ngai n'a jamais dû exister ; les années 318-296 que Se-ma Ts 'ien attribue à son règne appartiennent au roi Siang et c'est donc le roi Siang que les Annales désignent en l'appelant « le roi actuel»; telle est la conclusion à laquelle étaient déjà arrivés Siun Hiu (153) et Wei Heng (154). 
Faut-il aller plus loin et introduire une nouvelle correction dans la chronologie de Se-ma Ts'ien en disant que le roi qui régna, d'après l'historien, de 318 à 296, dut en réalité mourir en 299 ? Cette correction serait nécessaire si la tombe de $K i$ était la sépulture de ce roi, car, les Annales s'interrompant à l'année 299, il est vraisemblable que c'est à cette date qu'elles furent déposées dans la tombe en même temps que le cercueil du défunt. Nous avons indiqué dans une note de notre traduction (155) que, d'après Se-ma Tcheng, le roi qui

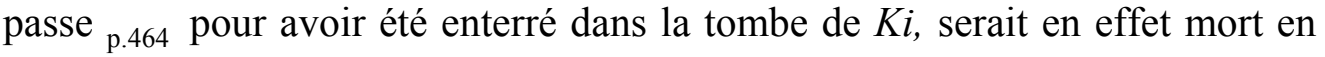
299, mais que, par piété filiale, son successeur aurait encore rapporté à so règne les trois années du deuil réglementaire. Point n'est besoin cependant de recourir à cette explication trop ingénieuse si l'on considère que la tombe de $K i$ peut fort bien, comme nous l'avons indiqué plus haut ${ }_{\mathrm{p} .462}$, lignes 9-12), n'avoir été que la sépulture d'un haut dignitaire du pays de Wei qui serait mort en 299, tandis que le roi régnant à cette époque aurait vécu trois années encore.

Reste enfin à rendre compte du désaccord qu'on remarque entre Tou $Y u(\underline{156})$ et le biographe de Chou Si ${ }_{(157)}$ d'une part qui font commencer les Annales à la dynastie Hia, et Ho Kiao (158) d'autre part qui fixe leur point de départ à Hoang ti. En fait, c'est Ho Kiao qui a raison, et les Annales telles que nous les avons aujourd'hui s'ouvrent au règne de Hoang ti. Tou Yu et le biographe de Chou Si n'ont parlé que par à peu près; leur dire a été invoqué à tort par certains critiques qui, ignorant le témoignage décisif de Ho Kiao, ont prétendu que les Annales actuelles étaient apocryphes puisqu'elles débutaient par Hoang ti et non par la dynastie Hia.

Si les lettrés de la fin du me siècle de notre ère qui furent contemporains de la découverte des fiches de bambou constituant le Tchou chou ki nien n'ont pas émis le moindre doute sur l'authenticité de cet ouvrage, les érudits qui vinrent après eux partagèrent leur conviction et firent un usage fréquent des Annales pour contrôler ou rectifier les textes historiques. Énumérer toutes les citations qu'ils en firent serait une tâche presque illimitée; il ne sera pas cependant sans utilité de signaler brièvement les principaux auteurs qui ont considéré le Tchou chou ki nien comme une source scientifique de première importance; leur multitude même constituera une très forte présomption en faveur de ce livre dont on a parfois contesté la valeur.

Les Annales sont invoquées à diverses reprises par un commentateur du Ts 'ien Han chou qui s'appelle lui-même « votre sujet, Tsan ». Les érudits, tels que $P^{\prime} e i$ Yn (deuxième moitié du Ve siècle de notre ère) et Yen Che-kou déclarent ignorer ${ }_{\text {p.465 }}$ qui pouvait être ce personnage que Li Tao-yuen $(\dagger 527)$ nomme Sie Tsa, tandis que Yao Tch'a (seconde moitié du VIe siècle) le nomme Yu Tsan, ces deux noms de famille étant déterminés au moyen de conjectures peu solides. Un critique de l'époque des Song, Song K' $i$ (998-1061), paraît avoir trouvé le mot de l'énigme (159) : il fait remarquer que ce Tsan cite les «écrits trouvés dans la tombe Mao» et les «ordonnances 
relatives aux emplois officiels à l'époque des Han »; or ces deux ouvrages ont été perdus lors des troubles qui, dans les premières années du IVe siècle, chassèrent les Tsin de Lo-yang à Nanking; comme, d'autre part, Tsan fait usage du Tchou chou ki nien qu'il désigne sous le nom de « le texte antique de la commanderie de $K i »$, il dut donc écrire entre 281, date où la tombe de $K i$ fut violée, et 317 , date où Nanking devint la capitale des $T \sin$. Dès lors il devient fort probable que Tsan n'est autre que le Fou Tsan dont il est question dans la Table des matières du Mou t'ien tse tchoan en ces termes :

«Le lang-tchong, reviseur des livres dans le bureau des archives secrètes, Fou Tsan, dit dans sa recension du Mou tien tse tchoan en caractères antiques : Ce livre, qui rappelle l'histoire du Fils du Ciel Mou, fut trouvé par un certain Piao Tchoen, originaire de la sous-préfecture de $K i$, quand il viola une ancienne tombe.

Ce Fou Tsan, ayant le titre officiel de reviseur des livres, il devait adresser ses travaux à l'empereur, et c'est pourquoi il se désignait lui-même en s'appelant « votre sujet, Tsan »; d'autre part, comme il fut contemporain de la découverte des livres dans la tombe de $K i$ et qu'il fut chargé de l'examen d'un de ces livres. le Mou t'ien tse tchoan, on comprend qu'il ait été à même de connaître et d'apprécier le Tchou chou ki nien (160).

p.466 L'un des plus anciens commentateurs de Se-ma Ts'ien, Siu Koang, mort en 425 av. J.-C., cite les Annales sous le nom de «les Annales de la tombe de $K i \gg(\underline{161})$.

C'est à $P$ 'ei $Y n$ (seconde moitié du Ve siècle de notre ère) que nous devons la conservation des fragments de Siu Koang qui nous sont parvenus ; il s'est aussi inspiré souvent du commentaire du Ts'ien Han chou par (Fou) Tsan. Cependant il a eu parfois recours personnellement au Tchou chou ki nien, car les emprunts qu'il fait à ce livre ne sont pas toujours amenés par la mention de Siu Koang ou de (Fou) Tsan (162).

Li Tao-yuen, qui mourut en 527, s'est servi à plus de cent reprises du Tchou choie ki nien dans son célèbre commentaire du Choei king.

Le Commentaire du Heou Han chou, publié en 676 par une commission de lettrés ayant à sa tête le prince Li Hien, fait des citations des Annales qui, bien que présentant avec le Tchou chou ki nien actuel quelques variantes, s'accordent parfois si exactement avec le texte du Heou Han chou qu'on peut se demander si l'auteur même de ce grand ouvrage historique, Fan Ye († 445), n'a pas puisé directement dans les Annales pour rédiger certains passages de son livre (163).

Les deux grands commentateurs de Se-ma Ts'ien à l'époque des T'ang, Se-ma Tcheng qui écrivait dans la première moitié du VIIIe siècle, et Tchang Cheou-tsie qui p.467 date sa préface de l'année 736, font tous deux fréquemment appel aux Annales (164); mais, tandis que Tchang Cheou-tsie les invoque surtout pour l'époque des $Y n$ et du commencement des Tcheou, Se- 
ma Tcheng y a recours principalement pour la période des Royaumes combattants, en particulier lorsqu'il s'agit de l'histoire de ce royaume de Wei dont la dernière partie des Annales sont la chronique.

Dans son important ouvrage de critique historique publié en 710 sous le titre de Che t'ong, Lieou Tche-ki à parlé à diverses reprises du Tchou chou ki nien.

«Les Annales écrites sur bambou, dit-il (ㅌ5), sont, dans les événements qu'elles rapportent, entièrement en accord avec le Tch'oen ts'ieou de Lou. Mencius (166) a dit :

« Dans le pays de Tsin ce qu'on appelle Tch'eng, dans le pays de Tch'ou ce qu'on appelle Tao-ou, et dans le pays de Lou ce qu'on appelle Tch'oen-ts'ieou, ce sont en réalité des ouvrages de même sorte. "

Ainsi donc, Tch'eng et Annales, de même que Tao-ou, ne sont que des noms différents (appliqués à des livres identiques au) Tch'oen-ts 'ieou ». Ailleurs (167) Lieou Tche-ki montre comment le Tso tchoan, éclipsé à l'époque des Han par les commentaires de Kong-yang et de Kou-leang, fut remis en honneur grâce à la publication des Annales qui en démontrèrent la parfaite véracité ; il rappelle à ce propos le mot de Chou Si déclarant que,

« si ce livre avait fait son apparition au temps des Han, Lieou Hin n'aurait pas été gouverneur de Ou-yuen.

En effet, sous le règne de l'empereur Ngai (6-1 av. J.-C.), Lieou Hin avait dû quitter la cour et demander un poste en province pour échapper à la haine des lettrés p.468 qui lui reprochaient d'avoir soutenu la supériorité du commentaire de Tso sur ceux de Kong-yang et de Kou-leang : si Lieou Hin avait pu prouver le bien-fondé de sa théorie en s'appuyant sur le Tchou chou ki nien, il aurait fermé la bouche de ses détracteurs et n'aurait pas été obligé de s'éloigner de la capitale.

Rappelons enfin, sans entrer dans le détail, les auteurs et les ouvrages qui, en dehors de ceux que nous venons. d'énumérer, font les plus fréquentes citations des Annales; ce sont: Kouo P'o (276-324) dans ses commentaires du Chan hai hing et du Mou t'ien tse tchoan ; Li Chan, dans son commentaire du Wen siuen publié en 658 ; Lo Pi dans le Lou che publié en 1170, et Lo $P$ 'ing, fils du précédent, à qui on attribue un commentaire du Lou che qui est peu-être l'œuvre de Lo Pi lui-même; Kin Li-siang (1232-1303) dans ses « livres antérieurs du Kang-mou »; Hou Yng-lin (fin du XVIe siècle), dans le Pi ts'ong ; Ho K'ie (docteur en 1625), dans le Che king che pen kou i; Ma sou (docteur en 1659) dans le I che; Kou Yen-ou, dans le Je tche lou publié vers 1673 ; Kao Che-k'i (1645-1704), dans le Tch'oen-ts'ieou ti li k'ao lio ; Li K'ie, dans le Chang Che qu'il composa de 1730 à 1746 ; Leang Yu-cheng, dans le Che Ki tche $i$. Mentionnons encore parmi les ouvrages qui font un fréquent usage du Tchou chou ki nien les encyclopédies telles que : le $I$ wen 
lei tsiu, compilé par Ngeou-yang Siun (557-645) et d'autres au commencement du VIIe siècle ; le Pei t'ang chou tch'ao de Yu Che-nan (558638) ; le Tch'ou hio Ki composé par Siu Kien (659-729) et d'autres; le T'ai p'ing yu lan publié en 983 ; enfin ${ }_{\text {p.469 }}$ les dictionnaires, répertoires de rimes et encyclopédies qui ont vu le jour sous la dynastie actuelle.

Comme on peut ainsi le constater, les Annales écrites sur bambou n'ont pas cessé de jouir du plus grand crédit depuis la date où elles furent découvertes jusqu'à nos jours. Elles ont cependant rencontré, du moins sous leur forme actuelle, des détracteurs dont l'opinion a reçu comme l'estampille officielle en étant admise dans la grande Bibliographie impériale intitulée $\mathrm{Se}$ k'ou ts'iuen chou tsong mou (chap. XLVII), qui fut publiée en 1782. Examinons donc ce que vaut leur thèse.

L'auteur de la notice insérée dans la Bibliographie impériale déroule une longue liste de citations des Annales qu'on peut relever dans divers ouvrages depuis l'époque où la tombe de $K i$ livra ses trésors jusqu'au XIIe siècle et il montre que ces passages, ou sont absents du Tchou chou ki nien actuel, ou en contredisent le témoignage. Il ajoute, comme considération accessoire que le Tchou chou ki nien rappelle deux faits tirés l'un du chapitre Yun tcheng,l'autre $\mathrm{du}$ chapitre Yue ming du Chou king; or ces deux chapitres font partie du pseudo-texte antique qui paraît être celui que retrouva Mei Tsi au temps de l'empereur Yuen (317-323); comment donc le Tchou chou ki nien, qui fut exhumé dès l'année 281, a-t-il pu connaître des textes qui furent mis au jour une quarantaine d'années plus tard? Enfin la Bibliographie impériale soutient que le Tchou chou ki nien actuel doit être postérieur au fameux commentaire de Hou Ngan-kouo (1074-1138) sur le Tch'oen ts'ieou, car ainsi seulement peut-on expliquer le fait que les Annales présentent une combinaison du calendrier des Hia avec le calendrier du Tch'oen ts'ieou. En conclusion, les Annales écrites sur bambou étaient bien à l'origine un livre authentique qui se transmit depuis l'année 281 ap. J.-C. jusqu'au XII' siècle, mais qui ensuite fut perdu. Elles ont dû être refaites sous la dynastie des Ming par quelque érudit qui les reconstitua au moyeu de divers livres.

A supposer même que cette opinion fût exacte, elle serait loin d'enlever toute valeur aux Annales telles que nous les avons. On sait que plusieurs ouvrages qui semblaient irrémédiablement anéantis, out été reconstruits avec une patience et une précision admirables par des ${ }_{\text {p.470 }}$ savants qui se sont ingéniés à en recueillir et à en agencer les fragments épars de ci et de là dans la vaste littérature chinoise. On remarquera qu'à côté de la cinquantaine de citations dont l'auteur de la notice de la Bibliographie impériale signale l'absence dans le Tchou chou ki nien, il en existe des milliers d'autres qui s'y retrouvent fort exactement; on est donc autorisé à déclarer que, dans son ensemble, le Tchou chou ki nien actuel n'est pas fort différent de ce qu'il était lorsqu'on le retira de la tombe de $K i$. Mais bien plus, la multitude même de ces concordances, et surtout le fait que bon nombre d'entre elles se produisent dans des cas où la citation n'est pas textuelle et n'a donc pas pu servir à 
rétablir la leçon originale, nous obligent à rejeter la thèse de la Bibliographie impériale et à admettre que la transmission des Annales ne s'est jamais interrompue. Aussi bien serait-il fort surprenant qu'un ouvrage universellement connu jusqu'au XIIe siècle ait soudain disparu en totalité. Comment donc répondrons-nous aux objections qu'on élève contre l'authenticité du Tchou chou ki nien actuel?

Considérons d'abord l'argument tiré des citations qui ne se retrouvent plus aujourd'hui dans le Tchou chou ki nien. On a vu que, lcrs de l'ouverture de la tombe de $K i$, les lamelles de bambou sur lesquelles était écrit ce livre, gisaient pêle-mêle au milieu d'un nombre formidable de fiches analogues dont on fit des dizaines de charretées. Parmi ces fiches, plusieurs traitaient de matières historiques, et, ne pouvant être groupées en un tout continu, furent désignées sous le nom générique de «Paroles fragmentaires». Si maintenant on se rappelle que les fiches de bambou sur lesquelles étaient écrits les livres antiques étaient fort étroites et contenaient chacune une seule ligne de caractères, que par conséquent recueillir et classer les innombrables fiches d'un ouvrage lorsqu'elles avaient été dispersées et mêlées à d'autres fiches, était une tàche extrêmement délicate et difficile, on conçoit que des divergences d'opinion se soient produites, les uns prétendant que certaines fiches pouvaient être rattachées à tel ouvrage, tandis que les autres voulaient les en exclure; c'est ainsi que, suivant les éditeurs, des fiches furent tantôt incorporées aux Annales, et tantôt rejetées dans la catégorie des Paroles fragmentaires. Maint passage a donc dû autrefois être inséré dans les Annales qui en fut plus tard éliminé par une critique plus sévère. Ainsi s'explique sans doute qu'on puisse relever depuis le IVe jusqu'au VIIIe siècles ${ }_{\text {p.471 }}$ des citations qui ne figurent plus maintenant dans le Tchou chou ki nien.

Pour se rendre compte des incertitudes qui n'ont cessé de planer sur les limites exactes du texte des Annales, il suffit d'étudier le commentaire original qui l'accompagne; ce commentaire est mis sous le nom de Chen Yo qui vécut de 441 à 513. Mais il n'est dû que pour une faible part à ce lettré ; il renferme, à côté de paragraphes qui décèlent une date postérieure au Ve siècle, un assez grand nombre de passages que la critique moderne tantôt attribue aux Paroles fragmentaires et tantôt suppose avoir fait primitivement partie des Annales elles-mêmes. Si on n'est pas parvenu à tracer bien nettement la ligne de démarcation, entre le texte des Annales et le commentaire original, on comprend que le même flottement ait pu se produire aussi lorsqu'il s'est agi de distinguer entre le texte des Annales et d'autres phrases des Paroles fragmentaires qui n'ont pas été conservées dans le commentaire original.

La remarque faite par la Bibliographie impériale que, en deux endroits, les Annales paraissent s'inspirer du pseudo-texte antique du Chou king n'autorise aucune conclusion. En effet, si le pseudo-texte antique est l'œuvre de Mei Tsi, quelle raison a pu empêcher ce faussaire d'emprunter quelques-unes de ses affirmations aux Annales, et de quel droit vient-on soutenir que ce sont au 
contraire les Annales qui ont dû puiser dans les chapitres du Chou king fabriqués par Mei Tsi ? Si, d'autre part, comme je le crois, le pseudo-texte antique n'est pas forgé de toutes pièces, mais est bien plutôt composé avec des débris de matériaux antiques plus ou moins habilement soudés les uns aux autres, qui nous empêche d'admettre que les deux faits relatés à la fois par le pseudo-texte antique et par les Annales appartenaient au patrimoine commun de l'histoire la plus ancienne, en sorte que ni les Annales n'ont eu à s'inspirer de $M e i$ Tsi, ni Mei Tsi des Annales?

Abordons enfin la troisième observation de la Bibliographie impériale : les Annales actuelles, combinent le calendrier du Tch'oen ts'ieou avec le calendrier des Hia. Pour comprendre cette critique, il convient d'instituer une discussion nécessairement un peu longue. Nous avons déjà eu l'occasion d'indiquer que, d'après Tou Yu, les Annales se servaient du calendrier des Hia qui fait commencer l'année au mois $y n$ (168); la même ${ }_{\text {p.472 }}$ affirmation est d'ailleurs reproduite par Wei tcheng dans le Soei chou (chap. XXXIII, p. 3 $\left.\mathrm{r}^{\circ}\right)$; il devait donc y avoir pour la période Tch'oen ts'ieou un désacord de deux mois entre les dates des Annales et les dates du Tch'oen ts'ieou; Tou Yu lui-même nous en a fourni un exemple probant en nous disant que la date qui était pour les Annales, le onzième mois de la onzième année du comte Tchoang, de $K^{\prime} i u-o u$, correspond au premier mois de la première année du duc $Y$, de Lou.

Il n'y a pas lieu d'être surpris que les Annales aient employé le calendrier des Hia même pendant la période Tch'oen ts'ieou: Les Annales en effet étaient une chronique particulière de l'État de Tsin, puis de Wei, comme le prouvent encore aujourd'hui des expressions telles que «nos soldats" désignant les troupes de $T \sin$ ou de $W e i$. Or, les princes de $T$ sin se servaient du comput des Hia, tandis que les rois de la dynastie Tcheou fixaient deux mois plus tôt le commencement de l'année; le premier mois des $T$ sin était donc le troisième mois des Tcheou; c'est ce qui explique pourquoi le Tso tchoan, lorsqu'il emprunte ses renseignements aux chroniques de $T$ sin est en désaccord de deux mois avec le Tch'oen ts'ieou; Legge (Chinese Classics, vol. V, Prol. p. 98) en a signalé trois exemples significatifs et a pu conclure que «Tsin évidemment réglait son calcul des mois sur le calendrier des Hia ». Il est donc tout naturel que le Tchou chou ki nien, qui était une chronique de Tsin, se soit conformé au calendrier des Hia.

Si cependant les Annales étaient, dans leur dernière partie, une chronique particulière de l'État de $T \sin$, puis de celui de $W e i$, elles devaient donc classer les événements d'après les règnes des princes de $T \sin$, puis de $W e i$, tout de même que le Tch'oen ts 'ieou, chronique particulière de l'État de Lou, se guide sur les règnes des ducs de Lou. En effet, sous leur forme primitive, les Annales, à partir de l'année 770 av. J.-C., étaient distribuées suivant les règnes des princes de $T$ sin, et, à partir de l'année 403 av. J.-C., suivant les règnes des princes de Wei. Tch'en Fong-heng, dans son édition du Tchou chou ki nien publiée en 1813, a pu grouper (chap. XLIII, p. $5 \mathrm{v}^{\circ}$ et suiv.), 108 citations des 
Annales faites par Li Tao-yuen dans son commentaire du Choei king, et ces 108 passages expriment les dates d'après les années des princes de Tsin ou de Wei. De même aussi les citations du Tchou chou Ki nien faites par Se-ma Tcheng attestent que, au VIIIe siècle de notre ère, les Annales étaient encore disposées de la même manière.

Actuellement, les Annales se présentent à nous sous une forme bien p.473 différente. Du commencement à la fin, elles sont rangées d'après les règnes des Fils du Ciel, et, dans la période Tch'oen ts'ieou et la période des Royaumes combattants, les princes de $T$ sin et de Wei se sont effacés devant les rois de la dynastie Tcheou. Ainsi donc, à une date postérieure au VIIIe siècle de notre ère, on a dû remanier profondément la dernière partie des Annales pour substituer à une chronologie fondée sur les règnes des princes de $T$ sin et de Wei une chronologie fondée sur les règnes des rois de la dynastie Tcheou. Par exemple, si nous comparons les dates exprimées dans le Tchou chou ki nien tel que le cite $L i$ Tao-wen au VIe siècle de notre ère avec les mêmes dates telles qu'elles sont exprimées dans le Tchou chou ki nien actuel, nous trouvons les équivalences suivantes :
Autrefois
Aujourd'hui
$12^{\mathrm{e}}$ an. Tchoang-po, de $K^{\prime}$ iu-ou
$1^{\mathrm{e}}$ an. roi Hoan (719).
$14^{\mathrm{e}}$ an. duc Hoei, de Tsin
$15^{\mathrm{e}}$ an. roi Siang (647).
$5^{\mathrm{e}}$ an. duc Tch'ou, de $T$ sin
$6^{\mathrm{e}}$ an. roi Yuen (470).
$9^{\mathrm{e}}$ an. roi Hoei-tch'eng, de Leang (ou $\left.\mathrm{Wei}\right) 7^{\mathrm{e}}$ an. roi Hien (362), etc., etc.

Lorsqu'il s'agit des mois, ce remaniement des Annales paraît y avoir introduit la plus grande confusion, car tantôt, on a fait la correction nécessaire pour réduire le calendrier des Hia au calendrier des Tcheou et tantôt on l'a omise. Ainsi, lorsque les Annales nous disent :

« La cinquantième année (720) du roi P'ing, au printemps, le deuxième mois, le jour ki-se, il y eut une éclipse de soleil, que :

elles sont en accord rigoureux avec le Tch'oen ts'ieou qui nous apprend

«La troisième année du duc Yn (720), au printemps, le deuxième mois du calendrier royal, le jour $k i$-se, il y eut une éclipse de soleil.

Voici au contraire un exemple où la correction n'a pas été faite :

Li Tao-yuen cite un passage du Tchou chou ki nien primitif qui était ainsi conçu :

« La $25^{\mathrm{e}}$ année (652) du duc Hien, de Tsin, le premier mois, les Ti attaquèrent $T$ sin.

Le Tchou chou ki nien actuel écrit : 
«La $25^{\mathrm{e}}$ année (652) du roi Hoei (de la dynastie Tcheou), au printemps, le premier mois, les $T i$ attaquèrent $T$ sin.

Puisque le premier mois du calendrier des Hia correspond au troisième mois du calendrier des Tcheou, il aurait fallu substituer le troisième mois au premier, du moment qu'on remplaçait le duc Hien par le roi Hoei ; si cette correction avait été faite, l'attaque des $T i$ contre $T$ sin se serait trouvée reportée au dernier mois du printemps et les Annales auraient alors été assez près de s'accorder avec le Tch'oen ts'ieou qui p.474 place cette incursion des barbares dans l'été de la huitième année du duc Hi (652). Ainsi, tantôt les Annales suivent le calendrier des Tcheou, tantôt elles restent fidèles au calendrier des Hia. Il ne me semble donc pas qu'il y ait lieu de dire, comme le fait la Bibliographie impériale, que les Annales actuelles combinent le calendrier des Hia avec le calendrier Tch'oen ts'ieou suivant un système savant emprunté à Hou Ngan-kouo ; mais bien plutôt il paraît évident que les Annales ont été remaniées fort maladroitement; qu'on n'a pas su réduire d'une manière uniforme les dates exprimées d'après le calendrier des Hia en dates exprimées d'après le calendrier des Tcheou.

Nous ne songeons point à dissimuler la gravité des altérations qu'a subies de ce chef le texte du Tchou chou ki nien; il est évident que, dans toute la section qui prend son point de départ à l'année 770 av. J.-C., la rédaction de ces Annales devait avoir primitivement un aspect fort différent de celui qu'elle offre aujourd'hui; classée pour les années d'après les règnes des princes de $T \sin$ ou de $W e i$ et appliquant avec régularité pour les mois le calendrier des Hia, elle était bien, comme le disait déjà Lieou Tche-ki (169), l'équivalent dans le pays de Tsin de ce que le Tch'oen ts-ieou fut dans le pays de Lou; il est fort regrettable que cette chronique locale ait perdu son véritable caractère grâce à l'intervention fâcheuse d'un homme trop zélé qui a voulu en faire le cadre d'une histoire générale de la Chine ancienne.

La partie des Annales qui traite des événements postérieurs à l'année 771 ne forme cependant guère plus du tiers de l'ouvrage total. Les deux autres tiers ont donc échappé à la cause de trouble que nous venons de signaler et paraissent moins altérés. Ce n'est pas à dire toutefois qu'ils soient sortis entièrement indemnes des mains des éditeurs successifs du Tchou chou ki nien. On remarquera, en effet que, dans tout le cours de l'ouvrage, un grand nombre de dates sont exprimées avec l'indication des caractères du cycle sexagénaire; or, on sait que, même à l'époque où écrivait Se-ma Ts'ien, c'est-à-dire vers l'an 100 av. notre ère, le cycle sexagénaire formé au moyen des deux séries kia, $i$, ping, ting... et tse, tch'eou, yn, mao... n'était pas encore appliqué à la notation des années; il est donc bien impossible que ce cycle ait pu figurer dès l'année 299 av. J.-C. dans les Annales. En fait, aucune des citations du Tchou chou ki nien, antérieure à l'époque des T'ang, ne présente de caractères cycliques. C'est dans le chapitre du Soei chou p.475 sur le calendrier (chap. XVII, p. $6 \mathrm{r}^{\circ}$ ) que nous relevons pour la première fois une date du Tchou chou ki nien, accompagnée de caractères cycliques. « D'après 
le Tchou chou ki nien, lisons-nous, la première année de Yao fut l'année ping tse ». Ce chapitre du Soei chou est l'œuvre d'une commission de lettrés, présidée par Tchang-suen Ou-ki (d. 659), qui présenta son travail à l'empereur en l'année 656. C'est donc au milieu du VIIe siècle que les caractères cycliques font leur apparition dans le texte du Tchou chou ki nien et nous avons tout lieu de croire que c'est vers cette époque qu'ils y furent introduits.

Ce passage du Soei chou est encore intéressant à un autre point de vue. Il donne en effet à entendre que la date de la première année de Yao est la plus ancienne qui, dans le Tchou chou ki nien, tel qu'on le connaissait en l'an 656 de notre ère, fût exprimée en caractères cycliques. Cette indication s'accorde bien avec le Tchou chou ki nien actuel qui ne marque les caractères cycliques qu'à partir de Yao. La question se pose maintenant de savoir pourquoi, puisque le Tchou chou ki nien commence à Hoang-ti, les caractères cycliques n'y ont été ajoutés que depuis le règne de Yao. La raison de cette singularité se laisse aisément apercevoir. Elle provient de l'incertitude où s'est trouvé l'interpolateur au sujet du règne de l'empereur Tche: d'une part, dans le Tchou chou ki nien actuel, on trouve mentionné,immédiatement après l'empereur Hoang-ti, «l'empereur Tche qui fut Chao-hao»; mais aucune durée de règne ne lui est assignée; d'autre part, dans le «Commentaire original », après l'empereur K'ou et avant l'empereur Yao, on lit «Tche, fils de l'empereur, prit le pouvoir; au bout de neuf ans il fut dégradé ». Il est évident que ces deux indications contradictoires rendent suspecte la chronologie antérieure à $Y a o$; l'interpolateur à qui on doit l'adjonction des caractères cycliques s'est donc arrêté à Yao; aussi bien ce souverain est-il celui auquel commence la littérature classique représentée par le Chou king.

A vrai dire cependant, le choix est facile à faire entre les deux témoignages du Tchou chou ki nien et du Commentaire original. En plaçant l'empereur Tche après l'empereur $K$ 'ou, le Commentaire original est d'accord avec Se-ma Ts 'ien; en le plaçant après Hoang ti, le ${ }_{\text {p.476 }}$ Tchou chou ki nien est conforme au système de Lieou Hin (fin du $1^{\mathrm{er}}$ siècle av. J.-C. et çommencement du $1^{\mathrm{er}}$ siècle ap. J.-C.), tel qu'il est exposé dans le Lu li tche du Ts'ien Han chou. A priori il y a tout lieu de croire que le Commentaire original représente la leçon primitive des Annales qui sont, dans leur ensemble, plus près de la chronologie de Se-ma Ts'ien que de celle de Lieou Hin (170). Mais on peut aller plus loin et apporter une preuve décisive de l'exactitude du texte qui place Tche après $K$ 'ou et lui attribue 9 ans de règne ; ce texte en effet nous permet d'établir un accord rigoureux entre les Annales et un passage du Tso tchoan ( $8^{\mathrm{e}}$ année du duc Chao, 534 av. J.-C.) dans lequel la mort de l'empereur Tchoan-hiu est assignée à une année choen-ho, c'est-à-dire, si l'on convertit cette date en notation moderne, à une année marquée du signe hai (171); en effet, en remontant dans le Tchou chou ki nien à partir de la $1^{\mathrm{e}}$ année de Yao qui est une année ping tse (2145 av. J.-C.), on trouvera, si on adopte la leçon du Commentaire original, que la première année de Tche sera l'année 2154 (=2145+9), qui est une année ting mao, que 
la première année de $K^{\prime}$ ou sera l'année $2217(=2151+63)$, qui est une année kia-tse, et que, par conséquent, l'empereur Tchoan hiu, qui précède $K^{\prime}$ ou, mourut en l'année 2218 qui est une année koei-hai. La date que nous obtenons ainsi est en accord absolu avec celle que suppose le passage précité du Tso tchoan daté de l'année 534 av. J.-C., et cette coïncidence prouve la haute antiquité de quelques-uns des principes chronologiques que suppose le Tchou chou ki nien.

Après avoir déterminé la place que doit occuper l'empereur Tche et la durée de son règne, rien ne nous empêche plus de continuer le calcul des dates jusqu'à l'origine même du Tchou chou ki nien, p.477 c'est-à-dire jusqu'à Hoang ti. La première année de l'empereur Tchoan-hiu sera l'année 2295 $(=2217+78)$ qui est une année ping-ou, et la première année de Hoang ti sera l'année $2395(=2295+100)$ qui est une année ping yn. En faisant ces constatations, nous ne saurions encourir le reproche de rien ajouter au texte de notre propre chef; nous nous bornons à compléter l'interpolateur qui, sans modifier en quoi que ce soit le Tchou chou ki nien, a exprimé au moyen du cycle sexagénaire les dates résultant nécessairement des durées de règne des souverains. Remarquons en effet, que le Tchou chou ki nien est un livre d'Annales, c'est-à-dire que sa prétention est de disposer les événements suivant les années classées d'après les règnes des souverains; il faut donc nécessairement que, dès le début de cet ouvrage, tous les règnes successifs aient été enregistrés avec leur durée exacte, et, si l'empereur Tche seul échappe en apparence à la règle, c'est là une anomalie que le Commentaire original nous permet de faire disparaître. Le Tchou chou ki nien appartenait à une classe de livres que Se-ma Ts'ien connaissait bien :

« J'ai lu, dit-il (chap. XIII, p. 1 r ${ }^{\circ}$ ), les Mémoires fondés sur les listes (de souverains); à partir de Hoang ti, tous indiquent les durées en années (des règnes des souverains).

Puisque le Tchou chou ki nien lui-même était encore caché sous la terre à l'époque où écrivait $S e-m a T s$ 'ien, ce n'est donc pas à ce livre mais à des ouvrages analogues, qu'il fait ici allusion; son témoignage nous atteste que le Tchou chou ki nien n'était pas unique en son genre et que d'autres auteurs encore adoptaient une chronologie dont le point de départ était Hoang $t i$.

Le sens critique de Se-ma Ts'ien a fait justice de ces anciennes chronologies en établissant qu'elles ne pouvaient s'accorder avec les textes historiques et que toute tentative de fixer des dates précises antérieurement à l'année 841 av. J.-C. était chimérique. Il n'en reste pas moins avéré que, quelle que soit sa valeur intrinsèque, le système chronologique du Tchou chou ki nien est le plus ancien qui nous soit connu. On ne doit donc pas être surpris qu'il ait conservé quelque faveur auprès des érudits chinois et que, par exemple, $\mathrm{Li}$ Tchao-lo (première moitié du XIXe siècle) l'ait adopté dans sa table supplémentaire des dates antérieures à l'année 140 av. J.-C. (172), p.478 de 
préférence au système bien postérieur qui fut combiné au XIe siècle de notre ère par Chao Yong (173) et qui a pris droit de cité dans la sinologie (174).

Le seul argument de quelque poids qu'on puisse alléguer contre l'antiquité de la chronologie du Tchou chou ki nien est tiré du passage de la biographie de Chou Si dans lequel il est dit (175) que, d'après les Annales, la dynastie Hia eut une durée plus grande que la dynastie $Y n$, ce qui est contraire aux données du Tchou chou ki nien actuel. Legge (176) en a conclu que, en introduisant les caractères cycliques, on avait dû altérer la chronologie primitive des Annales de manière à rendre la dynastie Hia plus courte que la dynastie $Y n$ (cf. p. 455, n. 1). p.479 Il ne me semble pas qu'un témoignage unique, et peut-être fautif, rende nécessaire une conclusion aussi radicale, car enfin l'auteur de la biographie de Chou $\mathrm{Si}$ a pu se tromper; on ne voit pas trop quelles raisons auraient pu motiver des changements profonds dans les indications que présentait le Tchou chou ki nien primitif au sujet des dynasties Hia et Yn. Le témoignage de la biographie de Chou Si me paraît, comme d'ailleurs à Tch'en Fong-heng, inexplicable.

En conclusion, les Annales écrites sur bambou nous semblent être un livre d'une authenticité incontestable. Sans doute elles ont subi des remaniements de forme qui ont altéré leur physionomie, surtout dans la section qui traite des événements postérieurs à l'année 771 av. J.-C. ; sans doute aussi elles ont pu être éditées de manières notablement différentes suivant qu'on a considéré certaines des fiches trouvées dans la tombe de $K i$ comme faisant ou non partie de cet ouvrage ; mais, ces réserves faites, elles doivent, dans l'État où elles sont aujourd'hui, reproduire encore assez exactement les Annales qui furent enfouies dans la tombe de $K i$ en l'année 299 av. J.-C. ; elles sont donc pour l'historien un document d'une réelle importance. 


\section{APPENDICE II \\ Le voyage au pays de $S i$-wang-mou.}

p.480 Dans un mémoire récent intitulé «Mu wang und die Königin von Saba» (Mitteilungen des Seminars für Orientalische Sprachen zu Berlin, Jahrgang VII, 1904), M. A. Forke a cherché à démontrer l'identité de Siwang-mou et de la reine de Saba; sans entreprendre une réfutation de cette théorie, je voudrais préciser en quelques mots ma propre opinion, puisque $\mathrm{M}$. Forke me reproche, à la fin de son article (p. 172), d'avoir soutenu que la visite à $\mathrm{Si}$-wang-mou était une tradition d'origine étrangère qui fut rattachée artificiellement à l'histoire de Chine par l'introduction du roi Mou primitivement absent de cette légende (101).

Considérons d'abord le nom de Si-wang-mou que je tiens pour être à l'origine le nom d'une tribu barbare de l'Ouest. Dans le Tchou chou ki nien, il est dit que, «la neuvième année de l'empereur Choen, Si-wang-mou vint rendre hommage »

De même, on lit dans les Rites de Tai l'aîné (Ta Tai li, § 76, chao-kien) que, au temps de 1'empereur Choen, "Si-wang-mou vint offrir son tube de jade blanc (au moyen duquel on observait les émanations). »

L'empereur Choen est un personnage mythique de la très haute antiquité : les chronologies traditionnelles le font vivre un millier d'années environ avant le roi Mou; par conséquent, si on trouve ${ }_{\text {p.481 }}$ mentionné le nom de $\mathrm{Si}$-wangmou à la fois à l'époque de Choen et à celle du roi Mou, les textes qui, comme les Annales écrites sur bambou, contiennent cette double mention supposent implicitement que Si-wang-mou est, non une personne, mais un peuple, ou un prince désigné par le nom de son peuple. C'est déjà la remarque qu'avait faite le critique chinois Hou Yng-lin (fin du XVIe siècle) qui dit (102) : "Si-wangmou figure déjà ici (sous le règne de Choen); ce n'est (donc) pas pour la première fois (que ce nom apparaît) au temps du roi Mou, de la dynastie Tcheou. A mon avis, ce nom doit désigner un prince d'un royaume étranger ». Cette hypothèse se trouve d'ailleurs confirmée par le passage suivant du Eul ya (§ 9, che ti) : «Le Kou-tchou (au nord), le Pei-hou (au sud), le Si-wangmou (à l'ouest) et le Je-Hia (103) (à l'est) sont ce qu'on appelle les quatre régions extrêmes ».

Le Mou t'ien tse tchoan qui, de même que les Annales écrites sur bambou fut trouvé dans la tombe de $K i$, et qui est donc un texte certainement antérieur à l'année 299 av. J.-C., est un journal de route où sont consignées les lointaines pérégrinations au cours desquelles le Fils du Ciel Mou visita le pays de $\mathrm{Si}$-wang-mou; il peut donc nous servir à déterminer la position de ce pays. A l'examiner de près, cette relation traite de deux voyages successifs; le 
premier, qui dure 643 jours, nous ramène en fin de compte dans le Tcheou ancestral (104), nom par lequel on désignait la ville de Kao (auj. s.-p. de Tch'ang-ngan, faisant partie de la ville préfectorale de Si-ngan fou) ; quatre jours plus tard, le Fils du Ciel quitte cette localité pour une nouvelle tournée qui dure 634 jours, et qui se termine à Nan-Tcheng, à quelque ${ }_{\text {p.482 }}$ distance au nord de la préfecture secondaire actuelle de Hoa. Entre la ville de Hao et celle de Nan-Tcheng, la distance n'est guère que de $160 \mathrm{li}$; on voit donc que ces deux voyages aboutissent tous deux au même territoire qui devait être celui où le Fils du Ciel Mou avait sa résidence habituelle. Nous ne nous occuperons ici que du premier voyage qui seul nous intéresse pour la localisation du royaume de $\mathrm{Si}$-wang-mou. On peut suivre l'itinéraire au-delà de la grande boucle du Hoang-ho jusqu'à la rivière Noire qui paraît être la rivière de Chatcheou (105); trente-huit jours plus tard, les voyageurs arrivent au royaume de Si-wang-mou; comme l'a bien montré Terrien de Lacouperie dans une des études les plus pondérées et les plus précises qu'il ait jamais écrites (106), ce royaume paraît, d'après les indications même du Mou t'ien tse tchoan, avoir été situé dans la région qui s'étend entre Karachar et Koutcha.

D'après 1e Mou t'ien tse tchoan, l'aller et le retour durèrent en tout 643 jours. D'après les Annales au contraire, le roi Mou serait allé dans le pays de $\mathrm{Si}$-wang-mou en la dix-septième année de son règne, et le chef de $\mathrm{Si}$-wangmou lui aurait rendu sa visite dans le courant de la même année. Il est vraisemblable que le Mou t'ien tse tchoan est ici plus digne de créance que les Annales, mais le témoignage de ce dernier ouvrage prouve du moins que le pays de $S i$-wang-mou ne passait pas pour être situé à la formidable distance que suppose M. Forke en le plaçant dans l'Arabie Heureuse et en Éthiopie. Si le voyage tel que le relate le Mou t'ien tse tchoan dura fort longtemps, c'est parce que le prince s'arrêta souvent dans sa tournée pour recevoir des chefs locaux porteurs de tribut, pour leur offrir des banquets, pour chasser et pour faire des sacrifices.

Il est à remarquer que, tant dans le Mou t'ien tse tchoan que dans les Annales, rien ne peut faire supposer que Si-wang-mou soit une femme (107). Cependant les caractères mêmes dont on s'était ${ }_{\text {p.483 }}$ servi pour transcrire ce nom étranger donnèrent bientôt lieu à une étymologie populaire qui fut l'origine de toutes les légendes relatives à la "Mère reine d'Occident». Le même phénomène s'est passé à une époque beaucoup plus récente pour le royaume laotien de $\mathrm{Pa}$-po-si-fou [a][b][c][d] (Xieng-hong et Xieng-mai) qui, dans l'imagination du vulgaire, est devenu le royaume des « huit cents épouses ", alors que selon toute vraisemblance les caractères [a][b] sont la transcription d'un mot indigène signifiant «homme»(108). Cette transformation du personnage de Si-wang-mou paraît s'être produite antérieurement à Se ma Ts'ien, car dans une composition littéraire de Se-ma Siang-jou (d. 117 av. J.-C.), Si-wang-mou est représentée comme une immortelle dont la tête toute blanche est surmontée d'une aigrette, parure féminine (109). 
Si le Mou t'ien tse tchoan nous semble être la relation d'un voyage qui eut effectivement lieu et qui eut pour aboutissement la région de Karachar et de Koutcha, faut-il admettre que le héros de ce voyage fut le roi Mou ? Je ne le crois pas, et voici pourquoi : dans les Annales principales des Tcheou, lorsque Se-ma Ts'ien parle du ${ }_{\text {p.484 }}$ roi Mou (tome I, p. 250-265), il ne mentionne pas le fameux voyage et se borne à rappeler en quelques mots (p. 259) une expédition assez malheureuse que le roi Mou fit contre les K'iuen-Jong; d'autre part, il traite au contraire assez longuement de ce voyage dans les chapitres consacrés aux royaumes de $T$ s'in (tome II, p. 5-9) et de Tchao (tome V, p. 8-10). Je crois pouvoir en conclure que Se-ma Ts'ien, qui est un compilateur fort attentif à ne pas altérer ses sources, n'a pas relevé d'allusion au voyage du roi Mou dans les textes provenant du pays des Tcheou, tandis qu'il a trouvé la tradition de ce voyage très vivace dans les pays de $T S$ 'in et de Tchao ; il nous indique ainsi où nous devons chercher l'origine de ce récit.

Les princes de $T s$ 'in occupèrent, dès le VIIIe siècle avant notre ère, le Chàn-si actuel; les princes de Tchao, dont la fortune fut plus tardive, dominèrent à partir du Ve siècle avant notre ère, dans le centre et le nord de la province actuelle de Chan-si. Ces deux familles, dont les territoires étaient contigus, étaient issues, comme l'indique Se-ma Ts'ien (110), du même ancêtre. Elles se trouvaient placées dans une position intermédiaire entre les États proprement chinois au Sud et à l'Est, et les peuplades nomades, de race vraisemblablement turque, au Nord et à l'Ouest. Auquel de ces deux groupes ethniques se rattachaient-elles? Sans doute elles avaient subi profondément l'influence chinoise qui devait finir par les transformer d'une manière radicale ; mais un certain nombre de faits donnent à penser qu'elles étaient sorties de cet immense océan des tribus turques dont le flux et le reflux incessants ont, au cours des siècles, tantôt recouvert, tantôt abandonné la Chine septentrionale (111). Voici quelques-uns de ces faits : les princes de $T s$ 'in jusque vers le milieu du IVe siècle avant notre ère, n'étaient pas considérés comme faisant partie des Royaumes du milieu; on les traitait comme des barbares (112). De même, en 307 av. J.-C., le roi Ou-ling, de Tchao, adopta formellement les vêtements et les coutumes des peuples guerriers du Nord, mesure que l'historien présente comme inspirée par des raisons politiques, mais qui n'était p.485 vraisemblablement qu'un retour aux anciennes mœurs (113). C'est dans le pays de $T$ s'in qu'apparaît pour la première fois en 678 av. J.-C., la détestable pratique d'enterrer avec un prince défunt ses plus fidèles serviteurs (114); cette coutume est signalée chez les Hiong-nou (Mém. hist., chap. CX, p. $\left.5 \mathrm{r}^{\circ}\right)$, et nous savons par Hérodote $(\mathrm{IV}, 71)$ que c'était là aussi un usage des Scythes. Dans le pays de Tchao, on voit un prince faire du crâne de son ennemi mort une coupe à boire ; nous retrouvons encore la même particularité chez les Hiong-nou qui sont de race turque (115). Tous ces indices concourent à montrer que les pays de $T s$ 'in et de Tchao, voisins et parents l'un de l'autre, appartenaient à la grande famille des peuplades turques. 
Si maintenant nous considérons la tradition relative au voyage du roi $\mathrm{Mou}$, nous y remarquons le rôle important joué par des coursiers merveilleux qui, au nombre tantôt de quatre, tantôt de huit, sont cités par leurs noms. Or ces noms ne signifient rien en chinois ; ils sont orthographiés d'une manière différente dans Se-ma Ts'ien et dans le Mou t'ien tse tchoan (116): ils ont tout l'aspect de mots étrangers transcrits en caractères chinois. D'autre part, le fait même que ces coursiers sont associés aux exploits du voyageur, nous rappelle invinciblement cette fameuse inscription turque de Kul tegin (732 ap. J-C.) dans laquelle on ne manque pas de signaler pour chaque bataille le nom et les hauts faits du cheval que montait le héros. Ainsi, une tradition qu'on trouve dans des régions où l'élément ethnique turc devait prédominer, porte en elle-même une singularité qui révèle une origine turque, n'est-ce pas là la preuve qu'elle n'a pas pris naissance chez les Chinois ?

Pourquoi cette tradition non chinoise a-t-elle été incorporée à l'histoire de Chine par l'introduction du roi Mou qui ne devait point y figurer primitivement? A cette question on peut d'abord faire une réponse générale : l'histoire ancienne de la Chine ne devient intelligible que si l'on comprend qu'elle s'est constituée précisément en s'assimilant des traditions locales dont plusieurs sont étrangères à ${ }_{\text {p.486 }}$ l'esprit chinois : comment se fait-il, par exemple, que l'empereur $Y a$, fondateur de la dynastie Hia, soit représenté comme ayant réuni les seigneurs et comme étant mort sur le mont Koei-ki (117) qui est à Chao-hing fou dans le Tche-kiang, c'est-à-dire fort loin de la région dans laquelle a été cantonné le peuple chinois pendant toute la haute antiquité ? A mon sens, la seule réponse à faire est celle-ci : lorsque les Chinois entrèrent en contact avec les peuples apparentés aux Annamites de nos jours qui occupaient alors toutes les côtes du sud de la Chine, ils rencontrèrent chez eux des traditions relatives à un grand souverain qui aurait assemblé autour de lui plusieurs princes vassaux et qui serait mort sur le mont Koei-ki; cette légende pouvait présenter quelques traits de ressemblance avec celle de l'empereur $Y u$; c'est pourquoi les Chinois assimilèrent l'un à l'autre les deux personnages et, inconsciemment, accordèrent la naturalisation chinoise à un héros du pays de Yue. Jules César n'en fit-il pas autant lorsque, pénétrant en Gaule il baptisait des noms de Mercure, Apollon, Mars, Jupiter, Minerve les divinités indigènes (118) ? De même, l'histoire de Chine fait régner, plus de mille ans avant notre ère, le vicomte de $K i$ dans le Tch'ao-sien coréen, tandis que le nom du Tch'ao-sien n'apparaît réellement pour la première fois que sous le règne de $T s$ 'in Che-hoang-ti à la fin du IIIe siècle avant notre ère (119); l'anomalie s'explique si l'on admet que les Chinois trouvèrent à leur arrivée en Corée une tradition relative à un prince sage qui avait promulgué un code admirable en huit articles (120); ils s'empressèrent d'identifier ce législateur coréen avec le vicomte de $K i$ auquel on attribue la composition des neuf sections du traité de philosophie politique appelé le Hong fan ; c'est ainsi que le vicomte de $K i$ émigra en Corée, quand bien même tout le reste de sa biographie y contredit (121). 
p.487 Pour le voyage du roi Mou le cas est le même : c'est une tradition des peuples turcs de $T s^{\prime}$ in et de Tchao que les Chinois ont faite leur en la rattachant au nom du roi Mou que son expédition chez les K'iuen-Jong prédestinait au rôle de grand voyageur.

Il semble d'ailleurs que, lorsqu'il s'agit de ce dernier phénomène de transposition, on puisse aller plus loin et conjecturer avec assez de probabilité quel est le protagoniste réel auquel on a substitué le roi Mou. En effet, nous n'avons pas affaire ici à une anecdote plus ou moins vague, recueillie de la bouche d'un peuple étranger; nous nous trouvons en présence, dans le Mou t'ien tse tchoan, d'une relation de voyage fort précise rédigée en chinois, ce qui n'est point pour nous surprendre, car le chinois devait être la langue écrite officielle dans les pays turcs de $T s$ 'in et de Tchao, comme il l'est encore aujourd'hui en Corée. Or un texte écrit ne se laisse pas aussi facilement déformer qu'une tradition orale et, pour que le Mou t'ien tse tchoan ait pu être rattaché ultérieurement au nom du roi $\mathrm{Mou}$, de la dynastie Tcheou, il faut que quelque coïncidence 1'y ait prédisposé. Cette coïncidence ne serait-elle pas toute trouvée si nous admettons que le vrai héros du Mou t'ien tse tchoan est, non le roi Mou, de la dynastie Tcheou, mais son homonyme, le duc Mou, de $T s^{\prime}$ in, qui régna de 659 à 621 av. J.-C. ? Se-ma Ts 'ien nous apprend en effet que, en 623 av. J.-C., le duc Mou battit le roi des barbares de l'Ouest (122) : il s'annexa douze royaumes et s'ouvrit un territoire de mille $l i$; il devint alors le chef suprême de tous les barbares de l'Ouest. Le Mou t'ien tse tchoan pourrait fort bien être le récit de la tournée triomphale que fit le duc Mou dans ses nouvelles possessions occidentales pour recevoir solennellement l'hommage des chefs soumis : ce récit dut être écrit au jour le jour, mais ne put être terminé que lorsque le duc Mou fut définitivement rentré dans son pays ; or il semble que la mort du duc Mou, survenue en 621, ait eu lieu immédiatement après ce retour ; c'est ce qui explique pourquoi, dans le titre de la relation, le prince figure avec son nom posthume «Mou ». En conclusion donc, la rédaction du Mou t'ien tse tchoan dut être achevée en 621 av. J.-C. ou fort peu après. Cette date est bien plus vraisemblable que la date, de trois ou quatre siècles plus ancienne, qu'il faut admettre si on rapporte la composition du Mou t'ien tse tchoan au règne du roi Mou, de la dynastie Tcheou; en effet, vers l'an 1000 avant notre ère, la p.488 littérature chinoise était encore trop en enfance pour produire un monument aussi nettement scientifique.

L'objection qu'on fera à cette théorie est que le héros du Mou t'ien tse tchoan est constamment appelé «le fils du Ciel», épithète qui, en droit, ne peut convenir qu'à un roi de la dynastie Tcheou. Mais je me demande si nous ne découvrons pas ici la raison même qui fit plus tard substituer le roi Mou au duc Mou : il est fort possible en effet que le duc Mou, parvenu au faîte de sa puissance, se soit arrogé le titre de fils du Ciel ; après quelques générations écoulées, on oublia que le fils du Ciel Mou était le duc Mou et on supposa tout naturellement que ce Fils du Ciel ne pouvait être que le roi Mou. Au fond, la 
question qui se pose en ce moment est tout à fait semblable à celle qui a été si souvent agitée à propos des fameux Tambours de pierre de la dynastie des Tcheou ; il me paraît infiniment probable que ces inscriptions ont été gravées par un roi de $T s$ 'in postérieur au roi Hoei-wen (337-311 av. J.-C.) ; mais la plupart des épigraphistes chinois les attribuent au contraire, qui au roi Siuen (827-782 av. J.-C.), qui au roi Tch'eng (vers 1100 av. J.-C.), sous le prétexte que les épithètes de «Fils du Ciel» et de « roi par hérédité », qui figurent dans ces inscriptions, ne peuvent s'appliquer qu'à un roi de la dynastie Tcheou. En réalité, ces arguments légitimistes, qui aboutissent à assigner tant au Mou t'ien tse tchoan qu'aux Tambours de pierre une antiquité inadmissible, ne sauraient prévaloir contre la vraisemblance historique qui nous fait placer la composition du Mou t'ien tse tchoan vers 621 av. J.-C., et celle des Tambours de pierre aux environs de l'an 300 av. J.-C., les rapportant ainsi à des époques où leur apparition est toute naturelle. Il suffit en somme de supposer que les puissants princes de $T s$ 'in ont assumé le titre de Fils du Ciel pour que rien ne subsiste des raisonnements sur lesquels se fondent les érudits chinois pour prouver que seuls les rois de la dynastie Tcheou ont pu inspirer l'auteur de la relation de voyage et celui des inscriptions.

En résumé, à la thèse de $\mathrm{M}$. Forke qui voit dans les traditions relatives aux pérégrinations du roi $\mathrm{Mou}$ le souvenir d'un voyage que ce souverain aurait effectué au Xe siècle avant notre ère pour aller visiter en Arabie la reine de Saba, j'oppose la thèse suivante : vers 623 av. J.-C., le puissant chef de race turque qui régnait dans le Chàn-si actuel réussit à imposer sa domination sur le Kan-sou et sur ${ }_{\text {p.489 }}$ le Turkestan oriental; il fit alors, pour recevoir l'hommage de ses nouveaux sujets, une tournée triomphale qui le mena jusque dans la région de Koutcha ; son char était tiré par des coursiers excellents qui, suivant la coutume turque, sont associés par le narrateur aux exploits du héros; les noms de ces coursiers trahissent d'ailleurs une origine non chinoise ; le cocher chargé de conduire le merveilleux attelage était un parent du duc Mou et fut lui-même l'ancêtre des princes turcs du pays de Tchao. Peu après son retour, le duc mourut en 621 av. J.-C. ; c'est alors qu'on acheva de rédiger, en chinois, langue écrite officielle du pays de $T s$ 'in, le récit intitulé Mou t'ien tse tchoan, la plus ancienne de toutes les relations de voyage qu'il y ait en Chine. Dans cet opuscule, le duc Mou est désigné par le titre de Fils du Ciel qu'il s'était sans doute arrogé. C'est ce qui explique pourquoi, lorsque les Chinois incorporèrent ce récit dans leur propre histoire, ils n'eurent aucune peine à substituer au duc Mou, son homonyme le roi Mou qui avait vécu trois ou quatre siècles plus tôt et qui, lui, avait de droit le titre de Fils du Ciel. Cependant le roi Mou n'est ici qu'un intrus : en effet, $1^{\circ}$ les documents historiques appartenant en propre à la maison des Tcheou et utilisés par Se-ma $T s^{\prime}$ 'ien dans les Annales principales des Tcheou, ignorent totalement le voyage du roi $\mathrm{Mou} ; 2^{\circ}$ la tradition relative à ce voyage est localisée dans les pays de $T s^{\prime}$ in et de Tchao et porte d'ailleurs en elle-même l'empreinte de la race turque qui habitait ces régions; $3^{\circ}$ étant donné ce que nous savons de l'évolution de la littérature chinoise, il est absolument invraisemblable qu'un 
récit de voyage tel que le Mou t'ien tse tchoan ait pu être rédigé dès le Xe siècle avant notre ère. Telles sont les principales raisons pour lesquelles nous déclarons que le roi Mou n'a rien à faire ici, tandis que le duc Mou satisfait au contraire à toutes les conditions du problème et doit donc être considéré comme le véritable héros du voyage. 


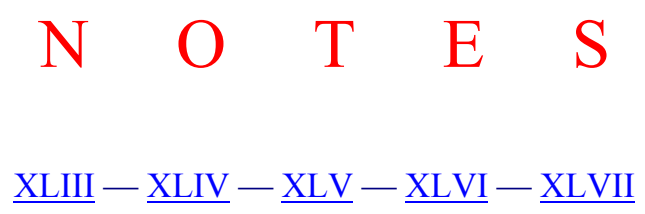

Les $n^{\circ}$ de note sont précédés du $n^{\circ}$ de chapitre. Les renvois à des notes du même chapitre ne mentionnent pas le $n^{\circ}$ du chapitre, à la différence des renvois à des notes d'autres chapitres.

\section{CHAPITRE XLIII : Treizième maison héréditaire. Tchao}

43.(101) La famille Tchao passe pour avoir pris son nom de la ville de Tchao (au S.-O. de la s.-p. actuelle de Tchao, préf. sec. de Houo, prov. de Chan-si) qui aurait été donnée en fief à Tsao-fou, le cocher qui conduisait les huit coursiers du roi Mou, de la dynastie Tcheou, lors de sa légendaire expédition dans les pays d'Occident.

- Cette famille commença à devenir puissante en 661 av. J.-C., lorsque Tchao Sou reçut en apanage la ville de Keng (au S.-E. de la s.-p. actuelle de Ho-tsin, préf. sec. de Kiang, prov. de Chan-si).

- En 497 Tchao Kien-tse, et en 454 Tchao Siang tse, nous apparaissent comme résidant à Tsin-yang qui est aujourd'hui la s.-p. de T'ai-yuen (préf. de T'ai-yuen, prov. de Chan-si).

- En 457, Tchao Siang-tse s'empara du pays de Tai c'est-à-dire de la région de Ta-t'ong fou, dans le nord du Chan-si, et doubla ainsi son territoire.

- En 454, les familles Fan et Tchong-hang furent anéanties et leurs terres furent partagées entre les quatre familles Tche, Tchao, Wei et Han ; l'année suivante, Tchao, Wei et Han s'unirent pour triompher de la famille Tche : c'est ainsi, que les six hauts dignitaires du pays de $T$ sin se trouvèrent réduits à trois, par la suppression de deux, puis d'un d'entre eux.

- En 424, les Tchao eurent pour capitale la. ville de Tchong-meou, à l'ouest de la sous-préfecture actuelle de T'ang-yn (préf. de Tchang-té, prov. de Ho-nan).

- En 403, Tchao reçut du Fils du Ciel le titre de seigneur, en même temps que Wei et Han ; ainsi fut consommé le démembrement du royaume de $T \sin$.

- En 386, Tchao fixa sa capitale à Han-tan, qui est aujourd'hui la sous-préfecture de ce nom (à 50 li au S.-O. de la préf. de Koang-p'ing, prov. de Tche-li), Cette ville fut conquise et le royaume de Tchao fut détruit par Ts'in en 228 av. J.-C.

On remarquera, dans ce chapitre, le rôle important que joue le merveilleux ; les songes, les prédictions et les apparitions d'êtres surnaturels y sont en plus grand nombre que dans n'importe quelle autre partie des Mémoires historiques.

43.(102) Cf. tome II, n. 05.126.

43.(103) C'est le Mong-hi Tchong-yen des Annales principales des Ts 'in ; cf. tome II, p. 3.

43.(104) Empereur de la dynastie Yn; cf. tome I, p. 190.

43.(105) Cf. tome II, p. 4.

43.(106) Dernier souverain de la dynastie $Y n$.

43.(107) Il faut considérer cette désignation comme un surnom de Mong-tseng; sur l'emplacement de Kao-lang, cf. tome II, n. 05.119. 
43.(108) D'après Se-ma Tcheng et Tchang Cheou-tsie, [a] signifie « quatre » et [b] signifie « deux »; l'expression [ab] donnerait donc à entendre que l'attelage de Tsao-fou se composait de huit coursiers ; ces huit chevaux sont en effet énumérés dans le Mou t'ien tse tchoan (cf. tome II, n. 05.120). Cependant, comme Se-ma Ts'ien, aussi bien ici que dans les Annales principales des $T s$ 'in, ne nomme que quatre chevaux, je considère l'expression [ab] comme désignant simplement un quadrige.

- Dans le musée chinois de la procure des missions jésuites à Amiens, on voit un petit bronze qui paraît bien figurer Tsao-fou et ses huit chevaux (Cf. la revue «Chine, Ceylan Madagascar », $\mathrm{n}^{\circ}$ de mars-juin 1903, p. 364).

43.(109) $K i$ est le nom d'un des quatre chevaux auxquels les trois autres furent assortis pour la couleur et pour la force.

43.(110) T'ao-lin était le nom d'un territoire autrefois boisé qui s'étendait entre la sous-préfecture de Ling-pao (anciennement appelée T'ao-lin; dans la préf. secondaire de Chàn, prov. de Ho-nan) et le fameux défilé de T'ong. C'est là que Tsao fou trouva ses chevaux merveilleux.

43.(111) Dans le tome II, dernière ligne de la p. 7 et première ligne de la note initiale de la $\mathrm{p}$. 8, j'ai dit que Se-ma Ts'ien passait sous silence le nom de Si wang mou; on voit que cette assertion n'est pas exacte. Dans cette même note, j'ai montré que le nom de Si wang mou pouvait à l'origine n'avoir été que la transcription du nom d'un chef barbare. Cependant, dès l'époque des Han, Si wang mou était devenue une divinité du sexe féminin qui présidait à l'Occident; nous en avons la preuve dans les miroirs des Han reproduits par le Kin che souo (section Kin souo, fasc. 6), où la Si wang mou «mère reine d'Occident » est soit représentée, soit mentionnée, en compagnie du Tong wang fou «père roi d'Orient». Voici, par exemple, l'inscription qu'on relève sur l'un d'eux :

« Le chef de la famille $H o$ a fait ce miroir qui est véritablement très bon ; sur lui se trouvent le Tong wang fou, la Si wang mou et les immortels Tse-kao, Tch'e-song tse et Kiang Tsie-yun. Que les personnages précités protègent éternellement mes deux parents et fassent du bien à mes descendants. De bon augure.

Tse-kao est mentionné dans le chap. XXVIII des Mém. historiques (t. III, p. 436), et Tch'e-song tse dans le chap. LV (p. $\left.5 \mathrm{v}^{\circ}\right)$.

43.(112) Cf. tome II, n. 05.123.

43. (113) L'ancienne ville de Tchao-tch'eng était au sud-ouest de la sous-préfecture actuelle de ce nom, préfecture secondaire de Houo, province de Chan-si.

43.(114) Cf. tome I, n. 04.387. D'après le Tch'oen ts'ieou ti li k'ao che (H. T. K. K., chap. CCLII, p. $11 \mathrm{r}^{\circ}$ et $\mathrm{v}^{\circ}$ ), la plaine de Ts'ien-meou était dans la sous-préfecture de Kie-hieou, préfecture de Fen-tcheou, prov. de Chan-si. — La date de la bataille de Ts'ien-meou est incertaine; le Kouo yu et Se-ma Ts'ien, dans les Annales principales des Tcheou (cf. t. I, p. 277), la rapportent à la $39^{\mathrm{e}}$ année du roi Siuen, soit 789 av. J.-C. ; d'autre part, dans ses Tableaux chronologiques (Mém. hist., chap. XIV), Se-ma Ts 'ien mentionne cette bataille à la $10^{\mathrm{e}}$ année du marquis Mou, de Tsin, soit 802 av. J.-C.

43.(115) Cf. t. IV, p. 259-260, où le nom de ce personnage est transcrit, par erreur, Tchao Wei.

43.(116) Sur ces trois États qui se trouvaient dans la province de Chan-si, cf. tome IV, $\mathrm{n}$. 35.106 , et tome IV, n. 39.129 et 39.130 . Tous trois avaient des princes qui appartenaient au clan $K i$.

43.(117) Le nom du Houo-t'ai-chan signifie « la grande montagne du pays de Houo »; cette montagne, qu'on appelle aujourd'hui le Houo chan est à une trentaine de li à l'Est de la sous-préfecture de Houo. On en trouvera la monographie dans le chap. XL de la section Chan 
tch'oan tien du T'ou chou tsi tch'eng. - La divinité du Houo-t'ai-chan joue un rôle important dans l'histoire du royaume de Tchao; voyez plus bas la prédiction qu'elle fit à Tchao Siang-tse.

43.(118) Sur cet emploi du mot [], signifiant «cause ou principe du mal», cf. t. IV, p. 379, ligne 23: "c'était le Ho qui était la cause du mal », Plus loin (chap. XLIII, p. $2 \mathrm{v}^{\circ}$ et chap. $\mathrm{XLV}$, p. $1 \mathrm{v}^{\circ}$ ), on lit la phrase [...] « ceux qui, après avoir accompli une grande œuvre, n'étaient pas satisfaits, étaient la cause du mal ».

43.(119) Cette date ne se rapporte pas à la naissance de Kong-mong; elle est celle de la victoire remportée par Tsin sur les princes de Houo, Wei et Keng.

43.(120) Cette femme était une fille des barbares Li-Jong; cf. tome IV, n. 39.120; sur les troubles auxquels fait ici allusion Se-ma Ts'ien, cf. t. IV, p. 264 et suiv.

43.(121) La mère de Tch'ong-eul était une fille des barbares Ti (cf. t. IV, p. 259, lignes 9-10) ; c'est ce qui explique pourquoi Tch'ong-eul se réfugia chez les $T i$. Ces $T i$ sont aussi appelés Jong-Ti, et le TSO tchoan ( $28^{\mathrm{e}}$ année du duc Tchoang) dit que la mère de Tch'ong-eul s'appelait Hou-ki et était une fille des grands Jong. Certains commentateurs placent les grands Jong dans la préfecture de Yen-ngan, province de Chàn-si ; mais Kiang Soei (H. T. K. K., chap. CCLII, p. $20 \mathrm{v}^{\circ}$ ) est d'avis qu'ils occupaient le territoire de la sous-préfecture de Kiao-tch'eng, à 120 li au sud-ouest de la ville préfectorale de T'ai-yuen, province de Chan-si.

43.(122) Cf. tome IV, n. 39.201. Les Tsiang-kao jou sont encore mentionnés par le Tch'oen-ts'ieou, à la date de la $9^{\mathrm{e}}$ année du duc Tch'eng (588).

43.(123) Tchao Siuen-tse.

43.(124) Cette femme est une autre personne que celle que Tchao Tch'oei épousa plus tard lorsqu'il fut chez les $T i$.

43.(125) Cf. t. IV, p. 299, n. 2. Le Kouo ti tche place l'ancienne ville de Yuen à 2 li au nord-ouest de la sous-préfecture de Tsi-yuen.

43.(126) Voyez le chapitre XXXIX des Mémoires historiques.

43.(127) Cf. tome IV, n. 39.242.

43.(128) Ces événements, qui sont ici rappelés très succinctement, ont été racontés en détail dans le chapitre XXXIX ; cf. tome IV, p. 313-316.

43.(토) Cf. tome IV, n. 39.300.

43.(130) Le nom de Tchao Cho est placé en tête de la phrase comme un titre de paragraphe ; il ne se relie à aucun autre mot.

43.(131) D'après le Tso tchoan $\left(12^{\mathrm{e}}\right.$ année du duc Siuen), on voit qu'il y avait trois armées. Le Tso tchoan $\left(28^{\mathrm{e}}\right.$ année du duc $\left.\mathrm{Hi}\right)$ nous apprend encore que ce fut en l'an 632 que Tsin organisa ses troupes en trois corps d'armée et qu'en 588 il créa six corps d'armée ( $3^{\mathrm{e}}$ année du duc Tch'eng).

43.(132) Cf. t. IV, p. 317-318.

43. (133) Le récit qui va suivre a donné naissance au fameux drame de l'époque des Yuen, intitulé «L'orphelin de la famille Tchao ». On sait que cette pièce de théâtre a été traduite par le P. Prémare en 1731 et imprimée en 1735 par le P. du Halde dans le tome III de sa description de la Chine ; Fourmont l'aîné, à qui le manuscrit était destiné et aurait dû être remis, se plaignit du procédé du P. du Halde ; celui-ci répliqua. On trouvera les pièces de ce débat qui prouve que l'odium sinologicum est aussi vieux que la sinologie elle-même, dans la préface qu'un certain Sorel Desflottes mit en tête d'une réédition de la traduction du P. Prémare publiée en 1755 ; cette année 1755 est celle où Voltaire fit jouer sa tragédie « l'Orphelin de la Chine » dont il avait pris le sujet dans le livre de du Halde ; c'est sans doute le succès de cette 
pièce qui engagea un imprimeur à rééditer sous forme de plaquette la traduction que le public ne pouvait guère aller chercher dans les gros in-folios de la Description de la Chine. En 1834, Stanislas Julien fit paraître une nouvelle traduction de la pièce chinoise. - Ce récit historique dont la fortune a été si grande au théâtre, ne se trouve pas dans le Tso tchoan; on ne sait pas de quelle source Se-ma Ts'ien l'a tiré. Le Tso tchoan se borne à mentionner, en 587, les rapports adultères que Tchao Yng, frère cadet de Tchao Toen, entretint avec la femme de Tchao Cho.

43.(134) On se rappelle que Chou-tai est l'ancêtre de la famille Tchao qui vint le premier s'établir dans le royaume de $T \sin$.

43.(135) Le mot [] désigne les fissures qui se formaient sur l'écaille de tortue chauffée au feu et desquelles les devins tiraient leurs pronostics.

43.(136) Sur Han kiue, appelé aussi Han Hien-tse, voyez le chap. XLVII des Mém. hist.

43. $(\underline{137})$ Cf. n. 118.

43.(138) Cf. t. II, p. 3, où il est dit que Tchong-yen avait un corps d'oiseau et une voix humaine.

43.(139) Dans le Tso tchoan ( $8^{\mathrm{e}}$ année du duc Tch'eng), ces événements sont rappelés d'une manière plus succincte et ne comportent pas l'élément dramatique qu'on remarque dans le récit de Se-ma Ts 'ien. Cf. aussi t. IV, p. 322-323.

43.(140) Ce texte prouve la croyance des Chinois à la survivance des morts sous la terre; cf. tome II, note 06.464 et note 09.126 .

43.(141) Tchao Siuen-mong n'est autre que Tchao Toen ; cf. p. 15, lignes 9-10.

43.(142) Dans le Sin Siu (chap. VII) de Lieou Hiang (80-9 av. J.-C.), tout ce récit de Se-ma $T s$ 'ien est reproduit ; l'auteur termine en disant que Tch'eng Yng, quelques grands que soient ses mérites, fit cependant une faute lorsqu'il se tua pour aller porter sous terre la nouvelle du succès de son entreprise.

43.(143) Le [a] est le pectoral de deuil. D'après les livres de rites, le [ba] était le vêtement en grosse toile bise dont les bords étaient ourlés ; il servait pour le deuil d'une mère, ou deuil d'un an ; le [ca] n'était pas ourlé et ses bords étaient effilés ; on le portait pour le deuil d'un père, ou deuil de trois ans. Cf. P. Couvreur, trad. du Li ki, tome I, p. 423, n. Tchao Ou porta le deuil de Tch'eng Yng en revêtant la tunique qui convient au deuil d'une mère, mais il la garda pendant trois ans comme s'il s'était agi du deuil d'un père.

43.(144) Cf. tome IV, n. 39.317 et p. 326.

43.(145) Les Tableaux chronologiques écrivent "petit-fils». Mais la leçon «arrière-petit-fils » est seule correcte, comme le montre la généalogie du duc Tao exposée dans le Che kia de Tsin; cf. t. IV, p. 327, lignes 13 et suiv.

43.(146) Cette date est fautive; il faut lire 544. Cf. t. IV, p. 7 et suiv. et les Tableaux chronologiques.

43.(147) Il serait plus correct de dire soit Tchao Ou, soit Tchao Wen-tse, Wen-tse étant le nom posthume de Tchao Ou.

43.(148) Cf. t. IV, p. 331-332, où la prédiction relative à la chute prochaine de la famille Kiang est mise dans la bouche de Chou-hiang. Mais la rédaction que nous avons ici est plus admissible, car c'est Yen Yng qui, venant du pays de $T s$ 'i, pouvait exprimer son opinion sur l'avenir de ce royaume.

43.(149) Les six hauts dignitaires étaient les chefs des familles Tchao, Wei, Han, Tche, Fan et Tchong-hang. 
43.(150) Cf. t. I, p. 298.

43.(151) Cf. t. IV, p. 332-333. D'après le Tso tchoan (28 e année du duc Tchoang), le duc de $T$ sin fit périr en $514 K^{\prime} i \mathrm{Yng}$, fils de $K^{\prime} i \mathrm{Ou}$ et petit-fils de $\mathrm{K}^{\prime} i \mathrm{Hi}$, ainsi que $\mathrm{Se}$-wo, de $\mathrm{Yang}$, fils de Chou-hiang, et membre de la famille Yang-cho, puis il extermina les familles $K^{\prime} i$ et Yang-cho. Les hauts dignitaires se partagèrent leurs terres ; celles de la famille $K^{\prime} i$ formèrent sept préfectures ; celles de la famille Yang-cho en formèrent trois.

43.(152) Cf. Mém. hist., chap. CV.

43.(153) Il est fait allusion à ce songe du duc Mou dans le Traité sur les sacrifices fong et chan; cf. t. III, p. 423.

43.(154) Sur Kong-suen Tche, cf. tome II, n. 05.201. — Tse-yu ou Tse-kiu était, d'après le $\underline{\text { Tso }}$ tchoan $\left(6^{\mathrm{e}}\right.$ année du duc $\left.W e n\right)$, le père des trois jeunes hommes qui furent mis à mort en 621 sur la tombe du duc Mou; cf. t. II, p. 45, où Tse-yu est donné, par erreur, comme un nom de famille.

43.(155) L’Empereur est ici le souverain céleste.

43.(156) C'est-à-dire que les règles de la pudeur ne seraient plus observées. — Le sens de toutes ces prédictions va être indiqué quelques lignes plus bas.

43.(157) Au lieu du mot [a], le commentaire de Se-ma Tcheng indique la leçon [b] qui implique l'idée que l'écriture fut gravée sur des planchettes de bois.

43. (158) Ces troubles sont ceux qui furent suscités en 656 par l'ambition de $\mathrm{Li} \mathrm{Ki}$, femme du duc Hien (cf. t. IV, p. 264 et suiv.). Ils n'étaient pas encore survenus au temps du songe du duc Mou; il faut donc admettre que ce songe, qui les prédisait, eut lieu entre 659, date de l'avènement du duc Mou, et 656 .

43.(159) Cf. t. II, p. 39-40.

43.(160) La réalité de ces faits prouve que le songe du duc Mou avait été véridique.

43. (161) Le mot [a] désigne la roue du potier. L'expression [ab] donne donc à entendre que l'évolution du ciel forme les êtres de même que la roue du potier en tournant façonne les objets d'argile.

Voici quelques textes où se rencontre cette expression :

- Se-ma Ts 'ien, chap. LXXXIII, p. $6 \mathrm{v}^{\circ}$ : « C'est pourquoi le roi saint, quand il dirige les hommes et règle les mœurs, se borne à opérer sa transformation dans les hauteurs du (Ciel) formateur; il ne se laisse pas attirer par les propos qui sont vils et qui jettent le trouble ; il ne se laisse pas prendre par les paroles de la multitude ». En d'autres termes, l'action régénératrice du souverain se conforme uniquement à celle du Ciel qui forme les êtres comme le potier façonne l'argile avec son tour et sa roue.

- Ts’ien Han chou, chap. XLVIII, p. $2 \mathrm{v}^{\circ}:$ « Le grand Formateur (=le Ciel) distribue les êtres ; il est immense et sans limites ».

- Tchang Heng, Poème sur la capitale occidentale (Ki kou ko wen siuen, chap. II, p. 1 $\mathrm{v}^{\circ}$ ) : «Autrefois, le grand Empereur trouva à son gré le duc Mou, de Ts 'in, et lui donna audience ; il le régala de la musique Vaste du ciel formateur.

- Hoai-nan tse, chap. I, p. $2 \mathrm{r}^{\circ}$ : « La roue du potier évolue, la roue du char tourne ; quand elles ont terminé leur cercle, elles recommencent leur circuit ». C'est encore le Ciel qui est ici désigné par ces métaphores.

- Tchoang tse (chap. II, p. $22 \mathrm{v}^{\circ}$; cf. Legge, S. B. E., vol. XXXIX, p. 185) dit que l'homme saint « trouve son repos dans l'action formatrice du Ciel ». 
- Enfin le Tch'oen ts'ieou de Lu Pou-wei (chap. XIII, p. $1 \mathrm{v}^{\circ}$ ), énumérant les huit régions du ciel, donne le nom de $[\mathrm{ab}]$ à la région du centre.

43.(162) La musique Vaste est fréquemment mentionnée dans le Mou t'ien tse tchoan; ainsi, dès la première page de cet opuscule, on trouve la phrase : «Le Fils du Ciel alors fit exécuter la musique Vaste ».

43.(163) Hia, Yn, Tcheou.

43.(164) Ces deux animaux symbolisent les deux hauts dignitaires Fan et Tchong-hang qui furent vaincus par Tchao Yang en 490.

43.(165) Les deux boîtes représentent deux principautés barbares qui appartenaient toutes deux au clan [], et c'est pourquoi les boîtes sont assorties. Tchang Cheou-tsie dit que ces deux principautés sont la principauté de Tai, d'une part, et la famille Tche, d'autre part ; mais cette explication est peu satisfaisante.

43.(166) Ce garçon était le propre fils de Tchao Kien-tse ; c'était donc le personnage qui devait être nommé plus tard Tchao Siang-tse.

43.(167) Ce chien figure la principauté de Tai qui fut conquise par Tchao Siang-tse.

43.(168) Les sept princes de Tsin qui sont ici désignés sont les ducs : Ting (511-475), Tch'ou (474-457), Ngai (456-438), Yeou (437-420), Lie (419-393), Hiao (392-378) et Tsing (377-376). En 376, le duc Tsing, qui n'avait plus d'ailleurs qu'un semblant de pouvoir, fut déposé et la lignée des princes de $T \sin$ s'interrompit.

43.(169) C'est la famille Tchao elle-même dont le nom de clan était Yng. Quant à ceux qui appartenaient au clan des Tcheou, ce sont les princes de Wei, issus du roi Wen. En 372, le marquis Tch'eng, de Tchao, attaqua Wei et lui prit 73 villes.

43.(170) [ab]. On ne sait pas où se trouvait exactement cette localité que Se-ma Tcheng présume avoir été située sur le territoire du pays de Tchao. Peut-être faut-il transcrire ce nom Fan-toei; d'après le Chouo wen phonétique, en effet, le mot [b] est ici l'équivalent du mot [c], et Tchang Cheou-tsie confirme cette explication en disant : « la berge d'un cours d'eau est ce qu'on appelle: [b]. De même, dans le Kouo Yu (section Tcheou yu, $3^{\mathrm{e}}$ partie), la phrase [...] signifie, d'après les commentateurs : "Le roi Yeou détruisit (la haute montagne sous la forme de laquelle est symbolisée la dynastie des Tcheou) et en fit un monticule ([bd]) et un tas de fumier $»$.

43.(171) Malgré l'importance des succès remportés en 372 par le marquis Tch'eng, de Tchao, le royaume de Wei continua à subsister et ne fut anéanti qu'un siècle et demi plus tard par Ts'in Che-hoang-ti.

43.(172) C'est le roi Ou-ling (325-299) qui est ici désigné ; on trouvera plus loin, dans les pages qui le concernent, la confirmation de cette prophétie.

43.(173) D'après Se-ma Tcheng, Tchao Kien tse, sans se souvenir d'abord des circonstances où il avait déjà vu cet homme, le reconnaît et se rappelle son nom qui est [] ; il lui dit donc : «Vous êtes Tche.»

43.(174) Cf. n. 164.

43.(175) Cf. n. 165.

43.(176) C'est le roi Ou-ling (325-299) qui est ici désigné. On lira plus loin comment ce souverain fit une véritable révolution dans son royaume en y introduisant le costume des peuples nomades du nord.

43.(177) Tchang Cheou-tsie voit ici une allusion aux expéditions militaires faites par le roi Ou-ling en l'an 306 (voyez plus loin) : cependant il n'est pas aisé de dire avec exactitude quelles sont les deux principautés barbares qui sont visées par la prédiction. 
43.(178) Tchao Ou-siu n'est autre que Tchao Siang-tse.

43.(179) La montagne Tch'ang est identique à la montagne Heng (cf. tome I, n. 02.128). La montagne Heng, ou Pic du nord, est à $20 l i$ au S. de la s.-p. de Hoen-yuen (préf. de Ta-t'ong, prov. de Chan-si), et à $140 l i$ au N.-O. de la s.-p. de K'iu-yang (préf. de Tchen-ting, prov. de Tche-li). Du haut de cette montagne on pouvait voir vers le nord s'étendre le territoire de la préfecture de Ta-t'ong, c'est-à-dire l'ancien pays de Tai.

43.(180) Il n'y avait donc aucun sceau véritable caché sur la montagne Tch'ang; mais l'observation qu'on pouvait faire du sommet de cette montagne équivalait à un sceau qui aurait assuré à celui qui l'aurait trouvé la possession du pays de Tai. - Le Che ki p'ing lin compare l'épreuve à laquelle Tchao Kien-tse soumit ses fils à celle qui fut proposée aux six fils de Che Tai-tchong, comme le rapporte le chapitre T'en kong du Li ki (trad. Legge, S. B. E., vol. XXVIII, p. 181).

43.(181) Fan Tchao-tse, appelé aussi Fan Ki-i et Tchong-hang Wen-tse, appelé aussi Siun Yn, étaient deux des six hauts dignitaires du pays de Tsin. - On remarquera que la famille Tchong-hang et la famille Tche étaient toutes deux issues du clan Siun; Siun Yen grand-père de Tchong-hang Wen-tse, avait été commandant de l'armée du centre dans le pays de Tsin, et c'est pourquoi Tchong-hang devint le nom de famille de ses descendants ; ceux-ci pouvaient cependant continuer à être désignés par leur nom de clan ; c'est ainsi que Tchong-hang Wentse est aussi appelé parfois Siun Li.

43.(182) Pour comprendre cette phrase et toute la suite de ce paragraphe, il faut se reporter au Tso tchoan $\left(14^{\mathrm{e}}\right.$ année du duc Ting) : En l'an 500, Tchao Yang avait assiégé la capitale du pays de $W e i$; les gens de $W e i$, pour obtenir la paix, lui avaient livré cinq cents familles qui furent internées à Han-tan; Tchao Yang désira, en 497, transférer ces familles dans la ville de Tsin-yang qui lui appartenait en propre. - Tsin-yang est aujourd'hui la sous-préfecture de T'ai-yuen.

43.(183) Tchao Yang (=Tchao Kien-tse) était le chef du clan Tchao auquel appartenait aussi $\mathrm{Ou}$, gouverneur ou seigneur de Han-tan. Quand donc Tchao Yang eut fait périr $\mathrm{Ou}$, il invita, en sa qualité de chef du clan, les gens de Han-tan à choisir un parent de Ou pour le remplacer. - Le commentaire Tcheng-i du Tso tchoan explique la parenté de Tchao Yang et de Ou en disant que Tchao Yang était le descendant à la cinquième génération de Tcho Tch'oei tandis que $O u$ était le descendant à la cinquième génération de Tchao Sou. Tchao Tch'oei aurait été frère cadet de Tchao Sou, ce qui est en contradiction avec les données de Se-ma Ts'ien pour qui Tch'ao Tch'oei est le petit-fils de Tchao Sou. La branche du clan Tchao à laquelle appartenait $\mathrm{Ou}$ était la famille Keng.

43.(184) Tchao Tsi était le fils de (Tchao) Ou.

43.(185) (Tchao) Ou était le fils d'une sœur de Siun Yn (=Tchong-hang Yn=Tchong-hang Wen-tse ; cf. tome IV, n. 39.344). — Le fils de Siun Yn avait épousé la fille de Fan Ki-i (=Fan Tchao-tse ; cf. tome IV, n. 39.345).

43.(186) C'est-à-dire Siun Yn et Fan Ki-i.

43.(187) Siun Li, appelé aussi Tche po ou Tche Wen-tse.

43. (188) Le Tso tchoan ajoute ici cette phrase intéressante : «Le texte écrit en a été mis dans le $H o »$. C'est-à-dire que, après avoir fait le décret, le duc jeta le texte dans le Hoang ho pour prendre à témoin la divinité du fleuve.

43.(189) Tchong-han Yn, Fan Ki-i et Tchao Yang.

43.(190) Comme on le voit par le Tso tchoan (14 ennée du duc Ting), il y eut là une machination des ennemis de la famille Tchao qui voulaient se débarrasser de Tong Ngan-yu dont ils craignaient l'habileté. Tchao Yang savait bien que les griefs formulés contre son sage conseiller étaient sans fondement ; mais, ayant fait nouvellement sa soumission, il craignait de 
déplaire en refusant de sacrifier Tong Ngan-yu; celui-ci le tira d'embarras en se suicidant; pour reconnaître son dévouement, la famille Tchao admit Tong Ngan Yu aux honneurs de son temple ancestral.

43.(191) Cf. Tch'oen-ts'ieou, $13^{\mathrm{e}}$ année du duc Ting. On voit, par ce passage, que Se-ma $T s$ 'ien attribue formellement la rédaction du Tch'oen-ts'ieou à Confucius lui-même.

43.(192) Dans le Han che wai tchoan (chap. VII) de Han Yng (IIe siècle av. J.-C. ; cf. la courte notice qui lui est consacrée dans le chap. CXXI des Mém. hist.), on lit le récit suivant concernant Tcheou Cho :

«Tchao Kien-tse avait un officier nommé Tcheou Cho qui resta debout au pied de sa porte pendant trois jours et trois nuits. Tchao Kien-tse envoya quelqu'un lui demander pour quelle affaire il désirait le voir. Tcheou Cho répondit :

— Je désire être votre officier grondeur; avec mon stylet trempé dans l'encre et ma tablette tenue en main, je surveillerai les fautes de Votre Seigneurie; ainsi, chaque jour il y aura un rappel, chaque mois un résultat obtenu, chaque année un enseignement.

Quand Tchao Kien-tse restait dans sa demeure, il restait avec lui, et quand Tchao Kien-tse sortait, il sortait avec lui. Peu de temps après, Tcheou Cho mourut. Tchao Kien-tse fut comme s'il avait perdu un fils. Plus tard, se trouvant à boire avec ses officiers sur la terrasse Hong-po, quand on fut échauffé par la vin, Tchao Kien-tse se mit à pleurer. Ses grands officiers se retirèrent tous en disant :

- Nous avons commis quelque faute envers vous, mais nous ne savons laquelle.

Tchao Kien-tse leur dit :

- Aucun de vous, ô grands officiers, n'a commis de faute. Mais autrefois j'avais Tcheou Cho; or il y a ce dicton: Les peaux de mille moutons ne valent pas l'aisselle d'un seul renard. Les murmures d'assentiment d'une multitude d'hommes ne valent pas les gronderies d'un seul brave. Autrefois, Tcheou, de la dynastie Chang se perdit grâce au silence (de ceux qui auraient dû le reprendre), tandis que le roi $O u$ devint glorieux grâce aux gronderies (de ses officiers). Maintenant, depuis peu Tcheou Cho est mort, je n'entends plus parler de mes fautes ; ma perte doit être prochaine et voilà pourquoi je pleure.

La même anecdote se trouve rapportée avec quelques variantes dans le Sin siu (chap. I) de Lieou Hiang (80-9 av. J.-C.).

Dans la biographie du prince de Chang (Mém. hist., chap. LXVIII, p. 3 r ${ }^{\circ}$ ), Tchang Leang (d. 186 av. J.-C.) cite les deux phrases : «Les peaux de mille moutons ne valent pas l'aisselle d'un seul renard; les murmures d'assentiment de mille hommes ne valent pas les grondements d'un seul brave. »

43.(193) Cf. t. IV, p. 205-206.

43.(194) Cf. tome IV, n. 31.153.

43.(195) A 12 li au N.-O. de la s.-p. actuelle de T'ang-chan (préf. de Choen-té, prov. de Tche-li).

43.(196) Cf. tome IV, n. 31.218.

43.(197) Cf. t. IV, p. 31. - Dans deux autres passages (t. II, p. 53-54 et t. IV, p. 334), Se-ma $T$ s'ien dit au contraire que ce fut le roi de $O u$ qui obtint la préséance. 
43.(198) Tchao Kien-tse aurait dû prendre le deuil de trois ans à la mort de son souverain; il ne prit que le deuil d'un an, et cela prouve que les princes de $T$ sin avaient perdu leur autorité et leur prestige.

- Le sens du mot $k^{\prime} i$ est ici le même que dans cette phrase du chapitre Sang fou siao ki du Li $k i$ : «Au bout d'un an, on quitte le deuil »; le commentaire dit en effet « le mot $k$ 'i signifie une révolution du ciel ».

43.(199) En 475, Keou-tsien assiégea la capitale de Ou (aujourd'hui Sou-tcheou fou), mais ce ne fut que deux ans plus tard qu'il anéantit l'État de $\mathrm{Ou}$; cf. t. IV, p. 32 et le Tso tchoan.

43.(200) La capitale de Tcheng était la s.-p. de Sin-tcheng (préf. de K'ai fong, prov. de Honan).

43.(201) Il est à remarquer que, d'après le Tso tchoan (partie supplémentaire, $20^{\mathrm{e}}$ année du duc Ngai), Ou-siu (ou Tchao Siang-tse) fut en deuil de son père dès l'année 475.

43.(202) Quoique Tchao Siang-tse eût déjà fort réduit sa nourriture journalière parce qu'il était en deuil de son père, il la réduisit encore en signe d'affliction quand il apprit que le roi de $\mathrm{Ou}$ était menacé. Le Tso tchoan, qui est d'ailleurs plus explicite sur ces faits, les rapporte à l'année 475. La date de 457 donnée par Se-ma Ts'ien est certainement fautive, car, à cette époque le royaume de $O u$ avait cessé d'exister depuis de longues années. D'après le Che kia de $O u$ et les Tableaux chronologiques, c'est en 473 qu'eut lieu la destruction du royaume de $\mathrm{Ou}$ (dont la capitale se trouvait sur l'emplacement de la ville de Sou-tcheou, prov. de Kiang-sou) : cf. t. IV, p. 32.

43.(203) Nous ne savons pas quelle était l'origine de la famille princière qui régnait sur le pays de Tai avant que Tchao Siang-tse en eût fait la conquête. Le nom de l'ancienne principauté de Tai s'est conservé jusqu'à nos jours, car il existe dans le nord de la province de Chan-si une préfecture secondaire de Tai. Mais c'est vraisemblablement près de Ta-t'ong fou que devait être la capitale de ce royaume.

43.(204) La montagne Hia-ou est indiquée par les cartes chinoises actuelles au nord de la préfecture secondaire de Tai dont elle est séparée par la grande muraille intérieure.

43.(205) Au lieu de [], Siu Koang indique la variante []: il faut alors traduire : « il ordonna secrètement à l'aide de cuisine nommé $L o$ de frapper... »

43.(206) Mo-ki signifie « l'épingle aiguisée ». D'après le Kouo ti tche, cette montagne était à $150 l i$ au N.-O. de l'ancienne s.-p. de Fei-hou qui correspond à la s.-p. actuelle de Koang-tch'ang (préf. sec. de $I$, prov. de Tche-li).

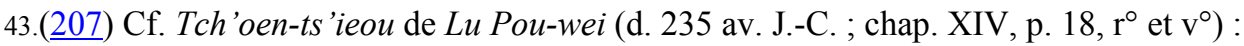

«Quand Tchao Kien-tse tomba malade, il appela auprès de lui son héritier présomptif et lui dit :

- Après ma mort, lorsque j'aurai été enterré et quand vous serez encore revêtu du pectoral de deuil, vous monterez sur la montagne Hia-ou pour regarder au loin.

L'héritier présomptif le promit. Quand Tchao Kien-tse fut mort et qu'il eut été enterré, (Tchao Siang-tse), encore revêtu du pectoral de deuil manda ses principaux ministres et leur annonça son intention de gravir la montagne Hia-ou pour regarder au loin. Ses principaux ministres l'en blâmèrent, disant :

- Gravir la montagne Hia-ou pour regarder au loin, c'est faire une excursion ; faire une excursion en étant revêtu du pectoral de deuil, cela ne se doit pas.

Tchao Siang-tse répliqua : 
— C'est là un ordre qui m'a été laissé par le souverain défunt; je ne saurais y manquer.

Les ministres assemblés ayant donné leur assentiment, Tchao Siang-tse gravit la montagne Hia-ou pour observer de loin comment se comportait la population de Tai ; ses réjouissances étaient fort belles à voir ; Tchao Siang-tse dit alors :

— Voilà maintenant ce qu'avait voulu m'apprendre le souverain défunt.

Puis il s'en revint et songea aux moyens de s'emparer de Tai. Il commença par le bien traiter; le prince de Tai aimant les belles femmes, il lui offrit en mariage sa sœur aînée et le prince de Tai l'accepta. Quand sa sœur aînée fut partie, il se rendit agréable à Tai en une multitude de façons. Comme la région des chevaux (c.-à-d. les pays situés au nord du Chan-si et du Tche-li) est propice à l'élevage des chevaux, le prince de Tai présenta d'excellents chevaux à Tchao Siang-tse. Tchao Siang-tse alla rendre visite au prince de Tai et l'invita à un banquet; c'est ainsi que la région des chevaux fut entièrement conquise. (En effet, Tchao Siang-tse) avait ordonné préalablement à plusieurs centaines de danseurs de placer des armes parmi leurs plumes ; (en outre,) il avait préparé d'avance une grande cuiller de métal. Quand le prince de Tai fut arrivé et qu'on fut échauffé par le vin, (Tchao Siang-tse) retourna la cuiller et l'en frappa; dès le premier coup, sa cervelle souilla la terre. Les danseurs saisirent leurs armes et combattirent ; ils tuèrent tous ceux qui étaient de la suite (du prince). Alors avec le char du prince de Tai on alla chercher sa femme; sa femme, ayant appris de loin ce qui s'était passé, aiguisa son épingle de tête et s'en perça. C'est pourquoi maintenant encore dans la famille Tchao il y a l'histoire de l'épingle meurtrière et le nom de la cuiller renversée.

43.(208) On a vu plus haut (p. 38, lignes 16-17) que la plus grande partie des territoires des familles Fan et Tchong-hang était revenue au duc de Tsin; c'est ce qui explique l'irritation du duc quand il se vit dépouillé de ces terres par les chefs des familles Tche, Tchao, Han et Wei.

43.(209) Le Che kia de Tsin (cf. t. IV, p. 334) et les Tableaux chronologiques appellent ce duc le duc Ngai. En outre, le Che kia de Tsin rapporte la mort du duc Tch'ou à l'année 458, tandis que les Tableaux chronologiques fixent l'avènement du duc Ngai à l'année 456. Ici, la mort du duc Tch'ou devrait être, d'après les indications du texte l'année 454.

43.(210) Cf. p. 39, lignes 8-17.

43.(211) Tsin-yang est aujourd'hui la sous-préfecture de T'ai-yuen, qui dépend de la préfecture de T'ai-yuen (prov. de Chan-si). Cette ville aurait été, d'après une tradition assez mal établie, l'ancien royaume de T'ang, et c'est là que l'empereur Yao aurait eu sa capitale (cf. tome IV, n. 39.101, à la fin); on la considère donc aussi parfois comme le berceau de la maison princière de $T \sin$, puisque cette maison reçut en apanage la principauté qui avait appartenu aux princes de T'ang, descendants de Yao (cf. t. IV, p. 251). Quoi qu'il en soit, aux époques où l'histoire devient certaine, Tsin-yang nous apparait comme appartenant au chef de la famille Tchao, qui était l'un des six hauts dignitaires de Tsin; c'est ainsi que, en 497, Tchao Yang, menacé par le duc de $T \sin$, vint se réfugier à Tsin-yang (cf. t. IV, p. 333); de même, en 454, Tchao Siang-tse attaqué par Tche po se mit à l'abri dans sa ville de Tsin-yang.

43.(212) D'après la géographie Kouo ti tche, cette localité était à 7 li au sud de l'ancienne sous-préfecture de Tcheng-p'ing (auj. préf. sec. de Kiang, prov. de Chan-si).

43.(213) Le fait qu'aucun des deux nœuds n'était percé prouve que c'est par un vrai miracle qu'un écrit put se trouver à l'intérieur du bambou, comme on le verra plus loin.

43.(214) Je crois que ce sont là les noms des trois dieux qui étaient apparus à Yuen Kouo. Sur le Houo-t'ai chan, qui est ici divinisé, cf. n. 117. Je ne sais ce que peut être le marquis de Chan-yang. 
43.(215) Tchao Ou-siu (Tchao Siang-tse) se trouvait assiégé dans Tsin-yang par Tche po et sa situation paraissait fort critique ; l'oracle lui prédit que c'est lui, au contraire, qui triomphera de Tche po.

43. (216) C'est-à-dire les barbares (Hou) Lin. Dans les pages qui concernent le roi Ou-ling (cf. plus loin), on trouvera l'expression « les trois peuples Hou » qui désigne les Tong Hou, les Lin Hou et les Leou-fan; on y verra en outre que les Tong Hou étaient à l'est du pays de Tchao, tandis que les Lin Hou et les Leou fan étaient à l'ouest. - Dans le chap. CX des Mém. hist. (p. $2 \mathrm{v}^{\circ}$ ), les Lin Hou sont mentionnés comme étant au nord du pays de Tsin ; P'ei Yn cite le commentateur Jou Choen d'après qui les Lin Hou ne seraient autres que les Tan-lin qui furent détruits par le général $\mathrm{Li}$ Mou. D'autre part, le Kouo ti tche dit, à propos de l'arrondissement de Cho, que c'était autrefois d'après Jou Choen, le pays des Tan-lin. L'arrondissement de Cho est aujourd'hui la préf. sec. de ce nom (préf. de Cho-p'ing, prov. de Chan-si) ; c'est donc dans cette région, à l'ouest de l'ancienne principauté de Tai, qu'il faut placer les Tan-lin ou Lin Hou.

- Dans le chap. CII, p. 3 r $^{\circ}$, des Mém. hist. (cf. Ts 'ien Han chou, chap. L, p. $3 \mathrm{r}^{\circ}$ ), il est parlé de la campagne que le général $\mathrm{Li} \mathrm{Mou}$ fit contre les barbares du Nord à l'époque du roi Hiao-tch'eng, de Tchao (265-245 av. J.-C.) et il est dit :

« (Li Mou) écrasa les Tong Hou et il anéantit les Tan-lin.

D'après Se-ma Tcheng, un texte donne la leçon Tan-lan au lieu de Tan-lin. En effet, dans la biographie de Li Mou (Mém. hist., chap. LXXXI, p. 5 r ${ }^{\circ}$ ) on lit :

« Il anéantit les Tan-lan; il écrasa les Tong Hou et soumit les Lin Hou.

D'après Siu Koang, au lieu de Tan-lan on trouverait aussi la variante Tan-lin. Il est à remarquer cependant que, dans ce dernier texte, les Tan-lan ou Tan-lin paraissent être distincts des Lin Hou. Dans le chapitre CX, p. 4 vº des Mém. hist. on apprend que

« en automne, quand les chevaux sont gras, les Hiong-nou tiennent une grande réunion à Tai-lin et vérifient le compte des hommes et des animaux domestiques.

Ce passage a donné lieu à deux interprétations différentes, mais celle qui paraît la plus admissible identifie le nom de Tai-lin avec celui de Tan-lan ou Tan-lin mentionné dans la biographie de Li Mou. Enfin le nom de Tai-lin est indiqué par le T'ang chou (chap. CCXVII, a, p. $1 \mathrm{v}^{\circ}$ ) comme celui d'un arrondissement qui fut établi en l'an 642 ap. J.-C. sur le territoire d'une tribu ouigoure (cf. mes Documents sur les Tou-kiue occidentaux, p. 91, n. 5). — Le commentateur Yen Che-kou (cité dans Mém. hist., chap. CX, p. $4 \mathrm{v}^{\circ}$ ), explique le nom de Tailin d'une toute autre manière (c'est la seconde interprétation à laquelle nous faisons allusion quelques lignes plus haut): «Le mot tai signifie qu'on tournait autour des arbres de la forêt pour sacrifier; c'était une coutume Sien-pi qui s'était transmise depuis l'antiquité; au sacrifice d'automne, là où il n'y avait pas les arbres d'une forêt, on plantait en terre des branches de saule et la multitude des cavaliers galopait autour; quand ils en avaient fait trois fois le tour, ils s'arrêtaient; c'était là un vestige de l'ancienne coutume. - E. H. Parker (Some new facts about Marco Polo's Book, Asiatic Quart. Review, Janvier 1904), croit que le vieux nom de tai-lin s'est conservé dans celui de tailgan par lequel on désigne de nos jours encore chez les Mongols certaines réunions solennelles (cf. le témoignage de Potanin cité dans le Marco Polo de Yule, réédité par Cordier, t. I, p. 249).

43.(217) Cette prédiction vise le roi Ou-ling (325-299).

43.(218) Je n'adopte pas ici la ponctuation du Che ki luen wen qui place un point après le mot [] et un autre point après le mot [], ce qui me paraît inintelligible.

43. (219) Nous avons déjà vu (t. IV, p. 406) le mot [] dans l'expression [][] signifiant « un grand oiseau à bec recourbé »). 
43.(220) Le roi Ou-ling adopta les vêtements des Hou qui, contrairement à la coutume chinoise, s'agrafaient à gauche.

43.(221) L'expression [] donne donc à entendre que le roi Ou-ling enseigna à ses sujets à monter à cheval tout armés; il substitua, pour se conformer aux coutumes des barbares, la cavalerie aux chars de guerre qui jusqu'alors avaient été seuls en usage dans les armées des royaumes du Milieu.

43.(222) Le Ho est, entre les quatre grands cours d'eau, celui qu'on considère comme l'ancêtre. Mais l'expression Ho-tsong désigne en outre la famille issue de celui qui préside au Ho, c'est-à-dire du personnage déifié sous le nom de Comte du Fleuve (cf. t. III, p. 534, t. IV, p. 291 et p. 320). Dans le chapitre I du Mou t'ien tse tchoan, on lit que le Fils du Ciel arriva à la montagne de Yang-ngeou;

« c'était la résidence du Comte du Fleuve, Ou-i, qui n'est autre que Ho-tsong, Ho-tsong Po-yao vint à la rencontre du Fils du Ciel sur la montagne Yen jan.

D'après Tchang Cheou-tsie, le territoire de Ho-tsong correspondrait aux arrondissements de Lan (auj. s.-p. de ce nom, prov. de Chàn-si) et de Cheng (auj. s.-p. de Yu-lin, prov. de Chàn-si). La montagne Yen jan est placée, sur les cartes chinoises en Mongolie, au nord de l'Ourato et au sud-ouest du Mao-ming-ngan.

43.(223) Les Me sont les barbares du Nord.

43. (224) Cette expression désigne les villes qui appartenaient aux familles Han et Wei, et qui étaient, en fait, détachées du territoire des princes de Tsin.

43.(225) Le nom de Hei-kou, qui désigne un peuple barbare, paraît ne se rencontrer que dans ce texte ; il en est de même du nom de Hieou-hoen que nous avons vu plus haut.

43. (226) Ces trois dieux sont les trois personnages surnaturels qui étaient apparus à Yuen Kouo. - La croyance à la véracité de la prédiction faite par le dieu de la montagne Houo en faveur de Tchao Ou-siu s'était conservée très vivace à l'époque des T'ang. Nous en avons la preuve dans un curieux passage du Kieou T'ang chou (chap. I, p. 2 r ${ }^{\circ}$ ) : en l'année 617 p. C., le septième mois, le futur fondateur de la dynastie $T$ 'ang guerroyait contre les généraux des Soei ;

« Le jour ping-tch'en, ses soldats firent halte dans la sous-préfecture de Ling-che (aujourd'hui encore s.-p. de Ling-che, dépendant de la préfecture secondaire de Houo, et voisine de la montagne Houo) et établirent leur camp au poste de Kou-hou. Le ou-ya lang tsiang (titre militaire) de (la dynastie) Soei, Song Lao-cheng s'établit dans la ville de Houo pour s'opposer aux soldats de la justice (c.-à-d. aux soldats des $T^{\prime}$ 'ang). Il se trouva que des pluies continues tombèrent pendant plusieurs dizaines de jours; les transports de vivres n'arrivaient plus en quantité suffisante. Kao-tsou donna l'ordre de la retraite; mais T'ai tsong (Li Che-min, fils de Kao-tsou et futur empereur T'ai-tsong) s'y étant opposé avec énergie, il y renonça. Il y eut un vieillard vêtu de blanc qui se présenta à la porte du camp et dit :

- Je suis l'envoyé élu dieu de la montagne ; je suis venu auprès de l'empereur de la dynastie T'ang pour lui dire : le huitième mois, les pluies cesseront; allez par le sud-est de la ville de Ноио et je ferai passer vos soldats.

Kao-tsou dit :

— Ce dieu n'a pas menti à Tchao Ou-siu; comment pourrait-il me tromper ?

43. (227) Il y a ici une inexactitude. D'après un texte du Tchan kouo ts'e qu'on retrouvera plus loin dans Se-ma Ts'ien (chap. XLIV, année 266, la rivière qui fut détournée sur Tsin-yang était la rivière $T \sin$; ce petit cours d'eau passe au S.-O. de la s.-p. de T'ai-yuen (l'ancien Tsin-yang) et se jette dans la rivière Fen (cf. Ta Ts'ing i t'ong-tche, chap. XCVI, p. 4 rº). 
43.(228) Littéralement «trois planches »; on sait que les murs chinois étaient faits de terre qu'on battait entre deux rangs de planches superposées; on pouvait donc évaluer la hauteur d'un mur d'après le nombre de planches qu'il avait fallu superposer pour le construire; la planche étant naturellement posée de champ et couchée dans le sens de sa longueur, c'était la largeur de la planche qui servait d'étalon pour mesurer un mur; la valeur d'une "planche » était, dit un commentaire du Tchan kouo ts'e (chap. VI, p. $2 \mathrm{r}^{\circ}$ ), de deux pieds. Quand on dit donc qu'il n'y avait plus que trois «planches » des remparts de Tsin-yang qui ne fussent pas sous l'eau, cela signifie que la partie qui émergeait n'avait plus que six pieds de haut.

43.(229) La même particularité est indiquée dans le récit détaillé du siège de Tsin-yang qu'on trouve chez Han Fei-tse (chap. III p. $6 \mathrm{v}^{\circ}$ ) et chez Hoai-nan tse (chap. XVIII, p. 11 ro).

43.(230) Ce personnage est appelé Kao Ho par Han Fei-tse et Hoai-nan tse (loc. cit.).

43.(231) Les trois royaumes sont Tchao, Wei et Han.

43.(232) Dans le Che kia de Wei (Mém. hist., chap. XLIV), à la date de 266, on relèvera une intéressante indication sur la manière dont Wei et Han qui s'étaient alliés à Tche po pour assiéger Tchao dans Tsin-yang, comprirent soudain que l'ambition de Tche po les menaçait eux-mêmes, et, faisant volte-face, s'unirent brusquement à Tchao. - Dans le livre de Hoainan tse (d. 122 av. J.-C.), on lit le récit suivant (chap. XII, p. 340-420) :

«Tchao Kien-tse ayant choisi (Tchao) Siang-tse pour son successeur, Tong Yue-yu dit :

— Ou-siu est de basse naissance; pourquoi maintenant le nommez-vous votre successeur?

(Tchao) Kien-tse répliqua :

- Il est un homme qui sait supporter un affront quand il y va des dieux du sol et des moissons (c-à-d. quand il y va du bien de l'État).

Un autre jour, Tche po se trouvant en train de boire avec (Tchao) Siang-tse le frappa à la tête ; les grands officiers (de Tchao Siang-tse) lui demandèrent la permission de tuer (Tche po), mais (Tchao) Siang-tse leur dit :

- Quand mon père défunt m'a nommé son successeur, il a dit que c'était parce que je pouvais supporter un affront quand il y allait des dieux du sol et des moissons; comment aurait-il dit que c'était parce que je pouvais tuer un homme?

Dix mois plus tard, Tche po assiégea (Tchao) Siang-tse dans Tsin-yang ; (Tchao) Siang-tse déploya des bataillons et combattit contre lui ; il fit essuyer une grande défaite à Tche po ; il brisa sa tête et en fit une coupe à boire. »

La même anecdote est rapportée dans le Chouo yuan (chap. III, à la fin) de Lieou Hiang (80-9 av. J.-C.) ; dans cette seconde rédaction, la phrase finale devient :

« il enduisit de vernis sa tête et en fit une coupe à boire.

Prendre le crâne d'un ennemi pour en faire une coupe à boire est un trait qui n'a rien de commun avec les mœurs chinoises mais qui se retrouve au contraire chez les peuples turcs, et ceci semblerait prouver que le pays de Tchao avait fortement subi l'influence des tribus barbares qu'il s'était annexées en conquérant le pays de Tai. Dans le chap. CXXIII, p. 1 ro, des Mém. hist. nous apprenons que le chan-yu Lao-chang (d. 161 av. J.-C.), après avoir vaincu le roi des Ta Yue-tche, fit de son crâne une coupe à boire; d'après le Ts'ien Han chou (chap. XCIV, b, p. $3 \mathrm{r}^{\circ}$ ), sous le règne de l'empereur Yuen (48-33 av. J.-C.), deux ambassadeurs chinois allèrent chez les Hiong-nou pour conclure un traité, et, afin de sceller la convention, ils burent du sang avec les chefs turcs dans le crâne du roi des Ta Yue-tche dont le chan yu Lao-chang avait fait une coupe à boire. Cf. le passage suivant de Tite-Live (XXIII, 
XXIV, à la date de 216 av. J.-C.) qui atteste la même coutume chez un peuple galate, les Boïens :

«Les dépouilles et la tête du consul (Postumius) furent portés en triomphe par les Boïens dans le temple le plus respecté de leur nation, puis la tête fut vidée et, selon l'usage de ces peuples, le crâne orné d'un cercle d'or leur servit de vase sacré pour offrir des libations dans les fêtes, ce fut aussi la coupe du pontife et des prêtres du temple. (Trad. Bertrand).

43.(233) Cf. notes 214 et 226.

43.(234) La famille $K^{\prime}$ 'ong-t'ong était une tribu des Jong occidentaux qui demeurait sur la montagne $K$ 'ong-t'ong. Mais on ne sait si la montagne $K$ 'ong-t'ong qui lui donna son nom est celle qui était à 40 li à l'ouest de la ville préfectorale de P'ing-leang, dans le Kan-sou, ou celle qui était sur le territoire de Sou-tcheou (cf. tome I, n. 01.121). D'après Se-ma Ts'ien, la famille $K$ 'ong-t'ong descendait de la dynastie $Y n$ (cf. t. I, p. 208).

43.(235) Le marquis Hien transféra sa capitale de Keng (cf. p. 7, lignes 7-9 de la n. 1) à Tchong-meou. Cette ville de Tchong-meou était au pied de la montagne Meou, à l'ouest de la sous-préfecture de T'ang-yn (préf. de Tchang-té, prov. de Ho-nan); elle se trouvait donc au nord du Hoang ho et ne doit pas être confondue avec une autre ville de Tchong-meou, qui dépendait du royaume de Tcheng et qui est aujourd'hui encore la sous-préfecture de Tchong-meou (préf. de K'ai-fong, prov. de Ho-nan). Cf. H. T. K. K., chap. CCLIV, $9^{\mathrm{e}}$ année du duc Ting.

43.(236) La principauté de Tchong-chan (Cf. tome II, n. 05.401) que nous voyons apparaitre pour la première fois en cette année 414, fut détruite en l'an 300 par le roi Ou-ting, de Tchao, et définitivement anéantie en 296 par le roi Hoei-wen. D'après Siu Koang, le duc Ou, de Tchong-chan, était le fils du duc Hoan, de la branche des Tcheou occidentaux (cf. t. I, p. 300), et, par conséquent, le petit-fils du roi Ting, de la dynastie Tcheou. Ce témoignage est plausible, mais on ne sait sur quels textes il se fonde.

43.(237) Au S. O. de la sous-préfecture de Yang-kao (préf. de Ta-t'ong, prov. de Chan-si).

43.(238) Il semble qu'il y ait ici une inexactitude et qu'il faille lire : on honora Hoan du nom de marquis Hien. On a vu plus haut que le nom personnel de ce prince était Hoan; quand son fils eut pris le titre de seigneur, on conféra rétrospectivement à Hoan le nom posthume de marquis Hien.

43.(239) Tchang Cheou-tsie identifie cette ville avec celle de [] qui est mentionnée dans le Kouo ti che, et qui figure ... dans le Ts'ien Han chou (chap. XXVIII, a. p. $12 \mathrm{v}^{\circ}$ ) parmi les sous-préfectures dépendant de la commanderie de Tch'ang-chan. Cette ville était au S.-E. de la sous-préfecture de P'ing-chan (préf. de Tcheng-ting, prov. de Tche-li).

43.(240) Cette phrase me paraît signifier que Kong-tchong profite de la question du prince pour introduire auprès de lui les trois sages, sous couleur de lui proposer des terres.

43.(241) C'est-à-dire : gouverneur de la capitale.

43.(242) C'est-à-dire un habillement complet formé d'un vêtement simple et d'un vêtement doublé.

43.(243) Han-tan, qui devait dès lors rester la capitale du royaume de Tchao, est aujourd'hui la sous-préfecture de ce nom, à 50 li au S.-O. de la ville préfectorale de Koang-p’ing, dans la province de Tche-li.

43.(244) Les indications des commentateurs (dans les divers passages où la ville de Lingk'ieou est mentionnée) concordent à la placer à l'E. de la sous-préfecture actuelle de Lingk'ieou (préf. de Ta-t'ong, prov. de Chan-si). Comme cependant nous apprenons dans le Che kia de $T s^{\prime} i$ (à la date de 378), que Ling-k'ieou était une ville de $T s^{\prime} i$, cette localisation dans le nord du Chan-si apparaît comme peu vraisemblable. 
43.(245) A $70 l i$ au S.-E. de la sous-préfecture de Fan (préf. de Ts'ao-tcheou, prov. de Chan-tong).

43.(246) Ces localités de Tou-t'ai et de Kang-p'ing, dit Tchang Cheou-tsie, étaient toutes deux au nord du Hoang-ho.

43. (247) Les mots [a Wei] et [b Wei] devenant identiques en transcription, j'adopterai la convention suivante : quand les deux pays de [a] et de [b] se trouveront mentionnés dans la même page, le mot Wei tout seul désignera toujours [a], tandis que le nom de l'État de Wei [b] sera toujours accompagné du caractère chinois.

43.(248) La ville de $K i$ - $p$ 'ou devint, sous les Han, la sous-préfecture de $P$ 'ing-ki; elle était à 3 $l i$ au S. de la préfecture secondaire de Tchao (prov. de Tche-li).

43.(249) La septième année (380), ajoutent les Tableaux chronologiques (chap. XV, p. $16 \mathrm{r}^{\circ}$ ), Tchao attaqua $T s$ ' $i$ et arriva jusqu'à Sang- $k$ 'ieou.

43. (250) La géographie Kouo ti tche place l'ancienne ville de Hoang tch'eng au S. de la sous-préfecture de Koan-che, laquelle était au N. de la sous-préfecture actuelle de Koan, préf. de Tong-tch'ang, prov. de Chan-tong). Dans les Tableaux chronologiques (chap. XV, p. 16 $\mathrm{r}^{\circ}$ ), on lit, à cette date, que Tchao attaqua $W e i[\mathrm{~b}]$ à l'improviste, mais ne fut pas vainqueur.

43.(251) Au S.-O. de la sous-préfecture de Kao-i (préf. secondaire de Tchao, prov. de Tche-li).

43.(252) Tchong-jen était, d'après la géographie Kouo ti tche, à 41 li au N.-E. de la sous-préfecture de T'ang (préf. de Pao-ting, prov. de Tche-li).

43.(253) En plein été.

43.(254) Dans ce nom propre, dit Siu Koang, un texte donne la leçon tch'eng, au lieu de meou.

43.(255) A l'O. de la préfecture secondaire de Yong-ning, (préf. de Fen-tcheou, prov. de Chan-si).

43. (256) D'après Tchang Cheou tsie, Kao-ngan devait se trouver dans la commanderie de Ho-tong, c'est-à-dire dans le S.-O. du Chan-si.

43.(257) Kiuen, qui fut plus tard la sous-préfecture de Kiuen-tch'eng, était à 20 li à l'E. de la préfecture secondaire de Pou (préf. de Ts'ao-tcheou, prov. de Chan-tong).

43.(258) Localité non identifiée.

43.(259) Il ne peut s'agir ici que d'un débris de l'ancien royaume de Tcheng, car ce pays avait été vaincu et annexé par Han dès l'année 375 (cf. t. IV, p. 484).

43.(260) Aujourd'hui, sous-préfecture de Tchang-tse (préf. de Lou-ngan, prov. de Chan-si).

43.(261) Nous ne savons pas quel était le tracé de cette muraille. Nous avons ici un exemple nouveau de la coutume qu'avaient alors les peuples de race chinoise d'élever des remparts tout le long des parties de leurs frontières exposées aux attaques de l'ennemi. Nous avons vu (tome IV, n. 40.375) que le roi de $T s^{\prime} i$ avait de même interposé une muraille entre lui et Tch'ou. Dans le chapitre CX des Mémoires historiques, nous trouverons l'énumération des travaux de fortifications qui, exécutés à diverses époques sur la frontière septentrionale de la Chine, furent coordonnés par $T$ s'in Che-hoang-ti et constituèrent alors la grande muraille par excellence (cf. BEFEO, t. III, p. 221, n. 4).

43. (262) L'emplacement de cette localité n'est pas bien déterminé ; il est probable qu'elle tirait son nom de la rivière Tchouo qui, d'après le Kouo ti tche, prenait sa source au N.-E. de la préfecture secondaire de Kie (prov. de Chan-si). Elle se serait ainsi trouvée dans le voisinage de la ville de Ngan-i (au N. de la s.-p. de Hia) qui était alors la capitale de l'État de Wei.

43.(263) Vraisemblablement dans sa capitale qui était alors Ngan-i. Cf. la note précédente. 
43.(264) Ce long mur était celui que $T s^{\prime} i$ avait élevé pour se garantir contre $T c h$ 'ou (cf. tome IV, n. 40.375). D'après le Kouo ti tche, Tchao pénétra dans le pays de $T s$ ' $i$ jusqu'à $30 l i$ au sud de l'arrondissement de Mi (auj. sous-préfecture de Tchou-tch'eng, préf. de Ts'ing-tcheou, prov. de Chan-tong).

43.(265) Il n'est fait aucune mention de cet événement dans les Annales principales des Tcheou.

43.(266) D'après les Annales principales des Tcheou, c'est en 426 que les Tcheou se divisèrent effectivement en occidentaux et orientaux (cf. t. I, p. 300-301). Dans la note 04.497 (tome I), nous avons résumé les événements qui se passèrent alors, mais, à la ligne 16 de cette note, il faut lire 426, au lieu de 376 qui est une erreur).

43.(267) Ngo devint, sous les Han, la sous-préfecture de Tong-ngo ; elle était à 50 li au N.-E. de la sous-préfecture actuelle de Yang-kou (préf. de Yen-tcheou, prov. de Chan-tong).

43.(268) Cf. n. 257.

43.(269) Dans la région comprise entre la rivière Fen et le Hoang ho.

43.(270) Chao-leang était à 22 li au sud de la sous-préfecture de Han-tch'eng (préf. de T'ong-tcheou, prov. de Chàn-si).

43.(271) D'après le Kouo ti tche, la ville de Koai, ou Koai-choei, était à 25 li au S.-E. de l'ancienne sous-préfecture de I-tch'eng. Celle-ci était elle-même à $35 l i$ au S.-E. de la sous-préfecture actuelle de I-tch'eng (préf. de P'ing-yang, prov. de Chan-si). La localité de $P$ 'i-lao devait être dans le voisinage de Koai.

43.(272) Le mot [] implique que la rencontre fut fortuite; lorsqu'il s'agit d'une rencontre préméditée, on emploie le mot [].

43.(273) Aujourd'hui, ville préfectorale de Lou-ngan (prov. de Chan-si).

43.(274) A $60 l i$ au N.-E. de la sous-préfecture de Ts'in-choei (préf. de Tse-tcheou, prov. de Chan-si).

43.(275) Je n'ai pas pu identifier cette localité. D'après le Wei che kia (voyez plus loin, chap. XLIV), l'entrevue des princes de Wei et de Tchao se produisit à Hao (auj. sous-préfecture de Kao-i, préf. sec. de Tchao, prov. de Tche-li).

43.(276) A la date de la dix-huitième année (357), le Tableau chronologique (chap. XV, p. 19 $\mathrm{r}^{\circ}$ ) ajoute cette indication : "Tchao Mong se rendit dans le pays de $T s^{\prime} i$ ».

43.(277) Au N. de la sous-préfecture de Wen-chang (préf. de Yen-tcheou, prov. de Chan-tong).

43.(278) Cette ville de Ngo ou Ngo occidental à ne doit pas être confondue avec la ville de $N g o$ ou $N g o$ oriental dont il a été question plus haut (cf. n. 267). Le $N g o$ occidental était à 50 li au N.-O, de l'ancienne sous-préfecture de Kao-yang, qui était elle-même à $25 l i$ à l'E. de la sous-préfecture actuelle de ce nom (préf. de Pao-ting, prov. de Tche-li). D'après le Kouo ti tche, le Ngo occidental était l'ancienne ville de Ko et parfois aussi était appelée ville de $I$.

43.(279) D'après la géographie Kouo ti tche, cet édifice était à $2 l i$ au N. de l'ancienne sous-préfecture de Lin-ming, laquelle se trouvait à $15 l i$ à l'O. de la sous-préfecture actuelle de Yong-sien (préf. de Koang-p'ing, prov. de Tche-li).

43.(280) C'est-à-dire la capitale même du royaume de Tchao; cf. n. 101.

43.(281) Cette localité paraît être identique à la ville de Koei qui, d'après la géographie Kouo ti tche, était à $21 l i$ au N.-E. de l'ancienne sous-préfecture de Tch'eng-che, laquelle était au S.-O. de l'actuelle sous-préfecture de Kiu-ye (préf. de Ts'ao tcheou, prov. de Chan-tong). 
43.(282) La rivière Tchang (cf. tome I, n. 02.126) coule au S. de Han-tan. C'est vraisemblablement près de la sous-préfecture de Lin-tchang préf. de Tchang-té, prov. de Honan, qu'eut lieu l'entrevue des princes de Tchao et de Wei.

43.(283) Cf. n. 255.

43.(284) D'après une note de Se-ma Tcheng aux Tableaux chronologiques (chap. XV, p. 20 $\mathrm{v}^{\circ}$ ), le nom personnel de ce prince était $Y u$.

43.(285) Cf. n. 274.

43.(286) Aujourd'hui, sous-préfecture de T'oen-lieou (préf. de Lou-ngan, prov. de Chan-si).

43.(287) Aujourd'hui, sous-préfecture de Hoa-yn (préf. de T'ong-tcheou, prov. de Chàn-si). Yn-tsin était alors une ville du pays de Wei. En 332 av. J.-C., elle tomba au pouvoir du roi de $T s$ 'in qui lui donna le nom de Ning-ts' in (cf. t. II, p. 69).

43.(288) Kao-T'ang, qui fut une sous-préfecture à l'époque des Han, était à 40 li au S.-O. de la sous-préfecture actuelle de Yu-ch'eng (préf. de Tsi-nan, prov. de Chan-tong).

43.(289) Tchang Cheou-tsie se borne à nous dire que cette localité devait se trouver au N. du Hoang ho.

43.(290) Wei Yang. Cf. chap. LXVIII.

43.(291) Siu Koang place cette sépulture dans l'arrondissement de Tch'ang (auj. préf. de Tcheng-ting, prov. de Tche-li).

43.(292) A $13 l i$ au N. (ou, suivant Li Tchao-lo, à 25 li au N.-.E) de la sous-préfecture de Wen-choei (préf. de T'ai-yuen, prov. de Chan-si).

43.(293) Nom d'un défilé qui se trouvait à l'ouest de l'ancienne sous-préfecture de $Y u$, laquelle était à $80 l i$ au N.-E. de la sous-préfecture actuelle de Yang-k'iu (préf. de T'ai-yuen, prov. de Chan-si).

43.(294) Ce personnage a déjà été mentionné plus haut ; cf. p. 57, ligne 13.

43.(295) D'après Tchang Cheou-tsie, cette ville se serait trouvée sur le territoire de l'arrondissement de Wei (à l'E. de la sous-préfecture actuelle de Yuen-tch'eng, préf. de Ta-ming, prov. de Tche-li).

43.(296) Suivant Lieou Po-tchoang, ce long mur allait de la commanderie de Tai à celle de Yun-tchong; partant du nord de l'arrondissement de $Y u$ (auj. préf. sec. de ce nom, dans la préfecture de Siuen-hoa, prov. de Tche-li), il s'étendait à l'ouest jusqu'au nord de l'arrondissement de Lan (auj., s.-p. de ce nom, dans la préfecture de T'ai-yuen, prov. de Chan-si) et couvrait ainsi toute la frontière septentrionale de Tchao. - Tchang Cheou-tsie cite cependant une autre opinion d'après laquelle ce long mur aurait été construit dans la partie méridionale du royaume de Tchao et cette seconde manière de voir doit être préférée. En effet, d'une part, d'après le chap. CX (p. $\left.3 \mathrm{r}^{\circ}\right)$ des Mémoires historiques, le long mur au nord du royaume de Tchao n'aurait été construit qu'à l'époque du roi Ou-ling (325-299); d'autre part, on verra quelques pages plus loin, que le roi Ou-ling lui-même attribuait à son prédécesseur la construction d'un long mur dans la région des rivières Fou et Tchang, c'est-à-dire dans le sud du pays de Tchao.

43.(297) Li-che est aujourd'hui la préfecture secondaire de Yong-ning (préf. de Fen-tcheou, prov. de Chan-si). Lin était un peu plus à l'ouest (cf. n. 255).

43.(298) Général du pays de Han.

43.(299) Cette localité de Sang-k'ieou était près de l'ancienne sous-préfecture de Soei-tch'eng, laquelle se trouvait à 25 li de la sous-préfecture actuelle de Ngan-sou (préf. de Pao-ting, prov. de Tche-li). En ce temps, $T s ' i$ ayant attaqué Yen, les trois royaumes de Han, Wei et 
Tchao étaient venus au secours de ce dernier. Le Sang-k'ieou dont il est ici question devait donc être sur le territoire de Yen; il ne faut pas le confondre avec le Sang-k'ieou qui était voisin de la préfecture actuelle de T'ai-ngan, dans le Chan-tong.

43.(300) Son nom personnel était Yong, dit Se-ma Tcheng.

43.(301) C'est-à-dire de Wei, car depuis l'année 340, la capitale de Wei était la ville de Ta-leang (auj. Kai-fong fou).

43.(302) Dans l'ancienne sous-préfecture de Lin-ming (à 15 li à l'O. de la sous-préf. actuelle de Yong-nien).

43.(303) L'expression san lao désigne les vieillards de plus de cinquante ans qui étaient revêtus de fonctions officielles dans chaque district. Au-dessous des san lao étaient les ou keng qui étaient des vieillards investis d'une autorité moindre. On explique les mots san « trois » et ou " cinq » en disant que les san lao étaient comparables aux trois luminaires (le soleil, la lune et les étoiles), et les ou keng aux cinq planètes, et qu'ainsi ils éclairaient l'empire. Suivant une autre glose, ces deux catégories de vieillards symboliseraient les trois vertus et les $c i n q$ actes (cf. t. IV, p. 220 et 224) dont il est question dans le chapitre Hong fan du Chou king (cf. P'ei wen yun fou, s. v. san lao).

43.(304) La deuxième année, disent les Tableaux chronologiques.

43.(리) Cf. tome IV, n. 34.151.

43.(306) Localité non identifiée qui devait se trouver au N. du Hoang ho.

43.(307) Wei, Han, Tchao, Yen, et $T s^{\prime} i$. Mais, comme on le voit par ce qui suit, il faut retrancher ici Tchao de l'énumération.

43.(308) Cf. t. II, p. 71, où on voit que les princes coalisés contre $T s$ 'in avaient fait cause commune avec les Hiong-nou. Les Tableaux chronologiques et les Annales principales des $T s$ 'in rapportent cette campagne à l'année 318 .

43.(309) A $18 l i$ à l'E. de l'ancienne sous-préfecture de Toen-k'ieou laquelle se trouvait à $25 l i$ au S.-O. de la s.-p. actuelle de Ts'ing-fong (préf. de Ta-ming, prov. de Tche-li).

43.(310) Au lieu de Si-tou et Tchong-yang, les Tableaux chronologiques (chap. XV, p. 25 ro) mentionnent ici Tchong-tou, Si-yang, et Ngan-i. — Le nom de Ngan-i paraît introduit ici par erreur, car cette ville, qui avait été la capitale de Wei jusqu'en 340, était encore en la possession des princes de Wei qui s'en dessaisirent en faveur de $T$ s'in en l'an 286 (cf. t. II, p. 84). Quant aux deux autres villes, leurs noms doivent être lus Tchong-tou et Tchong-yang. Tchong-tou était au N.-O. de la sous-préfecture actuelle de P'ing-yao (préf. de Fen-tcheou, prov. de Chan-si); Tchong-yang était à $25 l i$ à l'O. de la sous-préfecture actuelle de Ning-hiang (préf. de Fen-tcheou, prov. de Chan-si).

43.(1ㅡ) Cf. t. IV, p. 140-142.

43.(312) Le chap. XXXIV des Mémoires historiques ne fait aucune allusion à ces événements. Il est vraisemblable, comme l'explique $P$ 'ei Yen, que, voyant les troubles qui agitaient l'État de $\mathrm{Yen}$, le roi Ou-ling fit une tentative pour placer sur le trône de Yen un membre de la famille princière de ce royaume qui se trouvait réfugié dans le pays de Han; mais, pour des raisons que nous ignorons, l'entreprise dut être abandonnée.

43. $(\underline{313}) O u$, d'après une variante Tchao $P^{\prime} i$.

43.(314) En réalité, le roi Hoei mourut en 311.

43. $(\underline{315})$ Cf. Note 292.

43.(316) Bignonia grandiflora (Bretschneider, Plants mentioned in classical works, $\left.\mathrm{n}^{\circ} 448\right)$. 
43.(317) Tchang Cheou-tsie, considère le mot [] comme étant ici l'équivalent de []. On pourrait alors traduire : « On me célèbre, on me célèbre, (en disant) que personne... ».

43.(318) Ou Koang passait pour un descendant de l'empereur Choen; le nom de famille [] était en effet considéré comme l'équivalent phonétique du nom de $Y u$ [] qui était celui du fief appartenant à Choen. La fille de Ou Koang, Mong-Yao, pouvait donc, elle aussi, être regardée comme issue de l'empereur Choen, et c'est pourquoi on trouve dans son nom le mot Yao qui avait été le nom de famille de Choen. Par le mariage de cette jeune fille avec le roi Ou-ling se réalisait la prédiction faite à Tchao Kien-tse vers l'an 500 av. J.-C. (cf. n. 172).

43.(319) Il y a ici une obscurité, car on ne voit pas bien pourquoi la fille de Ou Koang avait le nom de famille Yng. Un reviseur du Che ki p'ing lin, Fang Pao, a signalé cette difficulté ; pour la résoudre, il a recours à l'explication suivante : ce serait $O u$ Koang, qui, pour que sa fille pût être considérée comme la femme appelée Yng qui était apparue en songe au roi, lui aurait donné le nom de Yng. Mais ce n'était pas son véritable nom.

43.(320) Sur le territoire de la préfecture de Tcheng-ting, prov. de Tche-li.

43.(321) D'après le Kouo ti tche, la terrasse Ye était à $63 l i$ au S.-O. de la sous-préfecture de Sin-lo qui existe aujourd'hui encore sous ce nom (préf. de Tcheng-ting, prov. de Tche-li).

43.(322) Cf. t. II, p. 76. Cet événement eut lieu en l'année 307, et non en 108 comme il est dit ici.

43. $(\underline{323})$ Cf. n. 302.

43.(324) Cf. p. 65, ligne 16.

43. $\underline{325})$ Cf. tome II, n. 05.401 .

43.(326) Cf. n. 251.

43.(327) D'après Fang Pao, Ou-k'iong était le nom d'une porte qui avait été élevée par Tchao Siang-tse. Mais cela ne nous renseigne pas sur sa situation.

43.(328) La montagne Hoang-hoa, qu'on appelle aussi la montagne Lin-lu, était à $20 l i$ à l'ouest de la sous-préfecture de Lin (préfecture de Tchang-té, prov. de Ho-nan). Cf. commentaire du T'ong kien kang mou, à l'année 307 av. J.-C.

43.(329) La rivière Fou prend naissance au N.-O. de la préfecture secondaire de Ts'e (préf. de Koang-p'ing, prov. de Tche-li).

43. $(\underline{330})$ Cf. tome I, n. 02.126 .

43.(31) Cf. n. 296.

43.(3ㅡ) Cf. n. 255.

43.(333) Localité indéterminée.

43.(34) Ce sont les Lin-Hou; cf. n. 216.

43.

43.(36) C'est-à-dire que l'existence de la principauté de Tchong-chan, peu éloignée de notre capitale, menace nos parties vitales. Cf. Han Fei-tse (chap. I, p. 7 r ${ }^{\circ}$ ) :

«Han est pour $T s^{\prime}$ in ce que serait pour un homme une maladie attachée à son ventre ou à son cœur.

43.(3ㄱ) C'est-à-dire les Tong hou.

43. $(\underline{338})$ Cf. n. 216. 
43.(339) D'après le Kouo ti tche (chap. III, p. $16 \mathrm{v}^{\circ}$ ), le territoire des barbares Leou fan n'est autre que l'arrondissement de Lan (auj., s.-p. de ce nom, préf. de T'ai-yuen, prov. de Chan-si).

43.(340) Tchan kouo ts'e : section de Tchao. Chap. XIX, p. $4 \mathrm{r}^{\circ}$ et $\mathrm{v}^{\circ}$.

43.(341) Tout ce qui suit est tiré du chap. XIX du Tchan kouo ts'e; mais le texte a subi des modifications importantes. Dans le Tchan kouo ts'e, l'entretien du roi Ou-ling avec Fei I commence en ces termes :

«Le roi Ou-ling en un jour tranquille se trouvait de loisir; Fei I, assis à ses côtés, lui dit :

- Votre Majesté a-t-elle réfléchi aux modifications des circonstances à notre époque ? A-t-elle apprécié l'usage des cuirasses et des armes de guerre ? A-t-elle songé aux exemples que nous ont laissés Kien et Siang? A-t-elle fait des plans pour s'assurer l'avantage (de conquérir) les Hou et les Ti ?

Le roi répondit :

- Pour celui qui est monté sur le trône par droit d'hérédité, ne pas oublier la vertu de ses prédécesseurs, c'est la conduite d'un véritable prince. D'une manière stable et sincère travailler à mettre en lumière la supériorité du souverain, c'est le devoir d'un véritable sujet. Ainsi, un prince sage, en restant calme, suit la voie raisonnable et son peuple s'empresse de le servir; dans ses enseignements, constamment il met en lumière les mérites des générations passées de l'antiquité. Celui qui est sujet, quand il est entravé (dans sa carrière), se conduit en bon frère cadet, honore ses supérieurs, est poli et humble; quand il réussit, il s'applique à aider le peuple et à être utile à son souverain. Telles sont les attributions du prince et telles sont celles des sujets... »

43.(342) Tchao Kien-tse et Tchao Siang-tse.

43.(343) Dans le Tchan kouo ts'e, cette phrase fait partie du discours de Fei I; cf. n. 341.

43.(344) La leçon [], que nous avons ici me paraît mauvaise ; je préfère la leçon [] du Tchan kouo ts'e (cf. ligne 1 de la note 341). Le sens est évidemment que, lorsqu'un sujet n'a pas accès aux fonctions publiques, il doit pratiquer les vertus privées ; que, lorsqu'au contraire il est admis aux charges officielles, il doit travailler au bien-être du peuple et à la gloire du souverain.

43.(345) Ici, les mots [][][] ne s'appliquent qu'aux deux sortes d'attributions qui incombent au sujet, suivant qu'il est, ou non, chargé de fonctions publiques. Dans le Tchan kouo ts'e, ils s'appliquent, d'une part aux devoirs du souverain, d'autre part aux devoirs du sujet (cf. dernière ligne de la note 341 ).

43.(느) Moi, le roi, je suis disposé à me conduire comme doit le faire un roi, mais, dans tout le monde, je ne vois personne qui se conduise comme doit le faire un sujet, c'est-à-dire qui soit prêt à aider le peuple et à être utile à son souverain. En d'autres termes, le roi Ou-ling se plaint de ce que, voulant introduire dans son pays un changement de mœurs destiné à assurer son triomphe sur les barbares, il ne trouve parmi ses sujets personne qui le seconde.

43.(347) C'est-à-dire : en adoptant les vêtements des Hou.

43.(348) Tchan kouo ts' $e$ : « est en butte aux suspicions craintives des gens vulgaires ».

43.(349) Les Miao étaient révoltés contre Choen; au lieu de les combattre par les armes, Choen voulut toucher leur cœur par le spectacle de la vertu; il fit donc exécuter des danses accompagnées le chants, et en effet les Miao se soumirent. Cf. Chou King, chap. Ta Yu mo.

43.(타) Cf. Hoai nan tse (chap. I, p. $8 \mathrm{v}^{\circ}$ ) : 
«C'est pourquoi, quand $Y u$ se rendit dans le royaume des (hommes) nus, il ôta ses vêtements pour y entrer; il en sortit avec ses vêtements et sa ceinture : ainsi il se conforma (aux mœurs établies).

Le royaume des hommes nus est ici une expression vague désignant les peuples du sud : à l'époque des T'ang, ce terme est appliqué par I-tsing tantôt aux îles Nicobar (Religieux éminents, trad. fr., p. 120-121), tantôt au Pa-nan ( = Fou-nan, bassin inférieur du Mékong ; cf. Takakusu, A record of the buddhist religion..., p. 10); le Choei king tchou de Li Tao-yuen (commencement du VIe siècle) appelle ainsi, dit P. Pelliot, « la région des Moï de la chaîne

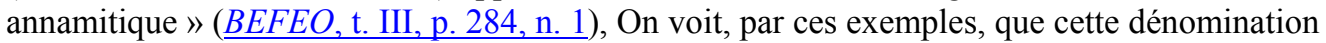
n'a rien de précis.

43. (351) Au lieu de cette dernière phrase, on lit dans le Tchan kouo tse: "Que votre Majesté mette donc aussitôt ce projet à exécution. »

43. (352) A la leçon [] « examiner » qui n'offre aucun sens plausible, je substitue la leçon [] « triste, affligé » du Tchan kouo ts'e.

43.(5ㅗ) Tchan kouo ts'e : «Wang-suen Sie ».

43.(354) Le Tchan kouo ts'e donne la leçon : «Tels étaient les devoirs généraux qui existaient sous les anciens rois ».

43. $(\underline{355})$ Tchan kouo ts'e: «je n'ai pu me mettre en route au plus vite et «c'est pourquoi je ne suis pas venu auprès de vous le premier $»$.

43.(ㅌ6) Suivant $K^{\prime}$ ong Yen (commencement du VIe siècle), au lieu de [], il faudrait lire [] et le sens serait : « dénuder son épaule droite »; si l'on adopte ce sens, on peut alors donner à la phrase précédente [][] le sens usuel de « tatouer son corps ».

43.(357) D'après Se-ma Tcheng, le commentateur dont le nom de famille est Lieou (peut-être Lieou Pao de l'époque des Tsin) dit que de son temps les gens de Tchou-yai et de Tan-eul (c.-à-d. de l'île Hai-nan) sont appelés Ngeou-jen. — Ce qui est plus certain, c'est que, au deuxième siècle avant notre ère, on appelait Tong Ngeou ou Ngeou oriental, la ville qui était la capitale du Yue-tong-hai et qui est aujourd'hui la ville préfectorale de Wen-tcheou, dans le Tche-kiang; d'autre part, le nom de Si Ngeou ou Ngeou occidental désignait un royaume près de Hanoï (cf. tome IV, n. 41.101). — Dans le chap. CXIII des Mém. hist., on voit que vers l'an 180 av. J.-C., le Si Ngeou-lo (c.-à-d. le Tonkin) se soumit au roi de Nan Yue (capitale Canton), et ce roi de Nan Yue dit lui-même que, à l'ouest de son territoire (les princes du) Ngeou-lo et du royaume des hommes nus (cf. n. 350) se sont donné le titre de « roi ». D'après $P$ 'ei Yn, qui cite le Han chou yn i, Ngeou-lo serait aussi appelé Lo-yue. - Ainsi le terme Ngeou nous apparaît comme un ethnique important qui désigne une branche de la race de Yue, c.-à-d. de la race annamite.

43.(358) La coutume de se noircir et de se laquer les dents était fort répandue dans tout le sud de la Chine et en Indo-Chine (cf. Pelliot, dans BEFEO, vol. III, p. 281, n. 3 ).

43. (359) Au lieu de [], le Tchan kouo ts'e donne la leçon [], ou, suivant une variante, [], ce qui paraît signifier « porter des bonnets faits avec la peau de certains poissons ».

43.(타) Le Tchan kouo ts'e donne la leçon [] qui doit avoir le sens de « les coutures faites à l'aiguille »; il faut alors entendre que ces coutures étaient faites autrement que cela ne se pratiquait en Chine et peut-être plus grossièrement, ce qui nous ramène au sens de Se-ma Ts'ien.

43. (361) Sur le pays de Ou, dont la capitale occupait l'emplacement de la ville préfectorale de Sou-tcheou, dans le Kiang-sou, cf. tome IV, p. 1 et suiv. - L'expression que nous avons ici devrait être traduite littéralement «le royaume de grand $O u$ »; l'épithète est directement accolée au nom du royaume et paraît en faire partie, de même que dans les expressions Ta-ts'in, Ta yue-tche, etc.

43.(즈) C'est sans doute Confucius qui est désigné ici. 
43.(363) L'État de Tchao était fort montagneux dans sa partie septentrionale.

43.(364) A cette époque, le Hoang ho se jetait dans la mer près de T'ien-tsin, et, pendant une partie de son cours, limitait à l'est le pays de Tchao (cf. la carte insérée dans le t. III, p. 526).

43.(365) D'après Siu Koang, Po-lo était le nom d'un gué de la rivière Tchang, à l'ouest de la s.-p. de King, du royaume de Ngan-p'ing; cette ville était à 20 li à l'E. de la s.-p. de Koang-tsong (préf. de Choen-té, prov. de Tche-li).

43.(366) Le Hoang ho séparait le pays de Tchao de celui de $T s^{\prime} i$; la rivière Tchang le séparait du royaume de Tchong-chan.

43.(6ㅜ) C'est-à-dire la montagne Heng.

43. $(\underline{368})$ Cf. n. 273.

43.(하) $)$ Cf. n. 216.

43. $(\underline{370})$ Cf. n. 339.

43.(기) D'après le texte du Tchan kouo ts'e, il faudrait dire :

«C'est pourquoi je vais réunir pour mon service des bateaux et des rames et réquisitionner les populations riveraines des rivières, afin de défendre les fleuves $\mathrm{Ho}$ et $\mathrm{Po}-\mathrm{lo}$; je changerai les vêtements et (j'organiserai des escadrons d'archers à cheval...

43.(372) Cf. n. 216.

43.(373) Tchao Kien-tse ou Tchao Yang.

43.(374) Tsin-yang (s.-p. de T'ai-yuen) était la ville principale et le lieu de résidence de Tchao Kien-tse, mais il ne s'y enferma pas et c'est pourquoi il put s'emparer du Chang-tang (préf. de Lou-ngan, dans le S.-E. du Chan-si).

43.(375) Tchao Kien-tse ou Tchao Ou-siu.

43.(376) Cf. tome IV, n. 34.151.

43.(377) Tchao Kien-tse et Tchao Siang-tse.

43.(378) Une partie de leurs discours se retrouve dans le Tchan kouo ts'e.

43.(379) Les cinq Empereurs et les trois dynasties (Hia, Yn, Tcheou).

43.(380) Il semble bien que cette énumération (Fou-hi, Chen-nong, Hoang ti, Yao et Choen) soit la plus ancienne liste que nous possédions des cinq empereurs de la haute antiquité. Cette liste fut modifiée plus tard quand on voulut l'accommoder à la théorie des cinq éléments et qu'on admit une série de trois souverains (san hoang) avant les cinq Empereurs (ou ti); cf. Introduction, p. CXC-CXCII.

43.(381) Les gens de Tseou et de Lou portaient des brides de chapeau fort longues, ce qui rendait leur accoutrement assez extraordinaire ; cela ne les empêcha pas de compter parmi eux des hommes éminents tels que Confucius et plusieurs de ses disciples.

43.(382) Or ils en eurent, puisque, par exemple le pays de Ou produisit Ki-tcha (cf. t. IV, p. 7 et suiv.).

43.(383) Ning-kia, ou, suivant une variante, Wan-kia était une ville du pays de Tchong-chan.

43.(384) Sur la rive nord du Hoang-ho, à l'angle oriental de la grande boucle de ce fleuve.

43.(로) Cf. n. 216. 
43.(386) Le mot Tchao me paraît être ici une superfétation; l'armée de Tchao en effet était celle que dirigeait le roi en personne; Tchao Hi ne devait avoir sous ses ordres que les troupes venues du pays des Hou et de la région de Tai.

43.(387) Hing est aujourd'hui la sous-préfecture de Tsing-hing (préf. de Tcheng-ting, prov. de Tche-li).

43.(388) K'iu-yang fut, sous les Han, la sous-préfecture de Chang K'iu-yang. C'est aujourd'hui la sous-préfecture de K'iu-yang (préf. secondaire de Ting, prov. de Tche-li).

43.(389) Une note de Tchang Cheou-tsie tendrait à faire croire que cette localité se trouvait sur le territoire de la préfecture de Choen-té. Mais il est vraisemblable que Tan-k'ieou était, comme les deux autres localités dont il va être question, beaucoup plus au nord.

43.(390) Hoa-yang devait être dans le voisinage immédiat du Heng chan ou Pic du nord, car un des noms de cette montagne était «terrasse de Hoa-yang ». Le Heng chan est à 140 li au N.-O. de la sous-préf. de K'iu-yang (préf. de Tcheng-ting, prov. de Tche-li), et à $20 l i$ au S. de la préf. sec. de Hoen-yuen (préf. de Ta-t'ong, prov. de Chan-si).

43.(391) La barrière de Tche est identifiée par Tchang Cheou-tsie avec l'ancienne passe Hong-chang qui était à $60 l i$ au N.-E. de la s.-p. de T'ang (préf. de Pao-ting, prov. de Tche-li).

43.(현) Cf. tome IV, n. 34.151.

43.(393) Tong-yuen était le nom que porta jusque sous les Han la ville appelée plus tard Heng tcheou ou Tch'ang-chan; elle se trouvait à 8 li au S. de la s.-p. actuelle de Tcheng-ting, qui fait partie de la ville préfectorale du même nom (prov. de Tche-li). - Che-i était à $35 l i$ au S. de l'ancienne sous-préfecture de Lou-ts'iuen qui dépendait de Heng tcheou (Tcheng-ting fou). - Fong-long était ainsi appelée à cause de la montagne Fong-long ou Fei-long qui était à 45 li au S. de cette même sous-préfecture de Lou-ts'iuen.

43.(394) Cette reine Hoei qui mourut en 301, n'est autre que Mong-Yao, fille de Ou Koang (cf. p. 68, lignes 12-14). C'est par erreur que Se-ma Tcheng la considère comme l'épouse principale du roi Ou-ling et la mère de l'ex-héritier présomptif Tchang; pour ce commentateur, Mong-Yao devrait être identifiée avec la reine Hoei-wen, qui mourut en 264 ; il se trompe, car la reine Hoei-wen fut la femme, non du roi Ou-ling, mais du roi Hoei-wen et c'est pour cette raison même qu'elle reçut ce nom posthume.

43.(보 $)$ Fils du roi Ou-ling et de la reine Hoei. Cf. la note précédente.

43.(396) Cf. tome IV, n. 34.102, et t. V, n. 203.

43.(397) Yun-tchong correspond à Koei-hoa tch'eng, dans la partie occidentale du territoire des Mongols Toumedh.

43.(398) Kieou-yuen était dans le territoire d'Ourato, au N. de la grande boucle du Hoang ho.

43.(ㅎ9) Cf. n. 395.

43.(400) C'était Mong-yao, fille de Ou Koang. Je traduis comme signifiant « la Belle, et je ne considère pas ce mot comme un nom propre : en effet, on a lu plus haut la phrase qui ne peut signifier que :

« il fit entrer (dans le palais) sa fille, qui était la belle Mong-yao, (dont le nom de famille était) Yng.

43.(401) Les Tableaux chronologiques (chap. XV, p. $27 \mathrm{v}^{\circ}$ ), nous fournissent les deux indications suivantes qui sont omises ici :

- «La première année (298) de son règne, le roi Hoei wen nomma conseiller le kongtse Cheng et lui conféra le titre de prince de P'ing yuen » (voyez la biographie du prince de P'ing-yuen dans le chap. LXXVI des Mém. hist.). 
- «La deuxième année (297), le roi Hoai, de Tch'ou, vint en fugitif, mais on ne l'accueillit pas ».

43.(402) Le Si-ho ou Ho occidental était la partie du territoire de Tchao comprise entre la rivière Fen et le Hoang-ho: il correspond à la préfecture de T'ai-yuen et à la préfecture secondaire de Fen dans le Chan-si.

43. $(\underline{403})$ Cf. n. 339.

43.(404) La sous-préfecture de Fou-che fait aujourd'hui partie intégrante de la ville préfectorale de Yen-ngan prov. de Chàn-si.

43.(405) Sous-préfecture actuelle de Ling-cheou (préf. de Tcheng-ting, prov. de Tche-li).

43.(406) Le Ngan-yang dont il est ici question est le Ngan-yang oriental qui se trouvait au N.-E. de la préf. secondaire de Yu (préf. de Siuen-hoa, prov. de Tche-li).

43.(407) Allusion à une parole prononcée en 650 av. J.-C. par Siun Si du pays de Tsin (cf. tome IV, p. 270, lignes 21-24). Il est à remarquer cependant que tout ce discours de Fei I sonne faux, car le "père du souverain» était encore vivant et pouvait le délier de son serment; or Fei I parle comme s'il avait pris un engagement que la mort de son souverain aurait rendu irrévocable. L'exercice de rhétorique est ici manifeste.

43.(408) D'après Tchang Cheou-tsie, le mot [] se prononce ici Chen. Se-ma Tcheng identifie ce personnage avec le Kao Chen dont il sera question plus loin.

43.(409) Le prince Tchang et son conseiller T'ien Pou-li.

43.(410) Faire un coup d'État après s'être assuré de la personne du souverain.

43.(411) Je prends ici le mot [] dans le sens de «décret céleste conférant à un homme le pouvoir souverain $»$.

43.(412) On verra plus loin que c'est en supposant faussement un ordre du «père du souverain » que le prince Tchang et T'ien Pou-li cherchèrent à attirer le roi dans une embûche.

43.(413) C'est-à-dire s'il y a un ordre vrai ou faux du "père du souverain » mandant le roi auprès de lui.

43.(414) Le prince Tchang; cf. n. 406.

43.(415) A 20 li (suivant d'autres textes, 30 ou 40 li) au N.-E. de la sous-préfecture de P'ing-hiang (préf. de Choen-té, prov. de Tche-li) (ap. Kouo ti tche, chap. IV, p. 5 r ${ }^{\circ}$ ); Cha-k'ieou est déjà mentionné dans les Annales principales des $Y n$ (cf. t. I, p. 200).

43.(1ㅏ) Cf. n. 412.

43.(417) Cf. n. 408.

43.(418) D'après Yng Chao, le roi Ou-ling fut enterré dans la sous-préfecture de Ling-k'ieou, qui dépendait à l'époque des Han de la commanderie de Tai, et qui relève aujourd'hui de la préfecture de Ta-t'ong, dans le nord du Chan-si.

43.(419) Le roi étant absolument seul dans le palais, personne n'assista à sa mort et ce n'est que quelque temps plus tard qu'on la constata.

43.(420) Cette rédaction est inexacte ; car le roi Hoei-wen était monté sur le trône quatre ans auparavant, quand le roi $\mathrm{Ou}$-ling, son père, avait abdiqué en sa faveur.

43.(421) Ces deux places se trouvaient sur le territoire de la commanderie de Tchouo qui correspond à la préfecture secondaire actuelle de ce nom (préf. de Tcheng-ting, prov. de Tche-li). 
43.(422) D'après les Tableaux chronologiques (chap. XV, p. $28 \mathrm{v}^{\circ}$ ), la septième année de son règne (292), le roi Hoei-wen alla chercher femme dans le pays de $T s$ 'in.

43.(423) La ville appelée le Hing-t'ang méridional était au N. de la sous-préfecture actuelle de Hing-t'ang (préf. de Tcheng-ting, prov. de Tche-li).

43.(424) Wei, ainsi nommé à cause de sa capitale Ta-leang (K'ai-fong fou).

43.(425) Lou-koan paraît être identique à Lou-yang, ville qui correspond à la préfecture actuelle de Lou-chan (préf. sec. de Jou, prov. de Ho-nan).

43.(426) Il faut reporter cet événement au $10^{\mathrm{e}}$ mois de l'année 288 ; cf. Tableaux chronologiques (chap. XV, p. $28 \mathrm{v}^{\circ}$ ) et t. II, p. 84, lignes 1-4.

43.(427) C'est-à-dire vraisemblablement que, en récompense du concours qu'il lui avait donné pour attaquer Song, le roi de Tchao reçut du roi de Wei la ville de Ho-yang. - D'après le dictionnaire de Li Tchao-lo, Ho-Yang était à 35 li à l'ouest de la sous-préfecture de Mong (préf. de Hoai-k'ing, prov. de Ho-nan).

43.(428) Aujourd'hui, sous-préfecture de Ts'ing-yuen (préf. de T'ai-yuen, prov. de Chan-si). Les Tableaux chronologiques donnent la leçon Koei-yang, qui paraît fautive.

43.(2ㅗ) Cf. n. 424.

43.(430) Cette princesse, dit Se-ma Tcheng, était fille de $O u$ la Belle, et sœur cadette du roi Hoei-Wen.

43.(431) D'après le contexte, il semblerait que Ling-k'ieou dût être une ville du pays de $T s$ ' $i$ et ne pût donc pas être identifiée avec la sous-préfecture actuelle de Ling-k'ieou (préf. de Ta-t'ong, prov. de Chan-si).

43.(432) A 25 li à l'O. de la sous-préfecture actuelle de Ning-hiang (préf. de Fen-tcheou, prov. de Chan-si).

43.(433) D'après les Tableaux chronologiques, dans cette campagne contre Ts'i, Tchao eut pour sa part de butin la ville de Si-yang (chap. XV, p. 29 r $^{\circ}$ ). Mais le présent chapitre des Mémoires historiques rapporte la prise de cette ville à l'année suivante (283) ; voyez plus loin.

43.(434) Capitale du pays de $T s$ 'i. Sur ces événements, voyez le chap. XLVI, à la date de 284 .

43.(35) Sou Li était un frère cadet de Sou Ts'in (cf. Mém. hist., chap. LXIX). L'édition du Tchan kouo ts'e de 1581 met aussi ce discours dans la bouche de Sou Li, mais elle indique que l'édition de 1355 l'attribue à Sou Tsin, et c'est la leçon que nous trouvons en effet dans la réimpression lithographique du Tchan kouo ts'e faite à Chang-hai en 1896.

43.(436) Tchan kouo ts' $e$ : section de Tchao; chap. XVIII, p. 4 vº $-5 \mathrm{v}^{\circ}$.

43.(437) Ce préambule me paraît avoir le sens suivant : Sou $L i$ veut donner au roi de Tchao le conseil de changer de politique ; pour que son avis soit accepté, il commence par montrer que, même à l'époque des rois sages de l'antiquité, quand l'âge d'or semblait établi sur la terre, ces souverains cherchaient encore les moyens de mieux gouverner, car ils se rendaient compte que leurs vertus, leurs enseignements et leurs sacrifices n'étaient pas aussi parfaits qu'ils auraient pu l'être. Si donc ces rois admirables de l'antiquité croyaient eux-mêmes que leur conduite pouvait être améliorée, le roi de Tchao ne doit pas trouver étrange qu'on lui propose de modifier sa manière d'agir.

43.(438) En d'autres termes: quoique le roi de Tchao ait mis sa sagesse et ses forces au service de $T s^{\prime}$ in, $T s^{\prime}$ 'in ne lui en sait aucun gré, car il est insatiable et estime que le roi de Tchao ne s'est pas suffisamment employé en sa faveur. D'autre part, quoique le roi de Tchao combatte $T s^{\prime} i$, il n'a pas contre lui des causes profondes de haine. C'est donc une double erreur qu'il commet lorsqu'il s'allie à $T s^{\prime}$ in et qu'il attaque $T s^{\prime} i$. 
- Au lieu du mot $T s^{\prime} i$, le Tchan kouo ts'e donne la leçon Han, et cette substitution est constante dans tout le discours; comme le fait remarquer en effet l'éditeur de 1581, le texte du Tchan kouo ts'e suppose qu'on veut dissuader Tchao d'attaquer Han, tandis que le texte de Se-ma Ts'ien est un plaidoyer en faveur de $T s^{\prime} i$; d'ailleurs le Tchan kouo ts'e est inconséquent avec lui-même puisqu'il introduit ce discours par les mots :

«Quand Tchao eut recueilli tout l'empire, il se disposa à attaquer Ts'i. Sou $\mathrm{Li}$ adressa une requête en faveur de $T s^{\prime} i$ au roi de Tchao en lui écrivant la lettre suivante :...

Tout ce morceau, aussi bien dans le Tchan kouo ts'e que dans Se-ma Ts'ien, paraît fort altéré et la suite des idées y est parfois inintelligible.

43.(439) Ts'in réquisitionne les soldats de Han sous le prétexte d'aider le royaume de Tchao, son allié à attaquer $T s^{\prime} i$; mais en réalité il projette d'affaiblir ainsi Han pour pouvoir le détruire.

43.(440) Les campagnes dirigées par $T s^{\prime}$ 'in et les seigneurs contre Tch'ou permirent à Tchao d'anéantir le royaume de Tchong-chan qui ne pouvait plus compter sur aucun secours. C'est pourquoi, dans les Annales principales des Ts'in (t. II, p. 79), la destruction du royaume de Tchong-chan en 299 est mentionnée immédiatement après les attaques contre Tch'ou.

43.(441) On appelle époque des six royaumes l'époque où la Chine était divisée entre $T s$ 'in, d'une part, et, d'autre part, les six royaumes de Tchao, Han, Wei, Tch'ou, Yen et Ts'i. Ici, puisqu'il s'agit du partage de l'État de $T s$ ' $i$, il faut admettre que l'expression « six royaumes " désigne Ts'in, Tchao, Han, Wei, Tch'ou et Yen; mais il reste encore cette difficulté que, d'après la teneur de la phrase de Se-ma-Ts'ien, Tchao doit partager le territoire de $T s$ ' $i$ avec les six royaumes et ne devrait donc pas être compté comme l'un d'entre eux.

43.(442) Les Tcheou orientaux et occidentaux.

43.(443) Les fameux trépieds qui étaient comme le gage du pouvoir souverain (cf. t. I, p. 296 et t. IV, p. 351-353).

43.(444) La région de San-tch'oan était ainsi nommée parce qu'on y trouvait trois cours d'eau, à savoir le Hoang-ho et les rivières $I$ et Lo. La capitale du pays de Han (s.-p. actuelle de Sintcheng, préf. de K'ai-fong, prov. de Ho-nan) était située dans ce territoire. La phrase signifie donc : quand Han aura perdu sa capitale, c'est-à-dire sera détruit.

43.(445) Ici, de même, le sens est: quand Wei aura perdu sa capitale (Ngan-i, dit Tchang Cheou-tsie; mais à la date à laquelle on rapporte ce discours, cette capitale devait être Ta-leang, c'est-à-dire K'ai-fong fou).

43.(446) C'est-à-dire : en un seul jour.

43.(447) En d'autres termes, Tchao, Wei et Han ont des destinées étroitement unies; si Wei et Han viennent à être détruits, Tchao ne tardera pas à périr à son tour.

43. $(\underline{448})$ Cf. n. 415.

43.(449) Kiu-lou correspond à la ville sous-préfectorale de P'ing-hiang, (préf. de Choen-té, prov. de Tche-li) (ap. Kouo-ti-tche, chap. IV, p. 5 r ${ }^{\circ}$ ).

43.(450) Le Chang-tang (préfecture de Lou-ngan, dans le S.-E. du Chan-si) appartenait alors à Han ; ce n'est qu'en 262 que ce territoire fut annexé par Tchao.

43.(451) [], c'est-à-dire «le territoire ». Cette expression me paraît supposer l'ancienne formule d'investiture qui assimilait la durée d'un fief à celle du Hoang-ho et du T'ai-chan; cf. tome III, p. 121 lignes 8-13 et n. 18.102.

43.(452) La commanderie de Chang avait son centre à Soei-te-tcheou dans le nord du Chàn-si. 
43.(453) Yu-tchong était un territoire situé dans la partie N.-E. et à l'intérieur de la grande boucle du Hoang-ho; il touchait à la commanderie de Chang et ne pouvait donc pas en être éloigné de $1.500 \mathrm{li}$; le texte me paraît inintelligible.

43.(454) Que vient faire ici le Chang-tang qui appartenait au royaume de Han?

43.(455) D'après le Kouo-ti-tche (chap. III, p. 17, $\mathrm{r}^{\circ}$ ), la montagne T'ai-hang est à 25 li au N. de la s.-p. de Ho-nei qui dépend de l'arrondissement de Hoai; on y trouve la colline Yang-tch'ang. La s.-p. de Ho-nei dépend aujourd'hui de la préfecture de Hoai-k'ing dans le Ho-nan. - D'après un commentaire du T'ong-kien-kang-mou $\left(15^{\mathrm{e}}\right.$ année du roi Ngan de la dynastie Tcheou), la colline Yang-tch'ang était à $106 l i$ au S.-E. de la s.-p. de Hou-koan (préf. de Lou-ngan, prov. de Chan-si); cette localisation concorde assez bien avec la précédente.

43.(456) La montagne Keou-tchou, dit le Kouo-ti-tche (chap. III, p. 13 r $^{\circ}$ ) est aussi appelée montagne Si-king; elle est à $40 l i$ au N.-O. de la s.-p. de Yen-men qui dépend de l'arrondissement de Tai. - La s.-p. de Yen-men est aujourd'hui la ville préfectorale secondaire de Tai, dans le Chàn-si.

43.(457) Le Heng-chan; cf. n. 390.

43.(458) Ce texte tendrait à prouver que, dès le commencement du IIIe siècle avant notre ère, on importait en Chine le jade venu de Khoten, région où la tradition plaçait les montagnes Koen-loen.

43.(459) D'après Tchang Cheou-tsie, les cinq royaumes seraient Ts'in, Ts'i, Han, Wei et Yen; mais cette explication est difficile à admettre puisque, au contraire, $T s^{\prime} i$ nous est représenté dans ce texte comme faisant opposition aux cinq royaumes.

43.(460) En 288, le roi de $T s$ 'in avait pris le titre d'empereur d'Occident, et le roi de $T s$ ' $i$ celui d'empereur d'Orient ; puis tous deux avaient renoncé à ces titres (cf. t. II, p. 84).

43.(461) D'après le Kouo-ti-tche (chap. III, p. 18 ro), Kao-p'ing était à 40 li à l'ouest de la s.-p. de Ho-yang, qui dépendait de l'arrondissement de Hoai. — L'ancienne sous-préfecture de Ho-yang était à 35 li à l'ouest de la s.-p. actuelle de Mong (préf. de Hoai-k'ing, prov. de Honan). - A la date de la $4^{\mathrm{e}}$ année du marquis Ngai, de Wei (315), le Tchou-chou-ki-nien rapporte que le marquis de Tcheng rendit au prince de Wei les villes de Yang, (qui avait autrefois appartenu à) Tsin, et de Hiang ; le prince de Wei éleva des remparts à Yang et à Hiang, puis il changea le nom de Yang en celui de Ho-yong, et le nom de Hiang en celui de Kao-p'ing. Dans le chap. LXXIX, n. $5 \mathrm{v}^{\circ}$, des Mém. hist., on lit que, la $42^{\mathrm{e}}$ année de son règne, le roi Tchao, de Ts'in, prit à Han les villes de Chao-k'iu et Kao-p'ing.

43.(462) Emplacement indéterminé.

43.(463) Cette expression serait l'équivalent du terme qui, selon le Kouo-ti tche, est un autre nom de la montagne Keou-tchou, à $40 l i$ au N.-O. de la préfecture secondaire de Tai (cf. n. 456).

43.(464) Au dire de Tchang Cheou-tsie, Sien-yu est l'équivalent de Si-yu, nom d'une montagne qui se trouvait sur le territoire de la préfecture secondaire de Tai.

43.(465) C'est-à-dire qu'il mettra à votre service son royaume tout entier.

43.(466) Cf. Mém. hist., chap. LXXXI.

43.(467) L'ancienne ville de Si-yang, dit le Kouo- ti-tche (chap. III, p. $16 \mathrm{r}^{\circ}$ ), est aussi appelée Yang-tch'eng; elle est à l'est de la sous-préfecture de Lo-p'ing, qui dépend de l'arrondissement de Ping. - La s.-p. de Lo-p'ing, qui était, à l'époque des Han, la s.-p. de Tche, (et non $I$, comme on l'imprime dans le commentaire de Tchang Cheou-tsie), était à 80 li au sud de la préfecture secondaire actuelle de P'ing-ting (prov. de Tche-li). — D'après le Tch'oen-ts'ieou che ti ming (cité par le Kouo ti tche), Si-yang avait été la capitale du royaume de Fou, c'est-à-dire de la branche des $T i$ blancs dont le nom de famille était $F o u$. 
43.(468) D'après le Kouo ti tche (chap. IV, p. $1 \mathrm{v}^{\circ}$ ), l'ancienne ville de Po-yang qui fut appelée Han-hoei à l'époque des Han, se trouvait à $55 l i$ à l'O. de la s.-p. de Ye qui dépendait de l'arrondissement de Siang. — La s.-p. de Ye était à $40 l i$ au S.-O. de la s.-p. actuelle de Lin-tchang (préf. de Tchang-té, prov. de Ho-nan).

43.(469) Che-tch'eng était à 90 li au S.-O. de la s.-p. de Lin-lu (auj., s.-p. de Lin, préf. de Tchang-té, prov. de Ho-nan) ; cf. Kouo ti tche, chap. IV, p. $2 \mathrm{v}^{\circ}$. - Il ne faut pas confondre cette ville avec la s.-p. de Che-tch'eng, qui d'après le Ti li tche du Ts'ien Han chou, se trouvait dans la commanderie de Yeou-pei-p'ing, et qui correspond à la ville préfectorale de Fong-t'ien dans la province mandchoue de Cheng-king.

43.(470) Tong-yang avait autrefois fait partie de l'État de Wei et appartenait maintenant à Tchao. Cette ville se trouvait sur le territoire de l'ancienne sous-préfecture de $L i$ - $t$ 'ing (ap. Kouo ti tche, chap. IV, p. $6 \mathrm{r}^{\circ}$ ), laquelle était à 40 li à l'O. de la s.-p. actuelle de Ngen (préf. de Tong-tch'ang, prov. de Chan-tong). Le Hoang-ho passait alors au S.-E. de cette ville, et la rive méridionale était sur le territoire de $W e i$; le général de Tchao, Wang Tsai se rendit donc dans la ville de Tong-yang pour pratiquer là sur la rive droite du Hoang-ho une brèche et inonder ainsi le pays de Wei.

43.(471) Cf. Mém. hist., chap. LXXII.

43.(472) C'est-à-dire qu'il lui rendit la ville qu'il lui avait prise deux ans auparavant; cf. n. 468.

43.(473) Les commentateurs sont muets au sujet de cette ville de Me-k'ieou; peut-être faut-il lire Chou-k'ieou; cette dernière localité est mentionnée à la date de 488 par le Tso-tchoan comme une ville du pays de $T \sin$; mais elle se trouvait à la frontière du pays de $T s$ ' $i$, car on la place au S.-O. de la s.-p. de Hia-i (préf. de Koei-té, prov. de Ho-nan ; cf. H. T. K. K., chap. CCLIV, p. $\left.35 \mathrm{v}^{\circ}\right)$.

43.(474) D'après les tableaux chronologiques, Lin Siang-jou (cf. chap. LXXXI) assistait à cette entrevue qui eut lieu à Mien-tch'e (le caractère [] se prononce ici mien), aujourd'hui encore sous-préfecture de ce nom (préf. et prov. de Ho-nan). Cette localité étant au sud du Hoang-ho pouvait être dite «en dehors du Si-ho » puisque le Si-ho était la partie occidentale du Chan-si, limitée à l'ouest et au sud par le Hoang-ho.

43.(475) Ou p'ing était à 72 li au N. de l'ancienne sous-préfecture de Wen-ngan (ap. Kouo ti tche, chap. IV, p. $7 \mathrm{v}^{\circ}$ ), laquelle se trouvait elle-même à 30 li à $1^{\prime} \mathrm{E}$. de la sous-préfecture actuelle de Wen-ngan (préf. de Choen-t'ien, prov. de Tche-li). On verra plus loin que, en 272, le cours de la rivière Tchang fut de nouveau reporté au $\mathrm{S}$. de $O u$ p'ing.

43.(476) Cette ville, qui appartint tantôt à $W e i$, tantôt à $T s^{\prime} i$, devait se trouver entre la préfecture de Lou-ngan, du Chan-si et la préfecture de Tchang-té, du Ho-nan.

43.(구) Cf. n. 251.

43.(낭) Cf. n. 406.

43.(479) Le Kouo ti tche (chap.VI, p. $1 \mathrm{r}^{\circ}$ ) place Tch'ang-tch'eng à $40 l i$ au N.-E. de la sous-préfecture de Tse-tch'oan qui porte aujourd'hui encore ce nom (préf. de Tsi-nan, prov. de Chan-tong).

43.(480) Kao-t'ang était à 40 li au S.-O. de la sous-préfecture de Yu-tch'eng (préf. de Tsi-nan, prov. de Chan-tong)

43. (481) Le Kouo ti tche (chap. VI, p. $14 \mathrm{r}^{\circ}$ ) place cette localité de Hoa-yang à 40 (ou 30) li au S.(ou à l'O.) de l'ancienne sous-préfecture de Koan-tch'eng qui correspond aujourd'hui à la préfecture secondaire de Tcheng (préf. de Kai-fong, prov. de Ho-nan). D'après Se-ma Piao, elle se serait trouvée sur le territoire de la sous-préfecture de $M i$, c'est-à-dire un peu plus à l'ouest. 
43.(482) Nous suivons ici l'explication du Se-ma Tcheng, mais elle n'est pas sans faire quelque violence au texte. D'après Tchang Cheou-tsie, les Tong-hou dont il est ici question résidaient à Yng-tcheou qui est aujourd'hui la sous-préfecture de Tch'ang-li (préf. de Yang-p'ing, prov. de Tche-li).

43. $(\underline{483})$ Cf. n. 475.

43.(484) D'après le Tchan kouo ts'e, Tchao Pao était le frère cadet de la mère du roi Hoeiwen.

43.(485) A $40 l i$ au N.-E. de l'ancienne sous-préfecture de Tch'ang-lo (ap. Kouo ti che, chap. IV, p. $4 \mathrm{v}^{\circ}$ ) qui porte aujourd'hui le nom de Nan-lo (préf. du Ta-ming, prov. de Tche-li).

43.(486) Cette ville de Kieou-men, qui fut une sous-préfecture sous les Han, était à $25 l i$ au N.-O. de 1a sous-préfecture actuelle de Kao-tch'eng (préf. de Tcheng-ting, prov. de Tche-li).

43.(487) Le roi Hoei.

43.(488) Le Kouo ti tche (chap. III, p. $11 \mathrm{v}^{\circ}$ ) place le bourg de Yen-yu (qui avait pris sous les $T^{\prime}$ 'ang le nom de ville de $\mathrm{Ou}$-sou à $20 l i$ au N.-O. de l'ancienne sous-préfecture de T'ong-ti, laquelle se trouvait à $40 \mathrm{li}$ au S.-O. de la préfecture secondaire actuelle de Tch'en (prov. de Chan-si); c'est l'identification que nous avons indiquée tome II, n. 05.465. - Cependant Tchang Cheou-tsie paraît approuver, (à tort, selon nous) une autre explication d'après laquelle cette localité aurait pris son nom de la montagne Yen-yu qui était à $50 l i$ à l'O. de l'ancienne sous-préfecture de Ou-ngan (auj., s.-p. de Yong-nien, préf. de Koang-p'ing, prov. de Tche-li).

43.(489) Ce titre était inspiré du nom de la montagne Ma-fou (dompteur de chevaux), qui était à $10 l i$ au N.-O. de Han-tan.

43.(490) Tchan-kouo-ts'e : section de Tchao; chap. XXI, p. 6 v -7.

43.(491) Le prince de Tch'ang-ngan était le fils cadet de la reine douairière qui, d'après Se-ma Tcheng, était la reine Hoei-wen.

43.(492) Le Tchan-kouo-ts'e réunit le mot [] au mot [] et en fait un caractère unique. L'éditeur de 1581 dit que cette orthographe se justifie par la nécessité de distinguer le personnage mentionné ici du tso-che Tch'ou Long qui, d'après un texte du Chouo-yuan, aurait été le ministre de Kie, dernier souverain de la dynastie Hia.

43.(493) Quoique coupable de n'être pas venu plus tôt, le désir qu'il a de prendre des nouvelles de la reine douairière l'enhardit et il ose se présenter devant elle.

43.(494) L'habit militaire était de couleur noire.

43.(495) C'est-à-dire : avant que je sois mort, comme le vagabond qui roule dans le fossé sur le bord de la route.

- Cf. Tso-tchoan, $13^{\mathrm{e}}$ année du duc Tchao: «Quand les hommes de basse condition sont vieux et n'ont pas de fils, ils savent qu'(après leur mort) ils seront poussés dans le fossé ».

- Mencius (I, b, XII, 2) : «Les personnes vieilles ou faibles ont roulé dans les fossés ». Cf. II, b, IV, 2 ; III, a, III, 7 ; III, b, I, 2 ; V. b, VII, 5).

43.(496) En d'autres termes : qu'elle aime mieux sa fille que son fils.

43.(497) Au moment où la fille de la reine-douairière partait pour le pays de Yen où elle allait être reine, sa mère baignait de larmes les pieds mignons qui s'éloignaient d'elle pour toujours.

43.(498) C'est-à-dire : puisse-t-elle n'être pas répudiée par son mari.

43.(499) La reine-douairière consentait à se séparer de sa fille parce qu'elle souhaitait qu'elle régnât dans le pays de Yen et qu'elle eût des fils et des petits-fils qui fussent rois à leur tour. 
43.(500) D'après le commentaire de l'édition de 1581 du Tchan-kouo-t'se, l'expression signifierait les honneurs et les richesses.

43.(501) C'est-à-dire : quand la reine-douairière mourra.

43.(502) Tse-i était un sage du pays de Tchao.

43.(503) Le Kouo ti tche (chap. V, p. $12 \mathrm{v}^{\circ}$ ) place la ville de Ngan-p'ing à 19 li à l'E. de la s.-p. de Lin-tse (qui dépend aujourd'hui de la préf. de Ts'ing-tcheou, prov. de Chan-tong), et l'identifie avec l'ancienne ville de $H i$ de la principauté de $K i$ (cf. tome I, n. 00.158 et t. IV, p. 41 et 44) cette principauté fut détruite en 690 par le duc Siang de $T s^{\prime} i$.

43.(504) D'après Tchang Cheou-tsie, il n'y avait dans le pays de Yen aucune ville appelée Tchong-yang; selon toute vraisemblance l'historien veut parler de la ville de Tchong-chan. L'ancienne ville de Tchong-chan, dit le Kouo-ti-tche (chap. IV, p. $8 \mathrm{v}^{\circ}$ ) est aussi appelée relais de Tchong-jen; elle se trouvait à $41 l i$ au N.-E. de la s.-p. de T'ang (laquelle se trouvait à $8 l i$ au s. de la s.-p. actuelle de ce nom, préf. de Pao-ting, prov. de Tche-li); à l'époque tch'oen-ts'ieou, elle fut la ville de Tchong-jen qui appartenait à la principauté de Sien-yu.

43.(505) Cette localité est probablement identique à celle de Tchou-tch'eng, qui, d'après le Kouo-ti-tche (chap. VI, p. $18 \mathrm{r}^{\circ}$ ) était à 5 li au S.-O. de la s.-p. de Leang (auj. préf. sec. de Jou, prov. de Ho-nan).

43.(506) Le Chang-tang est le territoire de la préfecture de Lou-ngan, dans le Chan-si.

43.(507) C'est-à-dire : je m'en remets à la libéralité de Votre Majesté pour les récompenses que nous espérons obtenir d'elle.

43.(508) C'est-à-dire qu'il n'a plus besoin d'agir, car le temps travaille pour lui et le Changtang doit inévitablement lui revenir.

43.(509) Par les sacrifices d'hommes et d'argent que $T s$ 'in a faits pour s'assurer la possession du Chang-tang, on peut dire qu'il a en quelque sorte labouré et ensemencé et qu'il est en droit de compter sur la récolte.

43.(510) Il a fait des transports de grain le long de la rivière Wei et du Hoang-ho pour approvisionner les troupes qui combattaient contre Han.

43.(511) Le pays de Han dont les armées avaient une grande réputation de vaillance.

43.(512) Cette expression désigne ici le royaume de $T s$ 'in lui-même.

43.(513) Tchao Cheng, frère cadet du roi Hoei-wen; cf. chap. LXXVI.

43.(514) Le prince de P'ing-yuen.

43.(515) C'est Fong T'ing lui-même.

43.(516) Le chapitre LXXIX du Ts'ien Han-chou, qui est consacré à la biographie de Fong Fong-che, descendant de Fong T'ing, nous donne quelques détails sur les destinées ultérieures de la famille Fong. Après avoir livré le Chang-tang (auj. Lou-ngan-fou) à Tchao, Fong T'ing reçut du roi de Tchao le titre de prince de Hoa-yang; il périt lors de la bataille de Tch'angp'ing (260). Parmi ses descendants, on peut citer, à l'époque des Ts'in, Fong Ou-tse, Fong $K^{\prime}$ 'iu-tsi et Fong Kie (cf. t. II, index, n's 1297, 1298, 1300); à l'époque de l'empereur Wen, Fong T'ang ; enfin sous les règnes des empereurs Tchao, Siuen et Yuen, Fong Fong-che luimême, qui mourut en 40 av. J.-C. après avoir joué un rôle important dans les combats des Chinois contre les peuples de l'Asie Centrale. Fong Fong-che eut pour fille la célèbre Tchao-i Fong (cf. T'oung-pao, 1904, p. 184, n. 3, et p. 324),

43.(517) A 31 li à l'ouest de la sous-préfecture de Kao-p'ing (préf. de Tse-tcheou, prov. de Chan-si); cf. Kouo-ti-tche, chap. III, p. 12 v $^{\circ}$. 
43.(518) Les Tableaux chronologiques (chap. XV, p. $32 \mathrm{v}^{\circ}$ ) et les Annales principales des $T s$ 'in (t. II, p. 91) rapportent à l'année 260 les événements dont il va être question.

43.(519) Tchao Kouo était le fils de Tchao Cho (cf. chap. LXXXI).

43.(520) Dans la biographie de Po K'i prince de Ou-ngan (cf. chap. LXXIII), on trouvera le récit détaillé de ces faits.

43.(521) D'après les Tableaux chronologiques (chap. XV, p. $32 \mathrm{v}^{\circ}$ ), ce siège de Han-tan devrait être reporté à l'année 257.

43.(522) Ou-yuen était à $35 l i$ au S.-O. de la ville préfectorale de Ho-kien (prov. de Tche-li). Cette ville appartenait alors à Tchao, mais elle était limitrophe du pays de Yen et c'est ce qui explique pourquoi le préfet de cette localité put faire cause commune avec les révoltés de Yen.

43.(23) Aujourd'hui, sous-préfecture de Ling-k'ieou (préf. de Ta-t'ong, prov. de Chan-si).

43.(524) Dans la biographie de Ou-ki, prince de Sing-ling (chap. LXXVII), on voit que le roi de Tchao avait gagné les bonnes grâces de ce général en lui donnant à titre de fief personnel la ville de Hao (cf. n. 275).

43.(525) Tout ceci doit être reporté à l'année 257 ; cf. les Tableaux chronologiques.

43.(526) Au lieu de Tch'ang-tchoang; il faut lire Tch'ang-tch'eng. Cette ville était à 5 li au N.-O. de l'ancienne sous-préfecture de Sin-tou (cf. Kouo-ti-tche, chap. IV, p. 6. v'), qui correspond à la préfecture secondaire actuelle de $K i$ (prov. de Tche-li). Cette place appartenait alors au royaume de Tchao.

43.(527) Ce Yo Tch'eng était un parent de Yo Kien et était comme lui originaire du pays de Yen. D'après le chap. LXXX des Mém. hist., il était général de Yen lorsqu'il fut fait prisonnier par Tchao en 251 ; le roi de Tchao le traita fort bien, ainsi que Kien qui était aussi venu se réfugier auprès de lui (cf. t. IV, p. 147, deux dernières lignes). Cependant, le texte que nous traduisons en ce moment nous montre Yo Tch'eng au service de l'État de Tchao de l'année 256 : il est d'accord avec le Tchan-kouo-ts'e (chap. XXXI, p. $1 \mathrm{v}^{\circ}$ ) d'après qui, en 251, Yo Tch'eng était général de Tchao, et non de Yen.

43.(528) D'après Tchang Cheou-tsie, Sin-leang serait le surnom du général de $T s$ 'in plus connu sous le nom de Wang K'i. - D'après les Tableaux chronologiques, en 256, Han, Wei et Tch'ou seraient venus délivrer la ville de Sin-tchong, du pays de Tchao, qui était assiégée par $T s$ 'in. Le commentateur Siu Koang paraît vouloir établir un rapport entre les deux noms Sin-leang et Sin-tchong, mais cette opinion n'est pas soutenable.

43.(529) Cf. t. II, p. 94.

43.(530) C'était un grand officier (ta-fou) du pays de Tchao.

43.(531) Au N.O. de la sous-préfecture actuelle de Yuen-che (préf. de Tcheng-ting, prov. de Tche-li).

43.(532) D'après Siu-Koang, c'était un ancien général de $T$ s'in qui s'était soumis à Tchao.

43.(533) Cette mort eut lieu en 251, d'après les Tableaux chronologiques

43.(534) Wei-wen devait être une place dans le voisinage de la préfecture secondaire de $Y u$ (préf. de Siuen-hoa, prov. de Tche-li).

43.(535) Tchan-kouo-ts'e : section de Yen; chap. XXXI, p. 1.

43.(536) Sur tout ce qui suit, cf. t. IV, p. 146-147.

43.(537) Littéralement «pour le vin ». Le Tchan-kouo-ts'e écrit [], ce qui prouve que cet or était censé destiné à acheter le vin pour un banquet où on aurait souhaité longue vie au roi de Tchao. — La traduction « pot de vin » que j'ai donnée à la p. $146 \mathrm{du}$ t. IV est un contre-sens. 
43.(538) Cf. p. 119, lignes 2-8.

43.(539) Yo Kien était fils de Yo I; cf. t. IV, p. 145.

43.(나) $)$ Cf. tome IV, n. 34.149.

43. $(\underline{541)}$ « Trois contre un », dit le Tchan-kouo-ts'e. Les variantes sont d'ailleurs nombreuses dans la suite de ce texte et ne peuvent être toutes relevées.

43.(542) Cf. n. 275.

43. (543) C'est-à-dire : " prince de la supériorité guerrière », suivant l'explication de Tchang Cheou-tsie.

43. (544) Au nord de la sous-préfecture actuelle de T'ien-tchen (préf. de Ta-t'ong, prov. de Chan-si).

43.(45) Lien P'o.

43.(546) Cf. tome II, n. 05.108. - Cependant Siu Koang place Yu-ts'e sur le territoire de la commanderie (aujourd'hui préfecture) de T'ai-yuen.

43. (547) D'après le Kouo-ti-tche (chap. IV, p. $12 \mathrm{r}^{\circ}$ ), à $20 l i$ au S.-O. de l'ancienne sous-préfecture de Soei-tch'eng (laquelle se trouvait à $25 l i$ à l'ouest de la s.-p. actuelle de Ngan-sou, préf. de Pao-ling, prov. de Tche-li), était la montagne du dragon. Elle avait quatre versants sur chacun desquels on voyait une ouverture grande comme la roue d'un char; au printemps, du vent sortait de l'ouverture orientale ; en automne, en été et en hiver, ce vent sortait respectivement des ouvertures occidentales, méridionale et septentrionale : De là est venu vraisemblablement le nom de Long-toei « les orifices du dragon ».

43.(나) Fen-men paraît être une leçon fautive ; Tchang Cheou tsie propose de voir sous ce nom le défilé de Che-men dans lequel coulait la rivière Siu au S.-E. de l'ancienne sous-préfecture de Pei-p'ing (laquelle se trouvait à $2 l i$ à l'ouest de la s.-p. actuelle de Man-tch'eng, préf. de Pao-ting, prov. de Tche-li).

43. (549) Lin-lo est identifié par Tchang Cheou-tsie avec la ville de Lin-hiang qui, d'après le Kouo-ti-tche, était à 67 li de Kou-ngan (au S.-E. de la préfecture secondaire de la prov. de Tche-li).

43.(550) D'après le Kouo-ti-tche (chap. IV, p. 7 v ), la ville de Ko qu'on appelait aussi $I$ tch'eng, et Si-ngo-tcheng, était à $50 \mathrm{li}$ au N.-O. de l'ancienne s.-p. de Kao-yang (laquelle se trouvait à $25 l i$ à l'est de la s.-p. actuelle de Kao-yang, préf. de Pao-ting, prov. de Tche-li). Le nom de Si-ngo (Ngo occidental), lui était donné pour la distinguer de la ville de Tong-ngo ( Ngo oriental) qui appartenait au royaume de $T s$ 'i.

43.(51) Localité indéterminée.

43.(552) P'ing-chou était à 93 li au nord de l'ancienne sous-préfecture de Ling-k'ieou (cf. n. $523)$.

43.(53) Le futur Ts'in Che-hoang-ti.

43. (554) La ville de Fan-yang, qui était ainsi nommée parce qu'elle était située au nord de la rivière Fan, se trouvait à $27 l i$ au N.-E. de la sous-préfecture de Nei-hoang (préf. de Tchang-té, prov. de Ho-nan).

43. $(\underline{555})$ On pourrait aussi traduire « les grands préparatifs ». D’après Tchang Cheou-tsie, il s'agirait d'un rite qu'on accomplit alors.

43.(556) $P^{\prime}$ 'ing-i était à $30 l i$ au N.-E. de l'ancienne sous-préfecture de Tch'ang-lo, laquelle se trouvait au N.-O. de la s.-p. actuelle de Nan-lo (préf. de Ta-ming, prov. de Tche-li.) Tchong-meou tirait son nom de la montagne Tchong-meou, à 58 li à l'ouest de la sous-préfecture de T'ang-yn (préf. de Tchang-té, prov. de Ho-nan). — Ces deux villes, qui 
étaient au nord du Hoang-ho, dépendaient de Wei dont la capitale, Ta-leang (K'ai-fong-fou), était au sud de ce fleuve: Wei aurait voulu franchir le Hoang-ho pour rétablir ses communications avec P'ing-i et Tchong-meou, mais il n'y parvint pas.

43.(557) Ou-soei était au N.-E. de la s.-p. actuelle de Ou-kiang (préf. sec. de Chen, prov. de Tche-li). - Fang-tch'eng était à $17 l i$ au sud de Kou-ngan (au S.-E. de la préf. sec. de I, prov. de Tche-li). - Ces deux villes appartenaient à l'État de Yen.

43.(558) Le prince de Tch'oen-p'ing était l'héritier présomptif de Tchao.

43.(559) Le marquis de Wen-sin n'est autre que Lu Pou-wei, conseiller de $T s$ 'in.

43.(560) Les officiers militaires du palais.

43.(561) Dans le voisinage de la s.-p. actuelle de Ngan-ting (préf. de Yen-ngan, prov. de Chàn-si). - Je rétablis dans le texte le mot [], d'après le Tchan-kouo-ts'e; le marquis de $P$ 'ing-tou était sans doute un otage de $T s$ 'in envoyé à la cour de Tchao.

43.(562) A la date de 242, les Tableaux chronologiques disent que le conseiller de Tchao et le conseiller de $W e i$ se réunirent à $K o$ (cf. tome IV, n. 32.149), dans le pays de Lou, et conclurent un traité.

43.(563) D'après Siu Koang, cette ville se serait trouvée sur le territoire de Sin-fong (au N.-E. de la s.-p. actuelle de Lin-t'ong, préf. de Si-ngan, prov. de Chàn-si).

43.(564) A 130 li au S.-E. de la préf. sec. de Ts'ang (préf. de T'ien-tsin, prov. de Tche-li). Il est cependant assez bizarre que l'État de $T s^{\prime} i$ se soit étendu aussi au loin dans le nord.

43.(핟) Cf. n. 556.

43.(566) Sur la rive nord du Hoang-ho.

43.(567) C'est-à-dire sur la rive sud du Hoang-ho.

43.(568) Aujourd'hui, s.-p. de Jao-yang, (préf. sec. de Chen, prov. de Tche-li).

43.(569) A 40 li au S.-O. de la s.-p. de Lin-tchang (préf. de Tchang-té, prov. de Ho-nan).

43.(570) Au lieu de Li-yang, Tchang Cheou-tsie propose de lire Yu-yang; Yu-yang était à 18 li au sud de la s.-p. de Mi-yun (préf. de Choen-tien, prov. de Tche li).

43.(571) Cf. n. 569 et t. II, p. 115.

43.(572) Siu Koang (chap. XV, p. 36 r) l'appelle Yeou-min.

43.(573) Cf. tome II, n. 08.334 .

43.(574) D'après les Tableaux chronologiques, c'est P'ing-yang (et non Ou-tch'eng), qui fut alors assiégé par $T s$ 'in.

43.(575) I-ngan était à $20 l i$ au S.-O. de la s.-p. de Kao-tch'eng (préf. de Tcheng-ting, prov. de Tche-li).

43.(7ㄷ) Fei ou Fei-lei était à $7 l i$ à l'ouest de la s.-p. de Kao-tch'eng (cf. la note précédente).

43.(577) A $20 l i$ à l'Est de la s.-p. actuelle de Fang-chan (préf. de Choen-tien, prov. de Tcheli).

43.(578) Lo-siu se trouvait dans l'arrondissement de Tsin (auj. s.-p. de Lin-fen, préf. de P'ing-yang, prov. de Chan-si).

43.(579) P'ing-yn se trouvait dans l'arrondissement de Fen (auj. s.-p. de Fen-yang, préf. de Fen-tcheou, prov. de Chan-si).

43.(580) Le pays de $T s$ 'in se réjouit de l'infortune de Tchao. 
43.(8ㄷ) Les céréales maigres et sans épis ressemblent à des poils.

43.(582) Le Tchan-kouo-t'se (chap. XXI, p. $7 \mathrm{r}^{\circ}$ ) est plus explicite sur ces événements :

«Ts'in chargea Wang Tsien d'attaquer Tchao; Tchao chargea Li Mou et Se-ma Chang de lui tenir tête. $\mathrm{Li} \mathrm{Mou}$, à plusieurs reprises, vainquit et mit en fuite l'armée de $T s$ 'in; il tua le général Hoan $K^{\prime} i$ (cf. t. II, p. 115-117). Wang Tsien en fut fort ennuyé ; il donna alors des quantités considérables d'or à Kouo K'ai et aux autres favoris du roi de Tchao pour qu'ils semassent la division chez l'ennemi en disant :

- Li Mou et Se-ma Chang désirent faire alliance avec $T s$ 'in et se révolter contre Tchao afin de recevoir de $T s$ 'in des dotations importantes.

Le roi de Tchao, devenu soupçonneux, chargea Tchao Hou et Yen Tsiu de les remplacer dans leurs commandements; il décapita $\mathrm{Li} \mathrm{Mou}$ et dégrada Se-ma Chang. Trois mois plus tard, Wang Tsien en profita pour renouveler ses attaques avec vigueur; il battit complètement Tchao, tua l'armée de Tchao (ou, suivant une variante, « il tua Tchao Hou »), et fit prisonnier Ts'ien, roi de Tchao, ainsi que son général Yen Tsiu. Ainsi fut anéanti (le royaume de) Tchao.

43.(583) L'édition de Chang-hai intervertit ici par erreur l'ordre des mots et écrit [] mais elle donne la leçon correcte dans les notes critiques placées à la fin de ce chapitre. - Wang-suen est l'appellation de Fong Soei dont le père, Fong T'ang, avait plus de 90 ans à l'avènement de l'empereur $O u$ (140 av. J.-C.) ; sa famille était originaire de l'ancien royaume de Tchao et c'est ainsi qu'il pouvait connaître certains détails de l'histoire de ce pays (cf. Ts'ien Han chou, chap. L., p. $2 \mathrm{v}^{\circ}-3 \mathrm{v}^{\circ}$ ). Se-ma Ts'ien dit lui-même (chap. CII, p. $3 \mathrm{v}^{\circ}$ ) qu'il entretenait des rapports d'amitié avec Fong Soei.

43. (84) Cf. ligne 5 de la note 582.

43.(85) Cf. t. II, p. 120.

43.(ㅌ6) Cf. t. II, p. 122.

\section{CHAPITRE XLIV : Quatorzième maison héréditaire. Wei}

44.(101) La famille Wei tire son nom du fief de Wei (à 5 li au N. de la s.-p. de Joei-tch'eng, préf. sec. de Kie, prov. de Chan-si) qui fut conféré en 661 av. J.-C. à Pi Wan. - Une cinquantaine d'années plus tard, Wei Tao-tse transféra sa capitale à Houo (auj., préf. sec. de Houo, prov. de Chan-si). — Wei Kiang, fils de Wei Tao-tse, prit pour résidence la ville de Ngan- $i$ que la tradition considère comme l'ancienne capitale de la dynastie Hia (à 15 li au N.-E. de la s.-p. de Hia, préf. sec. de Kiang, prov. de Chan-si). — En 403, le prince de Wei fut promu officiellement au rang de seigneur en même temps que les princes de Tchao et de Han.- En 340, les progrès faits par le royaume de $T$ s'in étant une menace perpétuelle pour la ville de Ngan-i, le roi de Wei transporta sa capitale à Ta-leang (auj. ville préfectorale de $K^{\prime} a i$ fong, prov. de Ho-nan) ; à partir de ce moment, le royaume de Wei fut habituellement désigné sous le nom de Leang. Ce royaume fut anéanti en 225 av. J.-C. par Ts'in.

44.(102) La principauté de $P i$ correspond à la localité de $P i-y u e n$, à $5 l i$ au N. de la s.-p. de Hien-yang (préf. de Si-ngan, prov. de Chàn-si) ; cf. H. T. K. K., chap. CCLIII, p. 8 r ${ }^{\circ}$ Ce duc de $P i$ est souvent mentionné à l'époque du roi $O u$ (cf. t. I, p. 223, 235, 237, 249, 250). D'après un texte du Tso tchoan $\left(24^{\mathrm{e}}\right.$ année du duc de $\mathrm{Hi}$ ), il aurait été un des seize fils du roi Wen. Sema Ts 'ien se borne à dire qu'il était de la famille royale des Tcheou.

44.(103) Le dernier souverain de la dynastie $Y n$. 
44.(104) Cf. t. IV, p. 259, où le nom de Tchao Sou a été transcrit, par erreur, Tchao Wei. Sur l'expression « l'homme de droite », cf. tome IV, n. 32.198 ; p. 259, n. 2 ; p. 278, n. 1 ; p. 299, n. 1,

44.(105) $\underline{\text { Cf. tome IV }}$, notes 39.129, 39.130, 39.13.

44.(106) Telle est l'origine de la maison princière de Wei.

44.(107) Tso tchoan : $1^{\mathrm{e}}$ année du duc Min.

44.(108) En donnant à $P i$ Wan la terre de Wei, on a transformé son nom en Wei Wan, qui peut signifier « les myriades de $W e i$ » et qui présage par conséquent que les descendants de Pi Wan seront des seigneurs.

44.(109) Tout ce passage, tiré du Tso tchoan, a déjà figuré dans le chap. XXXIX (cf. t. IV, p. 260-261).

44.(110) Cf. tome IV, n. 32.264 .

44.(111) Je rétablis dans ma traduction le mot [] qui apparaît dans la citation de ce texte du Tso tchoan qui a déjà été faite au chap. XXXIX; dans le Tso tchoan même, comme ici, ce mot est omis, mais le sens le suppose

44.(112) Ces quatre fils sont $H i$-ts 'i, que le duc Hien avait désigné comme son héritier, Taotse, qui, de même que $H i$-ts ' $i$, fut assassiné après quelques jours de règne, I-ou qui fut le duc Hoei, et Tch'ong-eul, qui fut le duc Wen; cf. t. IV, p. 271 et suiv.

44.(113) D'après le Tso tchoan, le nom personnel de Ou-tse était Tch'eou. Cf. tome IV, p. 299 et note 40.246 .

44.(114) Cf. t. IV, p. 283, où Wei Ou-tse est mentionné parmi les compagnons de Tch'ong-eul.

44.(115) Aujourd'hui, préfecture secondaire de Houo, prov. de Chan-si.

44.(116) D'après le Tso tchoan ( $3^{\mathrm{e}}$ année du duc Siang), Wei Kiang mit à mort le cocher de Yang-kan; cf. t. IV, p. 329.

44.(117) A la date de 569 et à la date de 540, les Tableaux chronologiques (chap. XIV) disent : «Wei Kiang conseilla l'harmonie aux Jong-Ti : les Ti vinrent rendre hommage à Tsin.

La répétition de cette même mention à deux dates assez distantes l'une de l'autre semble prouver que ces événements sont assez mal localisés dans le temps. - Les Jong-Ti dont il est ici question sont vraisemblablement les Ti rouges, qui, d'après le Kouo ti tche (chap. III, p. 11 $\mathrm{r}^{\circ}$ ), occupaient autrefois l'arrondissement de Lou (auj., préfecture de Lou-ngan), au S. E. du Chan-si.

44.(118) Tout ce qui précède s'est déjà trouvé dans le chap. XXXIX (cf. t. IV, p. 329).

44.(119) Cf. n. 101.

44. (120) $\mathrm{Au}$ lieu de « étant vieux », le Tso tchoan $\left(28^{\mathrm{e}}\right.$ année du duc Tchao) donne la leçon « étant mort».

44.(121) Cf. tome IV, n. 39.343.

44.(122) Le détail de ce partage se trouve indiqué dans le $\underline{T s o}$ tchoan $\left(28^{\mathrm{e}}\right.$ année du duc Tchao).

44.(123) Tchao Kien-tse = Tchao Yang; Tchong-hang Wen-tse = Tchong-hang Yn (voyez index du t. IV) = Siun Yn; Fan Hien-tse = Che-yang (cf. t. IV, p. 333, n. 2).

44.(124) Cf. tome IV, n. 39.346. 
44.(125) Se-ma Tcheng identifie ce Wei Tch'e avec le personnage appelé Wei Man-to ou Wei Siang-tse dans le Tso tchoan $\left(13^{\mathrm{e}}\right.$ année du duc Ting). - Le Che pen mentionne, entre Wei Hien-tse et Wei Tch'e, un prince intermédiaire appelé Wei Ts'iu ou Wei Kien-tse ; mais il n'est pas possible de faire ici l'examen critique des généalogies du Che pen, ce qui serait une tâche fort longue et peu profitable; nous ne nous astreindrons donc pas à signaler toutes les divergences qui peuvent se présenter entre le Che pen et les Mémoires historiques.

44.(126) D'après une note de Se-ma Tcheng aux Tableaux chronologiques, le nom personnel de Wei Hoan-tse était Kiu; le même témoignage se trouve dans le Che pen.

44.(127) Han K'ang-tse avait pour nom personnel Hou; Tchao Siang-tse avait pour nom personnel Ou-siu.

44.(128) Tche po, c'est-à-dire Tche l'aîné, avait pour nom personnel Yao ; aussi est-il appelé parfois Tche Yao. On le trouve aussi appelé Siun Yao car Siun était son nom de famille. Quant à $T c h e$, c'était proprement le nom de la ville qui lui appartenait en fief; elle se trouvait à $40 l i$ au N.-O. de la s.-p. de Yu-Hiang (préf. sec. de P'ou, prov. de Chan-si),

44.(129) Les Tableaux chronologiques, d'accord avec le Che pen, donnent au marquis Wen le nom personnel $\mathrm{Se}$.

44.(130) Cf. tome II, n. 05.249. En 617, Tsin avait pris à $T$ s'in la ville de Chao-leang qui échut ensuite en partage à la maison de $\mathrm{Wei}$.

44.(131) Celui qui fut plus tard le marquis $O u$.

44.(132) Localités non identifiées.

44.(133) Cf. tome II, n. 05.375.

44.(134) Cf. tome II, n. 05.328.

44.(135) Cf. tome II, n. 05.401.

44.(136) Cf. t. III, p. 489 : «Quitter mes femmes et mes enfants sera à mes yeux aussi facile que d'ôter une sandale. » Cf. aussi Tsin chou, chap. LXXXVI, où un homme dit qu'il quittera un certain endroit aussi aisément qu'il enlèverait un soulier.

44.(137) Dans le Han che wai tchoan (Chap. IX, p. 10 r ${ }^{\circ}$ ) de Han Yng (IIe siècle av. J.-C.), la même anecdote est rapportée sous une forme un peu différente :

«T'ien Tse-fang s'étant rendu dans le pays de Wei, l'héritier présomptif avec un cortège de cent chars, vint à sa rencontre dans la banlieue. L'héritier présomptif se prosterna à deux reprises et se présenta à T'ien Tse-fang; mais T'ien Tse-fang ne descendit pas de son char. L'héritier présomptif, mécontent, dit :

— J'ose vous demander comment il se fait que vous vous permettiez d'outrager autrui.

T’ien Tse-fang répliqua :

- J'ai appris qu'il s'est trouvé des hommes qui se sont perdus pour avoir, étant en possession de l'empire, outragé autrui. Si on considère cela, on constate qu'un homme pauvre et humble peut outrager autrui. En effet, si il déplaît, il n'a qu'à mettre (?) ses souliers et à se rendre dans le pays de $T$ s'in ou dans celui de Tch'ou; en quel lieu ira-t-il où il ne puisse être pauvre et humble ?

Alors l'héritier présomptif se prosterna par deux fois et se retira en arrière. T'ien Tse-fang ne descendit donc pas de son char.

- Dans le Chouo-yuan de Lieou Hiang (chap. X, p. 8 r ${ }^{\circ}$ de l'édition du Han Wei ts'ong chou), on raconte une autre entrevue de T'ien Tse-fang et du prince héritier : 
T'ien Tse-fang était assis à côté du marquis Wen, de Wei. L'héritier présomptif, s'avançant rapidement, entra pour rendre visite (à son père). Les hôtes et les fonctionnaires se levèrent tous. T'ien Tse-fang seul ne se leva pas. Le marquis Wen eut l'air mécontent et il en fut de même de l'héritier présomptif. T'ien Tse-fang dit :

- Si je me lève en l'honneur du fils, je ne puis me justifier en ce qui concerne les rites ; si je ne me lève pas en l'honneur du fils, je ne puis m'excuser en ce qui concerne la faute. Je vous demande la permission de vous raconter, ô prince, l'histoire du roi Kong, de Tch'ou, au temps où il était héritier présomptif ; étant sorti dans l'intention de se rendre à Yun-mong, il rencontra le grand officier Kong Yn. Kong Yn se retira aussitôt précipitamment dans la maison d'un de ses serviteurs ; l'héritier présomptif descendit de son char, le suivit dans la maison du serviteur et lui dit:

- O grand officier, pourquoi vous conduisez-vous ainsi ? J'ai entendu dire que celui qui honore le père, ne réunit pas le fils dans les mêmes honneurs; si quelqu'un réunit le fils dans les mêmes honneurs, il n'est pas de plus grand malheur. O grand officier, pourquoi vous conduisez-vous ainsi ?

Kong Yn lui dit :

- Naguère, j'ai vu de loin votre visage ; dorénavant je me rappellerai votre cœur.

Si vous examinez attentivement ce qui s'est passé alors, qu'en penserez-vous?

Le marquis Wen dit :

- C'était fort bien agi.

L'héritier présomptif $K i$, s'avança et répéta les paroles du roi Kong ; quand il les eut récitées trois fois, il demanda à les mettre en pratique.

44.(138) $L o-y n$, ainsi nommée parce qu'elle se trouvait au $\mathrm{S}$. de la rivière $L o$ du Chàn-si, était, d'après le Kouo ti tche (chap. II, p. $12 \mathrm{v}^{\circ}$ ) à l'ouest de la préf. sec. de T'ong, prov. de Chàn-si. - Ho-yang est aujourd'hui encore la sous-préfecture de ce nom, qui dépend de la préf. sec. de T'ong.

44.(139) Yang-hou, dit le Kouo ti tche (chap. IV, p. 4, $\mathrm{r}^{\circ}$ ) était à $30 l i$ au N.-E. de la s.-p. de Yuen-tch'eng (préf. de Ta ming, prov. de Tche-li).

44.(140) Tse-hia est le surnom de Pou Chang, disciple de Confucius, qui était de quarante-quatre ans plus jeune que son maître. Après la mort de Confucius, il s'établit dans le Si ho, c'est-à-dire dans la partie du Chan-si comprise entre la rivière Fen et le Hoang ho ; comme ce territoire appartenait alors à l'État de Wei, Pou Chang entra en relations avec le marquis Wen, de Wei, qui le traita comme son maître. Cf. Mém. hist., chap. LVII, p. 5 vº $^{\circ}$

44.(141) Comme l'indique une note du T'ong kien tsi lan, Toan-kan est un nom de famille de deux caractères. C'est par erreur que certains auteurs coupent mal ce nom, en donnant Kan-mou comme le nom personnel. - Hoang-fou Mi (215-282 p. C.) dans son Kao che tchoan (chap. II, édition du Han Wei ts'ong chou), nous donne la notice suivante sur Toan-kan Mou :

«Toan-kan Mou était un homme du pays de Tsin; dans sa jeunesse, il était pauvre et aussi de basse condition; ses aspirations n'étaient pas satisfaites. Alors il mena une vie rigoureusement pure et s'en alla dans (la région du) Si-ho; il prit pour maître et servit Pou Tse-hia. Ainsi que Tien Tse-fang, Li K'o, Ti Hoang et $O u K^{\prime} i$, il demeura dans le pays de $W e i$; tous ces hommes devinrent généraux ; seul (Toan-)kan Mou s'attachait à la sagesse et n'exerçait aucune fonction publique. Le marquis Wen, de Wei, voulut le voir et se rendit à sa porte ; Toankan Mou passa par-dessus le mur pour éviter le marquis Wen. Le marquis Wen 
lui rendit les honneurs qu'on doit à un hôte. Étant sorti et passant devant sa demeure, il s'inclina sur la barre d'appui de son char. Son cocher lui demanda :

- (Toan-)kan Mou est un homme vêtu de toile (c.-à-d. un homme du commun peuple); Votre Altesse s'incline sur la barre d'appui de son char devant sa demeure ; n'est-ce pas excessif?

Le marquis Wen répondit :

- Toan-kan Mou est un sage. Il ne se remue pas pour obtenir le pouvoir ou les richesses; il conserve en lui la sagesse de l'homme supérieur. Il demeure caché dans une ruelle écartée et sa renommée vole à mille $l i$ de distance. Comment pourrais-je ne pas m'incliner sur la barre d'appui de mon char? (Toan-)kan Mou est au premier rang par la vertu ; moi, je suis au premier rang par la puissance. (Toan-)kan Mou est opulent en justice; moi, je suis opulent en richesses. La puissance n'est pas aussi honorable que la vertu; les richesses ne sont pas aussi hautes que la justice.

(Le marquis Wen) proposa en outre le titre de conseiller (à Toan-kan Mou), mais il le refusa. Plus tard, le marquis Wen, s'étant humilié lui-même et l'ayant prié avec instances, il le vit et s'entretint avec lui; le marquis Wen resta debout jusqu'à en être fatigué et n'osait pas respirer.

Si la renommée du marquis Wen dépassa celle du duc Hoan, de $T s$ ' $i$, c'est parce qu'il sut honorer Toan-kan Mou, respecter Pou Tse-hia et traiter comme un ami T'ien Tse-fang. »

44.(142) $\mathrm{Lu}$ Pou-Wei (d. 235 av. J.-C.) avait déjà raconté les mêmes anecdotes dans son Tch'oen-ts'ieou (chap. XXI, p. $4 \mathrm{v}^{\circ}$ et p. $6 \mathrm{r}^{\circ}-\mathrm{v}^{\circ}$ ); la réponse du marquis Wen à son cocher est ici la suivante :

- N'est-ce pas là la demeure de Toan-kan Mou? Or Toan-kan Mou est un sage : comment oserais-je ne pas m'incliner sur la barre d'appui de mon char? J'ai en outre entendu dire que Toan-kan Mou ne voudrait pas changer sa condition contre la mienne : comment oserais-je me montrer arrogant envers lui ? Toan-kan Mou est glorieux par sa vertu; moi, je suis glorieux par mon territoire. Toan-kan Mon est opulent en justice ; moi, je suis opulent en richesses.

Son cocher lui dit :

- S'il en est ainsi, ô prince, pourquoi ne le prenez-vous pas pour conseiller?

Le prince lui proposa donc le titre de conseiller, mais Toan-kan Mou refusa de l'accepter. Le prince lui donna alors un traitement d'un million (de pièces de monnaie) et se rendit fréquemment dans sa demeure. Les gens du royaume étaient tous joyeux et chantaient entre eux :

- Notre prince aime la rectitude et la preuve en est qu'il respecte Toan-kan Mou; notre prince aime la fidélité, et la preuve en est qu'il met à un haut rang Toan-kan Mou.

Peu de temps après, (le roi de) $T s$ 'in leva des soldats dans l'intention d'attaquer Wei. Se-ma T'ang fit des remontrances au prince de $T s$ 'in en lui disant :

- Toan-kan Mou est un sage, et (le prince de) Wei l'honore. Dans le monde, il n'est personne qui n'en soit informé. Non certes, on ne peut lui faire la guerre.

Le prince de $T s$ 'in approuva cet avis ; il renonça donc aux hostilités et n'osa pas attaquer (Wei). 
Enfin on lit dans le Chouo yuan (chap. VIII, p. 15 v, édit. du Han Wei ts'ong chou) de Lieou Hiang (86-15 av. J.-C.) :

« Le marquis Wen de Wei, ayant donné audience à Toan-kan Mou, se tint debout jusqu'à en être fatigué et n'osait pas respirer. Puis, quand il reçut Ti Hoang, il s'entretint avec lui en se tenant accroupi dans la salle. Comme Ti Hoang était mécontent, le marquis Wen lui dit :

- Toan-kan Mou, quand je lui ai offert une charge publique, l'a refusée ; quand je lui ai donné un traitement, ne l'a pas accepté. Vous, au contraire, vous avez désiré une charge publique et avez obtenu le titre de conseiller ; vous avez désiré un traitement et vous avez reçu celui de haut dignitaire. Après avoir accepté mes bienfaits, n'est-il pas difficile que vous me fassiez des reproches au sujet des égards que je vous dois?

44. $(\underline{143})$ [] «barre d'appui d'un char » a ici le sens de «s'incliner sur la barre d'appui d'un char » (cf. commentaire du Tch'oen ts 'ieou de Lu Pou-wei dans le texte cité plus haut, n. 142).

44.(144) Cf. tome III, p. 523, lignes 11-12 et note 29.114; Mém. hist., chap. CXXVI.

44.(145) Ce qui suit se retrouve, avec des variantes notables, dans le Chouo-yuan de Lieou Hiang (chap. II, p. $4 \mathrm{v}^{\circ}$ et suiv.) et dans le Han che wai tchoan de Han Yng (chap. III, p. $3 \mathrm{r}^{\circ}$ et suiv.).

44.(146) C'est-à-dire : Wei Tch'eng-tse, frère cadet du marquis Wen, et Ti Hoang.

44.(147) Dans le texte du Chouo yuan, ce développement prend la forme suivante :

«Le gouverneur du Si-ho, c'est moi qui l'ai fait nommer; le ki che nei che (il y a vraisemblablement une faute de texte ; il s'agit de $\mathrm{Si}$-men Pao qui administra le Ho-nei), c'est moi qui l'ai fait nommer; quand le roi a voulu attaquer le Tchong-chan, c'est moi qui ait recommandé Yo Yang; il n'y avait personne qu'on pût charger du gouvernement, c'est moi qui vous ai recommandé ; il n'y avait personne qu'on pût charger d'être le précepteur du fils du roi, c'est moi qui ai recommandé K'iu-heou Fou.

- Dans un autre passage du Chouo yuan (chap. II, p. $6 \mathrm{r}^{\circ}$ ), où se trouve relatée une conversation de T'ien Tse-fang avec Ti Hoang, ce dernier dit :

- Autrefois dans le Si-ho il n'y avait pas de gouverneur; j’ai recommandé $O u$ $K$ ' $i$, et la région du $S i-h o$ a joui du calme. (La ville de) Ye n'avait pas de préfet; j'ai recommandé Si-men Pao, et Wei n'a plus eu à souffrir de Tchao. (La ville de) Soan-tsao n'avait pas de préfet; j'ai recommandé Pei-men K'o ( ?) et Wei n'a plus été inquiété par $T s^{\prime} i$. (Le roi) de Wei a voulu attaquer le Tchong-chan; j'ai recommandé Yo Yang et le Tchong-chan a été pris. (Le roi de) Wei n'avait aucun ministre qu'il pût charger du gouvernement; j'ai recommandé $L i K$ 'o et le royaume de Wei a été bien gouverné.

- Le personnage appelé Yo Yang était un général qui avait le commandement des troupes de Wei chargées de réduire le prince de Tchong-chan; le fils de Yo Yang se trouvait dans la ville de Tchong-chan; on le tua, on le fit bouillir et on envoya le bouillon à son père dans l'espoir de l'effrayer; Yo Yang s'assit tranquillement sur une natte et avala un plein bol de ce breuvage. Le prince de Tchong-chan alors fit sa soumission. (Cf. Tchan kouo ts'e, discours de

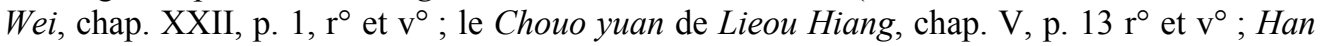
Fei-tse, chap. VII, p. 13, $\mathrm{r}^{\circ}$; Hoai-nan tse, chap. XVIII, p. 5, $\mathrm{r}^{\circ}$ et $\mathrm{v}^{\circ}$ ).

44. (148) C'était une colline sur le bord du Hoang ho à 2 li à l'ouest de la préfecture secondaire de Chàn (prov. de Ho-nan); cf. Kouo ti tche, chap. IV, p. 14 r $^{\circ}$.

44.(149) Cf. t. II, p. 104, n. 1. 
44.(150) Tchou était à 15 li à l'O. de l'ancienne s.-p. de Leang (auj. préf. sec. de Jou, prov. de Ho-nan); cf. Kouo ti tche, chap. VII, p. 18 r $^{\circ}$.

44.(151) Cf. tome IV, n. 40.305 .

44.(152) Cf. tome II, n. 05.344, et tome V, n. 43.287.

44.(153) La ville de $O u$, appelée aussi Ou-p'ing, était d'après le Kouo ti tche (chap. II, p. 12 $\mathrm{r}^{\circ}$ ), à 13 li au N.-E. de l'ancienne s.-p. de Tcheng, qui est aujourd'hui la préf. sec. de Hoa (préf. de T'ong-tcheou, prov. de Chàn-si).

44.(154) Cho, qui était fils du duc Ou, de Tchao, est appelé Tchao dans le chapitre sur Tchao (cf. p. 55, ligne 15), et dans les tableaux chronologiques.

44.(155) Ngan-i était encore alors la capitale de Wei.

44.(156) Wang-yuen, ainsi nommée parce qu'elle se trouvait près de la montagne Wang-ou (cf. tome I, n. 02.222), était à $20 l i$ au N.-O. de l'ancienne s.-p. de Yuen qui était elle-même à $20 l i$ à l'O. de la s.-p. actuelle de Yuen-k'iu (préf. sec. de Kiang, prov. de Chàn-si); cf. Kouo ti tche, chap. III, p. $7 \mathrm{v}^{\circ}$.

44.(157) Sang-k'ieou était sur le territoire de l'ancienne sous-préfecture de Soei-tch'eng, laquelle se trouvait à $25 l i$ à l'O. de la s.-p. actuelle de Ngan-sou (préf. de Pao-ting, prov. de Tche-li). Des indications contenues dans les tableaux chronologiques (chap. XV, p. 16, $\mathrm{r}^{\circ}$ ), il résulte que Sang-k'ieou était une ville de l'État de Yen qui, en 380, fut prise par Ts' $i$; Wei, Han et Tchao vinrent alors au secours de Yen contre Ts ' $i$, et arrivèrent jusqu'à Sang-k'ieou.

44.(158) La rivière Koai prend sa source au pied de la montagne Ou-ling, au sud de la s.-p. de I-tch'eng (préf. de P'ing-yang, prov. de Chàn-si) et se jette dans la rivière Fen sur le territoire de la préfecture secondaire de Kiang. - On voit par ce texte que, à cette époque, il y avait encore des tribus barbares dans le sud du Chan-si.

44.(159) Cf. note 43.244.

44.(160) Cf. tome II, n. 05.302, où ce nom est transcrit par erreur Li-yang. En 383, le duc Hien avait élevé des remparts à Yo-yang; il fit ensuite de cette ville sa capitale (cf. t. II, p. 63), et c'est vraisemblablement à cette occasion qu'il l'érigea en préfecture.

44.(161) Cf. note 43.256. La ville de Lin était appelée septentrionale parce qu'elle se trouvait au N.-O. du pays de Tchao.

44.(162) Cf. tome IV, n. 40.300 .

44.(163) Tchao et Han faisaient alors, comme on va le voir, cause commune contre Wei.

44.(164) Le marquis $I$, dont le nom personnel était $J o$, était le fils du marquis $N g a i$ qui régnait alors sur le pays de Han.

44.(165) Le roi Hoei, de Wei.

44.(166) D'après le Tchou chou ki nien, le marquis $O u$, de Wei, en la première année de son règne (386), avait donné un fief au prince Hoan (=Kong-tchong Hoan). Il avait voulu ainsi l'éloigner de la capitale; en 375, Hoan vint se réfugier à Han-tan, capitale de Tchao. Lorsque le marquis $\mathrm{Ou}$ mourut, en 371, Hoan dut apparemment faire valoir ses droits au trône de $\mathrm{Wei}$ et demander l'appui du prince de Tchao auprès duquel il avait cherché asile ; en même temps, Kong-suen K'i venait engager le prince de Han à secourir le prince de Tchao en lui montrant qu'il avait une belle occasion d'intervenir et de briser à jamais la puissance de Wei.

44.(167) Wang Ts'o ne resta pas longtemps au service du roi Hoei; dès l'année suivante (369) en effet, "le grand officier de Wei, Wang $T s$ 'o, sortit de son pays et se réfugia dans le royaume de Han » (Tchou chou ki nien).

44.(168) Le Chang-tang (Lou-ngan fou) était un territoire de Han. 
44.(169) Cf. note 43.262.

44.(170) Il fut assiégé dans sa capitale, Ngan-i.

44.(171) Song et Wei étaient de fort petites principautés.

44.(172) Cf. tome II, n. 05.339.

44.(173) Cf. tome II, n. 05.468.

44.(174) Koan correspond à la s.-p. actuelle de Koan-tch'eng (préf. de Ts'ao-tcheou, prov. de Chan-tong). - C'était autrefois une principauté qui passait pour avoir été l'apanage de $O u$ koan, le plus jeune fils de l'empereur $K^{\prime} i$, de la dynastie Hia (cf. Tchou chou ki nien, Legge, C. C. vol. III, prolég., p. 118).

44.(175) Tchai-yang, qu'on appelait aussi Pei-tchai, était à 17 li au S.-E. de la s.-p. de Yongyang (préf. de $K^{\prime}$ ai-fong, prov. de Ho-nan). - Le Che ki luen wen place le point après le mot [a] ; mais, dans les Tableaux chronologiques (chap. XV, p. 18, $\mathrm{r}^{\circ}$ ), on lit :

«(le prince de Wei) eut une entrevue avec Han à Tchai-yang; il éleva un rempart à $\mathrm{Ou}$-tou.

Dans le chap. XLV, p. $2 \mathrm{r}^{\circ}$, il est dit :

« (le prince de Han) eut une entrevue avec le roi Hoei de Wei, à Tchai-yang.

Il semble donc bien que le mot ne doive pas être rattaché au nom de Tchai-yang.

44.(176) Cf. n. 158.

44.(177) Cf. tome II, n. 05.176.

44.(178) Cf. t. II, p. 60. Les Tableaux chronologiques disent : «On fit prisonnier notre héritier présomptif.

Cf. t. V, p. 59, dernière ligne.

44.(179) Localité non-identifiée.

44.(180) Cf.. note 43.271, ad fin.

44.(181) Cf. tome IV, n. 34.151 .

44.(182) Tcheng désigne ici l'État de Han qui, depuis l'année 375, avait transféré sa capitale à Tcheng. Cf. chap. XLV.

44.(183) Au lieu de Cho-p'ing, il faut lire Tou-p’ing, comme dans les Tableaux chronologiques (chap. XV, p. $19 \mathrm{v}^{\circ}$ ) et dans les annales principales des $T s^{\prime}$ in (cf. tome II, $\mathrm{n}$. 05.327).

44.(184) Cf. tome IV, n. 31.218 .

44.(185) Cf. tome II, n. 05.249.

44.(186) Suen Pin était un descendant de Suen Ou. On trouvera sa biographie dans le chap. LXV des Mém. hist.

44.(187) Au N.-E. de la s.-p. de Ko-tse (préf. de Ts'ao-tcheou, prov. de Chan-tong).

44.(188) Auj., s-p. de Siang-ling (préf. de P'ing-yang, prov. de Chan-si).

44.(189) Kou-yang était dans le pays d'Ourato, en dehors de l'angle oriental de la grande boucle du Hoang-ho (cf. Ta Ts'ing $i$ t'ong tche, chap. CCCCVIII, $1^{\mathrm{e}}$ partie, p. $2 \mathrm{r}^{\circ}$ ). La barrière de Kou-yang fut toujours une position stratégique importante pour les Chinois. Sous les Han occidentaux, Kou-yang faisait partie de la commanderie de Ou-yuen et était la résidence du commandant de la section orientale ; elle était le point de départ d'une route qui comptait les étapes suivantes : au nord de Kou-yang, on sortait par Che-men tchang et on 
atteignait Koang-lou tch'eng ; plus au N.-O., on arrivait à Tche-tsieou tch'eng ; plus au N.-O., à T'eou-man tch'eng; plus au N.-O., à Hou-ho tch'eng; plus à l'O., à Sou-lou tch'eng (Ts 'ien Han chou, chap. XXVIII, b, p. $3 \mathrm{v}^{\circ}$ ). - Sous les Han orientaux, en 89 ap. J.-C., le général Teng Hong sortit par la barrière de Kou-yang, livra bataille aux Hiong-nou auprès de la montagne Ki-lo et leur fit essuyer une grande défaite (Heou Han chou, chap. IV, p. 2 r $^{\circ}$ ). Sous les Wei, en 391 ap. J.-C., l'empereur T'ai-tsou érigea une stèle au N. de la barrière de Kou-yang pour rappeler ses exploits (Wei chou, chap. II, p. $2 \mathrm{v}^{\circ}$ ).

D'après les indications de Tchang Cheou-tsie, le long mur construit par le roi de Wei en 352 av. J.-C. partait de Tcheng (auj., préf. sec. de Hoa, préf. Ta-t'ong, prov. de Chàn-si), longeait la rivière $L o$ du Chàn-si, puis se dirigeait vers le nord sur l'arrondissement de $Y n$ (à 80 li au N.-O. de la s.-p. de Mi-tche, préf. sec. de Soei-té, prov. de Chàn-si), et aboutissait enfin à Kou-yang, en dehors de l'angle oriental de la grande boucle du Hoang-ho.

44.(190) Cf. tome I, n. 02.126.

44.(191) L'emplacement de T'ong est indéterminé.

44.(192) L'auteur fait ici une confusion avec les événements de l'année 353 : à cette époque, $W e i$ avait attaqué Tchao qui implora le secours de $T s$ ' $i$; mais, en 341, Wei s'était allié à Tchao pour combattre Han, et c'est en faveur de Han que se produisit l'intervention de Ts' $i$ (cf. chap. LXV).

44.(193) Suen Pin : Cf. chap. LXV.

44.(194) Cf. tome II, n. 07.335. Wai-hoang se trouvait dans le pays de Song.

44.(195) Tchan kouo ts'e : section de Song; chap. XXXII, p. 2, $\mathrm{r}^{\circ}$ et v'.

44.(196) Kiu est aujourd'hui la préf. sec. de ce nom (préf. de I-tcheou, prov. de Chan-tong). Cette ville était à l'extrême sud-est de l'État de $T s^{\prime} i$; pour un envahisseur venu de l'ouest, annexer Kiu c'était donc avoir conquis le pays de $T s$ ' $i$ tout entier.

44.(197) Si l'héritier présomptif est vaincu, il ne sera jamais roi de Wei. Ce sens est confirmé par la dernière phrase de ce texte dans le Tch'an houo t'se :

« Il combattit contre les gens de $T s$ ' $i$ et il trouva la mort : en définitive il n'obtint pas (de régner sur) Wei.

44.(198) C'est-à-dire ceux qui désirent la bataille dans l'espoir d'y acquérir quelque gloire et, par suite, quelque profit. Le Tchan kouo ts'e :

«Ceux qui ont avantage à ce que vous livriez bataille et qui désirent satisfaire leur ambition sont légion ».

44.(199) D'après Siu Koang, dont l'avis est suivi par les commentateurs du T'ong kien kang mou et du Tong kien tsi lan, Ma-ling était au S.-E. de la s.-p. de Yuen-tch'eng (préf. de Ta-ming, prov. de Tche-li). Tchang Cheou-tsie a longuement critiqué cette opinion, et, d'après lui, Ma-ling était à 60 li au N.-E. de l'ancienne sous-préfecture de Kiuen-tch'eng, laquelle se trouvait à $20 l i$ à l'E. de la préf. sec. de P'ou (préf. de Ts 'ao-tcheou, prov. de Chan-tong).

44.(200) Les progrès de $T s^{\prime}$ 'in du côté de l'Orient avaient rendu Ngan-i intenable comme capitale; le roi Hoei se transporta donc à Ta-leang ( $K^{\prime}$ ai-fong fou). Le Tchou chou ki nien attribue ce transfert de capitale à la $4^{\mathrm{e}}$ année du roi Hien (365 av. J.-C,), en été, le $4^{\mathrm{e}}$ mois, le jour kia-yn (Legge, C. C., vol. III, proleg., p. 171).

44. (201) Comme l'indique $P$ 'ei $Y n$, il y avait, à l'époque des Han, une sous-préfecture de $P^{\prime}$ 'ing-ngo qui dépendait de la commanderie de $P$ 'ei; mais cette ville, qui se trouvait à $60 l i$ au S. de la s.-p. de Hoai-yuen (préf. de Fong-yang, prov. de Ngan-hoei), me paraît trop éloignée de l'État de Wei pour être la localité dont il est ici question.

44.(202) Sur ces trois personnages, dont le dernier n'est autre que le célèbre philosophe Mencius, voyez le chap. LXXIV des Mém. hist. 
44.(203) Mencius, I, a, 1.

44.(204) Le texte de Mencius est notamment abrégé et modifié par Se-ma Ts 'ien.

44.(205) On remarque ici une des divergences les plus notables entre la chronologie du Tchou chou ki nien et celle de Se-ma Ts'ien. D'après Se-ma Ts'ien, le roi Hoei règne 36 ans, de 370 à 335 ; il a pour successeur le roi Siang 334-319; puis vient le roi Ngai (318-296). D'après le Tchou chou ki nien, le roi Hoei-tch'eng, après avoir régné 36 ans de 370 à 335, commença un nouveau compte des années de son règne et mourut en 319 ; c'est donc un seul souverain qui fut sur le trône de 370 à 319 ; il eut pour successeur « le roi actuel », c'est-à-dire le roi à la mort duquel le Tchou chou ki nien s'interrompt, car cet ouvrage historique fut déposé dans la tombe de ce souverain où on le retrouva ; or le Tchou chou ki nien prend fin à l'année 299 ; c'est donc en cette année que serait mort « le roi actuel », c'est-à-dire le roi qui correspond au roi Ngai de Se-ma Ts'ien. Voyez l'appendice placé à la fin du présent volume.

44.(르) Cf. tome IV, n. 33.245.

44. (207) Ainsi le roi Hoei n'avait jamais pris de son vivant le titre de roi ; c'est après sa mort que son fils le lui conféra.

44.(208) D'après les Tableaux chronologiques, la bataille de Tiao-yn eut lieu en l'année 333 ; les Annales principales des Ts'in (t. II, p. 69) rapportent la défaite du général Long Kou à l'année 331. Quoi qu'il en soit, ce qui est certain, c'est que ce combat fut la cause qui fit tomber, en l'année 330, le territoire de Ho-si entre les mains de Ts'in.

44.(209) Tiao-yn était à 30 li au N. de la préf. sec. de Fou (prov. de Chàn-si). On voit que cette localité se trouvait à la limite entre le pays de $T$ 'sin et le territoire de Ho-si.

44.(210) Tsiao était dans le voisinage immédiat de la préfecture secondaire de Chàn (province de Ho-nan) ; cf. t. I, p. 238, n. 8 et tome II, n. 05.348. - K'iu-ou était à 300 li au S.-E. de cette même préfecture secondaire de Chàn. Il ne faut pas confondre cette localité avec la ville de même nom qui fut la capitale de $T \sin$ (cf. tome IV, n. 32.215).

44.(211) Le Ho-si est le territoire compris entre le Hoang-ho et la rivière Lo du Chàn-si.

44.(212) Cf. tome II, n. 05.347.

44.(리) Cf. tome II, n. 05.345 .

44.(214) Cf. tome II, n. 05.346.

44.(리) Cf. n. 210.

44.(르) Cf. tome IV, n. 40.304.

44.(217) Cf. tome II, n. 05.349.

44.(218) P'ou-yang, qui fut sous les Han la sous-préfecture de P'ou-fan, correspond à la préfecture de $P$ 'ou-tcheou (prov. de Chan-si). — La rédaction des Mémoires historiques est ici peu claire: en réalité, le roi de $T s$ 'in avait commencé par s'emparer de la ville de P'ou-yang; puis, sur le conseil de Tchang $I$, il la rendit à $W e i$ : le roi de Wei, à son tour, cédant aux suggestions de Tchang $I$, reconnut la générosité de $T s$ 'in en lui livrant la commanderie de Chang, qui était au nord du Ho-si. Par l'abandon du Ho-si en 330, et par celui de la commanderie de Chang en 328, Wei abandonna à $T s$ 'in toutes ses possessions de la rive droite du Hoang ho.

44.(219) Cf. n. 210.

44.(220) Cf. tome IV, n. 40.305.

44.(221) C'est-à-dire les principaux ministres, et non les seigneurs eux-mêmes.

44.(222) Cf. tome II, n. 05.357 . 
44.(223) Cf. n. 210, à la fin.

44.(224) Cette localité était sur le territoire de la s.-p. de Kie-hieou (préf. de Fen-tcheou, prov. de Chan-si).

44.(225) Tch'ou, Tchao, Wei, Han, Yen.

44.(226) A 25 li au S.-E. de la s.-p. de Tsao-k'iang, préf. sec. de Ki, prov. de Tche-li.

44.(227) Cf. n. 210, à la fin.

44.(228) Kong-suen Yen, général de Wei. Cf. t. II, p. 68, n. 1,

44.(2) $)$ Cf. tome II, n. 05.368.

44.(230) Cf. tome II, n. 05.372 .

44.(231) Les Tableaux chronologiques ajoutent: Il fit prisonnier Cheng-tse à P'ou.

44.(232) En 311, dit le Tchou chou ki nien, Ti Tchang attaqua Wei.

44. (233) Jou Eul était un grand officier du pays de Wei, dit Tchang Cheou-tsie; mais le Tchan kouo ts'e (voyez plus loin, année 266) le considère comme un ministre du prince de Han ; lorsqu'il vit que le prince de Wei était en danger, il vint lui proposer de le sauver en jetant la discorde entre le prince de Wei et son conseiller, le prince de Tch'eng-ling.

44.(234) Le texte me paraît être altéré et je crois qu'il faut lire $T s$ 'in au lieu de Wei. Cependant le chapitre concernant le royaume de Tchao ne rapporte qu'à l'année 270 le siège de la ville de Yen-yu par Ts'in (cf. p. 109); or le discours que nous traduisons en ce moment est censé être de l'année 311 ; il serait donc antérieur à cet événement et ne pourrait en parler comme d'un fait passé.

44.(235) Cf. $\underline{\text { n. } 43.455 .}$.

44.(236) Cf. n. 43.488.

44.(237) Si la correction de texte que nous avons proposée plus haut (n. 234) est admise, la suite des idées est celle-ci : précédemment, lorsque $T s$ 'in menaçait Tchao d'une destruction imminente, $W e i$, qui était le chef de la ligue du nord au sud, intervint en sa faveur ; maintenant $W e i$ doit éviter que $T s$ 'in ne secoure $W e i[\mathrm{~b}]$ et ne lui rende le même service que $W e i$ rendit jadis à Tchao; Wei ne doit donc pas mettre Wei [b] en péril, car ce serait assurer à $T$ s'in un nouvel allié.

44.(238) En d'autres termes, au dire de Jou Eul, le prince de Wei [b] estime que le roi de $\mathrm{Wei}$ n'est pas le maître dans son royaume, que l'autorité réelle est exercée par quelque haut dignitaire de la cour et que c'est ce personnage qu'il faut gagner par des présents. Pour savoir qui est ce ministre, traître à son pays, le roi de Wei n'aura qu'à observer qui est celui qui, le premier lui conseillera de délivrer $\mathrm{Wei}[\mathrm{b}]$; Jou Eul assurait ainsi la perte du prince de Tch'eng-ling qu'il avait auparavant décidé à intervenir en faveur de Wei [b].

44.(239) Cf. tome II, n. 05.372.

44.(240) Kong-suen Yen. - Sur Tchang I et Kong-suen Yen, cf. Mém. hist., chap. LXX, et Mencius, III, b, 2.

44.(241) Le gouverneur de Sie s'appelait T'ien Wen. Il était aussi surnommé «prince de Mong-tch'ang ».

44.(242) Tchan kouo ts'e : section de Wei; chap. XXIII, p. 4, $\mathrm{r}^{\circ}$ et v ${ }^{\circ}$.

44.(243) Sou Tai était le frère cadet, ou, suivant une autre tradition, le frère aîné, de Sou Ts 'in. Cf. Mém. hist., chap. LXIX. 
44.(244) Cet héritier présomptif fut plus tard le roi Tchao; Se-ma Tcheng se trompe en disant que ce fut le roi Siang.

44.(245) C'est-à-dire dans le pays de Wei.

44.(246) C'est-à-dire le roi de Wei.

44.(247) Cf. tome II, n. 05.347.

44.(248) Cf. tome II, n. 05.346.

44.(249) A la mort du roi $O u$, de $T s^{\prime} i n$, survenue en 307, son épouse principale, qui était une fille de la maison princière de $W e i$, n'avait pas d'enfants ; le pouvoir fut donc donné au frère du roi $O u$; deux ans plus tard, des troubles éclatèrent et la reine, femme du roi $O u$, fut obligée de se réfugier dans son pays natal (cf. t. II, p. 76-77).

44.(250) P'ou-fan est aujourd'hui la ville préfectorale de Fou-tcheou, dans la province de Chan-si, cf. p. 160, n. 8.

44.(251) Au lieu de Yang-tsin, il faut lire Tsin-yang comme dans les Tableaux chronologiques. Le Kouo ti tche place Tsin-yang à $35 l i$ à l'O. de la s.-p. de Yu-Hiang (préf. de P'ou-tcheou, prov. de Chan-si). - Il ne faut pas confondre cette ville avec Yang-tsin, qui était une ville de $W e i$, et qui se trouvait à 37 li au N.-O. de l'ancienne s.-p. de Tch'eng-che (laquelle était au S.-O. de la s.-p. actuelle de Kiu-ye, préf. de Ts'ao-tcheou, prov. de Chan-tong).

44.(252) Fong-ling se trouvait aussi dans le voisinage de la préfecture de P'ou-tcheou.

44.(253) Cf. tome II, n. 05.372.

44.(254) Cf. n. 250.

44.(255) J'ai précédemment admis (tome II, n. 06.504), la transcription Hien-kou; mais elle ne me paraît pas suffisamment justifiée et j'adopterai dorénavant la transcription Han-kou. D'après le Ta Ts'ing i t'ong tche (chap. CLXXV, p. $5 \mathrm{r}^{\circ}$ ), la passe de Han-kou, à l'époque des $T s$ 'in, était à 12 li au S.-O. de la s.-p. de Ling-pao (préf. sec. de Chàn, prov. de Ho-nan). Ts'oei Hao (ibid., chap. CLXXV, p. $1 \mathrm{v}^{\circ}$ ) est peut-être plus exact quand il dit que Han-kou était le nom général des parages montagneux et difficiles qui s'étendent depuis les collines Hiao à l'Est, jusqu'au gué de T'ong à l'Ouest; les collines Hiao sont à 50 ou $60 \mathrm{li}$ au N. de la s.-p. de Yong-ning (prov. de Ho-nan); quant à la passe T'ong, elle est le défilé qui se trouve au point où le Hoang ho, venant du nord, heurte les contreforts du Hoa chan et change brusquement de direction pour couler vers l'Est. Dans le texte que nous expliquons actuellement, les Tableaux chronologiques ajoutent que, après le combat qui se livra à Hanhou, « le Ho et le Wei eurent leur cours interrompu pendant un jour », sans doute à cause de la masse de cadavres qu'ils charriaient ; cette mention donne à supposer que la bataille de Hankou eut lieu à l'extrémité occidentale de la passe T'ong, près du confluent de la rivière Wei et du Hoang ho; ainsi se trouve confirmée l'opinion de Ts'oei Hao qui attribue un sens géographique assez large à l'expression " passe de Han-kou ». - Il est à remarquer enfin que, actuellement, le nom de "passe de Han-kou » est appliqué par les cartographes chinois à un défilé qui se trouve au N. de la s.-p. de Sin-ngan (préf. et prov. de Ho-nan), c'est-à-dire notablement plus à l'Orient.

44.(256) Le Ho-wai était un territoire au sud du Hoang-ho (cf. tome II, n. 05.509); mais c'est par erreur qu'il est mentionné ici ; les annales principales des $T s$ 'in (t. II, p. 81) nous fournissent la leçon correcte qui est Ho-pei; Ts'in restitua à Wei les villes de P'ou-fan et Tsin-yang situées au nord du Fleuve (Ho-pei), qu'il lui avait prises en l'année 303 (cf. p. 166, dernière ligne).

44.(257) Cf. n. 252.

44.(258) Il est à remarquer que le Tchou chou ki nien, qui fut déposé dans la tombe d'un roi, qui correspond au roi Ngai de Se-ma Ts'ien, se termine à la vingtième année de ce roi (299), 
d'où on peut conclure que le roi Ngai (en réalité, le roi Siang; cf. l'Appendice) régna vingt ans, et non vingt-trois, comme le dit Se-ma Ts'ien. D'après Se-ma Tcheng il aurait en effet régné vingt ans, mais son successeur aurait observé avec une rigueur toute particulière le deuil de trois ans, et n'aurait daté la première année de son règne qu'en l'année 295.

44.(259) Cf. tome II, n. 07.136.

44.(260) I-k'iue, communément appelé Long-men, est un défilé dans lequel coule la rivière $I$; il est à une trentaine de $l i$ au sud de la ville préfectorale de Ho-nan (cf. mon étude sur «le Défilé de Long-men », Journal Asiatique, juillet-août 1902, p. 133-158).

44.(261) Ce territoire était toute la partie du royaume de Wei qui était située au nord du Hoang ho ; il comprenait son ancienne capitale, Ngan-i, et la ville de P'ou-fan (cf. T'ong kien tsi lan, année 290).

44.(262) Mang Mao était un général de Wei (cf. t. II, p. 88).

44.(263) Kiu-yang était à $10 l i$ à l'O. de la s.-p. de Tsi-yuen Osa (préf. de Hoai-k'ing, prov. de Ho-nan). - Sin-yuen devait être dans le voisinage de Kiu-yang, mais on n'en connaît pas l'emplacement exact.

44.(264) Auj., s.-p. de Wen (préf. de Hoai-k’ing, prov. de Ho-nan).

44.(265) Cf. t. IV, p. 145. — Lin-tse était la capitale de $T s^{\prime} i$.

44.(266) Les rois de $T s^{\prime}$ in, Wei et Han eurent une entrevue dans la capitale, c'est-à-dire Lo-yang, et, disent le T'ong kien kang mou et le T'ong kien tsi lan, ils ne rendirent pas hommage au roi des Tcheou occidentaux.

44.(267) D'après le Kouo ti tche, Nan-tch'eng était à 17 li au S.-E, de l'ancienne sous-préf. de Jou-yang, laquelle se trouvait au N.-O. de la s.-p. actuelle de Chang-choei (préf. de Tch'entcheou, prov. de Ho-nan).

44.(268) K'ai-fong fou, capitale de Wei.

44.(269) Capitale de Tch'ou; cf. t. IV, n. 40.102.

44.(270) Les Tableaux chronologiques ajoutent ici : "On conféra au kong tse Ou-ki, frère cadet (du roi Ngan-hi), le titre de «prince de Sin-ling ».

44.(271) Cf. n. 264.

44.(272) Le Tchan kouo ts'e appelle ce personnage Toan-kan Tch'ong.

44.(273) Cf. t. II, n. 05.460.

44.(274) Au lieu de Sou Tai, le Tchan kouo ts'e écrit Suen-tch'en.

44.(275) Tchan kouo ts'e : section de Wei; chap. XXIV, p. 3 r'.

44.(276) Le Tchan kouo ts'e ouvre ce discours par le préambule suivant :

«Wei n'ayant pas, à la suite de sa défaite, détaché (une portion de son territoire pour la donner à $T s^{\prime}$ in) on pouvait dire de lui qu'il avait bien usé de sa non-victoire; d'autre part $T s^{\prime}$ in n'ayant pas, à la suite de sa victoire, arraché (à Wei une partie de son territoire), on pouvait dire de lui qu'il n'avait pas su profiter de sa victoire. Maintenant, au bout d'un an révolu, si vous désirez détacher une portion de votre territoire (pour la livrer à $T s^{\prime} i n$ ), c'est parce que vos officiers y trouvent leur intérêt privé, et que vous, ô roi, ne le savez pas.

En effet, l'orateur montre au roi que les négociations à ce sujet sont conduites entre Toan-kan Tch'ong et le roi de $T s^{\prime}$ in ; or Toan-kan Tch'ong espère recevoir du roi de $T s^{\prime}$ 'in un sceau, c'est-à-dire un apanage nobiliaire, et, par conséquent, il sera désireux de satisfaire le roi de $T s^{\prime}$ in en lui livrant une portion du territoire de $\mathrm{Wei}$. 
44.(277) Tchan kouo ts'e :

«Celui qui désire un sceau, c'est Toan-kan tse; or c'est précisément lui que Votre Majesté charge de détacher un territoire (pour le livrer à $T s^{\prime}$ in); celui qui désire un territoire, c'est $T s$ 'in, or Votre Majesté fait en sorte que ce soit lui qui ait à donner le sceau.

44. (278) C'est-à-dire que, si Wei livre une portion de son territoire à $T s$ 'in, les exigences de $T s$ 'in ne feront qu'augmenter, et ne cesseront pas aussi longtemps que Wei conservera encore quelque partie de son territoire. - Au lieu de cette phrase, le Tchan houo ts' $e$ écrit :

« Dans ces conditions, la destruction totale de Wei est assurée.

Il commence le développement suivant par la phrase :

« Des sujets pervers sont tous fermement désireux de rendre service à $T s^{\prime}$ in en lui offrant un territoire. Or, rendre service à $T s$ 'in en lui offrant un territoire, c'est comme... »

44. (279) [] signifie «apporter du secours en cas d'incendie». Si, sous le prétexte d'apporter du secours en cas d'incendie, on prend une brassée de bois mort, on ne fait qu'alimenter le feu, au lieu de l'éteindre.

44.(280) Tchan kouo ts'e :

«... le feu ne s'arrêtera pas; maintenant le territoire de Votre Majesté n'est pas inépuisable et les exigences de $T s$ 'in seront sans limites ; on peut leur appliquer ce qu'on dit du bois mort et du feu. »

44.(281) Le jeu dont il est ici question est le jeu des tablettes. Ces tablettes étaient au nombre de cinq et portaient les noms suivants : hiao (le hiao est une espèce de hibou qui, dit-on, mange sa mère), lou réchaud, tche faisan, tou veau, sai barrière (cf. commentaire du T'ong kien kang mou, année 273 av. J.-C.). Le joueur qui obtenait la tablette hiao, avait le droit, soit de manger, c'est-à-dire d'avancer sur l'échiquier, commentaire du Tchan kouo ts'e, édition de 1581), soit de rester stationnaire.

44.(282) Comme le joueur qui a la pièce hiao, le roi a le droit de choisir entre deux conduites : ou agir, ou s'abstenir.

44.(283) Cf. tome II, n. 05.468 .

44.(284) Le nom de cette ville est écrit Hing-k'ieou dans les Annales principales des Ts'in ; cf. tome II, n. 05.468 .

44.(285) Tchan kouo ts'e : section de $T s^{\prime}$ in ; chap. VI, p. $1 \mathrm{v}^{\circ} .-2 \mathrm{r}^{\circ}$.

44.(286) On retrouve ce texte, non seulement dans le Tchan kouo ts'e, mais encore dans le Chouo yuan de Lieou Hiang (chap. X, p. 9 v $^{\circ}-10$ r $^{\circ}$ ), et, d'après Se-ma Tcheng, dans Han Feitse et dans le Tch'oen ts'ieou heou yu publié sous les Tsin par K'ong Yen.

44.(287) Jou Eul était un ministre du roi de Han.

44.(288) Wei Ts'i était au service du roi de Wei.

44.(289) Sur T'ien Wen, prince de Mong-tch'ang, cf. chap. LXXV.

44.(290) Mang Mao est un général de Wei que nous avons déjà vu cité à différentes reprises ; cf. n. 262, et p. 171, ligne 2 .

44.(291) Allusion au siège de Tsin-yang en 454 av. J.-C. ; cf. p. 48-49.

44.(292) Cf. n. 43.227.

44.(293) Cf. $\underline{\text { n. } 43.228 .}$.

44.(294) Ngan-i était la ville de Wei Hoan-tse et fut plus tard la capitale de l'État de Wei; cf. n. 101. 
44.(295) Il ne peut être question ici de la rivière actuellement appelée rivière Kiang, qui prend sa source dans la montagne Kiang, sur le territoire de la préfecture de Kiang, et se jette dans la rivière Koai, affluent elle-même de la rivière Fen. - Quoique les commentateurs chinois ne donnent aucun éclaircissement sur ce passage, il est évident, d'autre part, que la rivière $F e n$ ne pouvait pas servir à inonder Ngan-i qui était beaucoup trop au sud; mais elle passait tout près de $P$ 'ing-yang et c'est pourquoi je pense qu'il faut corriger le texte et dire : « La rivière Fen peut servir à inonder P'ing-yang. " Cette correction doit en entraîner une autre et il faut admettre la phrase : «La rivière Kiang peut servir à inonder Ngan-i ». Mais la rivière Kiang actuelle ne peut pas plus inonder Ngan-i qui est trop au sud, que P'ing-yang qui est trop au nord. Il faut donc admettre que, sous le nom de rivière Kiang, le texte que nous étudions ici désigne la rivière $S o u$ qui prend sa source sur le territoire de la préfecture secondaire de Kiang et passe au nord de Ngan-i.

44.(296) $P$ 'ing-yang était la ville où résidait Han $K$ 'ang-tse.

44.(297) Se sentant menacés par les paroles de Tche-po, Han et Wei conviennent tacitement de s'allier contre lui. Cf. $\underline{\text { n. } 43.232}$.

44.(298) En d'autres termes, il avertit le roi de $T s$ 'in de prendre garde, car, en ce moment même, Han et Wei s'entendent sûrement pour s'unir contre lui.

44.(299) Tchan kouo ts'e : section de Wei; chap. XXV, p. 4 r ${ }^{\circ}$.

44. (300) Nous avons ici une phrase qui revient souvent dans le style historique et qu'il est assez malaisé de traduire en français; elle signifie que les envoyés se succédaient à de si courts intervalles que, sur la route, chacun d'eux pouvait voir de loin le bonnet officiel et le dais de celui qui l'avait précédé.

44.(301) T'ang Soei s'engage à ne pas quitter le pays de $T s$ 'in avant que les soldats de $T s$ 'in eux-mêmes soient sortis pour venir au secours de Wei.

44.(302) Le même sens du mot [] se retrouve dans Mencius, II a, II, 16.

44.(303) Il n'était donc pas nécessaire qu'un vieillard comme Tang Soei fit ce long voyage.

44.(304) C'est-à-dire s'il est comme son vassal prêt à défendre la frontière orientale de Ts 'in.

44. $(\underline{305})$ Cette phrase me paraît signifier que le roi de Wei reçoit l'investiture du roi de $T s$ 'in.

44.(르) Il n'est pas en danger pressant, et c'est pourquoi il demande du secours; si en effet, le péril était extrême il signerait la paix à tout prix avec ceux qui l'attaquent, et, dès lors, il n'aurait que faire de l'appui de $T s$ 'in.

44. (307) Il céderait à $T s^{\prime} i$ et à $T c h$ 'ou une partie de son territoire pour conclure la paix avec eux.

44.(요) La ligue tsong, ou ligue du Nord au Sud, était dirigée contre Ts 'in.

44.(309) Tchan kouo ts'e : section de Wei.

Ce paragraphe se retrouve, avec des modifications importantes, dans l'édition de $1581 \mathrm{du}$ Tchan kouo ts'e (chap. VII, p. $57 \mathrm{r}^{\circ}-58 \mathrm{r}^{\circ}$ ); mais je n'en ai pas découvert trace dans la réimpression lithographique (Chang-hai, 1896) de l'édition de Ts'ien Ta-hin.

44. (310) Ce détail manque dans le Tchan kouo ts'e. - Si l'on s'en tient au texte de Se-ma Ts'ien, Fan Ts'o, menacé par les soldats envoyés à sa recherche, monte sur le toit de sa maison et menace de se jeter en bas et par conséquent de se tuer, si on cherche à le prendre ; en même temps il prouve à ses agresseurs que le roi de Wei aurait intérêt à le laisser vivre jusqu'à ce que Tchao lui ait livré le territoire promis; en effet, une fois que Fan Ts'o sera mort, le roi de Tchao, qui aura obtenu ce qu'il désirait, pourra impunément violer son engagement et le roi de Wei deviendra, comme le dit le Tchan kouo ts'e, la risée de l'empire. 
44.(311) Le prince de Sin-ling, Ou-ki, kong-tse de Wei (cf. Mém. hist., chap. LXXVII), avait succédé à Fan Ts'o dans le poste de conseiller du roi de Wei.

44.(312) Le texte du Tchan kouo ts'e est ici plus explicite : Fan Ts'o montre que c'est parce qu'il a été autrefois conseiller de Wei et parée qu'il a lutté à ce titre contre Tchao, que le roi de Tchao lui a voué une haine mortelle. Or maintenant, le prince de Sin-ling, conseiller de Wei, dirige les hostilités contre $T s$ 'in ; ne le sacrifiera-t-on pas lui aussi si, plus tard, $T s$ 'in s'avise d'imiter Tchao et de demander la tête du prince de Sin-ling au prix d'un territoire?

44.(1ㅗ) Tchan kouo ts'e : section de Wei; chap. XXVI, p. 4 r'.

44.(314) Ou-ki n'est autre que le prince de Sin-ling, conseiller de Wei. — L'édition de 1581 du Tchan kouo ts'e donne, comme Se-ma Ts'ien, la leçon Ou-ki; la réimpression de Chang-hai (1896) écrit Tchou Se.

44.(리) Le roi Tchao-siang.

44.(1ㅡ) La reine-douairière Siuen, mère du roi Tchao-siang.

44.(317) Wei Jan, marquis de Jang et prince de Hoa-yang, était le frère cadet de la reine-douairière Siuen.

44. (318) Le prince de King-yang et le prince de Kao-ling étaient tous deux frères cadets du roi Tchao-siang et fils de la reine-douairière Siuen. — Les événements auxquels il est fait ici allusion se passèrent en 265 ; cf. t. II, p. 90, et Mém. hist., chap. LXXIX.

44.(319) Le royaume de Han avait alors à sa tête le roi Hoan-hoei (272-239), mais le che kia de Han (chap. XLV) ne nous apprend point que ce souverain fût monté jeune sur le trône, ni que sa mère eût exercé la régence.

44.(320) Tcheng (auj. s.-p. de Sin-tcheng, préf. de K'ai-fong, prov. de Ho-nan) était, depuis 375 , la capitale du royaume de Han ; cette ville était fort proche de Ta-leang ( $K^{\prime}$ ai-fong fou), capitale de $\mathrm{Wei}$.

44. (321) Dans le texte du Tchan kouo ts'e, il faut attribuer au mot [] le sens de «mettre un fardeau sur son dos »; on traduira alors de la manière suivante :

« Vous désirez recouvrer votre ancien territoire, mais si vous vous mettez sur le dos le fléau du puissant $T s^{\prime}$ in, pensez-vous, ô roi, que ce sera avantageux pour vous?

44.(322) En 270, Ts'in, après avoir vaincu Han, avait assiégé la ville de Yen-yu, qui appartenait à Tchao ; mais il fut vaincu par Tchao Cho, général de Tchao. Cf. p. 109-110.

44. $(\underline{323}) Y e$ (préf. de Tchang-té ) et Tchao-ko (s.-p. de Ki), toutes deux dans la partie de la province de Ho-nan située au nord du Hoang ho, étaient deux villes de l'État de Tchao.

44.(2ㄴ) Cf. tome I, p. 106, n. 02.126, et ‥ 43.329.

44.(르) Capitale de Tchao.

44.(326) Tche po causa sa perte en assiégeant en 454 la ville de Tsin-yang où s'était enfermé Tchao Siang-tse.

44. (327) Les «gorges montagneuses » sont celles du massif des monts Ts'in-ling; voyez la note suivante.

44.(328) D'après Tchang Cheou-tsie, le caractère [] doit se prononcer ici comme le caractère [], c'est-à-dire meng. La passe Meng-ngo est citée dans le Tch'oen ts'ieou de Lu Pou-Wei au nombre des neuf barrières célèbres de l'empire (cf. tome II, n. 05.222). D'après le Kouo ti tche (chap. VII p. $11 \mathrm{r}^{\circ}$ ), elle se trouvait dans la montagne Che-tch'eng, à $21 \mathrm{li}$ au S.-E. de l'arrondissement de Chen (lequel se trouvait à $40 l i$ au S. de la s.-p. actuelle de Sin-yang, préf. de Jou-ning, prov. de Ho-nan). Le commentaire de Li Tao-yuen au Choei king dit, de son 
côté, qu'on montrait la passe Meng-ngo dans la s.-p. de Meng (à 9 li au S.-O. de la s.-p. de Lo-chan, préf. de Jou-ning, prov. de Ho-nan). Ces deux indications, quoique légèrement différentes, s'accordent cependant à placer la passe Meng-ngo dans la chaîne des monts Hoaiyang qui séparent le bassin de la rivière Hoai de celui du Yang-tse, et qui forment la limite entre la province de Ho-nan et celle de Hou-pei.

- Maintenant, comment se rendait-on de Hien-yang (au nord de Si-ngan fou), capitale des $T s$ 'in, jusqu'à la passe Meng-ngo ? L'hypothèse qui paraît d'abord la plus vraisemblable est qu'on suivait la route dite orientale qui longeait la rive droite du Hoang ho (ce qu'on appelait alors le territoire de Ho-Wai) jusqu'à Ho-nan fou, puis jusqu'à Tcheng tcheou, tournait alors vers le Sud pour passer à Hiu tcheou, puis à Sin-yang tcheou, traversait les monts Hoai-yang à la passe $\mathrm{Ou}$-cheng (qui doit donc être pratiquement identique à la passe Meng-ngo), et aboutit à Han k'eou.

- Cependant le commentateur Lieou Po-tchoang, cité par Tchang Cheou-tsie croit qu'il s'agit ici, non de la route orientale, mais de la route occidentale, et il justifie son opinion par la présence dans le texte de Se-ma Ts'ien, des mots «si on passe par les gorges montagneuses qu'on traverse »; d'ailleurs il ne sera question que plus loin de la route du Ho-wai, c'est-à-dire de la route orientale. C'est donc bien à la route occidentale qu'il est fait ici allusion ; mais, comme cette route n'aboutissait pas à la passe Meng-ngo, il est probable que le nom de ce défilé n'est introduit que par une faute du texte; en effet, le Tchan kouo ts'e, au lieu de [] écrit [], ce qui substitue au terme « la passe Meng-ngo » l'expression vague « des défilés étroits et périlleux ».

Quoi qu'il en soit, nous allons chercher à déterminer exactement le tracé de la route dite occidentale, qui a joué un rôle important dans l'histoire de Chine : actuellement, pour aller de Si-ngan fou dans le sud du Chàn-si, on a le choix entre deux routes principales (voyez la carte de la Chine orientale au 1: 1.000.000 publiée par la «Kartographische Abtheilung der Königl. Preuss. Landes-Aufnahme ») : la première va au S.-O. de Si-ngan fou jusqu'à la sous-préfecture de Tcheou-tche; de là, elle tourne droit au Sud pour s'engager dans le massif des monts Ts'in-ling; elle passe à Hei-choei yu k'eou, traverse la ligne de partage des eaux entre le bassin du Wei et celui du Han, et débouche sur le t'ing de Fou-p'ing; de là, elle oblique vers l'O., et, à la passe $O u$, elle est rejointe par la seconde route. Cette seconde route va à l'ouest de Si-ngan fou et passe par Fong-siang fou et la sous-préfecture de Pao-ki; à partir de là, elle se dirige vers le sud pour franchir les $T s$ 'in-ling; ce chemin a été décrit en détail par Richthofen (China, vol. I, p. 563 et suiv.). Après la passe $O u$, la route reste unique jusqu'au relais de Hoang-cha (à l'O. de la s.-p. de Pao-tch'eng) où elle se divise en deux branches, dont l'une se dirige vers le Se-tch'oan, et l'autre vers le Hou-pei. — Il résulte des indications données par Lieou Po-tchoang, et de celles qu'on peut relever dans les Mémoires historique eux-mêmes (cf. tome III, n. 29.136) que la route dite occidentale, dans l'antiquité, ne coïncidait exactement ni avec celle dont la tête de ligne est à Tcheou-tche, ni avec celle dont le point de départ est $\mathrm{Pao}-k i$; sans doute, elle devait, comme ces deux voies, aboutir à la passe $O u$; mais pour y parvenir, elle suivait une ligne intermédiaire ; son origine était près de la s.-p. de Mei (préf. de Fong-siang, prov. de Chàn-si) ; elle remontait la rivière Ye, traversait les $T s$ 'in ling, et descendait le long de la rivière $P a o$, arrivant ainsi à la passe $O u$, puis à la s.-p. de Pao-tch'eng.

44.(329) La route orientale passait sur la rive droite du Hoang ho par les défilés appelés « passe Han-kou » (cf. n. 255).

44.(330) A partir de Tcheng tcheou, la route, qui se dirigeait jusque là vers Ta-leang (K'aifong fou), obliquait brusquement vers le Sud; on peut donc dire qu'elle tournait le dos à Ta-leang.

44.(331) Ts'ai était à $10 l i$ au S.-O. de la s.-p. actuelle de Chang-ts'ai (préf. de Jou-ning, prov. de Ho-nan) ; Chao-ling était à 45 li à l'E. de la s.-p. actuelle de Yen-tcheng (préf. sec. de Hiu, prov. de Ho-nan). Le voyageur qui se rend de la préfecture secondaire de Tcheng à la 
préfecture de Tch'en-tcheou, laisse à sa droite ces deux anciennes localités de $T s$ 'ai et de Chao-ling ; c'est donc par erreur que Se-ma Ts'ien écrit « laisser Ts'ai à sa droite et Chao-ling à sa gauche »; il faut revenir à la leçon de Tchan kouo ts'e qui est : "laisser à sa droite Chang-ts'ai et Chao-ling »

44.(332) Tch'en (auj. ville préfectorale de Tch'en-tcheou) était, depuis l'année 278 av. J.-C., la capitale du royaume de Tch'ou (cf. tome IV, n. 40.413).

44.(333) Par le fait de la victoire supposée qui lui aurait livré le royaume de Han.

44.(334) Hoai était à $11 l i$ à l'O. de la s.-p. de Ou-cho (préf. de Hoai-k'ing, prov. de Ho-nan); cf. Kouo ti tche, chap. III, p. $17 \mathrm{r}^{\circ}$.

44.(335) Mao qui est la ville de Ts'oan-mao « de l'époque tch'oen-ts'ieou, correspond au village actuel de Ta-lou à 20 li au N. de la s.-p. de Sieou-ou » (préf. de Hoai-k'ing, prov. de Ho-nan) ; cf. H. T. K. K., chap. CCLII, p. $10 \mathrm{r}^{\circ}$, et Tso-tchoan, $11^{\mathrm{e}}$ année du duc Hi, où les places de Hoai et de Ts'oan-mao sont mentionnées dans l'énumération des douze villes appartenant à Sou Fen-cheng.

44.(336) D'après le Kouo ti tche, chap. III, p. 16 ro, Hing-k'ieou est identique à l'ancienne ville de $P$ 'ing-kao ; or $P$ 'ing-kao qui fut une sous-préfecture à l'époque des Han et des Wei, se trouvait à 20 li à l'E. de la s.-p. de Wen (préf. de Hoai-k'ing, prov. de Ho-nan).

44.(337) Au lieu de Koei-tsin, Tchang Cheou-tsie propose de lire Yen-tsin; la ville de Yen-tsin était, d'après le Kouo ti tche (chap. IV, p. $3 \mathrm{v}^{\circ}$ ), à 26 li au S.-O. de la s.-p. de Ts'ing-k'i (auj. s.-p. de $K^{\prime} i$, préf. de Wei-hoei, prov. de Ho-nan). — Le texte du Tchan kouo ts'e qui rattache le mot [], par le moyen de la particule [], au nom des villes de Hoai, Mao et Hing-k'ieou, me paraît inintelligible, car on ne sait alors de quoi dépend le terme «Koei-tsin ».

44.(338) Kong est aujourd'hui la s.-p. de Hoei, qui dépend de la préf. de Wei-hoei, et Ki est la s.-p. de ce nom qui fait partie intégrante de la ville préfectorale de Wei-hoei.

44.(339) Toujours dans l'hypothèse que $T s$ 'in s'est annexé le royaume de Han dont la capitale était la ville de Tcheng.

44.(누) Le Kouo ti tche (chap. VI, p. $15 \mathrm{v}^{\circ}$ ) place la ville de Yuen-yong à 7 li au N.-O. de la s.-p. de Yuen-ou (préf. de Hoa-k'ing, prov. de Ho-nan). La ville de Yuen-yong appartenait à l'État de Wei.

44.(341) Yong-tse est une sous-préfecture située à 140 li à l'O. de Kai-fong fou; c'est là, semble-t-il, qu'une dérivation du Hoang-ho s'unissait à la rivière Pien qui prenait dès lors le nom de Hong-keou (cf. t. III, p. 522). Le Hong-keou passait immédiatement au nord de $K$ 'aifong fou et c'est sans doute de l'eau de ce canal que se servit en 235 av. J.-C. le général de Ts 'in, Wang Pen, pour inonder Ta-leang, c'est-à-dire Kai-fong fou (cf. t. II, p. 121).

44. (342) L'envoyé du roi de Wei s'est rendu dans le pays de $T s$ 'in pour convenir que Wei et $T s$ 'in s'allieraient contre Han : c'est déjà là une première faute.

44. $(\underline{343})$ A sa première faute, l'envoyé du roi de $\mathrm{Wei}$ en a ajouté une seconde qui a été de mal parler (du prince) de Ngan-ling. D'après le commentateur Li K'i, cité par le Kouo ti tche (chap. VI, p. $5 \mathrm{v}^{\circ}$ ). la ville de Ngan-ling, à l'époque des six royaumes, est identique à l'ancienne ville de Yen-ling qui se trouvait à 15 li au N.-O. de la s.-p. actuelle de Yen-ling (préf. sec. de Hiu, prov. de Ho-nan).

44.(344) D'après le Kouo ti tche (chap. VI, p. $5 \mathrm{r}^{\circ}$ ), Che-yang est identique à la s.-p. de Che de l'époque des T'ang (à $30 l i$ au S. de la s.-p. actuelle de Che, préf. de Nan-yang, prov. de Honan). - Koen-yang était à $25 l i$ au N. de cette même s.-p. de Che.

44. (345) Au nom de Ou-yang, le Tchan kouo t'se ajoute celui de Kao-ling mais c'est sans doute par erreur. Le Kouo ti tche (chap. VI, p. 5 r ${ }^{\circ}$ ) place Ou-yang à 10 li à l'E. de la s.-p. de Che (voyez la note précédente). D'après le commentaire du Tchan kouo ts'e, Ou-yang 
appartenait au prince de Ngan-ling, et c'est parce que cette ville de Ou-yang était toute voisine de Che-yang et de Koen-yang, villes de $T s$ 'in, que $T s$ 'in haïssait le prince de Ngan-lin. - D'après Tchang Cheou-tsie, Ou-yang appartenait au royaume de Wei.

44.(년) Cf. la note précédente.

44.(347) D'après le Kouo ti tche (chap. VI, p. 4 v), l'ancienne ville de Hiu était à 30 li au S. de la s.-p. de Hiu-tch'ang (au N.-E. de la préf. sec. actuelle de Hiu, prov. de Ho-nan).

44.(348) Nan-kouo est une autre dénomination du territoire de Hiu (cf. la note précédente). La ville de Hiu appartenait au royaume de Han, et, comme elle se trouvait au sud du pays de Wei, on la désignait parfois sous le nom de Nan-kouo « le royaume méridional».

44. (349) Hiu étant menacé par Ts 'in, Ta-leang (Kai-fong fou) sera par là même en danger.

44. (350) Le Tchan kouo ts'e écrit « ne pas recevoir » ce qui signifie « de ne pas recevoir dans votre amitié »).

44.(351) En d'autres termes, les griefs que vous avez contre Han et le prince de Ngan-ling ne doivent pas vous engager à laisser l'animosité de $T s$ 'in s'exercer contre les territoires qui leur appartiennent.

44.(352) A l'époque des Tcheou, le Ho-si, ou territoire à l'ouest du Fleuve, désigne la préfecture de T'ong-tcheou, dans le sud-est du Chàn-si. Quand le pays de Ts'in se bornait à occuper le Ho-si, il n'avait point encore commencé à inquiéter ses voisins par ses empiètements.

44.(ㅌ3) La capitale de $T \sin$ était la ville de Kiang qui est aujourd'hui la préfecture secondaire de ce nom, dans le Chan-si.

44.(354) Leang n'est autre que Ta-leang, c'est-à-dire K'ai-fong fou.

44.(355) Se-ma Tcheng identifie Lin-hiang avec la localité de Fei-lin ou Fei (qui est mentionnée par le Tso tchoan $\left(12^{\mathrm{e}}\right.$ année du duc Wen, $1^{\mathrm{e}}$ année du duc Siuen) comme une ville du royaume de Tcheng. En effet, Kiang Yong retrouve la localité de Fei-lin dans la ville de Lin-hiang, qui est à 25 li à l'E. de la s.-p. de Sin-tcheng (préf. de K'ai-fong, prov. de Ho-nan).

- Aucun texte n'indique à quelle époque exactement doivent être rapportées les hostilités qui eurent pour théâtre la localité de Lin-hiang.

44.(356) Le mot [] a le même sens que le mot [] ; aussi Se-ma Tcheng pense-t-il qu'il est fait allusion ici à la localité de Pou-t'ien, le Kouo ti tche (chap. VI, p. $14 \mathrm{r}^{\circ}$ ) place les marais de Pou-t'ien à 3 li à l'E. de la s.-p. de Koan-tcheng (qui est aujourd'hui la préf. sec. de Tcheng, préf. de $K^{\prime}$ ai-fong, prov. de Ho-nan).

44.(357) Le Kouo ti tche (chap. VI, p. $6 \mathrm{v}^{\circ}$ ) place la terrasse Wen à 65 li au N.-O. de la s.-p. de Yuen-kiu (au S.-O. de la ville préfectorale de Ts'ao-tcheou, prov. de Chan-tong).

44.(358) D'après Se-ma Tcheng, Tou est le nom d'un temple funéraire qui se trouvait à Tch'oei, mais je n'ai pas pu identifier cette localité. La terrasse Wen et le temple Tou appartenaient à $\mathrm{Wei}$.

44.(359) D'après Tchang Cheou-tsie, T'ao doit correspondre à la s.-p. actuelle de Ting t'ao (préf. de Ts'ao-tcheou, prov. de Chan-tong). — D'autre part, Wei désignerait la ville de Tch'ou-k'ieou (auj. s.-p de Hoa, préf. de Wei-hoei, prov. de Ho-nan), qui fut la capitale du duc Wen (659-635) de Wei (cf. tome IV, n. 37.101).

44. $(\underline{360})$ P'ing était, sous les Han, une sous-préfecture qui se trouvait à l'E. de la s.-p. actuelle de Mong-tsin (préf. et prov. de Ho-nan).

44.(361) Au mot Kien il faut substituer la leçon K'an du Tchan kouo t'se. La même confusion entre ces deux caractères se retrouve plus loin, dans le che kia de Han, à propos du nom de 
K'an Tche. Siu Koang place la localité de K'an dans l'ancienne s.-p. de Siu-tch'ang (laquelle était à 15 li au N.-O. de la préf. sec. de Tong-p'ing, préf. de T'ai-ngan, prov. de Chan-tong).

44.(362) La montagne dont il est ici question est la montagne Hoa au S.-E. du Chàn-si. A l'époque des sept royaumes, avant les empiètements de $T s$ 'in, Wei possédait les territoires qui étaient au nord de cette montagne, tandis qu'il partageait avec Han les territoires qui étaient au sud.

44.(363) Cf. n. 256.

44.(364) Cf. tome IV, n. 39.164.

44. $(\underline{365})$ Cf. n. 182.

44. $(\underline{366})$ Littéralement « le gratte ».

44.(367) C'est-à-dire de former une ligue où tous les royaumes se suivent les uns les autres comme les oies sauvages dans leur vol triangulaire.

44.(368) C'est-à-dire de livrer bataille.

44.(369) Le territoire de la préfecture de Lou-ngan, dans le Chan-si.

44.(370) D'après Tchang Cheou-tsie, Kong correspond à l'ancienne s.-p. de Kong-tcheng et qui est aujourd'hui la s.-p. de Hoei (préf. de Wei-hoei, prov. de Ho-nan).

44.(371) Ning correspond à la s.-p. de Sieou-ou (préf. de Hoai-k'ing, prov. de Ho-nan).

44. (372) Le Kouo ti tche (chap. VI, p. $15 \mathrm{v}^{\circ}$ ) place l'ancienne ville de Ngan-tch'eng (nom écrit dans Se-ma Ts'ien) à $10 l i$ au S.-E. de la s.-p. de Yuen-ou qui est aujourd'hui la s.-p. de Yang-ou (préf. de Hoai-k'ing, prov. de Ho-nan).

44.(근 $) W e i$ fera en même temps sa fortune et celle de Han.

44.(374) Capitale de Tchao.

44.(375) Sur les instances du roi de Tchao, le roi de Wei avait d'abord envoyé à son secours le général $T \sin P i$; mais ensuite, effrayé par les menaces du roi de $T s$ 'in, il avait contremandé son ordre et avait exigé du général $T \sin P i$ qu'il s'arrêtât à $Y e$ pour attendre les événements. Comment le prince de Sin-ling, Ou-ki, contrefit un ordre du roi de Wei pour enlever à $T \sin P i$ son commandement et aller au secours de Han-tan assiégée, c'est ce qu'on lira en détail dans le chap. LXXVII des Mém. hist. - D'après le Kouo ti tche, la localité où le prince de Sin-ling enleva à $T \sin P i$ son commandement, fut appelée en souvenir de cet événement, ville de Tsin-pi ou encore Wei-té tch'eng, c'est-à-dire « ville de la vertu de Wei », le prince de Sin-ling appartenant à la famille royale de Wei. Cette ville était à $50 l i$ au $\mathrm{N}$. de l'ancien arrondissement de Wei, lequel se trouvait à $15 l i$ au S.-O. de la s.-p. actuelle de Siun (préf. de Wei-hoei, prov. de Ho-nan).

44.(376) A la date de 256, les Tableaux chronologiques mentionnent que «Han, Wei et Tch'ou secoururent Sin-tchong (ville) de Tchao ».

44.(377) «Dans le Ho-wai», disent le T'ong kien kang mou et le T'ong kien tsi-lan, ce qui paraît plus conforme au texte des Annales principales des $T s$ 'in ; cf. tome II, n. 05.509.

44.(378) D'après Se-ma Tcheng, ce texte figurerait dans le Tchan kouo-ts'e; mais je n'ai pas su l'y retrouver.

44.(379) Le futur $T s$ 'in Che-hoang-ti.

44. (380) «La commanderie orientale »; le territoire de Wei était en effet à l'Est du pays de Ts'in. 
44.(381) Tchao-ho, au N.-E. de la s.-p. de $K^{\prime} i$, (préf. de Wei-hoei, prov. de Ho-nan), avait été autrefois la capitale de Wei (cf. tome IV, n. 37.101), mais elle était ensuite tombée au pouvoir du roi de $W e i$.

44. (382) A cette époque, la capitale du prince de Wei [b] était P'ou-yang (cf. tome IV, n. $37.101)$; cette ville fut prise, en même temps que Tchao-ko, par Ts'in; le prince de Wei [b] se réfugia alors à Ye wang (cf. tome II, n. 06.126). D'après une note du T'ong kien tsi lan, le prince Yuen, de Wei, était le gendre du roi de Wei et devait à ce dernier son élévation au trône ; il dépendait entièrement de lui.

44.(로) Cf. tome II, n. 05.507.

44.(384) Yuen était à $20 l i$ au N.-O. de la s.-p. de Yuen-k'iu (préf. sec. de Kiang, prov. de Chan-si).

44. $(\underline{385}) P^{\prime}$ 'ou-yang, ainsi nommée parce qu'elle était au N. de la rivière $P$ 'ou, se trouvait à 45 $l i$ au S. de l'ancienne s.-p. de Si-tch'oan (auj. préf. sec. de Si, prov. de Chan-si).

44. (하) Yen se trouvait sur le territoire de la préf. sec. de Tcheng (préf. de K'ai-fong, prov. de Ho-nan).

44.(라) Cf. t. II, p. 120.

44.(료) Cf. n. 341.

44. (요) $\mathrm{Ou}-\mathrm{ki}$.

44.(390) Ngo-heng est le nom personnel de I Yn qui fut l'excellent conseiller de T'ang le vainqueur, fondateur de la dynastie $Y n$ (cf. t. II, p. 178). — En d'autres termes, ce n'est pas un sage conseiller qui aurait pu sauver $W e i$, car le triomphe de $T s^{\prime}$ in était voulu par le Ciel.

\section{CHAPITRE XLV : Quinzième maison héréditaire. Han.}

45.(101) Le chapitre qui traite du royaume de Han est le plus court des trois chapitres consacrés aux trois Tsin, c'est-à-dire aux royaumes de Tchao, Wei et Han, entre lesquels fut démembré l'ancien État de $T \sin$. Cela tient à deux raisons : la première est que les événements auxquels il est fait allusion dans ce chapitre ont été pour la plupart racontés en détail dans les deux chapitres précédents; aussi l'historien se borne-t-il le plus souvent à les rappeler brièvement ; en second lieu, le royaume de Han est loin d'avoir eu l'importance de Tchao et de Wei; d'étendue beaucoup plus restreinte, il n'a pas joué un rôle politique aussi considérable.

- La famille Han tire son nom du fief de Han-yuen à $18 l i$ au S.-O. de la s.-p. actuelle de Han-tch'eng (préf. de T'ong-tcheou, prov. de Chàn-si). Vers le milieu du VIe siècle avant notre ère, Han Siuen-tse transporta sa résidence à Tcheou (au S.-E. de la s.-p. actuelle de Outche préf. de Hoai-k'ing, prov. de Ho-nan). Dans les premières années du Ve siècle, Han Tcheng-tse transféra sa capitale à P'ing-yang qui correspond pratiquement à la ville préfectorale de ce nom dans le Chan-si à une date qui est postérieure à l'année 453, la capitale des Han fut la ville de Yang-ti qui est aujourd'hui la préf. sec. de Yu (préf. de Kai-fong, prov. de Ho-nan). En 403, Han fut mis au rang des seigneurs, en même temps que Tchao et Wei. En 375, il conquit la principauté de Tcheng et prit pour capitale la ville même de Tcheng (s.-p. actuelle de Sin-tcheng, préf. de K'ai-fong, prov. de Ho-nan). Han fut anéanti par Ts'in en l'an 230 av. J.-C. et son territoire devint la commanderie de Yng-tch'oan (cf. tome II, n. 06.177).

45.(102) D'après la tradition, les anciens princes de Han seraient descendants d'un fils du roi $O u$; c'est ce que disent les commentateurs du Che king à propos de l'ode $\left(7^{\mathrm{e}}\right.$ de la $3^{\mathrm{e}}$ décade du $T a y a$ ) où on célèbre les louanges d'un marquis de Han. Mais il est vraisemblable que cette 
ancienne principauté fut détruite par Tsin et que le territoire en fut donné à un certain $\mathrm{HanO} O$ tse, pour le récompenser des services qu'il avait rendus aux Tsin: Han Ou-tse et ses descendants n'auraient donc aucune parenté avec les anciens princes de Han et ne seraient pas issus du roi $\mathrm{Ou}$.

45.(103) D'après le Kouo ti tche (chap. II, p. $14 \mathrm{v}^{\circ}$ ), Han-yuen était à 18 li (et non 8 li comme on le lit dans l'édition de Chang-hai) au S.-O. de la s.-p. de Han-tch'eng (préf. de T'ongtcheou, prov. de Chàn-si). D’après une autre indication du Kouo ti tche (chap. II, p. 14 r $^{\circ}$ ), la ville de Han, qui fut le fief de Han Ou-tse, était à 18 li au S. de la s.-p. de Han-tch'eng. Il semble donc bien que Han-yuen et la ville de Han soient une seule et même localité.

45.(104) Han Kiue est mentionné à diverses reprises entre les années 597 et 583 (cf. t. IV, p. 318, 320-322).

45.(105) Cf. p. 17, lignes 6-8.

45.(106) Cf. p. 17, lignes 28-31.

45. (107) Ce fut en définitive grâce à Han Kiue que l'orphelin de la famille Tchao put faire reconnaître ses droits. Cf. p. 20.

45.(108) Cf. tome IV, n. 32.207.

45.(109) Cf. t. IV, p. 66.

45.(110) Cf. n. 43.118.

45.(111) Tch'eng-ki, ou Tch'eng-tse est l'appellation de Tchao Tch'oei qui fut un des fidèles compagnons de Tch'ong-eul, duc Wen de Tsin.

45.(112) Le fameux orphelin de la famille Tchao ; cf. p. 21.

45. (113) Le Kouo ti tche (chap. III, p. 17 r ${ }^{\circ}$ ) identifie Tcheou avec l'ancienne sous-préfecture de Ou-té au S.-E. de la s.-p. actuelle de Ou-tche, préf. de Hoai-k'ing, prov. de Ho-nan). Le Tso tchoan $\left(11^{\mathrm{e}}\right.$ année du duc $\left.Y n\right)$ mentionne Tcheou au nombre des douze villes qui, en 712 av. J.-C., furent enlevées à Sou Fen-cheng.

45.(114) Cf. t. IV, p. 15.

45.(115) Se-ma Ts'ien est ici en désaccord avec le Tso tchoan, qui fait mourir Han Siuen-tse en l'automne de l'année 514.

45.(116) P'ing yang était au S.-O. de la ville préfectorale de P'ing-yang (prov. de Chan-si). D'après le Ti wang che ki, elle aurait été la capitale de l'empereur Yao. A l'époque tch'oen ts 'ieou, elle appartint à la famille Yang-cho. D'après le Tso tchoan (28 e année du duc Tchao), lors du partage des terres de la famille Yang-cho en 514, P'ing-yang échut à la famille Tchao, et Tchao Tch'ao en devint gouverneur. Elle dut plus tard passer entre les mains de la famille Han, puisque Se-ma Ts'ien nous apprend que, peu après l'année 497, Han Tcheng-tse transféra sa résidence dans cette ville.

45.(117) Cf. t. IV, p. 483.

45.(118) Cf. tome II, n. 06.123.

45.(119) D'après le Kouo ti tche (chap. VI, p. $12 \mathrm{r}^{\circ}$ ), le relais de Fou-chou était à 35 li au S.-O. de l'ancienne sous-préfecture de Yang-tch'eng de l'arrondissement de Lo. L'ancienne sous-préfecture de Yang-tch'eng était elle-même à 35 li au S.-E. de la s.-p. actuelle de Teng-fong (préf. et prov. de Ho-nan). A la date de 504 av. J.-C., Fou-chou est mentionné dans le Tso tchoan comme une place appartenant au territoire des Tcheou. - La note relative à Fou-chou insérée dans le tome I (n. 04.558) est fautive, car elle confond l'ancienne ville de Yang-tch'eng dans le Ho-nan avec la s.-p. actuelle de Yang-tch'eng dans le Chan-si. 
45.(120) Cf. t. II, p. 288, n. 1, et Kouo ti tche, chap. VI, p. $11 \mathrm{v}^{\circ}$. Cette ville de Yang-ti paraît avoir été à ce moment la capitale de Han, car, à la date de 375, le T'ong kien kang mou dit que Han transféra sa capitale de Yang-ti à Tcheng.

45.(121) La biographie de Nie Tcheng se trouve dans le chap. LXXXVI des Mém. hist., qui s'inspire en grande partie du Tchan kouo ts'e (dernière partie du chap. XXVII). Dans le Tchan kouo ts'e, Kia-lei est appelé Han Koei.

45.(122) Cf. tome IV, n. 07.244.

45.(123) Cf. tome II, n. 08.188.

45.(124) Cf. tome II, n. 06.289.

45.(125) Cf. $\underline{\text { n. } 44.157 .}$

45.(126) Cf. n. 43.244.

45.(127) Cf. t. IV, p. 336.

45.(128) Cf. t. IV, p. 484.

45.(129) Sous-préfecture actuelle de Sin-tcheng (préf. de K'ai-fong, prov. de Ho-nan). — A partir de ce moment, les princes de Han sont souvent appelés « rois de Tcheng » de même que les princes de Wei sont appelés «rois de Leang ", après qu'ils eurent, en l'année 340, transporté leur capitale à Ta-leang ( $K^{\prime}$ ai-fong fou $)$.

45.(130) Le Tchou chou ki nien nomme ce personnage Han Chan-kien.

45.(131) Le Tchou chou ki nien donne la même leçon, mais les Tableaux chronologiques appellent ce prince le marquis Tchoang.

45.(132) Cf. tome II, n. 05.339.

45.(133) Cf. n. 44.175.

45.(134) Cf. tome IV, n. 31.218.

45.(135) Ling-koan était sur le territoire de la préfecture actuelle de Yen-tcheou (prov. de Chan-tong).

45.(136) Hing-k'ieou était près de la sous-préfecture de Wen dans le Ho-nan (cf. tome II, n. 05.468). Mais cette leçon est fautive et il faut lire Lin-k'ieou, comme dans les Tableaux chronologiques et le T'ong kien kang mou; sur l'emplacement de Lin-k'ieou, cf. tome IV, n. 32.277. - Le Tchou chou ki nien nous apprend que, en 368, Tcheng (c.-à-d. Han) éleva un rempart à Hing-k'ieou; cette ville lui appartenait donc déjà, et il ne pouvait par conséquent pas la prendre en 353 aux Tcheou orientaux.

45.(137) Cf. Mém. hist., chap. LXIII.

45.(138) Cf. Li ki, chap. Jou hing, § 17 (Legge, S. B. E., vol. XXVIII, p. 408) « ceux qui pratiquent la conduite vertueuse, et cela par les mêmes méthodes »".

45.(139) Dans les Tableaux chronologiques, Se-ma Tcheng ... fait ... remarquer que le témoignage de l'historien est ici suspect, car il n'y a pas eu de duc Tao dans le royaume de Han et on ne sait pas qui est ce prince.

45.(140) Cf. tome II, n. 05.385 .

45.(141) K'iu I-kieou était un grand officier de Tch'ou qui se trouvait alors dans le pays de Wei.

45.(142) A la date de 311, le Tchou chou ki nien dit: «Wei battit le général de Tchao, Han Kiu ». Peut-être ce témoignage se rapporte-t-il au même événement que relate ici Se-ma Ts 'ien en le fixant à l'année 325 et en faisant de Han Kiu un général de Han. 
45.(143) Les Tableaux chronologiques rapportent ce fait à l'année 324. Jusqu'alors les princes de Han n'avaient pas pris le titre de roi.

45.(144) Cf. ‥ 43.306.

45.(145) Yen était à 15 li au N.-O. de la s.-p. de Yen-ling (préf. de K'ai-fong, prov. de Ho-nan).

45.(146) Tchouo-tse est une leçon fautive qui provient du Tchan kouo ts'e ; il faut lire Koantse comme dans le Tchao che kia et les Tableaux chronologiques; cf. n. 43.306.

45.(147) Tchan kouo ts'e : section de Han; chap. XXVI, p. 3 vo-4 r'.

45.(148) Se-ma Tcheng dit que Kong-tchong était conseiller d'État dans le pays Han, et que son nom personnel était Tch'e. Cependant le Tchan kouo ts'e l'appelle Kong-tchong Ming.

45.(149) D'après une note de l'édition de 1581 du Tchan kouo ts'e, le terme [] désigne ici les royaumes de l'Est des montagnes. A l'époque des royaumes combattants, on appelait royaumes de l'Est des montagnes ceux qui se trouvaient à l'Est des passes montagneuses qui défendaient le pays de $T \sin$ : cette expression comprenait donc tous les royaumes autres que $T s^{\prime}$ in. Il semble cependant que, dans le cas présent, elle s'applique plus spécialement à Tch'ou.

45.(150) Le roi de Tch'ou était alors le roi Hoai (328-299).

45.(151) D'après le commentaire de l'édition de 1581, ce seraient les revenus fournis par la ville importante qui permettraient d'équiper des soldats : il faudrait donc traduire : «si, en outre, il obtient de Han une ville importante pour équiper des soldats. »

45.(152) D'après le dictionnaire de K'ang-hi, les anciens appliquaient à un ambassadeur le mot sin qui a le même sens que le mot siun « interroger ou informer ». L'ambassadeur était ainsi l'homme chargé de demander des nouvelles ou d'en apporter.

45.(153) Première hypothèse: Han n'écoute pas les propositions d'alliance que lui fait Tch'ou; il ne peut cependant manquer d'être sensible à ses bons procédés et ne secondera $T s$ 'in que mollement.

45.(154) Cf. n. 367. Cette métaphore revient souvent dans les textes du Tchan kouo ts'e.

45.(155) Seconde hypothèse : Han fait alliance avec Tch'ou; Ts 'in alors l'attaquera.

45.(156) Celui qui n'a pas de céréales, c'est celui qui n'a pas de revenus ou de traitement. Par modestie, les princes se désignaient eux-mêmes de la sorte.

« Ce que les hommes détestent, lit-on dans le Tao té king (§ 42), c'est d'être orphelins, abandonnés, pauvres ; cependant les rois et les seigneurs s'appellent ainsi eux-mêmes.

Cf. $L i-k i$, chap. K'iu-li, b, § 9.

45.(157) Le Kouo ti tche (chap. VI, p. 4 r ${ }^{\circ}$ ) identifie Ngan-men avec la localité de Si-ou-t'ing, à 28 (ou 18) $l i$ au N.-O. de la s.-p. de Tch'ang-cho (laquelle se trouvait à l'O. de la s.-p. actuelle de Tch'ang-ko, préf. sec. de Hiu, prov. de Ho-nan).

45.(158) Cf. tome II, n. 05.373. Se-ma Tcheng considère Tan-yang comme un nom de lieu et l'identifie avec l'ancienne capitale de Tch'ou (cf. tome IV, n. 40.101). Pour Tchang Cheoutsie, c'est la ville de Tche-kiang qui, étant devenue capitale de Tch'ou après Tan-yang (cf. tome IV, n. 40.101), prit aussi le nom de Tan-yang (T'ong kien kang mou, année 312 av. J.-C.).

45.(159) D'après Siu Koang, ce roi serait appelé le roi Siang-ngai dans d'autres textes.

45.(160) Cf. tome II, n. 05.372.

45.(161) Cf. tome IV, n. 40.324 . 
45.(162) Ou-soei était à 70 li de $P$ 'ing-yang qui avait été capitale de Han au cinquième siècle av. J.-C. (cf. n. 100, et t. IV, p. 396, lignes 2-3; la note 40.325 du t. IV est fautive, car P'ing-yang était au S.-O. de la ville préfectorale de ce nom, prov. de Chan-si).

45.(163) Les Tableaux chronologiques disent: «L'héritier présomptif Yng eut une entrevue avec le roi de $T$ s'in à Lin-tsin; à la suite de cela, il alla à Hien-yang (capitale de $T s$ 'in), puis revint ».

45.(164) Cf. tome II, n. 05.440.

45.(165) Cf. tome IV, n. 40.333.

45.(166) Tout ce qui suit est fort obscur. L’héritier présomptif Yng dont la mort est annoncée ici paraît être identique au Kong-chou Po-yng qui apparaît plus loin comme vivant encore.

45.(167) Le Tchan kouo ts'e écrit ce nom avec l'orthographe [][].

45.(168) Tchan kouo ts' $e$ : section de Han; chap. XXVIII, p. 3 vº-4 r'.

45.(169) Le Tchan kouo ts' $e$ met ce discours dans la bouche d'un certain Ling Hiang.

45.(170) Han Kieou paraît être identique au kong-tse Kieou dont il a été question plus haut; cependant, puisque le kong-tse Kieou disputait à $K i$-che le titre d'héritier présomptif, il est impossible que son interlocuteur lui donne le conseil de prendre l'initiative de faire rentrer $K i$ che dans le pays de Han. Il faut donc ou admettre que Han Kieou est un autre personnage que le kong-tse Kieou, ou substituer à Han Kieou le nom de Kong-tchong comme le propose Ou Che-tao, commentateur du Tchan kouo ts'e à l'époque des Yuen.

45.(171) La montagne Fang-tch'eng (cf. tome IV, n. 40.240) était sur la frontière nord du pays de Tch'ou. Dire que les soldats de Tch'ou sont au delà de Fang-tch'eng c'est dire qu'ils sont déjà entrés en campagne.

45.(172) Yong-che ville de Han, était ainsi nommée, dit le Kouo ti tche (chap. VI, p. $11 \mathrm{v}^{\circ}$ ) en souvenir d'un certain Yong-fou, ministre de Hoang-ti, qui, d'après la légende, fabriqua un pilon et un mortier. Cette ville était à $25 l i$ au N.-E. de la s.-p de Yang-ti qui occupait, suivant la tradition, l'emplacement de la capitale de l'empereur $Y u$, et qui, pour cette raison, est aujourd'hui appelée la préfecture secondaire de $Y u$ (préf. de $K^{\prime}$ 'ai-fong, prov. de Ho-nan).

45.(173) Tchan kouo ts'e: « afin de s'y opposer ».

45.(174) La leçon du Tchan kouo ts'e est préférable :

«Quand $K i$-che aura obtenu de rentrer, il vous en sera reconnaissant et il ne manquera pas de mettre à votre service (toutes les forces de) Han et de Tch'ou.

45.(175) Tchan kouo ts'e : section de Han; chap. XXVII, p. 1 v

45.(176) Tchan kouo ts'e :

«Tch'ou assiégeant Yong-che, (le roi de) Han ordonna à Ling Hiang d'emprunter des renforts à $T s^{\prime}$ in. (Le roi de) $T s^{\prime}$ in à cette occasion envoya Kong-suen Mei comme ambassadeur dans le pays de Han.

45.(177) Nan-tcheng était à $2 l i$ à l'E. de la s.-p. actuelle de ce nom (préf. de Han-tchong, prov. de Chàn-si).

45.(178) Lan-t'ien était à 30 li à l'O. de la s.-p. actuelle de ce nom (préf. de Si-ngan, prov. de Chàn-si). D’après le Kouo ti tche (chap. II, p. $9 \mathrm{v}^{\circ}$ ), à 90 li au S.-E. de la s.-p. de Lan-t'ien se trouvait la passe Lan-t'ien, qui n'est autre que la passe Yao de l'époque des Ts 'in). - Comme on le voit, Nan-tcheng désigna la route occidentale ou méridionale, et Lan-t'ien la route orientale, ces deux voies étant celles qui menaient du pays de Ts 'in dans celui de Tch'ou (cf. n. 44.328). 
45.(179) Il semble qu'il y ait là une contradiction, car le roi de $T s^{\prime}$ 'in ne peut pas passer à la fois par la route du Sud et par celle de l'Est. Le texte du Tchan kouo ts'e est plus explicite :

«Le roi de $T s$ 'in a tenu ce langage :

« Je propose de passer par Nan-tcheng et Lan-t'ien pour pénétrer dans le pays de Tch'ou et l'attaquer, de faire sortir mes soldats dans le San-tch'oan pour vous attendre. Il semble qu'il y ait contradiction (entre ce dernier projet) et le fait de camper à Nan-tcheng ».

En d'autres termes, il y a une contradiction suspecte dans le langage du roi de Ts'in, car s'il veut passer par Nan-tcheng, au sud de ses États, qu'a-t-il besoin de passer par Lan-t'ien et de se rendre dans le San-tch'oan, qui est à l'est? En réalité, comme on le verra plus loin, le roi de $T s$ 'in projetait, non de secourir Han, mais de s'emparer du San-tch'oan.

45.(180) En d'autres termes, le roi Tchao, de $T s$ 'in se propose de suivre maintenant (300) à l'égard de Han la même politique que, sur les conseils de Tchang I, le roi Hoei-wen de Ts'in, avait suivie trente ans auparavant à l'égard du royaume de Wei. Il feindra de le secourir pour qu'il s'engage dans la lutte contre $T c h$ 'ou, puis, il profitera de son embarras pour lui enlever son territoire.

45.(181) Le royaume de Wei dont la capitale était Ta-leang.

45.(182) D'après Se-ma Tcheng, le mot [] a ici le sens de « tromper ».

45.(183) Le territoire extérieur au Si-ho (entre le Hoang ho et la rivière Fen du Chan-si) est le Ho-si (entre le Hoang ho et la rivière Lo du Chan-si). C'est en l'année 330 que Wei dut céder à $T$ s'in le $H o-s i$ (cf. t. II, p. 69).

45.(184) D'après le commentaire de Tchang Cheou-tsie, le mot a ici le sens de «disposer, étaler ». Le San-tch'oan, c'est-à-dire la région de Ho-nan fou arrosée par le Hoang ho et les rivières $I$ et $L o$, était le lieu où se trouvait la capitale du Fils du Ciel de la dynastie Tcheou. Le texte signifie donc que, si Han est vainqueur, Ts'in étalera aux yeux du Fils du Ciel la gloire qu'il s'est acquise en lui prêtant son secours et en agissant comme un hégémon. Au lieu de [], le Tchan kouo ts'e écrit [], et, d'après le commentaire, il faudrait traduire :

« $T s$ 'in profitera avec vous de (la victoire remportée sur) Tch'ou, pour ne s'en retourner qu'après s'être emparé du San-tch'oan. »

45.(185) Au lieu de Se-ma keng, le Tchan kouo ts'e écrit Se-ma K'ang. Ce personnage devait être un haut fonctionnaire du pays de $T s^{\prime}$ in, mais il ne nous est pas connu par ailleurs.

45.(186) Par Yng, il faut entendre ici la ville de Jo qu'on appelait aussi Yen-yng, et qui fut la capitale du royaume de Tch'ou de 504 à 278 av. J.-C. Cf. tome IV, n. 40.101.

45.(187) Kan Meou était conseiller de Ts'in; cf. t. II, p. 75-77.

45.(188) localité non identifiée. Le Tchan kouo ts'e écrit [] « à la frontière ».

45.(189) Tchao Yu, dont le nom est écrit Tchao Hien par le Tchan kouo ts'e, devait être conseiller de Tch'ou.

45.(190) Le sceau dont il est question doit être un sceau militaire; Kan Meou eut une entrevue avec Tchao $Y u$ pour lui prendre le sceau qui l'investissait de son commandement, et par conséquent pour arrêter l'attaque de Tch'ou contre Han. On pourrait aussi admettre que le sceau était l'insigne par lequel $T c h a o Y u$ recevait de $T s$ 'in un titre officiel.

45.(191) En réalité il semble bien que $T s^{\prime}$ in et $T c h$ 'ou aient fait un accord pour attaquer Han.

45.(192) C'est-à-dire : préoccupez-vous de trouver par vous-même les moyens de sauver Han et n'ajoutez pas foi aux fausses promesses, renouvelées de Tchang I, par lesquelles le roi de $T s$ 'in vous garantit des secours qui ne viendront point. 
45.(193) En d'autres termes, vous vous serez tenu en garde contre les stratagèmes trompeurs que le roi de $T$ s'in a empruntés au souvenir de Tchang $I$, et vous ne serez point privé de l'appui de $T s$ 'in puisque, en tout état de cause, vous ne deviez pas l'obtenir réellement.

45.(194) Mi Jong est cité comme général de $T s$ 'in en 299 av. J.-C. (cf. tome II, n. 05.397). Il est aussi connu sous le nom de prince de Sin-tch'eng; aussi le Tchan kouo ts'e débute-t-il ici par les mots : «On dit au prince de Sin-tch'eng :... »

45.(195) La reine-douairière Siuen, mère du roi Tchao-siang, de Ts'in, était issue de la maison princière de $T c h$ 'ou dont le nom de famille était $M i$ (cf. t. II, p. 76-77).

45.(196) Tchan kouo ts' $e$ : section de Han; chap. XXVII, p. 3 v'.

45.(197) Kong-chou Po-yng, le kong-tse Ki-che et le kong-tse Kieou étaient tous trois fils du roi Siang, de Tch'ou. Quand Po-yng était héritier présomptif, il avait pu craindre de se voir supplanté par $\mathrm{Ki}$-che, et c'est sans doute à cette époque que se rapporte ce discours ; mais on voit que l'historien a interverti à tort l'ordre chronologique des textes du Tchan kouo ts'e en plaçant ce discours après celui de Sou Tai à Han Kieou (cf. p. 212-213) qui suppose que Po-yng est mort (cf. n. 166) et que la rivalité n'existe plus qu'entre le kong-tse Ki-che et le kong-tse Kieou.

45.(198) Cet otage n'est autre que le kong-tse Ki-che.

45.(199) D'après Se-ma Tcheng, le sens est celui-ci : si le roi de Tch'ou consent à accepter comme otage une autre personne que le kong-tse Ki-che, ce sera la preuve qu'il n'a pas l'intention de se servir de ce dernier pour susciter des embarras à l'héritier présomptif Po-yng.

- D'après Tchang Cheou-tsie au contraire, le texte de l'historien est fautif et il est nécessaire d'ajouter la négation avant le mot; si le roi Tch'ou ne consent pas à faire rentrer le kong-tse $K i$-che dans le pays de Han, il montrera qu'il n'a pas l'intention de lui faire obtenir, au détriment de Po-yng, la place d'héritier présomptif.

45.(200) C'est-à-dire demander à Tch'ou d'envoyer dans le pays de $T s$ 'in le kong-tse Ki-che.

45.(201) Tch'ou tiendra Mi Jong en haute estime parce qu'il aura besoin de lui pour obtenir que $T s^{\prime}$ in l'aide à lutter contre Han, Ts' $i$ et $W e i$.

45.(202) Cf. n. 44.256. Ce texte nous permet de comprendre comment s'est produite l'erreur de Se-ma Ts'ien que nous avons signalée plus haut (p. 168, ligne 1); en 296, Ts'in rendit à Wei le Ho-pei et donna à Han le Ho-wai; c'est pour avoir confondu ces deux faits que l'historien dit par erreur que $T$ s'in restitua à Wei le Ho-wai.

45.(203) Quelques lignes plus bas, on lit que, en 290, Han livra de nouveau à $T s$ 'in cette ville de Ou-soei. Tchang Cheou-tsie ajoute qu'elle devait se trouver près de I-yang et j'ai moimême adopté cette opinion dans le tome IV, n. 40.325.; mais je crois qu'elle est erronée ; cf. n. 162.

45.(204) Dans le t. III, p. 41, au bas de la seconde colonne, ce roi est appelé, par inadvertance, « le roi Hi-kieou » ; en réalité Kieou est son nom personnel.

45.(205) Les Annales principales des $T s$ 'in disent qu'il coupa deux cent quarante mille têtes (Cf. t. II, p. 82).

45.(206) Cf. $\underline{\text { n. } 44.260 .}$.

45.(207) Yuan est la ville préfectorale de Nan-yang (prov. de Ho-nan). Elle constituait, à l'époque des Tcheou, la principauté de Chen; cf. tome I, n. 04.407.

45.(208) Cf. n. 162 et n. 203.

45.(209) Cf. n. 44.266. 
45.(210) On sait que les Tcheou orientaux et les Tcheou occidentaux s'étaient partagé la capitale (auj. Ho-nan-fou); il y avait apparemment un intervalle ménagé entre les deux parties de la ville qu'occupaient les deux princes rivaux (cf. tome I, n. 04.497), et c'est là que durent se rencontrer le roi de $T s$ 'in et le roi de Han.

45.(211) Cf. tome II, n. 08.180.

45.(212) Cf. tome II, n. 05.459. - D'après Se-ma Piao, il faudrait considérer Hoa-yang comme le nom d'une montagne qui se trouvait sur le territoire de la sous-préfecture de $M i$ (préf. de K'ai-fong, prov. de Ho-nan).

45.(213) Tchan kouo ts' $e$ : section de Han; chap. XXVIII, p. 5 r'.

45.(214) Le Tchan kouo ts'e nomme ce personnage T'ieng Ling.

45.(215) Euphémisme pour désigner le long voyage de la capitale de Han (Sin-tcheng du Honan) à la capitale de Ts'in (Hien-yang du Chàn-si).

45.(216) Wei Jan, marquis de Jang, était conseiller de Ts'in; cf. t. II, p. 86.

45.(217) Un ambassadeur d'État, c.-à-d. un ambassadeur officiel.

45.(218) C'est-à-dire qu'il cesserait de se rattacher à $T s$ 'in et qu'il ferait alliance avec Tchao et Wei. Le raisonnement est le même qu'à la p. 177, lignes 9-10.

45.(219) Il est inutile que $T c h$ 'en Che aille voir le roi de $T s$ 'in; le marquis de Jang se charge d'envoyer les troupes demandées.

45.(220) Cette localité était à $20 l i$ au N.-O. de la s.-p. de K'iu-ou (préf. de $P^{\prime}$ 'ing-yang, prov.de Chan-si).

45.(221) Le T'ai-hang est une chaîne de montagne étendue (Cf. tome I, n. 02.223). Mais, d'après Tchang Cheou-tsie, il s'agirait plus spécialement ici des montagnes qui étaient à $25 l i$ au N. de la s.-p. de Ho-nei (préf. de Hoai-k'ing, prov. de Ho-nan).

45.(222) Cf. p. 116-119.

45.(223) Tchao Kouo, cf. tome II, n. 07.191.

45.(224) Cf. ‥ 43.517.

45.(225) Cf. n. 119. Yang-tch'eng est la localité qui est mentionnée par Mencius à propos de $Y u$ le grand et du fils de l'empereur Choen; cf. tome I, n. 02.298.

45.(226) Cf. tome II, n. 05.503 .

45.(227) Cf. tome II, n. 06.109.

45.(228) Il est vraisemblable que, lorsque Fou Ting livra le Chang-tang à Tchao en 262 (cf. p.116 et suiv.), une petite partie de ce territoire continua à appartenir à Han ; c'est pourquoi l'historien dit que, en 259, Ts'in prit « le Chang-tang de Tchao », et que, en 247, il s'empara de tout ce qui restait de "notre Chang-tang », c'est-à-dire du Chang-tang de Han.

45.(229) La biographie du célèbre Han Fei-tse se trouve dans le chap. LXIII des Mém. hist.

45.(230) En d'autres termes, on peut être surpris au premier abord, de voir que les Han devinrent seigneurs bien qu'ils n'eussent pas été une famille très glorieuse du pays de $T$ sin; mais leur grandeur s'explique si on considère qu'elle fut la récompense décernée aux mérites de leur ancêtre Han Kiue; en faisant rendre ses dignités et ses terres à l'orphelin de la famille Tchao, Yan Kiue accomplit une bonne action dont la vertu ou l'influence secrète fut une source de bénédiction pour ses descendants. 


\section{CHAPITRE XLVI : Seizième maison héréditaire. T’ien King-Tchong Wan.}

46.(101) Ce chapitre fait suite au chap. XXXII, car il expose l'histoire du pays de $T s$ ' $i$ sous les princes issus de la famille T'ien qui s'étaient substitués à l'ancienne maison souveraine dont le nom de famille était $L u$. Dès la première moitié du Ve siècle, les T'ien avaient pris un tel pouvoir dans le pays de $T s$ 'i qu'ils nommaient ou déposaient les ducs à leur gré. Ce ne fut cependant qu'en 391 qu'ils usurpèrent définitivement le trône de $T s$ ' $i$, et en 386 que le titre de seigneur leur fut reconnu par le Fils du Ciel. Comme les $L u$, les T'ien eurent leur capitale à Lin-tse qui est aujourd'hui la s.-p. de ce nom (préf. de Ts'ing-tcheou, prov. de Chan-tong). En 284, le roi Min, de $T s^{\prime} i$, fut dépouillé de sa capitale et de la plus grande partie de ses États. Ses descendants, qui n'eurent plus qu'un territoire fort restreint, furent incapables de résister aux attaques de $T s^{\prime}$ 'in, et, en 221, le dernier roi de $T s$ ' $i$ abandonna tout son pouvoir entre les mains du roi de $T s^{\prime}$ 'in qui prit, cette même année, le titre de $T s$ 'in Che-hoang-ti.

46.(102) T'ien est le nom de famille; King-tchong, le nom posthume; Wan, le nom personnel.

46.(103) On verra plus bas comment le nom de famille Tch'en fut changé plus tard en T'ien.

46.(104) Cette prédiction, où se trouve annoncée la grandeur future des descendants de Tch'en Wan dans le pays de $T s ' i$, a déjà figuré dans le chap. XXXVI des Mém. hist.; le lecteur est donc prié de se reporter aux notes $\underline{36.108}$ et $\underline{36.109}$ du tome IV.

46. $(\underline{105})$ Cf. tome IV, n. 35.102.

46.(106) Cf. tome IV, n. 36.106.

46.(107) Cf. Tch'oen-ts'ieou, $6^{\mathrm{e}}$ année du duc Hoan (706). Ainsi, d'après Se-ma Ts'ien, c'est dans l'intention de blâmer le duc $L i$ que le Tch'oen ts'ieou l'appelle Tch'en T'o, au lieu de l'appeler «T'o, marquis de Tch'en ». Cependant cette explication du grand historien ne paraît pas exacte; le Tch'oen-ts'ieou fait mourir T'o en 706, l'année même qui suit l'assassinat du duc Hoan, de Tch'en, et peut-être, comme l'explique Legge (C. C., t. V, p. 49 b) ; est-ce parce que T'o n'avait pas encore été reconnu comme marquis de Tch'en qu'on le mentionne ici sans son titre ; d'autre part, le Tch'oen-ts'ieou annonce en l'année 700 (12 ${ }^{\mathrm{e}}$ année du duc Hoan) la mort de Yo, marquis de Tch'en, et c'est ce personnage qui, d'après le Tso tchoan $\left(22^{\mathrm{e}}\right.$ année du duc Tchoang) eut le titre posthume de duc $L i$ et fut le père de Tch'en Wan. Cf. tome IV, $\mathrm{n}$. 36.106 .

46.(108) La vingt et unième année (672), d'après le che kia de Tch'en (cf. t. IV, p. 173), et cette leçon est la seule exacte, puisque nous lisons ici même, quelques lignes plus bas, que Wan se réfugia dans le pays de $T s^{\prime} i$ la $14^{\mathrm{e}}$ année du duc Hoan, c'est-à-dire en 672.

46.(109) Pour tout ce qui suit, voyez tome IV, p. 174, et Tso tchoan, $22^{\mathrm{e}}$ année du duc Tchoang.

46.(110) Cf. tome IV, n. 36.113.

46.(111) Cf. tome IV, n. 36.114.

46.(112) Il semble qu'il soit fait allusion ici, d'une part à T'ien $K^{\prime} i$, d'autre part à T'ien $H o$, qui eut le titre posthume de T'ai-kong. Mais la généalogie indiquée plus loin par Se-ma Ts'ien rapporte $T^{\prime} i e n K^{\prime} i$ à la sixième génération et $T^{\prime} i e n ~ H o$ à la dixième.

46.(113) D'après Se-ma Tcheng, Tche serait le nom personnel, et Mong-i l'appellation.

46.(114) Quand Tch'en Wan fut entré dans le pays de $T s^{\prime} i$, il ne voulut pas que son nom de famille $T c h$ 'en rappelât le pays d'où il était originaire, et c'est pourquoi il échangea le caractère Tch'en contre le caractère T'ien dont la prononciation était assez analogue ; à partir de ce moment, lui et ses descendants forment donc la famille T'ien. Il est à remarquer cependant que le Tso tchoan continue à désigner les membres de cette famille sous le nom de 
Tch'en, ce qui tendrait à faire croire que l'adoption du nom T'ien fut postérieure à l'époque Tch'oen-ts'ieou.

46.(115) Le caractère [] se prononce ici yng (cf. Dict. de K'ang-hi). Le Tso tchoan et Se-ma Ts'ien lui-même en d'autres passages (cf. t. IV, p. 69), appellent ce personnage Loan Yng.

46.(116) Cf. Mém. hist., chap. LXII.

46.(117) Yen Yng.

46.(118) Cf. t. IV, p. 74-75, et Tso tchoan, $3^{\mathrm{e}}$ année du duc Tchao. - A la date de 516, les Tableaux chronologiques rapportent une autre anecdote qui montre quelles suspicions la famille T'ien excitait dans l'esprit de Yen Yng : Une comète apparut. Yen-tse dit :

— Les bienfaits que la famille T'ien a rendus au (peuple de) $T s$ ' $i$ sont à redouter.

46.(119) Ce paragraphe se retrouve dans le che kia de $T s^{\prime} i$ : Cf. t. IV, p. 78.

46.(120) «... parmi les sujets révoltés », dit le che kia de $T s$ 'i, et cette leçon est plus exacte, puisque Fan et Tchong-hang n'avaient pas le titre de seigneur et n'étaient, malgré leur puissance, que des sujets révoltés du duc de $T$ sin.

46.(121) Pour tout ce qui suit, cf. t. IV, p. 79-81.

46.(122) Auj. préf. sec. de Kiu (préf. de I-tcheou, prov. de Chan-tong).

46.(123) Au lieu de Yen Jou-tse, le che kia de Ts'i (t. IV, p. 80) dit: "Yen Yu » et cette leçon est préférable, car, ainsi qu'on le verra par la suite du récit, Yen Jou-tse ne put pas s'enfuir et resta entre les mains des conjurés. Quant à Yen Yu, c'était, d'après Kia K'oei, le fils de Yen $Y n g$; il n'est cependant pas mentionné dans la biographie de ce personnage (Mém. hist., chap. LXII).

46.(124) Cf. tome IV, n. 32.248.

46.(125) Yen Jou-tse, c.-à-d. «l'enfant Yen », et «Jou-tse T'ou », c.-à-d. «l'enfant T'ou», sont un seul et même individu; T'ou est son nom personnel; Yen paraît être son nom posthume.

46.(126) Le Tch'oen-ts'ieou (supplément pour l'année 481) appelle ce personnage Tch'en Heng.

46.(127) Le Tso tchoan et le Che kia de Ts'i (cf. t. IV, p. 82) l'appellent K'an Tche. Se-ma Tcheng indique que le caractère [] peut se prononcer ici soit Kien, soit $K^{\prime}$ 'an; j'adopte la seconde prononciation.

46.(128) Cf. p. 228, lignes 17 et suiv.

46.(129) D'après Se-ma Tcheng, cette chanson serait satirique et donnerait à entendre que le gouvernement de $T s^{\prime} i$ était sur le point de tomber entre les mains de T'ien Tch'eng-tse.

46.(130) C'est évidemment le cocher du duc lui-même.

46.(131) D'après Se-ma Tcheng, l'historien se trompe, et Tse-ouo ne peut être que l'appellation de $K$ 'an Tche lui-même.

46.(132) Dans le che kia de $T s^{\prime} i$, ces événements sont racontés d'une manière différente et d'ailleurs plus vraisemblable ; cf. tome IV, n. 32.262.

46.(133) Cf. tome IV, n. 32.264.

46.(134) Cf. n. 131.

46.(135) Cf. tome IV, n. 32.273. 
46.(136) Pao doit être Pao Mou; Yen est peut-être Yen Yu ou quelque autre descendant de Yen Yng.

46.(137) D'après le Kouo ti tche, la ville de Ngan-p'ing était à 19 li à l'est de la sous-préfecture de Lin-tse (préf. de Ts'ing-tcheou, prov. de Chan-tong). — La note 4 de la page $86 \mathrm{du}$ tome IV est donc fautive. - Cette ville de Ngan-p'ing portait autrefois le nom de Hoei et appartenait à la principauté de $K i$; le Tch'oen ts'ieou nous apprend que, en 691 av. J.-C., un frère cadet du prince de $K i$ fit sa soumission au duc de $T s$ ' $i$ en lui livrant la ville de Hoei (cf. tome II, n. 06.558).

46.(138) Nous ne savons pas la date exacte de la mort de T'ien Tch'ang. Les Tableaux chronologiques (chap. XV, p. $4 \mathrm{v}^{\circ}$ ) nous apprennent qu'il vivait encore en 464 : cette année-là, en effet, Tche po attaqua Tcheng ; Se Hoan-tse se rendit dans le pays de Ts'i pour demander du secours; le secours fut accordé et les soldats de Tsin durent se retirer ; Tchonghang Wen-tse dit alors à T'ien Tch'ang : «Maintenant certes Tche (c.-à-d. Tche po), à cause de cela, est perdu $\gg$.

46.(139) Han, Tchao et Wei.

46.(140) T'ien Siang-tse qui projetait de se substituer au duc de $T$ ' ' $i$, fait cause commune avec Han, Tchao et Wei qui, dans le pays de Tsin, avaient des visées semblables aux siennes.

46.(141) Le Kouo ti tche place Hoang-tch'eng à 10 li au S. de l'ancienne sous-préfecture de Koan-che qui était au N. de la s.-p. actuelle de Koan (préf. de Tong-tch'ang, prov. de Chantong).

46.(142) D'après le Kouo ti tche, Yang-hou se trouvait à 30 li au N.-E. de l'ancienne sous-préfecture de Yuen-tch'eng qui était à l'est de la s.-p. actuelle de ce nom (préf. de Ta-ming, prov. de Tche-li.

46.(143) La ville de Lou (ainsi nommée parce qu'elle servait autrefois de lieu de halte aux princes de Lou quand ils venaient rendre hommage à la cour) était, d'après le Kouo ti tche, à $40 l i$ au S. de l'ancienne s.-p. de Hiu-tch'ang (au N.-E. de la préf. sec. actuelle de Hiu, prov. de Ho-nan).

46.(144) L'ancienne ville de Ko ou Tch'ang-ko était, selon le Kouo ti tche, à 12 li au N. de la s.-p. de Tch'ang-ko (qui dépend de la préf. sec. de Hiu, prov. de Ho-nan).

46. (145) Ngan-ling, est le nom que prit, à l'époque des six royaumes, l'ancienne ville de Yenling (cf. tome IV, n. 39.319), laquelle se trouvait à 15 li au N.-O. de la s.-p. actuelle de Yenling (préf. de K'ai-fong, prov. de Ho-nan).

46.(146) Il y a ici une divergence entre les Mémoires historiques et le Tchou chou ki nien; voir l'Appendice à la fin de ce volume.

46.(147) D'après le Kouo ti tche, la ville de Tch'eng était à 50 li au N.-O. de la s.-p. de Se-choei (préf. de Yen-tcheou, prov. de Chan-tong). Au commencement du Ve siècle avant notre ère, elle avait été la place forte d'une des puissantes familles de l'État de Lou, la famille Mong (cf. tome IV, n. 33.237). Il semble bien d'ailleurs que cette ville doive être identifiée avec l'ancienne principauté de Tch'eng qui fut l'apanage d'un des fils du roi Wen (cf. tome $\underline{\text { IV }}$, n. 35.105, où la localisation indiquée s'appuie sur l'autorité du Tch'oen ts'ieou ti li k'ao che de Kiang Yong, H. T. K. K., chap. CCLII, p. $6 \mathrm{v}^{\circ}$ ).

46. (148) Cette localité était à $56 l i$ au sud de l'ancienne s.-p. de $T s i-y n$, laquelle se trouvait au N.-O. de la s.-p. actuelle de Ts'ao (préf. de Ts'ao-tcheou, prov. de Chan-tong).

46.(149) Le mot [] est peu clair; il est remplacé dans les Tableaux chronologiques par le mot [] qui est plus usuel lorsqu'il s'agit d'exprimer l'idée qu'un homme se révolte en prenant pour centre et pour instrument de sa rébellion une ville dévouée à sa cause. 
46.(150) Cf. tome IV, n. 32.277. - Cet événement est présenté sous une forme différente dans le Tchou chou ki nien:

«La dix-septième année (409) du roi Wei-lie,... Kong-suen Hoei se révolta à Ling k'ieou (litt.: en se servant de Ling-k'ieou) contre Tchao. T'ien Pou assiégea Ling-k'ieou. Ti-kio, K’ong Siao de Tchao, et les soldats de Han vinrent au secours de Ling-k'ieou; ils livrèrent bataille à T'ien Pou près de l'étang de Long ; les soldats de T'ien (Pou) furent vaincus et s'enfuirent.

46. (151) Les Tableaux chronologiques disent que, la onzième année (394) du duc K'ang, Ts' $i$ attaqua Lou et lui prit la ville de Tsoei.

46.(152) Au N. de la s.-p. actuelle de Wen-chang (préf. de Yen-tcheou, prov. de Chan-tong).

46.(153) C'est par erreur, comme le fait remarquer Se-ma Tcheng, que les Tableaux chronologiques indiquent ici la date de 389.

46.(154) Cette localité paraît être identique au [] mentionné dans le che kia de Tchao (cf. $\underline{\text { n. }}$ 43.262).

46. $(\underline{155})$ Le début de ce passage est emprunté au Tchan kouo ts'e (section de $T s$ ' $i$; chap. VIII, p. $2, \mathrm{v}^{\circ}$ ) et est reproduit plus loin, à la date de 341 , avec la suite qu'il comporte dans le Tchan kouo ts'e. Cette répétition est une inadvertance de l'historien; ce texte ne devrait figurer qu'à la date de 341.

46.(156) Tseou Ki fut au service du roi Wei (378-343) de Ts’i (cf. Mém. hist., chap. LXXIV, p. $\left.1 \mathrm{v}^{\circ}\right)$. Le Tchan kouo ts'e ne mentionne ici ni Tseou Ki ni sa réponse.

46.(157) Au lieu de Toan-kan P'ong, Se-ma Tcheng dit que le Tchan kouo ts'e donne la leçon Toan-kan Luen, ce qui n'est qu'à moitié vrai, car Toan-kan Luen est mentionné par le Tchan kouo ts'e dans le paragraphe qui précède celui-ci ; lors de la délibération relative aux secours demandés par Han, le Tchan kouo ts'e actuel présente la leçon Tchang Mien. Dans la répétition de ce passage qu'on trouve plus loin à la date de 341, Se-ma Ts 'ien met la réponse de Toan-kan P'ong dans la bouche de T'ien $\mathrm{Ki}$.

46.(158) A la date de 341 (voyez plus loin), les paroles de T'ien Tch'en-se sont remplacées par d'autres paroles qui sont mises dans la bouche de Suen-tse et qui se retrouvent dans le Tchan kouo ts'e, mais attribuées à T'ien Tch'en-se. — Se-ma Tcheng dit ici que, au lieu de la leçon T'ien Tch'en-se, le Tchan kouo ts'e donne la leçon T'ien K'i-se; or le Tchan kouo ts'e actuel écrit, comme Se-ma Ts'ien, T'ien Tch'en-se; on en peut conclure, avec les commentateurs du Tchan-kouo ts'e, que le texte que nous possédons de cet ouvrage est différent de celui que connaissait Se-ma Tcheng. Enfin, d'après Se-ma Tcheng, qui cite une phrase du Tchou chou ki nien, absente dans ce livre tel qu'il est actuellement, T'ien Tch'en-se ou T'ien K'i-se ne serait autre que T'ien $K i$.

46.(159) Tch'ou et Tchao étant occupés à secourir Han, $T s$ ' $i$ n'aura plus à craindre d'être attaqué par eux et aura ses coudées franches pour agir contre Yen.

46. (160) Il l'avertit faussement qu'il accordera son appui à Han, mais comme il a l'intention de ne pas tenir son engagement, il ne parle qu'en secret à l'ambassadeur.

46.(161) Cf. $\underline{\text { n. } 44.157 .}$.

46.(162) Cf. n. 43.244. Nous trouvons pour Ling-k'ieou deux identifications; d'une part, $P^{\prime}$ 'ei Yn (Mém. hist., chap. XLIII, p. $6 \mathrm{v}^{\circ}$ ) assimile cette localité à la sous-préfecture de Ling-k'ieou dans la commanderie de Tai, ce qui revient à la placer dans la sous-préfecture actuelle de Ling-k'ieou, à l'E. de la préf. de Ta-t'ong, dans la province de Chan-si; d'autre part, Tchang Cheou-tsie identifie Ling k'ieou avec la sous-préfecture de Wei-tcheou, qui est aujourd'hui la préf. sec. de Wei au S.-O. de la préf. de Siuen-hoa, dans la prov. de Tche-li. Il suffit cependant de jeter les yeux sur la carte pour constater que ces deux localisations sont fort voisines l'une de l'autre et qu'il n'y a pas contradiction réelle entre les commentateurs. Je reviens sur 
l'opinion que j'ai exprimée dans la note 43.244 , et, en présence de l'unanimité des commentateurs à placer Ling-k'ieou dans la région que nous venons d'indiquer, je me demande si les possessions du royaume de $T s$ ' $i$ ne s'étendaient pas effectivement jusque-là.

46.(163) Le Kouo ti tche place la ville de Yang-koan sur la rive orientale de la rivière Wen, à 29 li au S. de la s.-p. de Po-tch'eng, laquelle se trouvait au S.-E. de la ville préfectorale de T'ai-ngan (prov. de Chan-tong).

46.(164) Tchang Cheou-tsie place Po-ling à l'O. de l'arrondissement de Tsi, lequel se trouvait au S.-O, de la s.-p. actuelle de Kiu-ye (préf. de Ts'ao-tcheou, prov. de Chan-tong). Au lieu de Po-ling, les Tableaux chronologiques donnent la leçon Choan-ling (ou Tchoan-ling). En cette même année 373, les Tableaux chronologiques mentionnent encore que Yen battit $T s ' i$ à Lin-yng (cf. t. IV, p. 139).

46.(165) Le Ta Ts'ing i t'ong tche, chap. CXXX, p. 2 v$^{\circ}$, place Sie-ling au N.-E. de la s.-p. de Yang-kou (préf. de Yen-tcheou, prov. de Chan-tong).

46.(타) Cf. n. 43.257.

46.(167) Auj., s.-p. de Tsi-mo (préf. de Lai-tcheou, prov. de Chan-tong),

46.(168) Auj., s.-p. de Tong-ngo (préf. de T'ai-ngan, prov. de Chan-tong).

46.(169) En 370 ; cf. plus haut, p. 242, ligne 5.

46.(170) En 372 ; cf. plus haut, p. 242, ligne 4.

46.(171) Cf. n. 43.262 , et n. 154 .

46.(172) Il est vraisemblable que la ville de Koan dont il est ici question correspond à l'ancien royaume de Koan, qui fut sous les Han orientaux la s.-p. de Wei, et qui se trouvait à l'O. de la s.-p. actuelle de Koan-tch'en (préf. de Ts'ao-tcheou, prov. de Chan-tong).

46.(173) Il est difficile de savoir à quel long mur il est fait ici allusion; il est peu vraisemblable que ce long mur soit celui qui avait été construit dans la seconde moitié du Ve siècle par le roi Siuen (cf. tome IV, n. 40.375), car, même dans sa partie la plus occidentale (s.-p. de P'ing-yn, préf. de T'ai-ngan), cette muraille était assez éloignée du pays de Tchao.

46.(174) Le Lie niu tchoan attribue la conversion soudaine du roi Wei à l'une de ses femmes, $Y u-k i$, qui le mit en garde contre son mauvais ministre Tcheou P'o-hou et lui recommanda un sage nommé maître Pei-kouo; Tcheou P'o-hou accusa à son tour $Y u-k i$ de tenir ce langage parce qu'elle avait été autrefois la maîtresse de maître Pei-kouo et il réussit à la faire enfermer dans une tour à neuf étages ; mais le roi reconnut l'innocence de sa femme et fit bouillir vif Tcheou P'o-hou.

46.(175) Sur Tseou Ki, voyez le chap. LXXIV des Mémoires historiques.

46.(176) C'est-à-dire dans la chambre qui était à droite de la sienne propre.

46.(177) Le bois d'éléococca servait à faire les boîtes de résonance des instruments à cordes.

46.(178) Sur Choen-yu K'oen, cf. Mém. hist., chap. LXXXIV. Dans le livre de Mencius (IV, a, chap. 17, et VI, b, chap. 6), on trouve relatées deux conversations de ce célèbre sophiste avec Mencius. Le Han che wai tchoan (chap. VI, p. $7 \mathrm{r}^{\circ}-\mathrm{v}^{\circ}$ ) met aussi en scène ces deux interlocuteurs.

46.(179) Dans les lignes qui suivent, Choen-yu K'oen va proposer sous une forme très énigmatique cinq préceptes relatifs au gouvernement, et Tseou Ki-tse montrera par ses réponses qu'il a immédiatement compris le sens de ces paroles obscures.

46.(180) Le ministre qui observe sans aucune défaillance tous ses devoirs envers son prince, réussit; celui qui omet quelques-unes de ses obligations envers son prince se perd. 
46.(181) Tseou Ki-tse prouve qu'il a saisi le sens caché des paroles de Choen-yu K'oen en disant qu'il ne s'écartera jamais du prince afin d'être toujours prêt à le servir.

46.(182) La graisse de porc et l'essieu en bois de jujubier symbolisent les conseillers du prince ; mais, de même qu'un essieu, quoique solide et bien graissé, ne tournera pas si on l'engage dans un moyeu percé d'un trou carré, de même les ministres du souverain ne pourront pas faire avancer le char de l'État si on leur fait obstacle.

46.(183) Pour faire un arc, on se sert de bois sec et vieux qu'ont réunit au moyen de colle forte; si cependant le bois est fendu, les parties de l'arc ne resteront pas jointes. De même, le peuple est uni par l'autorité du souverain; mais il ne faut pas que les diverses parties constitutives du peuple se dissocient et c'est pourquoi il est nécessaire de veiller à ce que les rites et les lois maintiennent la concorde entre elles.

46.(184) La fourrure de renard était chère ; un vêtement en peau de renard ne pouvait donc être réparé avec une peau de qualité fort grossière. De même on ne saurait introduire des gens méprisables parmi les hommes sages qui participent au gouvernement de l'État.

46.(185) Il faut contrôler les matériaux avec lesquels on fabrique un char ou un instrument de musique, si on veut que le char ou l'instrument réponde à ce qu'on attend de lui. De même, pour que l'État soit prospère, il faut avoir soin d'éliminer les mauvais fonctionnaires et d'appliquer avec exactitude les lois.

46.(186) On peut comparer ce texte de Se-ma Ts'ien au passage suivant du Sin siu (chap. II, p. $5 \mathrm{r}^{\circ}$ et $\mathrm{v}^{\circ}$ ) de Lieou Hiang (80-9 av. J.-C.) :

«Autrefois Tseou Ki, à cause de son habileté à jouer du luth, fut admis en présence du roi Siuen, de $T s$ 'i ; le roi Siuen l'apprécia fort, Tseou Ki lui dit :

— Le luth est ce qui symbolise le gouvernement.

Il expliqua alors au roi la manière dont le luth symbolisait le gouvernement, ainsi que la façon dont se conduit un roi hégémon. Le roi Siuen, très satisfait, conversa avec lui pendant trois jours et le nomma aussitôt conseiller. Il y avait à $T s ' i$ les maîtres au pied de (la porte) $T s i$ (voyez plus loin l'explication de ce terme, à la date de 325), qui aimaient à discuter sur les affaires d'État. Quand Tseou Ki fut devenu conseiller de $T s$ ' $i$, le maître au pied de (la porte) Tsi, Choen-yu K'oen, et ses adhérents au nombre de 72 hommes (sur le nombre 72, cf. tome II, n. 08.108), méprisaient tous (Tseou) Ki en disant que, si on instituait un débat, Tseou Ki ne pourrait les égaler; s'entraînant donc les uns les autres, ils allèrent ensemble voir Tseou $\mathrm{Ki}$; les partisans de Choen-yu K'oen se montraient arrogants, tandis que Tseou $\mathrm{Ki}$ les traitait avec humilité. Choen-yu K'oen et les siens dirent :

- Un vêtement fourré en renard blanc, si on le répare avec une peau de mauvais mouton, qu'est-ce que cela signifie?

Tseou Ki répondit :

- Je comprends bien. Permettez-moi de ne pas oser mêler avec des sages des gens indignes.

Choen-yu K'oen dit :

— Dans un carré un cercle d'essieu rond, qu'est-ce que cela signifie?

Tseou Ki dit :

- Je comprends bien. Permettez-moi d'avoir soin de ne pas oser retenir des étrangers dans ma demeure.

Choen-yu K'oen et les siens dirent : 
- Trois hommes gardaient ensemble un mouton; le mouton ne pouvait pas manger et les hommes de leur côté ne pouvaient pas se reposer; qu'est-ce que cela signifie?

Tseou Ki dit :

- Je comprends bien. (Il faut) réduire (le nombre des) fonctionnaires et diminuer (le nombre des) magistrats pour qu'ils ne tourmentent pas le peuple (c.-à-d. que, de même qu'il ne faut pas trois hommes pour garder un seul mouton, il est mauvais qu'il y ait un trop grand nombre de fonctionnaires pour surveiller le peuple).

Choen-yu K'oen et les siens prononcèrent ainsi trois (énigmes) et Tseou Ki les expliqua trois fois comme un écho qui répond. Choen-yu K'oen et les siens, vaincus dans la discussion, se retirèrent ; Tseou $K i$ les traitait avec arrogance et Choen-yu K'oen et les siens se comportaient avec humilité.

46.(187) Cf. tome II, n. 07.129.

46.(188) Cette ville de $P$ 'ing-lou, qui est appelée ailleurs (t. III, p. 434) le P'ing-lou oriental était à la limite occidentale du pays de $T s^{\prime} i$; elle se trouvait au N. de la s.-p. de Wen-chang (préf. de Yen-tcheou, prov. de Chan-tong).

46.(189) Han che wai tchoan; chap. X, p. $4 \mathrm{v}^{\circ}$. Le Han che wai tchoan suppose que la conversation qui va suivre eut lieu entre le roi Siuen (342-324), de Ts'i, et le roi Hoei (370335), de Wei. Comme Se-ma Ts'ien cite (chap. CXXI, p. $3 \mathrm{v}^{\circ}-4 \mathrm{r}^{\circ}$ ) le Che wai tchoan de maître Han, son contemporain, il a pu le lire, et c'est pourquoi cet ouvrage peut être mis au nombre des sources dont s'est inspiré l'historien.

46.(190) C'est-à-dire le roi de Wei (capitale Ta-leang).

46.(191) Pour le roi de $T s$ 'i, les vrais joyaux d'un royaume ce sont les hommes éminents qui font sa grandeur.

46.(192) T'an est un nom de famille; tse est un terme honorifique qu'on employait en parlant des grands officiers ( $t a$ fou).

46.(193) Peut-être faut-il traduire « mes villes méridionales ».

46.(194) D'après Se-ma Tcheng, on compterait parmi les douze seigneurs les princes de Tchou, Kiu, Song et Lou. cf. tome IV, n. 40.383.

46.(195) P'an-tse n'est autre que T'ien P'an qui est mentionné dans le che kia de Tch'ou à la date de 333 (cf. t. IV, p. 385).

46.(196) Cf. tome IV, n. 32.214. Cette ville était à l'Est du pays de $T s$ ' $i$ et se trouvait voisine de l'ancien cours du Hoang ho.

46.(197) Cf. tome IV, n. 32.273. Cette ville était à l'extrême nord du pays de $T$ s' $i$.

46.(198) Les gens de Yen et de Tchao redoutent d'être attaqués par Ts'i; pour attaquer Yen, les soldats de $T s^{\prime} i$ seraient sortis par la porte septentrionale de la ville capitale de $T s ' i$; pour attaquer Tchao, ils seraient sortis par la porte occidentale; c'est pourquoi les gens de $T s$ ' $i$ adressent des sacrifices à la porte septentrionale et les gens de Tchao à la porte occidentale, afin d'empêcher qu'elles livrent passage à des armées dirigées contre eux.

46.(199) Non seulement on ne vole pas, mais même on ne ramasse pas les objets qui ont égarés sur la grande route.

46.(200) Capitale de Tchao; cf. n. 43.101.

46.(201) Tchan kouo ts'e; section de $T s^{\prime} i$; chap. VIII, p. $2 \mathrm{v}^{\circ}$. 
46.(202) Cf. n. 216.

46.(203) Tchang Cheou-tsie place Siang-ling sur le territoire de la s.-p. de Tseou (préf. de Yentcheou, prov. de Chan-tong).

46. (204) Ce texte étant peu clair dans les Mémoires historiques, je vais traduire ici la rédaction du Tchan kouo ts'e qui est plus intelligible :

«Lorsque Han-tan était en péril, Tchao implora le secours de Ts'i. Le prince (dont le nom de famille était) T'ien (c.-à-d. le roi de $T s^{\prime} i$ ) convoqua ses principaux ministres et délibéra avec eux, disant :

- Vaut-il mieux secourir Tchao ou ne pas le secourir?

Tseou tse dit :

— Le mieux est de ne pas le secourir.

Toan-kan Luen dit :

— Ne pas le secourir ne serait pas avantageux pour nous.

- Comment cela ? demanda le prince (dont le nom de famille était) T'ien.

- Si le prince de Wei, (répliqua Toan-kan Luen), s'annexe Han-tan, quel profit $T s^{\prime} i$ en retirera-t-il ?

Le prince (dont le nom de famille était) T'ien approuva ces paroles ; il leva alors des troupes en disant qu'il allait camper dans la banlieue de Han-tan. Toan-kan Luen dit :

- Lorsque je recherchais ce qui était avantageux et ce qui n'était pas avantageux, ce n'est pas à cela (que je voulais arriver). En effet, si vous secourez Han-tan et que vous campiez dans sa banlieue, il en résultera que Tchao ne sera pas conquis et que Wei restera intact. C'est pourquoi le mieux est d'aller au Sud attaquer Siang-ling pour épuiser Wei, quand Han-tan aura été pris (par Wei), vous profiterez de l'épuisement de $W e i$; de cette manière, Tchao aura été détruit et $W e i$ sera affaibli.

Le prince (dont le nom de famille était) T'ien approuva cet avis ; il leva donc des soldats et alla au Sud attaquer Siang-ling; le septième mois, Han-tan fut pris ; $T s$ ' $i$ profita alors de l'épuisement de $W e i$ et lui fit subir une grande défaite à Koei-ling.

46.(205) Tchan kouo ts'e; section de $T s^{\prime} i$; chap. VIII, p. 3 r ${ }^{\circ}$.

46.(206) Ici encore, le texte du Tchan kouo ts'e est notablement différent et réunit le passage que nous avons ici avec celui qu'on lira neuf lignes plus bas :

- Tseou $K i$, marquis $T c h$ 'eng, qui était conseiller de $T s$ 'i, et $T$ 'ien $K i$, qui était général, ne s'aimaient pas. Kong-suen Han dit à Tseou Ki :

- Pourquoi ne conseillez-vous pas au roi d'attaquer $W e i$ ? Si on est vainqueur, ç'aura été grâce à vos conseils et vous pourrez en tirer de la gloire. Si on est vaincu dans le combat et si T'ien $K i$ ne s'est pas avancé dans la mêlée et n'est pas mort, on trouvera quelque détour pour le faire périr.

Tseou $K i$ approuva ce langage et parla au roi pour qu'il envoyât $T$ 'ien $K i$ attaquer $\mathrm{Wei}$. T'ien $\mathrm{Ki}$ livra trois combats et remporta trois victoires. Tseou Ki en informa Kong-sien Han : celui-ci envoya alors un homme, tenant en main dix livres d'or, consulter les sorts sur la place publique ; (cet homme) dit : 
— Je suis au nombre des gens de T'ien Ki; ( $T$ 'ien $K i$ m'a chargé de dire en son nom:) J'ai livré trois combats et j'ai remporté trois fois la victoire; ma renommée en impose à tout l'univers; je désire faire une grande entreprise (c.-à-d. me révolter pour m'emparer du trône de $T s^{\prime} i$ ); les sorts sont-ils propices ou non?

«Quand celui qui était venu consulter les sorts fut sorti, (Kong-suen Han) ordonna à des gens de se saisir du devin qui lui avait donné cette consultation, et prouva ainsi en présence du roi son accusation. T'ien $K i$ alors s'enfuit.

46.(207) Tchang Cheou-tsie place Koei-ling à 21 li au N.-E. de la s.-p. de Tch'eng-che (laquelle se trouvait elle-même au S.-O. de la s.-p. actuelle de Kiu ye, préf. de Ts'ao-tcheou, prov. de Chan-tong). Le Tchou chou ki nien écrit Koei-yang (ce qui est fautif), et rapporte cette bataille à la $15^{\mathrm{e}}$ année (354) du roi Hien de la dynastie Tcheou.

46.(208) D'après Se-ma Tcheng, il s'agirait ici d'un grand officier dont le nom de famille serait Meou et l'appellation Sin. Les Tableaux chronologiques font cependant de Meou Sin le nom d'une femme du roi.

46.(209) Tchan kouo ts'e; section de $T s^{\prime} i$; chap. VIII, p. $2 \mathrm{v}^{\circ}$.

46.(210) Lin-tse était la capitale de $T s ' i$. Dans le chap. LXXV des Mém. hist., il est dit que $T$ 'ien $K i$ attaqua à l'improviste une ville sur la frontière du pays de $T s$ ' $i$.

46.(211) Sur le prince de Chang, dont le nom de famille était Kong-suen, et le nom personnel Yang, cf. Mém. hist., chap. LXVIII.

46.(212) Cf. t. I, p. 304, et t. II, p. 66, où ce fait est rapporté à l'année 343.

46.(213) D'après le Kouo ti tche (chap. VI, p. $17 \mathrm{v}^{\circ}$ ), cette ville de Leang était nommée, à l'époque des royaumes combattants, Nan-leang c.-à-d. Leang méridional, pour la distinguer de Ta-leang (K'ai-fong fou) et de Chao-leang (près de Han-tch'eng hien). Nan-leang était à 200 pas au S.-O. de la préf. sec. de Jou, (prov. de Ho-nan), c.-à-d. qu'elle était pratiquement identique à la ville actuelle de Jou. Elle appartenait autrefois aux chefs Man qui avaient le titre de vicomte et qui apparaissent à diverses reprises dans le Tso tchoan (cf. Legge, Chinese Classics, vol. V, prolégomènes, p. 125, § 5). La résidence de ces chefs Man était dans la ville de Ma-tch'eng dont le nom n'est qu'une corruption de la dénomination Ma-tch'eng « la ville des Man »; Ma-tch'eng se trouvait aussi dans le voisinage de la préf. sec. de Jou.

46.(214) Tchan kouo ts'e; section de $T s^{\prime} i$; chap. VIII, p. $2 \mathrm{v}^{\circ}-3 \mathrm{r}^{\circ}$.

46.(215) Le Tchan kouo ts'e dit: «le prince dont le nom de famille était T'ien», ce qui n'indique point de quel souverain de $T s$ ' $i$ il est question. Il est douteux que Se-ma Ts'ien ait raison en datant ce texte du Tchan kouo ts'e de la seconde année (341) du roi Siuen. D'après le Tchou chou ki nien, en effet, c'est la $26^{\mathrm{e}}$ année (343) du roi Hien de la dynastie Tcheou, que l'armée de Wei combattit à Ma-ling contre T'ien P'an, général de $T s$ 'i.

46.(216) Cette phrase ne se retrouve pas ici dans le Tchan kouo ts' $e$; cf. p. 240, lignes 1-2 et n. 156. C'est dans la délibération relative aux secours demandés par Tchao, délibération qui précède immédiatement celle qui est relative aux secours demandés par Han, que le Tchan kouo ts'e (chap. VIII, p. $2 \mathrm{v}^{\circ}$ ) cite la réponse de Tseou Ki. Cf. n. 204.

46.(217) Le Tchan kouo ts'e dit: Tchang Mien. Cf. n. 157.

46.(218) D'après Se-ma Tcheng, il s'agirait ici de Suen Pin. Le Tchan kouo ts'e met ces paroles dans la bouche de T'ien Tch'en-se. D'après le commentateur Ou Che-tao, Se-ma Tcheng dit, dans son commentaire Souo yn, que le Tchan kouo ts'e donne la leçon T'ien K' $i$ se ; ceci prouve une fois de plus que Se-ma Tcheng connaissait un texte du Tchan kouo ts'e différent de celui que nous avons aujourd'hui et sur lequel déjà $O u$ Che-tao faisait son commentaire à l'époque mongole. 
46.(219) C'est nous qui aurons besoin du secours de Han, et qui devrons par conséquent subir ses conditions.

46.(220) Tchan kouo ts' $e$ : « D'ailleurs Wei a résolu de détruire Han ».

46.(221) Ou Che-tao discute la question controversée de l'emplacement de Ma-ling et se rattache à l'opinion de $Y u$ Hi qui le met à $60 l i$ au N.-E. de la ville de Kiuen (préf. sec. de P'ou, préf. de Ts'ao-tcheou, prov. de Chan-tong).

46.(222) Tchao, Wei, Han.

46.(223) Le Kouo ti tche (chap. VII, p. $3 \mathrm{r}^{\circ}$ ) place l'ancienne ville de Po-wang à 45 li au S,-E. de la s.-p. de Hiang-tch'eng laquelle se trouvait au S. de la s.-p. actuelle du Nan-tchao (préf. de Nan-yang, prov. de Ho-nan).

46.(224) Cf. n. 44.201.

46.(225) Cf. n. 43.257.

46.(226) Se-ma Tcheng signale ici encore la grave divergence qui existe entre Se-ma Ts'ien et le Tchou chou ki nien au sujet du roi Hoei. Cf. $\underline{\text { n. } 44.205}$.

46.(227) Cf. tome IV, n. 33.245.

46.(228) Cf. t. IV, n. 33.245.

46.(229) Cf. p. 64, lignes 1-4.

46.(230) Cf. Mém. hist., chapitre LXXIV. Dans le chapitre sur les monuments de la littérature (I wen tche : chap. XX, p. $13 \mathrm{v}^{\circ}$ ), le Ts'ien Han chou cite le livre de Tseou-tse, en 49 chap. et le Tseou tse tchong che en 56 chap. Une addition en petits caractères nous apprend que $T$ seoutse avait pour nom personnel Yen; qu'il était originaire du pays de $T s$ 'i, qu'il fut le maître du roi Tchao de Yen, qu'il fut au nombre des (savants qui se rassemblaient) au pied de (la porte) $T s i$ (cf. plus loin, n. 236), enfin qu'on le surnomma "Yen divin dans la discussion ». Ces deux ouvrages de Tseou Yen sont classés par le Ts'ien Han chou dans l'école du yn et du yang.

46.(231) Cf. Mém. hist., chap. LXXIV.

46.(232) Le I wen tche du Ts'ien Han chou (chap. XXX, p. $12 \mathrm{v}^{\circ}$ ) cite l'ouvrage de T'ien-tse en 25 chapitres, qu'il range dans l'école du tao. Il ajoute que T'ien-tse avait pour nom personnel $P$ 'ien, qu'il était originaire du pays de $T s$ ' $i$, qu'il fut au nombre des voyageurs (qui se rassemblaient) au pied de (la porte) Tsi (voyez plus bas, n. 236), et qu'il eut le surnom de "P'ien à la bouche divine». Ce surnom, dit le Ts'i lio de Lieou Hiang cité dans le Che ki p'ing lin, lui fut décerné à cause de son habileté dans la discussion.

46.(233) D'après Tchang Cheou tsie, le I wen tche du Ts'ien Han chou citerait le livre de Tsie $Y u$ en 2 chapitres au nombre des ouvrages de l'école du tao. Mais je ne trouve mentionné dans le $I$ wen tche (p. $\left.13 \mathrm{r}^{\circ}\right)$ que le livre en 2 chapitres d'un certain Tsie-tse qui est de l'époque de l'empereur $\mathrm{Ou}$, de la dynastie $\mathrm{Han}$, et ne doit donc pas être confondu avec Tsie Yu.

46.(234) Dans le $I$ wen tche du Ts'ien Han chou (p. $14 \mathrm{v}^{\circ}$ ) on trouve rappelé, parmi les ouvrages de l'école des lois, le livre de Chen tse en 42 chapitres.

46.(235) Dans le chap. LXXIV (p. $2 \mathrm{v}^{\circ}$ ) des Mém. hist., on voit que Hoan Yuen composa son livre en 2 chapitres. On remarquera que, dans cette énumération, ne figure pas le nom de Mencius qui cependant eut de nombreuses conversations avec le roi Siuen; cette omission s'explique si on remarque que les relations de Mencius et du roi se tendirent assez rapidement et aboutirent à une rupture ; cf. Legge, C. C., t. II, prolég., p. 25-29.

46.(236) Cette expression que nous avons eu déjà l'occasion de mentionner dans des notes précédentes (cf. n. 230 et n. 232) est expliquée dans le Pie lou de Lieou Hiang (cité par P'ei $Y n$ ) de la manière suivante: [a][b] Tsi men était le nom d'une des portes de la capitale du 
royaume de $T s$ ' $i$; les discoureurs se donnaient rendez-vous au pied de cette porte. D'après $S e$ ma Tcheng, qui se fonde sur le $T s^{\prime} i$, la porte $T s i$ était la porte occidentale de la capitale; comme elle était à côté de [c] la rivière, on la nomma la porte $T s i$, à cause de la prononciation analogue des mots [a] et [c]. Cette hypothèse me paraît d'ailleurs peu vraisemblable. Se-ma Tcheng cite encore l'opinion d'un certain $Y u H i$ : dans le pays de $T s$ ' $i$, dit cet auteur, il y avait une montagne appelée la montagne Tsi au pied de laquelle on avait construit une hôtellerie pour y recevoir les sophistes voyageurs.

46.(237) Cf. tome II, n. 05.357.

46.(238) Cf. n. 44.221.

46.(239) Cf. tome II, n. 07.135. T'ien Yng est aussi connu sous son nom posthume de prince de Tsing-kouo (cf. Mém. hist., chap. LXXV). - D'après le Tchan kouo ts'e (chap. VIII, section de $T s^{\prime} i$ ), lorsque le roi de $T s^{\prime} i$ voulut donner Sie en fief à T'ien Yng, le roi de Tch'ou en fut irrité et se disposait à s'y opposer lorsqu'un certain Kong-suen Han le fit changer d'avis en lui montrant que le roi de $T s^{\prime} i$ s'affaiblissait lui-même lorsqu'il détachait de ses possessions une ville importante pour la donner à T'ien Yng.

46.(240) Cette localité est aussi appelée Koan-tsin. Cf. n. 44.226.

46.(241) Cf. tome II, n. 05.375.

46.(242) Général de Tch'ou; cf. t. II, p. 74.

46. (243) Haut dignitaire du pays de $T s$ ' $i$.

46.(244) Sans doute, la porte de la ville; peut-être s'agit-il de la porte $T s i$ (cf. n. 236).

46.(245) Han P'ing était conseiller de Han; Tchang I était conseiller de $T s$ 'in. Le prince de Wei s'adresse à ces deux hommes pour qu'ils conseillent aux princes de Han et de Ts'in de le secourir contre $T s^{\prime} i$.

46.(246) Tchou-tsao devait être une ville de Wei; Siu Koang la place dans la commanderie de $T s i-y n$ (dont le centre administratif était à $4 l i$ au N.-O. de la s.-p. de Ting-t'ao, préf. de Ts'aotcheou, prov. de Chan-tong).

46.(247) Si Han et $T s^{\prime}$ in viennent à son secours.

46.(248) Il me semble que la suite des idées exigerait qu'on dît: "Le prince de Wei se détournera de Han et de $T s^{\prime}$ in pour suivre $T s^{\prime} i »$. En effet, le prince de Wei ayant vainement imploré le secours de Han et de $T s^{\prime}$ in, fera soudain volte-face et acceptera les conditions de paix que lui imposera $T s$ ' $i$.

46. (249) Le prince de $T s$ 'in n'aura plus aucun besoin des conseils de Tchang I, puisque Tchang I l'invitait à secourir Wei et que cette politique est rendue impossible par le changement d'attitude de $W e i$.

46.(250) Tandis qu'auparavant $T s^{\prime} i$ luttait contre Wei, et $T c h$ 'ou, contre $T s$ 'in, maintenant au contraire (si on admet la correction proposée dans la note 248) Wei s'est soumis à $T s^{\prime} i$, et $T s$ 'in, n'ayant plus à intervenir en sa faveur, est devenu l'ami de $T s^{\prime} i$ et de $T c h$ 'ou. Dans ce cas, $T s^{\prime} i$ aura remporté un succès complet.

46.(251) T'ien Tchen fait observer à son interlocuteur que son raisonnement suppose que Han et $T$ s'in ont refusé de venir au secours de $W e i$; mais si Han et T'sin viennent au secours de $W e i$, que va-t-il se passer?

46.(252) On ne voit pas bien ce que Song vient faire dans cette galère.

46.(253) Ts'in, Han et Wei.

46. (254) K'iu Kai était le général de Tch'ou qui venait d'être battu par $T s$ 'in. 
46.(255) Cf. n. 253.

46.(256) Le royaume de Wei.

46.(257) Il faut lire [], comme dans l'édition japonaise du Che ki p'ing lin, et non [], comme dans l'édition de Chang-hai. Si je comprends bien ce texte fort embrouillé, Tchang I veut dire que, en secourant $W e i$, le roi de $T$ s'in se sera substitué au Fils du Ciel dont la capitale (Lo-yang) était dans la région de San-tch'oan (cf. n. 45.184), car il aura fait précisément ce qu'aurait dû faire le Fils du Ciel.

46.(258) C'est Sou Tai qui parle en s'adressant à T'ien Tchen, conseiller de $T s$ 'i.

46.(259) Cf. $\underline{\text { n. 45.184 }}$, où le mot est expliqué de la même manière. Le sens semble être que le roi de $T s$ 'in pourra se vanter auprès du Fils du Ciel (dont la capitale était dans le San-tch'oan) d'avoir rétabli le bon ordre dans l'empire et pourra obtenir le titre d'hégémon.

46.(260) Pourquoi Han Ping, qui était conseiller de Han, apparaît-il maintenant comme conseiller de $T s$ 'in, c'est ce que je renonce à comprendre. Tout ce qui suit est fort obscur.

46.(261) Il aura obtenu que le prince de Wei vienne à lui.

46.(262) Sou Tai s'adresse à T'ien Tchen.

46. (263) Le mot [] désigne la double planchette de bois sur laquelle on inscrivait un compte ; ainsi, dans les Annales principales de Kao-tsou (t. II, p. 327, lignes 1 et 2), on lit l'histoire de deux marchandes qui «brisaient leur compte», c.-à-d. qui annulaient leurs factures. La planchette de droite était entre les mains de celui qui avait reçu une marchandise; la planchette de gauche appartenait à celui qui l'avait livrée et qui était par conséquent le créancier. C'est ainsi que le Tao té king (\$ 79) compare le sage qui répand ses bienfaits sur les hommes sans demander aucun paiement, à un créancier qui «tient la moitié de gauche du contrat et qui ne réclame rien aux autres ». La phrase que nous avons ici dans les Mémoires historiques est toute semblable. En d'autres termes, $T s$ ' $i$ aura rendu service à $T s$ 'in et à Han en leur faisant acquérir des territoires ; il sera donc dans la posture d'un créancier qui tient en main la partie gauche du contrat pour prouver qu'il a droit à un paiement.

46.(264) C'est-à-dire Tchang $I$.

46. (265) Les Tableaux chronologiques et le Che kia de Tch'ou rapportent ces événements à l'année 301 ; cf. tome IV, n. 40.333.

46.(266) Cf. tome II, n. 05.394.

46.(267) T'ien Wen, prince de Mong-tch'ang, était le fils de T'ien Yng et avait hérité de son père le fief de Sie (cf. n. 44.241). Sa biographie se trouve dans le chap. LXV des Mém. hist.

46.(268) Cf. Mém. hist., chap LXXV.

46.(두) Cf. $\underline{\text { n. } 44.255 .}$

46.(270) Cf. n. 44.256.

46.(271) Cf. p. 94-95.

46.(272) Cf. p. 89. C'est en 296 que le Tchong-chan fut anéanti.

46.(273) Tchan kouo ts'e : section de Ts'i; chap. XI, p. $5 \mathrm{r}^{\circ}-\mathrm{v}^{\circ}$.

46.(274) L'édition du Tchan kouo ts'e de l'époque des Yuen et l'édition de Yao Hong en 1145 (réimpression de Chang-hai 1896) donnent la leçon fautive «Sou Ts'in ». L'édition de 1581 écrit «Sou tse », ce qui ne préjuge rien. La leçon «Sou Tai» des Mémoires historiques est correcte.

46. $(\underline{275})$ Le Tchan kouo ts' $e$ dit « la porte méridionale Tchang-hoa » (Hoa-tchang, d'après la leçon de l'édition de 1145). Mais cette leçon est fautive, car le Kouo ti che, cité par Ou 
Che-tao, nous informe que, dans la ville de $T s^{\prime} i$ (c.-à-d. à Lin-tse, capitale de $T s^{\prime} i$ ) à l'Est, il y a la porte $L u$ et les portes $O u$-lou et Tchang-hoa. le commentaire de Tchang Cheou-tsie me paraît citer inexactement le texte du Kouo ti tche en disant: Dans la ville de $T s$ ' $i$, à l'Est de Tchang-hoa, il y a la porte $L u$ et la porte $\mathrm{Ou}$-lou.

46.(276) Le titre d'empereur restera intact, soit que vous laissiez $T s$ 'in s'en parer le premier, soit que vous prétendiez l'assumer en même temps que lui.

46.(277) Le prince Yen, de Song, commettait de telles orgies qu'on lui avait donné le surnom de Kie Song, c'est-à-dire Song semblable à Kie, le souverain dont les crimes amenèrent la chute de la dynastie Hia; cf. tome IV, n. 38.206.

46.(278) La capitale du royaume de Song correspond à la s.-p. actuelle de Chang-k'ieou (préf. de Koei-té, prov. de Ho-nan).

46. (279) P'ou-yang était la capitale des princes de $W e i$, et d'ailleurs le seul territoire qui leur fût resté ; cf. tome IV, n. 37.101.

46.(280) Tong-ngo (cf. n. 43.267); comme cette ville appartenait alors à Tchao et qu'elle était située dans l'Est de ce royaume, on l'appelait «le royaume oriental», c.-à-d. la partie orientale du royaume : Le Tchan kouo ts'e écrit « la partie (du royaume) de Tchao qui est à l'Est du Ho sera en danger ».

46. (281) T'ao, qui est aujourd'hui la s.-p. de Tsing-t'ao, et $P$ 'ing-lou, qui était au N. de la s.-p. de Wen-chang (cf. tome III, n. 28.203), étaient toutes deux à l'Est de Ta-leang (K'ai-fong fou), capitale du royaume de Wei. Si Ts'i s'emparait de T'ao et de P'ing-lou, le roi de Wei, sentant l'ennemi si proche, n'oserait plus ouvrir les portes de sa ville.

46.(282) Le Kouo ti tche (chap. VI, p. $2 \mathrm{r}^{\circ}$ ) place Sin-tch'eng sur le territoire de la s.-p. de Song-tch'eng (laquelle se trouvait au S. de la s.-p. actuelle de Chang-k'ieou, préf. de Koei-té, prov. de Ho-nan).

46.(283) D'après le Kouo ti tche (chap. VI, p. 6 v ${ }^{\circ}$ ), Yang-tsin était à 37 li au N.-O. de la s.-p. de Tch'eng-che (laquelle se trouvait au S.-O. de la s.-p.. actuelle de Kiu-ye, préf. de Ts'aotcheou, prov. de Chan-tong).

46.(284) Il semble que ce Han Nie était le général ou le conseiller de $T s$ 'i.

46.(285) C'est-à-dire : s'il s'annexe tout le territoire de Song.

46.(286) En 286, en effet, Wei offrit à Ts'in la ville de Ngan-i (cf. t. II, p. 84).

46.(287) Cf. p. 2, lignes 13-19.

46.(288) Si les dispositions de $T s^{\prime} i$ ne vous sont pas bien connues, c'est que tous les autres États ont intérêt à vous les montrer sous un faux jour.

46.(289) D'après Se-ma Tcheng, le Tchan kouo ts'e écrirait [] au lieu de []; il faudrait alors traduire : «le territoire Song ne pourra pas jouir du calme ». Cette remarque de Se-ma Tcheng prouve qu'il connaissait une édition du Tchan kouo ts'e où figurait le texte que je ne puis pas retrouver dans les éditions de 1581 et de 1896 du Tchan kouo ts'e.

46.(290) Les plus âgés, et par suite les plus expérimentés, parmi les sophistes qui voyageaient de pays en pays pour proposer aux princes leurs plans machiavéliques.

46.(291) C'est-à-dire : se succédant à intervalles rapprochés sur les routes.

46.(292) Cf. tome IV, n. 39.238.

46.(293) Cf. n. 194, et t. IV, p. 407. 
46.(294) Se-ma Ts'ien omet ici de rappeler que le roi de Yen fut l'instigateur de l'attaque dirigée contre $T s^{\prime} i$ et qu'il ne fit d'ailleurs que venger la grande défaite infligée au roi son père par Ts' $i$ en l'an 314 ; cf. t. IV, p. 143 et suiv.

46.(로) Le mot [] est insuffisant; il faut suppléer, après ce mot, le mot [] « les soldats ».

46.(296) Capitale de $T s^{\prime} i$; cf. n. 101.

46.(297) Cf. tome IV, n. 31.209. Tseou et Lou, quoique formant deux principautés distinctes, étaient fort voisins l'un de l'autre ; aussi sont-ils souvent, comme ici, nommés de compagnie ; cf. tome IV, n. 40.398.

46.(298) Cf. tome IV, n. 32.140. Kiu était une ville de Ts'i dont Yen n'avait pu s'emparer. Nous lisons en effet dans le Tchan kouo ts'e (chap. XIII, p. $1 \mathrm{v}^{\circ}$; section de $T s^{\prime} i$ ) :

«Yen attaqua Ts' $i$ et lui prit soixante-dix villes; seules, les villes de Kiu et Tsi-mo ne se rendirent pas.

46.(299) Tout ceci est assez obscur. Le texte suivant du Tchan kouo ts'e (chap. XIII, p. $1 \mathrm{r}^{\circ}$ ) nous fournit quelques indications nouvelles qui ne suffisent pas cependant à tout éclaircir :

« Parmi les gens du peuple qui habitaient les faubourgs de (la capitale de) $T s$ ', il y avait un certain Hou Hiuen qui énonçait ouvertement ses critiques ; le roi Min le fit décapiter dans le carrefour de T'an. La population cessa d'être attachée au (roi de) $T s$ ' $i$. Un certain Tch'en Kiu, qui était un membre d'une famille issue d'un petit-fils de souverain ${ }^{1}$, dit franchement :

- (Le roi) a tué cet homme à Tong-lu; la famille royale n'est plus de cœur avec lui.

Se-ma Jang-ts' ${ }^{\prime} u^{2}$ était à la tête du gouvernement; (le roi Min) le tua; les principaux ministres ne furent plus attachés (au roi). C'est pourquoi (le roi de) Yen leva des soldats, mit à leur tête le prince de Tch'ang-kouo ${ }^{3}$ et l'envoya attaquer ( $\left.T s^{\prime} i\right)$. (Le roi de) $T s^{\prime} i$ chargea Hiang tse de prendre le commandement de ses troupes pour lui tenir tête. L'armée de $T s$ ' $i$ fut défaite; Hiang tse s'enfuit avec un seul char; Ta tse recueillit les soldats qui restaient et les remit en campagne ; il combattit contre Yen; il demanda à recevoir quelque récompense ; le roi Min ne voulut point lui en accorder. L'armée fut battue et se débanda. Le roi s'enfuit (dans la ville de) Kiu. Nao Tch'e lui fit des remontrances, disant :

- Entre Ts'ien-tch'eng et Po-tch'ang ${ }^{4}$ sur une superficie de plusieurs centaines de $l i$, il a plu du sang qui a mouillé les vêtements ; ô roi, le savez-vous ?

Le roi dit :

- Je l'ignorais.

(Nao Tch'e reprit) :

- Entre Yng et $P{ }^{1}{ }^{1}$, la terre s'est fendue jusqu'aux sources ${ }^{2}$; ô roi, le savez-vous?

\footnotetext{
${ }^{1}$ Il était donc encore considéré comme faisant partie de la famille royale.

2 Dans le chap. LXIV des Mém. hist., on lit la biographie de Se-ma Jang-ts'iu qui vivait dans le royaume de $T s$ ' $i$ à l'époque du duc King (547-490) et qui ne doit donc pas être confondu avec le personnage de même nom qui est mentionné ici.

${ }^{3}$ Le prince de Tch'ang-kouo n'est autre que Yo I.

4 D'après une note du Tchan kouo ts'e, Ts'ien-tch'eng était sur le territoire de l'arrondissement de $T$ s'ing, qui est aujourd'hui la préfecture de $T$ s'ing-tcheou, prov. de Chan-tong. Po-tch'ang était une localité qui dépendait de Ts'ien-tch'eng.
} 
— Je l'ignorais, dit le roi.

(Nao Tch'e dit encore) :

- Il y a des gens qui devant la porte de votre palais se lamentent; quand on les cherche, on ne les trouve pas ; quand on s'éloigne, on entend leurs voix ; ô roi, le savez-vous?

— Je l'ignorais, répondit le roi.

Nao Tch'e dit :

— Quand le Ciel fait pleuvoir du sang jusqu'à en mouiller les vêtements, c'est le Ciel qui ainsi vous accuse; quand la Terre se fend jusqu'aux sources, c'est la Terre qui ainsi vous accuse ; quand il y a des hommes qui se lamentent devant la porte de votre palais, c'est l'Homme qui ainsi vous accuse. Ainsi, le Ciel, la Terre et l'Homme vous accusent tous trois et vous ignorez leurs avertissements ! Comment pourriez-vous éviter le dernier supplice ?

Alors il tua le roi Min dans le quartier de $\mathrm{Kou}^{3}$. L'héritier présomptif quitta ses tuniques et enleva ses habits et se réfugia dans la famille du t'ai-che où il fut occupé à arroser le jardin; la fille du t'ai-che, dame Heou, qui fut (plus tard) la reine $\mathrm{Heou}$, reconnut qu'il était un homme de haute condition et le traita fort bien. T'ien Tan, grâce à la ville de $T s i-m o{ }^{4}$ et à ce qui restait des soldats précédemment battus et fugitifs, vainquit les soldats de Yen et fit tomber dans une embûche $K i K_{i e}{ }^{5}$; il reconstitua le royaume de $T s{ }^{\prime} i$; il se hâta d'aller chercher à Kiu l'héritier présomptif et le nomma roi. Quand le roi Siang fut monté sur le trône, la reine Heou devint reine ${ }^{6}$; elle enfanta Kien, roi de $T s^{\prime} i$ ».

46.(300) Tchan kouo ts' $e$ : section de $T s^{\prime} i$; chap. XIII, p. $4 \mathrm{r}^{\circ}-\mathrm{v}^{\circ}$.

46. $(\underline{301})[\mathrm{a}][\mathrm{b}][\mathrm{c}]$ Cette fille du $t$ 'ai -che s'appelait dame Heou; quand elle fut devenue reine, on ne put lui donner le titre ordinaire de $[\mathrm{b}][\mathrm{c}]$, car alors il aurait fallu répéter le mot [c] et l'appeler $[\mathrm{b}][\mathrm{c}][\mathrm{c}]$, ce qui eût été inintelligible ; on substitua donc le titre de $[\mathrm{a}][\mathrm{b}]$, à celui de [b][c] (note de l'édition de 1581 du Tchan kouo ts'e).

46.(302) Le Tchan kouo ts'e ajoute ici ce qui suit :

« A la mort du roi Siang, son fils, Kien, monta sur le trône et fut roi de Ts'i. La reine Heou servit $T s^{\prime}$ 'in avec attention et fut de bonne foi envers les seigneurs; c'est pourquoi Kien régna pendant plus de quarante ans sans avoir à souffrir de la guerre. Ts'in Che-hoang envoya un jour un émissaire offrir à la reine Heou des anneaux de jade entrelacés en disant :

- A Ts' $i$ on est fort savant ; mais peut-on détacher ces anneaux ?

La reine Heou les montra à ses officiers assemblés, mais ils ne surent pas les détacher. La reine Heou prit un marteau et en frappa les anneaux qu'elle brisa ; puis elle remercia l'envoyé de $T$ s'in en lui disant :

${ }^{1}$ Ces deux localités se trouvaient sur le territoire de la préfecture de T'ai-ngan.

${ }^{2}$ Les Chinois ont reconnu que, sous la terre, il y a des sources. D'où le nom de « sources jaunes » donné au séjour des morts, parce que les morts habitent sous la terre et que la couleur jaune est la couleur de la terre.

${ }^{3}$ C'était le nom d'un quartier de la ville de Kiu.

${ }^{4} T$ si-mo et Kiu étaient les deux seules villes qui fussent restées au pouvoir de $T s ' i$ : cf.n. 298.

${ }^{5}$ Ki Kie était un général de Yen.

${ }^{6}$ L'héritier présomptif étant monté sur le trône reçut après sa mort le titre posthume de roi Siang ; il épousa la fille du t'ai-che, dame Heou, qui devint la reine Heou. 
— J'ai eu soin de les détacher. (Cf. l'anecdote d'Alexandre le Grand et du nœud gordien).

Quand la reine Heou fut malade et près de mourir, elle avertit Kien en lui disant :

— Parmi nos officiers, ceux qui sont dignes d'être employés par vous sont tels et tels.

Kien dit :

— Permettez-moi d'écrire leurs noms.

- Fort bien, répondit la reine Heou.

(Kien) prit un style et une tablette pour recueillir ses paroles, mais la reine Heou dit :

— Moi, vieille femme, je suis morte.

Après la mort de la reine Heou, Heou Cheng devint conseiller de $T s$ ' $i$; il reçut en grande quantité de l'or et des objets précieux que $T s^{\prime}$ in lui donnait secrètement; il envoya dans le pays de $T s^{\prime}$ in des étrangers qui (à leur retour), tenaient tous des discours mensongers pour exhorter le roi à rendre hommage à $T s^{\prime}$ in et à ne pas faire de préparatifs de guerre.

46.(303) Ngan-p'ing, dit Tchang Cheou-tsie, était à 19 li à l'E. de la s.-p. de Lin-tse (préf. de $T s$ 'ing-tcheou, prov. de Chan-tong); c'était autrefois la ville de Hi qui appartenait à la principauté de $K i$.

46. $\underline{304}$ ) Cf. tome II, n. 05.464 .

46.(305) D'après Se-ma tcheng, le Tchan kouo ts'e placerait ce discours dans la bouche de Sou $T s$ 'in, ce qui est une erreur, car, à cette époque, Sou Ts'in était mort depuis longtemps. En outre, le Tchan kouo ts'e substituerait dans tout ce texte le nom du royaume de Yen à celui du royaume de Tch'ou. Je n'ai pas retrouvé dans le Tchan kouo ts'e le passage auquel fait allusion Se-ma Tcheng.

46.(306) Dans les Annales principales des Tcheou on lit (t. I, p. 317-318) que ce fut sept années après l'année 256 que le roi Tchoang-siang anéantit les Tcheou orientaux et les Tcheou occidentaux. Il est certain que cet événement eut lieu la première année du roi Tchoang-siang; mais c'est une question de savoir si cette première année correspond à l'année 249 ou à l'année 250. D'après les Tableaux chronologiques, qui n'attribuent que trois années de règne au roi Tchoang-siang, ce roi dut commencer à régner en 249; mais si l'on s'en rapporte aux Annales principales des $T s$ 'in qui font durer ce règne pendant quatre années, il faut dire que la première année du roi Tchoang-siang est l'année 250 (cf. tome II, p. 96, n. $3)$.

46.(307) Cf. p. 275, dernière ligne.

46.(308) Cf. n. 44.380.

46.(309) Le futur Ts' in Che-hoang-ti.

46.(1ㅡ) Il ne peut être question ici de la montagne $L i$ qui se trouvait dans la s.-p. actuelle de Yong-tsi (préf. de P'ou-tcheou, prov. de Chan-si). Je ne crois pas non plus qu'il s'agisse de la ville de $L i$, qui fut une sous-préfecture à l'époque des Han, et qui était au nord de la s.-p. actuelle de Kou-tch'eng (préf. de Ho-kien, prov. de Tche-li). Peut-être faut-il admettre que $L i$ désigne ici l'ancienne sous-préfecture de Li-tch'eng qui porte aujourd'hui encore ce nom (préf. de Tsi-nan, prov. de Chan-tong). 
46.(311) Kong fut, sous les T'ang, la s.-p. de Kong-tch'eng ; c'est aujourd'hui la s.-p. de Hoei (préf. de Wei-hoei, prov. de Ho-nan).

46.(리) Cf. p. 276, lignes 2-5 de la note 302.

46.(록) Cf. n. 311 .

46.(314) L'étranger auquel il est fait allusion est Tch'en Tch'e qui sut attirer dans le pays de $T s^{\prime}$ in le roi de $T s$ ' $i$, et qui le fit interner à Kong dans un bois d'arbres funéraires où il mourut de faim, comme nous l'apprenons par le passage suivant du Tchan kouo ts'e (chap. XIII, p. 4 $\left.v^{\circ}-5 r^{\circ}\right)$ :

«Quand Kien, roi de $T s$ ’i, (se disposait à) aller rendre hommage au (roi de) $T$ s'in, le se-ma de la porte Yong s'avança et lui dit :

- Quand on met un roi sur le trône, est-ce pour les dieux du sol et des moissons, ou est-ce pour le roi lui-même qu'on le nomme roi ?

— C'est pour les dieux du sol et des moissons, répondit le roi.

Le se-ma reprit :

- Si on le nomme roi pour les dieux du sol et des moissons, pourquoi, ô roi, abandonnez-vous vos dieux du sol et des moissons pour aller auprès de $T s$ 'in ?

Le roi fit tourner son char et revint à Tsi-mo. Le gouverneur de Tsi-mo, apprenant que le se-ma de la porte Yong lui avait adressé des remontrances et avait été écouté, pensa que le (roi) pouvait être conseillé. Il se rendit donc en présence du roi de $T s$ ' $i$ et lui dit :

— Le territoire de $T s$ ' $i$ a une superficie de plusieurs milliers de $l i$; il a plusieurs millions d'hommes capables de porter la cuirasse; or les grands officiers des trois $T \sin$ sont tous mal disposés pour $T$ s' in et ceux qui se trouvent entre $N g o$ et Kiuen sont au nombre d'une centaine. Si, ô roi, vous les accueillez et si vous leur donnez une multitude d'un million d'hommes, vous ferez qu'ils recouvreront l'ancien territoire des trois $T \sin$ et alors la passe de Lin-tsin pourra être franchie. Les grands officiers de Yen-yng (ancienne capitale de Tch'ou, prise par $T$ s'in en 278) qui ne désirent pas agir en faveur de $T s$ 'in et qui se trouvent au pied et au sud de notre muraille sont au nombre d'une centaine; si vous les accueillez et si vous leur donnez une armée d'un million d'hommes, vous ferez qu'ils récupéreront l'ancien territoire de Tch'ou, et la passe $O u$ pourra être franchie. De cette manière le prestige de $T s$ ' $i$ pourra être établi et le royaume de $T s$ 'in pourra être ruiné. D'ailleurs, renoncer à vous tourner le visage vers le Sud pour donner des ordres souverains, et vous tourner vers l'Ouest pour servir $T s$ 'in, je pense, ô grand roi, que vous ne sauriez vous y résoudre.

Le roi de $T s$ 'i n'écouta pas ces avis. (Le roi de) $T s$ 'in envoya Tch'en Tch'e attirer le roi de $T s^{\prime} i$ par de fausses promesses et le faire entrer (dans le pays de $\left.T s^{\prime} i n\right)$ en lui garantissant le don d'un territoire de cinq cents $l i$. Le roi de $T s^{\prime} i$ n'écouta pas le gouverneur de Tsi-mo et crut aux paroles de Tch'en Tch'e; il se rendit donc dans le pays de $T s$ 'in; on le plaça à Kong dans un bois de pins et de cyprès où il mourut de faim. Avant (qu'il fût mort), les gens de $T s$ ' $i$ firent sur lui une chanson ainsi conçue :

«Parmi les pins, parmi les cyprès, celui qui a établi Kien à Kong, c’est l'étranger $\gg$.

46.(리) Cf. p. 225, lignes 1-14.

46.(리) Cf. p. 227, lignes 6-18. 
46.(317) Dans la prédiction telle que nous l'avons actuellement, il n'est pas question de révolte. - Les événements auxquels fait allusion $\mathrm{Se}$-ma Ts 'ien sont sans doute l'assassinat de Yen Jou-tse à l'instigation de T'ien K'i (489), et celui du duc Kien lors de la révolte de T'ien Tch'ang (481). Se-ma Tcheng prétend cependant que le premier des deux princes assassinés est le duc Tao, et non Yen Jou-tse ; cette opinion est sans doute dictée au commentateur par la considération que Yen Jou-tse n'eut pas de nom posthume et ne fut pas véritablement duc de $T s^{\prime} i$; mais elle ne peut guère se soutenir, car le duc Tao fut tué par Pao Mou en 485, et T'ien $K^{\prime} i$, qui était déjà mort à cette époque, ne peut être rendu responsable de ce meurtre.

\section{CHAPITRE XLVII : Dix-septième maison héréditaire. K’ong-tse.}

47.(101) Dans une Note additionnelle placée à la fin de ce chapitre, j'ai essayé de faire la critique de la biographie de Confucius écrite par Se-ma Ts'ien; j'ai montré comment elle avait été constituée et j'ai indiqué qu'elle me paraissait sur plusieurs points incertaine ou arbitraire. - Dans les Prolégomènes du premier volume de ses Chinese Classics (p. 56-90), Legge a raconté, d'une manière trop dogmatique à mon avis, la vie de Confucius en se fondant sur les recherches érudites qui forment les deux premiers chapitres de l'ouvrage de Kiang Yong (1680-1762) intitulé Hiang tang t'ou k'ao (H. T. K. K., chap. CCLXI et CCLXII).

47.(102) Cette ville de Tseou est appelée Tcheou dans le Luen yu (III, 15) où Confucius est désigné comme étant le fils de l'homme de Tseou; elle est appelée [] dans le texte du Tso tchoan (10 année du duc Siang) où il est fait mention du père de Confucius. Enfin on écrit parfois ce nom [], ce qui a conduit certains auteurs, comme par exemple Li Tao-yuen dans son commentaire au Choei-king, à confondre par erreur la ville où naquit Confucius avec l'ancienne principauté de Tseou ou Tchou qui est aujourd'hui la sous-préfecture de Tseou (cf. tome IV, n. 31.209). D'après le Kouo ti tche, l'ancienne ville de Tseou (celle où naquit Confucius) était à $60 \mathrm{li}$ au S.-E. de la s.-p. de Se-choei (préf. de Yen-tcheou, prov. de Chan-tong). K'ong Ngan-kouo, cité par Siu Koang, nous apprend que le père de Confucius, Chou-leang Ho, était gouverneur de cette ville.

On dit souvent que Confucius est né à K'iue-li et on place ce canton à $3 l i$ au sud-ouest de l'ancienne capitale de Lou qui est aujourd'hui la sous-préfecture de K'iu-feou (préf. de Yen-tcheou, prov. de Chan-tong); le « temple de l'ancien maître parfaitement saint » (c.-à-d. Confucius), qui se trouve à l'intérieur de la porte méridionale de $K^{\prime} i u-f e o u$, marquerait l'emplacement même de l'ancienne demeure de Confucius à K'iue-li. - En réalité, le nom de K'iue-li, d'après le Kouo ti tche (chap. V, p. $3 \mathrm{v}^{\circ}$ ), désigna d'abord un canton situé à 50 li au S. de la s.-p. de Se-choei, par conséquent dans le voisinage immédiat de cette ville de Tseou que Se-ma Ts'ien indique comme le lieu de naissance de Confucius; quand Confucius fut devenu grand, il se transporta dans la ville de $K^{\prime} i u-f e o u$ et l'endroit ou il résida prit le nom de K'iue-li; c'est parce qu'on a méconnu les deux applications différentes du nom de K'iue-li qu'on a parfois considéré à tort la ville de $K^{\prime} i u-f e o u$ comme ayant donné naissance à Confucius.

47.(103) D'après le Kouo ti tche, le district de Tch'ang-P'ing tirait son nom de 1a montagne Tch'ang-p'ing qui était à $60 l i$ au S. de la s.-p. de Se-choei (préf. de Yen-tcheou, prov. de Chan-tong).

47.(104) La généalogie traditionnelle de Confucius est exposée dans le $§ 39$ (pen sing kie) du Kia yu. En nous servant de ce texte et des indications que Se-ma Ts'ien nous donne, tant dans le présent chapitre que dans d'autres parties de son œuvre, nous pouvons exposer cette généalogie comme suit : Au début de la dynastie Tcheou, lorsque le fils du dernier souverain $Y n$ se fut révolté, le roi Tch'eng ${ }_{\text {p.285 }}$ conféra à $K^{\prime} i$ (ou $K^{\prime} a i$; cf. t. II, p. 214, n. 3), vicomte de

Wei, le territoire de Song (auj. s.-p. de Chang-k'ieou, préf. de Koei-té, prov. de Ho-nan), pour qu'il y accomplît les sacrifices en l'honneur de la maison des $Y n$ (cf. t. I, p. 208, et t. IV, p. 
231) ; $K^{\prime} i$ était le fils aîné, mais de naissance secondaire, de l'empereur $I$, avant-dernier souverain de la dynastie $Y n$ (cf. t. IV, p. 214), et c'est pourquoi il fut choisi pour représenter cette famille déchue ; après qu'il eut reçu le fief de Song, on le connut sous le nom de $K^{\prime} i$, vicomte de Wei et prince de Song ». K'i eut pour successeur son frère cadet Tchong-se, dont le nom personnel était Yen ou Sie; c'est celui que Se-ma Ts'ien (t. IV, p. 232) appelle Weitchong, c.-à-d. le cadet, (prince de) Wei. Celui-ci engendra Ki, duc de Song, qui, à son tour, eut pour successeur son fils Chen, duc Ting.

A partir d'ici, nous trouvons une divergence notable entre le Kia yu et Se-ma Ts'ien :

— d'après le premier de ces ouvrages, le duc Ting engendra Kong, duc Min et Hi, duc Siang ; ce dernier engendra Fou-fou Ho et Fang-se, duc $\mathrm{Li}$.

— d'après Se-ma Ts'ien (t. IV, p. 232), le duc Ting eut pour fils Kong, duc Min, et Hi, duc Yang, qui se succédèrent sur le trône ; le duc Yang fut assassiné par Fou-se (ou, suivant une bonne variante indiquée par Siu Koang, Fang-se) qui fut le duc Li. Se-ma Ts'ien considère ce Fou-se (ou Fang-se), duc $L i$, comme le fils du duc Min ; il n'indique pas quel était le rapport de parenté qui unissait Fou-fou Ho au duc $\mathrm{Li}$; nous pouvons admettre avec le Kia yu que Fou-fou Ho était le frère aîné du duc $L i$, car la chose semble confirmée par le passage du Tso tchoan ( $7^{\mathrm{e}}$ année du duc Tchao) où il est dit que Fou-fou Ho aurait eu plus de droits que le duc $\mathrm{Li}$ à monter sur le trône de Song. $\underline{\Omega}$ C'est à Fou-fou Ho que le Tso tchoan $\left(7^{\mathrm{e}}\right.$ année du duc p.286 Tchao) rattache expressément la généalogie de Confucius, et c'est ainsi que Confucius est regardé comme un descendant des princes du pays de Song, ou, en remontant plus haut encore, comme un rejeton des empereurs de la dynastie $Y n$.

- Fou-fou Ho engendra Song-fou Tcheou.

- Song-fou Tcheou engendra Che-tse Cheng ; ce personnage est omis dans le Che pen.

- Che-tse Cheng engendra Tcheng K'ao-fou ; sur la date à laquelle vécut Tcheng K'ao-fou, et sur le rôle qui lui est attribué par Se-ma Ts'ien dans la composition des odes sacrificatoires des Chang, cf. tome IV, n. 38.209.

- Tcheng K'ao-fou engendra K'ong-fou Kia. Ce personnage est le premier qui ait eu le nom de K'ong ; le Kia yu donne de l'origine de ce nom deux explications ;

- suivant la première, la règle voulait que, après cinq générations, les branches collatérales de la famille princière fussent considérées comme définitivement détachées de cette famille et prissent un nom de famille distinct; c'est ainsi que K'ong-fou Kia, descendant à la cinquième génération du duc Min, fut le fondateur de la famille $K^{\prime}$ ong ;

- $\quad$ suivant l'autre tradition, $K^{\prime}$ 'ong-fou est le surnom qui fut donné à $K^{\prime} o n g-f o u$ Kia à sa naissance, et ce surnom devint le nom de famille de sa postérité ; Kiang Yong approuve cette seconde explication.

Si Se-ma Ts'ien désigne ici K'ong Fang-chou, et non K'ong-fou Kia, comme l'ancêtre de la famille $K^{\prime}$ 'ong, c'est parce que K'ong Fang-chou se transporta du pays de Song dans celui de Lou et qu'il peut être ainsi considéré comme le véritable fondateur de la famille $K$ 'ong du pays de Lou. K'ong-fou Kia fut tué en 710 av. J.-C. par Hoa Tou qui convoitait sa femme (cf. t. IV, p. 235).

- K'ong-fou Kia engendra Mou-kin-fou; d'après le Che pen, Mou-kin-fou, en butte à l'animosité de la famille de $\mathrm{Hoa}-\mathrm{Tou}$, ne fut plus, comme l'avaient été ses ancêtres, haut dignitaire dans le pays de Song et tomba au rang de simple patricien.

- Mou-kin-fou engendra Kao-i, que le Che pen appelle K'i-fou.

- Kao-i engendra (K'ong) Fang-chou, qui, pour échapper à l'inimitié persistante de la famille Hoa, dut quitter le pays de Song et se réfugia dans la principauté de Lou. - 
Fang-chou, dit Kiang Yong, est ainsi nommé parce qu'il fut gouverneur de la ville de Fang qui était au N.-E. de la s.-p. de Fei (préf. de Yen-tcheou, prov. de Chan-tong).

- Kong Fang-chou engendra Po-hia.

- Po-hia engendra Chou-leang Ho qui fut le père de Confucius.

47.(105) Chou-leang Ho est mentionné à deux reprises dans le Tso tchoan: en $\underline{563}$, les troupes des seigneurs avaient attaqué la ville de Pi-yang ; les assiégés ouvrirent une de leurs portes qui, au moyen d'un mécanisme, pouvait être remontée de bas en haut; les assaillants se précipitèrent vers cette entrée, mais la porte retombant les emprisonna dans la ville; Chou-leang Ho se trouvait parmi eux; grâce à sa grande vigueur, il put soulever la porte et permit ainsi à ses compagnons de s'échapper. En 556, Chou-leang Ho apparaît comme l'un des trois chefs militaires, qui à la tête de 300 hommes du pays de Lou, attaquent de nuit l'armée de $T s$ ' $i$ et l'obligent à se retirer. - Dans le premier de ces textes, Chou-leang Ho est appelé [Tseou..] et, dans le second [Tseou..]; cela prouve, dit Kiang Yong, qu'il était gouverneur de la ville de Tseou, car lorsqu'on parlait d'un gouverneur de ville, c'était la coutume de faire précéder son nom personnel de celui de sa ville.

47.(106) L'expression [] est expliquée par Se-ma Tcheng et Tchang Cheou-tsie comme faisant allusion à la trop grande différence d'âge qu'il y avait entre le vieux Chou-leang Ho et sa jeune femme. D'après une ancienne théorie chinoise que rappelle Tchang Cheou-tsie, la vie de l'homme est réglée par le nombre de huit : à huit mois, il pousse ses dents de lait; à huit ans il les perd ; à seize ans $(2 \times 8)$, la voie du yang s'ouvre, c'est-à-dire qu'il devient pubère ; à soixante-quatre ans $(8 \times 8)$, la voie du yang se ferme. La vie de la femme est dominée par le nombre sept : à sept mois elle pousse ses dents de lait; à sept ans elle les perd ; à quatorze ans ( 2 x 7), la voie du yn s'ouvre, c'est-à-dire qu'elle devient nubile ; à quarante-neuf ans (7 x 7), la voie du $y n$ se ferme. Toute union contractée par un homme avant seize ans ou après soixante-quatre ans, et par une femme avant quatorze ans ou après quarante-neuf ans, est contraire à la règle.

L'expression [] signifie donc que Chou-leang Ho se maria après avoir dépassé l'âge de soixante-quatre ans.

47.(107) Le Kia yu, dans la section 39, nous donne les renseignements suivants sur le mariage de Chou-leang Ho :

«Chou-leang Ho avait épousé une fille de la famille Che et en avait eu neuf filles, mais aucun fils; sa concubine avait enfanté Mong- $P$ ' $i$ qui eut aussi le surnom de Po-ni; comme Mong-p'i avait une infirmité des pieds, (Chou-leang $\mathrm{Ho}$ ) chercha donc à contracter un mariage dans la famille Yen. Le père Yen avait trois filles dont la plus jeune se nommait Tcheng-tsai. Le père Yen interrogea ses trois filles en leur disant :

- Quoique le père et le grand-père du gouverneur de Tseou (c.-à-d. Chou-leang $\mathrm{Ho}$ ) aient été de simples patriciens, cependant ses ancêtres sont des descendants des saints rois. Maintenant cet homme a une stature de dix pieds de haut et sa vigueur aux combats est extraordinaire. Pour moi, je désire fort (m'allier avec lui). Bien qu'il soit vieux et d'un caractère austère, il n'y a pas lieu à hésiter. Qui de vous, mes trois enfants, veut être sa femme?

Deux des filles ne répondirent pas ; Tcheng tsai s'avança et dit :

— J'obéirai à ce que mon père ordonne ; à quoi bon m'interroger?

Son père lui dit :

— Eh bien, soit.

Il la maria donc (à Chou-leang Ho). Après que Tcheng-tsai eut été présentée dans le temple ancestral (de sa nouvelle famille), considérant que son mari était 
âgé, elle craignit de n'avoir pas de fils en temps utile et se rendit secrètement à la montagne $\mathrm{Ni}$ k'ieou pour y prier. Elle enfanta K'ong-tse dont le nom personnel fut donc K'ieou, et l'appellation Tchong-ni. »

Ce texte du Kia yu complète heureusement le témoignage trop succinct de Se-ma Ts'ien et mérite de retenir quelques instants notre attention. Si Chou-leang Ho contracta un mariage dans sa vieillesse avec une fille de la famille Yen, c'est dans l'espérance qu'elle lui donnerait un fils capable de s'acquitter des sacrifices ancestraux; de sa première épouse il n'avait eu en effet que des filles; quant au fils qu'avait enfanté sa concubine, c'était un infirme ; or nous trouvons dans le Tso tchoan (à la date de 535) un passage intéressant qui prouve qu'un infirme était considéré comme mal qualifié pour succéder au chef de la famille : le duc Siang, de Wei, avait deux fils dont l'aîné Mong-tche, avait les pieds en mauvais état et marchait difficilement : après avoir consulté les sorts, on choisit le cadet pour monter sur le trône à la place de son père ;

- Mong(-tche), dit le devin chargé d'interpréter l'augure, n'est pas un homme (complet); il ne pourra pas prendre rang dans le temple ancestral; il ne peut être appelé l'aîné.

- La mère de Confucius s'appelait Tcheng-tsai de son nom personnel; ceci nous est confirmé par un passage du chapitre T'an kong du Li ki :

«Lorsqu'un nom se compose de deux mots, il n'est pas défendu d'employer ces mots chacun séparément. (Ainsi) la mère de Confucius s'appelait Tcheng-tsai ; le Maître, après la mort de sa mère, employait encore les mots tsai, tcheng, mais séparément, sans jamais les unir l'un à l'autre (trad. Couvreur, t. I, p. 242).

- La bravoure de Chou-leang Ho nous est attestée par les deux textes du Tso tchoan que nous avons cités plus haut (cf. n. 105). Quant à sa stature de dix pieds, elle explique pourquoi Confucius lui-même eut une fort haute taille. Se-ma Ts'ien nous apprend en effet (voyez plus loin, p. 298, ligne 9) que Confucius mesurait neuf pieds et six pouces et qu'il était considéré par ses contemporains comme un géant.

47.(108) Cette montagne $N i$ ou Ni-k'ieou est placée par le Ta Ts'ing $i$ t'ong tche (chap. CXXIX, p. $2 \mathrm{v}^{\circ}$ ) à $60 \mathrm{li}$ au S.-E. de la s.-p. de K'iu-feou, à la limite entre les sous-préfectures de Se-choei et de T'seou. Suivant une indication du Yuen ho kiun hien tche (publié en 813 par $\mathrm{Li} \mathrm{Ki-fou),} \mathrm{la} \mathrm{montagne} \mathrm{Ni}$-k'ieou était à $50 \mathrm{li}$ au S. de la s.-p. de Se-choei. Le Kouo ti tche (publié en 642 par Tai, roi de $W e i$ ) dit :

«Le temple de Chou-leang Ho, qu'on appelle aussi sanctuaire de la montagne $\mathrm{Ni}$ k'ieou, est à $50 \mathrm{li}$ de la sous-préfecture de Se-choei qui dépend de l'arrondissement de Yen, à la base orientale de la montagne $\mathrm{Ni}$-k'ieou.

47.(109) Dans les Tableaux chronologiques, Se-ma Tsien rapporte aussi la naissance de Confucius à la $22^{\mathrm{e}}$ année du duc Siang (551). D'autre part, à la fin du présent chapitre, il dit que Confucius mourut la $16^{\mathrm{e}}$ année du duc de $\mathrm{Ngai}(479)$, le $4^{\mathrm{e}}$ mois, le jour $\mathrm{ki}$-tch 'eou et qu'il était alors âgé de 73 ans (à la manière de compter chinoise), ce qui est en accord avec la date donnée pour sa naissance. Cependant les commentaires du Tch'oen ts'ieou placés sous les noms de Kong-yang et de Kou-leang assignent tous deux la naissance de Confucius à la $21^{\mathrm{e}}$ année du duc Siang (552) et au jour keng-tse que Kong-yang place dans le $11^{\mathrm{e}}$ mois, et Kou-leang dans le $10^{\mathrm{e}}$ mois. En ce qui concerne cette dernière divergence, on peut trancher la question en faveur de Kou-leang, car les indications chronologiques du Tch'oen ts'ieou nous permettent d'établir que, la $21^{\mathrm{e}}$ année du duc Siang, le joui keng-tse fut le $21^{\mathrm{e}}$ du $10^{\mathrm{e}}$ mois.

Qui maintenant a raison, de Se-ma Ts'ien ou de Kou-leang? Les éditeurs du Tch'oen ts 'ieou à l'époque de $K$ 'ang-hi opinent pour Se-ma Ts'ien (cf. Legge, C. C., vol. V, p. 492) ; Kiang Yong (H. T. K. K., chap. CCLXII, p. $6 \mathrm{r}^{\circ}$ et $\mathrm{v}^{\circ}$ ) au contraire se prononce en faveur de Kou-leang et tout son Tableau chronologique (H. T.K.K., chap. CCLXI, p. $\left.2 \mathrm{r}^{\circ}\right)$ est fondé sur la date de 552 comme étant l'année de la naissance de Confucius. En réalité, les deux 
témoignages sont parfaitement conciliables : dans le Tch'oen tsieou, l'année commence avec le premier mois du printemps ; mais, à l'époque de $S e$-ma $T s$ 'ien, jusqu'à la réforme introduite par le calendrier t'ai-tch'ou en 104 av. J.-C, le début de l'année est le dixième mois. Si on admet que Se-ma Ts'ien applique ici le calendrier qui avait cours de son temps, le mois qui, dans le Tch'oen ts 'ieou, est le $10^{\mathrm{e}}$ de la $21^{\mathrm{e}}$ année du duc Siang, commencera pour lui la $22^{\mathrm{e}}$ année ; ainsi s'explique qu'il reporte à la $22^{\mathrm{e}}$ année un événement que Kou-leang place dans la $21^{\mathrm{e}}$; le désaccord n'est qu'apparent, et, en fait, les deux auteurs ont bien en vue la même date.

47.(110) Le mot k'ieou signifie tertre ou colline. Le crâne de Confucius avait vaguement l'aspect d'une colline aux bords escarpés, et c'est pourquoi son nom personnel fut K'ieou. Quant à l'appellation Tchong-ni qui signifie « $N i$ le puîné », elle paraît dériver aussi de la même particularité (ce qui est normal puisque, dans l'antiquité, il y avait en général une correspondance entre le nom personnel et l'appellation $\left(H . T . K . K\right.$., chap. CXCV, p. $\left.31 \mathrm{v}^{\circ}\right)$; en effet, $N i$ doit être ici l'équivalent phonétique du mot $n i$, au sujet duquel le Chouo wen (radical 293) dit :

$$
\text { « C'est une colline au sommet renversé qui reçoit de l'eau. }
$$

Confucius était donc appelé $N i$ le puîné parce que son crâne avait la forme d'une colline dont le sommet évasé retenait l'eau tombée du ciel. C'est bien ce que dit le commentateur Se-ma Tcheng qui compare le crâne de Confucius à un toit de maison renversé, parce qu'il était concave au sommet et qu'il se relevait sur les bords. Il est à remarquer que cette explication est encore satisfaisante parce qu'elle établit, comme le veut le Kia yu (cf. n. 107) une relation entre le nom et l'appellation de Confucius d'une part et le nom de la colline Ni-k'ieou d'autre part. En effet, le Eul ya dit, pour expliquer le mot k'ieou:

$$
\text { « Là où un amas d'eau s'arrête, c'est ce qu'on appelle ni-k'ieou » }
$$

Ainsi, Confucius étant né à la suite des prières que fit sa mère sur le mont $N i k^{\prime} i e o u$, et son crâne ayant présenté une forme particulière qui le faisait ressembler précisément à une colline sur le sommet évasé de laquelle les eaux s'accumulent, son nom personnel de K'ieou et son appellation Tchong-ni font allusion simultanément à l'aspect de sa tête et à celui de la montagne $\mathrm{Ni}$ - $k^{\prime}$ 'ieou. La seule objection qu'on puisse faire à cette théorie est la suivante : d'après le Kia yu (cf. n. 107), le frère aîné de Confucius avait l'appellation de Po-ni, c.-à-d. Ni l'aîné, tandis que Confucius lui-même reçut l'appellation de Tchong-ni, c.-à-d. Ni le cadet ; par conséquent, le nom de $N i$ avait été choisi par le père de Confucius avant la naissance de celui-ci et on ne peut plus rattacher cette dénomination ni à la montagne $N i-k$ 'ieou, ni à la forme du crâne de Confucius. On répondra à cela que le texte du Kia yu n'est pas une autorité suffisante pour prouver que le frère aîné de Confucius eut, dès sa première enfance, l'appellation de $P o-n i$, et il est fort possible que quelque érudit trop ingénieux ait imaginé après coup cette appellation par analogie avec l'appellation de Confucius, ou encore que, lorsque Confucius fut devenu célèbre, on ait pris l'habitude de désigner son frère acné par une appellation qui était semblable à celle de Confucius lui-même.

47.(111) D'après le Kia yu, Chou-leang Ho mourut quand Confucius était âgé de trois ans.

47.(112) La montagne Fang est à 30 li à l'E. de la s.-p. de K'iu-feou (Ta Ts'ing i t'ong tche, CXXIX, p. $\left.2 \mathrm{v}^{\circ}\right)$.

47.(113) Pour quelle raison la mère de Confucius lui aurait-elle intentionnellement caché l'emplacement de la tombe de son père? A vrai dire, on n'en voit aucune; aussi Se-ma Tcheng donne-t-il ici la glose suivante : Cela veut dire que, Confucius devenu orphelin très jeune, ne sut pas exactement où était placée la tombe de son père, mais cela ne veut pas dire qu'il ne connut pas l'emplacement des sépultures (parmi lesquelles se trouvait celle de son père). Tcheng-tsai s'était mariée avec Chou-leang Ho à l'âge où les filles commencent à porter l'épingle de tête (15 ans); peu après, son mari mourut de vieillesse ; Tcheng-tsai se trouva veuve toute jeune et eut de la répugnance à suivre le convoi funèbre; c'est pourquoi 
elle ne sut pas l'endroit où était la tombe ; elle ne put donc pas en informer (Confucius), mais ce n'est pas à dire qu'elle lui tut intentionnellement la chose. — On prendra cette explication pour ce qu'elle vaut.

47.(114) Le Kouo ti tche place la route des Cinq pères à 2 li au S.-O. de la s.-p. de K'iu-feou qui était la capitale de l'État de Lou; d'après le Ta Ts'ing $i$ t'ong tche (CXXX, p. $\left.4 \mathrm{v}^{\circ}\right)$, il faudrait dire S.-E. et non S.-O. La route des Cinq pères est mentionnée dans le Tso tchoan à la date de la $11^{\mathrm{e}}$ année du duc Siang.

47.(115) Il eut la prudence de ne faire qu'un enterrement provisoire, en sorte qu'il lui fut facile plus tard de réunir le corps de sa mère à celui de son père. Dans le chap. T'an kong du Li Ki (trad. Couvreur, t. I, p. 117), la même anecdote est racontée, mais avec quelques détails en plus :

« $K^{\prime}$ ong-tse, qui était fort jeune quand son père était mort, ne savait pas où était sa tombe. (Quand sa mère mourut), il fit un enterrement provisoire près de la route des Cinq pères; ceux qui virent (la cérémonie) crurent que c'était un enterrement définitif, tant avait été grand le soin (qu'y avait apporté Confucius). Après s'être informé auprès de la mère de Wan-fou, (de la ville) de Tseou, il put réunir la sépulture (de sa mère à celle de son père) à Iang.

A côté de cette interprétation traditionnelle de,ce texte du $\mathrm{Li} K \mathrm{Ki}$, on a proposé une autre explication plus subtile que Kiang Yong approuve (H.T.K. K., chap. CCLXII, p. $\left.7 \mathrm{v}^{\circ}\right)$, mais qui est en complet désaccord avec le témoignage de $S e-m a T s$ 'ien; si l'on adopte cette nouvelle manière de voir, il faut traduire :

«K'ong-tse, qui était fort jeune quand son père était mort, ne savait pas que la sépulture qu'on lui avait faite près de la route des Cinq pères n'était qu'un enterrement provisoire ».

En d'autres termes, le cercueil du père de Confucius n'avait pas été enfoui profondément comme lorsqu'il s'agit d'un enterrement définitif; il n'avait été recouvert que d'une légère couche de terre; c'était donc un enterrement provisoire et on pouvait sans inconvénients déplacer le corps. Mais Confucius ne savait pas si l'enterrement avait été fait d'une manière provisoire ou définitive ;

« ceux qui avaient vu la cérémonie pensaient d'ailleurs tous qu'il s'agissait d'un enterrement définitif.

Dans l'incertitude où se trouvait Confucius, il n'osait pas prendre parti, « tant était grande sa circonspection »

Enfin la mère de Wan-fou lui ayant révélé que l'enterrement de son père avait été fait d'une manière provisoire, il put déplacer cette sépulture et enterrer ensemble son père et sa mère sur la colline Fang.

- Sur la coutume d'enterrer les femmes à côté de leurs maris morts avant elle, cf. De Groot, The religious system of China, Book I, p. 800 et suiv.

47.(116) La famille $K i$ était une des trois grandes familles de Lou issues du duc Hoan ; cf. tome IV, n. 33.185 .

47.(117) Yang Hou chercha à supplanter les trois familles issues du duc Hoan, et, en 501, fut obligé de quitter le pays de Lou (cf. t. IV, p. 126 ; mais au moment où Confucius était jeune, il se trouvait à l'apogée de sa puissance.

47.(118) Comme le fait remarquer Se-ma Tcheng, cette anecdote paraît contenir un blâme à l'adresse de Confucius, qui n'aurait pas dû se mêler à une réjouissance alors qu'il portait encore la ceinture de deuil. 
47.(119) Cette indication nous ramènerait à l'année 535 av. J.-C. En réalité cependant, Mong Hi-tse ne mourut qu'en 518, comme nous l'apprend le Tchoen ts-ieou ( $24^{\mathrm{e}}$ année du duc Tchao) ; Confucius était alors âgé de trente-quatre ans ; on comprend donc qu'il ait pu être désigné par Mong Hi-tse comme le maître et le conseiller de son fils. L'erreur de Se-ma Tsien s'explique par le fait que le Tso tchoan, anticipant sur les événements, rapporte sous l'année $535\left(7^{\mathrm{e}}\right.$ du duc Tchao) les paroles que tint Mong Hi-tse, à son lit de mort, dix-sept ans plus tard; par inadvertance, Se-ma Tsien a cri que ces paroles avaient été effectivement prononcées en 535 .

47.(120) Mong Hi-tse était le chef d'une des trois grandes familles issues du duc Houan; cf. tome IV, n. 33.185 .

47.(121) Mong Hi-tse s'appelait Ho-ki de son nom personnel. I est son nom posthume. Ce personnage est mentionné dans le $\underline{\text { Luen yu }}$ (II, 5), comme un disciple de Confucius.

47.(122) $\underline{\text { Tso tchoan, }} 7^{\mathrm{e}}$ du duc Tchao.

47.(123) Cet homme saint est T'ang, fondateur de la dynastie $Y n$; on sait que, par l'intermédiaire des princes de Song, Confucius se rattachait aux empereurs de la dynastie $Y n$ (Cf. note 104.)

47.(124) Cf. p. 285, lignes 25-30 de la note.

47.(125) Arrière-petit-fils de Fou-fou Ho. Cf. p. 286 lignes 7-10 de la note

47.(126) Ce trépied se trouvait dans le temple funéraire de Tcheng $K$ 'ao fou. Certains ouvrages archéologiques de peu de valeur (ainsi le [] publié en 1843 par Ts'ien Koen-sieou) donnent une image de ce trépied qu'ils représentent avec quatre pieds ; ils reproduisent en outre, un prétendu fac-similé de l'inscription qui était gravée sur le fond du vase. Mais c'est là pure fantaisie et en réalité le texte du Tso tchoan répété par Se-ma Ts'ien est seul à nous avoir conservé $1^{\mathrm{e}}$ souvenir de ce monument. - D'autre part, cependant le célèbre épigraphiste Yuen Yuen, dans son [], publié en 1804, déclare authentique et reproduit (chap. IV, p. 19) une autre inscription d'un trépied de Tcheng K'ao-fou ; cette inscription est ainsi conçue :

«Le quatrième mois, au premier jour faste, Tcheng K'ao-fou a fait ce trépied précieux de l'espèce tsuen dédié au roi Wen, afin que, pendant dix mille années sans limites, ses descendants s'en servent et en jouissent éternellement comme d'un objet précieux.

D'après Yuen Yuen, le roi Wen dont il est ici question serait l'empereur de la dynastie Yn que le Tchou chou ki nien appelle Wen-ting, tandis que Se-ma Ts'ien (t. I, p. 198) l'appelle T'aiting; Wen-ting serait appelé ici le roi Wen, de même que, dans le Che king ( $3^{\mathrm{e}}$ ode sacrificatoire de Chang, str. 3), T'ang le vainqueur ou T'ang le guerrier est appelé le roi $O u$; il est à remarquer d'ailleurs que Lieou Tche-ki, dans l'ouvrage de critique historique qu'il publia en 710 sous le titre de Che t'ong, cite le Tchou chou ki nien en donnant à Wen-ting le nom de Wen-wang, comme dans notre inscription ; les éditions modernes du Che t'ong (voyez Che t'ong t'ong che, réimpression de 1885, chap. XIII, p. $6 \mathrm{r}^{\circ}$ ) ont corrigé cette leçon qu'elles considèrent comme fautive; mais il est fort possible que le Tchou chou ki nien que connaissait Lieou Tche-ki donnât effectivement la leçon Wen-wang. - Tcheng K'ao-fou, rattachant sa généalogie à la dynastie $Y n$, il est naturel qu'il ait consacré à un empereur de cette dynastie, c'est-à-dire à un de ses ancêtres, un vase destiné aux sacrifices.

47.(127) En d'autres termes, plus Tcheng K'ao-fou s'élevait en dignité, plus il affectait d'humilité dans son maintien. - D'après les Rites de Tai l'aîné (chap. XII ; § 28, p. 1 vº), chez les marquis et les comtes, les hauts dignitaires avaient trois nominations, les grands officiers avaient deux nominations ; les patriciens avaient une nomination. Cette règle devait s'appliquer au pays de Lou dont les seigneurs avaient proprement le titre de marquis ; Tcheng $K$ 'ao-fou, étant au service des princes de Lou, devint donc successivement patricien, grand officier et enfin haut dignitaire. 
47.(128) Tcheng K'ao-fou aurait dû occuper le trône de Song ; cf. p. 295, lignes 1-3.

47.(129) Cf. n. 119.

47.(130) Le nom personnel de Nan-kong King-chou était Yue, ainsi que nous l'apprend le Tso tchoan. Se-ma Tcheng dit que Nan-kong King-chou était, aussi bien que Mong I-tse, fils de Mong Hi-tse ; ce serait donc par inadvertance, que Se-ma Ts'ien l'appellerait ici « un homme de $L o u »$, comme s'il s'agissait d'un inconnu.

47.(131) Cf. t. IV, p. 120 et Legge. C. C., vol. V, p. 619. Ki Ou-tse était le chef de la famille $K i$, une des trois familles issues du duc Hoan.

47.(132) Confucius a dit lui-même (Luen yu, IX, 6) :

«Lorsque j'étais jeune, j'étais de condition humble ; c'est pourquoi j'ai acquis plusieurs talents divers, mais c'était dans des matières de peu d'importance.

47.(133) Se-ma Tcheng indique qu'un texte donne la leçon [], et cette variante paraît en effet préférable puisqu'elle se retrouve dans Mencius $(\mathrm{V}, \mathrm{b}, 5)$; si nous l'adoptons, il faudra en conclure que Confucius ne fut pas au service de la famille $K i$; la charge de ki che, c'est-à-dire de gardien des greniers publics, devait être une fonction publique dans la principauté de Lou.

47.(134) Le mot [] est ici l'équivalent du mot [] qui désigne un pieu auquel on attachait le bétail.

47.(135) Se-ma Ts'ien résume ici en quelques mots les principaux événements de la vie de Confucius et anticipe sur la suite du récit. Nous retrouverons donc racontés plus loin en détail les divers faits qui ne sont ici mentionnés que par une brève allusion.

47.(136) On a vu précédemment (note 107) que, d'après le Kia yu, Chou-leang Ho, père de Confucius, avait dix pieds de haut ; il n'y a donc rien de surprenant à ce que son fils ait eu luimême une taille peu commune. - Le Kin che souo reproduit un pied en cuivre de l'année 81 ap. J.-C. et dit que cet étalon a la même dimension que celui qui avait cours à l'époque des Tcheou; or ce pied mesure $23 \mathrm{~cm}$. dans mon exemplaire du Kin che souo; si on admet cette valeur du pied, on trouvera que Confucius avait 2 mètres 20 de haut, ce qui est probablement un peu exagéré. Il est évident en effet que ce calcul peut être vicié par trop de causes d'erreur pour être considéré comme ayant une valeur absolue.

47.(137) Cette phrase paraît être destinée à expliquer la proposition qui termine le paragraphe précédent: "puis il revint dans (le pays de) Lou». Toute cette première partie de la biographie de Confucius est fort mal rédigée.

47.(138) Ce serviteur devait jouer le rôle de cocher, comme l'indique le Kia yu (section Koan Tcheou).

47.(139) Le point doit être placé avant le mot []. La leçon du Kia yu enlève d'ailleurs toute incertitude :

«(Le duc Lou) donna à Confucius, un char, deux chevaux et un domestique pour servir de cocher. King-chou avec lui (c.-à-d. avec Confucius) alla dans (le pays des) Tcheou.

Dans le tome II, n. 06.313, la note relative à ce texte est fautive, comme je l'ai fait remarquer $t$. III, p. 705.

47.(140) C'est-à-dire à Lo-yang (Ho-nan fou).

47.(141) La formule [...] implique l'idée qu'il s'agit, non d'un fait certain, mais d'une opinion de l'auteur (tome IV, n. 32.104). En d'autres termes, Se-ma Ts'ien, se trouvant en présence de deux traditions, l'une relative au voyage que Confucius aurait fait à la capitale des Tcheou, l'autre relative à l'entrevue que Confucius aurait eue avec Lao-tse, établit de son autorité 
propre un rapport entre les deux récits, et il dit : C'est sans doute à l'occasion de son voyage à la capitale des Tcheou que Confucius vit Lao-tse.

- Les principaux textes relatifs aux prétendues conversations de Confucius avec Lao-tse sont les suivants :

- en premier lieu, Se-ma Ts'ien lui-même, dans sa biographie de Lao-tse (Mém. hist., chap. LXIII), rapporte une critique assez vive que Lao-tse aurait adressée à Confucius et le jugement que Confucius aurait à son tour prononcé sur Lao-tse.

- Dans le paragraphe Koan Tcheou du Kia yu, on lit que Confucius fit part à Nan-kong King-chou de son désir de se rendre dans le pays des Tcheou pour y interroger Lao Tan sur les rites et sur la musique. Avec l'autorisation du prince de Lou, Nan-kong King-chou et Confucius allèrent ensemble à la capitale de Tcheou. Confucius s'enquit des rites auprès de Lao Tan et de la musique auprès de Tch'ang-Hong. Les paroles que Lao-tse aurait adressées à Confucius au moment de son départ sont, à quelques variantes près, identiques dans le Kia yu et dans le chapitre XLVII des Mémoires historiques.

- Dans le chapitre Tseng tse wen du Li ki (trad. Couvreur, t. I, p. 431-435, 457-459, 460-461, 463), Confucius rappelle ce qu'il a entendu dire à Lao Tan en quatre occasions différentes. Dans l'un de ces cas, dit-il, une éclipse de soleil vint à se produire. Or le Tch'oen ts'ieou mentionne une éclipse de soleil dans le cinquième mois de la vingt-quatrième année du duc Tchao (518). L'érudit Kiang Yong (H. T. K. $K$, chap. CCLXII, p. $12 \mathrm{r}^{\circ}$ et $\mathrm{v}^{\circ}$ ) en conclut que c'est en cette année-là que Confucius, alors âgé de 34 ans, dut rendre visite à Lao-tse.

- Le chapitre Yo ki du Li ki confirme d'autre part que $K$ 'ong-tse fut en relation avec Tch'ang Hong, comme le dit le Kia yu (cf. Se-ma Ts'ien, trad. fr., t. III, p. 279, et aussi p. 402 et 428 ; un commentaire à un passage de Hoai nan tse, chap. XIII, p. 17 $\mathrm{v}^{\circ}$, explique dans quelles circonstance Tch'ang Hong fut mis à mort en 492 av. J.-C.). L'ouvrage intitulé Kong ts'ong (dans le Han Wei ts'ong chou) s'ouvre par le jugement que Tch'ang Hong porta sur Confucius à la suite de son entrevue avec lui dans la capitale des Tcheou.

- Dans le livre de Tchoang-tse, Confucius est représenté à plusieurs reprises en conversation avec des docteurs taoïstes qui remportent facilement l'avantage sur lui ; Lao-tse lui-même est souvent son interlocuteur; d'après un de ces textes (trad. Legge, SBE, vol. XXXIX, p. 354), Confucius était âgé de cinquante et un ans lorsqu'il vit pour la première fois Lao Tan à $P^{\prime} e i$ (auj. s.-p. de P'ei, préf. de Siutcheou, prov. de Kiang-sou).

- Enfin les bas-relief du IIe siècle de notre ère, dans le Chan-tong, figurent la visite de Confucius à Lao-tse, ce qui prouve que cette scène était familière au public de cette époque (cf. La sculpture sur pierre en Chine, p. 69-71).

De l'examen de ces divers témoignages il résulte que la réalité historique des entrevues de Confucius et de Lao-tse n'est point établie ; cette tradition nous apparaît bien plutôt comme une invention des taoïstes qui avaient imaginé de mettre leur patron le plus vénéré en présence du chef de l'école rivale afin de pouvoir accabler ce dernier de leurs sarcasmes. L'origine manifestement taoïste de ces récits suffit à en rendre suspecte l'authenticité, car les écrivains taoïstes donnent volontiers libre cours à leur fantaisie et n'ont aucune prétention à l'exactitude qui est la première vertu de l'historien.

47.(142) Formule de modestie.

47.(143) Au lieu de [], le Kia yu donne la leçon qui paraît préférable : "grandement pénétrant $\gg$. 
47.(144) En d'autres termes : Une grande intelligence et une profonde instruction sont choses pernicieuses pour qui les possède ; celui qui s'acquitte des devoirs de la piété filiale et celui qui agit en sujet loyal ne se possèdent plus eux-mêmes, car ils sont à la merci, l'un de ses parents, l'autre de son prince. C'est la condamnation de l'intelligence, de la piété filiale et du loyalisme qui sont les principes essentiels de la doctrine de Confucius.

47.(145) La section Koan Tcheou du Kia yu donne, sur le séjour de Confucius dans la capitale des Tcheou, quelques autres indications qui ont été résumées par Legge $(C . C$., vol. I, prolégomènes, p. 66 [css : rechercher : 'while at lo']).

47.(146) Le Kia yu, dont le témoignage est ici fort suspect, dit que le nombre de ses disciples s'éleva alors à trois mille. Cf. Legge, C. C., vol. I, Prolégomènes, p. 67. [css : édition/rechercher : 'three thousand']

47.(147) Le duc P'ing étant mort en 532, il semble que, pour Se-ma l's'iciz, le voyage de Confucius à la capitale des Tcheou dut être antérieur à cette date.

47.(148) Cf. t. IV, p. 331-332.

47.(149) Sur l'expression, cf., tome II, n. 10.164.

47.(150) On sait que le royaume à demi barbare de Tch'ou n'était pas considéré comme faisant partie de la confédération des Royaumes du Milieu ; cf. tome IV, n. 41.162.

47.(151) Ici encore (Cf. n. 141) le mot indique qu'il s'agit, non d'un fait attesté directement par un témoignage digne de foi, mais d'une conclusion à laquelle l'historien aboutit par le raisonnement.

47.(152) Cf. t. IV, p. 75.

47.(153) Le Kia yu (section 73, hien kiun) et le Chouo yuan (section tsuen hien) donnent la leçon « son gouvernement était bon ». Avec cette variante la phrase est mieux rythmée.

47.(154) Po-li Hi. Cf. t. II, p. 27.

47.(155) Ce membre de phrase est supprimé dans le Kia yu (section hien kiun) mais est conservé dans le Chouo yuan (section tsuen hien)..L'expression se retrouve dans le Luen yu $(\mathrm{V}, 1)$.

47.(156) Il s'agit ici de la royauté du Fils du Ciel ou royauté universelle qui est supérieure à l'hégémonie prise par un seigneur.

47.(157) Le duc King fut satisfait parce qu'il pensa que Confucius l'approuvait implicitement d'avoir pris un sage tel que Yen Yng pour conseiller. Dans le Luen yu $(\mathrm{V}, 16)$, Confucius a parlé avec éloge de Yen Yng.

47.(158) Cf. t. IV, p. 121-122.

47.(159) Cf. tome IV, n. 33.185, et n. 33.221.

47.(160) Ici encore on peut signaler une négligence de Se-ma Ts'ien. Le duc Tchao commença en effet par se réfugier dans le pays de $T s^{\prime} i$; mais, en 514 , il quitta ce royaume pour aller dans celui de $T \sin$ et c'est alors qu'il fut installé à Kan-heou, qui était une localité de Tsin (et non de $T s^{\prime} i$, comme le dit ici Se-ma Ts 'ien). Cf. tome IV, n. 33.215, et p. 124.

47.(161) Sur Kao Tchao-tse ou Kao Tchang, voyez t. IV, p. 78-80.

47.(162) Comme le remarque Se-ma Tcheng, il semble que Se-ma Ts'ien réunisse ici à tort deux témoignages distincts du Luen yu :

— d'une part, en effet, le Luen yu (III, 23) nous apprend que

«Confucius parla sur la musique au grand maître de la musique du pays de Lou

(et non de $T s^{\prime} i$, comme le dit Se-ma Ts'ien). 
—D'autre part, ce même ouvrage (VII, 13), rapporte que «quand le maitre était dans le pays de $T s^{\prime} i$, il entendit (la musique chao), et pendant trois mois ne connut pas le goût de la viande ».

— La musique chao était attribuée à l'empereur mythique Choen (cf. t. III, n. 24.195).

- Dans le Chouo yuan (section sieou wen) de Lieou Hiang (80-9 av. J.-C.), on lit :

"Quand K'ong-tse se rendit dans (le pays de) $T s$ ' $i$, en dehors de la porte du faubourg il rencontra un jeune garçon qui portait un pot et marcha en sa compagnie ; le regard (de cet enfant) était clair; son cœur était droit; sa démarche était assurée. K'ong-tse dit à son cocher :

- Pressez les chevaux! Pressez les chevaux! La musique chao se manifeste déjà.

(En d'autres termes, Confucius a hâte d'arriver dans le pays de $T s^{\prime} i$ où la musique chao a des effets si. merveilleux que les enfants eux-mêmes subissent son heureuse influence). Quand K'ong-tse fut arrivé (dans le pays de $T s^{\prime} i$ ), il entendit la musique chao, et, pendant trois mois il ne connut pas le goût de la viande... »

— La phrase « il ne connut pas le goût de la viande » signifie que Confucius ne se nourrit que d'aliments maigres. D'après certains commentateurs du Luen yu, il faudrait comprendre les mots [] comme signifiant que Confucius étudia la musique chao pendant trois mois.

47.(163) Luen yu, XII, 11.

47.(164) Certains commentateurs du Luen yu ont voulu voir dans la réponse de Confucius une intention satirique ; la famille Tch'en (ou Tien; cf. n. 46.114) était devenue, disent-ils, trop puissante dans le pays de $T s^{\prime} i$; ainsi le prince n'avait plus toute l'autorité qui doit appartenir à un prince, et les sujets n'avaient pas la docilité que doivent témoigner des sujets. D'autre part, le duc King, épris d'une de ses concubines, désirait avoir pour successeur le jeune fils de cette favorite et se refusait à désigner comme héritier présomptif un de ses fils adultes; il ne se conduisait donc pas lui-même comme un père doit se conduire.

- Cette glose trop ingénieuse doit être rejetée ;

en premier lieu, le duc King approuve sans restriction la réponse de Confucius, ce qu'il n'eût pas fait s'il y eût senti un blâme à son adresse ;

en second lieu, Confucius, d'après Se-ma Ts'ien, se trouva dans le pays de $T s$ ' $i$ entre l'âge de 35 ans et celui de 42 ans, soit entre 517 et 510 av. J.-C. ; or les troubles suscités par T'ien $K^{\prime} i$ sont de l'année 493, et le refus du duc King de nommer un héritier présomptif est de l'année 490 (cf. t. IV, p. 78). Confucius ne pouvait donc faire allusion à des événements qui n'étaient point encore arrivés.

— La réponse que fit Confucius au duc King a été souvent citée comme l'exposé de la théorie des dénominations exactes : il est essentiel de rendre les dénominations exactes, c'est-à-dire d'agir de telle manière que les relations diverses qui existent entre les hommes soient adéquates aux idées parfaites que nous nous en faisons et que nous exprimons par les mots du langage. Mais nous verrons plus loin que l'expression [dénomination exacte] avait à l'origine un sens entièrement différent et visait en réalité la correction des caractères de l'écriture.

47.(165) Littéralement: "Même si j'avais le grain, comment pourrais-je le manger?» L'expression « le grain » désigne les redevances qui étaient payées au prince. - Le mot [], qui figure dans Se-ma Ts'ien, est absent dans le texte actuel du Luen yu, mais il devait s'y trouver à l'origine, car il apparaît dans les deux textes du Luen yu appelés le texte de Hoang et le texte de Corée (cf. la note additionnelle à la fin de ce chapitre); ce mot est aussi présent dans la citation que le Ts'ien Han chou (chap. LXIII, p. $2 \mathrm{r}^{\circ}$ ) fait de ce passage (cf. S. H. T. K. $K$., chap. 1065 , p. $12 \mathrm{r}^{\circ}$ ). 
47.(166) Dans le Luen yu (I, 5) on trouve l'expression [] employée dans le même sens.

47.(167) Yen tse, § 8, wai pien. Mo-tse, § 39, fei jou.

47.(168) A partir d'ici, toute la fin de ce paragraphe se retrouve, avec des variantes importantes, d'une part dans le livre de Yeng Yng ou Yen tse intitulé Yen-tse tch'oen- ts'ieou (wai Tien, $\S 8)$, d'autre part dans le livre de Mo-tse (§ 39, fei jou). De ces trois rédactions, celle de Yen-tse est la plus ancienne et la plus fidèle; celle de Mo-tse offre déjà des modifications assez graves; celle de Se-ma Ts'ien est la plus altérée et serait parfois inintelligible si on ne la comparaît pas aux deux autres.

47.(169) Je traduis par «les lettrés », quoique cette traduction soit ici un anachronisme puisque les lettrés sont définis comme étant ceux qui reconnaissent Confucius pour leur maître. On peut douter qu'à l'époque de Confucius le mot [] désignât une classe de penseurs formant une école distincte ; dans le seul texte du Luen yu (VI, 11) où ce mot apparaisse, il n'a point cette valeur. Dans Yen-tse qui nous donne la forme la plus ancienne du texte que nous étudions en ce moment, le mot [] ne figure pas; il ne fait son apparition que dans la rédaction de Mo-tse qui est d'une époque postérieure.

47.(170) Le terme [ab] n'est pas commenté ici ; mais il se retrouve dans les chap. LXXI, p. 1 $\mathrm{r}^{\circ}$ et CCXXVI, p. $1 \mathrm{r}^{\circ}$ de Se-ma Ts 'ien où il est suivi de gloses assez longues (cf. aussi Tse tche t'ong kien, chap. CCXLIX p.8 $\mathrm{r}^{\circ}$ ); deux explications principales sont en présence :

— d'après Tseou Tan (fin du Ve siècle de notre ère), le mot [a] signifie troubler), et le mot [b] signifie « identique »; l'expression formée de ces deux mots désigne d'habiles discoureurs qui font passer le faux pour le vrai et le vrai pour le faux, qui troublent l'esprit des auditeurs en rendant identiques les contraires.

- D'après Ts'oei Hao († 450 p. C.), le terme [ab] désigne une sorte de vase à vin qui peut déverser du vin sans interruption, et, par métaphore, on l'applique à des bouffons qui font sortir incessamment des bons mots de leur bouche. Le premier sens est celui de « sophiste » : le second sens est celui de « bavard incoercible ».

Enfin, d'après Yao Tch'a (533-606), cette expression aurait le sens de plaisanteries trompeuses et de stratagèmes sortant avec promptitude.

47.(171) Cette première phrase ne se trouve pas dans les textes de Yen-tse et de Mo-tse.

47.(172) Au lieu de [], Yen-tse et Mo-tse écrivent : « on ne peut se servir d'eux pour enseigner le peuple ». Avec la leçon de Se-ma Ts'ien, je traduis le mot comme signifiant « être à la tête de, diriger»; de même, plus bas, on a les phrases : « on ne saurait leur faire diriger les mœurs », " on ne saurait leur faire diriger l'Etat. »

47.(173) On sait que Mo-tse défendit la thèse de la simplicité dans les funérailles et combattit sur ce point la doctrine des lettrés (cf. De Groot, Religious system of China, vol. II, liv. 1, p. 664-685). Il est intéressant de constater que le débat paraît s'être élevé dès l'époque même de Confucius.

47.(174) D'après le T'ang yun (cité dans le dict. de $K^{\prime}$ 'ang-hi), le mot [] est au jou cheng quand il signifie " emprunter », comme dans l'expression que nous avons ici; il est au k'iu cheng quand il signifie « prêter».

47.(175) Quand les grands sages apparurent, les rites et la musique furent parfaits ; mais plus tard, quand les Tcheou tombèrent en décadence, les rites et la musique s'altérèrent.

47.(176) Mo-tse : «multiplie les formes extérieures et met en honneur les belles apparences afin de fasciner les gens $»$.

47.(177) Au lieu de [],Yen-tse et go-tse donnent tous deux la leçon qui est seule intelligible. On trouvera en effet dans le $L i k i$ de nombreuses prescriptions sur la marche rapide et sur la marche en étendant les bras comme les ailes d'un oiseau; voyez notamment le chap. $k$ 'iu $l i$ 
(trad. Couvreur, t. I, p. 21). - Se-ma Ts'ien ne parle ici que des rites. Dans les textes de Yentse et de Mo-tse, Confucius est aussi accusé d'avoir modifié la musique d'une manière fâcheuse.

47. $(\underline{178})$ « durant des années ».

47.(179) On remarquera ce réquisitoire véhément où apparaissent déjà les principaux griefs que les ennemis des lettrés n'ont pas cessé d'invoquer contre eux.

47.(180) Yen-tse et Mo-tse : « il ne l'interrogea plus sur sa doctrine »

47.(181). Le Luen yu (XVIII, 3) rapporte ce texte comme s'il s'agissait d'un propos que le duc King aurait tenu en s'adressant à ses grands officiers. — Le chef de la famille $K i$ étant le plus puissant dignitaire du pays de Lou, et le chef de la famille Mong venant en dignité aussitôt après lui, le duc King faisait encore un insigne honneur à Confucius en lui accordant un traitement intermédiaire entre ceux que le prince de Lou donnait à ces deux hauts personnages. Il ne faut donc point voir là une des raisons pour lesquelles Confucius aurait quitté le pays de $T s$ ' $i$.

47.(182) Cf. Luen yu (XVIII, 3). Le duc King s'excuse de ne pas prendre Confucius pour conseiller en disant qu'il se sent trop vieux pour changer sa méthode de gouvernement

47. $(\underline{183})$ Kiang Yong (H. T. K. K., chap. CCLXII, p. $\left.15 \mathrm{v}^{\circ}\right)$ cherche à établir que Confucius ne serait guère resté qu'un an dans le pays de $T s$ ' $i$, de 517 à 516 . Mais le raisonnement sur lequel il se fonde pour obtenir cette conclusion est bien subtil. Tout ce qu'on peut dire, si l'on s'en rapporte au témoignage de Se-ma Ts 'ien, c'est que le séjour de Confucius dans le pays de $T s$ ' $i$ est postérieur à l'année 517 et antérieur à l'année 510.

47.(184) Cf. t. IV, p. 125 et $\underline{\text { n. } 33.215 .}$

47.(185) Ce paragraphe est tiré du Kouo yu, section Lou yu, 2de partie. Il est reproduit dans le Chouo yuan (section 10, pien ou) et dans le Kia yu (section 16, pien ou).

- Le k'oei, dit le dictionnaire Chouo wen, ressemble au dragon, mais n'a qu'une patte. D'après d'autres traditions recueillies par Tchang Cheou-tsie et Se-ma Tcheng, le k'oei serait un animal fantastique à un pied qui habite les montagnes et qui ressemble à un homme ; c'est l'être que les gens du pays de Yue appellent le sao des montagnes.

- Le wang leang, dont le nom est écrit dans le Kouo yu, se plaît à imiter la voix humaine et à induire les hommes en erreur.

— Le wang-siang dévore les hommes ; on l'appelle aussi mou-tchong.

- Le fen yang ou mouton fen est produit spontanément par la terre et n'est pas issu de l'accouplement d'un mâle et d'une femelle.

L'encyclopédie T'ai p'ing yu lan, dans le chap. 902, cite un passage du Han che wai tchoan (ce passage ne se retrouve pas dans le texte de ce livre tel qu'il figure dans le Han wei ts'ong chou), où l'anecdote que nous étudions est présentée d'une manière un peu différente :

« Le duc Ngai, de Lou, avait chargé des hommes de creuser un puits : au bout de trois mois (de travail), ils ne trouvèrent pas de source, mais ils trouvèrent un mouton de jade. Le duc pensa que c'était un heureux présage; il chargea ses invocateurs de faire à cette occasion de la musique et des danses et il se proposait d'offrir au ciel (cette victime); mais le mouton ne put pas être offert. K'ong-tse vit le duc et lui dit :

— L'essence de l'eau est le jade ; l'essence de la terre est le mouton. Je désire que vous ne voyiez point là un prodige - le foie de ce mouton est en terre.

Le duc fit tuer (le mouton) et, quand on examina son foie, on constata qu'il était en terre. 
Dans Hoai nan tse (chap. XIII, p. $27 \mathrm{v}^{\circ}$, section se luen hiun), on lit :

«Les montagnes produisent le hiao yang; l'eau donne naissance au wang-siang ; le bois donne naissance au pi-fang ; les puits donnent naissance au mouton fen. - Le k'oei, le wang-siang et le pi-fang sont mentionnés, en compagnie d'autres êtres fantastiques, dans le Tong king fou ou Éloge de la capitale orientale, de Tchang Heng (78-139 ap. J.-C, ; voy. le Wen siuan, chap. III).

47.(186) Ce paragraphe est tiré du Kouo yu, section Lou yu, 2de partie; il est reproduit dans le Chouo yuan (section 10, pien ou) et dans le Kia yu (section 16, pien ou).

47.(187) Le prince de Yue avait été cerné par les troupes de Ou sur le mont Koei-ki (au sud de Chao-hing fou, prov. de Tche-kiang; cf. t. IV, p. 421, ligne 7). C'est en faisant des terrassements et des tranchées militaires sur cette hauteur que le roi de $O u$ exhuma un ossement gigantesque.

- Si l'anecdote qui va être rapportée a un fondement historique, elle prouve que, en Chine aussi bien qu'en Europe, on admettait volontiers que les hommes d'autrefois avaient eu une taille extraordinairement élevée ; on était donc porté à considérer comme des débris de ces races antiques des ossements qui, selon toute vraisemblance, devaient appartenir à des animaux de la faune paléontologique. C'est ainsi que, en France, des ossements trouvés en 1613 dans les environs de Romans (Dauphiné), furent attribués au géant Teutobochus, roi des Teutons, qui avait été vaincu en 102 av. J.-C. par Marius; ce ne fut qu'en 1835 que Blainville prouva que ces ossements avaient appartenu à un mastodonte (cf. Dastre, «La stature de l'homme aux diverses époques », Revue des Deux-Mondes, 1 sept. 1904, p. 205).

47.(188) Dans d'autres textes (Tso tchoan, $7^{\mathrm{e}}$ année du duc Ngai; Se-ma Ts'ien, t. I, p. 171, lignes 8-9), il est dit que $Y u$ réunit les seigneurs dans une localité située au sud du Yang-tse ; l'expression, «la foule des divins» est donc ici équivalente à «les seigneurs ». En effet, comme Confucius va le rappeler lui-même, les seigneurs sont ceux qui président aux sacrifices qu'on fait aux dieux des montagnes et des cours d'eau; à ce titre, ils peuvent être appelés eux-mêmes « les dieux » ou les divins ».

47.(189) Le Tchou chou ki nien (cf. Legge, C. C., t. III, Prolégomènes, p. 118) rapporte aussi que Fang-fong fut mis à mort par $Y u$.

— Le Chou i ki, qui passe pour avoir été écrit par un certain Jen Fang au VIe siècle de notre ère, mais qui a été perdu puis reconstitué à une époque bien postérieure (cf. Wylie, Notes on Chap. Lit., p. 15), raconte (chap. I, p. $1 \mathrm{v}^{\circ}$ ) que, dans les régions de $O u$ et de Yue, il y a des temples de Fang-fong où ce personnage est représenté avec une tête de dragon, des oreilles de bœuf et des sourcils se réunissant sur un oeil unique ; quand on lui sacrifie, on pousse des mugissements en soufflant dans des tubes de bambou longs de trois pieds, tandis que trois hommes dansent les cheveux épars. - Le culte de Fang-fong paraît être un ancien culte local du pays de Yue dont la légende a été incorporée dans l'histoire chinoise.

47.(190) Se-ma Ts'ien emploie le mot [a] qui est amphibologique puisqu'il désigne ici les divinités mêmes des montagnes et des cours d'eau, tandis que, dans la phrase suivante, le même mot désigne " les divins », c'est-à-dire les seigneurs qui président aux sacrifices rendus à ces divinités. Le Koиo yu et le Chouo yuan ne sont pas aussi obscurs, car ils écrivent [b] dans le premier cas, et [a] dans le second.

47.(191) L'influence attribuée aux dieux des montagnes et des cours d'eau vient de ce qu'ils sont capables de produire les nuages et d'amener la pluie. En effet les nuages s'assemblent sur les montagnes et les vapeurs se forment au-dessus des cours d'eau.

47.(192). Le Kouo yu est ici plus explicite : Au-dessous des seigneurs féodaux qui président aux sacrifices adressés aux montagnes et aux cours d'eau de leur territoire, sont les simples ducs et marquis qui n'ont à sacrifier qu'à leurs dieux du sol et des moissons. 
47.(193) Les seigneurs féodaux, aussi bien que les ducs et marquis, dépendaient du roi suprême c'est-à-dire du Fils du Ciel.

47.(194) Au lieu de Wang-wang, il faut lire Wang-mang, comme dans le Kouo yu et le Chouo yuan.

47.(195) Le Ou hing ki de Chan K'ien-tche (cité dans le commentaire du Kouo yu par Wang Yuen-suen) dit que la montagne Fong était à $18 l i$ à l'est de la s.-p. de Ou-k'ang (dépendant de la préf. de Hou-tcheou, prov. de Tche-kiang); la montagne $Y u$ était à 30 li plus au sud.

47.(196) Cf. t. IV, n. 33.199 , p. 116 et p. 241, ligne 11.

47.(197) La leçon du Kouo yu est plus claire : «quels sont les extrêmes (en grandeur et en petitesse) de la taille humaine?»

47.(198) Dans le Kouo $y u$ (avant-dernier texte de la $4^{\mathrm{e}}$ partie de la section $T \sin y u$ ), les Tsiao-yao sont mentionnés, non comme un peuple, mais comme formant une des huit catégories de gens infirmes. Dans le Tchou chou ki nien, au contraire, les Tsiao-yao apparaissent comme une peuplade :

« La $29^{\mathrm{e}}$ année (de l'empereur Yao), le chef des Tsiao-yao vint rendre hommage à la cour, et apporta en tribut des plumes qui s'enfonçaient dans l'eau.

(Legge, C. C., vol. III, prol., p. 114).

Le Heou Han chou (chap. II, p. $8 \mathrm{v}^{\circ}$ ), à la date de 74 p. C., cite les Tsiao-Tao dans une énumération des peuples barbares du Sud-Ouest qui vinrent faire leur soumission à la Chine. Le Chan hai king (section Hai wai nan king) mentionne le royaume de Tcheou jao qu'on appelle aussi Tsiao-yao ; le commentateur Ho I-hing (vers 1800 ; Giles, B. D., n 636), émet l'opinion que le terme tchou-jou, qui signifie « un nain », n'est qu'une autre prononciation de ce même mot Tcheou-jao ou Tsiao-yao, quoique le texte du Kouo-yu auquel nous avons fait allusion plus haut dans la présente note distingue les Tsiao-yao des tchou-jou pour en faire deux catégories différentes d'infirmes, nous serions cependant disposés à croire que l'explication de Ho I-hing est valable et que les termes tsiao-yao et tchou-jou ont la même origine.

- La géographie Kouo ti tche, publiée en l'an 642, rapproche du nom des Tsiao-yao la légende des Pygmées et des grues :

«Le royaume des petits hommes est au sud de $T a T s$ 'in; ces gens n'ont que trois pieds de haut; à l'époque des labours et des semailles ils craignent d'être mangés par les grues; aussi $T a T s$ 'in vient-il à leur secours. C'est le royaume des Tsiao yao ; ces gens vivent dans des cavernes.

Ce texte est fort important, puisqu'on y trouve pour la première fois en Chine la fable des combats entre les Pygmées et les grues; il nous a été conservé dans le commentaire de Tchang Cheou-tsie au chap. CXXIII, p. 3 ro de Se-ma Ts'ien.

47.(199) La stature des hommes les plus grands, tels que Fang-fong, serait donc de 30 pieds.

47.(200) Les événements auxquels il est fait ici allusion sont racontés dans le Tso tchoan $\left(5^{\mathrm{e}}\right.$ année du duc Ting). Ils suivirent immédiatement la mort de Ki P'ing-tse (505 av. J.-C). que Se-ma Ts 'ien a rappelée plus haut (p. 310) ; c'est par un défaut de composition que l'historien a interrompu son récit pour intercaler deux paragraphes du Kouo yu dont l'un au moins rapporte un incident de l'année 494 (cf. p. 312), c. à. d. postérieur de onze ans aux faits qui vont être maintenant exposés : On saisit ici sur le vif le procédé de rédaction de Se-ma T'sien qui cherche à loger tant bien que mal entre les textes historiques proprement dits les textes de provenances fort diverses où Confucius est mentionné.

- Le personnage appelé Kong-chan Pou-nieou par le Tso tchoan et par Se-ma T'sien est celui qui apparaît dans le Luen yu (XVII, 5) sous le nom de Kong-chan Fou-jao.

47.(201) Cf. tome III, n. 15.110. 
47.(202) Vers la fin de ce chapitre Se-ma Ts'ien parlera plus en détail de cette importante question.

47.(203) Song Siang-fong, dans ses études sur le sens du Luen yu publiées en 1840 (S. H. T. K. $K$., chap. CCCLXXXIX, p. $1 \mathrm{r}^{\circ}$ ) rapproche de la phrase de Se-ma Ts'ien le texte du Luen yu $(\mathrm{I}, 1, \S 2)$ où Confucius dit :

— N'est-il pas agréable d'avoir des amis qui viennent des contrées éloignées ?

47.(204) Cf. t. IV, p. 126, et Tso tchoan, $8^{\mathrm{e}}$ année du duc Ting.

47.(205) Il y a ici une erreur, car Confucius, né en 551, devait avoir cinquante et un ans en 501 , suivant la manière de compter chinoise.

47.(206) Cf. t. IV, n. 33.148, et n. 40.357.

47.(207) Sur ce sens du mot [], cf. Luen yu, II, 11.

47.(208) Dans le Luen yu, IX, 6, la phrase à signifie : «comme je n'avais pas de fonctions publiques $»$.

47.(209) Cf. t. I, n. 40.357. Le sens est celui-ci : Les rois Wen et $O u$ qui furent les glorieux fondateurs de la dynastie Tcheou, régnaient à l'origine dans des localités fort peu importantes. Ma sagesse ne pourrait-elle pas faire que la petite ville de $P i$ devienne de même le berceau d'une illustre dynastie?

47.(210) C'est-à-dire : rois suprêmes, Fils du Ciel.

47.(211) Luen yu, XVII, 5.

47.(212) C'est-à-dire : Ne ferai-je pas de lui le fondateur d'une dynastie qui égalera celle des Tcheou, et qui, ayant son siège dans l'est de l'empire, pourrait être appelée un Tcheou oriental?

47.(213) Se-ma Ts'ien expose ici, avec quelques détails complémentaires, un fait qui est rapporté dans le Luen yu, XVII, 5. Cet incident de la vie de Confucius a donné lieu à de nombreuses discussions de la part des lettrés chinois qui ont voulu excuser leur grand sage d'avoir pensé à se mettre au service d'un rebelle.

47.(214) La ville de Tchong-tou était à l'ouest de la sous-préfecture actuelle de Wen-chang (préf. de Yen-tcheou, prov. de Chan-tong). A l'époque tch'oen-ts'ieou, elle appartenait à l'État de Lou mais elle tomba ensuite au pouvoir de $T s$ ' $i$ et prit le nom de P'ing-lou, ou, pour parler plus exactement, elle disparut et une nouvelle ville appelée $P$ 'ing-lou fut élevée par $T s$ ' $i$ au nord de la sous-préfecture actuelle de Wen-chang (Ta Ts'ing i Long tche, chap. CXXX, p. $2 \mathrm{v}^{\circ}$; Cf. Se-ma Ts'ien, t. III, n. $\underline{28.203}$ et t. V, $\underline{\text { n. 46.188) }}$.

— Le Li ki (chap. T'an kong, III, 4) rappelle que

«lorsque le Maître gouvernait Tchong-tou, il ordonna que les cercueils intérieurs eussent quatre pouces d'épaisseur et que les cercueils extérieurs en eussent cinq.

- Le Kia yu (au début) nous a décrit l'âge d'or qui régnait à Tchong-tou sous l'administration de Confucius (cf. Legge, C. C., vol. I, Prolégomènes, p. 73 [css: édition/rechercher 'as magistrate']).

47.(215) Le Kia yu écrit : «les seigneurs d'Occident le prenaient pour modèle ». Le pays de Lou étant le plus oriental des Royaumes du Milieu, tous les autres pouvaient être désignés par rapport à lui sous le nom de « les seigneurs d'Occident».

47.(216) Cf. Kia yu (au début). - Kiang Tong (H. T. K. K., chap. CCLXII, p. 17 ro) fait observer que c'était le chef de la famille Mong-suen qui exerçait les fonctions de ministre des travaux publics dans le pays de Lou; Confucius ne pouvait donc être que son assesseur. 
47.(217) Le Tso tchoan ( $1^{\mathrm{e}}$ année du duc Ting) rappelle que, lorsque Confucius fut devenu ministre de la justice, il réunit par un fossé la tombe du duc Tchao avec celles des autres membres de la famille ducale. Il détruisit ainsi l'œuvre mauvaise du chef de la famille $K i$ qui avait voulu poursuivre de sa haine le duc Tchao même après sa mort en isolant sa tombe, et, d'après le Kia yu (chap. I, p. $1 \mathrm{v}^{\circ}$ ). il adressa à ce puissant seigneur de hardies remontrances. - D'après le Li ki (chap. T'an kong, I, 3), Confucius aurait exercé la charge de ministre de la justice jusqu'au moment où il dut quitter le pays de Lou.

47.(218) Cf. tome IV, n. 32.236. Nous avons ici un récit détaillé de la fameuse entrevue à laquelle Se-ma Ts'ien a déjà fait allusion dans d'autres chapitres (t. IV, p. 77 et p. 127). On peut comparer avec ce passage les textes suivants : Tso tchoan $\left(10^{\mathrm{e}}\right.$ année du duc Ting); commentaires de Kong-yang et de Kou-leang (à la même date) ; le Kia yu (chap. I, p. 1 v -2 r $^{\circ}$ ) ; le Sin yu (section pien houo) de Lou Kia (fin du IIe sièrle av. J.-C.).

47.(219) Le mot [a] signifie ici "amitié, entrevue amicale». [ab] a donc le sens de «aller comme à une entrevue amicale ». Cf. Tso tchoan $\left(10^{\mathrm{e}}\right.$ année du duc Ting) : «vous, ces deux princes, vous vous réunissez pour une entrevue amicale ».

47.(220) en se servant des chars qu'on monte habituellement, par opposition aux chars de guerre. Dans les planches annexées à l'édition impériale (de K'ang-hi) du Li ki (cf. LXXX, p. $34 \mathrm{v}^{\circ}$ ), on trouvera l'indication des différences qui existaient entre le char de guerre et le char ordinaire.

47.(221) Il y a ici une difficulté chronologique, car Se-ma Ts'ien dira plus loin que ce fut seulement en 496 que Confucius quitta sa charge de ministre de la justice pour exercer les fonctions de conseiller. Il semble donc qu'en l'an 500 Confucius dût être encore ministre de la justice. En plusieurs autres endroits cependant, Se-ma Ts'ien confirme ce qu'il dit ici et rappelle que c'est en l'an 500 que Confucius devint conseiller de Lou (cf. t. IV, p. 24, 77, 333, 378 ; t. V, p. 137). Il faut d'ailleurs toujours entendre que Confucius exerça provisoirement les fonctions de conseiller d'État, mais sans avoir réellement ce titre.

47.(222) L'expression [ab] désigne les entrevues de princes; le mot [a] signifie proprement les entrevues concertées à date fixe, et le mot [b] les entrevues accidentelles. Cf. Li ki, chap. K'iu li, II, $2, \S 12$.

47.(223) Le P'ei wen yun fou ne donne pas d'autre exemple de cette expression que le texte même que nous avons ici. Il me semble qu'on peut identifier cette musique avec celle des barbares des quatre points cardinaux qui est mentionnée dans le Tcheou li (trad. Biot., t. II, p.67). On verra plus loin, en effet, que Confucius condamne cette musique comme étant celle des barbares $I$ et $T i$.

47.(224) On attendrait plutôt: "plumes et flûtes », chaque danseur tenant d'une main une plume emmanchée et de l'autre une flûte.

47.(225) On projetait, à la faveur du tumulte causé par cette danse guerrière, de tuer ou de prendre le duc de Lou. Confucius sentit le danger et le prévint par sa décision.

47.(226) Dans le chap. Yo ki du Li ki (tr. Couvreur, t. II, p. 87), on se plaint que la musique moderne soit déshonorée par des histrions et des nains qui ressemblent à des singes.

— Sur l'origine probable de l'expression tchou-jou, cf. n. 198.

47.(227) Cette leçon est aussi celle de Kong-yang. Le Kia yu écrit «traitent sans respect»; Kou-leang donne la leçon « se moquent de ».

47.(228) Je rétablis cette phrase d'après les textes de Kong-yang et du Kia yu.

47. $(\underline{29})$ «Leurs têtes et leurs pieds », disent Kong-yang, Kou-leang et le Sin yu de Lou kia. Le Kia yu, comme Se-ma Ts'ien, écrit « leurs mains et leurs pieds». 
47.(230) Cet incident n'est pas rapporté dans le Tso tchoan (10 année du duc Ting), et Kiang Yong (H. T. K. K., chap. CCLXII, p. $18 \mathrm{r}^{\circ}$ ) en conteste l'authenticité. car il le juge indigne du caractère de Confucius. On remarqàera cependant que tous les autres textes le relatent.

47.(231) Le duc King, de $T s^{\prime} i$, est ici désigné sous le nom de marquis de $T s^{\prime} i$, ce titre étant celui qui lui est constamment attribué dans le Tch'oen-ts'ieou.

47.(232) Au lieu de "Yun, Wen-yang et Koei-yn», le Tso tchoan et Kou-leang écrivent: «Yun, Hoan et Koei-yn », et Kiang long (H. T. K. K., chap. CCLIV, p. $32 \mathrm{r}^{\circ}$ ) explique que ces trois dernières localités appartenaient toutes au territoire appelé « les champs de Wen-yang », ce qui ne paraît pas exact, étant donnés leurs emplacements respectifs.

Les champs de Wen-yang étaient les terres situées au nord de la rivière Wen, laquelle sort de la sous-préfecture de Lai-ou (préf. de T'ai-ngan, prov. de Chan-tong) et coule vers le sud-ouest pour se jeter près de Tsi-ning tcheou dans la rivière $T s i$ qui fait aujourd'hui partie du grand canal.

La ville de Yun dont il est ici question est le Yun occidental qui est aujourd'hui la s.-p. de Yun-tch'eng (préf. de Ts'ao-tcheou, prov. de Chan-tong). Il ne faut pas la confondre avec le Yun oriental qui appartenait à la famille Ki-suen, du pays de Lou, et qui était à quelque distance de la principauté de Kiu (auj. préf. sec. de Kiu, dans la préf. de I-tcheou, prov. de Chan-tong).

La ville de Hoan était au sud-ouest de la s.-p. actuelle de Fei-tch'eng (préf. de Tsi-nan, prov. de Chan-tong).

La localité de Koei-yn, en vertu de son nom même, devait être au nord de la montagne Koei ; or cette montagne se trouvait au S.-O. de la s.-p. de Sin-t'ai, et au N.-E. de la s.-p. de Se-choei.

En résumé, on voit que, des trois localités de Yun, Hoan et Koei-yn, celle de Hoan seule était au nord de la rivière Wen et appartenait aux champs de Wen-yang; Se-ma Ts'ien est donc dans son droit, en remplaçant le nom de Hoan par celui de Wen-yang, et la leçon : «Yun, Wen-yang et Koei-yn » est parfaitement légitime.

- Sur les identifications géographiques proposées dans cette note, voyez Kiang Yong, dans H. T. K. K., chap. CCLII, p. $11 \mathrm{v}^{\circ}$; chap. CCLIII. p. $1 \mathrm{r}^{\circ}$, p. $23 \mathrm{r}^{\circ}$, p. $24 \mathrm{v}^{\circ}$, p. $26 \mathrm{r}^{\circ}$ et $\mathrm{v}^{\circ}$; chap. CCLIV, p. $4 \mathrm{r}^{\circ}$ et $\mathrm{v}^{\circ}$ et p. $32 \mathrm{r}^{\circ}$ et $\mathrm{v}^{\circ}$.

47. $(\underline{233})$ Cette date est inexacte; il faut lire : «la douzième année (498)». Cf. t. IV, p. 127, et Tso tchoan, $12^{\mathrm{e}}$ année du duc Ting.

47.(234) Le tche est une mesure qui s'applique aux murailles et qui équivaut à 30 pieds de long; un mur de cent tche est donc un mur de 3.000 pieds de circuit.

Dans le Tso tchoan, $1^{\mathrm{e}}$ année du duc $Y u$, on lit :

«Quand le mur d'une ville dépasse cent $t c h e$ de long, c'est un mal pour l'État.

Cet aphorisme concorde avec celui qui est exprimé par Confucius.

Comme on va le voir, Confucius se proposait de rétablir l'autorité ducale en faisant démanteler les trois places fortes qui appartenaient aux trois familles Mong, Chou-suen et Ki, issues du duc Hoan ; il attire donc l'attention du duc sur le fait que les murailles de ces villes dépassent la mesure prescrite. Legge $(C$. $C$., vol. V, p. 781, $a)$ a bien montré quelles étaient les circonstances favorables qui permettaient à Confucius de tenter cette entreprise.

47.(235) Tso tchoan, $12^{\mathrm{e}}$ année du duc Ting.

Tchong-yeou: Tse-lou, un des plus célèbres disciples de Confucius.

47.(236) Heou, place forte de la famille Chou-suen; Pi, de la famille Ki; Tch'eng, de la famille Mong. Cf. tome IV, n. 33.237. 
47.(237) Cf. n. 200, à la fin.

47.(료) Le Kia yu ( $§ 1$, Siang Lou) écrit : « arrivèrent auprès du belvédère ». Cette leçon s'accorde mieux avec le contexte, puisque nous voyons que Confucius chargea deux officiers de descendre du belvédère pour repousser les assaillants.

47.(239) Deux grands officiers du pays de Lou.

47.(240) A 45 li à l'est de la s.-p. de Se-choei, dit. le Kouo ti tche. La s.-p. de Se-choei dépend de la préfecture de Yen-tcheou.

47.(241) Le Tso tchoan dit : «Si vous feignez de l'ignorer, moi du moins je ne démantèlerai pas (cette ville) ».

47.(242) Cf. p. 326, n. 4 [renvoi fautif].

47.(243) Ce paragraphe se retrouve dans le Kia yu, $\S 2$, che tchou. - Le sens des mots «s'humilier devant les autres hommes » est confirmé par un texte du Luen yu, XII, 20.

47.(244) Après sept jours de gouvernement, disent Siun tse et le Kia yu.

47.(245) L'exécution du chao-tcheng Mao n'est pas relatée dans le Tso tchoan et il n'y est fait allusion, ni dans le Luen yu, ni dans Mencius. Aussi Kiang Yong (H. T. K. K., chap. CCLXII, p. $18 \mathrm{v}^{\circ}$ ) met-il en doute l'authenticité du fait.

D’autre part cependant, de nombreux textes mentionnent cet événement.

Siun tse (IIIe siècle av. J.-C. ; cf. Mém. hist., chap. LXXIV) paraît être l'auteur le plus ancien qui l'ait relaté; dans la section 28 (yeou tso) de l'ouvrage qui porte son nom, il raconte que Confucius ayant mis à mort le chao-tcheng Mao, un de ses disciples lui en fit des reproches; il se justifia en montrant que le supplicié réunissait en lui les cinq plus graves défauts et qu'il méritait d'être tué ; il rappela sept occasions dans lesquelles des personnages vertueux de l'antiquité se virent de même obligés de faire subir la peine capitale à des coupables.

Le Kia yu $(\S 2)$ présente ce récit dans des termes presque identiques.

La rédaction est notablement différente dans le Chouo yuan de Lieou Hiang (chap. XV, tche ou).

Enfin Hoai-nan tse (chap. XIII, se luen hiun) fait une simple allusion à l'exécution de Mao, en disant: "Quand K'ong-tse eut fait périr le chao-tcheng $M a o$, les vices du royaume de Lou furent réprimés ».

47.(246) Dans le tch'oen ts'ieou de Lu Pou-wei (section sien che lan, § 5), on lit :

«Quand (Confucius) eut exercé ses fonctions pendant trois ans (sic), les hommes marchaient sur la droite de la route, les femmes marchaient sur la gauche de la route. Quand quelque objet de valeur avait été laissé par mégarde, il n'était personne dans le peuple qui le prît.

47.(247) Ce paragraphe est, dans le Kia yu (§ 1), la fin d'un passage plus développé qui se retrouve dans le sin siu (section tsa che, $\S 1$ ) de Lieou Hiang. Cf. aussi Siun tse (§ 8, jou hiao), et Lu Pou-wei (voyez la note précédente).

47.(248) Dans l'espérance que ce don gracieux conciliera à Ts 'i le bon vouloir de Lou .

47.(249) Ce Li Tch'ou nous est déjà apparu plus haut (p. 319), comme l'instigateur d'un stratagème destiné à briser la puissance du prince de Lou. A vrai dire, il semble que son intervention répétée fasse double emploi.

47.(250) A partir d'ici, le texte est parallèle à celui du Kia yu (§ 19, Tse-lou tch'ou kien). — Le Luen yu (XVIII, 4) dit simplement : 
«Les gens de $T s$ 'i envoyèrent en présent des danseuses ; Ki Hoan-tse les reçut ; pendant trois jours il n'y eut pas d'audience à la cour. K'ong-tse partit.

Han Fei-tse ( $\left(31\right.$, nei tch'ou chouo, b, $\mathrm{n}^{\circ} 6$ ), attribue aussi le stratagème à Li Tch'ou qu'il appelle $\mathrm{Li}$ Ts'ie ; mais il dit, par erreur, que ces musiciennes furent envoyées au duc Ngai ; or le duc Ngai ne commença à régner qu'en 494.

47.(251) Il n'est question que de six danseuses ou musiciennes dans le texte de Han Fei-tse qui est le plus ancien, puisque Han Fei-tse vivait dans la seconde moitié du IIIe siècle avant notre ère. - Le Kia yu (§ 19) compte quatre-vingts femmes et quarante quadriges.

47.(252) Le yong-ki est aussi défini comme une danse accompagnée de musique.

47.(253) Le Kia yu (§ 19) ajoute ici la phrase : « ce sera la preuve qu'il ne néglige pas encore les règles essentielles $»$.

47.(254) Luen yu, XVIII, 4.

47.(255) Les Tableaux chronologiques (chap. XIV, p. $65 \mathrm{v}^{\circ}$ ) et le chapitre sur le pays de Lou (t. IV, p. 197) rapportent cet événement à l'année 498. D'après le chapitre sur le pays de $W e i$ (t. IV, p. 205), c'est en 497 que Confucius quitta le pays de Lou. Kiang Yong (H. T. K. K., chap. CCLXII, p. $20 \mathrm{v}^{\circ}$ ) croit que son départ doit être en effet fixé au printemps de l'année 497. Cependant, d'après ce qu'a dit plus haut Se-ma Ts'ien (p. 326), ce départ ne pourrait pas être antérieur à l'an 496.

- C'est après que Confucius fut parti du pays de Lou que commence la longue série de ses pérégrinations; d'après les textes les plus anciens, Confucius en quittant Lou se serait rendu dans le pays de Tch'ou, dit Han Fei-tse (§ 31) « il partit et alla dans le pays de Tch'ou »; et le Li ki (chap. T'an kong, II, 3, § 4) nous informe que lorsque Confucius eut quitté la place de ministre de la justice dans le pays de Lou, il prit ses mesures pour se rendre à King, c'est-à-dire dans le royaume de Tch'ou (cf. tome I, n. 04.127 et tome IV, n. 32.172). Ce témoignage cependant ne s'accorde pas avec ce qu'on va lire dans Se-ma Ts 'ien.

47.(256) D'après P'ei Yn, T'oen était une localité située au sud de le capitale de Lou (cette capitale étant la sous-préfecture actuelle de $K^{\prime} i u-f e o u$ ). Le Kia yu écrit [], ce qui semble donner à entendre que cette localité formait un faubourg de la capitale.

47.(257) Ces femmes étaient des chanteuses; c'est pourquoi Confucius incrimine leurs bouches.

47.(258) Ce texte figure dans le Kia yu (§ 19).

Un livre sur la musique intitulé $K^{\prime}$ 'in ts'ao, qu'on attribue à $T s^{\prime}$ 'ai Yong (133-192), nous a conservé le texte de deux autres odes chantées qui auraient été composées par Confucius au moment où il venait de quitter le pays de Lou (cf. H. T. K. K., chap. CCLXII, p. 21 r $^{\circ}$ ); elles ont été traduites par Legge, C. C., vol. I, Prolégomènes, p. 76-77 [css : édition/rechercher: 'On leaving']

Je ne citerai ici que la. première d'entre elles : après avoir quitté la capitale du pays de Lou, Confucius voulut lui jeter un dernier regard, mais il ne put le faire parce que la montagne Koei (cf. n. 232) s'interposait entre lui et la ville. Il dit alors :

J'ai voulu regarder de loin (la capitale de) Lou, - mais la montagne Koei me la cache ;

Dans ma main je n'ai pas de hache ;

Que puis-je contre la montagne Koei ?

D'après les explications que fournit le K'in ts-ao (cité dans le K'ong-tse tsi yen de Suen Sinyen, chap. XII, à la fin), Confucius veut donner à entendre que Ki Hoan-tse s'est interposé entre lui et le prince, comme la montagne Koei entre lui et la ville ; il regrette de n'avoir pas 
eu en main assez de puissance pour faire périr Ki Hoan-tse ; il ne peut rien contre lui, non plus que contre la montagne Koei.

47.(259) Je n'ai retrouvé ce paragraphe dans aucun autre texte.

47.(260) La capitale de Wei était alors la ville de Ti-k'ieou, ainsi nommée parce qu'elle passait pour occuper l'emplacement de la ville de l'antique empereur Tchoan-hiu. Le Ta Ts'ing $i$ t'ong-tche la place à $70 l i$ au N.-E. de la s.-p. de Hoa (préf. de Wei-hoei, prov. de Ho-nan) ; elle était donc à l'O. de la préf. sec. de K'ai (préf. de Ta-ming, prov. de Tche-li).

47.(261) Mencius (v, a, 8) dit que, lorsque Confucius était dans le pays de Wei, il demeurait chez Yen Tch'eou-yeou. Il ne dit point que ce personnage fût le frère aîné de la femme de Tselou mais comme, aussitôt après l'avoir mentionné, il parle de la femme de Tse-lou, on comprend comment une erreur a pu se glisser dans le texte de Se-ma Ts 'ien.

47.(262) On ne sait de quelles mesures il est ici question. Tchang Cheou tsie veut que ces 60,000 mesures de grain aient équivalu à un traitement de 2,000 che à l'époque des Han, mais ce calcul parait fort arbitraire.

47.(263) La capitale de l'État de Tch'en correspond à la préfecture actuelle de Tch'en-tcheou, dans la province de Ho-nan.

47.(264) Dans le voisinage de la s.-p. de Tch'ang-yuen (préf. de Ta-ming, prov. de Tche-li). $K$ 'oang appartenait alors au pays de Song.

47.(265) Yen K'o, dont l'appellation était Tse-kiao, était originaire du pays de Lou; il était de cinquante ans plus jeune que Confucius, ce qui explique l'imprudence du propos qu'il va tenir. Cf. Kia $y u, \S 38$.

47.(266) Cette parole pouvait faire croire aux gens de K'oang que les voyageurs avaient autrefois pris part à un assaut dirigé contre leurs murs.

47.(267) Luen yu, XI, 22.

47.(268) Ce texte du Luen yu me parait établir que les disciples de Confucius avaient, comme lui-même, une foi invincible dans sa mission divine. De même que Confucius va se déclarer inviolable puisque le Ciel a fait de lui le dépositaire de la perfection, de même Yen Yuen est persuadé qu'il ne mourra pas tant que son maître sera en vie et aura besoin de lui. L'interprétation que propose Lieou Pao-nan (S. H. T. K. K., chap. 1064, p. $17 \mathrm{v}^{\circ}$ ) est plus terre à terre : Yen Yuen était arrivé en retard, soit parce qu'il s'était caché, soit parce qu'il avait pris des chemins détournés afin d'échapper au péril ; il explique sa conduite à son maitre en lui disant: Je savais bien que vous étiez resté vivant et c'est pourquoi je n'ai pas jugé nécessaire de m'exposer à la mort. Yen Yuen savait en effet que les gens de K'oang ne voulaient pas de mal à Confucius et que la méprise qui leur avait fait confondre Confucius avec Yang Hou ne tarderait pas à se dissiper.

47. (269) Luen yu, IX, 5.

47.(근) C'est-à-dire en lui-même, Confucius.

47.(271) Moi qui suis le successeur du roi Wen, lequel est mort.

47.(272) Ning Ou-tse est mentionné dans le Luen yu (V, 20); il était bien un officier du pays de $W e i$, mais il vivait à la fin du VIIe siècle de notre ère et était mort depuis plus de cent ans lorsque Confucius fut arrêté par les gens de K'oang. Kiang Yong (H. T. K. K., chap. CCLXII, p. $21 \mathrm{v}^{\circ}$ ) n'a pas manqué de signaler le grave anachronisme que commet ici Se-ma Ts'ien.

D'après une autre tradition qui est rapportée dans le Kia yu (§ 22, k'oen che), dans le Han che wai tchoan (chap. VI, p. $11 \mathrm{v}^{\circ}-12 \mathrm{r}^{\circ}$ ), et dans le Chouo yuan (chap. XVII, tsa yen, p. $10 \mathrm{v}^{\circ}$ ), Confucius, que les gens de $K^{\prime}$ oang avaient pris pour Yang Hou, était cerné avec ses disciples par une bande d'hommes armés que commandait un certain Kien-tse ; il invita Tse-fou à 
chanter, tandis que lui-même l'accompagnait de la voix ; au bout du troisième air, le cercle hostile qui les enserrait se dispersa. Tchoang tse (chap. XVII) a embelli cette anecdote dont il a fait un récit de pure fantaisie (cf. Legge, SBE, vol. XXXIV, p. 385-387).

47.(273) D'après le Kouo ti che, l'ancienne ville de $P$ 'ou était à 15 li au nord de la s.-p. de $K$ 'oang-tch'eng qui n'est autre que la ville même de $K$ 'oang où Confucius fut mis en péril ; cf. n. 264 ; Kiang Yong (H. T. K. K., chap. CCLXII, p. 21 ro) identifie $P^{\prime}$ ou avec la s.-p. actuelle de Tch'ang yuen.

47.(274) K'iu Yuen, dont l'appellation est Po-yu, est considéré comme un des disciples de Confucius. Il exerçait des fonctions publiques dans l'État de Wei; la tradition veut que, dès l'année 544 av. J.-C., il ait conversé avec le fameux $K i$-tcha, envoyé du roi de $O u$ (cf. t. IV, p. 14 , ligne 3 ). Il est mentionné à deux reprises d'une manière fort élogieuse dans le Luen yu (XIV, $26 ; \underline{\mathrm{XV}, 6})$.

47.(275) Nan-tse était célèbre pour sa dépravation. En 496, la rumeur populaire l'accusait formellement d'entretenir des rapports incestueux avec son frère Tchao (cf. Tso tchoan, $14^{\mathrm{e}}$ année du duc Ting, texte cité dans notre tome II, n. 06.398). Ce Tchao était d'une beauté remarquable (Luen yu, VI, 14). - D'après Se-ma Ts'ien, Confucius paraît s'être trouvé dans le pays de $W e i$ en 495 (voyez plus loin, n. 286) ; d'après les recherches de Kiang Yong (H. T. $K$. $K$., chap. CCLXII, p. $23 \mathrm{r}^{\circ}$ ), cette date devrait être l'année 496. Dans l'une et dans l'autre de ces hypothèses, la conduite scandaleuse de Nan-tse était de notoriété publique au moment où Confucius lui rendit visite.

47.(276) [] est le nom par lequel se désigne la femme d'un prince en présence d'un seigneur ( $\mathrm{Li} \mathrm{ki}$, chap Kiu li, I, 2, § 19).

47.(277) Confucius ne voyait pas la princesse qui était dissimulée derrière un voile, mais, en entendant le son de ses bijoux qui s'entrechoquaient, il comprit qu'elle lui rendait par deux fois son salut. Si l'anecdote paraît peu édifiante aux admirateurs de Confucius, elle ne manque pas du moins d'une certaine grâce.

47.(278) Luen yu, VI, 26.

47. (279) Le mot «flèche » a ici le sens de s'expliquer directement ou franchement, comme une flèche qui va droit au but.

47.(280) J'adopte ici l'explication du commentateur Loan Tchao, cité par Se-ma Tcheng: Confucius reconnaît qu'il a fait une faute, mais elle lui a été imposée par le Ciel ; il n'était pas plus libre d'agir à son gré que le roi Wen lorsqu'il était emprisonné à Yeou-li.

Legge, dans sa traduction du Luen yu (VI, 26), a suivi une autre interprétation qui est celle des commentaires officiels du texte classique : la formule est une formule de serment ou d'imprécation (cf. t. IV, p. 86, n. 1) ; d'autre part le mot [] a le sens de « rejeter, abandonner» et (c'est ici que l'explication me paraît arbitraire) le mot [] équivaut à « moi »; Confucius jure donc avec imprécations qu'il n'a rien fait de mal, et il dit :

— Si j’ai mal fait, que le Ciel me rejette ! que le Ciel me rejette !

47.(281) C'est la présence de l'eunuque dans le même char que le duc qui paraît avoir été le principal motif de scandale. Voyez la lettre de Se-ma Ts'ien à Jen Ngan (t. I, Introduction, p. CCXXVIII, lignes 11-13).

47.(282) Littéralement -. « il chargea Confucius de constituer le second équipage ». D'après le Kia yu (\$38, Tsi che eul ti tse), c’est Yen K’o (cf. n. 265) qui était en cette occasion le cocher de Confucius.

47.(283) Luen yu, IX, 17. 
47.(284) En voyant que, par amour pour Nan-tse, le prince de Wei commet les actes les plus répréhensibles, Confucius regrette que l'amour pour la vertu ne puisse exercer une aussi grande influence sur le cœur des hommes.

47. (285) La capitale de Ts'ao correspond à la s.-p. actuelle de Ting-t'ao (préf. de Ts'ao-tcheou, prov. de Chan-tong). Cette principauté était alors encore indépendante, car ce n'est qu'en 487 qu'elle fut anéantie par le royaume de Song (cf. t. IV, p. 168).

47.(286) Précédemment, Se-ma Ts'ien nous a dit que Confucius exerça les fonctions de conseiller dans le pays de Lou en 496 ; comme il séjourna ensuite une première fois dix mois et une seconde fois un mois dans le pays de $W e i$, il ne put quitter pour la seconde fois ce pays qu'en 495 au plus tôt. Se-ma Ts'ien est donc bien ici conséquent avec lui-même. Mais d'autres témoignages de lui ne se laissent pas concilier avec ces dates; c'est ainsi que, dans les Tableaux chronologiques et dans le chapitre sur Tch'en (t. IV, p. 181), l'historien dit que K'ong tse alla dans le pays de Tch'en en 496 ; or il n'alla dans le pays de Tch'en qu'après avoir quitté le pays de $W e i$ et par conséquent il n'était même pas resté jusqu'à la fin de l'année 496 dans ce dernier pays. Il ne paraît guère possible de fixer cette chronologie un peu trop flottante.

47.(287) Aujourd'hui, ville préfectorale de Koei-té, prov. de Ho-nan.

47.(288) Luen yu, VII, 22.

47.(289) Ici encore Confucius affirme que la mission divine dont il a été chargé par le Ciel le met à l'abri de tout péril (cf. p. 333).

Dans le chapitre sur Song (t. IV, p. 245), Se-ma Ts'ien dit que Confucius s'en alla sous un déguisement ; en outre, il assigne cet événement à l'année 492, date qui est inconciliable avec celle de 496 qu'il dit être celle de la venue de K'ong-tse dans le pays de Tch'en (t. IV, p. 101). En effet, Confucius ne se rendit dans le pays de Tch'en qu'après avoir passé dans celui de Song. - Sur Hoan T'oei, voyez Tso tchoan, $14^{\mathrm{e}}$ année du duc Ngai.

47.(290) La capitale de Tcheng correspond à la s.-p. actuelle de Sin-tcheng (préf. de K'ai-fong, prov. de Ho-nan).

47.(291) Le paragraphe qu'on va lire se retrouve dans le Kia yu ( $\$ 22, k$ 'oen che), dans le Po hou t'ong (chap. III, section cheou ming, de Pan Kou, † 92 ap. J.-C.), dans le Luen heng (chap. III, section hou siang, à la fin) de Wang Tch'ong (27-97 ap. J.-C.), et, sous une forme notablement différente, dans le Han che wai tchoan (chap. IX) de Han Yng (vers 150 av. J.-C. ; cf. Mém. hist, chap. CXXI),

47.(292) Le Kia yu dit: « en dehors de la porte du faubourg oriental ».

47.(293). Le Kia yu ajoute ici :

« il a une stature de neuf pieds six pouces; il a des yeux comme le fleuve (c'est-à-dire grands et de forme très régulière, dit le commentaire) et un front élevé ».

47.(294) Le Kia yu, le Luen heng et le Po hou t'ong donnent tous trois la leçon « par la tête ».

47.(295) Kao-yao est réputé comme un des plus sages ministres de l'empereur Choen ; cf. t. I, p. 150 et suiv.

47.(296) Tse-tch'an fut conseiller du prince de Tcheng et fut célèbre pour ses vertus. Il mourut en 496 et fut regretté de Confucius qui l'avait connu personnellement dans le pays de Tcheng (cf. t. IV, p. 489-482). Quand Confucius arriva dans le pays de Tcheng, Tse-tch'an venait de mourir, si on accepte la date de 495 comme étant celle de la venue de Confucius dans le pays de Tcheng.

47.(297) Yu le Grand, le fameux empereur dont les travaux sont légendaires. 
47.(298) Dans une famille où la mort vient de pénétrer, chacun est dans l'affliction et ne boit ni ne mange; le chien ne reçoit plus le traitement auquel il est habitué et se trouve tout déconcerté. Confucius, séparé de ses disciples, paraissait embarrassé, et c'est pourquoi on le compare à un chien qui ne sait que devenir dans une famille en deuil où chacun s'occupe du mort. La comparaison plut à Confucius qui errait vainement par le monde à la recherche d'un prince sage et qui se sentait désorienté dans une époque où ne régnait pas la justice. Voyez cidessous le texte du Han che wai tchoan.

47. (299) 《la dernière chose », donc la moins importante. Le Kia yu, le Po hou t'ong et le Luen heng écrivent « en ce qui concerne la forme extérieure du corps, ce n'est pas encore cela », c'est-à-dire la description est imparfaite.

47.(300) Dans le Han che wai tchoan (chap IX) de Han Yng, cette anecdote est racontée d'une manière bien différente :

«K'ong-tse étant sorti par la porte orientale de la capitale du pays de) Wei, vit Kou-pou $T s e-k$ 'ing qui s'avançait à sa rencontre ; il dit (à ses disciples) :

- Vous autres, menez le char de manière à laisser la voie libre ; voici venir un homme qui certainement sera celui qui lira sur ma physionomie, notez bien (ce qu'il dira).

Kou-pou Tse-K'ing dit de son côté (à ceux qui l'accompagnaient) :

- Vous autres, menez le char de manière à laisser la voie libre ; voici venir un homme saint.

K'ong-tse descendit (de son char) et se mit à marcher; Kou-pou Tse-K'ing l'observa pendant qu'il venait à sa rencontre pendant cinquante pas et il le considéra pendant qu'il s'éloignait de lui pendant cinquante pas. Il se retourna vers Tse-kong et lui dit :

- Qui est cet homme?

Tse-kong répondit :

— C'est mon maître, à moi Se ; c'est celui qu'on appelle K'ong K'ieou, de Lou.

Kou-pou Tse-K'ing répliqua :

— Ah ! c'est Kong K'ieou, de Lou ; certes j'ai entendu parler de lui.

Tse-kong demanda :

— Que pensez-vous de mon maître ?

Kou-pou Tse-K'ing dit :

- Il a le front de Yao, les yeux de Choen, le cou de Yu, la bouche de Kao-Sao ; à le regarder par devant, il est très majestueux et semble quelqu'un qui doit régner; à le regarder par derrière, ses épaules sont hautes et son épine dorsale est faible; en cela seulement il n'est pas l'égal des quatre personnages saints (que je viens de citer).

Tse-kong ayant soupiré, Kou-pou Tse-K'ing lui dit :

- Pourquoi vous affliger? (ici deux phrases que je ne comprends pas. Quand on le regarde de loin, il est embarrassé comme le chien d'une famille où il y a un mort. Pourquoi vous affliger?

Tse-kong rapporta ces paroles à $K^{\prime}$ 'ong-tse ; K'ong-tse n'eut rien à y reprendre ; il refusa seulement (de s'appliquer la parole relative au) chien d'une famille où il y a un mort, et dit :

- Moi K'ieou, comment oserais-je (m'appliquer cette comparaison ?) 
Tse-kong lui dit :

- (Il répète les deux phrases peu claires citées plus haut); cela je comprends (pourquoi vous l'acceptez); mais je ne sais ce qui vous fait refuser la phrase relative au chien d'une maison où il $\mathrm{y}$ a un mort.

Le Maître lui répondit :

- Ne voyez-vous donc pas comment est le chien d'une famille où il y a un mort? (Les gens de cette famille) sont occupés à habiller le mort dans son cercueil et à le placer dans le second cercueil; ils disposent les ustensiles pour sacrifier; (quand le chien) regarde autour de lui, il ne voit personne et il a l'intention de veiller à tout (c'est-à-dire que, en l'absence de toute personne vaquant aux occupations habituelles de la famille, c'est le chien qui sent qu'il doit veiller à tout). (De même, maintenant), en haut il n'y a pas de souverain intelligent; en bas il n'y a pas d'hommes sages et de chefs locaux; la conduite des rois s'est pervertie; le bon gouvernement et l'instruction se sont perdus; les forts oppriment les faibles; le grand nombre est cruel envers ceux qui sont isolés; le peuple se livre à tous ses désirs et il n'y a personne pour lui imposer une règle. C'est pourquoi certes on voudrait que ce soit moi K'ieou qui joue ce rôle (de souverain et de régulateur ; comment oserais-je (l'assumer) ? »

On voit que, dans ce texte, contrairement à ce que dit Se-ma Ts'ien, Confucius refuse de se laisser assimiler au chien d'une maison où il y a un mort, car il comprend cette expression comme signifiant qu'il est appelé à prendra la place d'un véritable souverain.

47.(이) Aujourd'hui, ville préfectorale de Tch'en-tcheou (prov. de Ho-nan).

47.(302) Le même témoignage nous est donné par Mencius (V, a, 8). - Tcheng est le nom posthume d'un officier qui était alors au service du prince de Tch'en, mais qui, par la suite, se rendit dans le pays de Song où il exerça les fonctions de surveillant des remparts; il n'avait pas encore cette charge quand Confucius logeait chez lui.

47.(03) Cf. t. IV, p. 181, lignes 20-21.

47.(304) D'après Kiang Yong (H. T. K. K., chap. CCLXII, p. $\left.22 \mathrm{v}^{\circ}-23 \mathrm{r}^{\circ}\right)$, tous ces événements devraient être rapportés à l'année 494. C'est en effet en 494 que Tchao Yang (Tchao Kien-tse) attaqua les chefs des familles Fan et Tchong-hang à Tchao-ko (cf. t. V, p. 38); et c'est aussi en 494 que Fou-tch'ai, roi de Ou, cerna Keou-ts'ien, roi de Yue, sur le mont Koei-ki (cf. t. IV, p. 25-26 et p. 420-423). Mais ce n'est qu'en 493, d'après le chapitre sur la principauté de $T s^{\prime} a i$, que le marquis de $T s^{\prime}$ 'ai fut assiégé par le roi de Tch'ou et se transporta sur le territoire de $O u$ (cf. t. IV, p. 161).

47.(305) Kouo yu; Lou yu, b, chap. V, p. 6 v)

47.(306) Le mot est un terme assez vague qui désigne plusieurs sortes de petits oiseaux de proie. - L'anecdote qu'on va lire est tirée du Kouo yu et se retrouve dans le Kia yu, (§ 16, pien ou).

47.(307) L'arbre hou est mentionné dans le tribut de $Y u$ comme se trouvant dans le Hou pe et le Hou-nan actuels.

47.(308) Dans le tribut de $Y u$ le mot apparaît à deux reprises comme désignant des pointes de flèche en pierre ; cf. t. I, p. 123 et 129. — Dans le San kouo tche (section Wei tcho, chap. IV, p. $13 \mathrm{r}^{\circ}$ ), il est dit que, en l'année 262 de notre ère, le gouverneur du Leao-tong informala Cour des $W e i$ que le royaume des Sou-chen avait envoyé en tribut 30 arcs longs de 3 pieds et 5 pontes, 300 flèches en bois hou, longues de 1 pied et 8 pouces et munies d'une pointe en pierre, etc. - On voit par ce texte du San kouo tche, que sept siècles et demi après le séjour de Confucius dans le pays de Tch'en, les Sou-chen occupant la Mandchourie continuaient à se 
servir des flèches singulières dont Confucius sut reconnaître l'origine quand on lui en présenta un spécimen.

47.(09) Le duc Min, de Tch'en, régna de 501 à 478. C'est par erreur, semble-t-il, que le Kouo $y u$ et le Kia yu font intervenir ici le duc Hoei qui régna de 533 à 506.

47.(310) Il a dû en effet être blessé dans le pays des Sou-chen.

47.(311) Les Sou-chen sont mentionnés dans la Préface du Chou king (Legge, C. C., vol. III, p. 12) comme des barbares de l'Est qui vinrent rendre hommage au roi Tch'eng, de la dynastie Tcheou. Se-ma Ts'ien, citant ce passage de la Préface du Chou king, donne la leçon Si-chen (t.I, p. 249). Dans une fort curieuse pièce officielle de l'année 533 av. J.-C. qui nous a été conservée par le Tso tchoan ( $9^{\mathrm{e}}$ année du duc Tchan), les Sou-chen figurent dans l'énumération des pays qui sont au nord des possessions de la dynastie Tcheou. Nous avons peut-être dans ce nom des Sou-chen la plus ancienne transcription chinoise du nom du peuple Joui-tchen qui, comme l'on sait, était étroitement apparenté aux Mandchous modernes.

47. $(\underline{312})$ Le roi $O u$.

47. $(\underline{313})$ Le texte paraît être ici tronqué. Il faut le rétablir comme suit, d'après le Kouo yu et le Kia yu:

«L'ancien roi, dans le désir de montrer clairement que sa vertu excellente attirait les éloignés, et afin de faire voir aux hommes futurs un exemple qu'ils pussent éternellement contempler, grava ces mots sur la coche de ces flèches : Flèche apportée en tribut par les Sou-chen. Il les donna en partage à Ta-ki... »

47.(14) $T a-k i$ ou $K i$ l'aînée était la fille aînée du roi $O u$.

47.(315) Le premier prince de Tch'en était un descendant de Choen (appelé aussi Yu); cf. t. IV, p. 169.

47.(1ㅡ) Dans le Kouo yu, Confucius termine son discours en disant :

- O prince, si vous chargez un officier de faire des recherches dans les anciens magasins (du palais), vous devrez trouver (ces flèches).

On chargea des gens de faire ces recherches et ils trouvèrent (ces flèches), comme (l'avait dit Confucius), dans le coffre bardé de métal.

Ainsi, en voyant la flèche dont est mort un épervier, Confucius déclare que cet oiseau a dû être blessé dans le pays de Sou-chen et il prouve l'exactitude de son dire en faisant rechercher dans les dépôts officiels du pays de Tch'en les antiques flèches des Sou-chen qui y étaient conservées depuis l'origine de la principauté.

47.(317) Mencius (VII, b, 37)

47. $(\underline{318})$ Mencius (VII, b, 37) cite cette même parole de Confucius :

«Wang Tchang demanda :

- Quand K'ong-tse était dans le pays de Tch'en, il dit : «Pourquoi K'ong-tse, se trouvant dans le pays de Tch'en, pensait-il aux étudiants trop ardents du pays de Lou? "

Si on examine la suite du récit de Se-ma $T s$ 'ien, on s'aperçoit qu'en réalité Confucius ne manifesta à cette époque aucune velléité de retourner dans le pays de Lou. D'autre part, plus loin, à la date de l'année 492, Se-ma Ts'ien rapporte que Confucius, étant de nouveau dans le pays de Tch'en et songeant réellement à rentrer dans sa patrie, tint le langage suivant [...] ; Cette citation est tirée textuellement du Luen yu (V, 21). Comme le fait remarquer Se-ma Tcheng, le texte de Mencius et celui du Luen yu sont en réalité deux leçons d'un seul et même propos de Confucius, et c'est à tort que Se-ma Ts'ien en fait deux paroles distinctes que 
Confucius aurait prononcées à deux dates différentes. - Si maintenant nous considérons la leçon de Mencius, qui est la première de $S e-m a$ Ts'ien, nous y trouvons le sens suivant: Confucius, ne parvenant point à découvrir dans les divers royaumes étrangers qu'il a parcourus les hommes sages qui mettraient en pratique sa doctrine, songe à retourner dans son pays où du moins ceux qui ont embrassé son parti ont certaines qualités : ils sont ardents, mais négligents ; ils sont tout disposés à aller de l'avant pour saisir la sagesse, mais en même temps ils n'oublient pas leur ancienne nature et retombent dans leurs défauts coutumiers. - Dans le texte du Luen yu, Confucius dit que ses disciples du pays de Lou sont ardents, mais négligents, qu'ils réalisent parfois avec élégance la perfection, mais qu'ils ne savent comment régler leur activité.

47.(로) Cf. n. 273.

47.(20 $)$ Le Kia yu (§22, k’oen che), qui présente aussi ce récit, dit :

«K'ong-tse se rendit dans le pays de $W e i$; le chemin passait par $P^{\prime}$ ou ; or en ce moment, le chef de la famille Kong-chou s'était révolté dans cette ville contre Wei.

On comprend dès lors pourquoi les gens de $P$ 'ou arrêtèrent Confucius.

47.(르) Cf. n. 263.

47.(322) Le Kia yu donne une leçon plus vraisemblable en disant :

« Il tira son épée et réunit une troupe avec laquelle il se proposait de livrer bataille.

47.(23) La porte orientale s'ouvrait sur une route qui ne menait pas à la capitale de Wei, puisque celle-ci était droit au nord de $P^{\prime}$ ou ; cf. n. 260, n. 273, et n. 320.

47.(324) La ville de P'ou faisant partie de l'État de Wei, et Confucius ayant dû dissimuler la direction qu'il prenait lorsqu'il sortit de cette ville, il est vraisemblable que c'est à cet incident que font allusion Tchoang tse (chap. XX ; Legge, SBE, vol. XL, p. 34) et Lie-tse (chap. VII, p. $10 \mathrm{r}^{\circ}$ ) lorsqu'ils disent que Confucius « cacha la trace de ses pas dans le pays de Wei»

47.(르) Dans le Kia yu, Confucius répond :

- On m'a fait violence pour m'imposer un serment ; ce n'était pas justice.

On peut rapprocher de la réponse que fait ici Confucius le passage suivant du Tso tchoan $\left(9^{\mathrm{e}}\right.$ année du duc Siang, 564 av. J.-C.) où la même théorie est soutenue à propos de la violation d'un serment extorqué par la force :

« Dans un serment imposé par la violence, il n’y a pas de vérité et les dieux n’y sont pas présents. ils ne sont présents que là où il y a sincérité ; la sincérité est le joyau des paroles et le principe de toute excellence; aussi les dieux sont-ils présents (là où elle se trouve). Les dieux claivoyants n'ont pas rendu pur un serment imposé par la violence ; il est permis de le rompre.

47.(26) Le Kia yu (§22, k'oen che) dit :

- Mes grands officiers estiment que $P^{\prime}$ ou est ce en quoi Wei se confie contre $T \sin$ et Tch'ou. L'attaquer, n'est-ce pas une chose qu'on ne doit pas faire?

En d'autres termes, $P^{\prime}$ 'ou est la ville qui sert à $W e i$ de forteresse avancée et qui le protège contre les attaques de Tsin et de Tch'ou. Ne serait-ce pas folie, de la part de Wei, de se l'aliéner définitivement en l'attaquant?

47. $(\underline{327})$ 《 mourir de cela ou pour cela » est une expression très elliptique qui signifie qu'on est prêt à sacrifier sa vie pour une cause, ici pour la patrie.

47.(르) Le Kia yu omet la phrase : « Les femmes désirent protéger le Si-ho ». 
— Le Hoang-ho passait alors à l'ouest de la ville de P'ou (cf. t. III, p. 526, carte) ; le Si-ho ou $H o$ occidental (qu'il ne faut pas confondre avec le $S i$-ho du pays de Tchao; cf. t. V, n. 43.402) était ainsi le territoire sur lequel se trouvait la ville même de $P$ 'ou.

— Le sens est celui-ci : Dans la ville de $P$ 'ou, les hommes sont prêts à faire le sacrifice de leur vie pour leur prince ou leur patrie ; ils sont donc restés fidèles dans le fond de leur cœur au duc Ling; quant aux femmes, leur seul désir est que le territoire dans lequel est située la ville de $P$ 'ou soit à l'abri des troubles. Si donc le duc Ling attaque la ville de P'ou, il n'aura aucune peine à la soumettre car il n'y trouvera guère que quatre ou cinq hommes qui soient résolus à faite cause commune avec le rebelle Kong-chou.

47.(329) Luen yu, XIII, 10.

47.(330) Cette indication est prématurée, car les trois paragraphes qui vont suivre se rapportent encore au séjour de Confucius dans le pays de Wei.

47.(331) La ville de Tchong-meou était à l'ouest de la s.-p. de T'ang yn (préf. de Tchang-té, prov. de Ho-nan). Cette ville devait appartenir aux familles Fan et Tchong-hang, et non à Tchao Kien-tse comme le dit par erreur le commentaire attribué à K'ong Ngan-kouo (S. H. T. K. K., chap. 628, p. $12 \mathrm{r}^{\circ}$ ).

47.(332) Luen yu, XVII, 7.

47.(333) Tse-lou intervient ici de la même manière que lors de l'invitation adressée par Kong-chan Pou-nieou à Confucius ; cf. p. 318.

47.(334) De même, celui qui est vraiment un sage pourra entrer en con tact avec des hommes pervers sans que son caractère en soit altéré.

47.(335) Je suis ici l'explication qui est généralement acceptée par les commentateurs chinois : une calebasse peut rester toujours pendue au même endroit parce qu'elle ne mange ni ne boit ; Confucius au contraire est un être qui mange et qui par conséquent doit se déplacer. D'après une autre explication, serait ici l'équivalent de «qu'on ne peut manger ». Aussi Legge (C. C., vol. I, p. 18) propose-t-il la traduction suivante :

- Am I a bitter gourd! How can I he hung up out of the way of being eaten ?

Le sens est alors que Confucius désire être employé à des fonctions publiques et ne pas être semblable à une courge amère qui reste suspendue à l'endroit où elle a poussé parce qu'elle est immangeable. Cette interprétation ingénieuse n'est pas sans faire quelque violence au texte, car les mots [] signifient " qui ne mange pas », et non « qui n'est pas mangeable »; elle peut cependant être confirmée par un texte du Koиo yu (section Lou yu, b, p. 2 r $^{\circ}$ )

« la courge amère n'est pas conformée pour l'homme (c.-à-d., comme l'explique Wei Tchao, qu'on ne peut la manger); elle sert donc seulement à passer l'eau (c.-à-d., dit Wei Tchao, que ceux qui veulent traverser une rivière s'attachent de ces courges au corps afin de surnager).

Ce texte peut d'ailleurs fournir une interprétation nouvelle du mot dans le passage du Luen yu cité par Se-ma Ts'ien; on traduira en effet ce passage ainsi :

- Suis-je une calebasse qu'on peut s'attacher (au corps), mais qu'on ne peut pas manger.

Cette traduction a le mérite de faire disparaître la difficulté qu'il y avait à considérer comme un verbe passif, car ce n'est plus « la calebasse », c'est « on » qui devient le sujet des verbes. D'autre part cependant ce sens me paraît peu satisfaisant, puisqu'il fait évanouir l'idée de " rester suspendu en un même endroit», idée qui est essentielle pour expliquer la parole de Confucius. 
- Sur l'emploi que les Chinois font des gourdes pour surnager sur l'eau, voyez dans le $\underline{C}$ e king les deux premiers vers de l'ode 9 du livre III de la section Kouo fong.

- Comme lors de l'invitation de Kong-chan Pou-nieou (cf. p. 318 ), Confucius, cette fois encore, suivit les sages avis de Tse-lou.

47.(36) Luen yu, XIV, 42.

47.(337) Le texte du Luen yu nous apprend que Confucius se trouvait alors dans le pays de Wei. L'homme qui portait un panier pour les herbes était un sage qui, dégoûté de la vie active, se cachait-dans une humble situation; en entendant jouer Confucius, il reconnaît aussitôt son grand cœur, mais, un instant après, il discerne dans cette musique l'opiniâtreté de caractère qui faisait que Confucius s'obstinait à tenter d'obtenir un emploi officiel ; il l'en blâme et lui conseille de se résigner puisque personne ne sait reconnaitre ses éminentes qualités. Dans le Luen yu, Confucius répond que cette résignation n'est pas chose difficile; il donne à entendre par là que le sage ne doit pas se satisfaire d'une abdication qui serait trop aisée, mais qu'il doit lutter quelles que soient les résistances qu'il rencontre. Nous voyons ici l'opposition de la morale taoïste à la morale confucéenne.

47.(338) Han che wai tchoan, chap. V. Kia yu, § 35.

47.(339) Tout le paragraphe qui suit se retrouve aussi dans le Kia yu (§ 35); mais le Kia yu, sous sa forme actuelle, date du IIIe siècle de notre ère et ne peut donc être considéré comme une des sources directes des Mém. hist. Il n'en est pas de même du Han che wai tchoan que Se-ma Ts'ien a dû connaître puisqu'il en parle dans la biographie de Han Yng (chap. CXXI, p. $\left.3 \mathrm{v}^{\circ}-4 \mathrm{r}^{\circ}\right)$.

47.(년) Le Kia yu (§ 35) ajoute ici :

Siang-tse lui dit :

- Quoique ma fonction officielle soit de jouer de la pierre sonore, cependant je m'entends aussi au luth.

Dans le paragraphe du Luen yu (XVIII, 9) où il est parlé des maîtres de musique de Lou qui se dispersèrent à l'étranger, Siang-tse, est en effet qualifié comme un joueur de pierre sonore.

47.(341) Cette parole de Siang-tse est omise dans le Han che wai tchoan qui ajoute par contre ceci :

«Quelque temps après, (Siang-tse) lui dit :

— Maître, vous pouvez aller plus avant.

( $K^{\prime}$ ong-tse) répondit :

- Moi K'ieou, j'ai saisi qui était cet homme, mais je n'ai point encore saisi de quelle sorte il était.

Au bout de quelque temps, il dit :

- Dans le recul des âges regardant au loin, (je vois) un homme très majestueux et très ordonné ; c'est certainement lui qui a fait cette musique...

47.(342) Le visage sombre du roi Wen indique la profondeur de ses pensées. C'est sans doute pour la même raison que, dans les représentations qu'on fait de Confucius, on donne parfois à son visage une teinte très foncée (cf. Legge, C. C., vol. I, Prolégomènes, p. 89, lignes 17-19 et n. 3 [css : édition/rechercher : 'swarthy']).

47.(343) La métaphore peut paraître au premier abord bizarre. Mais nos littérateurs n'ont-ils pas souvent parlé du regard profond et rêveur des bœufs ?

47.(344) Le Han che wai tchoan dit : 
- Silencieux, il est extraordinaire ; de haute taille, il est grand. Il est celui qui règne sur le monde et qui reçoit l'hommage des seigneurs. N'est-il pas le roi Wen?

47.(년) Il se lève de son siège en signe de respect.

47.(346) Cette phrase montre que, jusqu'ici, Confucius n'avait pas encore quitté le pays de Wei. Cf. n. 330.

47.(347) En réalité, comme on va le voir, Confucius ne put mettre à exécution ce projet et il n'alla jamais dans le pays de $T \sin$.

47.(348) Le Hoang ho passant alors à l'ouest de la capitale du pays de Wei, il fallait traverser ce fleuve pour aller du pays de Wei dans le pays de Tsin. - Depuis les mots "arrivé au fleuve... » jusqu'aux mots «... afin d'exprimer son affliction à ce sujet », ce texte se retrouve dans le $\S 22$ du Kia $y u$.

47.(4ㅗ) Le Kia yu appelle ce personnage Teou Tch'eou Ming-tou. Le Kouo yi, chap. XV, p. 4 $\mathrm{r}^{\circ}$ (section Tsin $y u$, dernière partie) mentionne en effet Teou Tch'eou, qui était un grand officier de Tsin. Il semble donc bien que, comme l'indique Se-ma Tcheng, Teou soit ici le nom de famille, Tch'eou le nom personnel, et Ming-tou l'appellation. On verra cependant que, dans le texte du Sin siu cité plus loin (p. 353), il est question de Tou Tch'eou et de To-ming comme de deux personnages distincts, tandis que Choen-hoa disparaît entièrement.

47. $(\underline{350})$ Le $k^{\prime} i$ et le $\operatorname{lin}$ sont le mâle et la femelle d'un quadrupède fantastique, dont la venue est de bon augure.

47.(351) Le dragon kiao assemble les nuages et fait tomber la pluie en mettant l'harmonie entre les deux principes fondamentaux de la nature.

47.(352) Le fong et le hoang sont, pour les oiseaux, ce que le $k^{\prime} i$ et le lin sont pour les quadrupèdes.

47. $(\underline{353})$ Le commentaire du San kouo tche (section Wei tche, chap. XXI, p. $6 v^{\circ}$ ) cite un passage du Sin siu de Lieou Hiang qui rapporte la même anecdote. En voici le début :

«Tchao Kien-tse, désirant devenir seul maître de tout l'empire, dit à son conseiller :

- Dans le pays de Tchao il y a Tou Tch'eou; dans le pays de $T$ sin il y a To Ming; dans le pays de Lou il y a K'ong K'ieou; quand j'aurai tué ces trois hommes, je pourrai régner sur tout l'empire.

Alors il manda Tou Tch'eou et To Ming et les interrogea sur le gouvernement, puis il les fit périr. Il envoya des émissaires inviter K'ong-tse dans le pays de Lou et venir à sa rencontre sur les bords du Ho en lui apportant en présent de la viande d'un bœuf gras. Les émissaires dirent aux bateliers :

- Quand K'ong K'ieou sera monté dans le bateau, au milieu du Fleuve, ne manquez pas de profiter du courant pour le faire périr.

Quand K'ong-tse fut arrivé, les émissaires lui communiquèrent l'ordre qu'ils avaient reçu et lui offrirent la viande du bœuf gras. K'ong-tse leva les yeux au ciel et dit en soupirant :

— Qu'elle est belle cette onde dont l'étendue est immense !...

La suite est fort analogue au texte de Se-ma Ts'ien. Il est à remarquer que ce passage du Sin siu ne se retrouve pas dans le Sin Siu tel qu'il nous est parvenu. 
- Voyez encore la même anecdote dans le Chouo yuan (section k'iuan meou), dans le K'in ts'ao qu'on attribue à Ts'ai Yong, et dans le Commentaire du Choei king par Li Tao-yuan (Ho choei, partie 5).

47.(354) Cette localité de Tseou ne doit pas être confondue avec celle qui portait le même nom et qui se trouvait dans le pays de Lou.

47.(355) Ce chant est ici désigné par le nom de la localité où il fut composé. Le Kia yu l'appelle « l'air $p$ 'an » à jouer sur la cithare

1.

47.(하 $)$ Cf. n. 274.

47.(5ㄱ) Luen yu, XV, 1.

47.(358) L'étal sert à disposer les viandes et !e vase teou contient les grains destinés aux sacrifices.

47.(ㅎ5) Le Luen yu ajoute : « Le lendemain même (K'ong-tse) partit. » Le paragraphe qui suit immédiatement celui-ci dans le Luen yu rappelle l'aventure au cours de laquelle Confucius et ses disciples faillirent mourir de faim dans le pays de Tch'en; aussi certains critiques, et notamment le célèbre Tchou Hi ont-ils pensé que cette aventure doit être placée ici, au moment où Confucius quitta le pays de Wei pour se rendre dans le pays de Tch'en; mais, comme on le verra plus loin (n. 401), c'est à une date postérieure que Se-ma Ts'ien, avec raison semble-t-il, rapporte cet événement.

47.(60) Depuis les mots «.., s'entretenait avec K'ong-tse » jusqu'aux mots «K'ong-tse aussitôt partit », ce passage se retrouve dans le § 22 du Kia yu.

47.(361) Le Kia yu écrit : « et parut mécontent »

47.(362) Cf. n. 263.

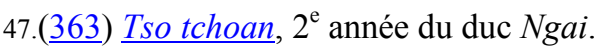

47.(364) Cf. tome IV, n. 31.153.

47.(6ㄷㄴ) Se-ma Ts'ien suit ici fidèlement le récit du Tso tchoan $\left(2^{\mathrm{e}}\right.$ année du duc Ngai), ce qu'il n'avait pas fait dans le chapitre sur le royaume de Wei (cf. tome IV, n. 37.142).

- On sait que K'oai-wai était le fils du duc Ling et que, accusé d'avoir voulu faire périr la trop célèbre Nan-tse, il avait dû s'exiler en 496 ; il avait trouvé refuge dans le pays de Tsin auprès de Tchao Yang ou Tchao Kien-tse ; il s'y rencontra avec un autre exilé politique, Yang Hou, du pays de Lou, qui lui aussi s'était mis sous la protection de Tchao Kien-tse. En 493, lorsque le duc Ling mourut, son trône échut à son petit-fils Tcho, qui était le propre fils de K'oai-wai.

Cependant Tchao Kien-tse entreprit de faire rendre ses états à $K^{\prime}$ 'oai-wai; s'il ne parvint pas à le réintégrer dans la capitale de $W e i$, il réussit du moins à l'installer dans la ville de $T s$ ' $i$, à $7 l i$ au N. de la préf. sec. de K'ai (préf. de Ta-ming, prov. de Tche-li). Yang Hou facilita la réussite de l'expédition par quelques mesures habiles; il engagea K'oai-wai à prendre le bonnet de deuil afin qu'il se présentât, non en conquérant, mais en fils affligé qui vient recueillir la succession qui lui échoit par la mort de son père ; c'est pour la même raison que K'oai-wai fit son entrée dans la ville de $T s^{\prime} i$ en pleurant; d'autre part, pour faire croire que K'oai-wai revenait appelé par le désir de tout son peuple, Yang Hou imagina de faire porter les marques de deuil à une huitaine d'hommes qui passèrent pour être en deuil de leur prince défunt, le duc Ling, et pour venir de la capitale de Wei à la rencontre du prétendant légitime K'oai-wai.

47.(ㅎ6) Cf. t. IV, $\underline{\text { n. } 35.120}$ et n. 35.102 .

47.(367) Se-ma Ts'ien commet ici une légère confusion : il est bien exact que, la troisième année (492) du duc Ngai, K'ong-tse était âgé de 60 ans; mais, d'autre part, tous les 
événements dont il a été question dans ce paragraphe sont de la deuxième année (493) du duc Ngai.

47.(ㅌ8) C'est le duc Tch'ou, de $W e i$, qui attaquait dans la ville de $T s^{\prime} i$ son propre père, l'héritier présomptif $K^{\prime}$ 'oai-wai ; voyez plus haut, n. 365.

47.(369) Nan-kong King-chou avait reçu les enseignements de Confucius (cf. p. 297). Le $\underline{\text { Tso }}$ tchoan $\left(3^{\mathrm{e}}\right.$ année du duc Ngai) décrit longuement la manière fort habile dont il organisa les secours lors de cet incendie.

47.(370) Se-ma Ts'ien écrit [], leçon obscure, puisque si Confucius avait appris ce qui s'était passé, il n'avait pas grand mérite à dire que les temples funéraires des ducs Hoan et $\mathrm{Hi}$ avaient été incendiés.

La leçon du Tso tchoan est préférable : Confucius, se trouvant dans le pays de Tch'en, fort loin par conséquent du pays de Lou, entend dire qu'un incendie a eu lieu dans la capitale de Lou; la rumeur publique n'indique point encore quels édifices ont été détruits par le feu ; c'est alors que Confucius a le pressentiment que l'incendie a dû atteindre les temples funéraires des ducs Hoan et $\mathrm{Hi}$, ce qui fut reconnu vrai par la suite.

Le Kia yu (§ 16) écrit : «K'ong-tse dit :

— Les édifices qui ont été atteints sont les temples funéraires des ducs Hoan et Hi.

Le marquis de Tch'en lui demanda :

- Comment le savez-vous?

K'ong-tse dit :

- D'après les rites, l'aïeul a de la gloire, et l'ancêtre a de la vertu; c'est pourquoi on ne détruit pas leurs temples funéraires. Maintenant, la parenté (des ducs) Hoan et $H i$ est épuisée ; d'autre part, leur gloire et leur vertu ne sont pas suffisantes pour justifier le maintien de leurs temples funéraires. Cependant (le prince de) Lou n'a pas détruit (ces temples) ; c'est pourquoi ils ont été atteints par une calamité venue du Ciel.

Trois jours plus tard, un messager vint du pays de Lou, et, en l'interrogeant, on apprit que c'étaient en effet (les temples des ducs) Hoan et Hi (qui avaient été détruits par le feu) ».

- Pour comprendre ce texte, il convient de rappeler quelles étaient les règles rituelles concernant les temples funéraires. D'après le chapitre Tsi fa du Li ki (trad. Couvreur, t. II, p. 262-263), un prince féodal (tel que l'était le prince de Lou) avait droit à cinq temples funéraires. Le premier était consacré au premier ancêtre et ne devait jamais être détruit. Les quatre autres étaient consacrés respectivement au père défunt, au grand-père, au bisaïeul et au trisaïeul du prince régnant. Au bout de ces quatre générations, la parenté était considérée comme épuisée et, par conséquent, à chaque génération nouvelle, on devait détruire le temple du trisaïeul de la génération précédente pour le remplacer par celui du trisaïeul de la génération actuelle. Dans le texte du Kia yu, il est fait allusion à une coutume différente, car ici ce n'est pas seulement un temple, celui du premier ancêtre qui ne doit jamais être détruit ; deux temples jouissent en réalité de ce privilège : celui de l'aïeul et celui de. l'ancêtre : cette distinction entre l'aïeul et l'ancêtre est mentionnée dans un passage du chapitre Tsi fa du Li ki (tr. Couvreur, t. I, p. 258) où il est dit que les Tcheou honoraient Wen wang comme leur aïeul et $\mathrm{Ou}$ wang comme leur ancêtre.

- A la suite de ces explications, le texte du Kia yu devient clair : Confucius rappelle que les ducs Hoan et $H i$ n'ont eu ni la gloire ni la vertu du premier aïeul et du premier ancêtre et que, par conséquent, leurs temples funéraires n'étaient pas indestructibles comme le sont ceux du premier aïeul et du premier ancêtre ; d'autre part les ducs Hoan et $H i$ étaient les ancêtres, l'un à la huitième, l'autre à la sixième génération, du duc Ngai actuellement régnant dans le pays 
de Lou; leur parenté était donc, comme on dit, épuisée (cf. plus haut, ligne 4 de cette note), et les rites exigeaient qu'on détruisit leurs temples funéraires. Les hommes ne s'étant pas acquittés de cette tâche, c'est le Ciel qui l'a accomplie en incendiant les deux édifices. Confucius savait que ces temples étaient voués à la destruction ; aussi devine-t-il aussitôt, quand il entend parler d'un incendie dans le pays de Lou, que ce sont eux qui ont dû être brûlés.

- Dans le Chouo yuan (section k'iuan meou), nous trouvons une version fort différente de cette même anecdote : Confucius étant dans le pays de $T s$ ' $i$, auprès du duc King, un messager du pays des Tcheou, vient annoncer qu'un incendie a détruit un temple funéraire des Tcheou; Confucius déclare aussitôt que ce temple doit être celui du roi $H i$ (681-677), ce qui fut reconnu ensuite exact. Confucius a deviné qu'il s'agissait du temple du roi $\mathrm{Hi}$ parce que le Ciel devait punir tôt ou tard ce souverain d'avoir violé les sages ordonnances des rois Wen et $O u$ et d'avoir vécu dans un luxe exagéré.

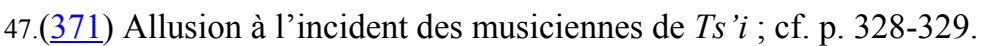

47.(372) Jan K'ieou, appellation Tse-yeou, est un disciple de Confucius qui est mentionné à plusieurs reprises dans le Luen yu. Cf. Legge, C. C., t. I, Prolégomènes, p. 116, $\mathrm{n}^{\circ} 5[\operatorname{css}$ : édition/rechercher : 'Zan Ch'iu'].

47.(그) Luen yu, V, 21.

47.(374) En voyant partir pour le pays de Lou son disciple Jan K'ieou, Confucius exprime son désir de retourner lui-même dans sa patrie afin de pouvoir donner une meilleure direction morale aux jeunes hommes de Lou qui sont disposés à pratiquer sa doctrine. Ce n'est que plus tard cependant que Confucius put donner suite à ce projet. - Dans une note précédente (n. 318), nous avons eu l'occasion de discuter le sens de ce propos de Confucius que Se-ma $T s$ 'ien a déjà rapporté par erreur à une autre époque.

47.(375) En 493, le prince de $T$ s'ai avait transféré sa capitale à Tcheou-lai (appelé depuis lors Hia-is 'ai), à 30 li au nord de la préf. sec. de Cheou (préf. de Fong yang, prov. de Ngan-hoei). C'est là que Confucius (si l'on s'en tient au présent texte de Se-ma Tsien) dut aller en 491. Dans le chapitre sur le royaume de Tch'en (t. IV, p. 161), Se-ma Ts'ien fait venir Confucius à $T s^{\prime}$ ai en 493, avant que la capitale eût été transportée à Tcheou-lai; mais ce témoignage est inconciliable avec la chronologie de la biographie de Confucius.

- Nous résumerons plus loin la discussion fort ingénieuse de Kiang Yong qui conclut que, en 491, Confucius se rendit, non à Tcheou-lai, capitale de la principauté de $T s$ 'ai, mais à Chang-ts'ai, ville qui, après avoir été l'ancienne capitale de la principauté de $T s$ 'ai, était tombée au pouvoir du roi de Tch'ou.

47.(근) Cf. Tso tchoan, $4^{\mathrm{e}}$ année du duc Ngai.

47.(377) Le duc King, de Ts'i, ne mourut qu'en 490.

47. (378) Nous indiquons la date de 489 parce que nous admettons que l'année dont il s'agit est celle qui suivit l'année 490 où mourut le duc King (voyez la note précédente),

47.(379) Aujourd'hui s.-p. de Che (préf. de Nan-yang, prov. de Ho-nan.

- Che appartenait alors au royaume de Tch'ou et c'est pourquoi, suivant la coutume de ce royaume, le gouverneur de cette ville portait le titre de kōung (cf. tome II, n. 08.136 ; t. IV, p. 182, n. 3). Le Tso tchoan ( $4^{\mathrm{e}}$ année du duc Ngai) nous apprend que, en 491, le gouverneur de Che s'appelait Tchou-leang. C'est sans doute auprès de lui que se rendit Confucius en 490, D'autre part, dans le Tso tchoan, à la date de la $16^{\mathrm{e}}$ année du duc Ngai (479; cf. Se-ma Ts'ien, vol. IV, p. 182 et 382 ), il est longuement question du rôle que joua le gouverneur de Che pour rendre le trône au roi Hoei, de Tch'ou; dans ce texte, nous voyons que le gouverneur de Che s'appelait Chen Tchou-leang et que son appellation était Tse-kao ; en outre, nous lisons que, au moment où les troubles survinrent, le gouverneur de Che était à $T s$ 'ai; il faut entendre par 
là que Chang-ts'ai, l'ancienne capitale du royaume de $T s$ 'ai, était, comme la ville de Che dont elle était assez peu éloignée, une possession du royaume de Tch'ou et qu'elle était sous la juridiction du gouverneur de Che.

47.(료) Luen yu, XIII, 16.

47.(381) Le Luen yu dit : « rendre heureux ceux qui sont proches et attirer à soi ceux qui sont éloignés. 》

Mo-tse (postérieur à Confucius et antérieur à Mencius) rapporte la réponse de Confucius d'une manière un peu différente ( 946 , keng tchou) :

«Le gouverneur de Che, Tse-kao (cf. n. 379), interrogea Tchong-ni sur le gouvernement en lui demandant :

- Celui qui gouverne bien, comment agit-il ?

Tchong-ni répondit :

- Celui qui gouverne bien attire près de lui ceux qui sont éloignés et rénove ceux qui sont trop anciens.

47.(르) Luen yu, VII, 18.

47.(포) Tse-lou ne sut comment lui répondre.

47.(384) Nom personnel de Tse-lou.

47.(385) Ces deux phrases sont tirées d'un autre passage du Luen-yu (VII, 2) où elles se présentent avec deux légères variantes.

47.(386) Tant il est préoccupé d'atteindre au but qu'il s'est proposé. - Confucius devait être alors àgé de 63 ans. - Dans Tchoang-tse (chap. Jen kien che; trad. Legge, SBE, vol. XXXIX, p. 210-214), on trouvera une variation taoïste de pure fantaisie sur le thème d'un entretien de Confucius avec le gouverneur de Che.

47.(387) C'est donc sur le chemin de Che à $T s$ 'ai qu'il faut placer la scène de l'anecdote qui va être racontée. Que $T s^{\prime}$ 'ai soit ici Hia-ts'ai, comme le donne à entendre Se-ma Ts'ien qui en parle comme de la capitale de la principauté de $T s$-ai, ou que ce soit Chang-ts'ai, comme le pense Kiang Yong, toujours est-il que Confucius, en quittant Che, dut se diriger vers le sud-est. Peut-être cependant la route, en sortant de Che, obliquait-elle d'abord légèrement vers l'ouest, ce qui permettrait d'admettre le témoignage que voici du Kouo ti tche (chap. VI, p. 5 $r^{\circ}$ et $\left.v^{\circ}\right)$ :

«La montagne Hoang-tch'eng est appelée vulgairement montagne Ts'ai ; elle est à $25 l i$ au sud-ouest de la sous-préfecture de Che (cf. n. 379) qui dépend de l'arrondissement de Hiu. Le mémoire sur les sépultures des sages dit: La montagne Hoang-tch'eng est l'endroit où labouraient Tch'ang-tsiu et Kie-ni; au pied est un cours d'eau qui coule vers l'Est ; c'est l'endroit où Tse-lou demanda où était le gué.

47.(388) Luen yu, XVIII, 6.

47.(389) On explique ces deux noms comme signifiant «le longuement arrêté » et «le fermement. enfoncé. » Ces sobriquets s'appliquent à deux personnages dont on ne connaît ni le nom de famille ni le nom personnel; on les désigne d'après l'attitude qu'ils avaient au moment où Confucius les rencontra; occupés aux travaux des champs, l'un restait immobile à la même place ; l'autre avait les pieds enfoncés dans l'eau ou dans la boue. Peut-être aussi ces noms rappellent-ils que ces deux sages vivaient dans une retraite absolue, comme «enfoncés » dans l'obscurité, et « arrêtés » dans la solitude. 
47.(390) Ce membre de phrase ne se trouve pas dans le Luen-yu; de fait, il est inutile : la question de Confucius était parfaitement simple et ne comportait aucun sous-entendu; elle ne présupposait point que ceux à qui on l'adressait étaient des sages.

47.(이) Cette demande prouve que la réputation de Confucius était grande.

47.(392) Un homme ordinaire pourrait ne pas connaître le gué ; mais Confucins a parcouiu l'empire dans toutes les directions ; il n'est pas un endroit où il ne soit allé ; il doit donc savoir où est le gué. Cette réponse est une critique de la conduite de Confucius allant de lieu en lieu pour chercher à s'employer.

47.(393) Il semble qu'en prononçant ces mots Kie-ni ait montré du doigt les eaux tumultueuses qui coulaient à peu de distance ; il compare l'empire à leur cours désordonné.

47.(394) C'est-à-dire : plutôt que de faire comme Confucius qui évite certaines personnes sous le prétexte qu'elles ne sont pas vertueuses, ne vaut-il pas mieux se retirer entièrement du monde?

47.(포) Cette opération est celle qu'on pratique aujourd'hui avec la herse ; elle devait se faire autrefois avec la houe ou tout autre instrument analogue.

47.(으) Dans le Luen yu, Confucius complète sa pensée en disant :

«Si je ne me fais pas le compagnon des hommes tels qu'ils sont, avec qui frayerai-je? ? Tchoang tse (chap. Chan mou; Legge, SBE, vol : XL, p. 34 semble s'être souvenu de ce refus de Confucius de s'associer aux quadrupèdes et aux oiseaux, dans le passage où il le représente converti aux idées taoïstes et quittant ses disciples pour aller chez les animaux puis chez les oiseaux.

47.(397) Luen yu, XVIII, 7.

47.(398) Affirmation que les travaux de l'agriculture sont fort supérieurs à la recherche d'une vaine sagesse. Tse-lou ne peine pas dans les champs et ne s'occupe pas des cinq sortes de céréales; il ne fait que suivre Confucius dans ses incessantes pérégrinations. Quand il demande où est le Maître, le solitaire affecte de ne pas même comprendre qui est ce Maître qui n'est qu'un passant sur la route.

47.(399) Cf. t. IV, n. 36.137 et p. 379. La ville de Tch'eng-fou appartenait au royaume de Tch'ou et défendait sa frontière septentrionale (cf. t. IV, p. 372, lignes 9-11). C'est de là que le roi de Tch'ou comptait partir pour aller au secours de Tch'en qui était plus à l'ouest. Tch'eng-fou était au nord de Che (cf. n. 379), et non éloigné de Chang-ts'ai et de Tch'en; il est donc tout naturel que lorsque le roi de Tch'ou arriva dans cette ville, on lui ait parlé de Confucius qui se trouvait précisément entre Tch'en et Chang-ls'ai.

47.(누) Il n'est pas tout à fait exact de dire, comme Se-ma Ts 'ien le fait ailleurs (tome IV, n. 36.138 et p. 380), que Confucius se trouvait alors à $T c h$ 'en, c'est-à-dire dans la capitale même du pays de Tch'en.

47.(401) Telle est la manière dramatique, mais peu vraisemblable, dont Se-ma Ts'ien (d'accord avec le Kia $y u, \S 20$, qui paraît ici le suivre plutôt que lui servir de modèle) introduit le récit fameux concernant la situation presque désespérée où se trouvèrent Confucius et ses disciples dans la région comprise entre $T c h$ 'en et $T s^{\prime}$ 'ai. Il est évident cependant, pour qui a étudié comment l'historien procède en composant la biographie de Confucius, que son témoignage peut être discuté. Ici, comme dans la plupart des autres cas, Se-ma Ts 'ien était en présence de tout un cycle de traditions ayant trait à des incidents qui se passèrent entre Tch'en et $T s^{\prime}$ 'ai; mais ces traditions, qui étaient localisées dans l'espace ne l'étaient pas dans le temps ; c'est par une conjecture personnelle que Se-ma Ts 'ien les rapporte à l'année 489 et les met en relation avec la venue du roi de Tch'ou à Tch'eng fou; il est donc nécessaire d'examiner si cette explication est plausible. Le célèbre Tchou Hi (1130-1200) avait déjà fait remarquer à quelles difficultés elle se heurte en ce temps, Tch'en implorait le secours de 
Tch'ou contre $\mathrm{Ou}$; il ne devait donc rien faire qui pùt mécontenter le roi de Tch'ou, et quand ce souverain manifestait le désir d'appeler Confucius auprès de lui, ce n'était certes pas aux grands officiers de Tch'en à s'y opposer. Quant aux grands officiers de $T$ s'ai, ils étaient tout aussi incapables de nuire de propos délibéré à Confucius si le $T s$ 'ai dont il s'agit était la ville de Chang-ts'ai qui était alors une possession du royaume de Tch'ou (cf. n. 379); il est vrai que pour Se-ma Ts'ien (cf. n. 387), Ts'ai est ici Hia-ts'ai ; mais cette manière de voir doit être abandonnée, car l'expression «la région comprise entre Tch'en et $T s^{\prime} a i$ » suppose que ces deux localités sont voisines l'une de l'autre ; or tel est le cas pour Tch'en et Chan-ts'ai, tandis qu'une grande distance sépare Tch'en de Hia-ts'ai. — L'intervention malveillante des grands officiers de Tch'en et de Ts'ai étant ainsi rejetée comme invraisemblable, il n'y a plus aucune raison pour rapporter à l'année 489 la mésaventure de Confucius. Tchou Hi propose la date de 492 qu'il justifie en montrant que d'après le Luen yu, XV, 1, Confucius souffrit de la faim dans le pays de Tch'en (et non : entre Tch'en et Ts'ai ; ailleurs cependant, le Luen yu, XI, 2, parle de Tch'en et Ts'ai) aussitôt après avoir quitté le duc Ling, de Wei, qui l'avait interrogé sur une question d'art militaire. Mais la thèse de Tchou Hi a été combattue par Kiang Yong (H. T. K. K., chap. CCLXII, p. 25, $\mathrm{r}^{\circ}$ et $\mathrm{v}^{\circ}$ et p. $27 \mathrm{r}^{\circ}$ ) : s il est vrai que, en 493, Confucius soit allé de Wei à Tch'en, ce n'est qu'en 491 qu'il se rendit de Tch'en à Ts'ai (cf. n. 375), et ce n'est donc qu'à cette année 491 qu'on peut assigner l'anecdote de Confucius et de ses disciples mourant de faim, entre Tch'en et $T$ s'ai.

Il est évident d'ailleurs, : $1^{\circ}$ que $T s^{\prime}$ ai doit être ici Chang-ts'ai, $2^{\circ}$ que Confucius et ses disciples ont $\mathrm{pu}$ être dans une situation fort périlleuse parce que les vivres vinrent à leur manquer et sans qu'il soit nécessaire de recourir à l'intervention d'hommes armés qui les auraient cernés.

47.(402) Luen yu, XV, 1.

47.(403) Confucius et ses disciples se trouvèrent privés de vivres « pendant sept jours », dit le Kia yu. La même indication nous est donnée dans les textes de Siun tse, du Han che mai tchoan et du Chouo yuan,

47.(404) La traduction que nous donnons des mots est confirmée par une phrase de Che tse (chap. II, p. $30 \mathrm{v}^{\circ}$ ) qui est ainsi concue : « celui qui observe la sagesse et qui reste ferme dans l'adversité peut mépriser les rois et les ducs (c.-à-d. les puissants de ce monde) ».

47.(405) Il eut honte de s'être laissé aller à l'irritation. Les mots signifient littéralement : « la couleur se produisit (sur son visage) ».

47.(나). Luen yu, XV, 2.

47.(07) Se est le nom personnel de Toan-mou Se, dont l'appellation est Tse-kong.

47.(408) Depuis les mots «... appela Tse-lou» jusqu'à la fin du paragraphe, ce texte se retrouve dans le $\S 20$ du Kia yu.

47.(409) Ces deux vers sont tirés de la dernière ode de la section siao yu du Che king ; ils sont prononcés par des soldats qui se plaignent d'être envoyés dans des contrées lointaines. Confucius les applique à sa situation présente.

47.(10) Dans le Kia yu (§ 20), Tse-lou fait des reproches directs à Confucius :

- L'homme supérieur, dit-il, n'est jamais en détresse. A mon avis, c'est parce que, ô Maître, vous n'êtes point encore bon que les hommes ne nous croient pas; à mon avis, c'est parce que, ô Maître, vous n'êtes point encore sage que les hommes ne mettent pas en pratique nos préceptes.

Les mots [] me paraissent signifier « ne pratiquent pas nous, c.-à-d. nos préceptes », de même que les mots [] signifient « ne nous croient pas ». D'après Wang Sou cependant, les mots [] signifieraient « ne nous laissent pas aller »; la phrase finale aurait alors le sens suivant : 
«C'est parce que, ô Maître, vous n'êtes point encore sage que ces hommes ne nous laissent pas aller

et nous réduisent ainsi à l'extrémité. Cette interprétation a le tort de faire apparaître ici les hommes qui, d'après Se-ma Ts'ien et le Kia yu, tenaient étroitement cernés Confucius et ses disciples ; mais l'existence de ces gens malintentionnés est fort hypothétique (cf. n. 401) et le texte doit pouvoir s'expliquer sans leur intervention.

47.(411) Po-i et Chou-ts' $i$ moururent de faim sur la montagne Cheou-yang pour avoir voulu rester loyalement attachés à la dynastie $Y n$ que venait de renverser le roi Ou ; cf. Mém. hist., chap. LXI.

47.(412) Cf. t. I, p. 206. - Dans le Kia yu, ce développement oratoire continue encore pendant plusieurs lignes; mais la brièveté même de la leçon de Se-ma Ts'ien paraît prouver qu'il nous a conservé un texte plus ancien que l'amplification des rhétoriciens n'avait pas encore altéré.

47.(1ㅗ) Cf. n. 407.

47.(414) Le Kia yu omet ici ces deux phrases qui sont en effet la répétition fort inutile des lignes qui terminent plus loin la réponse de Yen Hoei.

47.(415) Parce que Yen Hoei aurait les mêmes idées que Confucius sur l'emploi qu'il convient de faire de ces richesses.

A côté de ce récit commun au Kia yu et à Se-ma Ts'ien, il en faut citer un autre qui se retrouve dans Siun tse ( $\$ 29$, yeou tso), dans le Han che wai tchoan (chap. VII, p. $3 \mathrm{v}^{\circ}-5 \mathrm{r}^{\circ}$ ) et dans le Chouo yuan (chap. XVII, tsa yen, p. $8 \mathrm{r}^{\circ}-10 \mathrm{v}^{\circ}$ ); quoique ces trois textes soient loin d'être identiques, l'argumentation reste la même dans tous les trois et ils ne diffèrent que par les exemples qu'ils invoquent à l'appui de leur dire.

Ils contiennent, en résumé, ceci : au moment où Confucius et ses disciples sont exténués de faim, Tse-lou demande comment son maître peut être réduit à une telle extrémité s'il est vrai que le Ciel doive récompenser par le bonheur celui qui fait le bien et punir par le malheur celui qui fait le mal.

Confucius répond :

En premier lieu, les sages ne réussissent pas toujours dans le monde ; l'histoire a conservé le souvenir d'un grand nombre de personnages qui furent célèbres par leurs vertus et qui eurent des fins tragiques; la seule chose dont l'homme soit maître, c'est son propre cœur; le succès ou la ruine dépendent des circonstances ;

en second lieu, de nombreux cas peuvent être invoqués où nous voyons des hommes, après s'être trouvés dans des situations presque désespérées, parvenir ensuite aux plus hautes destinées ; on ne peut donc pas dire que l'adversité soit toujours mauvaise ; elle est souvent une épreuve d'où les caractères sortent plus énergiques ;

enfin, l'époque dans laquelle nous vivons exerce une grande influence sur notre vie ; tel qui, sous un souverain sage, est parvenu au faite des honneurs, aurait subi le dernier supplice s'il avait été à la cour d'un tyran. Le bonheur et le malheur ne sont donc point la mesure de la valeur intrinsèque d'un homme.

Nous ajouterons que, chez certains écrivains, notamment chez les Taoïstes, la mésaventure de Confucius est devenue le thème de récits divers où le Maître et ses disciples ne sont pas toujours présentés sous un jour très favorable; voyez notamment Tchoang-tse, chap. XX et XXVII (Legge, SBE, vol. XL, p. 32, 37 et 160). 
47.(416) Il ne faut pas entendre que Tse-kong se rendit à la capitale du pays de Tch'ou dans le Hou-pei ; il alla auprès du roi Tchao qui était à Tch'eng-fou, dans le Ho-nan (cf. n. 399.).

47.(417) Quoique Se-ma Ts'ien ait omis de le dire, on voit que Confucius, une fois délivré, avait dû se rendre auprès du roi de Tch'ou. Nous lisons en effet plus loin que Confucius partit de Tch'ou pour retourner dans le pays de $W e i$; s'il en partit, il avait donc dû d'abord y aller. Mais c'est par erreur que Legge $(C$. C., vol. I, Prolégomenes, p. 83 [css: édition/rechercher: 'conducted him'].) en conclut que le roi Tchao, de Tch'ou, conduisit Confucius dans sa capitale qui était la ville de $J_{o}$ (aujourd'hui, s.-p. de I-tch'eng, dans la préf. de Siang-yang, province de Hou-pei). En réalité, Confucius se borna à aller auprès du roi de Tch'ou qui campait à Tch'eng-fou (au S.-E. de la préf. sec. de Jou, dans la province de Ho-nan), et qui mourut dans cette localité à la fin de l'année 489.

47.(418) Le mot ne désigne pas ici la mesure de longueur appelée $l i$; il s'applique au groupement social élémentaire qui est composé de 25 familles; le Tcheou li (chap. XV, article soei jen) dit en effet : «Cinq familles forment un lin; cinq lin font un $l i$ ». « Dans chaque $l i$, dit Se-ma Tcheng, on avait un dieu du sol c'est pourquoi le Li ki (chap. Kiao t'o cheng, trad. Couvreur, t. I, p. 587) dit que « lorsqu'on célébrait le sacrifice du dieu du sol, tout le hameau (li) s'y rendait »

Les familles groupées autour d'un dieu du sol étaient enregistrées, c'est-à-dire qu'elles étaient inscrites sur les registres du cens; de là l'expression. — Voici d'autres exemples de cet emploi du mot :

Siun tse (chap. III, p. $19 \mathrm{r}^{\circ}$; article 7, Tchong-ni pien) « il lui donna trois cents groupes de familles enregistrées.

$\underline{T \text { so tchoan }}\left(15^{\mathrm{e}}\right.$ année du duc Ngai $)$ : « il donna à Wei un territoire comprenant cinq cents groupes de familles enregistrées. »

Tso tchoan $\left(25^{\mathrm{e}}\right.$ année du duc Tchao) : « je vous propose de vous donner (un territoire comprenant) mille groupes de familles » (littéralement : mille dieux du sol) ; cf. t. II, p. 75, n. 2, où il y a une inexactitude, car le Tso tchoan, aussi bien que Se-ma Ts'ien, emploie l'expression []; ce sont les commentateurs qui l'expliquent comme signifiant 25.000 familles.

47.(19 $)$ Tse-si qui avait le titre de ling-yn, c'est-à-dire de conseiller d'État, dans le royaume de $T$ ch'ou, était le frère cadet du roi défunt et l'oncle du roi alors régnant (cf. t. IV, p. 375 , lignes 11-12).

47.(420) Toan-mou Se (appellation Tse-kong), Yen Hoei (appellation Tse-yuen), Tchong Yeou (appellation Tse-lou et Tsai Yu (appellation Tse-ngo) sont quatre des plus célèbres disciples de Confucius. Tse-si attire l'attention du roi de Tch'ou sur le danger qu'il y aurait à donner un apanage considérable à un sage qui est entouré d'hommes éminents.

47.(421) Le duc de Tcheou et le duc de Chao se partagèrent la surveillance de l'empire après la mort du roi $\mathrm{Ou}$, fondateur de la dynastie des Tcheou (t. IV, p. 133-131).

47.(422) Cf. tome I, $\underline{\text { n. } 04.145}$ et n. 04.247; tome IV, n. 33.122.

47.(년 $)$ Ainsi, d'une part Confucius empêchera Tch'ou de s'agrandir et l'obligera à rester dans la situation infime où il était au commencement de la dynastie des Tcheou; d'autre part, il est à craindre que Confucius lui-même ne devienne trop puissant.

47.(424) Cf. t. IV, p. 379-380.

47.(2도 $)$ Ce Tsie-yu était un sage qui feignait d'être fou, comme le fit autrefois le vicomte de $K i$ (cf. t. I, p. 206), afin d'éviter les dangers de la vie publique. C'est pourquoi le Tchan kouo $t s^{\prime} e$ dit (chap. V, p. $3 \mathrm{r}^{\circ} ; 3^{\mathrm{e}}$ partie de la section de $T s^{\prime}$ in) : " Le vicomte de $K i$ et $T$ sie-yu enduisirent de vernis leur corps et se rendirent affreux ; ils laissèrent épars leurs cheveux et, se firent passer pour fous. » 
Tsie-yu est aussi associé au vicomte de $K i$ dans un passage d'une requête adressée par Tseou Yang au roi Hiao, de Leang, qui régna de 168 à 144 av. J.-C. : « Le vicomte de $K i$ feignit d'être fou; Tsie-yu se retira du monde " (Mém. hist., chap.LXXXIII, p. $4 \mathrm{v}^{\circ}$ ). Cette même phrase se trouvait d'ailleurs déjà dans Siun tse (chap. XX, p. 25 r $^{\circ} ; \S 32$, Yao wen).

Tsie-yu est souvent cité dans l'ancienne littérature chinoise :

Le Han che wai tchoan (chap. II, p. $11 \mathrm{r}^{\circ}-\mathrm{v}^{\circ}$ ) raconte que le roi de Tch'ou lui offrit cent livres d'or pour qu'il acceptât le poste de gouverneur du territoire au sud du Hoang ho; Tsie-yu, conseillé par sa femme, repoussa ces propositions. et, changeant de nom, s'en alla sans que jamais personne pût savoir où il s'était retiré.

Dans le poème intitulé Cho kiang de la section des Élégies de Tch'ou appelée «Les neuf pièces », Tsie-yu est mentionné au nombre des sages qui furent méconnus de leur temps.

Enfin dans Tchoang-tse, Tsie-yu apparaît à trois reprises (trad. Legge, S. B. E., vol. XXXIX, p. 170, 221, 260) ; tout particulièrement intéressant est le passage qui se trouve dans le chap. Jen kien che (S. B. E., vol. XXXIX, p. 221), car il raconte sous une autre forme que le Luen yu et Se-ma Ts'ien l'incident de la rencontre de Tsie yu et de Confucius.

Le nom de $T$ sie-yu a été expliqué de trois manières différentes :

Les uns font de Tsie un nom de famille et de $Y u$ un nom personnel ; en effet, Tsie apparaît comme nom de famille dans le nom du personnage appelé Tsie Yu (cf. p. 259).

D'autres commentateurs suivent l'opinion, assez peu fondée, semble-t-il, de Hoang-fou Mi qui, dans son Kao che tchoan, dit que Tsie-yu est l'appellation d'un homme dont le nom de famille était Lou, et le nom personnel T'ong.

Enfin une troisième explication, que je serais disposé à accepter, considère Tsie-yu comme une simple désignation; c'est «celui qui se trouvait auprès du char »; ne sachant point le nom de ce sage mystérieux, la tradition l'appelle en disant que c'était l'homme qui se trouvait près du char de Confucius quand il adressa la parole à ce dernier; en effet, dans les deux paragraphes du Luen yu qui suivent celui-ci, d'autres solitaires sont introduits qui sont désignés d'une manière analogue (cf. n. 389); la seule objection qu'on puisse faire à cette interprétation du nom de Tsie -yu, c'est que, d'après le texte de Tchoang-tse, Confucius était dans sa maison, et non sur son char, quand Tsie-yu lui adressa la parole.

47.(426) C'est Confucius qui est ici symbolisé par le phénix. D'après la fable, le phénix n'apparaît que lorsqu'il y a des princes sages ; dans les époques troublées, il reste caché ; Confucius est un phénix dont la vertu est bien dégénérée puisqu'il ne craint pas de se montrer en un temps où l'empire est mal gouverné.

47.(427) Suivant une autre interprétation, ces paroles ne viseraient pas directement Confucius, et il faudrait comprendre la phrase ainsi : "Le passé, on ne peut le conserver; l'avenir, comment pourrait-on lui courir après ? » Cette explication se justifie par la leçon de Tchoangtse (S. B. E., vol. XXXIX, p. 221) : «Le futur, on ne peut l'attendre ; le passé, on ne peut l'aller chercher. »

47.(428) Suivant une autre explication, il faudrait traduire : «Ceux qui prennent part au gouvernement le tiennent en suspicion. » Il y aurait ici une allusion au fait que Tse-si, conseiller de Tch'ou, avait mis en garde le roi de Tch'ou contre Confucius (cf. p. 372). 
47.(429) Il faut comprendre que Confucius « descendit de son char», si on admet que le nom de Tsie-yu signifie "celui qui était auprès du char». Mais si on accepte la version de Tchoang-tse d'après laquelle Tsie-yu s'adresse à Confucius au moment où il passe devant sa maison, il faut dire que Confucius « descendit de la salle » pour aller aborder Tsie-yu.

47.(430) Plus : exactement de Tch'eng-fou. Cf. n. 417.

47.(431) Tseng était à $30 l i$ à l'est de la s.-p. actuelle de $I$ (préf. de Yen-tcheou, prov. de Chan-tong). Cf. Ta Ts'in i t'ong tche, chap. CXXX, p. $2 \mathrm{r}^{\circ}$.

47.(432) Toan-mou Se, disciple de Confubius.

47.(433) La rédaction est ici ambiguë; on ne sait si l'historien veut dire que, grâce à Tse-Kong, Ki K'ang-tse put éviter d'avoir à se rendre en personne auprès du roi $\mathrm{Ou}$, ce qui est la version du Tso tchoan $\left(7^{\mathrm{e}}\right.$ année du duc $\left.\mathrm{Ngai}\right)$, ou s'il faut entendre que l'intervention de Tse-kong permit au prince de Lou de ne pas livrer les cent groupes de victimes qui lui avaient été demandés, ce qui s'accorderait avec ce qu'a dit ailleurs Se-ma Ts 'ien (t. IV, p. 28), mais ce qui est en contradiction avec le témoignage du Tso tchoan.

47.(434) Luen yu, XIII, 7.

47.(435) Le duc de Tcheou, ancêtre des ducs de Lou, et le puîné prince de $K^{\prime}$ 'ang, chef de la lignée princière de $W e i$, étaient tous deux fils du roi Wen. Le Tso tchoan $\left(6^{\mathrm{e}}\right.$ année du duc Ting) dit :

« De tous les fils de T'ai-Se (femme du roi $W e n$ ), le duc de Tcheou et le puîné prince de $K$ 'ang étaient ceux qui étaient dans les termes les plus amicaux.

Cette phrase est mise dans la bouche d'un vieillard qui veut empêcher le duc de Wei d'ouvrir des hostilités contre le duc de Lou et qui lui rappelle que les deux États doivent avoir entre eux des relations fraternelles. Le Ts'ien Han chou (chap. LXXIX, p. $5 \mathrm{r}^{\circ}$ ) nous a conservé une chanson populaire dans laquelle on célébrait la manière dont une province avait été administrée successivement par les deux frères Fong Ye-wang et Fong Li :

«Leur gouvernement a été comme celui de Lou et de Wei et leur action, vertueuse et transformatrice a été égale ; - le duc de Tcheou et le puîné prince de $K$ 'ang sont comparables à ces deux hommes supérieurs. »

Si l'on tient compte de ce dernier texte, il semble bien que, dans la phrase qui nous a été conservée par le Luen yu, Confucius a voulu exprimer l'opinion que les États de Lou et de Wei avaient conservé dans leurs gouvernements respectifs l'empreinte des vertus des deux frères qui furent les ancêtres de leurs princes ; peut-être Confucius a-t-il prononcé cette parole pour expliquer pourquoi, obligé de quitter le pays de Lou, c'est dans le pays de Wei qu'il séjournait de préférence.

Quoique cette interprétation du texte nous paraisse la seule admissible, Se-ma Ts'ien nous en suggère une autre par la place même qu'il assigne à ce jugement de Confucius ; il le cite en effet immédiatement avant la critique fort vive que Confucius adresse au prince de Wei; il ne peut donc pas y avoir vu un éloge du gouvernement de $W e i$ mais bien plutôt il admet que, en représentant comme frères les gouvernements de Lou et de Wei, Confucius aura voulu dire ceci : de même que, dans le pays de Lou, les relations de prince à sujet étaient faussées par la trop grande puissance qu'avaient prise certaines familles, ainsi, dans le pays de Wei, les relations de père à fils étaient bouleversées par le fait que le fils occupait le trône qui aurait dû revenir à son père; les deux gouvernements se ressemblaient comme deux frères, car ils étaient aussi mauvais l'un que l'autre (cf. la discussion de ce passage par P'an Wei-tch'eng dans S. H. T. K. K., chap. 921, p. 5 r $^{\circ}$ ).

47.(436) Il s'agit de $K^{\prime}$ 'oai-wai, qui n'avait pu reprendre à son propre fils le trône de Wei et qui se trouvait toujours dans la ville de $T s^{\prime} i$. Cf. n. 365, et t. IV, p. 205-207. 
47.(437) Pour bien comprendre le passage qui va suivre, il importe de déterminer quelques dates. Le duc Ling, de Wei, père de K'oai-wai, et grand-père de Tchao, était né en 540, comme nous l'apprenons par le Tso tchoan ( $2^{\mathrm{e}}$ année du duc Tchao ; tr. Legge, p. 619, b) ; il mourut en 493, âgé de quarante-sept ans (quarante-huit, à la manière de compter chinoise). Son petit-fils Tcho ne pouvait donc alors être âgé que d'une dizaine d'années, et, lorsqu'on le mit sur le trône au détriment de son père K'oai-wai, il ne fut sans doute que l'instrument d'une faction. D'autre part, les paroles que Confucius prononça pour reprocher à Tcho d'occuper la place qui devait revenir à son père, sont rapportées par Se-ma Ts'ien à l'année 485, puisque, immédiatement après, l'historien dit: «l'année suivante » en parlant d'un événement qui eut lieu en 484. Or, en 485, on voit que Tcho devait être un jeune homme qui sortait de l'adolescence; il commençait à prendre conscience de ses actes et il était animé de bons sentiments puisqu'il désirait s'attacher Confucius. Celui-ci jugea donc le moment favorable pour exprimer sous une forme voilée sa désapprobation formelle de la conduite que Tcho avait tenue jusque-là à l'égard de son père et pour faire sentir au jeune prince la responsabilité morale qu'il encourait (cf. S. H. T.K. K., chap. 1066, p. $3 \mathrm{v}^{\circ}$ ).

47.(녕) Luen yu, XIII, 3.

47.(439) En traduisant les mots [ba] par «rendre les dénominations correctes », je leur donne le sens que leur attribuait certainement Se-ma Ts'ien. En effet, les lignes par lesquelles il introduit ce texte du Luen yu prouvent que, à son avis, Confucius avait l'intention de reprocher au duc de Wei de détenir le trône au détriment de son père; le fils occupant la situation qui aurait dû revenir à son père, le fils n'agissait pas en fils et le père n'agissait pas en père ; les dénominations n'étaient plus correctes.

Dans le chap. CXXX, p. 8 r', Se-ma Ts'ien, dit :

- Nan tse ayant pris en haine K'oai-wai, le fils et le père échangèrent leurs dénominations,

c'est-à-dire que, à en juger d'après les situations respectives qu'ils occupèrent, c'est le fils qui devint le père et le père qui devint le fils.

Le sens attribué par Se-ma Ts'ien à l'expression peut d'ailleurs se justifier par de nombreux textes. Pour ne citer que les plus notables :

on lit dans le chapitre Tsi-fa du Li ki (trad. Couvreur, t. II, p. 269) «Hoang-ti assigna à chaque chose une dénomination correcte »; en d'autres termes, il fut le grand nomenclateur.

De même, Lu Pou-wei, dans son tch'oen ts'ieou (chap. XVII, p. $3 \mathrm{r}^{\circ}$ et $\mathrm{v}^{\circ}$; section chen fen lan) expose comment la ruine de l'État peut être produite par l'emploi de dénominations incorrectes; il suppose qu'un homme appelle bœuf un cheval, et cheval un bœuf, et montre les conséquences désastreuses qui en résulteront ;

« tout cela, dit-il, a été causé parce que d'un bœuf on a fait un cheval, et d'un cheval un bœuf, et que les dénominations n'ont pas été correctes.

Mais si maintenant nous faisons abstraction du cadre dans lequel Se-ma Ts'ien insère ce texte du Luen yu, et si nous nous affranchissons de l'influence que l'opinion du grand historien a exercée sur les commentaires traditionnels du Luen yu, nous constaterons que l'expression [ba] peut être interprétée d'une tout autre manière. L'ancien érudit Tcheng Hiuen (127-200 p. C-) explique en effet ce passage du Luen yu, en disant :

«L'expression signifie "rendre corrects les caractères de l'écriture ». Dans l'antiquité, on appelait [a] ce que nous appelons aujourd'hui [c].

En effet, dans le chapitre $p^{\prime}$ ing $l i$ du $\underline{I l i}$ [css : ?], il est dit : 
«Quand (un message) comptait plus de cent caractères, on l'écrivait sur des fiches ; quand il avait moins de cent caractères, on l'écrivait sur une tablette.

Dans le Tcheou li (trad. Biot, t. II, p. 120), on lit que le wai che «a la charge de faire comprendre les caractères de l'écriture dans les régions des quatre points cardinaux » et encore (ibid., t. II, p. 407) que la

«neuvième année on réunit les aveugles et les scribes, les uns pour vérifier les caractères de l'écriture (les autres) pour déterminer les sons de la prononciation.

Si on prend le mot [a] dans ce sens, il faut donc admettre que, lorsque Confucius disait qu'il importe de rendre corrects les [a], il avait en vue la correction des caractères de l'écriture. C'est bien ainsi que, en fait, ces paroles de Confucius ont souvent été comprises :

- Lorsque, en 425 p. C., l'empereur Che-tsou, de la dynastie Wei, inventa plus de mille caractères nouveaux, il rendit un décret dans lequel, après s'être plaint des inconvénients que présente une écriture non uniformisée, il ajoute :

« La parole de Confucius que, si les caractères de l'écriture ne sont pas corrects, les entreprises ne réussissent pas, c'est à cela (c.-à-d. à ces inconvénients) qu'elle s'applique. (Wei chou, chap. IV, a, p. 1, vº).

— D'autre part, vers 560 p. C., un certain Li Hiuen composa un «Traité sur les caractères » parce qu'il s'affligeait de voir les inexactitudes de l'écriture et

«parce qu'il était sensible à cette parole de Confucius qu'il est essentiel de rendre corrects les caractères de l'écriture. (Pei Ts'i chou, chap. XLIV, p. 2 vº).

- On peut encore rappeler que l'histoire des Soei (Soei chou, chap. XXXII, p. 14 v $^{\circ}$ ) mentionne un traité en un chapitre sur l'écriture sous le titre "Les caractères rendus corrects $»$.

- Enfin nous constaterons un peu plus loin (p. 384, n. initiale) que Hiu Chen lui-même, l'illustre auteur du Chouo wen, admet dans sa préface que Confucius parle ici des caractères de l'écriture.

Ainsi, malgré l'autorité de Se-ma Ts'ien, il apparaît comme vraisemblable que ce texte du Luen yu ne renferme aucune censure de la conduite du duc de Wei; il se rapporte simplement à la correction de l'écriture; si un lecteur européen peut s'étonner que Confucius fasse de la correction de l'écriture le premier principe d'un bon gouveçnement et voie dans les caractères fautifs l'origine des plus graves désordres de l'État, il convient cependant de considérer, d'une part, l'importance officielle que les Chinois ont de tout temps attribué à leur écriture, et, d'autre part, la propension fâcheuse qu'a l'esprit chinois de raisonner par voie de propositions successives qui partent d'un fait particulier pour y rattacher des conceptions de plus en plus vastes et aboutir à la considération de l'empire entier ou de l'univers.

Quoi qu'il en soit, cette discussion, dont les éléments principaux ont été empruntés à l'excellent ouvrage de Lieou Pao-nan (S. H. T. K. K., chap. 1066, p. $2 \mathrm{r}^{\circ}$ et suiv.), a du moins été utile en ce qu'elle nous permet d'apercevoir les divergences profondes qui existent entre l'interprétation que Se-ma Ts'ien nous donne de certains textes du Luen yu et l'explication qu'on peut proposer de ces mêmes textes quand on les aborde sans idée préconçue.

47.(440) Le mot [] signifie « s'écarter de, être loin de ». L'exemplaire du Luen yu sur lequel travaillait Tcheng Hiuen donnait la leçon qu'on trouve en effet, avec ce même sens, dans plusieurs autres textes. Voyez notamment Li ki, chap. Wen wang che tse (trad. Couvreur, t. I, p. 475) A combien plus forte raison s'écartera-t-il (de la voie ordinaire)...» - Ici, Tse-lou, tout surpris de la réponse que lui fait Confucius, lui reproche de s'écarter de la question.

47.(441) Après ces mots, le Luen yu ajoute la phrase [......].

- L'expression formée de ces deux mots serait d'après Jou Choen une locution populaire qui avait cours dans le pays de $T s^{\prime} i$ et qui voulait dire : «ne pas parler de ce qu'on ne sait pas. » 
La phrase du Luen yu aurait donc le sens suivant : «L'homme supérieur, qnand il s'agit de ce qu'il ne connaît pas, garde le silence. » Ce serait un reproche que Confucius adresserait à Tselou qui avait osé croire qu'il s'écartait de la question.

A dire le vrai cependant, c'est là expliquer obscurum per obscurius; dans le texte du Ts'ien Han chou notamment, il est fort douteux que les mots aient le sens qu'on leur attribue, et Yen Che-kou en donne une interprétation plus plausible en considérant [] comme le nom personnel de Confucius. D'autre part, dans le texte du Luen yu, pour tout lecteur non prévenu, le mot [] sera une particule, le mot [] aura le sens d'omettre, et la phrase signifiera: "L'homme supérieur, dans les cas où il ne connaît pas, omet. » Mais cette réponse de Confucius à Tse-lou n'a plus aucun sens, puisque Tse-lou n'a rien omis.

Qui ne voit que c'est précisément pour cette raison que $S e-m a T s$ 'ien a supprimé cette phrase qui l'embarrassait?

- Examinons maintenant si l'énigme ne se laissera pas résoudre dans l'hypothèse que, en parlant de rectifier les [a], Confucius a voulu parler des caractères de l'écriture qui devaient être rendus corrects. Dans le Luen yu $(\mathrm{XV}, 25)$, on lit le passage suivant : [..............]

Pour comprendre ce texte, il faut se rappeler que, dans l'antiquité, on distinguait six arts libéraux (cf. Tcheou li, art. pao che; trad. Biot, t. I, p.297); le quatrième de ces arts était l'art de conduire les chars ; le cinquième avait pour objet les six sortes de caractères écrits. Il n'y a donc rien de surprenant à ce que l'art de conduire les chars et l'art de l'écriture soient choses associées dans l'esprit chinois ; c'est ainsi qu'on lira dans le Tchong yong (XXVIII, 3)

«les chars ont des essieux de même dimension; l'écriture a des caractères uniformes.

En second lieu, le mot [] n'a pris que tardivement le sens spécial d « historien »; à l'origine, il a une acception beaucoup plus vaste et désigne d'une manière générale ceux qui savent écrire, « les scribes ». C'est ainsi que, dans les Règlements élaborés par Siao Ho († 193 av. J.C.), « ceux qui savaient lire et écrire neuf mille caractères ou davantage pouvaient devenir che (c.-à-d. scribes) » (Ts'ien Han chou, chap. XXX, p. 8 v ${ }^{\circ}$.

- En tenant compte de ces observations, nous traduirons le texte précité du Luen yu $(\mathrm{XV}, 25)$ de la manière suivante :

« Le Maître dit: J'ai encore vu le temps où les scribes omettaient des caractères et où ceux qui possédaient un cheval le prêtaient à d'autres pour l'atteler. Mais maintenant il n'y a plus rien de tel.

Cette phrase signifie que, au temps où les hommes étaient vertueux, les scribes omettaient les caractères qu'ils ne savaient pas écrire correctement, et ceux qui étudiaient l'art de conduire un char, quand ils étaient incapables de dresser un cheval, confiaient ce soin à de plus expérimentés qu'eux; dans sa jeunesse, Confucius a encore vu l'époque où ces deux arts libéraux étaient ainsi pratiqués d'une manière consciencieuse, mais le désordre a tout envahi et maintenant, dit le Maître, il n'y a plus rien de tel.

- Cette interprétation est confirmée par un passage du Ts'ien Han chou (chap. XXX, p. 9 ro) où il est dit :

« D'après les anciens règlements, l'écriture avait des caractères uniformes; quand on ignorait (un caractère), on l'omettait, puis on s'enquérait auprès des vieillards expérimentés; mais, quand on arriva aux époques de décadence, le vrai et le faux ne furent plus fixes et les hommes suivirent leurs propres inspirations. C'est pourquoi K'ong-tse a dit: " J'ai encore vu le temps où les scribes omettaient des caractères. Mais actuellement il n'y a plus rien de tel. »

- De même Hiu Chen, l'auteur du Chouo wen, dans sa préface en date de l'an 100 ap. J.-C. écrit ceci : 
«K'ong tse a dit: « J'ai encore vu le temps où les scribes omettaient des caractères : mais actuellement il n'y a plus rien de tel. » Par là, il blâme ceux qui, lorsqu'ils ignorent (un caractère), ne s'informent pas auprès d'autres personnes mais suivent leur propre inspiration. »

- Reprenons maintenant la phrase du Luen yu (XIII, 3) qui est le point de départ de cette note; elle devient parfaitement claire, car elle n'est que l'affirmation de l'idée même que nous venons de trouver exprimée sous une autre forme. Confucius, voulant montrer à Tse-lou combien il est important de rendre corrects les caractères de l'écriture, commence par rappeler le principe que, plutôt que d'écrire des caractères fautifs, il vaut mieux laisser en blanc la place des caractères qu'on ignore ; il dit donc : «L'homme supérieur, dans les cas où il ne connaît pas (un caractère), l'omet, » Il expose ensuite les graves inconvénients qui résultent de l'emploi de caractères incorrects. C'est bien ainsi que l'auteur du dictionnaire étymologique Chouo wen, Hiu Chen, comprenait la parole de Confucius, car il la reprend pour son compte, à la fin de la première partie de sa préface, en disant « quant à ce que j’ignorais, je l'ai omis. »"

- En conclusion donc, lorsque Confucius parlait de rectifier les [a], il avait en vue les caractères de l'écriture ; c'est pour avoir méconnu ce sens du mot que Se-ma Ts'ien a été amené à retrancher du texte du Luen yu une phrase qui devient en effet inintelligible si on suppose, comme le fait l'historien, que Confucius parlait de rendre les dénominations correctes.

47.(442) Ce passage est cité dans le Heou Han chou (chap. LXIV, p. 2 r ${ }^{\circ}$ ) sous la forme suivante :

«'ong-tse a dit :

- Si les supplices et les punitions ne sont pas équitables, le peuple ne sait plus où mettre la main ni le pied.

Le mot tchong est un terme qui signifie : ni trop léger ni trop sévère. »

47.(443) Le Luen yu écrit : « (L’homme supérieur) peut certainement former des paroles avec les dénominations (qu'il applique aux choses; il peut certainement mettre à exécution ses paroles. »)

47.(444) Dans le commentaire de Kou-leang au Tch'oen ts'ieou (16 ${ }^{\mathrm{e}}$ année du duc Hi), on trouve une phrase analogue :

«L’homme supérieur, quand il s'agit d'apparitions étranges, ne fait rien à la légère. »

47.(445) Jan Yeou n'est autre que Jan K'ieou, dont l'appellation était Tse-yeou. On se rappelle que, en 492, ce disciple de Confucius avait été appelé dans le pays de Lou pour aider $K i$ $K$ 'ang-tse de ses conseils (cf. p. 358). Comme on va le voir plus loin, c'est grâce à lui que Confucius put rentrer dans le pays de Lou en 484. - Les combats que livra Jan K'ieou en 484 pour repousser une armée de $T s$ ' $i$ qui avait envahi le pays de Lou sont racontés dans le $\underline{T S O}$ tchoan $\left(11^{\mathrm{e}}\right.$ année du duc Ngai).

47.(446) Le Kouo ti tche place la localité de Leang à 53 li à l'ouest de la s.-p. de T'eng, qui dépend aujourd'hui de la préfecture de Yen-tcheou, dans le Chan-tong.

47.(447) Cette phrase et les deux suivantes ne deviennent intelligibles que si on se reporte à un texte du Tchong yong (chap. 29 ; Legge, C. C., t. I, p. 289-291). Ce texte du Tchong yong doit être considéré comme prononcé par Confucius qui trace le portrait du souverain parfait, et qui indique ainsi ce qu'il aurait été lui-même si la destinée l'avait mis à la tête des hommes ; il termine sa description en disant : « Jamais il n’y a eu un homme supérieur qui, étant tel, n'ait pas obtenu une prompte renommée dans l'empire. » Le mot « renommée » est ici [c], qui est expliqué par [ac] dans le commentaire de Kong Yng-ta. Or c'est précisément le mot [a] dont 
se sert Jan Yeou pour dire à K'ang-tse que, si Confucius exergait une fonction publique, il aurait de la gloire.

47. (448) Le mot signifie « répandre », et par suite «publier, annoncer ». Cf. Chou king, chap. K'ang kao et Lu hing (Legge, C. C., t. III, p. 394 et p. 598). Dans le texte du Tchong yong, nous lisons : « il fait prouver (l'excellence de sa conduite) par le peuple. »

47.(449) La leçon du Tchong yong est la même. Le sage interroge les divinités sur l'excellence de sa conduite afin de faire attester par eux cette excellence.

Quant à l'expression [], elle désigne les forces divines qui agissent les unes sur la terre et les autres dans le ciel.

47.(450) La phrase se retrouve dans le $\underline{\operatorname{Luen} y u}(\mathrm{~V}, 25)$.

47.(451) Cette conduite vertueuse est la conduite de l'homme supérieur qui fait précisément l'objet de la description du Tchong yong dans le texte auquel nous renvoyons (chap. 29; Legge, C. C., t. I, p. 289).

47.(452) Littéralement : « mille dieux du sol ». Au total, vingt cinq mille familles (cf. n. 418).

47.(453) On se rappelle que, lorsque Confucius était auprès du roi de Tch'ou, ce dernier fut détourné par son conseiller Tse-si de donner en apanage à Confucius un territoire considérable (of. p. 372). Ici, Jan Yeou réfute d'avance l'argument qu'on pourrait faire valoir contre le rappel de Confucius et déclare que, quelque important que fût l'apanage qu'on donnerait à Confucius, celui-ci ne s'en servirait jamais pour satisfaire son ambition personnelle.

47.(454) Je prends ici le mot [] avec le sens qu'il a dans le Luen yu (VII, 35) : « La parcimonie mène à l'étroitesse (du caractère)», et dans Mencius (VI, b, 3) : "Combien étroite est l'opinion du vieux Kao au sujet de cette ode. »

Kiang Yong (H. T. K. K., chap. CCLXII, p. $29 \mathrm{r}^{\circ}$ ), en citant ce texte de Se-ma Ts'ien, substitue le mot [] au mot []; il faut alors traduire: "Si vous désirez le mander auprès de vous, ne vous servez pas des hommes de peu comme intermédiaires (entre vous et lui). » Mais cette correction de texte me paraît absolument arbitraire.

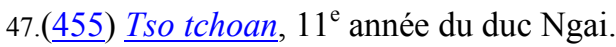

47.(456) Wen est le nom posthume du personnage dont le nom personnel est $Y u$ (cf. t. IV, p. 207, ligne 8). Dans le Luen yu (V, 14), Confucius explique pour quelles raisons on lui conféra ce nom posthume de Wen. En 484, il était un haut dignitaire dans le pays de Wei et y détenait toute l'autorité. C'est peu après sa mort que, en 484, K'oai-wai, fils du défunt duc Ling, réussit à reprendre à son propre fils le trône de $W e i$; Kong $K^{\prime} o e i$, fils de $K^{\prime} o n g Y u$, fut le principal agent de cette restauration (cf. t. IV, p. 207-209).

47.(457) T'ai-chou Tsi, connu aussi sous le nom posthume de Tao-tse, était le fils de T'ai-chou I-tse. Il avait épousé une fille de Kong $Y u$ et c'est parce qu'il avait outragé sa femme en prenant une seconde épouse, que Kong Yu voulait l'attaquer (cf. Tso tchoan, $11^{\mathrm{e}}$ année du duc Ngai).

47.(458) Le Tso tchoan nous a conservé le texte de la réponse de Confucius ; comme lorsqu'il s'adressait au duc Ling, de Wei (cf. p. 354), Confucius, en cette occasion encore, déclara qu'il n'avait étudié que les questions relatives aux rites et qu'il n'avait jamais cherché à s'instruire dans l'art militaire.

47.(459) Confucius peut aller à sa convenance dans tel ou tel royaume, de même que l'oiseau peut choisir l'arbre sur lequel il se pose; mais un royaume ne peut pas garder Confucius contre son gré, de même que l'arbre ne peut pas retenir l'oiseau.

47.(460) Les exemplaires modernes des Mémoires historiques donnent tous la leçon « chasser, expulser ", qui n'est guère admissible. Mais K'ong Yng-ta (574-648), citant ce texte de Se-ma 
Ts'ien dans son commentaire au tch'oen-ts'ieou ( $11^{\mathrm{e}}$ année du duc Ngai), donne la leçon « envoyer », que nous pouvons donc adopter.

47.(461) Cette indication nous permet de reporter à l'année 497 l'époque où Confucius avait quitté le pays de Lou (cf. n. 255).

47.(462) Cette sentence ne se trouve pas dans le Luen yu.

47.(463) Luen yu, XII, 21.

47.(464) La phrase se trouve deux fois dans le Luen yu (II, 19 et XII, 21). On l'explique ordinairement comme signifiant: «Promouvoir les bons et dégrader les méchants. » Mais cette interprétation traditionnelle se heurte à deux difficultés : en premier lieu, si les méchants sont dégradés et mis de côté, on ne voit pas quelle chance pourra leur rester de devenir bons ; Confucius dit cependant «alors les méchants deviendront bons ». En second lieu, le mot ne saurait signifier «dégrader»; ..... notre phrase ne peut donc avoir que l'un de ces deux sens :

ou bien «Élever les bons (aux situations supérieures) et placer les méchants (dans les grades inférieurs) »

ou bien «Élever les bons pour les placer au-dessus des méchants 》 (cf. Lieou Pao-nan, dans S. H. T. K. K., chap. 1052 , p. $17 \mathrm{v}^{\circ}$ et chap. 1065 , p. $19 \mathrm{r}^{\circ}$ ). Il est évident que les méchants, n'étant pas absolument écartés et occupant encore des places inférieures, pourront s'amender et que l'humiliation qui leur a été infligée les incitera à se corriger. - Dans ce texte, les mots que nous traduisons par «les bons » et «les méchants », signifient proprement « les droits » et « les courbes. »

47.(6ㄷㄴ Luen yu, XII, 18.

47.(466) Nous avons ici une application du principe confucéen que la vertu des gouvernants produit nécessairement celle des gouvernés. Le vol a pour origine la convoitise; si donc le prince et ses ministres étaient sans convoitise, leurs subordonnés aussi ignoreraient ce sentiment ; ils ne voleraient donc pas, même si on leur offrait une récompense pour le faire.

47.(467) Le mot "Lou» désigne à la fois le duc Ngai et son ministre tout puissant $K i$ K'ang-tse.

47.(468) Le Che est l'ensemble des poésies; le Chou est l'ensemble des Documents historiques.

47.(469) Dans l'Introduction à ma traduction de Se-ma Ts'ien (t. I, Introduction, p. CXXXV), j'ai essayé de montrer que la préface du Chou king attribuée à Confucius, ne formait pas à l'origine un tout continu; elle était morcelée en autant de paragraphes qu'il y avait de chapitres dans le Chou king, et chaque paragraphe devait former l'introduction du chapitre auquel il se rapportait. Se-ma Ts'ien a encore affirmé ailleurs (t. III, p. 2) que la préface du Chou king avait été écrite par Confucius ; il a d'ailleurs fait à ce texte de nombreux emprunts ; cf. t. I, p. 166, 176, 180, 185, 187, 188, 189, 191, 196, 248, 249, etc.

47.(470) C'est-à-dire que Confucius limita le Chou king entre l'époque de Yao et de Choen et celle du duc Mou de Ts'in. - Le témoignage de Se-ma Ts'ien prouve que les textes du Chou hing revisé par Confucius se trouvèrent compris entre deux dates extrêmes, marquées l'une par l'empereur Yao, l'autre par le duc Mou, de Ts'in. Mais il ne nous indique ni la quantité des documents sur lesquels s'exerça la sélection de Confucius, ni le nombre de ceux sur lesquels s'arrêta son choix. Dans le Ts'ien Han chou (chap. XXX, p. 2 v ${ }^{\circ}$ ), Pan Kou est plus explicite sur le second point; il dit: "Lorsque K'ong-tse fit sa recension, en haut il interrompit (la série des documents) à $Y a o$; en bas il la termina à $T s$ 'in; (cela forma) en tout cent chapitres pour lesquels il fit des préfaces où il disait dans quelles intentions on les avait composés cf. t. I, Introduction, n. 180. 
47.(471) C'est-à-dire : les sujets dont traitaient les textes relatifs aux rites des trois dynasties Hia, $\mathrm{Y} n$ et Tcheou. - Il y a certainement ici quelque interversion dans les phrases de Se-ma $T s$ 'ien. L'historien, en effet, avait commencé par parler des travaux de Confucius sur les rites et il avait dit : «(K'ong-tse) rechercha et suivit à la piste les (textes relatifs aux) rites des trois dynasties. » Puis il s'interrompt brusquement pour indiquer que Confucius a composé la préface du Chou king; après quoi, il revient à la question des rites. Il est évident qu'il faut placer le paragraphe concernant le Chou king soit avant, soit après celui qui concerne les rites; il faut donc considérer comme se faisant immédiatement suite l'une à l'autre les deux phrases : " (K'ong-tse) rechercha et suivit à la piste les (textes relatifs aux) rites des trois dynasties. Il groupa et classa les sujets dont ils traitaient. » C'est en effet la lecture qu'adopte l'excellent critique Lieou Pao-nan (H. T. K. K., chap. 1052, p. $23 \mathrm{v}^{\circ}$ ).

47.(472) Luen yu, III, 9.

47.(473) Les princes de $K$ ' $i$ étaient considérés romme des descendants de $Y u$ le grand, ancêtre de la dynastie des Hia (cf. t. IV, p. 183, lignes 1-2 et 6-8). De même, les princes de Song étaient les représentants de la dynastie $Y n$ (cf. t. IV, p. 231, lignes 21-23). En vertu de cette origine, les princes de $K^{\prime} i$ et ceux de Song avaient conservé le privilège d'accomplir certaines cérémonies réservées au Fils du Ciel, comme, par exemple, le sacrifice kiao.

Aussi lit-on ceci dans le chapitre Li yun du Li ki (trad. Couvreur, t. I, p. 508) :

« (Les princes de $K^{\prime} i$ font le sacrifice kiao à cause de $Y u$ (c'est-à-dire, parce qu'ils ont pour ancêtre $Y u$, ancêtre de la dynastie des Hia); (les princes de) Song font le sacrifice kiao à cause de Sie (c'est-à-dire parce qu'ils ont pour ancêtre Sie, ancêtre de la dynastie des $Y n$ ). Ainsi ils ont conservé des coutumes qui appartiennent au Fils du Ciel.

On comprend dès lors quelle est l'idée de Confucius : il connaît et peut décrire les rites des Hia et ceux des $Y n$; mais les deux royaumes où ces rites auraient eu quelque chance de se conserver ne les pratiquent plus guère; on ne peut donc pas vérifier au moyen de pratiques actuelles l'exactitude des traditions écrites relatives aux rites des Hia et des Yn. Ainsi, Confucius ne peut fournir la vérification de ce qu'il dit au sujet de ces rites, et, par conséquent, il reconnaît n'avoir aucune chance de les remettre en vigueur. En effet, dit-il ailleurs (Tchong yong, XXIX, 2) :

«Ce qui est antique quoique excellent, ne peut être vérifié ; n'étant pas vérifié, on n'y ajoute pas foi ; n'y ajoutant pas foi, le peuple ne le met pas en pratique.

La conclusion nécessaire est donc qu'il faut se borner à mettre en pratique les rites de la dynastie des Tcheou, puisque ceux-là seuls sont encore actuellement en vigueur ; c'est en effet ce que dit Confucius dans le texte du Tchong yong (XXVIII, 5) que nous citerons au cours de la note suivante.

47.(474) Ce texte est tiré du Luen yu (III, 9), mais avec une modification importante qui résulte de la suppression de la phrase [] avant la phrase finale. Cette suppression est parfaitement légitime comme nous allons essayer de l'établir. La phrase incriminée signifie :

«C'est parce que les textes écrits et les sages ne suffisent pas.

En d'autres termes, Confucius disait ceci : Les royaumes de $K^{\prime} i$ et de Song ne peuvent fournir la preuve de l'exactitude de mes dires au sujet des rites des Hia et des Yn; la raison en est que, dans ces deux royaumes, on ne trouve plus en suffisance les textes décrivant ces rites et les sages pratiquant ces mêmes rites; si j'avais ces textes et ces hommes, je pourrais fournir la preuve de l'exactitude de mes dires.

En premier lieu on remarquera que la phrase a l'allure d'une glose introduite après coup ; elle est une explication de ce qui précède ; mais, si on l'a supprimé, la suite des idées ne se trouve nullement interrompue, comme nous l'avons montré dans la note précédente. 
En second lieu, cette glose est elle-même peu admissible ; en effet, si Confucius n'avait pas à sa disposition de textes écrits concernant les rites des Hia et des Yn, comment aurait-il pu connaître ces rites et en parler?

En troisième lieu, cette glose inutile et inexacte ne figure pas dans le passage suivant du Tchong yong (XXVIII, 5) qui offre beaucoup de ressemblance avec le texte du Luen yu que nous étudions :

«Le Maître dit : J'ai discouru sur les rites des Hia, mais $K^{\prime} i$ n'a pu me fournir une vérification suffisante ; j'ai étudié les rites des $Y n$, mais Song n'avait plus que l'existence (c.-à-d. que la principauté de Song avait cessé d'observer les institutions qui firent autrefois sa gloire et se bornait à continuer à vivre). J'ai étudié les rites des Tcheou; ils sont maintenant en vigueur ; je pratiquerai donc (les rites des) Tcheou.

Enfin, dans le chapitre Li yun du Li ki (trad. Couvreur, t. I, p. 502), Confucius dit :

« J'ai voulu voir les usages des Hia et c'est pourquoi je me suis rendu dans (le pays de) $K^{\prime} i$; mais $\left(K^{\prime} i\right)$ ne m'a pas fourni une vérification suffisante ; j'ai (du moins) trouvé le calendrier des Hia. J'ai voulu voir les usages des Yn; c'est pourquoi je me suis rendu dans (le pays de) Song; mais (Song) ne m'a pas fourni une vérification suffisante ; j'ai (du moins) trouvé (les écrits sur) la Terre et le Ciel. C'est grâce aux explications concernant (les écrits sur) la Terre et le Ciel, et grâce aux paragraphes successifs du calendrier des Hia que j'ai pu voir (ce qu'étaient les rites des Hia et des $Y n$ ).

Dans ce passage, Confucius établit nettement qu'il a connu les usages des Hia et des Yn d'après des textes écrits, mais qu'il n'a pu les voir pratiqués dans les pays de $K^{\prime} i$ et de Song ; Legge (SBE, vol, XXVII, p. 368, n. 1) a bien remarqué qu'il y avait là un témoignage en opposition formelle avec la phrase : la contradiction disparaît si, comme le fait avec raison $\mathrm{Se}$ ma Ts 'ien, on supprime cette phrase qui n'est qu'une interpolation maladroite.

- Pour en finir avec ce passage du Luen yu, nous rappellerons que Pan Kou (Ts'ien Han chou, chap. XXX, p. $6 \mathrm{v}^{\circ}$ ) le cite d'une manière fort inattendue et fort peu justifiable à propos du Tch'oen ts-ieou; Confucius aurait prononcé cette parole pour expliquer les raisons qui l'empêchaient d'écrire l'histoire des Hia et des $Y n$; trouvant insuffisants les documents concernant les deux dynasties, il se serait rabattu sur le royaume de Lou et, de concert avec Tso K'ieou-ming, aurait étudié les mémoires de ses historiens ; ainsi aurait pris naissance le Tch'oen ts'ieou.

47.(나) Luen yu, II, 23.

47.(476) Si nous nous en tenons au texte de Se-ma Ts'ien, cette phrase se rattache d'une manière parfaitement logique à ce qui précède et à ce qui suit. Après avoir réuni et classé ce qu'on pouvait savoir de son temps sur les rites des trois dynasties Hia, Yn et Tcheou, Confucius commence par rappeler que, en ce qui concerne les rites des Hia et des Yn, les théories qu'il expose ne sauraient être mises en pratique, car ces rites sont tombés en désuétude même dans les principautés de $K^{\prime} i$ et de Song qui auraient dû les conserver. Confucius ajoute maintenant que le travail qu'il a fait pour montrer les additions et les suppressions que les Hia et les Yn ont introduites dans les rites aura du moins cette utilité que, même cent générations plus tard, on saura à quoi s'en tenir sur les rites de ces deux antiques dynasties.

Passant ensuite à la considération des rites de la dynastie Tcheou, Confucius déclare qu'ils renferment en eux tout ce qu'il y avait de bon dans les rites des Hia et des Yn; c'est donc les rites des Tcheou qu'il pratiquera.

- Étudions maintenant le texte du Luen yu (II, 23). Le commentaire de Tcheng Hiuen explique ici le mot [] comme ayant le sens de "générations ayant des noms de famille 
différents »; il serait donc l'équivalent de notre mot «dynastie. » $\mathrm{Si}$ on adopte cette interprétation, la question de Tse-tchang serait celle-ci : « Peut-on, après dix dynasties, savoir (ce qui existait dix dynasties auparavant? » Il me semble cependant que ce paragraphe reste intelligible, même si on conserve au mot son sens ordinaire de « génération ».

Je proposerai la traduction suivante :

«Tse-tchang ayant demandé si, après dix générations, on pouvait savoir (ce qui existait dix générations auparavant, le Maître dit :

- Les $Y n$ se conformèrent aux Hia et on peut savoir les suppressions et les additions qu'ils firent aux rites; les Tcheou se conformèrent aux $Y n$ et on peut savoir les suppressions et les additions qu'ils firent aux rites. S'il doit arriver qu'(une dynastie nouvelle) succède à celle des Tcheou, même après cent générations on pourra savoir (ce qu'étaient les rites à l'époque des Tcheou).

Ainsi, à la question de Tse-tchang, Confucius répond par des faits; il montre qu'on peut connaître les rites des Hia, car on sait les modifications qui y furent apportées par les $Y n$, et qu'on peut connaître les rites des $Y n$, car on sait les modifications qui y furent apportées par les Tcheou; notre connaissance remonte donc bien plus loin que dix générations avant la nôtre ; aussi pouvons-nous dire avec certitude que, si la dynastie des Tcheou vient à être remplacée par une autre, même cent générations plus tard, on saura encore ce qu'étaient les rites des Tcheou. Il est possible d'ailleurs que, comme le donne à entendre Se-ma Ts'ien, Confucius ait prononcé ces paroles à propos de ses travaux sur les rites ; c'est grâce à ces travaux qu'on peut remonter dans le passé jusqu'aux rites des dynasties Hia et Yn; c'est grâce à eux que les rites des Tcheou resteront connus dans un avenir qui peut s'étendre jusqu'à cent générations.

Dans ce texte du Luen yu, la ponctuation doit être placée avant, et non après le mot [] dans les deux cas où ce mot apparaît; c'est ce que prouve le passage suivant du Ts'ien Han chou (chap. LX, p. $5 \mathrm{r}^{\circ}$ ) :

«Les $Y n$ se conformèrent aux Hia et mirent en honneur le fond; les Tcheou se conformèrent aux $Y n$ et mirent en honneur la forme.

47.(477) Les Tcheou, qui sont venus après les $Y n$ et les Tcheou, ont eu l'avantage de pouvoir observer les rites de ces deux dynasties et sont parvenus ainsi à avoir eux-mêmes des institutions plus parfaites.

47.(강) Cf. notes 473 et 476.

47.(479) [] désigne le Chou king dont la partie dite de texte moderne paraît bien être restée telle à peu près qu'elle sortit des mains de Confucius. Quant au terme [] [css : traduit par 'les mémoires sur les rites'], il ne saurait s'appliquer ici à l'ouvrage.appelé aujourd'hui $L i$ ki, car le $L i$ ki sous sa forme actuelle n'existait pas encore à l'époque de Se-ma Ts'ien.

47.(낭) Luen yu, III, 23.

47.(ㅅ1) Ce grand maître de la musique est peut-être le personnage appelé Tche qui est mentionné à deux reprises dans le Luen yu (VIII, 15 et XVIII, 9). Suivant une autre théorie cependant, le maître de musique Tche serait bien antérieur à Confucius et aurait vécu à l'époque du roi P'ing (770-720).

47.(482) C'est-à-dire : on peut savoir comment la musique doit être jouée. - Cette phrase est parfaitement intelligible si, comme le fait Se-ma $T s$ 'ien, on réunit les deux textes qui sont isolés l'un de l'autre dans le Luen yu actuel (III, 23 et IX, 14). En effet, dans le second texte, Confucius se félicite d'avoir rendu la musique correcte ; c'est pourquoi il dit, dans le premier texte, que dorénavant on saura comment la musique doit être jouée.

47.(483) Le début de la musique était en effet marqué par un coup frappé sur la cloche qui donnait le diapason et qui permettait ainsi aux autres instruments de trouver l'accord. 
47.(484) ... on peut aussi conserver au mot [] son sens propre et dire que, une fois que l'accord a été indiqué par le coup de cloche, tous les autres instruments le suivent. Ce dernier sens peut être justifié par un commentaire de Wei Tchao qui dit, à propos d'un texte du Koиo yu :

«Quand l'accord a été mis dans la musique par le coup de cloche, les huit sortes d'instruments le suivent.

47.(ㅅ5) On peut épiloguer longuement sur la valeur de ces trois termes : le sens le plus simple me paraît être que les différents instruments, et peut-être aussi les chanteurs, forment un ensemble harmonieux, où cependant chaque partie ne se confond pas avec les autres, et où il n'y a jusqu'à la fin aucune solution de continuité.

47.(나) $\underline{\text { Luen } y u}$, IX, 14.

47.(487) Il est question en ce moment de la musique, et non du Che king; par conséquent, les termes ya et song désignent ici certains airs de musique, et non les parties du Che king appelées le ya et le song. On verra en effet un peu plus loin que Se-ma Ts 'ien mentionne le ya et le song comme des airs de musique au même titre que le chao et le ou.

Voici l'un des textes qui prouvent que le ya et le song de la musique ne doivent pas être confondus avec le ya et le song du Che king. Les Rites de Tai l'aîné (chap. XII, section t'eou hou, à la fin) disent :

«Des vingt-six pièces qui composent le $y a$, il y en a huit qui peuvent être chantées; ce sont: le lou ming (siao ya, I, 1), le li cheou (titre d'une ode perdue ; cf. tome III, n. 24.276, et $\underline{\text { n. 28.180) }}$, le ts'io tch'ao (fong, Chao nan, 1), le $t$ s'ai fan (fong, Chao nan, 2), le ts'ai pin (fong, Chao nan, 4), le fa t'an (fong, Wei, 6), le po kiu (Siao ya, IV, 2), et le tseou yu (fong, Chao nan, 14). Huit autres pièces ont été perdues et ne peuvent être chantées. Sept pièces (composant) le Chang (section du song) et le $T s^{\prime} i$ (section du fong) peuvent être chantées. Trois pièces appartiennent au chant intermédiaire.

Il est évident que le ya dont il est question ici est le ya de la musique, et non le ya du Che king; en effet, il ne comprend que 26 pièces tandis que le Siao ya et le Ta ya du Che king en comptent en tout 111 ; d'autre part, dans l'énumération qui est faite des huit premières de ces 26 pièces, on en trouve 5 qui appartiennent au fong, et non au ya, du Che king; enfin sept autres de ces 26 pièces comprenaient des odes qui font partie, les unes d'une section des odes sacrificatoires, ou song, les autres du fong. On voit donc bien que le ya de la musique est différent du ya du Che king.

On trouvera d'autres textes confirmant cette conclusion dans le commentaire de Lieou Pao-nan (S. H. T. K. K., chap. 1060, p. $18 \mathrm{v}^{\circ}$ ).

En somme, dans ce paragraphe, Se-ma Ts 'ien ne parle que de la musique. Ce n'est que dans le paragraphe suivant qu'il traitera des travaux de Confucius sur le Che king.

47.(8ㅗ) On désigne sous le nom de Che l'ensemble des poésies.

47.(489) Sie est l'ancêtre des Yn; Heou-tsi est l'ancêtre des Tcheou.

47.(490) Le roi $L i$ dut s'enfuir de son royaume en l'an 842 (cf. t. I, p. 274); le roi Yeou (781-721) est celui qui fut cause que les Tcheou durent transférer leur capitale à Lo-yang (cf. t. I, p. 285).

47.(91) Ailleurs (t. III, p. 16-17), Se-ma Ts'ien a dit :

«Quand la conduite des Tcheou cessa d'être bonne, les poètes prirent pour thème les nattes sur lesquelles on se couche et (l'ode) koan ts 'iu fut composée.

Les nattes sur lesquelles on se couche désignent ici les rapports sexuels ; 
Se-ma Ts'ien voyait dans l'ode koan ts-iu une satire contre les débauches du roi Kang; et, selon lui, ce serait de ces débauches ou de ces désordres qu'il serait parlé dans cette ode ; cette opinion est en effet celle qui prévalait à l'époque des Han.Legge (C. C., vol. IV. p. 5, col. 1) a indiqué quelques-uns des textes où se trouve cette théorie. Wang Tch'ong (27-97 p. C.) la rappelle dans son luen heng (chap. XII, section sie toan), mais c'est pour la réfuter en faisant observer qu'on ne sait rien sur les prétendues débauches du roi $K$ 'ang.

En réalité, l'expression est fort obscure; Se-ma Piao (240-305 p. C.) la comprenait tout autrement que Se-ma Ts'ien, car il disait :

«Les Annales n'étaient pas en bon état; aussi Tchong-ni (Confucius) les arrangea-t-il ; (l'ode koan ts'iu était en désordre ; aussi le maître de musique Tche la réforma-t-il.

( $T \sin$ chou, chap. LXXXII, p. $3 \mathrm{r}^{\circ}$ ). Ici, comme on le voit, il s'agit du texte ou de la musique de l'ode qui était en désordre et qu'on arrangea.

- Dans le Luen yu (VIII, 15) nous avons la phrase suivante []. Legge et Couvreur acceptent tous deux l'explication regardée comme orthodoxe et qui donne le sens suivant :

«Le Maître dit: Lorsque le maître de musique Tche commença (à exercer sa charge), comme le finale du koan ts'iu était magnifique et comme il remplissait l'oreille!

Le mot [] est alors pris dans le sens de « finale» ou dernier morceau d'une symphonie, $\mathrm{Ce}$ sens du mot est en effet bien connu : pour ne citer qu'un exemple, on lit dans le Yo ki (Legge, SBE, vol. XXVIII, p. 117 ; Couvreur, t. II, p. 87) :

«C'est l'instrument pacifique qui marque le commencement de la musique et c'est l'instrument militaire qui en marque la fin.

(cf. tome III, n. 24.240). Mais cette phrase même, avec son opposition entre les mots [] et [], nous suggère une nouvelle interprétation du texte du Luen yu où ces deux mêmes mots apparaissent. On peut en effet proposer la traduction suivante :

«Le Maître dit :

- Le début (de la musique tel que le jouait) le maître de musique Tche, et le finale du koan ts'iu, comme cela était magnifique et comme cela remplissait l'oreille!

(cf. S. H. T. K. K., chap. 916 , p. 8 v et suiv., et chap. 1059 , p. vo).

- Pour nous, nous ne saurions prendre parti entre toutes ces explications divergentes qui prouvent que le texte du Luen yu, aussi bien que celui des livres classiques plus anciens tels que le Che king et le Chou king, est souvent susceptible de recevoir plusieurs sens différents.

47.(492) Aujourd'hui encore les quatre sections du Che king commencent respectivement par les odes dont Se-ma Ts'ien indique ici le titre.

47.(493) Le Che king actuel comprend effectivement trois cent cinq pièces, plus les titres de six odes perdues.

47.(494) Le chao est la musique attribuée à Choen; le ou est la musique du.roi $O u$; le ya et le song sont ici des musiques, et non les parties du Che king appelées ya et song ; cf. n. 487.

47.(495) Je prends ici le mot «discipline» dans le sens de: ensemble de doctrines ou d'enseignements sur un sujet déterminé. Les six disciplines étaient les Poésies, les Documents historiques, les Rites, la Musique, les Annales, le I.

47.(496) Le fameux livre de divination connu sous le nom de I king. 
47.(497) On sait que le I king se présente à nous accompagné de dix appendices, appelés les dix ailes. Ces dix appendices se ramènent à sept, les trois premiers comprenant chacun deux ailes.

Les titres de ces dix appendices sont : 1 et 2, le t'oan; 3 et 4, le siang; 5 et 6 , le hi ts'e; 7, le wen yen; 8, le chouo koa; 9, le sin koa; 10, le tsa hoa. Comme on le voit, Se-ma Ts'ien énumère ici tous les appendices du $I$ king, sauf le dernier.

Après bien des hésitations, je me suis décidé à abandonner l'opinion traditionnelle d'après laquelle Se-ma Ts'ien attribuerait à Confucius la composition de ces appendices; dans le texte de l'historien, je ne trouve pas un seul mot qui signifie « écrire » ou « composer »; les titres des appendices me paraissent dépendre, au même titre que le nom du I king lui-même, du verbe [] ; à mon avis, la phrase ne peut avoir que ce sens : "Confucius se plut au $I$ king et à ses appendices $\gg$.

L'objection qui se présente aussitôt est celle-ci : si les appendices du I king sont antérieurs à Confucius, comment se fait-il qu'on y relève plusieurs passages précédés de la formule « Le Maître dit... » qui paraît introduire des jugements de Confucius lui-même ? Nous répondrons que cette objection embarrasse tout autant ceux qui attribuent la paternité des appendices à Confucius, car ce dernier n'aurait pas employé la formule « Le Maître dit... » pour exprimer ses propres opinions (cf. Legge, SBE, vol. XVI, p. 29). D'autre part, nous avons la preuve formelle que certaines parties des appendices sont certainement antérieures à Confucius, car le début du Wen yen ( $7^{\mathrm{e}}$ appendice) est cité à la date de 564 av. J.-C., c'est-à-dire treize ans avant la naissance de Confucius, par le Tso tchoan qui déclare que ce texte se trouve dans le $I$ des Tcheou.

En conclusion donc, nous croyons que les appendices du I king existaient avant Confucius ; mais ils ont été remaniés à une date postérieure à Confucius et c'est alors qu'un ou plusieurs auteurs anonymes y ont introduit les paragraphes commençant par la formule «Le Maître dit... »

- Si le témoignage de Se-ma Ts'ien nous semble établir que les appendices ne sont pas l'œuvre de Confucius puisque au contraire Confucius se plut à les étudier, il nous reste à montrer pourquoi les critiques chinois donnent à ce témoignage une signification diamétralement opposée en y introduisant implicitement le verbe « écrire » ou « composer » qui ne s'y trouve point (à moins qu'on ne donne ce sens au mot [], ce qui est difficilement admissible).

S'ils le font, c'est parce que, en réalité, ils voient le texte de Se-ma Ts'ien à travers celui de Pan Kou qui dit dans le Ts'ien Han chou (chap. XXX, p. 2 r ${ }^{\circ}$ ) que Fou-hi inventa les huit trigrammes, que Wen wang forma les soixante-quatre hexagrammes, et que

«Confucius fit pour cela (c.-à-d. pour être ajoutés à l'ouvrage ainsi formé) les dix chapitres, à savoir le t'oan, le siang, le hi ts'e, le wen yen, le siu koa, etc.

Ainsi le $I$ king se trouva constitué par la collaboration successive des trois plus grands sages de la Chine, de ceux qui représentent respectivement la haute, la moyenne et la basse antiquité.

Mais il est aisé de voir que c'est pour obtenir cette symétrie des trois sages et des trois antiquités qu'une part a été faite à Confucius dans la composition du I king; nous avons affaire ici à une systématisation arbitraire qui n'a aucune valeur historique et que Se-ma Ts 'ien n'a point connue.

47.(498) Confucius lut le $I$ king un si grand nombre de fois que les lanières de cuir qui rattachaient entre elles les fiches de bois composant le manuscrit furent usées et se rompirent à trois reprises.

47.(보) Luen yu, VII, 16. 
47.(500) [substitution de caractère]. Voici un autre exemple montrant la même substitution de caractère : dans le Tso tchoan ( $1^{\mathrm{e}}$ année du duc Hoan), et dans les Tableaux chronologiques de Se-ma Ts'ien (chap. XIV, p. $22 \mathrm{v}^{\circ}$ ). Il s'agit ici de l'échange que le duc de Tcheng fit avec le duc de Lou pour acquérir la localité de Hiu-t'ien; en 713 (cf. t. IV, p. 107), le duc de Tcheng avait donné au duc de Lou la localité de Pong, à condition que celui-ci lui donnerait Hiu-tien; en 711, les conditions de l'échange furent modifiées; le duc de Tcheng dut ajouter à son apport un anneau de jade ; la phrase des Tableaux chronologiques signifie donc :

«Se servant d'un anneau de jade, il le donna en plus à Lou pour échanger avec lui Hiu-tien.

Comme l'explique un commentaire cité par P'ei Yn (Mém. hist. chap. XXXIII, p. 5 ro) :

«(La localité de) Peng n'étant pas une compensation suffisante pour Hiu-tien, (le duc de) Tcheng y ajouta encore un anneau de jade.

Il faut donc, dans le texte du Tso tchoan, expliquer le mot [] comme ayant la valeur de [], et on traduira :

«Le comte de Tcheng, se servant d'un anneau de jade, le donna en plus pour (obtenir) Hiu-tien .

47.(501) Le texte de Se-ma Ts'ien est simple et clair; il n'en va pas de même pour le texte correspondant du Luen yu (VII, 16).

Legge et Couvreur acceptent l'interprétation traditionnelle qui revient à ceci :

« Le Maître dit :

- Si quelques années étaient ajoutées à ma vie, j'en donnerais cinquante à l'étude du $I$ et alors je pourrais arriver à ne plus commettre de grandes fautes.

Legge remarque cependant avec raison, dans une note, qu'on ne comprend pas comment Confucius, déjà âgé de soixante-huit ans, pouvait, même à titre de supposition, désirer que cinquante années fussent ajoutées à sa vie. D'ailleurs, en quelque estime qu'on tienne le $I$ king, c'est vraiment aller trop loin que de l'étudier cinquante années durant. Je n'entrerai pas dans l'examen des diverses hypothèses que les exégètes chinois ont proposées pour résoudre la difficulté ; on trouvera l'indication de quelques-unes d'entre elles dans la note de Legge $(C$. $C$., vol. I, p. 64) à laquelle je me suis déjà référé. Pour ma part, je crois que les mots ne peuvent résulter que d'une corruption du texte.

- Reste la phrase finale. Legge observe que cette proposition parait étrange, car Confucius n'a jamais prétendu être un homme parfait ; peut-être faut-il en effet donner à ces mots un sens plus directement en rapport avec le contenu du I king: le I king est un livre de divination; il indique à l'avance les cas dans lesquels il faut agir et ceux dans lesquels il faut s'abstenir; celui qui se conformera à ces indications évitera donc les fautes que commettraient des hommes non prévenus; c'est ce que Confucius veut donner à entendre quand il dit que, s'il pouvait se livrer à une étude approfondie du I king, il arriverait à ne plus tomber dans de grandes fautes; c'est encore ce qu'exprime un des appendices du I king en affirmant que l'homme qui aura attentivement tenu compte des pronostics du I king aura une bonne fortune constante et réussira dans tous ses actes (Legge, SBE, vol, XVI, p. 351, § 14).

47.(0ㅡ) Cf. n. 495.

47.(503) Sur la valeur mystique du nombre 72, voyez tome II, n. 6. Le Heou Han chou (chap. III, p. $7 \mathrm{r}^{\circ}$ ) parle des sacrifices qui furent offerts en l'an 86 p. C. à Confucius et à ses 72 disciples.

Cependant Se-ma Ts'ien lui-même, dans le chapitre LXVII de ses Mémoires (p. $1 \mathrm{r}^{\circ}$ ) cite une parole de Confucius qui aurait dit : 
— Ceux qui ont reçu mon enseignement et qui l'ont compris entièrement sont au nombre de soixante-dix-sept.

47.(504) D'après Tchang Cheou-tsie, le mot [] se prononce ici tsiu. Je n'ai pas pu identifier avec précision ces trois personnages qui ne sont pas au nombre des 72 disciples.

47.(505) Luen yu, VII, 24.

47.(506) Le mot désigne ici les enseignements qu'on peut tirer des Poésies, des Documents historiques, des Rites et de la Musique.

47.(07) Le mot [] est ici au k'iu cheng.

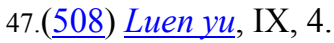

47.(09) Luen yu, VII, 12.

47.(510) Lorsqu'on jeûne avant d'offrir un sacrifice, il faut concentrer toutes ses pensées sur la cérémonie qu'on va accomplir si on veut pouvoir entrer en communication avec les dieux ; voyez les prescriptions relatives au jeûne dans le chapitre Tsi t'ong (§ 6) du $\mathrm{Li} k i$ (trad. Couvreur, t. II, p. 323-325 ; Legge, SBE, vol. XXVIII, p. 239-240). De même, quand on va livrer bataille, on doit prêter une attention soutenue à ce qu'on fait si on veut remporter la victoire. C'est pourquoi on lit dans le chapitre $L i k$ 'i (a, § 21) du Li ki (trad. Couvreur, t. I, p. 553 ; Legge, SBE, vol. XXVII, p. 403 ; cf. chap. Kiao t'o cheng, à la fin de la $1^{\mathrm{e}}$ partie ; Couvreur, I, p. 589 ; Legge, SBE, vol. XXVII, 426) :

«Dans la pratique des rites, l'homme supérieur ne manque pas de faire la plus grande attention... Confucius disait : si je livre bataille, je remporte la victoire, si j'offre un sacrifice j'obtiens les faveurs (du Ciel)

Dans ce texte, comme dans celui du Luen yu reproduit par Se-ma Ts'ien, nous voyons que la réussite dans le combat, de même que l'exaucement dans le sacrifice auquel on se prépare par le jeûne, sont obtenus grâce à une attention soutenue.

En cas de maladie, il importe de faire attention au régime qu'on suit et aux aliments dont on se nourrit.

47.(511) Luen yu, IX, 1.

47.(512) - Le mot [] est ici employé dans un sens favorable : ce n'est pas le profit matériel, comme l'entendent les hommes au caractère bas, c'est l'avantage réel qui est identique à la justice. Une action juste peut n'être pas profitable à celui qui l'accomplit; elle est cependant avantageuse en soi, par cela même qu'elle est juste.

— Le mot [] désigne la destinée bonne ou mauvaise que le Ciel assigne à chaque être. Dans le chap. XLIX des Mém. hist., p. $1 \mathrm{v}^{\circ}$, Se-ma Ts'ien dit :

«Si K'ong-tse parlait rarement de la destinée, c'est qu'en effet il est difficile d'en discourir. Si on n'a pas entièrement pénétré les transformations de l'obscur et du clair (c.-à-d. des deux principes qui règlent l'évolution universelle), comment connaîtrait-on la destinée naturelle?

— Le mot [] désigne la bonté parfaite réalisée dans l'homme.

Pourquoi Confucius parlait-il rarement de l'avantage, de la destinée et de la bonté absolue ? C'est, dit-on, parce qu'il vivait à une époque dégénérée et que les hommes de son temps n'auraient pu comprendre des notions aussi hautes. Mais ce que les critiques chinois ne parviennent guère à expliquer, c'est la contradiction qui existe entre l'affirmation que Confucius ne parlait que rarement de la bonté absolue, et le fait que le Luen yu présente des passages extrêmement nombreux où Confucius traite de cette même bonté absolue.

47.(513) Luen yu, VIII, 8. 
47.(514) Le Luen yu, qui met tout ce paragraphe dans la bouche de Confucius, ajoute ici la phrase « Devant celui qui ne cherche pas à parler, je ne m'exprime pas. »

47. (515) Les mots « soulever un coin » forment une expression très concise ; le texte du Luen $y u$ gravé sur pierre à l'époque des T'ang donne la leçon plus complète «quand il avait soulevé un coin pour le montrer »; mais, comme Se-ma Ts'ien n'a pas connu ces trois mots supplémentaires, peut-être ne sont-ils qu'une glose introduite à une époque postérieure et on a sans doute eu raison de ne pas les admettre dans le texte définitif du Luen yu.

47.(16) Luen yu, X, 1 .

47.(517) L'expression [] désigne le berceau familial, l'endroit où ont vécu les ancêtres d'un homme. Quand Confucius se trouvait dans le lieu où avaient demeuré ses pères et ses aînés, il affectait par modestie une attitude respectueuse et, dissimulant sa haute sagesse, il semblait incapable de parler. On peut rapprocher de cette phrase concernant Confucius ce que dit $\mathrm{Se}$ ma Ts'ien du général Li Koang (Mém. hist., chap. CIX, p. $4 \mathrm{v}^{\circ}$ ) :

«J'ai vu le général $L i$ : il semblait pénétré de respect comme s'il eût été un homme de basse condition et sa bouche était incapable de s'exprimer.

47.(518) Quand il était dans le temple ancestral du prince, pour aider aux sacrifices.

47.(19) $\underline{\text { Luen } y u}, \mathrm{X}, 2$.

47.(20) Dans le Luen yu, il est question d'abord des grands officiers inférieurs et ensuite des grands officiers supérieurs.

- Les grands officiers supérieurs étaient théoriquement au nombre de trois dans un pays tel que celui de Lou; ils avaient les titres de se-t'ou, se-ma et se-k'ong. Dans le pays de Lou, ces trois charges étaient exercées respectivement par les chefs des trois familles issues du duc Hoan, à savoir les familles Ki, Chou-suen et Mong-suen. En fait, il y avait en outre, dans le pays de Lou, un quatrième grand officier supérieur ; c'était le chef de la famille Chou qui était issue de Chou-hi frère cadet du duc Siuen (608-591); à l'époque de Confucius, le représentant de celte famille se nommait Chou Hoan

- Quant aux grands officiers inférieurs, la théorie aurait voulu qu'ils fussent cinq dans le pays de Lou ; mais ils paraissent avoir été plus nombreux. Confucius, lorsqu'il exerçait. des fonctions publiques dans le pays de Lou, était un des grands officiers inférieurs ; les autres grands officiers inférieurs étaient donc ses collègues et ses égaux, ce qui explique l'attitude qu'il prenait en leur parlant.

47.(21) Luen yu, X, 4.

47.(522) On franchissait successivement trois portes pour pénétrer dans le palais des ducs de Lou.

- La plus extérieure était la porte tche ;

cette porte était flanquée de deux tours ou observatoires appelés koan sur lesquels on pouvait monter, comme le prouve le début du chapitre $L i$ yun du $\underline{L i}$ ki ;

ces tours portaient aussi le nom de $k$ 'iue parce que, dit-on, c'est entre elles deux que se trouvait l'ouverture ( $k^{\prime}$ iue) par laquelle passait la route ;

un troisième nom de ces deux tours était siang wei; ce terme désigne proprement les textes écrits des lois et proclamations officielles (cf. Tso tchoan, $3^{\mathrm{e}}$ année du duc Ngai : " il ordonna de mettre à l'abri les textes des ordonnances officielles »), mais il fut appliqué aux tours de la porte parce que c'est contre ces tours qu'on suspendait les planchettes de bois sur lesquelles étaient écrites les ordonnances qu'on voulait rendre publiques; ces tours servaient ainsi à 
l'affichage officiel et prirent le nom des documents mêmes qu'on appliquait sur leurs murs.

- Après avoir franchi la porte $t c h e$, on devait traverser la porte $k^{\prime} o u$.

- Une troisième porte, de dimensions plus petites que les précédentes, ouvrait l'accès des bâtiments réservés aux usages privés du prince ; elle était appelée la porte lou, ou encore la porte $t$ ' 'in.

Quelle est celle de ces trois portes qui est désignée dans notre texte sous le nom de porte du duc? les érudits chinois dissertent à perte de vue sur cette question qui ne paraît pas susceptible de recevoir une solution définitive. Même, suivant certains critiques, le mot kōung devrait être considéré comme une superfétation qu'il faut retrancher du texte du Luen yu, et la porte dont il s'agit serait la porte du temple ancestral ; la raison qu'on en donne est que, dans un passage du $I$ li (section p'ing li; chap. XXIV, p. $22 \mathrm{v}^{\circ}$ ) qui offre la plus grande analogie avec ce texte du Luen yu, il est bien en effet question de la porte du temple ancestral ; voici ce passage du $I l i$ :

« Tenant en main la tablette, il entre par la porte (du temple) en pliant son corps comme s'il craignait de laisser échapper (cette tablette).

En d'autres termes, il porte cette tablette qui est très légère comme s'il pliait sous le poids d'un objet très lourd qu'il craint de laisser échapper.

47.(523) En marque de respect. L'expression [] signifiera « avoir une attitude respectueuse » et, par suite «être respectueux et attentif». C'est avec ce sens que cette expression apparaît souvent dans les textes historiques (cf. Mém. hist., chap. CVIII, dernière phrase; chap. CXXX, p. $11 \mathrm{v}^{\circ}$; Ts 'ien Han chou, chap. LXXIX, p. $5 \mathrm{v}^{\circ}$ ).

47.(524) Le Luen yu attribue cette démarche à Confucius dans deux occasions différentes :

- en premier lieu $(\mathrm{X}, 3)$ quand il était chargé de recevoir un prince étranger et qu'il venait du milieu de la salle jusqu'aux escaliers pour le saluer au nom de son souverain ;

— en second lieu $(\underline{\mathrm{X}, 4})$ quand il avait quitté la salle d'audience pour retourner à sa place et qu'il était arrivé au bas des escaliers.

D'après le texte tronqué de Se-ma Ts'ien, on pourrait croire que Confucius avait cette attitude en se rendant à la salle d'audience.

47.(525) Luen yu, X, 3.

47.(526) Se-ma Ts'ien écrit le mot [] que le Luen-yu écrit [b]. L'orthographe [a] est déclarée plus correcte par le Chouo wen. Ce mot désignait les fonctionnaires chargée de « recevoir les hôtes. » - Les commentateurs discutent longuement pour savoir si les hôtes que Confucius était chargé de recevoir étaient des princes ou s'ils étaient des hauts dignitaires ou des grands officiers ; ils arrivent à la conclusion que, en droit strict, le rang que Confucius occupait dans le pays du Lou ne lui permettait de recevoir que des grands officiers, mais que, en fait, sa profonde connaissance des rites put lui faire confier provisoirement la mission spéciale de recevoir des princes ; c'est de la même manière qu'il s'acquitta provisoirement des fonctions de conseiller dans le pays de Lou à l'époque où le véritable conseiller était Ki Hoan-tse (SHT $\mathrm{KK}$, chap. 918 , p. $3 \mathrm{r}^{\circ}$ et $\mathrm{v}^{\circ}$ ).

47.(527) Le caractère [] est ici un caractère emprunté qui est l'équivalent du caractère []. Ce dernier mot a le sens de « changer de couleur»; on l'explique aussi comme signifiant « avoir l'air animé », (S. H. T. K. K., chap. 1061, p. $\left.5 \mathrm{v}^{\circ}\right)$.

47.(르) Luen yu, X, 13.

47.(529) Cf. Li ki, chap. Yu tsao (trad. Couvreur, t. I, p. 705) : quand un officier était mandé par le prince, s'il était de service dans le palais il ne prenait pas le temps de mettre ses 
chaussures ; s'il était hors du palais, il n'attendait pas que sa voiture lût prête. - Mencius (V, b, 7, § 5): «Confucius, quand il était appelé par un ordre du prince, allait sans attendre que son char fût préf. » - Cf. aussi Mencius (II, b, 2, § 5).

47.(30) $\underline{\text { Luen yu }}, \mathrm{X}, 8$.

47.(31) Luen yu, X, 9.

47.(532) On voit que Se-ma Ts'ien fait se succéder immédiatement les deux phrases et qui offrent en effet un parallélisme rigoureux. La même connexion des deux phrases se retrouve dans Mo tse (chap. Fei jou), dans le Sin siu (chap. Tsie che), dans le Han che wai tchoan (chap. IX, p. $1 \mathrm{r}^{\circ}$ ) et dans le Chouo wen. Étant donné cet accord de ces quatre textes avec celui de Se-ma Ts'ien, il est probable que le texte du Luen yu (X, 8 et 9) a tort d'intercaler 70 mots entre ces deux phrases; on ne peut guère expliquer cette intercalation que par un désordre qui se serait introduit dans les fiches de bois sur lesquelles était écrit le manuscrit. du Luen yu ; telle est l'opinion exprimée par P'an Wei-tch'eng (S. H. T. K. K., chap. 918, p. 32 $\left.\mathrm{r}^{\circ}\right)$.

Le Luen yu mentionne encore dans un autre passage $(\underline{X, 13})$ l'habitude qu'avait Confucius de se conformer minutieusement aux rites en disposant régulièrement la natte sur laquelle il allait s'asseoir.

47.(3ㅡ) Luen yu, VII, 9.

47.(3ㄴ) Luen yu, IX, 9 et $\underline{\mathrm{X}, 16}$.

47.(35) Luen yu, VII, 21.

47.(36) Le texte du Luen yu gravé sur pierre à l'époque des T'ang donne la leçon []. Confucius en effet se compte au nombre des trois personnes dont il parle.

47.(537) Quand Confucius se trouvait avec deux autres personnes, si toutes deux approuvaient sa conduite, il y persévérait; si toutes deux la blâmaient, il se corrigeait. En d'autres termes, lorsque sur trois hommes deux sont d'un avis et un seul d'un autre avis, c'est l'opinion des deux premiers qui doit l'emporter ; c'est ce que prescrit le chapitre Hong fan du Chou king lorsqu'il s'agit de divination (cf. tome IV, n. 38.150). Dans le Tso tchoan (31 ${ }^{\mathrm{e}}$ année du duc Siang), Tse-tch'an, parlant des jugements que les gens du peuple portent sur ses actes politiques, dit : «Ce qu'ils trouvent bien, je le ferai ; ce qu'ils trouvent mal, j’y renoncerai ; ils seront mes maîtres ».

47.(538) Luen yu, VII, 3.

47.(539) Le mot [] a le sens de « se transporter », et, par suite, « aller vers ». L'expression «se porter vers ce qui est juste », se retrouve ailleurs dans le Luen yu (XII, 10).

47.(540) Confucius était tourmenté à la pensée que ses enseignements devaient être défectueux puisqu'ils ne parvenaient pas à détourner les hommes d'une conduite condamnable.

47.(41) Luen yu, VII, 31.

47.(542) Luen yu, VII, 20.

47.(543) Voyez dans le Luen yu $(\mathrm{XIV}, 6)$ un cas où Confucius garda le silence lorsqu'on l'interrogeait sur des hommes doués de force et d'habileté.

47.(ㄴ4) Cf. $\underline{\text { Luen } y u}, \mathrm{XI}, 11$.

47.(ㄴ5) Luen yu, V, 12.

47.(546) Lieou Pao-nan (S. H. T. K. K., chap. 1056, p. $14 \mathrm{r}^{\circ}$ et $\mathrm{v}^{\circ}$ ) soutient avec beaucoup d'ingéniosité que, par le terme [], il faut entendre ici les travaux de Confucius sur le Che king, le Chou king, les Rites et la Musique ; c'était là la partie de son œuvre qui était la plus intelligible pour ses disciples. Quant au terme «voie céleste» il désigne les présages 
favorables ou néfastes et la théorie du yin et du yang; il se rapporterait ici à la recension que Confucius fit du I king; de même, le terme «la nature», désignerait la nature ou voie humaine et il serait fait allusion ici au Tch'oen ts'ieou. Tse kong déclare donc que les enseignements donnés par Confucius dans le I king, et le Tch'oen-ts'ieou étaient ce qu'il y avait de plus difficile à comprendre dans son œuvre.

- Le Luen yu donne la leçon [], qui a été interprétée à l'époque des Han, notamment dans le Heou Han chou (cf. S. H. T. K. K., chap. 1056, p. $15 \mathrm{v}^{\circ}$ ) comme signifiant « la conformité de la nature humaine avec le ciel»; mais la leçon de Se-ma Ts'ien prouve que ce sens doit être rejeté et qu'il faut séparer d'un côté « la voie céleste », et de l'autre « la nature humaine », à laquelle Se-ma Ts'ien ajoute « la destinée».

47.(547) Luen yu, IX, 10.

47.(4ㅛ) Luen yu, IX, 2.

47.(549) Le mot [], que je traduis par a canton» désigne une petite circonscription administrative comprenant cinq cents familles. On ne sait pas où se trouvait le canton de Ta-hiang.

- Le Luen yu ne parle que d'un homme du canton de Ta-Hiang; c'est Se-ma Ts'ien qui indique que cette personne était un jeune garçon; quelques commentateurs identifient ce jeune garçon avec Hiang T'o je dont il est dit, dans le Tchan kouo ts'e (section Ts'in yu) que, à l'âge de sept ans, il fut le maître de Confucius ; il faut entendre par là que ce jeune garçon, ayant fait naïvement la réflexion que Confucius devait être un homme bien admirable puisqu'il était d'une compétence universelle, le sage, par humilité, prit cet éloge pour une critique, et résolut de se spécialiser dans le plus modeste des arts libéraux, l'art de conduire un char ; on peut donc dire que cet enfant fut le maître de Confucius.

47.(550) Luen yu, IX, 6.

47.(551) Ce Lao paraît être celui qui est mentionné par Tchoang-tse sous le nom de [] (Legge, SBE, vol. XL, p. 121, n. 2). D'après le Kia yu (chap. ts'i che eul ti tse), "K'in Lao était un homme du pays de Wei. Son appellation était Tse-k'ai, ou encore Tchang ». Le Kou kin jen piao du Ts'ien Han chou (chap. XX, p. $51 \mathrm{v}^{\circ}$ ) mentionne aussi $K^{\prime}$ 'in Lao.

La critique moderne (S. H. T. K. K., chap. 917, p. $6 \mathrm{r}^{\circ}$, et chap. 1060, p. 9) a cependant établi que $K$ 'in Lao n'a jamais existé et que le personnage, d'ailleurs inconnu, appelé Lao n'a rien de commun avec le personnage appelé K'in Tchang qui apparaît dans Tchoang tse (Legge, SBE, vol. XXXIX, p. 250), dans le Tso tchoan (20 année du duc Tchao; Legge, C. C., vol. V, p. 682 b) et dans Mencius (VII, b, 37, § 4).

47.(552) Tso tchoan, $14^{\mathrm{e}}$ année du duc Ngai.

47.(553) Ta-ye était le nom d'une plaine marécageuse qu'on appelait aussi Kiu-ye; elle se trouvait, d'après le Kouo ti tche, à douze $l i$ à l'est de la sous-préfecture de Kiu ye (qui dépend aujourd'hui de la préf. de Ts'ao-tcheou, prov. de Chan-tong).

47.(554) D'après le récit qui se trouve dans le $K$ 'ong ts'ong ( $\$ 5$, $k i$ wen, à la fin), ce lin ne fut pas capturé vivant; le chasseur ne s'en empara qu'après l'avoir tué, et c'est ce qui explique la parole de Confucius que nous trouverons quelques lignes plus bas (cf. p. 417). Voici le récit du Kong ts'ong :

«Un certain Tch'ou-chang, conducteur de char au service de Chou-suen, étant allé couper du bois dans la campagne, prit un animal (étrange); personne ne connaissait (cet animal) : il pensa que c'était un mauvais présage et l'abandonna au carrefour des Cinq pères (cf. n. 114). Jan Yeou (= Jan K'ieou ou Tse-yeou) dit au Maître :

- (Cet animal) a un corps de daim et une protubérance charnue en forme de corne. Comment serait-ce un mauvais présage envoyé par le Ciel ? 
Le Maître lui demanda :

— Maintenant où se trouve-t-il ? Je veux aller le voir.

Il se mit aussitôt en route. Il dit à Kao Tch'ai qui lui servait de cocher :

- D'après ce que m'a dit (Jan) K'ieou, c'est certainement un lin.

Quand il fut arrivé et qu'il le vit, il reconnut que c'était effectivement (un lin). Yen Yen (= Tse-yeou) lui demanda :

- Parmi les êtres qui volent le plus honorable est le phénix, et parmi les êtres qui marchent le plus honorable est le lin, car il est difficile de les faire venir. Je me permets de vous demander à qui répond ce (lin) qui apparaît maintenant.

Le Maître lui répondit :

- Quand le Fils du Ciel répand sa vertu bienfaisante et qu'il s'apprête à produire le calme universel, alors le lin, le phénix, la tortue koei et le dragon en sont par avance l'heureux présage. Maintenant l'auguste dynastie Tcheou est près de sa fin et dans le monde il n'y a pas de souverain (digne de ce nom). Pour qui vient donc (ce lin)?

Il se mit alors à verser des larmes et dit :

- Je suis parmi les hommes ce que le lin est parmi les animaux. Maintenant, quand le lin apparaît, il est mort ; c'est la preuve que ma carrière est terminée.

Il chanta alors ceci :

«Au temps de T'ang (Yao) et de Yu (Choen), le lin et le phénix venaient se promener.

Maintenant puisque ce n'est pas l'époque qui leur convient, que puis-je demander?

O lin, ô lin, mon cœur est tourmenté.

47.(55) Le Tso tchoan ajoute ici la phrase : « et le donna au garde des forêts ».

47.(556) C'est-à-dire qu'on prit le corps du lin pour l'apporter au duc de Lou.

47.(5ㄱ) Luen yu, IX, 8.

47.(5ㅗ) Le texte du Luen yu (IX, 8) est conçu un peu différemment :

«Le Maître dit :

— L'oiseau fong (le phénix) ne vient pas ; le Ho ne produit pas le Tableau. C'en est fini de moi.

Les combinaisons numériques exprimées par des cercles blancs et des cercles noirs sur le Tableau porté par un cheval sorti du Fleuve et sur l'Écrit porté par une tortue sortie de la rivière $L o$ ont fait l'objet de spéculations innombrables en Chine ; Legge a résumé la théorie la plus généralement admise dans quelques pages de son introduction à la traduction du $I$ king (SBE, vol. XVI, p. 14-18). - Dans un article intitulé Cupmarks as an archaic form of Inscription (J. R. A. S., July 1903, p. 517-543), J. H. Rivett-Carnac a émis l'hypothèse (déjà acceptée par Terrien de Lacouperie dans Journ. Roy. As. Soc., 1885, p. 436) que les cercles du Tableau et de l'Écrit devaient être en réalité de ces cupules gravées sur le roc qui semblent avoir formé un système de notation rudimentaire aux époques préhistoriques.

On remarquera que le Tableau du Fleuve et l'Écrit du Lo, sont souvent, comme dans le texte de Se-ma Ts 'ien, mentionnés en compagnie l'un de l'autre ; tel est le cas dans l'appendice $H i$ ts'e du I king (SBE, vol. XVI, p. 374.). Cependant, on trouve aussi, comme dans le texte du Luen yu, le Tableau du Fleuve mentionné isolément ; c'est ainsi que le Chou king (chap. Kou 
ming ; Legge, C. C., vol. III, p. 554) parle du Tableau du Fleuve comme d'un joyau conservé avec divers objets en pierre de prix, ce qui semble autoriser la supposition que ce Tableau luimême était gravé sur une plaque de pierre ; le Li ki (chap. Li yun, trad. Couvreur, t. I, p. 536) dit : «Le Fleuve produisit le Tableau (porté par) un cheval».

Le sens de la parole de Confucius semble être celui-ci : le Ciel ne fait pas apparaître les merveilles qui signalent la venue d'un prince sage ; c'est la preuve que mes enseignements n'ont pas atteint leur but ; c'en est fini de moi, je n'ai plus qu'à me retirer.

47.(559) Luen yu, XI, 8.

47.(560) Yen Yuen ou Yen Hoei était le disciple favori de Confucius.

47.(561) Le sens le plus vraisemblable de cette phrase est celui-ci : Le Ciel avait fait naitre Yen. Yuen pour.qu'il fût l'assistant de Confucius; en le faisant disparaitre, il annonce que Confucius va bientôt mourir lui-même et n'a plus besoin désormais de son disciple fidèle. Cette interprétation est confirmée par la place que Se-ma $T s$ 'ien assigne à ce propos de Confucius qu'il intercale entre deux phrases prédisant toutes deux la mort prochaine $\mathrm{du}$ Maître.

47.(562) Il s'agit de la chasse à Ta-ye (cf. p. 415) qui eut lieu dans l'ouest du pays de Lou, comme l'indique expressément le texte du Tso tchoan ( $14^{\mathrm{e}}$ année du duc Ngai).

47. $(\underline{563})$ Nous avons déjà trouvé cette phrase dans le texte du K'ong ts'ong; cf. n. 554. Elle figure aussi dans le récit que fait le commentaire du Tch'oen-ts'ieou attribué à Kong-yang.

47.(6ㄴ) Luen yu, XIV, 37.

47.(565) Cette parole de Confucius est obscure; les commentateurs modernes l'expliquent en y voyant une allusion au Tch'oen-ts'ieou. Confucius dirait donc ceci : Personne ne m'a connu, puisque je n'ai point réussi a être investi des fonctions de conseiller d'un prince ; cependant je n'en veux ni au Ciel, ni aux hommes, car en réalité cela me permet d'être le directeur spirituel, non de mon époque seulement, mais de tous les âges à venir; en effet, dans le Tch'oen-ts'ieou, j'étudie en bas les affaires humaines, je pénètre en haut la conduite des rois et je fais un ouvrage si parfait, que le Ciel seul pourra en apprécier tout le mérite et connaître ce que je vaux.

Quelque artificielle que soit cette glose, on ne voit pas bien quel autre sens on pourrait attribuer aux paroles de Confucius.

47.(66) Luen yu, XVIII, 8.

47.(567) Dans Se-ma Ts'ien, ce texte fait immédiatement suite au précédent et doit être considéré comme la continuation des paroles de Confucius.

47.(568) Sur po $I$ et chou $T s ' i$, qui se laissèrent mourir de faim plutôt que d'approuver la substitution de la dynastie des Tcheou à celle des Yn, voyez le chap. LXI des Mémoires historiques.

47.(69) L'opinion la plus communément admise est que Lieou-hia est un nom de lieu, mais on ne sait où se trouvait cette localité.

D'après un autre texte du Luen Yu $(\mathrm{XV}, 13)$, Hoei était contemporain de Tsang Wen tchong dont le fils Tsang Siuen chou et le petit-fils Tsang Ou tchong sont mentionnés par le Tso-tchoan, le premier en 591, et le second en 552. On voit par là que Tsang Ou tchong et par suite Hoei de Lieou-hia, devaient vivre à la fin du VIIe siècle avant notre ère.

47.(570) Chao-lien est mentionné dans le $L i K i$ (chap. Tsa ki, $3^{\mathrm{e}}$ part., $\S 14$; trad. Couvreur, t. II, p. 162) en compagnie de Ta-lien; ils appartenaient, nous dit-on, à une tribu barbare de l'Est de la Chine, et cependant ils surent observer parfaitement les règles du deuil.

47.(571) Le Luen yu ajoute ici la phrase : 
« dans leurs paroles ils furent d'accord avec la raison; dans leurs actes, ils furent d'accord avec l'opinion (que les hommes se font de la sagesse). »

47.(572) Yu-tchong désigne le plus souvent Tchong-yong, frère cadet de T'ai-po de Ou (cf. cependant tome IV, ‥ 31.109 et n. 39.156).

47.(573) On ne sait rien de précis sur ce personnage.

47.(574) Je suis dans ma traduction le commentaire de Pao Hien ( $1^{\mathrm{e}}$ moitié du $1^{\mathrm{er}}$ siècle p. C.) qui explique le mot [a] comme ayant ici le sens de [b]. La phrase [ac] signifierait donc : ils ne parlèrent plus désormais (des affaires de ce monde). Il faut avouer cependant que le mot $[\mathrm{a}] \mathrm{a}$ en général une valeur toute contraire et que [ac] devrait signifier : ils donnèrent libre cours il leurs paroles. C'est ce dernier sens qu'adopte Legge (CC, vol. I, p. 201).

47.(575) En d'autres termes, Confucius se laisse guider par la seule justice et sa conduite n'est pas inflexible comme celles des personnes trop systématiques qu'il vient d'énumérer.

47.(576) Cette négation répétée exprime l'idée de Confucius qu'il ne faut pas que la mémoire d'un homme supérieur périsse après sa mort.

47.(577) Luen yu, XV, 19.

47.(578) L'homme supérieur ne recherche pas la réputation de son vivant; mais il désire avoir accompli une œuvre telle qu'il laisse après sa mort une gloire impérissable.

47.(579) [ab] Cf. t. I, Introduction, n. 175 ; t. III, n. 14.117 ; t. IV, n. 36.120. - Même après que Se-ma Ts'ien eut donné à son ouvrage le titre de [ab], ce terme continua à être employé dans le sens vague qu'il avait autrefois et cela induisit parfois les commentateurs en erreur. C'est ainsi que le chapitre Ou hing tche du Ts'ien Han chou mentionne souvent le Che ki et Yen Che-kou a cru qu'il s'agissait des Mémoires historiques de Se-ma Ts'ien; mais un examen plus attentif permet de reconnaître que le Che ki cité à diverses reprises par le $O u$ hing tche n'est autre que le Kouo yu (cf. Ts'ien Han chou, chap. XXVII, b, $1^{\mathrm{e}}$ partie, notes critiques de l'édition de K'ien-long).

47.(580) Se-ma Ts'ien emploie ici le mot []. Nous avons vu qu'il se sert ailleurs du mot [] qui impliquerait plutôt l'idée d'un simple arrangement chronologique de documents préexistants. Cf. t. III, p. 18, n. 6.

47.(581) Les mots [ab] signifient proprement "printemps et automne»; ils ont le sens métaphorique de «années » parce que les noms de deux saisons ont été pris pour désigner l'année tout entière avec ses quatre saisons ; c'est de la même manière que les deux mots, qui signifient proprement « Est et Ouest » désignent les « objets » en général, c'est-à-dire tout ce qui se trouve dans les quatre directions de l'espace.

On rencontre fréquemment dans les historiens chinois l'expression [ab] employée pour exprimer en années l'âge d'un homme.

On voit donc comment cette même expression a pu arriver à signifier « Annales », ce qui est la vraie traduction du titre de l'ouvrage attribué à Confucius. Cf. Legge, C. C. vol. V, prolég., p. 7.

47.(582) Quoique la phrase soit obscure, je crois que le sens que je propose rend bien compte de la suite des idées. Se-ma Ts'ien a commencé par dire que le Tch'oen-ts'ieou est une chronique des règnes de douze ducs de Lou; cependant on y trouve aussi relatés des faits qui se rapportent à la dynastie des Tcheou ou même parfois aux deux dynasties plus anciennes des $H i a$ et des $Y n$; si Confucius put ainsi donner à son ouvrage plus d'extension qu'il ne semblait devoir en comporter, c'est parce que la parenté qui unissait la lignée des princes de Lou à celle des rois de la dynastie Tcheou l'y autorisait. Le commentaire que Se-ma Tcheng donne de la phrase [...] rend inintelligible le mot [] qui commence la phrase suivante. Legge, qui a tenu compte en quelque mesure de cette glose dans la traduction qu'il a faite de ce passage (Chinese classics, vol. V, prolég., p. 14), aboutit à l'interprétation fort peu satisfaisante que 
voici : «He kept close in it to (the annale of) Loo, showed hie affection for Chow, and purposely made the three dynasties move before the reader. »

- Une autre explication nous est suggérée par le critique moderne Lieou Pao-nan (S. H. T. K. $K$., chap. 1070 , p. $6 \mathrm{v}^{\circ}$ et $7 \mathrm{r}^{\circ}$ ). Le sens serait alors que Confucius, en écrivant le Tch'oen-ts'ieou, voulut « s'appuyer sur Lou pour en faire un nouveau Tcheou et y transporter les principes des trois dynasties. » En d'autres.termes, Confucius, qui avait eu autrefois l'idée de se mettre au service du rebelle Kong-chan Pou-nieou pour faire de sa ville la capitale d'un nouveau Tcheou oriental (cf. n. 212), aurait conçu un projet analogue au sujet de la principauté de Lou qu'il espérait pouvoir transformer en un nouveau Tcheou et égaler aux trois premières dynasties, Hia, Yn, Tcheou.

47.(583) Comme on le voit, Se-ma Ts'ien affirme que les termes dont se sert Confucius cachent des intentions profondes et il va donner la preuve de son dire.

47.(8ㄴ) Cf. tome I, n. 04.477 et 04.478 .

47.(585) Cette phrase et les deux suivantes sont un jugement général sur la valeur du Tch'oen-ts'ieou: à n'importe quelle époque, si on étudie de près le style de ce livre, on y trouvera des directions pour le temps où l'on vit; à n'importe quelle époque, un souverain, s'il est sage, comprendra le sens des réticences ou des expressions du Tchoen-ts'ieou et en fera son profit ; à n'importe quelle époque, si ce sens véritable est présent à l'esprit de tous, les fauteurs de rébellion et de mal seront saisis de crainte.

47.(866) Des deux exemples cités plus haut par Se-ma Ts'ien, l'un concerne un abaissement (le titre de vicomte étant substitué à celui de roi) ; l'autre montre une suppression ou réticence (Confucius passe sous silence le fait que le Fils du Ciel fut sommé de venir à Tsien-t'ou).

47.(587) Mencius (III, b, 9, § 11) dit :

«Quand K'ong-tse eut achevé le Tch'oen-ts'ieou, les sujets rebelles et les malfaiteurs furent saisis de crainte. »

47.(588) Pou Chang, dont l'appellation était Tse-hia, est un disciple de Confucius connu pour sa grande érudition.

D'après Legge (C. C., vol. V, Prolégomènes, p. 14), les mots [] signifieraient « les disciples de Tse-hia »; je crois qu'ils signifient : « les gens tels que Tse-hia », c'est-à-dire : Tse-hia et les autres personnes érudites comme lui.

Dans une glose de Siu Yen (fin de la dynastie T'ang) au commentaire du Tch'oen ts'ieou attribué à Kong-yang, on relève $\left(12^{\mathrm{e}}\right.$ année du duc Tchao $)$ une citation ainsi conçue de l'ouvrage intitulé Tch'oen ts'ieou chouo:

«K'ong-tse composa le Tchoen-ts-ieou en 18.000 mots; il l'écrivit en neuf mois. Quand il fut terminé, il le remit aux personnes telles que Yeou (= Yen Yen) et Hia (= Pou Chang); Yeou, Hia et les autres ne purent y changer un seul mot.

47. (589) Mencius (III, b, 9, § 8)

47.(590) D'après Lieou Hi (auteur du Che ming; Cf. Watters, Essays on the Chinese language, p. 35), cette phrase signifierait que : ceux qui rendront justice à Confucius seront les souverains qui suivent les excellents exemples de Yao et de Choen, tandis que ceux qui le condamneront seront ceux qui, étant rois ou ducs, se verront censurés par le Tch'oen-ts'ieou. - Cette explication me paraît moins extraordinaire qu'à Legge $(C$. C., vol. V, prol., p. 14, n. 3 ), et, pour ma part, je la trouve plausible.

47.(591) Le che kia de Wei (cf. t. IV, p. 209) semble rapporter la mort de Tse-lou à l'année 481 ; mais la date de 480 est confirmée par le Supplément au Tso tchoan $\left(15^{\mathrm{e}}\right.$ année du duc Ngai). 
47.(592) Li ki, chap. T'an kong. [trad. Couvreur, t. I, p. 144]

47.(593) Le Kia yu (§ 40) et le Li ki (chap. T'an kong) donnent la leçon « les mains derrière le dos et traînant son bâton »; cf. Legge C. C., vol. I, Prolégomènes, p. 87, [css : édition/rechercher : 'dragging']. et SBE, vol. XXVII ; p. 138. - Je dois dire que l'attitude indiquée par Se-ma Ts 'ien me paraît bien plus vraisemblable.

47.(594) Cette phrase est reportée plus loin par le Kia yu (§ 40 et par le Li ki (chap. T'an kong).

47.(595) Confucius compare sa mort prochaine à l'écroulement de la plus importante de toutes les montagnes ou à l'effondrement de la maîtresse poutre sur laquelle repose la charpente entière d'un édifice.

47.(596) Dans le Li ki (chap. T'an kong), cette phrase est placée plus loin et prend la forme suivante :

«Aucun souverain intelligent n'est apparu;.dans le monde y a-t-il quelqu'un qui ait été capable de me prendre pour maître ?

47.(597) La plate-forme placée devant la salle principale était abritée par un toit que supportaient deux colonnes; on y accédait par deux escaliers, l'un placé à l'Est, l'autre à l'Ouest. Le maître de la maison se servait de l'escalier oriental; le visiteur, de l'escalier occidental. Les rites des Hia supposaient que le mort était encore considéré comme le maitre de la maison; au contraire, les rites des Tcheou le traitaient comme un visiteur; les rites des $Y n$ lui assignaient un rang intermédiaire entre celui de maître de la maison et celui de visiteur.

Sur la coutume de disposer le cercueil dans la maison pendant un temps plus ou moins long, voyez De Groot, Religious system of China, Book I, p. 363 et suiv.

47.(598) On a vu plus haut (note 104) que la généalogie de Confucius se rattachait à la famille princière de Song qui elle-même passait pour descendre de l'antique dynastie Yn.

47.(99) Le jour ki-tch'eou était le onzième du quatrième mois (cf. la dissertation de K'ong Kouang-mou dans S. H. T. K. K., chap. 1415 , p. $15 \mathrm{r}^{\circ}$ et $\mathrm{v}^{\circ}$ ). Les indications de Se-ma Ts'ien au sujet de la naissance et de la mort de Confucius concordent parfaitement entre elles, car si Confucius naquit la $22^{\mathrm{e}}$ année (551) du duc Siang et s'il mourut la $16^{\mathrm{e}}$ année (479) du duc Ngai, il est bien exact de dire qu'il mourut à l'âge de 73 ans, suivant la manière chinoise de compter les années.

Il faut considérer comme fautive la note de Se-ma Tcheng qui prétend que si Confucius était né la $22^{\mathrm{e}}$ année du duc Siang, il était âgé de 72 ans (et non de 73) lorsqu'il mourut.

Les auteurs qui, comme Kiang Yong (H. T. K. K., chap. 261) admettent avec Kong-yang et Kouleang que Confucius naquit la $21^{\mathrm{e}}$ année du duc Siang (552), font mourir Confucius à 74 ans ; mais nous avons vu (note 109) que la divergence des opinions sur la date de la naissance de Confucius était purement formelle.

47.(000) Tso tchoan, $16^{\mathrm{e}}$ année du duc Ngai.

47.(601) Cet éloge est reproduit dans le $L i k i$, chap. T'an kong ( $1^{\mathrm{e}}$ partie, section 3, article 44 ; trad. Couvreur, t. I, p. 186-187) et dans le Kia yu (§ 40.)

47.(602) Le vieillard dont il est ici question est Confucius.

47.(603) Cette phrase est tirée du Che king (Siao ya, livre IV, ode 9, str. 6) ; mais au lieu de [], le duc Ngai dit [], ce qui est une expression synonyme, puisque le Fils du Ciel seul avait le droit de s'appeler "l'homme unique ». C'est peut-être la réminiscence du texte du Che king qui a amené le duc Ngai à s'arroger ici un titre auquel il ne pouvait prétendre, comme va le faire remarquer Tse-kong quelques lignes plus bas.

47.(604) Tchong-ni ou Confucius. 
47.(605) Tse-kong va montrer que les paroles prononcées par le duc Ngai présentent deux fautes graves; il en conclut que ce prince se conduira mal dans d'autres occasions et que, par conséquent, il ne pourra pas terminer tranquillement ses jours dans le pays de Lou. - En l'année 468, le duc Ngai fut en effet obligé de se réfugier dans le pays de Yue et c'est là qu'il dut mourir si la prédiction de Tse-kong est correcte (cf. Legge, C. C., Vol.. V, p. 861, b) ; cependant Se-ma Ts'ien, dans le che kia de Lou (t. IV, p. 129) donne à entendre que le duc Ngai put encore revenir dans le pays de Lou pour y mourir.

47. $(\underline{606})$ Cf. n. 603.

47.(607) La sépulture de Confucius se trouve dans l'endroit qu'on appelle aujourd'hui le Kong lin à 2 li au nord de la sous-préfecture de K'iu-feou (l'ancienne capitale du royaume de Lou); un mur d'enceinte de plusieurs $l i$ enclôt le terrain au milieu duquel elle est placée ; ce terrain est adossé à la rivière $S e$ et fait face à la rivière Tchou; la tombe elle-même est haute de 15 pieds; à une dizaine de pas à l'est, on voit la tombe de Po-yu, fils de Confucius; à une dizaine de pas au sud, est la tombe de Tse-se (=Yuen Hien, disciple de Confucius). Ces renseignements sont extraits du Ta Ts'ing i tong tche, chap. CXXX, p. $6 \mathrm{r}^{\circ}$.

- Le Hoang lan, ouvrage composé, semble-t-il, par Wang Siang à l'époque des Wei (220-264), nous a laissé une description assez détaillée de la sépulture de Confucius, description qui est citée dans les commentaires de Se-ma Ts'ien; on y relève cette indication que le terrain où se trouvait la sépulture était ombragé par une centaine d'arbres qui étaient tous d'essences différentes; la tradition voulait que ces arbres eussent été plantés par les disciples de Confucius, chacun d'eux ayant apporté un spécimen des arbres propres à la région d'où il était originaire.

47.(608) Ce témoignage semble prouver que les disciples ne suivirent pas l'avis de Tse-kong tel que le rapporte le Li ki (T'an kong, part. I, section 2, § 21 ; trad. Couvreur, t. I, p. 146) ; d'après le $L i k i$, en effet, Tse-kong fit observer que Confucius lui-même avait été en deuil de ses disciples Yen Yuen et Tse-lou comme s'ils eussent été ses fils, mais qu'il n'avait pas porté les vêtements de deuil ; Tse-kong proposa donc que les disciples de Confucius fussent en deuil de lui comme s'ils avaient perdu leur père, mais qu'ils ne portassent pas les vêtements de deuil. Ils se seraient donc bornés au deuil de cœur dont parle Se-ma Ts'ien lui-même lorsqu'il dit : «Au bout de trois ans, leur deuil de cœur étant terminé... ».

47.(609) Quoique n'étant pas très explicite, cette phrase donne à entendre que pendant les trois années de deuil, les disciples restèrent groupés auprès de la tombe de leur maître. C'est d'ailleurs ce que dit expressément le Kia yu $(\S 40)$ : «Les disciples demeurèrent tous auprès de la tombe $»$.

- Sur la coutume de passer les trois années de deuil, ou même un temps plus long, auprès de la tombe d'un mort, voyez De Groot, The religious system of China, Book I, p. 794 et suiv. De nos jours encore on peut relever en Chine quelques vestiges de cet ancien usage ; voyez dans la Gazette de Péking, trad. anglaise, 31 mai 1872, l'histoire d'un fils qui séjourne depuis huit ans à côté de la tombe de sa mère.

47.(610) Le Kia yu (§ 40) dit: "Quand le deuil de trois ans fut terminé, les une restèrent, les autres partirent. »

47.(611) Au lieu de «demeura dans une hutte sur le tertre de la tombe », le Kia yu (§ 40) écrit: "demeura dans une hutte auprès de la tombe». Cette seconde leçon est plus admissible, car les rites interdisaient de monter sur le tumulus.

47.(612) Tse-kong (= Toan-mou Se), après être resté près de la tombe de son maître pendant la période du deuil réglementaire de trois ans, séjourna là pendant encore trois autres années.

- Mencius (III, a, 4, § 16) nous dit :

«Autrefois, après la mort de Confucius, quand les trois années (de deuil) furent passées, ses disciples préparèrent leurs bagages et se disposèrent à retourner 
chez eux..Quand ils entrèrent pour saluer Tse-kong, ils s'entreregardèrent et se mirent à se lamenter jusqu'à en perdre tous la voix. Puis ils s'en retournèrent chez eux. Tse-kong revint se bâtir une habitation sur l'esplanade (qui était auprès de la tombe) et passa là seul trois années avant de s'en retourner chez lui.

47.(ㅌ13) Même témoignage à la fin du § 40 du Kia yu.

47.(614) Un k'ing vaut cent meou ou arpents; c'est une mesure de superficie assez considérable; elle évalue ici les dimensions de tout le terrain clos par une enceinte au milieu duquel se trouvait la tombe.

47.(615) J'accepte l'ingénieuse correction de texte proposée par Fang Pao qui propose d'intervertir l'ordre des caractères. La salle où demeurèrent autrefois les disciples est sans doute celle dans laquelle ils séjournèrent pendant les trois années du deuil.

47. (616) Ce fait est rapporté dans le Ts 'ien Han chou (chap. I, b, p. $8 \mathrm{v}^{\circ}$ ) à la date du onzième mois de la douzième et dernière année du règne de l'empereur $\mathrm{Kao}$, fondateur de la dynastie Han.

Sur le groupe de trois victimes (suovetaurilia) qui comprenait un bœuf, un mouton et un porc, cf. tome IV, n. 31.206 .

47.(617) Se-ma Ts 'ien dit que c'est une coutume constante sous la dynastie Han que, lorsqu'un nouveau seigneur reçoit en fief le pays de Lou, ou que, lorsqu'un fonctionnaire est envoyé dans ce pays en qualité de haut dignitaire ou de conseiller, ils aillent rendre hommage à la tombe de Confucius avant d'exercer leurs fonctions.

47.(618) D'après le Kia yu (§ 39), Confucius nomma son fils $L i$ « carpe » et lui donna l'appellation de $P o-y u$ « l'aîné Poisson », parce que, au moment de la naissance de cet enfant, le duc Tchao, de Lou, lui avait fait présent d'une carpe. Ce fils de Confucius est mentionné à trois reprises dans le Luen yu (XI, 7 ; XVI, 13 ; XVII, 10). Un de ces trois passages du Luen yu (XI, 7) semble admettre que Po-yu mourut avant le disciple Yen Hoei; la chose n'est pas impossible, puisque Yen Hoei paraît être mort en 481 (cf. p. 417) ; à cette date Confucius était âgé de 71 ans (à la chinoise); il pouvait donc, s'il s'est marié comme le dit le Kia yu à 19 ans, avoir perdu un fils qui, en 483, c'est-à-dire avant la mort de Yen Hoei, aurait été âgé de 50 ans. D'après une autre interprétation, le texte du Luen yu ne ferait que supposer la mort de Ро yu.

Confucius, parlant de son fils qui était encore vivant, indiquerait comment, à supposer qu'il fût mort, lui Confucius aurait agi ; pour justifier cette explication, on fait remarquer que, dans ce texte, Confucius appelle son fils par son nom personnel $L i$, ce qui eût été interdit par les rites s'il se fût agi d'une personne réellement morte. Mais cette règle rituelle est contestable quand il s'agit d'un père parlant de son fils.

47.(619) Tse-se est souvent cité par Mencius (II, b, $11 ; \underline{\mathrm{IV}, \mathrm{b}, 31} ; \underline{\mathrm{V}, \mathrm{b}, 3} ; \mathrm{V}, \mathrm{b}, 6$; $\mathrm{V}, \mathrm{b}, 7$; VI. $b, 6)$ qui, en quatre occasions différentes affirme qu'il fut à la cour du duc Mou, de Ts'in, et même (VI, b, 6) qu'il y eut la charge de ministre, Mais le duc Mou ne monta sur le trône qu'en l'année 407 et nous avons vu, d'autre part, que Po yu, père de Tse-se, dut mourir en 481 ou 480 ; le témoignage de Se-ma Ts'ien, quand il nous dit que Tse-se mourut à 62 ans nous apparaît donc comme erroné. Certains critiques ont supposé que le texte de Se-ma Ts 'ien avait été altéré, et qu'au lieu de 62, il fallait lire 82 ; si Tse-se était né peu avant la mort de son père, soit par exemple en 479, il aurait été âgé, en 407, de 73 ans (à la chinoise) et aurait donc pu être au service du duc Mou.

On peut encore imaginer d'autres combinaisons qui ne sont guère moins arbitraires; Cf. Legge, C. C., vol. I, Prolégomènes., p. 37 [css : édition/rechercher : 'Li himself'], notes 5, 6, 7.

D'après un passage du Li ki (chap. T'an kong, $1^{\mathrm{e}}$ partie, section $1, \S 4$ : trad. Couvreur, t. I, p. 111-112), Tse-se aurait répudié sa femme, suivant en cela l'exemple que lui avait donné Confucius lui-même; mais la valeur de ce témoignage est contestable. Cf. Legge, S. B. E., vol. 


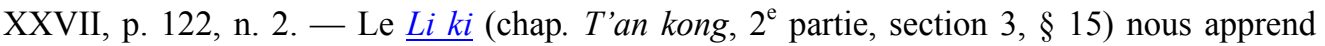
aussi que la mère de $T s e-s e$, femme de $P_{o-y u}$, se remaria après la mort de Po-yu. Cf. Legge, S. B. E., vol. XXVII, p. 194.

47.(20) D'après une note qui se trouve en tête du Tchong yong dans l'édition intitulée Sin ts'eng se chou pou tchou fou k'ao pei tche, on voit à quels événements il est fait ici allusion :lorsque Tse-se était âgé de 16 ans, il se rendit dans le pays de Song; à la suite d'une discussion trop animée avec le grand officier Yo Cho, celui-ci le fit arrêter; Tse-se ne fut délivré que par l'intervention du prince de Song en personne.

47.(621) Les critiques chinois s'accordent à reconnaître que ce témoignage est exact et que le Tchong yong est bien l'œuvre de Tse-se.

47.(22) Au lieu de Tse-king, le Ts'ien Han chou (chap. LXXXI, p. $7 \mathrm{v}^{\circ}$ ) écrit Tse-tchen.

47. $(\underline{623})$ Le Ts 'ien Han chou (chap. LXXXI, p. $7 \mathrm{v}^{\circ}$ ) appelle ce personnage Choen. C'est sous ce dernier nom qu'il figure dans les paragraphes 14-16 du Kong ts'ong tse ; une note de cet ouvrage ( $\$ 14$, au début) nous apprend que son nom personnel était $O u$ et que son appellation était Tse-choen. Il fut conseiller du roi Ngan-hi (276-243), de Wei, vers la fin du règne de ce prince.

47.(624) Kong Fou apparaît sous ce nom dans le chap. LXXXI, p. 7 vº du Ts'ien Han chou ; mais, dans le chap. LXXXVIII, p. $1 \mathrm{v}^{\circ}$, du même ouvrage, il est nommé $K^{\prime}$ ong Kia. On lui attribue la paternité du $K^{\prime}$ 'ong $t s^{\prime}$ 'ong $t s e$; il est fort douteux cependant que le livre que nous possédons aujourd'hui sous ce titre (incorporé dans le Han Wei ts'ong chou) soit bien celui qu'il avait écrit. Le Kong ts'ong tse (§ 17) lui-même nous donne d'assez longs détails sur $K$ 'ong Fou qu'il désigne souvent par son appellation $T s e-y u$; il nous raconte notamment dans quelles circonstances il se rattacha au parti de Tch'en Che.

- Le Song che (chap. CCII, p. $11 \mathrm{r}^{\circ}$ ) attribue à K'ong Fou la composition du Siao eul ya (sur cet ouvrage, voyez Watters, Essays on the Chinese language, p. 28). Mais le Siao eul ya est mentionné dans les chapitres sur l'histoire littéraire, dans le Ts 'ien Han chou, le Soei chou et les deux T'ang chou, sans que le nom de Kong Fou soit indiqué ; il semble que, à l'époque des cinq.petites dynasties (907-960), le Siao eul ya qui avait été jusqu'alors un. ouvrage anonyme, ait été introduit dans le Kong ts'ong tse qui fut alors reconstitué de toutes pièces avec des débris antiques recueillis de tous côtés; c'est du Kong ts'ong tse que les lettrés de l'époque des Song tirèrent de nouveau le Siao eul ya pour en faire un ouvrage à part, et, comme le Kong ts'ong tse passait pour avoir été composé par Kong Fou, Kong Fou fut dès ce moment regardé comme ayant écrit le Siao eul ya (cf. S. H. T. K. K., chap. CCCCX, p. $2 \mathrm{v}^{\circ}$ et suiv.).

47.(25) Sur Tch'en Che, voyez le chap. XLVIII des Mém. hist.

47.(626) Le Ts'ien Han chou écrit (chap. LXXXVIII, p. $1 \mathrm{v}^{\circ}$ : « en définitive, il (K'ong Kia) mourut en même temps que lui (Tch'en Che). »— Tch'en Che périt dans le mois de janvier de l'année 208 av. J.-C.

47.(627) D'après une tradition qui est rapportée dans la préface au Kong $t$ s'ong tse (édition du Han Wei ts'ong chou), lors de la proscription des livres par Ts'in Che hoang ti, Tse-siang aurait aidé son frère aîné Kong Fou à cacher un certain nombre de livres prohibés dans une muraille.

47.(2ㅇ) Le Ts'ien Han chou (chap LXXXVI, p. 7 v) écrit : «précepteur (du roi) de Tch'ang cha.» Cette seconde leçon est plus correcte, car, à l'époque de l'empereur Hiao-hoei, le territoire de Tch'ang-cha formait, non une commanderie dirigée par un gouverneur, mais un royaume à la tête duquel était un descendant de Ou Joei (cf. t. III, p. 105).

47.(629) On retrouve chez ce personnage la haute stature qui a déjà été signalée lorsqu'il a été question de Confucius lui-même et de son père (cf. n. 136). 
47.(630) Le Ts'ien Han chou (chap. LXXXI, p. 7 v) dit : «Siang engendra Tchong; Tchong engendra $\mathrm{Ou}$ et Ngan-kouo; Ou engendra Yen-nien. » Mais, comme le fait remarquer le commentateur Song K'i (998-1061), deux éditions du Ts 'ien Han chou présentent la variante suivante : «Siang engendra Tchong-ou et Ngan-kouo ; Tchong-ou engendra Yen-nien. » Il me paraît difficile de déterminer laquelle de ces trois généalogies (à savoir celle de Se-ma Ts 'ien, celle du Ts 'ien Han chou et celle de la variante de ce dernier ouvrage) est exacte.

47.(631) Le Ts'ien Han chou (chap. LXXXI, p. $7 \mathrm{v}^{\circ}$ ) expose quels furent les descendants de K'ong Yen-nien : il engendra $\mathrm{Pa}$ dont l'appellation fut $T s^{\prime}$ 'e-jou; $\mathrm{Pa}$ engendra Koang dont l'appellation fut Tse-hia. Ce K'ong Koang, qui vécut de 65 av. J.-C. à 5 ap. J-C., est l'objet d'une monographie dans le Ts'ien Han chou (chap. LXXXI, p. 7 v -11 r ${ }^{\circ}$ ).

47.(632) Le Lin-hoai était une commanderie dans le nord-est de la province actuelle de Ngan-hoei ; cf. t. II, p. 537. Dans le chap. CXXI, p. 3 ro, Se-ma Ts'ien dit encore une fois que K'ong Ngan-kouo fut gouverneur de Lin-hoai.

47.(3ㅗ) Le Ts'ien Han chou (chap. LXXXVIII, p. 7 r ${ }^{\circ}$ ) nous apprend que K'ong Ngan-kouo fut impliqué dans l'affaire des sortilèges qui éclata en 91 av. J-C. C'est donc sans doute alors que K'ong Ngan-kouo fut mis à mort. Puisque Se-ma Ts'ien parle de la mort de K'ong Ngankouo survenue en 91, et que, d'autre part, il désigne ici par le terme de «l'empereur actuel» l'empereur $O u$ qui mourut le 15 avril 87, nous voyons qu'il dut rédiger cette partie de son grand ouvrage historique dans les trois années comprises entre ces deux dates. - Sur K'ong

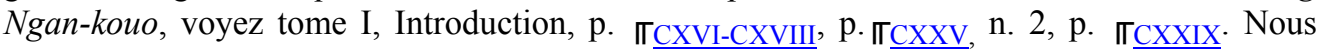
aurons à parler plus longuement de ce personnage dans nos notes au chap. CXXI des Mémoires historiques.

47.(634) Ces deux vers sont tirés du Che king (Siao ya, livre VII, ode 4, str. 5). Ils sont cités ici avec le sens qui leur est attribué dans le chap. Piao ki du Li ki (trad. Couvreur, t. II, p. 489, et trad. Legge, S. B. E., vol. XXVIII, p. 335) où ils sont expliqués comme indiquant l'effort constant que fait le sage pour aller toujours droit en avant sur le chemin de la vertu.

47.(635) C'est-à-dire que Confucius, quoique déçu dans ses espérances de faire triompher sa doctrine, persista cependant jusqu'à la fin de sa vie à tendre vers l'idéal qu'il savait être irréalisable. - Je modifie ici l'interprétation de ce passage que j'ai donnée dans l'Introduction du tome I, p. L.

47.(636) On a vu plus haut (p. 429) que les vêtements et le char de Confucius étaient conservés dans le temple funéraire qui lui avait été consacré.

47.(637) Quoi qu'étant un simple particulier.

47.(638) K'ong Ngan-kouo, qui était le contemporain de Se-ma Ts'ien, était le descendant de Confucius à la onzième génération. 


\section{NOTE ADDITIONNELLE}

\section{7.(639) Cf. t. I, Introduction, p. XLIX-LI.}

47.(낭) Cf. n. 119.

47.(641) Cf. n. 230.

47.(42) Cf. p. 310 , p. 312 et p. 340.

47.(녀) $)$. Cf. p. 412.

47.(644) Cf. n. 200.

47.(645) Cf. p. 307.

47.(466) Cf. p. 300 .

47.(647) Cf. n. 141.

47.(4ㅇ) Cf. p. 349.

47.(649) On trouvera la plupart de ces textes groupés par ordre de matières dans le K'ong-tse tsi yu publié en 1816 par Suen Sing-yen (1752-1818); cet ouvrage ne comprend pas moins de 17 chapitres.

47.(650) Le Kia yu a été partiellement et d'ailleurs assez mal traduit d'abord par le Rev. A. B. Hutchinson sous le titre The family sayings of Confucius (Chinese Recorder, vol. IX, 1878, X, 1879, et XI, 1880) puis par Mgr. De Harlez sous le titre The familiar Sayings of Kong-fu tze (Babylonian and oriental Record, vol. VI, 1893, et VII, 1894).

47.(651) Cf. p. 343 , et p. 423.

47.(652) Parmi les travaux de l'exégèse du XIXe siècle, ceux dont j'ai fait le plus fréquent usage sont le Luen yu kou tchou tsi tsien (S. H. T. K. K., chap. 909-928) de P'an Weitch'eng (sans date) et le Luen yu tcheng $i$ (S. H. T. K. K., chap. 1051-1074) que Lieou Pao-nan laissa inachevé à sa mort survenue en 1855, et que son fils Lieou Kong-mien termina et publia en 1866.

47.(ㄷ3) Cf. n. 439.

47. $(\underline{654})$ Cf. n. 401.

47.(655) Le Ts'ien Han chou (chap. XXX, p. $6 v^{\circ}$ ) mentionne le texte antique du Luen yu en 21 chapitres, et il ajoute :

«(Ce texte) fut tiré d'un mur (de la maison de) K'ong-tse; il divise en deux (le chapitre) Tse tchang.

Cette dernière indication nous explique pourquoi le texte antique comprenait 21 chapitres, c'est-à-dire 1 chapitre de plus que le Luen yu actuel. Il semble cependant résulter du témoignage de Se-ma Ts'ien que le texte antique ne se bornait pas à dédoubler le chapitre 19 du Luen yu, mais qu'en outre il devait comprendre toute une partie contenant le signalement des disciples, partie qui faisait défaut dans le Luen yu traditionnel.

47.(656) Cf. Ts'ien Han chou, chap. LXXXVIII, p. 7 ro. C'est à propos des travaux de Kong Ngan-kouo sur le texte antique du Chou king qu'on nous dit que Se-ma Ts'ien prit auprès de lui ses informations; mais il paraît légitime d'admettre que Se-ma Ts'ien s'initia aussi au texte antique du Luen yu en se mettant à l'école de K'ong Nga.n-kouo. (aj. Mao-ts'ai

47.(657) C'est l'avis qu'exprime Tsang Lin (app. Mao-ts'ai; fin du XVIIe siècle) dans son King i tsa $k i$; il dit en effet (H. T. K. K., chap. 195, p. $\left.22 \mathrm{r}^{\circ}\right)$ : 
« Dans les Mémoires historiques, le che kia de K'ong-tse et la monographie sur les disciples de Tchong-ni, ainsi que le Chouo wen de Hiu (Chen) s'inspirent tous du texte antique du Luen yu.

C'est aussi la thèse que soutient Chen T'ao (app. Si-yong) dans la préface à l'ouvrage qu'il publia en 1821 (S. H. T. K. K., chap. 627-628) pour démontrer que le commentaire du Luen yu attribué à K'ong Ngan-kouo a été imaginé par Ho Yen (app. Ping-chou, $3^{\mathrm{e}}$ siècle ap. J-C) ; ce dernier aurait eu recours à cet artifice afin de donner plus de poids aux arguments par lesquels il se proposait de combattre les dires de Tcheng Hiuen (app. K'ang-tch'eng ; 127-200).

47.(658) Wang Ming-cheng (1720-1798), dans son Che ts'i che chang hio (chap. V, p. 2 v ; sur cet ouvrage, cf. t. I, Introduction, p. CCXX), explique la phrase :

«Le signalement des disciples est tiré du texte ancien de $K^{\prime}$ 'ong; il est suffisamment exact,

en disant :

«C'est à savoir que des phrases telles que celle-ci : « (Tel disciple) était plus jeune que K'ong-tse de tant d'années », sont exactes et dignes de foi.

Ainsi, d'après Wang Ming cheng, ce.que Se-ma Ts'ien appelle le signalement des disciples comprend. non seulement la liste de leurs noms mais encore les indications relatives à leur âge. [css : voir la liste des disciples dans Legge, Chinese Classics, vol. I, Prolégomènes, [css : édition/rechercher : 'section III']

47.(659) Sur ces travaux, voyez Legge, Chinese Classics, vol. I, Prolégomènes, p. 12-14 et p. 19 [css : édition/rechercher : 'chapter II'],.

47.(660) Dans un ouvrage publié en 1823 et intitulé « Examen des leçons de (la recension de) Lou du Luen yu » (S. H. T. K. K., chap. 525), Siu Yang-yuen a dressé, d'après le Che wen de Lou Yuen-lang (app. Te-ming, 550-625) la liste des 23 leçons (en fait il y en a 25) de la recension de Lou qui ont été remplacées dans le Luen yu actuel par des leçons tirées du texte antique ; il a en outre comparé le texte du Luen yu actuel avec les fragments du texte gravé sur pierre à l'époque des Han, fragments qui nous ont été conservés dans le $L i$ che publié en 1167 par Hong Кouo ; ce texte gravé sur pierre devait s'inspirer de la recension de Lou, mais il paraît présenter des variantes qui lui sont propres. Quoi qu'il en soit, le travail de Sia Yangyuen nous prouve que les modifications apportées à la recension de Lou dans le Luen yu actuel sont rares et de peu d'importance.

- En ce qui concerne le Luen yu actuel, les éditions dont on peut disposer pour en établir le texte ont été énumérées comme suit par Yuen Yuen (1764-1849) en tête du [] (H. T. K. K., chap. 1016) ou « Etudes critiques sur le texte du Luen yu et des commentaires » [de Ho Yen ( $3^{\mathrm{e}}$ siècle ap. J.-C.) et de Hing Ping (932-1010)] :

$1^{\circ}$ le texte gravé sur pierre à l'époque des Han (voir plus haut, lignes 8-10 de la présente note) ;

$2^{\circ}$ le texte gravé sur pierre pendant la période k'ai-tch'eng (836-840) des T'ang (ces stèles font partie du Musée épigraphique Pei-lin de Si-ngan fou);

$3^{\circ}$ le texte gravé sur pierre pendant la période chao-hing (1131-1162) des Song (ces stèles sont conservées à Hang tcheou);

$4^{\circ}$ le texte avec commentaire de Hoang $K^{\prime}$ an, désigné souvent sous le nom de : texte de Hoang; Hoang K'an vivait à l'époque des Leang ( $1^{\mathrm{e}}$ moitié du VIe siècle); cet ouvrage a été retrouvé au Japon et publié par un Japonais nommé [] en 1850 ;

$5^{\circ}$ le texte coréen dont Yuen Yuen n'indique pas la date et dont il ne connaît que les citations faites par Tch'en Tchan dans l'ouvrage intitulé [] ; 
$6^{\circ}$ le Che hang pen, qui est de l'époque des Song, quoique quelques modifications aient pu être apportées à un petit nombre de planches sur les Yuen et les Ming, car une des pages présente la date de 1327 ;

$7^{\circ}$ le Min pen, édition faite au Fou-kien pendant la période kia-tsing (1522-1566) par Li Yuen-yang

$8^{\circ}$ le Pei kien pen, édition faite par le Kouo tse kien de Péking en 1586 ;

$9^{\circ}$ le Mao pen, édition publiée pendant la période tchong-tcheng (1628-1644) par Mao Tsin.

- A ces neuf textes, il convient maintenant d'en ajouter deux autres d'abord, le manuscrit de l'époque des T'ang qui a été retrouvé dernièrement au Japon par Tch'en Kiu,et publié en 1889 par Fou Yun-long (cf. Pelliot, BEFEO, t. II, p. 318 et 340) ; en second lieu, le Luen yu avec les Explications de Ho Yen ( $3^{\mathrm{e}}$ siècle ap. J.-C.), édition publiée au Japon en 1364, et réimprimée en 1884 dans le Kou i ts'ong chou sous le titre de "Reproduction du texte du Luen yu tsi kie de la période shôhei » (cf. Pelliot, BEFEO, t. II, p. 318).

\section{APPENDICE I : De l'authenticité des « Annales écrites sur bambou ».}

a51.(101) Le Tchou chou ki nien a été traduit par Ed. Biot (Journ. As., déc. 1841, p. 537-578, et mai 1812, p. 381-431), puis par Legge (Chinese Classics, vol. III ; Proleg., p. 105-183).

a51.(102) Ce texte est cité dans les 'Prolégomènes de l'édition des Annales publiée en 1813 par Tch'en Fong-heng sous le titre de Tchou chou ki nien tsi tcheng (section tsi chouo, p. 1 $\mathrm{r}^{\circ}-3 \mathrm{r}^{\circ}$ ). La Bibliothèque nationale ( $\mathrm{n}$. $\mathrm{f}$. chinois, $\mathrm{n}^{\circ}$ 4474-4476) possède un exemplaire de l'édition princeps de cet excellent ouvrage qui provient de la bibliothèque de $\mathrm{M}$. de Paravey (cf. une note de Ed. Biot dans le Journal Asiatique de février 1842, p. 203-207). Dans la bibliothèque de l'Université de Cambridge se trouve une autre édition datée de 1842 (cf. Catalogue de Giles, X, 123-129)..

a51.(103) Tou $Y u$ avait été le commandant en chef des troupes qui mirent fin à la dynastie de $\mathrm{Ou}$ : voyez sa biographie dans le chap. XXXIV du Tsin chou.

a51.(104) Aujourd'hui, la sous-préfecture de Kiang-ling fait partie de la ville préfectorale de King-tcheou, dans la province de Hou-pei.

a51.(105) Aujourd'hui, ville préfectorale de Siang-yang, dans la province de Hou-pei.

a51.(106) Aujourd'hui encore sous-préfecture de Ki, dans la préfecture de Wei-hoei, province de Ho-nan.

a51.(107) C'est-à-dire en forme de têtards. Ce nom est une dénomination populaire qu'on appliqua aux caractères antiques lorsque les fiches constituant le manuscrit en caractères antiques du Chou king réapparurent au deuxième siècle avant notre ère (Cf. Journ. Asiatique, janv. fév. 1905, p. 22, n. 2),

a51.(108) On voit, par ce témoignage de Tou Yu, que le manuscrit des Annales présentait, dès l'époque où il fut retrouvé, de grandes difficultés de lecture à cause de l'archaïsme de ses caractères.

a51.(109) C'est-à-dire que ces fiches de bois, si elles étaient recopiées sur des rouleaux de papier, formeraient soixante-quinze de ces rouleaux.

a51.(110) Tous ces appendices, au dire de Se-ma Ts'ien, furent composés par Confucius. Cf. p. 400 , n. 6 .

a51.(111) Cf. t. IV, p. 253. 
a51.(112) Cf. t. IV, p. 254. Le comte Tchoang, qui était le représentant de la branche cadette de la famille princière de Tsin et qui régna à K'iu-ou de 731 à 716, eut pour fils et successeur le duc $O u$ qui, en 679, déposséda entièrement la branche aînée et fonda une nouvelle lignée de princes de Tsin. Les Annales écrites sur bambou ne reconnaissaient comme légitime que cette seconde lignée et, sous leur forme primitive, dataient les événements d'après les années de règne de ses représentants même dès l'époque où ils n'étaient encore que princes de K'iu-ou.

a51.(113) Tou Yu indique ici la relation qui existe entre la chronologie des Annales et celle du Tch'oen ts'ieou dont le point de départ est le premier mois de la première année (722) du duc $\mathrm{Yn}$, de Lou; on voit que le onzième mois pour les Annales correspond au premier mois pour le Tch'oen ts'ieou; en effet, comme le fait observer Tou Yu dans la phrase suivante, les Annales se servaient du calendrier des Hia qui faisait commencer l'année au mois yn $\left(3^{\mathrm{e}} \mathrm{du}\right.$ cycle), tandis que le Tch'oen ts'ieou applique le calendrier des Tcheou d'après lequel le début de l'année est le mois tse ( $1^{\mathrm{er}}$ du cycle); par conséquent, lorsque les Annales parlent du premier mois, ce mois est appelé le troisième dans le Tch'oen ts-ieou, ou encore lorsque les Annales parlent du onzième mois, ce mois devient le premier de l'année suivante dans le Tch'oen ts'ieou. Nous montrerons plus loin que la dernière partie des Annales, sous sa forme actuelle, est rangée d'après les règnes des rois de la dynastie Tcheou et suit le calendrier des Tcheou ; mais il est bon de remarquer dès maintenant que, d'après Tou Yu, elle devait, sous sa forme primitive, noter les années d'après les règnes des ducs de $T$ sin et se servir du calendrier des Hia.

a51.(114) Nous aurons à examiner plus loin (p. 461-463) si Tou Yu a eu raison de considérer comme étant le roi Ngai le souverain de Wei à la vingtième année duquel s'interrompent, en 299 av. J.-C., les Annales.

a51.(115) En d'autres termes, les Annales sont, dans leur dernière partie, une chronique particulière de l'État de $T \sin$, puis, après le démembrement de $T \sin$, une chronique particulière de l'État de Wei.

a51.(116) Cette indication nous fournit la date exacte à laquelle Tou $Y u$ écrivit sa Postface au Tso tchoan.

a51.(117) Tou $Y u$ montre ensuite par quelques exemples comment certains faits sont exposés d'une manière un peu différente dans les Annales et dans le Tch'oen ts'ieou; cela provient de ce que l'auteur des Annales ne visait qu'à l'exactitude, tandis que Confucius a prétendu donner des leçons de justice dans le Tch'oen ts'ieou. - Tou Yu prouve encore que les Annales concordent d'une manière remarquable avec le Tso tchoan, mais sont en désaccord avec les commentaires de Kong-yang et de Kou-leang ; c'est un indice que ces deux derniers commentaires n'ont pas autant de valeur historique que le Tso tchoan. - Enfin, quoique les Annales ne coïncident pas toujours avec les témoignages du Chou king et des Mémoires historiques de Se-ma Ts'ien, elles peuvent cependant aider à l'intelligence correcte des faits qui y sont racontés. - Tои Yu ajoute qu'un chapitre distinct de cet ouvrage était un recueil de tous les faits de divination rapportés par le Tso tchoan; ce chapitre est intitulé Che Tch'oen, titre qui paraît être le nom de l'auteur. - Tou Yu termine en montrant la grande différence qui existe entre les Annales et le Chou king en ce qui concerne le récit des relations de l'empereur T'aikia avec son conseiller I Yn; Tou Yu semble croire qu'ici le Chou king est fautif par suite de quelque défaut de mémoire du vieux Fou Cheng qui le récita.

a51.(118) La biographie de Siun Hiu se trouve dans le chap XXXIX du Tsin chou. Nous y apprenons $\left(\right.$ p. $\left.5 \mathrm{v}^{\circ}\right)$ que, « lorsqu'on découvrit dans une sépulture de la commanderie de $K i$ les livres écrits sur bambou en caractères antiques, (Siun) Hiu fut chargé par décret impérial de les rédiger et de les classer pour en faire des livres de la bibliothèque impériale qui seraient placés dans les archives secrètes ». - La préface de Siun Hiu au Mou t'ien tse tchoan est citée dans les Prolégomènes du Tchou chou ki nien tsi tcheng (1813) de Tch'en Fong-heng (p. $\left.7 \mathrm{r}^{\circ}\right)$. 
a51.(119) Le dictionnaire Tcheng tse t'ong (publié en 1705), cité par le Kang hi tse tien au mot [], indique que, lorsque le caractère [] est un nom de famille, il doit se prononcer avec l'ancienne prononciation piao.

a51.(120) Ce prétendu roi Ling résulte simplement d'une mauvaise lecture du texte des Annales qui appellent « le roi actuel » le roi sous le règne duquel elles s'achèvent.

a51.(121) Il semble qu'il y ait ici une erreur, car la sous-préfecture de Ki est au Sud-Est (et non à l'Ouest) de la sous-préfecture de Hoei.

a51.(122) Ceci n'est pas tout à fait exact; il s'écoula 86 années depuis l'année 299, date où le Tchou chou ki nien se termine, jusqu'à l'année 213, qui est celle où Ts'in Che-hoang-ti proscrivit les livres ; mais les lettrés ne furent mis à mort qu'en 212.

a51.(123) Le mot [] semble n'exister que dans ce texte, s'il faut en croire le dictionnaire de K'ang-hi qui cite le passage de l'inscription de T'ai- kong d'après le Kin che lou de Tchao Ming-tch'eng (commencement du XIIe siècle). - Tong Yeou remarque que si ce caractère ne se trouve pas dans le Chouo men (publié en 100 ap. J.-C.), il figure dans le Tse chouo de Wei RongS (premier siècle ap. J.-C.) et dans le Tse tche de Kouo Tchao-k'ing. Il est vraisemblable d'ailleurs que Kouo Tchao-k'ing n'a fait ici que copier Wei Hong.

a51.(124) Nom personnel du roi Wen.

a51.(125) Wang est ici regardé comme le nom personnel de l'Illustre duc. D'après Se-ma Ts'ien cependant, T'ai kong-wang ne serait en réalité qu'un surnom signifiant "celui que l'Illustre duc a prévu » (cf. t. IV, p. 36, n. 1-3); si on adopte la manière de voir de Se-ma Ts'ien, le titre "l'Illustre duc" désignerait le père du roi Wen, tandis qu'ici ce terme s'applique évidemment au personnage même que le roi Wen prit pour conseiller.

a51.(126) Cette indication est en désaccord avec le Tchou chou ki nien actuel qui donne 430 années aux Hia et 507 aux Yn. Le Commentaire original assigne 471 années aux Hia et 496 années aux Yn. Cf. Legge, C. C., vol. III, prolég., p. 181-182.

a51.(127) Ki est le second empereur de la dynastie Hia. Le Tchou chou ki nien actuel ne dit point que $K$ ' $i$ ait tué $I$; cependant, comme Lieou Tche-ki (Che t'ong t'ong che, chap. XIII, p. 7 $\mathrm{r}^{\circ}$ ) attribue lui aussi ce dire au Tchou chou ki nien, il est probable que nous avons affaire ici à l'un de ces textes historiques que les premiers éditeurs des Annales crurent pouvoir admettre, mais qu'on rejeta plus tard dans la catégorie des Textes fragmentaires.

a51.(128) Cf. Legge, C. C., vol. III, prolég., p. 130.

a51.(129) Cf. Legge, C. C., vol. III, prolég., p. 138.

a51.(130) L'âge de cent ans est attribué au roi Mou par le chap. Lu hing du Chou king (cf. Legge, C. C., vol. III, p. 588).

a51.(131) Cf. notre traduction de Se-ma Ts 'ien, tome I, n. 04.381.

a51.(132) Tch'en Fong-heng (Prolég., chap. Tsi yu, p. 4 vº), écrit Kong-suen Kia.

a51.(133) On remarquera que, dans cette énumération, il n'est pas question du Tcheou chou qu'on désigne cependant souvent sous le nom de Tcheou chou de la tombe de $K i$, titre sous lequel cet ouvrage est réimprimé dans le Han Wei ts'ong chou; mais cette dénomination fautive provient d'une assertion du Soei chou (chap. XXXIII, p. 3 r $^{\circ}$ ) qui est dénuée de tout fondement. En réalité le Tcheou chou est déjà mentionné dans le chap. XXX, p. $2 v^{\circ}$ du $T s^{\prime} i e n$ $H a n$ chou, c'est-à-dire qu'il était connu à une époque où la tombe de $K i$ n'avait point encore été ouverte ; il ne provient donc pas de cette tombe. Cela n'ôte rien à la valeur de cet ouvrage, qui paraît être constitué, comme l'indique Yen Che-kou, avec les textes anciens que Confucius avait refusé d'admettre dans le Chou king; il serait fort désirable que nous eussions une bonne traduction du Tcheou chou basée sur l'excellente édition qu'en a donnée Tchou Yeou-ts'eng en 1846. Cette édition est reproduite dans S. H. T. K. K., chap. 1028-1038; 
voyez en outre les observations de Wang Nien-suen sur le Tcheou chou dans S. H. T. K. K., chap. 209-212 ; Tch'en Fong-heng, l'éditeur des Annales écrites sur bambou, a aussi publié en 1825 le Tcheou chou en y ajoutant un commentaire (Voyez Giles, Wade Collection of Chinese Books, B, 1081-1082).

a51.(134) Actuellement, ces chapitres (Soei chou, chap. XXXII à XXXV) sont mis sous le nom de Tchang-souen Ou-ki et de ses collègues, mais ils étaient bien en réalité l'œuvre de Wei Tcheng comme l'indiquent les éditeurs de l'époque K'ien-long à propos d'un passage de la notice placée à la fin du Soei chou dans l'édition des Song (voyez, à la fin de la réimpression du Soei chou publiée en caractères de plomb à Chang-hai en 1888).

D’ailleurs à la fin du chap. XXXII (p. $\left.15 \mathrm{v}^{\circ}\right)$ du Soei chou, Wei Tcheng se désigne bien luimême comme l'auteur du traité sur la littérature en introduisant son propre nom par la mention « votre sujet Wei Tcheng ».

a51.(135) Dans ce qui suit, Wei Tcheng reproduit assez fidèlement quelques-unes des observations faites par Tou $Y u$ dans sa Postface au Tch'oen ts'ieou (voyez plus haut, pp.449-450).

a51.(136) Chap. X, p. $1 \mathrm{v}^{\circ}$ du Che t'ong t'ong che (réimpression de 1885).

a51.(137) Se-ma Ts'ien, éd. lithographique de Chang-hai, 1888 chap. XLIV, p. 4 v$^{\circ}$, avant-dernière colonne.

a51.(138) Cf. p. 451, ligne 9 .

a51.(139) Cf. p. 453, ligne 12 .

a51.(140) Cf. p. 454, ligne 24.

a51.(141) Cf. p. 458, ligne : 9.

a51.(142) Cf. p. 459, lignes 12-13.

a51.(143) Cf. p. 448, ligne 12 et p. 450 n. 3.

a51.(144) Cf. p. 447, ligne 13.

a51.(145) C'est donc à tort que j'ai accepté la date de 279 dans mon Introduction (vol. I, p. CLXXXIX, ligne 1).

a51.(146) Cf. p. 448, ligne 4 .

a51.(147) Cf. p. 460, lignes 6-7.

a51.(148) Cf. p. 450, lignes 4-5.

a51.(149) Cf. p. 452, lignes 8-9, p. 458, ligne 30 et p. 459, lignes 13-14.

a51.(150) Cf. p. 454, lignes 26-27.

a51.(151) Cf. Mém. hist., chap. XCIV, p. $4 \mathrm{v}^{\circ}$ à $5 \mathrm{r}^{\circ}$ où les deux thèses sont exposées successivement dans les deux commentaires juxtaposés.

a51.(152) Cf. la note de Legge dans ses Prolégomènes (p. 33, n. 1) du vol. II des Chinese Classics.

a51.(153) Cf. p. 452, lignes 8-9.

a51.(154) Cf. p. 458, ligne 30 .

a51.(155) Cf. p. 168, n. 3 .

a51.(156) Cf. p. 449, ligne 3 .

a51.(157) Cf. p. 455, ligne 1 . 
a51.(158) Cf. p. 460, lignes 5-6.

a51.(159) La discussion instituée par Song $K^{\prime} i$ à ce sujet se trouve reproduite à la fin de la réimpression du Ts 'ien Han chou publiée à Chang-hai en 1888, dans une note à la Préface de Yen Che-kou, p. 3 ro.

a51.(160) Voici quelques-uns des passages ou (Fou) Tsan s'appuie sur l'autorité du Tchou chou ki nien : Ts 'ien Han chou, chap. XXVIII, a, p. $6 \mathrm{v}^{\circ}$ (cf. Tchou chou ki nien, $13^{\mathrm{e}}$ année du duc Hoan, 707) ; ibid., p. $9 \mathrm{v}^{\circ}$ (cf., T. c. k. n., $7^{\mathrm{e}}$ année de $P^{\prime}$ 'an-keng, 1309); ibid., p. $13 \mathrm{r}^{\circ}-14$ $\mathrm{V}^{\circ}$ (cf. T. c. k. n., $1^{\mathrm{e}}$ année de $T^{\prime}$ 'ai-k'ang, 1958, et $1^{\mathrm{e}}$ année de l'empereur Koei, 1589); chap. XXXVI, p. 10 r $^{\circ}$ (cf. T. c. k. n., auX dates de 1044 et de 1023); etc.

a51.(161) Voyez notamment Se-ma Ts'ien (éd. de 1888), chap. V, p. 12 r ${ }^{\circ}$, col. 11 ; chap. XLIII, p. 8 ro, col. 7 ; chap. XLIV, p. 3 r ${ }^{\circ}$, col. 9 ; etc.

a51.(162) Voyez Se-ma Ts'ien, chap. IV, p. 11 r $^{\circ}$, col. 11 : chap. XLIV, p. 4 r , col. 10 ; etc.

a51.(163) Voyez Heou Han chou (éd. de 1888), chap. CXV, p. 1 r ${ }^{\circ}$, col. 7, 8, 11, 12 ; chap. CXVII, p. $1 \mathrm{v}^{\circ}$, col. $5,6,7,11$; etc.

a51.(164) Pour les citations faites par Se-ma Tcheng, Voyez Se-ma Ts'ien, chap. V, p. 9 r ${ }^{\circ}$, col. 3 ; chap. XXXIV, p. $2 \mathrm{r}^{\circ}$, dern. col., p. $2 \mathrm{v}^{\circ}$, col. 3 ; chap. XXXVII, p. $5 \mathrm{r}^{\circ}$, col. 5 ; chap. XXXVIII, p. $7 \mathrm{r}^{\circ}$, col. 6 ; chap. XLI, p. $4 \mathrm{v}^{\circ}$, col. 9 ; chap. XLIV, p. 3 r ${ }^{\circ}$, col. 1, 2, 7, 8 ; p. 3 $\mathrm{v}^{\circ}$, col. 5 ; p. $4 \mathrm{r}^{\circ}$, col. $4,9,11$; p. $4 \mathrm{v}^{\circ}$, col. 3 ; p. $5 \mathrm{v}^{\circ}$, col. 10 , etc. -

Pour les citations faites par Tchang Cheou-tsie voyez Se-ma Ts'ien, chap. III, p. 1 r $^{\circ}$, col. 1 ; chap. III, p. $5 \mathrm{r}^{\circ}$, col. 3 ; chap. IV, p. $6 \mathrm{v}^{\circ}$, col. 2 ; p. $9 \mathrm{r}^{\circ}$, col. 7 , etc.

a51.(165) Che tong t'ong che (réimpression de 1885),.chap. I, p. 5 rº.

a51.(166) Cf. Mencius. IV, b. 21, § 2 .

a51.(167) Che t'ong t'ong che, chap. XIV, p. $19 \mathrm{v}^{\circ}-20 \mathrm{r}^{\circ}$.

a51.(168) Cf. p. 449, lignes 10-14 et n. 2.

a51.(169) Cf. p. 467, lignes 11-15.

a51.(170) Voyez Introduction, p. CXCXI-CXCXIV. Dans la note 1 de la p. CXCXIV, j'ai écrit par inadvertance: «Les grands synchronismes sont identiques dans les deux ouvrages et suffisent à prouver que l'un s'inspire de l'autre »; il faut dire : « ... suffisent à prouver qu'ils s'inspirent d'un même système. » Il est évident en effet que Se-ma Ts 'ien n'a pas pu connaître le Tchou chou ki nien enfoui sous terre en 299 av. J.-C. et exhumé seulement en 281 ap. J-C.

a51.(171) Sur la manière dont doit être faite cette conversion, voyez tome III, appendice III, p. 656-659.

a51.(172) Antérieurement à la $1^{\mathrm{e}}$ année de Yao qui est une année ping-tse (2145), Li Tchao-lo fait ses calculs d'une manière assez bizarre : aux 9 années de Tche, il ajoute 3 années pendant lesquelles ce souverain fut en deuil de son père; il reporte donc son accession au trône à l'année kia-tse $=2157$; la première année de $K^{\prime}$ ou se trouve dès lors rejetée à l'année sin-yeou $=2220$; la première année de Tchoan-hiu devient l'année keng-tse $=2301$, ce qui accuse une différence de 6 années avec nos calculs, comme si Li Tchao-lo avait encore admis soit pour $K^{\prime} o u$, soit pour Tchoan-hiu, une période supplémentaire de 3 ans motivée par le deuil ; avant Tchoan-hiu, Li Tchao-lo place Chao-hao auquel il attribue 87 années de règne (2388-2302) ; il cherche ainsi assez maladroitement à concilier le Tchou chou ki nien et le Commentaire original en dédoublant Tche et Chao-hao dont il fait deux personnages distincts ; enfin Li Tchao-lo admet vraisemblablement que les cent années du règne de Hoang $t i$ furent suivies de 3 années de deuil et c'est pourquoi il fixe la $1^{\mathrm{e}}$ année de Hoang $t i$ à l'année keng- $y n=2491$. 
a51.(173) Chao Yong (1011-1077 : cf. Giles, Biog. Dict., $\mathrm{n}^{\circ}$ 1683) fut le premier qui, dans son ouvrage intitulé Hoang ki king che chou, assigna le début du règne de Yao à l'année kia-tch'en=2357. Cette opinion fut adoptée par Kin Li-siang (1232-1303 ; cf. Giles, Biog. Dict., $\mathrm{n}^{\circ} 381$ ) dans le T'ong kien ts'ien pien et c'est à partir de ce moment qu'elle fut généralement reçue (cf. les remarques de Tch'en Fong-keng dans le Tchou chou ki nien tsi tcheng, $1^{\mathrm{e}}$ année de Yao).

a51.(174) Voyez les Tables chronologiques de Mayers et de Giles.

a51.(175) Cf. p. 455, lignes 9-10 et n. 1.

a51.(176) Cf. Legge, Chinese Classics, vol. III, Proleg., p. 181, lignes 30-36 et p. 182, lignes $1-15$.

\section{APPENDICE II : Le voyage au pays de Si-wang-mou.}

a52.(101) Le passage visé par M. Forke se trouve à la fin de la note de la p. 6 dans le tome II de ma traduction de Se-ma-Ts'ien.

a52.(102) Cité par Tch'en Fong-heng dans son édition du Tchou chou ki nien $\left(9^{\mathrm{e}}\right.$ année de Choen).

a52.(103) Les commentateurs expliquent ce nom de Je-Hia en disant qu'il désigne le pays qui est sous le soleil au moment où il se lève.

a52.(104) Cf. tome IV, n. 33.119.

a52.(105) Le Tang ho. Cf. tome I, n. 02.193.

a52.(106) Voyez Western origin of the early Chinese civilisation, Chap. VIII, p. 361-275: «The Si Wang mu and Muh Wang's Expedition to Turkestan in 986 B. C. ».

a52.(107) M. Forke (p. 165, n. 2) a contesté cette assertion en se fondant sur une variante d'une des poésies du Mou t'ien tse tchoan citées dans le commentaire du Chan hai king; M. Forke attribue à tort ces citations à $\mathrm{Pi}$ Yuan (1729-1797); elles proviennent en réalité du commentaire de Kouo P'o (276-324) qui, écrivant une quarantaine d'années après la découverte du Mou t'ien tse tchoan, ne peut être considéré comme nous apportant le dernier verdict de la philologie chinoise sur le texte du Mou t'ien tse tchoan; Kouo P'o est un écrivain taoïste qui, comme tous les auteurs appartenant à la même école, prend d'assez grandes libertés avec les documents historiques; il n'y a d'ailleurs rien de surprenant à ce qu'il ait considéré $S i$-wang-mou comme une femme puisque, au IVe siècle de notre ère, la légende taoïste de la déesse Si-wang-mou était déjà toute constituée. Je serais d'ailleurs disposé à aller plus loin, et, s'il est une partie du Mou t'ien tse tchoan dont l'authenticité me semble suspecte, ce sont précisément les poésies échangées entre le roi Mou et le personnage appelé Si-wang-mou, car elles rompent la suite du récit et en changent le ton; elles m'ont tout l'air d'une interpolation.

a52.(108) Cf. Devéria, La frontière sino-annamite, p. 157, n. 1.

a52.(109) Cf. Se-ma Ts'ien, chap. CXVII, p. $16 \mathrm{r}^{\circ}$. Le mot [], dit le commentateur Yen Che-kou, désigne un ornement de tête que portent les femmes.

a52.(110) Cf. t. V, p. 7 ; «Les aïeux de la famille Tchao se rattachent au même ancêtre que les Ts'in ».

a52.(111) C'était déjà l'avis de Legge (C. C., vol. IV, proleg., p. 141) : « in my mind there is no doubt that the people of $T s^{\prime}$ in was made up mainly of those barbarous tribes $»$.

a52.(112) Cf. t. II, p. 62, lignes 3-6. 
a52.(113) Cf. t. V, p. 70-84.

a52.(114) Cf. tome II, $\underline{\text { n. } 05.172}$; n. $05.240 ;$ n. 05.301 . Il est certain que cette pratique a fini par être suivie par les Chinois eux-mêmes ; mais ce n'est pas une raison pour dire, comme le fait M. De Groot (Religious System of China, vol. II, p. 723-724), qu'elle est d'origine chinoise. Biot avait déjà soutenu qu'elle était d'origine tartare ; cf. C. C., vol. IV, proleg., p. 141-142.

a52.(115) Cf. t. V, n. 43.232 .

a52.(116) Cf. t. II, p. 5, ligne 8 et n. 3 ; t. V, p. 9, ligne 9.

a52.(117) Cf. t. I, p. 162, dernière ligne, et p. 171, lignes 8-12; tome V, p. 312-314, et n. $\underline{47.189}$, à la fin.

a52.(118) De bello gallico, VI, 17.

a52.(119) Cf. t. II, p. 135, lignes 6-7.

a52.(120) cf. Heou Han-chou, chap. CXV, p. 4 v.

a52.(121) On remarquera avec quelle gaucherie Se-ma Ts'ien introduit la mention du Tch'ao-sien dans le chapitre où il parle du vicomte de $K i$ (t. IV, p. 230, lignes 17-18). Cette mention se trouve placée entre l'exposé des règles du Hong-fan et le récit d'une visite du vicomte de $K i$ à l'ancienne capitale des $Y n$.

a52.(122) Cf. t. II, p. 44-45. 
Chapitres : $\quad \underline{\mathrm{XLIII}}-\underline{\mathrm{XLIV}}-\underline{\mathrm{XLV}}-\underline{\mathrm{XLVI}}-\underline{\mathrm{XLVII}}-$ Appendices $: \underline{\mathrm{I}}-\underline{\mathrm{II}}$.

Notes : $\quad \underline{X L I I I}-\underline{X L I V}-\underline{X L V}-\underline{X L V I}-\underline{X L V I I}-$ App. : $\underline{I}-\underline{I I}$. 